Yhaverom 


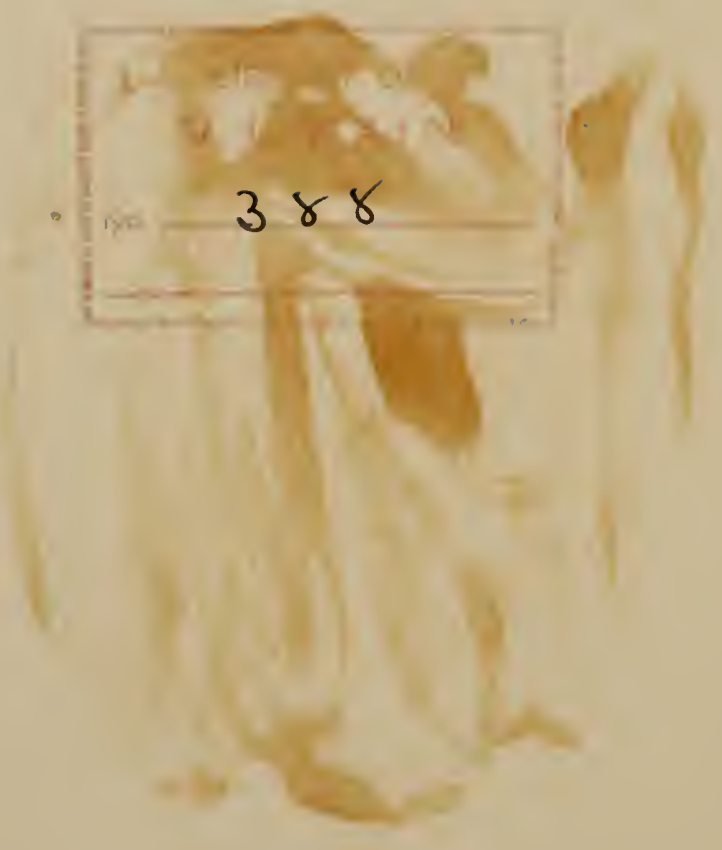





\section{LIPPINCOTT'S \\ FARM LIFE TEXT SERIES \\ EDITED BY \\ KARY C. DAVIS, Ph.D. (Cornele) \\ Horticulture}




\section{LIPPINCOTT'S FARM MANUALS}

Edited by K. C. DAVIS, Ph.D., Knapp School of Country Life, Nashville, Tenn.

PRODUCTIVE SWINE HUSBANDRY 1915

BY GEORGE E. DAY, B.S.A.

PRODUCTIVE POULTRY HUSBANDRY 1919 BY HARRY R. LEWIS, B.S.

PRODUCTIVE HORSE HUSBANDRY 1920

BY CARL W. GAY, D.V.M., B.S.A.

PRODUCTIVE ORCHARDING 1917

BY FRED C. SEARS, M.S.

PRODUCTIVE VEGETABLE GROWING 1918

BY JOHN W. LLOYD, M.S.A.

PRODUCTIVE FEEDING of FARM ANIMALS 1921

By F. W. WOLL, Ph.D.

COMMON DISEASES OF FARM ANIMALS 1919 BY R. A. CRAIG, D.V.M.

PRODUCTIVE FARM CROPS 1918

BY E. G. MONTGOMERY, M.A.

PRODUCTIVE BEE KEEPING 1918

BY FRANK C. PELLETT

PRODUCTIVE DAIRYING 1919

By R. M. WASHBURN, M.S.A.

INJURIOUS INSECTS AND USEFUL BIRDS 1918 BY F. L. IVASHBURN, M.A.

PRODUCTIVE SHEEP HUSBANDRY 1918

BY WALTER C. COFFEY, M.S.

PRODUCTIVE SMALL FRUIT CULTURE 1920

BY FRED C. SEARS, M.S.

PRODUCTIVE SOILS 1920

BY WILBERT W. WEIR, M.S.

LIPPINCOTT'S COLLEGE TEXTS

SOIL PHYSICS AND MANAGEMENT 1919

BY J. G. MOSIER, B.S., A. F. GUSTAFSON, M.S.

FARM LIFE TEXT SERIES

APPLIED ECONOMIC BOTANY 1919

BY MELVILLE T. COOK, Pr.D.

PRODUCTIVE PLAN'T HUSBANDRY 1918

BY KARY C. DAVIS

HORTICULTURE FOR HIGH SCHOOLS 1919

BY KARY C. DAVIS

PRODUCTIVE SOILS Abridged Edition 1920

BY IVILBER'T W. WEIR, M.S.

LABORATORY MANUALS AND NOTEBOOKS

ON THE FOLLOWING SUBJECTS

SOILS, BY J. F. EASTMAN and K. C. DAVIS I9I5 POULTRY, BY H. R.

LEWIS I9I8 DAIRYING, BY E. L. ANTHONY 1917 FEEDING, BY

F. W. WOLL 1917 FARM CROPS, BY F. IV. LATHROP I920 



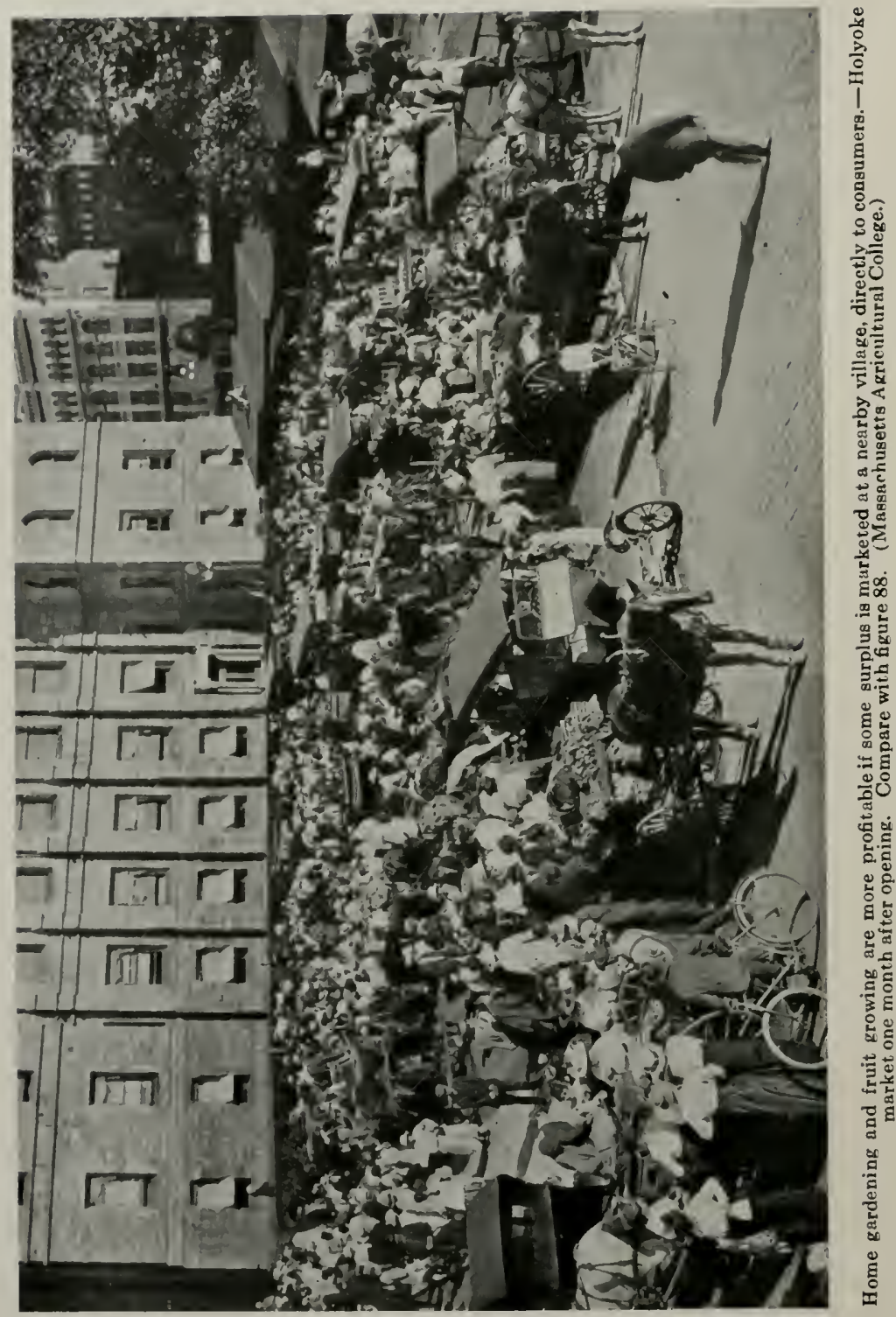




\section{FARM LIFE TEXT SERIES}

EDITED BY K. C. DAVIS, Ph.D. (Cornell)

\section{H O R T I C ULTURE}

A TEXT BOOK FOR HIGH SCHOOLS AND NORMALS

INCLUDING PLANT PROPAGATION; PLANT BREEDING; GARDENING; ORCHARDING; SMALL FRUIT GROWING; FORESTRY; BEAUTIFYING HOME GROUNDS; THE SOILS AND ENEMIES INVOLVED

BY

KARY CADMUS DAVIS, Ph.D. (Cornell) PROFESSOR OF AGRICULTURE, KNAPP SCHOOL OF COUNTRY LIFE, GEORGE PEABCDY COLLEGE FOR TEACHERS, NASHVILLE, TENNESSEE; AUTHOR OF PRODUCTIVE FARMING; EDITOR OF LIPPINCOTT'S FARM MANUAL SERIES, ETC.

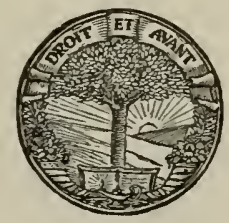


COPYRIGHT, IOI9

BY J B. LIPPINCOTT COMPANY

Electrotyped and Printed by J. B. Lippincott Company The Washing:on Square Press, Philadelphia, U.S.A. 


\section{FOREWORD}

Text-books should keep pace with the best educational thought. Too often they fail to do this; but when they do, educators may be expected to take advantage of this fact. The writer believes that the rapid establishment of high school courses of agriculture, due in part to the federal fund from the Smith-Hughes act, has made a demand for a single text book of horticulture suited to High Schools and Normals.

Purposes.-It is believed that the present text, combining as it does the subject of gardening, orcharding, and small fruits, will help solve several school problems: (1) It will save the instructor much time which might otherwise be spent in trying to seek out and formulate a suitable course in Horticulture. (2) It will save the time of the class for a better balanced agricultural course instead of putting a term each on plant propagation, gardening, orcharding, and small fruits. (3) It will obviate the necessity of students purchasing three or four books to cover the horticultural field. (4) It will offer subject matter for a school year where that much time can be allowed for it, or it may easily be condensed, by omitting a few chapters and some suggested lines of work, to one-half year.

Contents.-In the present volume six chapters are devoted to preliminary studies and plant propagation; six chapters to vegetable gardening; six chapters to various phases of orcharding; four chapters to small fruits, nuts, etc.; one chapter to the home wood lot and forestry; and one each to soil improvement, the home and school grounds, weeds, and birds.

It is believed this division of the subject of horticulture should meet the needs of students in High Schools, special Agricultural Schools, and Normals. Should any chapter seem to be superfluous in the course being pursued by any students, the instructor should feel free to omit such chapter or let it be gone over rapidly as review matter.

The arrangement of chapters should be changed by the instructor to suit the time of year when students are making the study. For example, the subject of hotbeds and coldframes should be 
taken up preferably in winter or early spring when their use is seasonable. Suit all studies to the season when possible.

Exercises and Projects.- The newer trend in agricultural teaching is to make the study as conerete and practical as possible. To atd in this as far as possible the present volume offers numerous suggestions for questionuaires, surveys, local investigations, practicums, ficld and laboratory exercises, field trips, home projects, reports, etc. These will be found at the close of the chapters. They are suggestive enough so that the thoughtful instruetor may casily adapt them to his local conditions. In many cases he will omit some and perhaps add other's. IVhere the school equipment is very limited the suggestions for home exercises and home projeets should all be followed and others added.

Chapters on seasonal suggestions, XIV, XV, and XXVI, should be of much aid in conducting home projects either by students or other praetical growers.

Illustrations.--No picture is given for embellishment, but each illustration is intended to teach something to the student. The figures are to bring to the mind more clearly some of the lessons of the text.

Questions are given at the close of each chapter. These are not merely for review, but also to extend the thought of the student to bis own local conditions and surroundings. They might be called "thought questions."

Acknowledgements.--The Author wishes to extend his grateful acknowledgements to many specialists in horticulture, agri('ulture, and agricultural education who have materially aided in the production of this volume. 'The bulletins of many such specialists have heen freely offered and their lessons embodied in this text. Illustrations have been supplied by many who have used their special knowledge in producing the photographs. Credit is given the different experiment stations under the cuts.

Thanks are especially due to Prof. A. V. Storm of the University of Minnesota, who first suggested the general plan of such a text and who has critically gone over the contents of the book, both before and after manuscript was written.

Mrs. K. C. Davis has made pen and ink drawings for many of the illustrations, and has read and criticised the manuseript and proof sheets. 


\section{CONTENTS}

CHAPTER

PAGE

I. Plant Life............................ 1

II. Propagation of Plants by Means of Seeds.......... 10

III. Principles of Plant Breeding and Their Application in

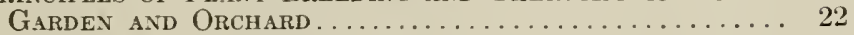

IV. Propagation by Undergrodnd Parts.............. 33

V. Cuttings and Laterings..................... 39

VI. Budding and Grafting. . . . . . . . . . . . . . . . 49

VII. The Hone Vegetable Garden.................. 61

VIII. Hotbeds, Coldfranes, and Flower Pits............. 81

IX. Tender and Hardy Vegetables............... $\$ 9$

X. Cool Season Vegetables of Early Spring and Fall... 95

Xi. Cool Season Vegetables that Endure Summer Heat... 106

XiI. Warm Season Vegetables.................. 121

XIII. Potatoes. . . . . . . . . . . . . . . . . . . . . . . 132

- XIV. Suggestions for Garden Work by Months for Northern

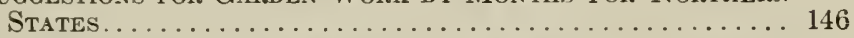

XV. Suggestions for Garden Work By Months in Southern

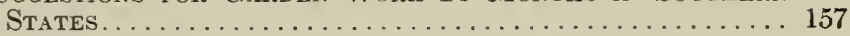

XVI. The Home Orchard-Apple, Pear, Quince........... 173

XVII. Enemies of the Apple, Pear, And Quince............ 195

XVIII. The Peach Orchard......................... 203

XIX. Cherries and Plums....................... 222

XX. Strawberries........................... 233

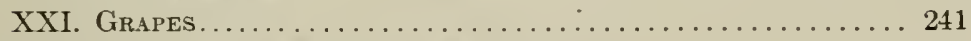

XXil. Bush Fruts in the Home Garden................ 252

XXili. Nuts and Subtropical Fruits.................. 270

XXIV. Legumes and Fertilizers-Soil Amendments. . . . . . . . 286

XXV. Principles of Spraying ...................... 303

XXVI. Work by Seasons in the Orchard, Fruit Garden, and

THE Howe Grounds. . . . . . . . . . . . . . . . . . . . . . 329

XXVII. Control of IVeeds..................... 347

XXVIII. The Hone IVoOd Lot . . . . . . . . . . . . . . . . 355

XXIX. Beautifying Hone Grounds.................. 366

XXX. Attracting Birds......................... 384

Appendix TABLES............................... 390 



\section{H O R T I C U L T U R E}

\section{CHAPTER I}

\section{PLANT LIFE}

Before taking up the special problems of gardening and fruit growing, let us make a rapid survey of the broader phases of plant life.

Importance of Plants.-All human life, and indeed, all animal life is dependent upon plants for sustenance. Most plants are able to obtain their nourishment from soil and air. The food thus produced is stored in the form of fruits, vegetables, and other crops, and is used for the maintenance of men and lower animals.

Without plants no animal life could long exist; as animals are not able to obtain their nourishment directly from soil and air alone.

Conditions for Plant Growth.-Because of the great value of plant growth to human life, it is quite necessary that we study carefully the needs of all plants and the special needs of all our crop plants.

The needs of plants may be grouped under six heads: (1) warmth, (2) moisture, (3) food supply, (4) air, (5) light, (6) freedom from enemies. If we are able to supply the best conditions under each of these heads we will secure the greatest crops. The great problems of gardening and orcharding are to place the growing plants in such favorabla conditions.

Warmth; Temperature.-Plants are not alike in their temperature requirements. Some grow in cold regions where snow and ice surround them. Others are found in torrid regions where frost never occurs. Wide differences are seen in the warmth required by our fruits and vegetables in the temperate zone. Lemons, oranges, certain grapes, and bananas can endure very little, if any freezing weather, even in the dormant season. Peaches are more easily winter-killed than apples and pears. Carden peas and let-

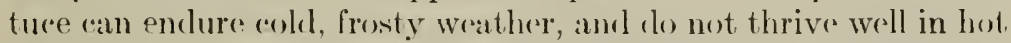
weather. Melons and leans prefor the hot weather. (Chapter IX). 
Moisture.-With respect to their water-loving habits plants have been elassified into three sueieties: Xerophytes, or desert plants, sueh as cactus, sage brush and mesquite. (2) Hydrophytes, or water-loving plants, as pond lily, cat-tail, water .cress, and alga. (3) Mesophytes, or mid-region plants, such as most of our garden, orchard, and farm plants.

The desert-loving plants have very extended root systoms with which to obtain moisture; and have limited leaf surface, and very leathery eovering to reduce evaporation.

Water-loving plants have much more leaf surface than root surface. Some have no true roots.

The mid-region plants differ widely in their cndurance of amd requirements for water. The quince, for example, has shallow roots and ean be made to grow on ground that is too wet for the peach (Chapter XVI).

Plant Food Supply.-Plants of the farm, garden, and orchard secure about five per cent of their food from the soil and the other ninety-five per cent from the air. Plants take mineral matter from the soil and organic matter from the air. That taken from the soil limits or controls the growth more than the other. In other words, the soil supply is more limited than the air supply. If the mineral supply is increased the plant can take more organic matter from the air. There is practically no limit to the supply of organic matter which plants ean take from the air, exeept that enough mineral matter must be taken from the soil to keep up the proper ratio of about one to nineteen, to suit the plant.

If a gardener increases the available plant food in the garden soil the erop, in using that, will also use about nineteen times as much from the air-with no additional cost to the grower.

The growers problems are: (1) to keep up the supply of plant food in the soil, (2) to make it available, (3) to make the soil conditions so favorable that the plant can secure the food, (4) to keep other plants, as weeds, from robbing th is food supply from the crop).

Plants Need Air.-Most of our crop plants need only the oxygen and earbon dioxide found in all air, but the legumes, such as clover, peas, and beans, also secure nitrogen either direcetly or indirectly from the air. ((hapter XXIV). Experiments with plants grown withont a proper supply of air show eonclusively that plants must have a normal supply of these eomponents of the air.

How Oxygen and Carbon Dioxide Are Obtained.-All the greenleaf plants breathe air into their leaves and green parts of their 
stems. They retain such parts of this as they may require. In daylight they retain ehiefly the earbon dioxide and a part of this is used to make starch and sugar in the cells of the leaves. The surplus oxygen is given off to the air again. (Exercise I.) At night the plant uses more oxygen than carbon clioxide. It then breathes off the latter into the air.

Light Requirements.--As just stated, the presence of light is necessary for the making of starch and sugar in plant cells. The green color bodies called chlorophyll, are also necessary. A green plant, growing in the sunlight, is truly a starch and sugar factory. The proclucts of this factory are used by the plant to build up the tissues, and this is ealled growth. We see then, how essential sunlight is to plant growth.

Leaf Function and Structure.-The leaves may be considered as both the breathing organs and digestive organs of plants. There are numerous openings, or mouths, called stomates, more numerous on the under surfaces of leaves. Through these the air containing oxygen and carbon dioxide is admitted and the by-products are given off. In the daylight the chief waste is oxygen, because "food getting" exceeds the "breathing." In the darkness the chief waste is carbon dioxide, because "breathing" exceeds "food getting."

The soft cells inside the leaf are provided with many small bodies bearing green chlorophyil. This gives the green color to the leaf. The upper and lower layers of epiclermis are composed of transparent cells through which the light passes readily. The layer of cells just beneath the upper epidermis are arranged in a columnar way as shown in the figure, and are called palisade cells. The others are more irregular and have spaces between them for the access of air which bathes the cells. All the thin-walled cells bearing chlorophyll, inside the leaves, are called parenchyma cells. The essential parts of a typical leaf are shown in figure 1.

Freedom from Enemies.-Among the conditions necessary for plant growtl is freedom from insect enemies, plant diseases, and weeds. For the best growth of garden and fruit crops, enemies of all kinds must be kept in check. Each of these classes of enemies is cliscussed in other chapters.

Germination of Seeds.-The first growth from seeds is called germination. The term "sprouting" ' more properly refers to breaking through the ground by this early growth. The seed contains the minute parts of the young plant. There is a store of plant food 
either (1) in the seed leaves, as in beans and peas, or (2) surrounding the parts of the plant, as in inorning-glory seed. This store of nourishment provides for the growth of the plant until it has developed enough to get its nourishment from the soil and air.

Best Conditions for Germination.-A proper amount of moisture is necessary to soften the seed coats and to provicle for the circulation of food which the seed contains. With many kinds of seeds, such as melons, earrots, parsnips, salsify, eelery, apple and others, it is a very great aid to germination to soak the seeds in water for a few hours before planting. Moisture is easily brought to seeds through the soil when planted, if the soil is firmed. This may be done with the foot, hoe, or planting board. On large fields farmers do this with rollers.

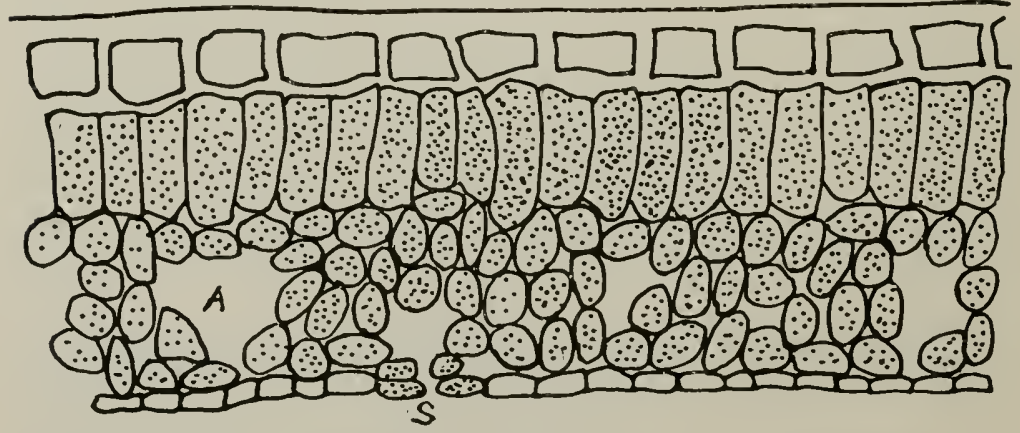

Fig. 1.-Cross section of leaf showing thick epidermis at top, columnar cells, loose parenchyma cells with air spaces, as at $A$; thin epidermis below with breathing mouth or stomate, $S$.

In the cases of radish, lettuce, garden peas, onions, and others which endure frost well, the seeds will germinate at rather low temperatures. For this reason early garden crops may be planted in early spring before the soil has become very warm.

On the other hand, such seeds as corn, beans, tomato, and molon will germinate much better if the soil is rather warm. It is partly for this reason that such erops are started late in the spring.

Air in the soil is necessary for the best germination of seeds. They will not start well in soils that are so wet as to exclucle the air. A seed bed should be so well loosened hy plowing or sparling as to allow the free areesis of air. Sere exercise 5 .

Parts of the Plant. - As the young plant grows it soon develops roots, stem, and leaves. The roots serve to loold the plant in places 
and to secure plant food from the soil. The stem is to raise the laves up to the light and air. There are many forms of stems. see the cross-section of a woody stem in figure 2. Many vines bring their leaves up to the light by climbing on supports of various kinds. Rumning vines extend the plant over larger areas to seek more air and light. Trees and other plants with rigid stems grow tall in competition with other plants near them. If they grow in more open places with less competition, they may beeome more branched and their arms often reach horizontally a long distance into the air.

The purposes of leaves are (1) to expose the green chlorophyll of the plant to the sunlight, (2) to "breathe" earbon dioxide and oxygen, and (3) to manufacture stareh and sugar. The work of leaves has already been cleseribed.

Important Work of Roots and Root-hairs.-The ehief purpose of plant roots is to take in food from the soil. The root-hairs are far the most effective in this work. The

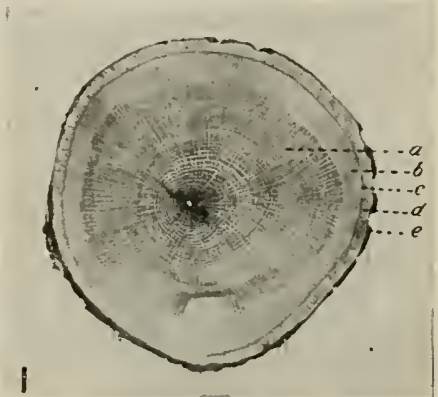

F1G. 2.-Cross section of woody stem; $a$, heart wood; $b$, sap wood; $c$, cambrium or growing layer; $d$, inner bark; $e$, outer bark. plant food taken in by roots must be in solution in the films of soil water which eling around the grains of soil.

The root-hairs are very numerous on the smaller rootlets, particularly on the young growth. They form a velvety covering of the roots and greatly increase the absorbing surface. (Fig. 3.) It is through the root-hairs that all, or nearly all of the food from the soil is taken into the plant.

How Roots Absorb Food.-Liquids may pass through a membrane by a process called osmosis. When two liquids are separated by a membrane they tend to trade places and mingle with each other. The thinner liquid passes through the membrane faster than the clenser liquid.

The soil water, containing some plant food in solution will thus enter the plant through the root membrane. A little waste material from the cell sap will escape at the same time. This trade of the two liquids through the surface of the root is necessary for the growth of the plant. If there be enough moisture in the soil the flow inward far exceeds the out-go, and growth will be rapid. When 
the soil is very dry growth is retarded, and in extreme cases the plant may actually lose as much or more than it receives. Then it will wilt and may die. Rainfall or irrigation will dilute the plant food in the soil and thus rapidly increase the osmotic action through the roots. Growth is thus greatly increased. Try an exercise as described under figure 4 .

Plant Food.-The plant requires a number of elements which it gets from the soil, such as nitrogen $(\mathrm{N})$, phosphorus $(\mathrm{P})$, potassium (K), caleium (Ca), sulfur (S), iron (Fe).

The first four of these are most likely to become deficient in any

FIG. 3.
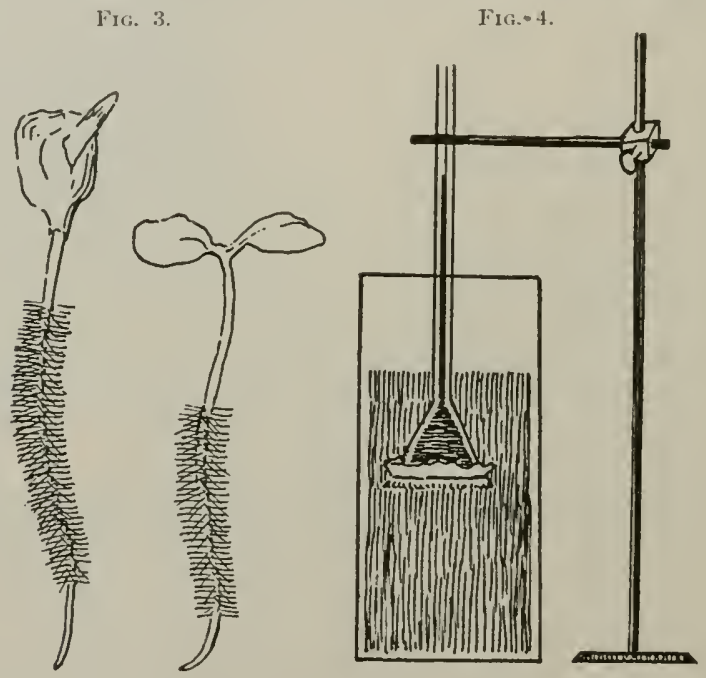

FIG. 3.-Root hairs form on all young roots except at the tip. They greatly increase the absorbing surface of the roots.

Fig. 4.-Osmosis apparatus. A funnel tube with mouth closed by an animal membrane then filled with thick syrup and suspended in water.

garden or farm soil. Usually they must be replenished by the grower.

Other elements required by the plant that are taken largely from the air, as already described, are oxygen $(\mathrm{O})$, carbon $(\mathrm{C})$, and hydrogen $(\mathrm{H})$. Really the oxygen and hydrogen are taken chiefly in the form of water $\left(\mathrm{H}_{2} \mathrm{O}\right)$ which enters the soil from the air and is then taken up by the roots.

Evaporation from Leaves. $\lambda$ s the plant food from the soil must be very dilute at the time it is taken in by the roots, it is 
evident that much surplus water is taken into the plant. This water aids in the circulation of foods in the plant. All that is not needed is evaporated from the leaves into the air. This process is called transpiration of water. This takes place through the little mouths or stomates which are so abundant on the lower surfaces of leaves.

Importance of Leaves.-The great importance of the leaf growth on all our common leaf-bearing plants may be understood when we realize that (1) the leaves make the starches, sugars, and similar products for the plants, constituting about ninety-five per cent of the food of the plant. (2) It is through the leaves that the necessary breathing takes place. (Fig. 5.) (3) The leaves give off to the air the surplus water no longer needed by the plant.

The increasing of leaf growth which is to accomplish all of these purposes, is often the main efforts of the orchardist and gardener. The use of manure and nitrogenous fertilizers aids in the leaf growth. Leaf-eating insects must be kept in control to prevent the destruction of leaves. Pruning may direct the growth in the best parts of the plant.

Bud Formation.-On all plants the leaves are formed from the unfolding of bucls. On the woody plants the buds are formed chiefly in the angles of leaves. They form on the new growth of shoots in spring and early summer, soon after the leaves of that year are well de-

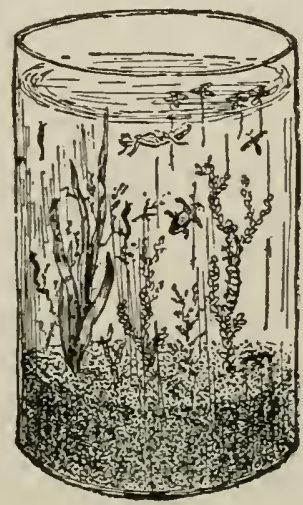

FIG.5.-A self-sustaining aquarium; balanced with plants to supply oxygen and water aninals to supply carbon dioxide. veloped. They become more plump later in the year, and really prepare for winter during the last half of the summer season.

The preparation for winter of fruit trees and other woody plants, usually consists of all or nearly all of the following processes: (1) Buds are formed and covered with winter scales for protection from changes of weather. (2) Hairy or waxy growth is provided to keep out water and ice. (3) In the fall the leaves drop off and the leaf scars are sealed with a corky growth. (4) The green parts of the twigs form thicker bark. (5) The breathing pores on the twigs become closed with corky growth called lenticle spots. The buds and twigs become drier by the retreat of sap. (7) The starch and other forms of stored plant-food become fixed in the buds, pith, and elsewhere. 
Two Kinds of Buds. - Nearly all woody plants, notaly the fruit trees and shrubs, form two kinds of huds-one kind for the formation of flowers and fruit and another for the growth of shoots next year.

These two kinds often differ in appearance enough so that the fruit grower may be able to distinguish between them in the autumn and winter. This is notably true on such trees as peaches, plums, and cherries. The fruit butls are usually shorter or more plump and are less tapering at the point. On these trees there may be one or two fruit buds formed in the same leaf-angle as a shoot bud. Thus if we see two or more buds located together on the sides of twigs, at least one of each group is likely to produce fruit. The grower can often foretell the prospect for fruit.

\section{FIELD AND LABORATORY EXERCISES}

1. Oxygen from Plants.-In a glass jar of water let a large supply of alga or other water plants be placed for growth. Over the plants invert a glass fumnel and a test tube or bottle in a manner to eatch the oxygen given off by the plants. Place the jar in a sunny place for a few hours and test for the presence of oxygen in the hottle by the nse of a glowing splinter. What has been taking place?

2. Disappearance of Chlorophyll.-Place a baard over some green grass so as to exclude the light for a few days. Then note the change in color of the grass Will crops growing in shaded places make as much growth as those in the light? Name some plants that endure shade well.

3. Effect of Available Plant Food.-Compare growth of plants of the same kinds on poor soils and rich soils. What are the chief differences? From which would you prefer to save seeds?

4. Structure of Leaves.-If a strong microscope is available, mount in water on a glass slip a piece of epidermis torn from a leaf. Try several kinds. Study the stomates and the chlorophyll-bearing cells. Also make cross-sections by placing the leaf between two pieces of pith and cutting with a razor. Thin sections will show under the microscope somewhat as shown in figure 1 .

5. Exercises in germination may be devised to show the best conditions for seed growth. After reading the conditions in this chapter, try them by germinating seeds under as many conditions as you can find to show the effects of proper moisture, warmth, and air.

6. Osmosis.- Try some experiments to show osmotic action. (1) Arrange an apparatus as shown in figure 4. Have water in the large glass and a strong sugar syrup in the funnel tube. The membrane tied closely over the funnel inouth may be from a bladeler or from a large intestine used over a piece of sausage. The funnel tube may be extended to any height desired by connecting more glass tubing through short pieces of rubber tubing. (2) An exercise with egg osmosis is described in Chapter I of Productive Farming. Repeat this. (3) Soak a withered poiato or apple in water and explain the results. Soak a fresh apple in strong syrup and explain why it shrivels.

7. Nitrogen in Air.-Invert a glass jar full of air, with the mouth immersed in a vessel of water over which is floating a large cork supporting at small burning candle. The candle will continue to burn for a short time in the jar of air and the water will slowly rise in the jar. When the flame goes out because of 
the exhaustion of the oyxgen, calculate what fraction of the air still remains. This is chiefly nitrogen. After the fumes dissolve in the water study the color and other properties of the nitrogen.

8. Properties of phosphorus and potassium should be studied by following directions given in some elementary book on chemistry .

9. A collection of fertilizer materials should be made by getting samples from dealers. Study these as to appearance, composition, and other properties Put the samples in bottles and label plainly.

10. Leaf Structure.- If a compound microscope is available let each student study the structure of leaves by first making sections and mounting them in water on glass slips. Surface views should also be mounted to study the stomates.

11. Bud formation on fruit trees should be observed during the spring season while the leaves and shoots are growing. How soon can you detect the new buds for the following year? Why are they formed so early?

12. Preparation for Winter.-Try to find on trees all the seven methods mentioned in this chapter by which the tree prepares for winter.

\section{QUESTIONS}

1. Mention the conditions which influence the growth of plants.

2. What can you say of their temperature requirements?

3. What are the three plant societies when classified with reference to moisture?

4. How could you prove that plants need air? How do they get it?

5. Describe examples you have observed showing the light requirements of plants.

6. What is the office of chloropyll? Where is it found?

7. What are the best conditions for germination?

8. What are the uses of roots?

9. Describe an experiment to show osmosis, and give its analogy to plant life.

10. What are the four most essential elements required in fertilizing soils?

11. Trace the function of water in the growth of plants.

12. How do trees prepare for winter?

13. How can you distinguish between fruit buds and shoot buds on a plum or peach tree?

References.-Foundations of Botany, Bergen. Ginn \& Co.; Botany for Secondary Schools, Bailey, Macmillan Co.; Applied Economic Botany, Mel. T. Cook, J. B. Lippincott Co. 


\section{PROPAGATION OF PLANTS BY MEANS OF SEEDS}

NEARLY all farm, garden, and orchard plants are of the seedproducing type. Other plants that do not produce seeds are represented by mushrooms, mosses, and ferns. These bear spores instead of seeds. A true seed contains the embryo of the plant which it is to produce. Spores do not contain plant embryos.

Why Seeds Are Produced.-There are several reasons for the production of seeds.

1. Seeds will live over winter better than the plants themselves. Many plants, called annuals, die in the autumn and their kind live over winter only in the seed form. Examples of this group are tomatoes, corn, beans, melons and many other farm and garden plants familiar to all.

2. Seeds are borne also for the purpose of increasing the number of plants. The number of seeds produced by a single plant is indeed surprising. If we count the number of seeds borne by one strawberry and multiply that by the number of berries on the plant in a season, we will find the product running up into many thousands. Similar results will be found with nearly all plants. Take the tomato, squash, watermelon, cucumber, blackberry and currant as examples.

3. By bearing seeds which are easily distrihuted, plants provide for their spread over extended areas. With many kinds of seeds there are edible portions, as berries and other fruits and vegetables. The edible portion induces animals to carry them away for food and thus spread the seeds. Some seeds, as carrots, parsnips, lettuce and others, are carried by the wind or will float on water to distant places.

How Seeds Are Produced.-Flowers of some kind must always precede the bearing of seeds. In other words, flowers produce the seeds. The essential parts of the flower are the stamens and pistil. The seeds are borne by the pistil as a result of the pollen growth after reaching the pistil. (Fig. 6.)

Other parts of the flower are the more or less leafy growth around the stamens and pistil. These are the petals and sepals and are not found in all flowers. They may serve to protect the essential parts or to attracet insects. 
Flowers of Several Types.-In some cases the stamens and pistils are borne in separate flowers, as in the case of Indian corn, cucumbers, melons, oaks, walnuts, and many others. These are monocious flowers. In other cases the two kinds of flowers are on different plants and are then called diccious. Familiar examples are paper mulberry, willow, poplar, and muscadine grapes. In such cases only the pistillate plants bear seeds.

When stamens and pistils are in the same flowers, the flowers are called perfect. (Fig. 6) We find perfect flowers in peaches, plums, apples, pears, quinces, and the common bush fruits. Straw-

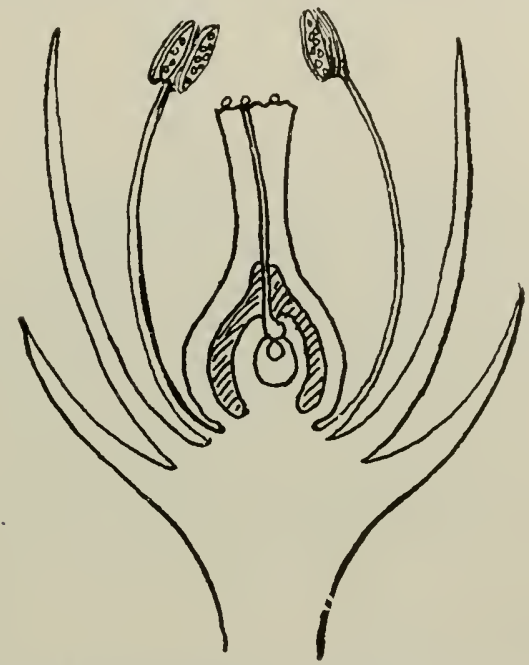

FIG. 6.-Section of perfect flower showing pistil in center with growth from pollen grain reaching the ovule. Stamens shed the pollen. Petals and sepals serve as protection and sometimes attract insects to carry pollen.

berries have perfect flowers in structure but in many varieties the stamens do not develop pollen which will grow on reaching the pistils. Such varieties must have others growing near them which have good pollen. (Chapter XX).

Methods of Pollination.-When flowers have both stamens and pistils they may be self-pollinated and this is very frequently the case. But there are very many varieties of orchard fruits in which the pollen does not grow well on pistils of the same variety. Thus we get better crops of fruit if several varieties of apples which blossom at the same time, are grown together. This is often true of peaches, pears and plums (Fig. 7). 
There are several clistinct plans in nature to prevent self-pollination eren in flowers which have both essential organs. These plans are to help onforeceross-pollination.

1. The stamens may seattor their pollen before the pistil is ready to receive pollen.

2. The pistil may be mature first and may have received its pollen from another flower before the stamens in its own flower have shed any pollen.

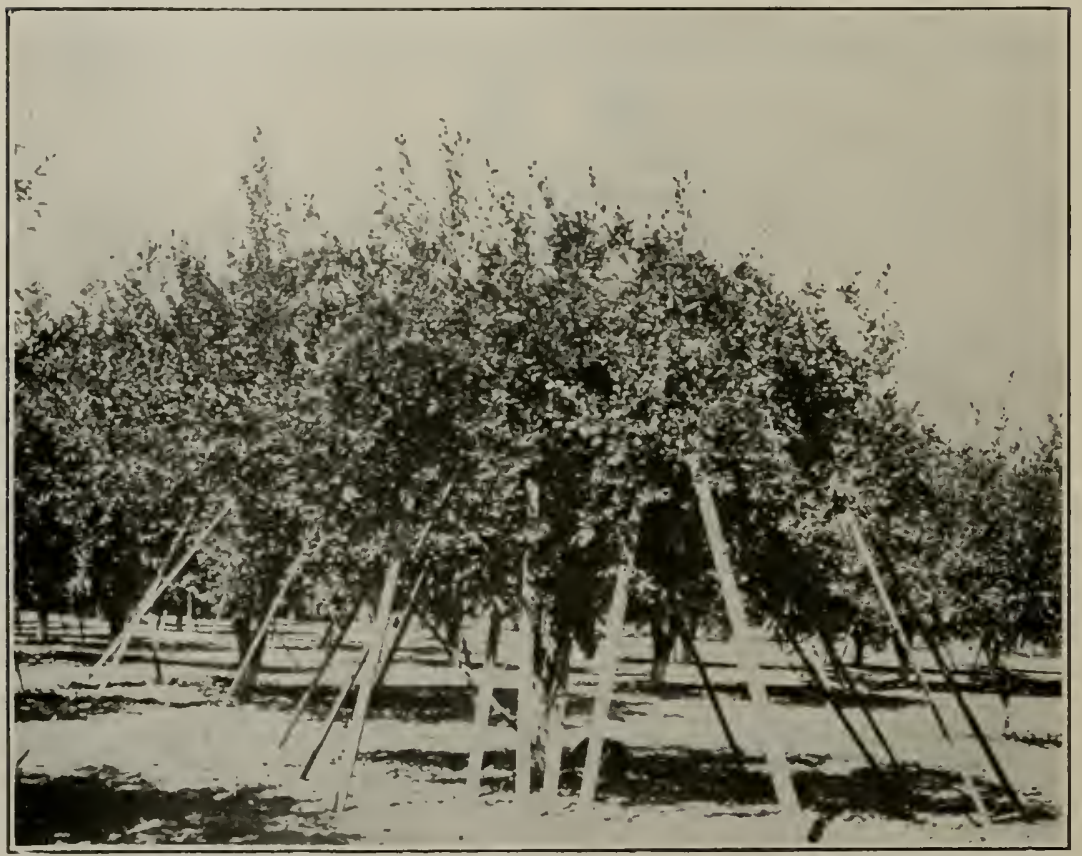

FrG. 7.-Bees aid in pollination of fruit blossoms. A bee hive was placed under this tree at blossom time, thus producing a heavy crop. (California station.)

3. In ereet flowers, sometimes the stamens are lower than the pistil so the pollen does not fall readily upon the stigma of the pistil.

4. In flowers which droop, sometimes the stamens are so much longer than the pistil that the pollen falls away from the pistil instead of upon it.

Cross-Pollination. - Not only is aross-pollination necessary in the four plans mentioned above, but also in the many kinds which have the stamens and pistils in separate flowers. 
There is considerable cross-pollination in nearly all flower.. In many cases, as orchard fruits already mentioned, the pollen carried from one plant to another may be more likely to grow well.

How Pollen Is Carried.-There are two general methods by which pollen may be carried from one flower to another, whether these be on the same plant or on different plants, viz., (1) by insects (Fig. 7 ) and (2) by wind. Of course pollen may be carried by hand on a soft brush. This is often done in greenhouses, and where crossing of two kinds is desired.

Pollination by Insects.- When insects, such as honey bees, are in seareh of nectar or pollen itself, they visit many flowers of the same kind and carry pollen from one to another. The pollen on their bodies and appendlages is rubbed against the stigma of the pistil and the eross-pollination is complete.

Flowers which insects like to visit have (1) sticky or heavy pollen, (2) are showy by having colored sepals or petals, or (3) bear nectar, and (4) are often fragrant. Usually all four of these characters are found in flowers pollinated by insects. ('ommon fruit blossoms are nearly all examples of this type of flowers.

Pollination by Wind.- When the pollen is to be carried by the wind it becomes dry and powdery and is comparatively light. The flowers have no need for being showy and no nectar or fragrance is found. Corn, grasses, some small grains, plantain, and many weeds are examples of flowers pollinated by yind.

Under-ground Pollination.-There are a few plants, as the violet, which hear two kinds of perfect flowers. The showy flowers which we commonly see in the spring, and others borne under the ground later in the season. These are small, closed buds and pollination takes place within them. Later the seed pods of the violet projeet above ground in order to spread the seed. (Fig. 8). Other plants which bear this type of hidden flowers are the hog-peanut, dalibarda and fringed wintergreen. Such flowers are ealled cleistogamous, meaning hidden-union. In such cases nature enforces selfpollination.

Under-ground Seeds.-Most seeds are borne in the air, but the peanut is a common exception to this rule. In this plant the showy flowers are staminate and are borne well up on the stems. Nearer the ground there are small pistillate flowers. After the pollen growth has fertilized these sma!l Howers, the flower stem elongates and they are thrust down into the ground, where the pods and seeds will mature. 
Growth of Seeds.-After pollen grows in the pistil the union with the young seed cells (ovules) is called fertilization. Rapid development of the seeds then takes place. It is a rather brief period from the time of this fertilization until the seeds are of full size. The garden pea develops seeds in a few days or a few weeks after blossoming. In the bush fruits this growth is rapid. Winter varieties of apples require nearly the whole season.

While the plant is developing the seed crop, much attention must be given it. Crood tillage and plenty of available plant food are both desirable. It is a critical time in the life of the plant and

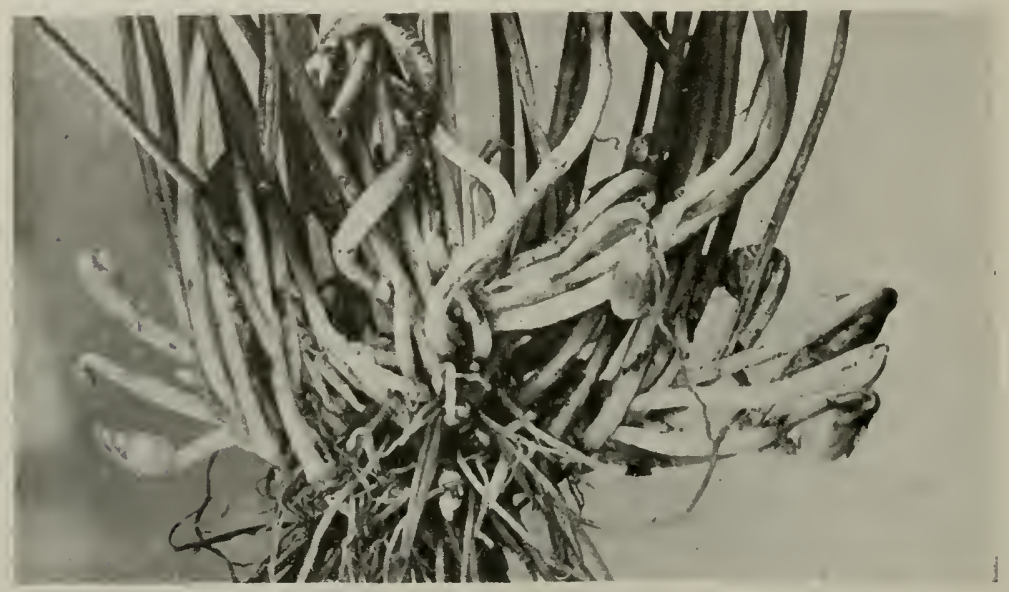

FIG. 8.-Cleistogamous or hidden blossoms at the base of a violet clump. (U. S. D. A.)

many crops of fruit and seeds are reduced by improper conditions during this time.

Store of Nourishment in Seeds.-The plant stores up a considcrable amount of nourishment in its seed crop. This explains why the maturing of seeds is so devitalizing to the plant.

The food stored in seeds sustains the life of the young plant until it is able to obtain nourishment through its roots and leaves. It is because of this store of nourishment that we use seeds of so many kinds for human food and for stock feed.

\section{SAVING GARDEN SEEDS}

Gardeners, both young and old, should save garden seeds more systematically. In many cases much better results can be obtained if we save seeds from our own gardens. 
Seed Selection.--In deciding just what seeds to save some attention must be given to the points desired in the crops. With many varieties of corn, tomatoes, beans, peas, and others, earliness is very desirable. Mark those plants which mature the crop in least time and save seed from those. Other qualities in tomatoss are proportion of flesh to seed pulp, smoothness of surface, color of fruits, and resistance to clisease.

In all crops choose seeds from the best and the next crop will be much improved.

Securing the Seed Crop.-When the gardener has decided what specimens are best for seeds he may mark them by tying strips of white eloth to the stems where they are growing. If the fruits are pulpy, as in the case of tomatoes, watermelons, squash, cucumber and others, the seeds may be easily washed from the pulp in a pan of water. The use of a sieve or strainer will help. When clean, spread the sceds out on papers in a sumny place until dry. Then put them into envelopes or pockets of folded paper. Properly label each lot and make such memoranda notes as desired.

Dry seeds, such as corn, radish, lettuce, onions, and others may be put into their envelopes right from the garden.

Storing Seeds. - Suitable places for storing seeds may be found in every home. They must be sealed in envelopes or boxes or these containers may be put into cans or jars with tightly fitting covers. This will keep out weevils, moths and mice.

They should be stored in a very dry place. Near a chimney in the attic may be best. After all surplus moisture has dried away, freezing does not hurt them.

Infested with Pests.-When seeds or stored products become infested with weevils, moths, or similar pests, they should be treated very early with carbon bisulfid. Put the seeds into a vessel that can be tightly closed. Set a small open dish containing the liquid in the top of the seed chamber and close it quickly. Use one teaspoonful to a space of two gallons or less. Or use one pint to about one thousand cubir feet. Keep the container closed for several hours, say over night. The liquid evaporates and penetrates all the space, killing every living insect. The eggs may hatch afterward and a second treatment may be necessary. This may be done about two weeks later. Have no flame near when the treatment is started, as the carbon bisulfid is very inflammable.

Seed Sources in America.-Many of the vegetable seeds of the temperate zone are grown under contract on farms in regions where 
the same crops are grown for market purposes; tomatoes in New Jersey, New York and Miehigan. ()kra in Ceorgia, Alabama and Mississippi and other southern states. The differulty of securing grood seeds for market is greatly increased for biennials, such as abbage, cauliflower, sugar beets, and garden beets. Whike much seed of this class came from France, the world war made it necessary to ehange the source of supply. California came to produce more beet, onion, cauliflower and cabbage seeds than before. Study elosely the map, figure 9.

Trial Grounds for Seeds.-Many large seed companies maintain trial grounds for seeds (Fig. 10) Three main purposes are in

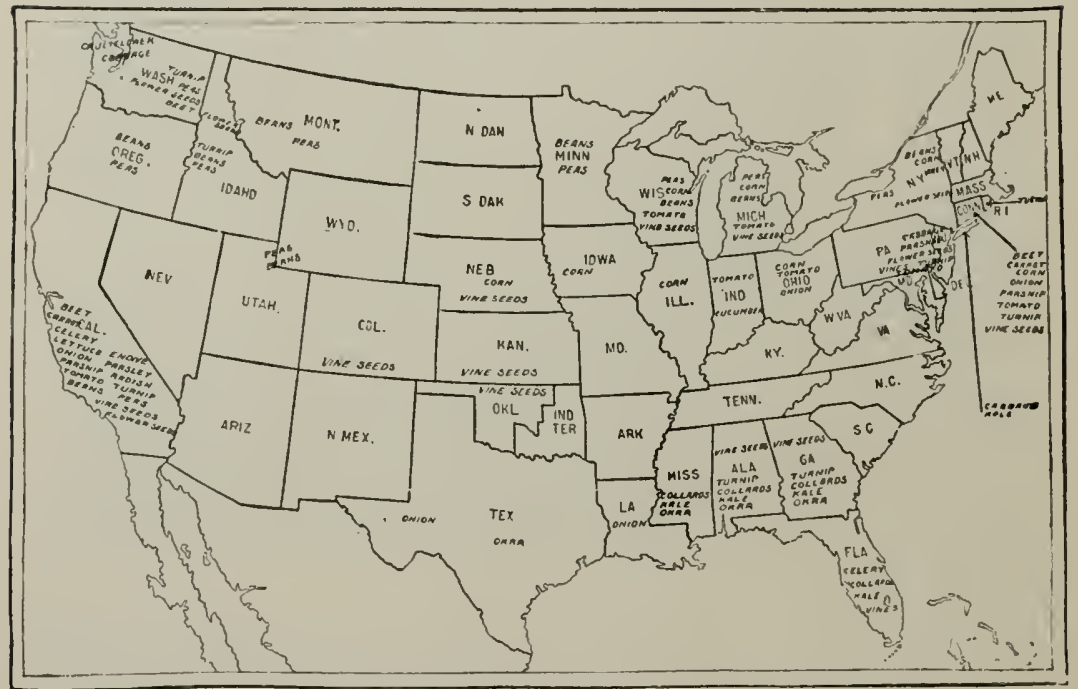

Fia. 9. - Chief sources of vegetable and flower seeds of the Lnited sitates. (I. S. D. A.)

view. (1) To select and breed new varieties. (2) To firmly establish and fix the most promising varieties before offering them to the public. (3) To test the uniformity and stability of new varieeties that are offered by other growers.

Buying Seeds.- It usually pays to study garden seed catalogs earefully. Much maty be learned ly such study. Some catalogs are too high in their praises of new varieties. In some ("ises thesere are old varieties under new names. In other cases they prove to be very similar to old varieties. "Be not the first by whom the new 
is tried." Try to select the variety that will suit your purpose, your soil, and your market. If yellow sweet corn is grown for a market demanding white corn, a great mistake is made. Some markets demand pink-fleshed tomatoes and will hardly take the yellower ones. Do not plant the large potato limas if the small prolific varieties are preferred. Early varieties of potatoes should seldom be grown for winter use. Others keep better.

In selecting garden seeds consider: earliness, bearing qualities,

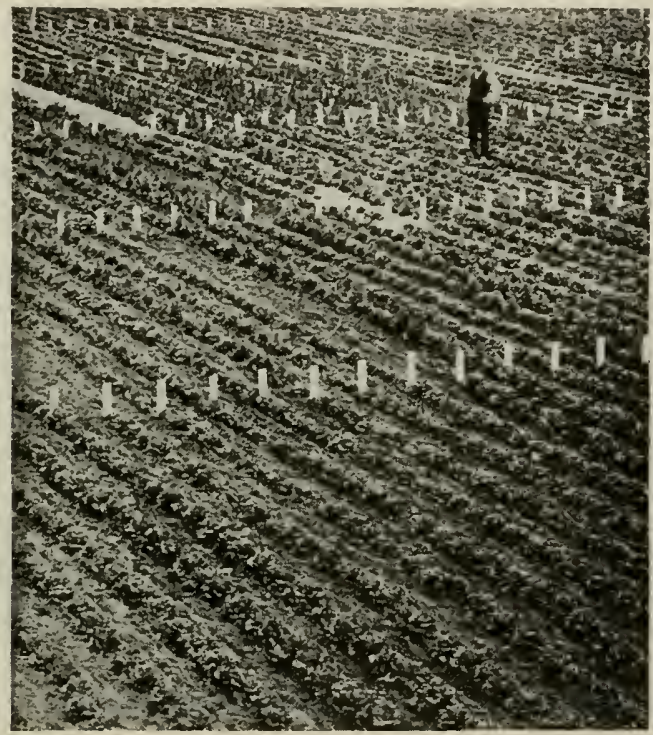

Fig. 10.- Seed companies test many of their seeds, particularly new varieties, before they are offered to the trade. (U. S. D. A.)

freedom from disease, endurance of heat or cold weather, freedom from waste in using the product, popularity, keeping qualities, etc.

Longevity of Seeds.-Old seeds are always less desirable than the fresh stock. Many kinds of seeds deteriorate rapidly with each year of age. Those kinds containing considerable oil in the storage matter are believed to endure less than others. If they are kept in very dry places the germs in seeds will live much longer.

Detecting Age of Seeds.-Old seeds may often be detected by their dull color or faded appearance. To overcome this appearance 
old seeds are sometimes polished or bleached or are mixed with fresh seeds.

Testing Seeds.-Probably the best way of detecting the value of seeds is to test their power of germination. If ninety or more out of a hundred will germinate well they may be used for planting. This would indicate maturity, good storage, freshness.

Simple Testers. - It is usually not necessary to purehase any apparatus for seed testing, either at bome or at school. A rag-doll tester, made of a piece of cloth, is one of the most satisfactory. (Fig. 11).

Mark the cloth with a soft lead pencil into areas about three or

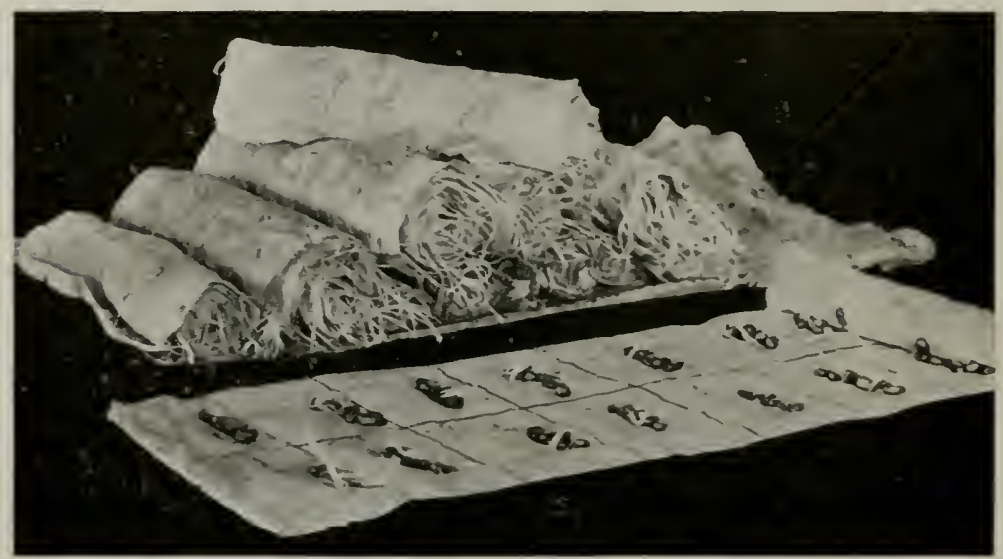

F1G. 11.-Rag doll method of testing seed corn. Each roll of cloth contains the sample kernels from about twenty or thirty ears. The open cloth show the variations in germination. (Photo from Iowa Esposition Stations).

four inches square. On each square mark a number and place a sample of the seeds to be tested. Use 25 each for large seeds, and 100 each for small seeds. Fold in the sides of the cloth. Then roll it up on a small stick the size of a pencil, and tie the roll. Slip out the stick to admit plenty of air. Soak it for an hour or two. Then allow the surplus water to drain off and keep it covered to hold the moisture, for a week or so. Examine by unrolling so carefully as to not displace the seeds from their own squares. Count how many sprout well and determine the percentage.

Testing may be done hy keeping the seeds moist on blotters between plates or pie-pans. They may also be sprouted in boxes of moist sand or soil. 
Seed Analysis.-There are three purposes of seed analysis: (1) to detect the presence of good seeds of other kinds which may be mixed with them; (2) to determine the kinds and percentages of weed seeds present; (3) to determine the amount of inert or clead matter present, such as chips, pulp, gravel, dirt, etc.

Detecting Impurities in Seed Samples.-Count out, or weigh out a fair sample of the seeds after thoroughly mixing the mass of soeds together. The sample should be examined by use of a hand lens. (Fig. 12.) The seeds may be placed on a piece of white paper in a very light place. With a wet pencil point pick up and sort them into a number of piles: (1) good seeds; (2) shriveled or small secds; (3) foreign good sceds of several kinds; (4) inert matter; (5)

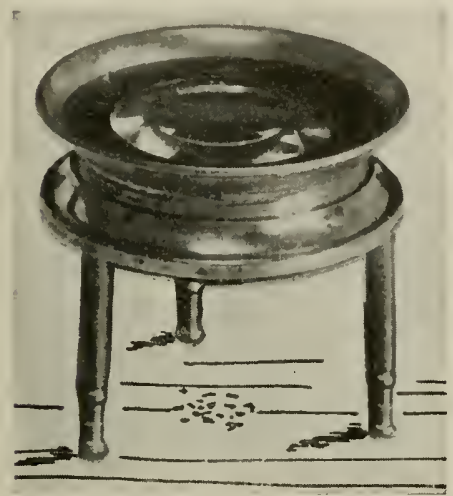

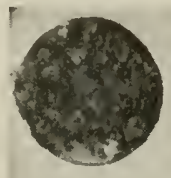

Curled Dock

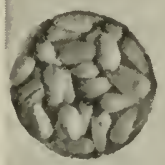

Saffron

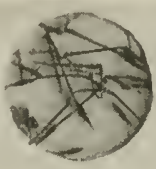

Alfilaria

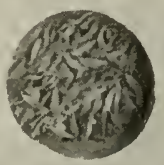

Curled Let tuce

FIG. 12.-Such a lens will aid in detecting weed seeds before planting. Four kinds of weeds are shown at the right, mounted in holes of heavy cardboard.

weed seeds in as many places as there are kinds. Then by count or by weight determine the percentage of each of those to the whole sample.

Buying Seeds by Sample.-If possible a sample of seeds should be examined and tested before a quantity of them are purchased.

State Analysis.-Many states now have laws requiring all or many common seeds to be sold only after they have been analyzed by the dealer or by the state laboratories. A guarantee of quality then goes with the seeds. If they fail to reach the standard the buyer is protected by the dealer. Where such laws are in operation the examination of samples before purchase by the grower is not so necessary. 


\section{HOME PROJECTS AND FIELD AND LABORATORY EXERCISES}

1. Methods of Pollination should be studied in the apple, peach, plum or cherry, and in the bush fruits. Also study the wild rose blossom as to the relation of stamens and pistil. Make similar studies with peas, sweet peas, beans, encumber, tomato, okra, and all blossoming plants in the garden. What oncs scem to have plans to prevent self-pollination?

2. Pollination by Insects.--Nake a list of vegetables, fruits, ormamental flowers, and weeds that are visited during the flowering stage by insects. Which ones have nectar or are fragrant? Which ones attract insects by their color only? Mark those that have sticky, heavy pollen.

3. Seed formation should be studied when blossoms are dropping their petals and losing their bright colors. Examine all common regetables and fruits during this stage, and a little later as the seeds or fruits are developing.

4. Food storage in seeds should be demonstrated by cutting open, dissecting, or sectioning seeds of several different types, such as corm, beans, peas, squash, apple, peach, ete. Test for starch by use of jodine applied to the cut surface of corn. Test for oil by mashing peanuts, castor beans, and others rich in oil. If mashed on white paper they will leave a grease spot. Test for sugar by using Fehling's solution from a drug store. Sections heated in this solution over a flame, will turn an orange color, if glucose is present. Taste the prussic acid in pits of peach, plum, and almond.

5. Appearance of starch grains may be studiea with a strong microseope.

6. Choice of Seeds.-Practice the selection of seeds in the garden. Compare plants from which seeds are to be saved, with others in the garden. Bear in mind earliness, quality, smoothness, or other market characteristics, abundance, resistance to disease, etc.

7. Seeds for Market.-A good home project for students is to produce seeds for market. Grow them, select, cure, store, label, prepare them for market, advertise and sell them.

S. Contest in Seed Saving.--Students may enter a contest to see which ones can save the largest variety of garden seeds (1) from their home gardens, (2) from the whole community. Compete for first, second, and third places in the contest. Get enough of each kind to plant a small home garden.

9. Testing samples of seeds for germinating power is a good exercise for winter or any other season before planting. Examine the same samples for signs of age, insect injury, etc.

10. Identify impurities found in the samples, and calculate losses if seeds were used having these impurities.

11. State regulations regarding purity of seeds should be obtained from the state experiment station or the secretary of agriculture. Compare the results in exercise No. 9 with the legal requirenents.

\section{QUESTIONS}

1. Enumerate three reasons for the production of seeds.

2. What is the relation between flowers and seeds?

3. Explain what is meant by the terms monceious, dinecious, and perfect flowers.

4. Mention four plans in mature to prevent self-pollination.

5. What are the characteristics of flowers that are pollinated by insects? By wind?

6. Mention some plants that bear seeds under ground. What plan in nature provides for this"?

7. What classes of food are sometimes stored in seeds?

8. Of what use is this food to the plant? 'To animals? 
9. Give reasons for saving seeds from the home garden,

10. How may they be labelled? How stored?

11. Give some valuable precautions in buying seeds.

12. Describe some good methods of testing seeds.

13. What are the benefits of seed testing?

14. What are the duties of a state seed analyst?

15. Of what value is state analysis to the grower? To honest seed dealers?

References.-U. S. Farmers' Bulletin: 382, Seed Adulteration; 415, Seed Corn; 434, Onion Seeds and Sets; 533, Good Seed Potatoes; 646, Crimson Clover Seed; 676, Hard Clover Seed; ;785, Seed-Flax Production; 948, Ragdoll tester. 


\section{CHAP'TER III}

\section{PRINCIPLES OF PLANT BREEDING AND THEIR APPLI- CATION IN GARDEN AND ORCHARD}

$\mathrm{By}$ plant breeding is meant the systematic raising or reproduction of plants either with or without an aim toward improvement. When gardeners or orehardists observe certain individuals or types with eharaeteristies which should be perpetuated, they may seleet these individual plants for breeding purposes. The points observed will probably be more or less noticeable in the offspring.

Causes of Variation.--It is said that no two plants are exactly alike. There is constant variation in nature between individuals even of the same kind. These differences may be noticeable or not by the grower. This tendency to vary from each other makes it possible for the plant breeder to select characteristies which he desires. This gives rise to new varieties and new strains. Careful observation is required to select the desired types. It is necessary to keep these ideals constantly in mind in establishing new varieties.

Among the eauses which tend to make plants vary may be mentioned (1) shade and sunlight, (2) differences in soil and variation in plant food, (3) proximity of other plants, that is, whether crowder or not, (4) weather and climate. Dandelions growing in dense high grass will grow tall; those growing in closely mowed quarters blossom near the ground. Many variations oceur in nature which cannot be explained by any of these causes.

Survival of the Like and Unlike.-Heredity is one of the most important factors for the plant breeder to study. This is the law, that all creatures inherit from their ancestors certain forms, characteristics, and qualities. The law of heredity may be expressed briefly by saying that "like produces like" and "similar produces similar."

Heredity, linked with natural variations are the two fundamental factors which when placed in the hands of the skilful breeder will attain wonderful results. Varieties without end are formed and yet these beeome so well established that the grower ean eonfidently depend upon their reproduction in garden, orehard, or farm work. 
If the survival of the like were an alssolute law there would be no possibility of change and all our plants would be alike. The enviromments of the plants set up variations and we may find that plants which are unlike are decendants from the same parents. These various forms may suit the different environments into which they may fall and the result is a survival of the unlike. Take the muscadine grape, for example. We find in nature numerous varieties, all apparently traceable to the same common parentage. $\mathrm{By}$ the aid of men, the varieties found among all garden and orchard plants are greatly improved and their characteristics fixed more firmly.

Extreme or Sudden Variation.-Mutation is a name given to any extreme or sudden variation from a type which we have been growing. The term "sports" is sometimes applied to these sudden variations. It is fairly well established by De Vries and others that the characteristics shown by mutations may be inherited by their offspring. Thus new extremely different varieties may be established somewhat quickly.

Reversion.--Any tendency of the plants of a new generation to assume forms differing from their parents, but resembling generations farther back, is called reversion. If variations are established by propagating mutants, or those with sudden variations, it is common to notice certain individuals in the line reverting to the old type from which the sudden variation sprang. The plant breeder may find it necessary to throw out all individuals showing this tendency to revert to the old forms. He must keep clearly in mind his ideal and select those individuals which show a strong tendency in that direction.

Influence of Soil and Surroundings.-The environment of plants has a strong influence upon their manifest characteristics. When the plant breeder is making his selection, he must note carefully the surrounding influences. Plants adapt themselves to their surroundings. Plants of the same origin glown in different soils may show very different results. Fertilizer and tillage should be uniform in all plant breeding plots.

It is believed by many scientists that the differences due to surroundings may be inherited by the offspring. The practices of some plant breeders are based upon this belief.

Power to Impress Characteristics.--Prepotency is the term given to the power of plants to project or impress their own characters upon their offspring. Some individuals fail to mark their 
offspring with their own individuality. Others have this power in a marked degree. When two parents are used which differ in certain respects, one or the other must dominate in fixing their differences upon the offspring. The characters which prevail are called dominant characters; those which are overshadowed are called recessant characters.

Breeders will naturally find it advisable to breed from those individuals exhibiting strong prepotent qualities.

Careful Selection.-The plant breeder will find it necessary to destroy hundreds and thousands of individuals in the selection of a few which meet his ideals. Great skill is required to do this. He must observe the many ways in which the individuals vary. He must weigh in his mind the practical points and the fanciful points. It is necessary for him to choose among these and retain those most desired. An effort to hasten the improvement of plants is exercising the powers given man by the Creator. This is an argument

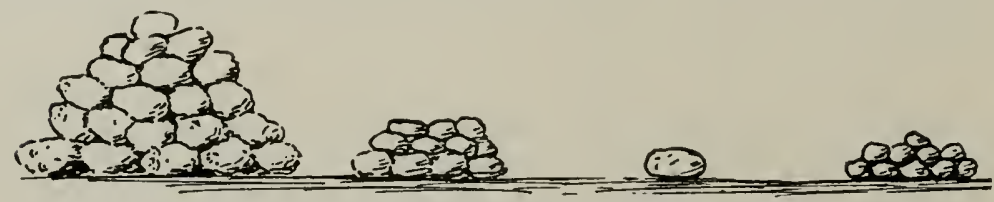

Fig. 13.-Two piles at left are the first and second grades of crop from good seed potatocs. Those at the right are from poor seed.

in favor of artificial selection. (Fig. 13) In nature, selection seems to be careless. The power of man's mind adds greatly to the improvement of plants and the establishment of varieties which yield infinitely better products than those found in nature. The importance of seed selection is shown in figure 14 .

The breeder must know the history of the type which he is trying to develop. He should keep the practical or economic aspect strongly before him. The laws of variation and heredity must be strongly in his mind.

Hybrids.-New forms are often created by crossing rather distinct forms. Pollen taken from one variety of apples and crossed on other varieties would produce seeds which are called hybrids. A Japanese plum of one variety may be crossed with a variety of European plum or American plum. The resulting offspring would be called a hybrid.

This method of producing new varieties of plants is quite commonly practiced by plant breeders. 
The process of pollinating the pistil of one plant with pollen from another is quite simple. A soft, camel's hair brush is rubber on the stamens to secure the pollen. This may be dusted into a small vial and properly labeled. When it is carried to the plant bearing the pistils the flowers must be emasculated; that is, the stamens should be clipped out with a pair of fine pointed scissors before the pollen is shed on the pistil. The new pollen from the vial is then dusted on the pistil with the soft brush. Paper bags

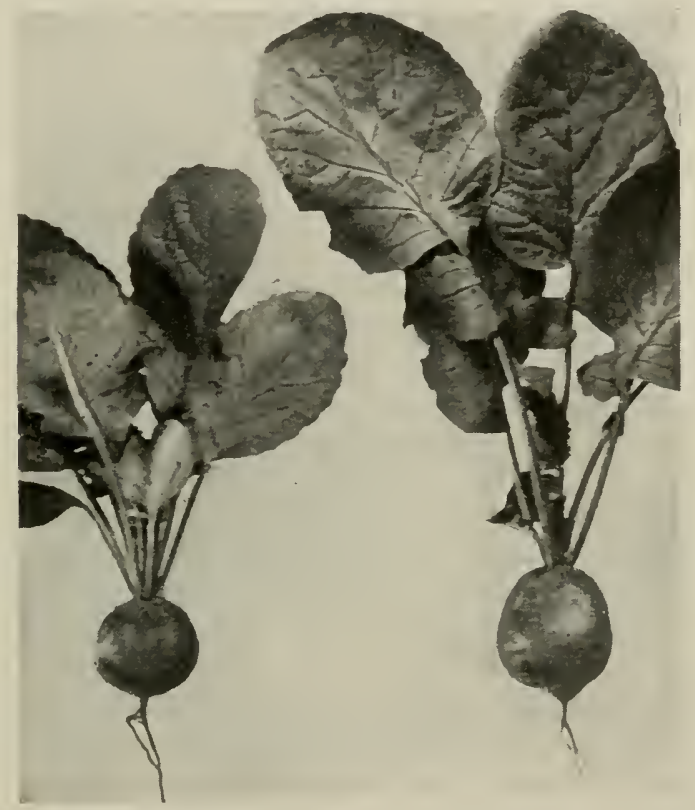

Fra. 14.-Relative sizes of radishes grown from small and large seed.

tied over the flowers will keep away the foreign pollen which might otherwise be brought by bees and wind.

Home gardeners will find much interest in studying the methods here described and they may be tried with such instruments as may be found in any home.

Mendel's Law of Fixation of Type.-When plants of different type have been used in plant breeding to form new types or varieties, the offspring will continue to vary in their characteristics and several generations will be required to reasonably fix the new type. 
Mendel formulated a law governing the rapidity with which plants tend to become fixed in their characters after the original crossing. If we consider one pair of eharacteristies, for example, wrinkledness and smoothness of garden peas, we find that in the first generation the seeds are all smooth, but in the next one fourth of the individuals will be pure wrinkled peas; one other fourth will be pure smooth peas; the other two fourths will bear the dominant characteristies of smoothness, but these two fourths will really be mixed.

In the next generation of those which are mixed one fourth will come as pure wrinkled, one fourth as pure smooth, and two fourths as mixed but having the dominant character of smoothness. The student will see that it will take many generations to entirely eliminate the mixed elements if this law continues to hold good for many generations.

Results of Mendel's Law.-It is readily seen that by the law there will always be an element which is mixed and which will never come true to the original type nor true to either of the pair of characteristies under consideration. If yellow and pink tomatoes are crossed, there will always be a number of individuals showing one or the other of the parent characteristics. We would expect never to be able to establish pure seed after erossing.

It is because of this law in nature that fruit growers abandon the propagation of apples, pears, peaches, plums, and other orchard fruits by means of seed. Other methods of propagation are deseribed in the next ehapter. When plants are propagated by buds, they come more nearly true to the original form and variation is eliminated.

Limits of Mendel's Law.-Plant breeders at the experiment stations in the different states and elsewhere have conducted trials many of which vinclieate the truth of Menclel's law.

The usefulness of the law, however, is limited because of the fact that it recognizes only one pair of characters at a time. In corn breeding, for example, one dominant character and the reessive character corresponding to it are all that can well be considered at a time in the numerieal formulas of this law. Yellow corn is dominant over white corn. While we are trying to select a pure type after crossing eorn of two different colors, we are certain to lose sight of some of the other characters which are perhaps more important.

Many pairs of Characters to be Considered.-If we continue the illustration of breeding, we will see that there are numbers of 
pairs of characters to be borne in mind by the grower who is trying to improve the strain. Some of these pairs may be mentioned here: white and pink cobs; long and short ears; large and small cobs; deep kernels and shallow kernels; ears high on the stalk or low on the stalk; many ears and few ears on the stalk; abundant suckering and little suckering; large stems and slender stems separating the ears; early maturity and late maturity; ear protruding beyond the shucks or well covered with the shucks.

In the breeding of any plant we will find numerous pairs of characters one of which is always dominant over the other. In deciding what pairs of characters to use or to keep uppermost in plant selection, the breeder should determine which are most practical or useful to man.

Pedigreed Seed.-Gardeners saving seed from their own plants know the history of those plants better than when seeds are purchased elsewhere. If plants of one variety, tomatoes for example, are grown in the home garden, the grower knows that there have been no tendencies to cross with other varieties. The seed is perhaps purer than any he could buy from the neighbors or growers where several varieties are produced. The term "pedigreed seed" simply means that seed is grown, the producer having knowledge of the parents, grandparents, etc. (Fig.15).

Need of Attention to Improvements. - It is important that the grower as well as the plant breeder should give attention to the improvement of plants. Too often we allow good varieties to deteriorate because of little attention to improvement. Selection should be practiced constantly, not merely for a generation or two. The gardener can easily watch for mutations and favorable variations which if used will greatly improve the strain or help to establish better ones.

Take the strawberry, for example. In any variety we find berries which far surpass those about them. They may be earlier, larger, sweeter, finer, more prolific, less subject to drouth, etc. Plants formed by runners from these may be used to start new beds with very satisfactory results.

The Peach.- Some seedling peaches come rather true to the parental characters. Others vary considerably. Probably this is because of pollen being introduced from other sources. The orchardist will be able to detect the best seedlings and find very promising variations. By taking buds from the best individuals, a nursery may be started and a new variety is the result. Our 
purpose should not be to multiply varieties needlessly. It should rather be to obtain products that are better than the best. Such an aim is a worthy Gie.

The Tomato.-When people are canning tomatoes or slicing them for the table, they will notice wide variations in the proportion of flesh to seed pulp. A little observation will show certain individuals with tough skin which would allow the fruits to be handled without much damage. Some individuals are deeply lobed and cause waste of the fruit at paring time; others are bad in color;

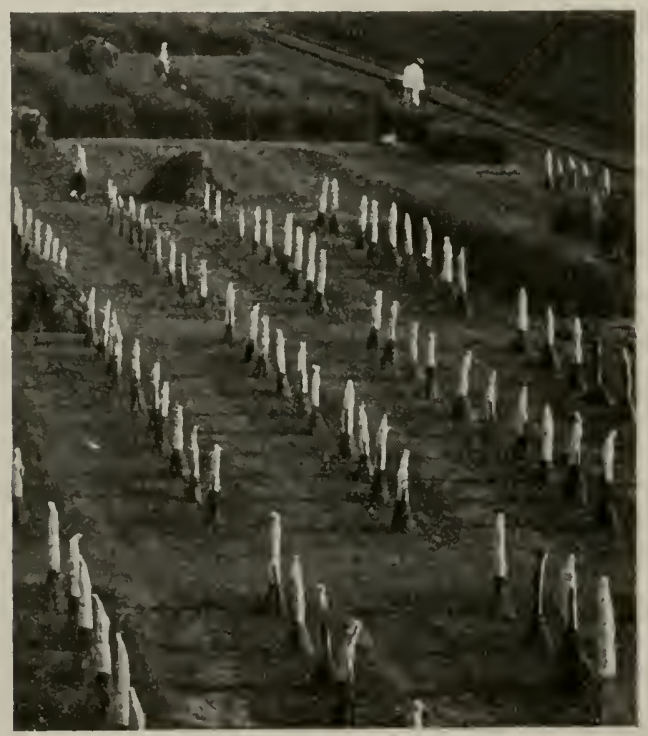

Fra. 15.-Breeding plots of plants must be protected from sparrows if comparisons are to be made in yield, ete. (Minnesota Station.)

still others may rot hadly, and some plants may suffer from blight. By saving seed from individuals that are most perfeet in all these characteristies the gardener is establishing a most benefieial practice. It may result in improving tomatoes for all the world.

Improving Seed Potatoes.- In saving seed from Irish potatoes (Fig. 16) and from sweet potatoes, we must remember that we are saving the buds or the roots from the parent plant. There is no pollinating or crossing involved in either case. If we save seed potatoes from the most productive plants, the tendency will be to 
increase production. If these potatoes are small, the offspring will tend to be small, if large the offspring will tend to be large. By noting the yield from each hill or plant, we are able to greatly improve our seed supply.

The yield of each plant can be saved separately by placing them in separate bags. Give each bag a number. Next season plant each of these lots in separate rows with stakes indicating the number. Then test the total yield of each row.

If each hill in this generation is saved for seed in separate bags, the best of the best will show greatly improved yields. We will find the results multiplied many fold. This is called the hill-row method of improving potatoes.

Corn Breeding.--Every corn grower should have some system of producing his own seed corn. He may have a seed plot where

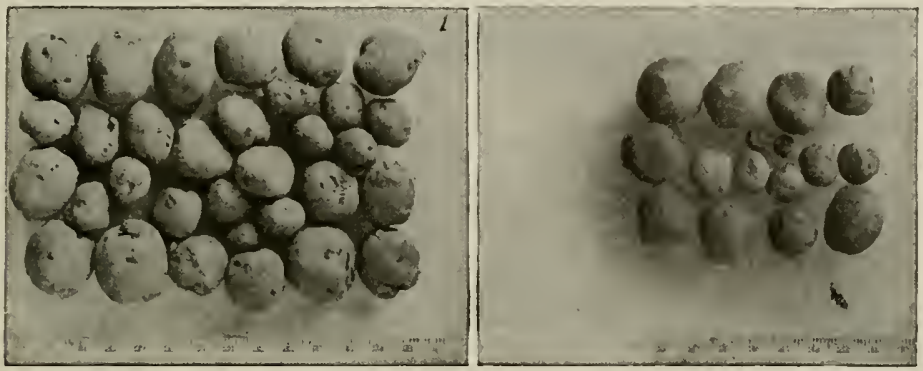

FIG. 16.-Good seed produces more than poor seed. These yields were from the same amounts of seed potatoes.

he does the selecting very carefully. He should have this plot located where pollen cannot mix from nearby fields. Many gardeners and farmers select their seed corn from the westerly side of the main field because the wind prevails from that direction and little if any mixing occurs from the east side of the field. If the best corn is planted each year the continued improvement will be very noticeable. It is a well established fact that corn is more vigorous when not self-pollinated. If pollen is obtained from other stalks of the same kind, the seed will be more vigorous. To insure cross-pollination, the tassels from every other row may be cut off before they scatter any pollen. Then the seed corn may be saved from the detasseled stalks.

It should be remembered that there are in all fields a few stalks which are barren or nearly so. These stalks should never be allowed 
to pollinate the seed ears. In other words both parents of the seed corn should be vigorous and productive. The barren stalks mity be cut out or their tassels cut off before any pollen is scattered by them.

To avoid cross pollination with nearby ficlds, seed corn growers plant their fields at long distances from other fields. They sometimes grow belts of willows or other trees between the different varieties.

The Ear-Row System of Improving Corn.- Suppose we select the ten best ears of eorn from a given garden or field. We may plant the seed from each of these ears in a row by itself. Compare the yield from each of these rows and select the best ears for seed from the best row. If desired, we may continue the ear-row method and continue to select from the best, indefinitely. Home gardeners will find this method entirely practical and beneficial.

Size and Weight of Seed.-If several samples of garden seeds are sorted by means of sieves into different sizes, it will be found that the largest seeds will give best results. With grains which are usually weighed instead of measured when purehased, it has been found that those which weigh heaviest for the measured bushel are most produetive.

The lesson to be learned here is that we should select the heaviest and best seeds when saving or buying seeds to plant in our home gardens.

Sifting and Weighing.-It pays to sift seeds through sieves which will separate the large seeds from the small. Not only will the best seeds be thus obtained for planting but many weed seeds may be eliminated. W'hen grass and elover seeds are to be sown in the home grounds, they should be earefully sifted and weighed to determine the proportion of seed and ehaff. Light seeds may be blown out by means of the fanning mill or other forms of seed eleaners.

\section{HOME PROJECTS, FIELD AND LABORATORY EXERCISES}

1. Studying Variation.-In a thick patch of weeds or other plants, note the variation in height, size of stem, number of leaves, color of foliage, and other characteristies. Explain as many of these differences as you can.

2. Extreme Variation.-Find examples of extreme variation in wild or tame fruits, or other plants. Of what advantage could these be in developing new varieties or strains?

3. Selection by Growers.-Visit truck gardeners, fruit growers, or professional plint breeders. Ask them to show results of careful selection in developing new strains. 


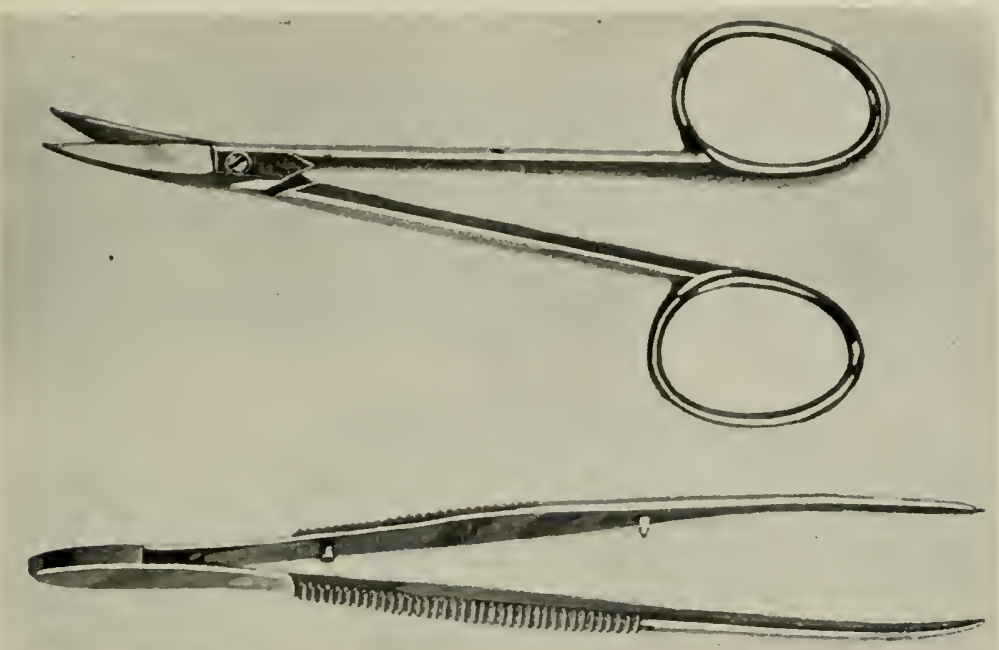

FIG. 17.-Tools used in removing stamens before they shed pollen. The operation is called emasculation.

4. Artificial Pollination.-With fine pointed scissors (Fig. 17) and fine soft brush practice artificial pollination of any flowers that may be available. Begin with large flowers first if possible. Also pollinate monœeious and diœcious blossoms that do not need emasculating. Tie paper bags over the crosspollinated flowers (Fig. 18) and note results to see if pollinating was successful.

5. Hybridizing.-A good home project may be conducted in hybridizing of plants. For example, collect pollen from five varieties of tomatoes, using a soft brush and small glass vial for each variety. Then pollinate twentyfive emasculated blossoms with each of these five kinds of pollen, making 125 blossoms in all. Bag and label each of these. The label should show the name or number of each parent. Study the results when the fruits ripen. Save the seeds of each specimen, and number them to agree with records kept of the crosses. Compare the specimens in all characteristics, such as earliness, smoothness, firmness of flesh, size, proportion of flesh to pulp. Plant the seeds of each and continue the project for one or more seasons, selecting the most promising strains developed.

6. Improving Seed Potatoes.Grow potatoes by the hill-row system. Stake and label each row or section. Compare the vields of potatoes planted from each hill. Again select the best

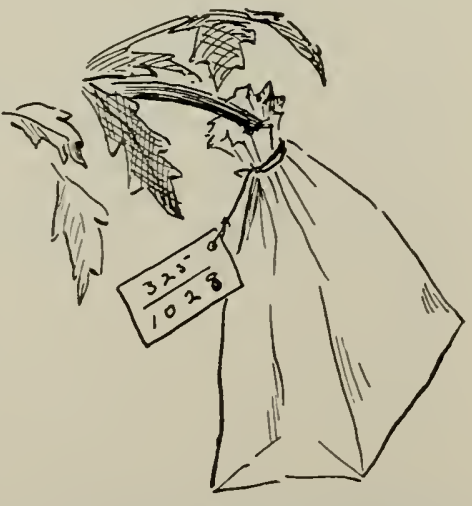

Fig. 18.-After hand pollination the flowers are "bagged" with paper to prevent other pollen from entering. Numbers on the label indicate the parentage. 
hills from the most productive row, and continue the project for one or more seasons.

7. Corn Improvement.- Seleet the best ears of corn in the field or garden. Plant the seed from each ear in a row by itself. Again seleet the best ears from the most productive row. Continue the project as long as desired. This is called the ear-row system of corn improvement.

S. Improving Peaches. - In the peach orchard seleet a tree that produces better fruit than any others of its variety. Use buds from this tree in propagating new peach trees, as deseribed in Chapter VI. Some of the buds may be used on trees of bearing age. They may yield fruit sooner than those budding on young stocks. Compare the fruits thus produced with others. If the improvement is pronounced, and is thus shown to be well fixed, the strain may be given a new name.

9. Weight of Seeds. - Visit an implement house or seed store where a fanning mill may be studied. If possible obtain permission to run a peck or a bushel of seeds through the machine. Weigh the sample before and after. Note the clifference in weights of a quart of uncleaned and cleaned seeds. study the cleanings. This exereise may be continued is a projeet by growing a sample of the cleaned and uncleaned seeds and comparing the yields. Calculate the advantage to the whole state if seed cleaning were practiced by all.

\section{QUESTIONS}

1. What are the most important causes of variation among plants?

2. What is meant by heredity? State the law briefly.

3. What is meant by the term "sports" in plant breeding?

4. What is De Vries' teaching regarding their use?

5 . What are the effects of reversion in plant breeding?

6. Explain the meaning of prepoteney.

7. How would you explain the importance of careful selection?

S. What are hybrids?

9. What is Mendel's law of fixation of type?

10. In what way is this law limited in use?

11. Give an example of the resuts of Mendel's law.

12. Give some advantages of using pedigreed seed.

13. Give an example of the value of attention to improvement.

14. How eould the peach be improved by a plant breeder?

15. State the same for the tomato.

16. Deseribe the hill-row system of improving Irish potatoes.

17. Outline a plan for improvement of corn.

18. Explain the use of a fanning mill in improving yields of erops.

References.-U. S. Farmers' Bulletin, 884, Saving Vegetable Seeds; Cornell Reading Courses No. 38, Principles and Methods of Plant Breeding; Improvement of Cotton Seed by Selection, Year Book, U. S. Dept. Agriculture, 1902, pp. 363-386. 


\section{CHAPTER IV}

\section{PROPAGATION BY UNDERGROUND PARTS}

Br plant propagation we mean the multiplication of plants by any means, with the intention of securing a number of individuals of the same kind as the parent stock.

\section{BY DIVISION OF ROOTS}

A great many perennial herbs and woody shrubs have buds near the crown, just beneath the surface of the ground. In nearly all such cases the plant may be dug up and the parts separated by splitting, cutting, or otherwise dividing the underground parts.

Important Conditions.-Roots bearing some of the buds near the upper part will be likely to grow when properly planted in a new place. The important point is to have some healthy buds with plenty of root surface. (Fig. 19.)

Herbs Propagated by Root Division.-Among the numerous herbaceous perennials which are readily propagated by this method are asparagus, rhubarb, some columbines, golden glow, lily-of-thevalley, peony (Fig 20), hardy chrysanthemum, pulsatilla (Fig. 21), marsh marigold, bleeding heart, larkspur, gold seal (Fig. 22) and others. Many of these have true stems under ground.

Shrubs Propagated by Root Division.-Those shrubs which have root-stocks or stolons, running out a short distance, can easily be propagated by division. Many hardy garden roses are of this type. The Japanese rose (Rosa rugosa) is an excellent example. Other common shrubs are barberry, spirea, some species of dogwood, common lilac, red raspberry, sweet syringa, and many others familiar to all.

Suckers are underground stems with shoots sent up at a short distance from the parent plant. These may be taken up with enough root for their support and may then be set out as new plants. Some types of cherries may be propagated by this method. The multiplication of red raspberries, already mentioned, is really of this type. The silver-leaved poplar is one of the worst trees about sending up too many suckers; their real roots send up shoots. 
Dividing and Transplanting.--Probably the best time to divide plants, either herbs or shrubs, is in the late autumm, after the leaves have fallen. The whole plant may be taken up with plenty of its roots. The dividing may be clone by means of a sharp spade, and by spreading the main parts until they separate. It is usually not necessary to treat the wounds in any way except to eover them with soil.

The divided plants should be set in their new places as soon as convenient.
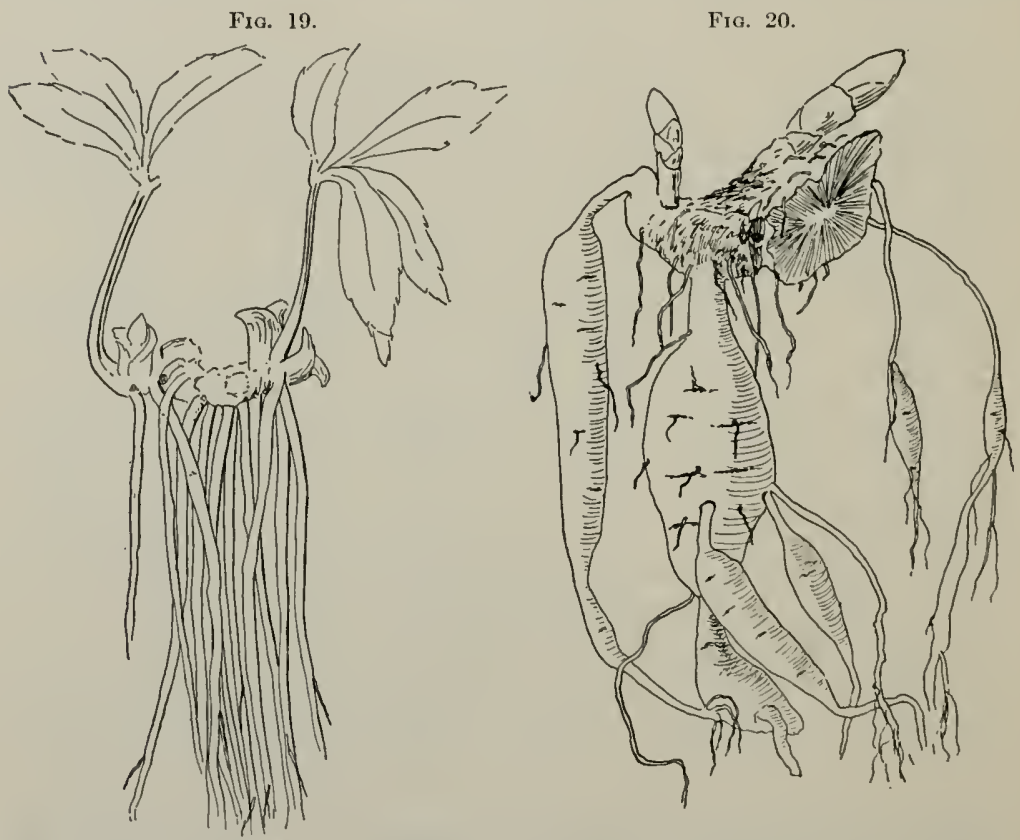

Fig. 19. - The Christrnas rose (Helleborus) is propagated by dividing the erown and roots.

Fig. 20.-The common peony is propagated by dividing the fleshy roots. Some of these may grow without the erown buds but do better with them.

\section{PROPAGATION OF BULBOUS PLANTS}

Propagation of plants by means of bulbs is sometimes called separation because the bulbs are vegetative organs that are naturally detachable.

Using Bulbs of Different Types.-The solid bulb, as found in cyclamen of the greenhouse, and in the Indian turnip of the woods, 
is sometimes called a corm. Gladiolus, crocus, and bulbous buttercup (Fig. 23.) are other familiar examples. These solid bulbs reproduce themselves by forming new ones on top or on the sides of the old one which dies away after its store of nourishment is used.

The true bulb is typified in many of the lilies. It is more like a very large bud with very thick, fleshy scales. The store of nourishment is chiefly in the scales themselves.

The coated bulb is seen in the common onion and hyacinth. The coats are in the form of rather complete rings. Hyacinth

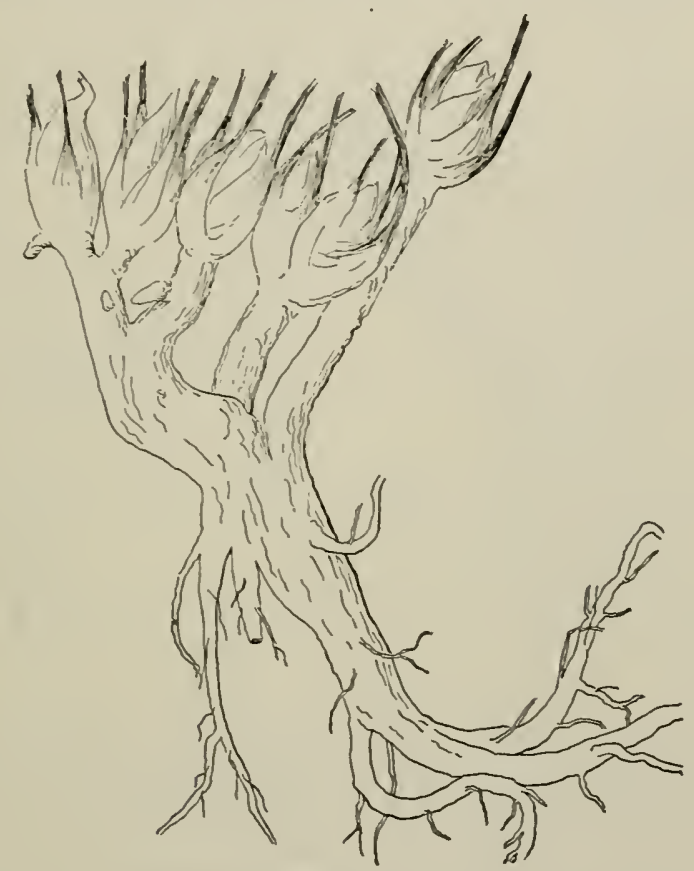

FIG. 21, - The beautiful pulsatilla is divided easily. lieep a bud and some root with each part.

bulbs, if cut in sections or crosswise, will form small bulbs along the cut surfaces. These may be separated and grown to full size. (Fig. 24.)

In the commercial propagation of hyacinth bulbs the strongest bulbs are selected. The bulbs are cut across or are hollowed out, or are cut deeply as if to make sections. They are then dried and stored through the summer and then put into sandy loam. One 
season is sufficient for the formation of numerous bulblets which start at the cut places. These are separated and planted in speeially prepared beds. They are here given good care and allowed to grow to full flowering strength, which may require from three to six years.

The bulbs grown by this method are propagated in large quantities in Holland, where the weather is moist, the soil favorable, and the winters not severe. Similar favorable conditions are found

FIG. 22.

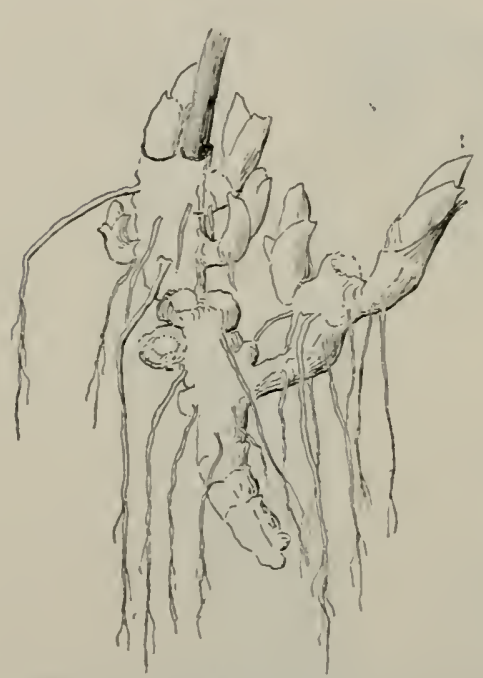

Fig 23.

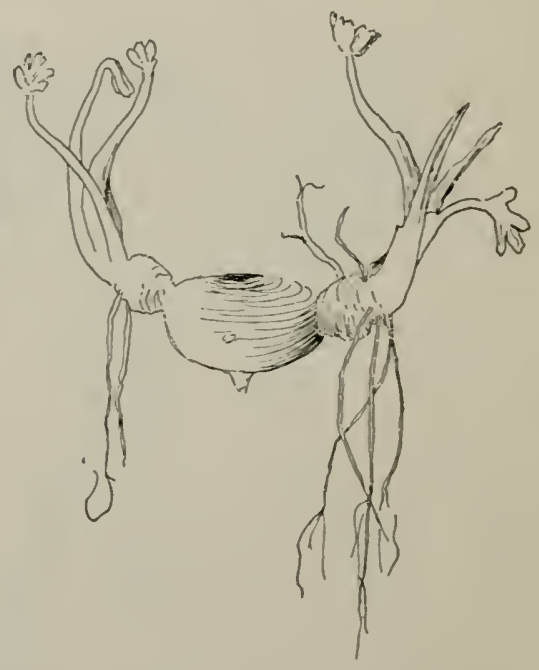

FIG. 22.-Gold seal (Hydrastis) is multiplied by tearing the roots apart a nd keeping crown buds on each part.

FIG. 23. - The old bulb of the bulbous buttercup will die and leave the young plants separated. This method of propagation my be hastened by separating the young bulbs from the old.

on the Pacific coast of Washington; and in recent years the bulbgrowing industry has greatly increased in the region of Bellingham and elsewhere.

Bulblets are small bulbs formed above ground. On plants of the onion family they are near the top of the stems like a flower cluster. On tiger lilies they are in the angles of the leaves along the stems. If separaterl from the parent plant and placed in the soil, they prorluce new plants. 
Tubers are used for propagation of all plants which yield them. The most common examples of tuber-forming plants are the Irish potato and the Jerusalem artichoke.

A tuber is a fleshy portion of the underground stem, bearing "eyes"' or true buds arranged in somewhat regular spirals.

The Potato.-An examination of several Irish potatoes will reveai the fact that the two ends are not alike. The stem end is where it was attached to the parent plant. The opposite end is called the "eye" end because the eyes or true buds are more abundant at that end. These eyes usually start growth sooner than the others. This gives us a suggestion for a good system of cutting potatoes before planting. Call the two ends the poles of the potato. Cut through the poles each time the potato is cut. The first cut makes two pieces. Hold these and cut again, making four pieces. If the seed potato is large it may be cut still further in the same way.

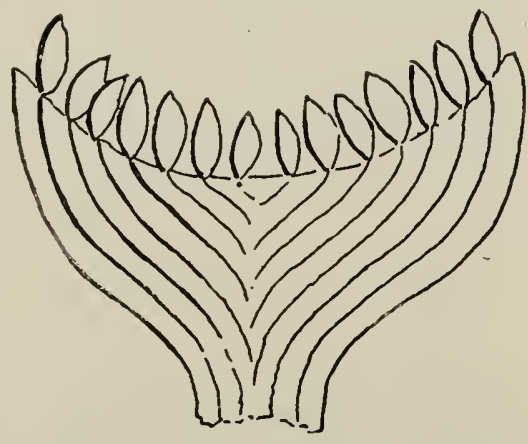

FIG. 24.-Section of hyacinth bulb showing bulblets forming at each scale. These are later set out and developed to full size.

Seed potatoes should be spread on a floor in a rather light place, but not in direct sunlight. If they remain here for several days they will become greenish in color and the sprouts will be strong and the subsequent growth will be more vigorous.

Propagation by True Roots.-Very few plants can be propagated by true roots alone. Plants of the blackberry group are very notable examples. Methods used in propagating blackberries are described under cuttings, in the next chapter.

The peony and some other fleshy-rooted herbaceous plants, including the sweet potato, will grow somewhat readily from the fleshy roots.

The apple, pear, quince, and some plums are quite commonly propagated by means of root grafts. But in this type of propagation the new twig with its buds is grafted on the root or piece of root. Aorather complete union is formed before the new plant begins growth. Root grafting is fully described in Chapter VI. 


\section{HOME PROJECTS AND GARDEN EXERCISES}

1. Root Division.-Dig, divide, and transplant a number of herbaceous plants, such as are mentioned on the first page of this ehapter.

2. Propagate a few shrubs by root division. In each case study the results to determine the importance of having healthy buds and good roots on each division. With what shrubs propagated is this most important? Which least? suckers.

3. Suckers.-Propagate cherries, plums, or other trees by means of

4. Multiplying Bulbs. - In autumn dig such bulbs as cannas, caladiums, dahlias, or others that are available. Study their multiplication. Record the numbers of new bulbs in several cases.

5. Kinds of Bulbs.-Make a collection of the different types of bulbs described in this chapter. Label each.

6. Quantity of Potato Seed.-Conduct a projeet using different rates of planting Irish potatoes. (1) Use whole potatoes. (2) Use half potatoes. (3) Two eyes on each piece. (4) One eye on each piece. (5) Use thick potato peelings. Use equal areas for these lots. Compare yields. Calculate profits, considering cost of seed, for each. Reduce the results to the acre basis.

\section{QUESTIONS}

1. What plants are readily propagated by root cuttings?

2. Mention vegetables and flowers that may be propagated by "root division."

3. What shrubs may be propagated by this method?

4. What are suckers, and how used?

5. Describe propagation or nyacinths or other bulbs.

6. Define "eye end" and "stem end" with reference to Irish potatoes.

7. Describe a good method of eutting Irish potatoes for planting.

References. -U. S. Farmers' Bulletin, 157, The Propagation of Plants. 


\section{CHAPTER V \\ CUTTINGS AND LAYERINGS}

Two of the most common methods of bud propagation are by cuttings and by layering.

Stems and Roots Compared.-There are several differences between true stems and roots. The student must not confuse underground stems with true roots. We seldom find roots growing above ground, particularly in woody plants, but we do frequently find stems underground. Among the differences between stems and roots may be mentioned (1) regularly placed buds on stems and none on roots, (2) scales or leaves are found near the buds on stems. These are entirely absent from roots. Ability of stems to send up shoots at the nodes. Roots seldom have the ability to send up shoots. There are some exceptions to this as we will notice later.

\section{CUTTINGS}

Types of Cuttings.-There are three main types of cuttings: (1) root cuttings or pieces of root are used; (2) hard wood cuttings, sometimes called ripe wood cuttings; (3) green wood, or soft wood cuttings. Each of these types has its particular use, and plants which are propagated by one of the methods are seldom propagated by another form of cutting.

Root Cuttings.-When plants are propagated by cuttings made of the true roots the roots are cut from the mature plants and are made of suitable length, say three to six inches. Thesearedropped in furrows and covered. They may or may not be stored over winter according to the circumstances or needs of the grower. One of the most common plants using this method of propagation is the common blackberry. The dewberry which is a close relative may also be propagated by root cuttings.

It may be said that sweet potatoes are propagated by root cuttings as they will grow readily from pieces of sweet potato, which are really true roots. There are no regular buds on the sweet potato or on the blackberry roots; the shoots are formed at any suitable place. There is no regularity about the arrangement of the shoots arising from these roots. 
Hard Wood, or Ripe Wood Cuttings.-There are several types of woody euttings: (1) simple euttings containing two or more buds, (2) mallet cuttings where a piece of the main stem remains attached to the branch containing the buds, (3) heel euttings where a portion is cut from the side of the main stem where the

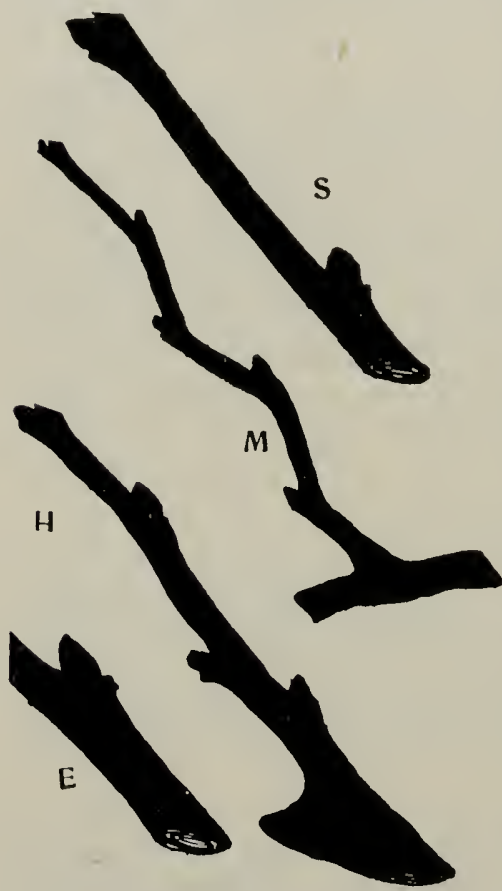

Fig. 25.-Forms of hard wood cuttings. S, simple; M, mallet; $\mathrm{H}$, heel; $\mathrm{E}$, single eye. branch used for the cutting originated, (4) single eye cuttings containing a short piece of stem bearing one bud only. These types are shown in figure 25.

Making Hard Wood Cuttings.-Probably the best time for making hard wood euttings is after the leaves have fallen from the twigs in late fall or early winter. A sharp pair of pruning shears or a sharp knife may be used. Large numbers of euttings ean be made without injury to the parent plants and little time is consumed in the proeess.

How Stored.-If the cuttings are made in the fall or early winter they should be stored. A suitable storage place is the common cellar or vegetable pit. The euttings are tied in bundles and properly labelled. A wooden label and soft peneil should be used. Indieate the number, kind and date. Immerse these bundles in wet sand or wet sawdust in boxes which are well drained and keep them thoroughly wet until planting time the next spring.

Callousing.-During the storage period the eut surfaces beeome calloused or healed over, and it is believed that the roots start best from near the calloused surfaces. Many hard wood euttings will not grow unless they have passed through the callousing period. There are a number of exceptions to this, however.

Planting Hard Wood Cuttings.-No definite rule ean be given regarding the best time for planting the cuttings in the open garden 
or nursery row. Better to err on the side of being rather late than too early with this work. Have the soil well prepared by deep plowing and thorough pulverizing, A rich black loam is to be preferred as it will hold moisture well. A trench or furrow may be made with a turning plow or single shovel plow. Place the cuttings along the straight side of the furrow. (Fig. 26). If simple, heel, or mallet cuttings are used one or two buds may be left protruding from the ground. An inch or two of the stem is enough, and the remainder should be in the ground even if the cuttings are eight or ten inches in length. Throw the soil back against the cuttings and firm it in place with the foot. This will bring the moisture to the

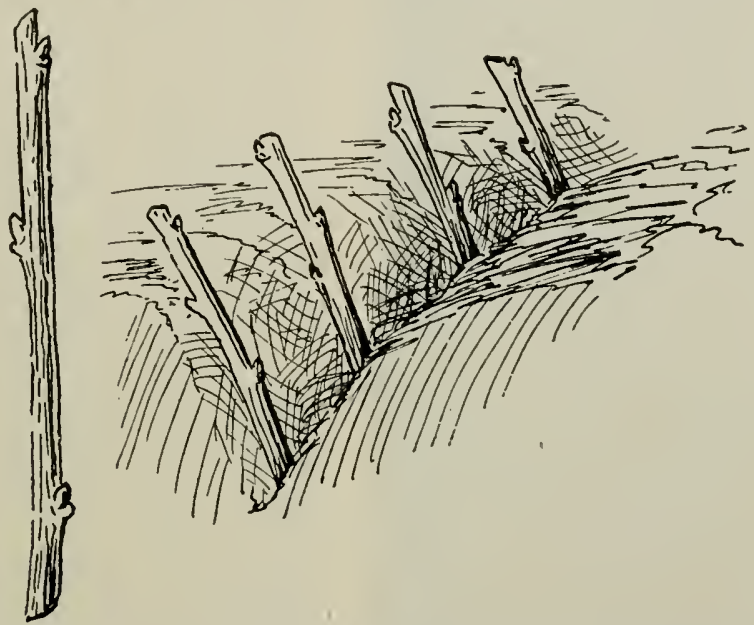

F1a. 26. - Cuttings of grape, currant and other woody plants should be planted so deep that only one or two buds are seen above ground when the trench is filled.

young plant and cause it to start growth. The distance between the plants should be arranged to suit the kind. Usually we would allow room for a hoe between plants in the row and the rows should be far enough apart to allow the use of a horse cultivator, say three or three and one-half feet.

Care and Management.-The young plants started from hard wood cuttings should be given thorough tillage throughout the growing season. Much care must be exercised by the man with a horse going between the rows. The careless driver will do much damage by breaking the cuttings or injuring the bark with a cultivator. 
Trees and Shrubs Grown from Hard Wood Cuttings.-Among our common fruits which may be grown from cuttings may be

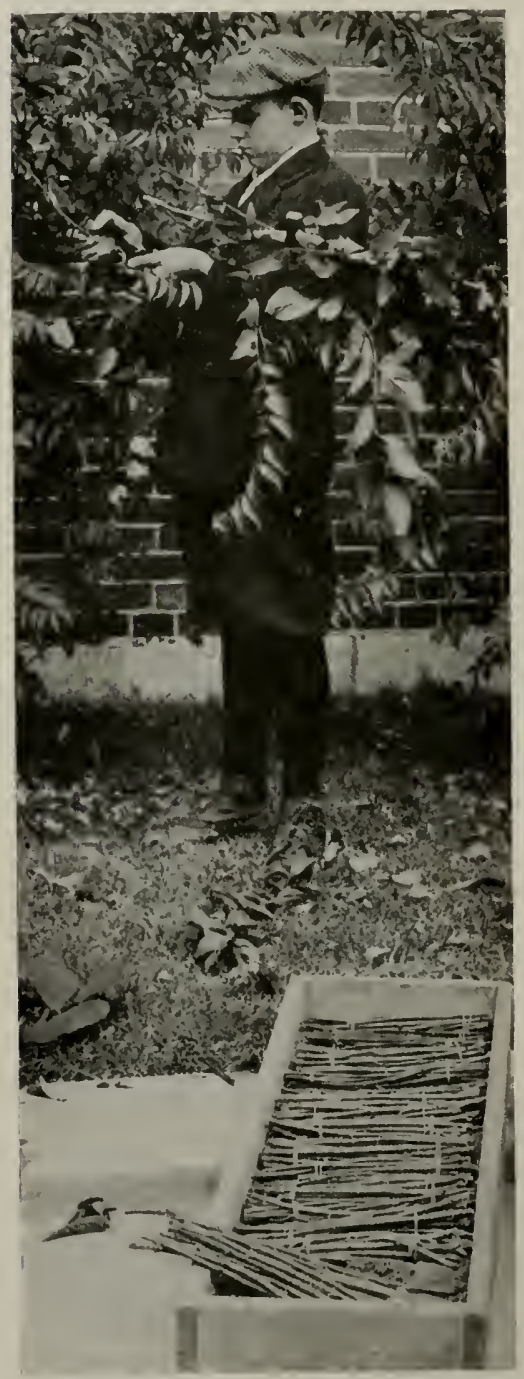

Fra. 27.--Practice in making cuttings of ripe wood about the time the leaves are ready to fall. They are stored for planting in the spring. mentioned currants, gooseberries and grapes. If slender twigs are taken from gooseberries this process of propagation is not. very successful. Fleshy twigs from certain types or varieties will succeed if conditions are favorable.

Willows and all kinds of poplars are more commonly propagated by this method than by any other.

A number of our ormamental shrubs can easily be propagated by hard wood cuttings taken either in late fall or very early spring if time is allowed for some callousing. Among these may be mentioned golden bell (Forsythia) (Fig. 27) Japanese rose (Rosa rugosa) barberry, privet, syringa, some dogwoods, and many others.

\section{Soft or Green Wood Cut-} tings.-There are at least two types of soft or green wood cuttings: (1) those in which the leaf is the chief part of the cutting, as in the case of fleshy begonia leaves, and (2) those which use a part of the green stem and one or more small leaves attached to this. The geranium is a good example of the second type.

Green wood cuttings may be started at any time if the plants are grown within doors. 
We seldom attempt to start cuttings from green wood out of doors. These are first rooted in boxes of sand or very light soil in some protected spot where close attention may be given to them.

Principles Involved.-There are several important principles to be kept in mind in rooting green wood cuttings.

1. There is much exposed evaporating surface which must be reduced by use of the knife or scissors.

2. The supply of moisture must be ample so that the cutting can obtain as much moisture as its leaf surface is giving off during the critical period before it develops roots.

3. Clean, sharp sand is best for the starting of young roots, as there is less tendency to decay of the epidermis or covering of the stem thrust into it.

4. Plenty of warmth must be provided without allowing too rapid evaporation. For this reason the box of cuttings may be kept in a sunny exposure but covered with newspaper or glass to retard evaporation. Extra heat supplied from below is helpful, and can be provided if the cuttings are being started in greenhouses or homes.

5. The cutting has no means of taking up nourishment during the rooting period; it must therefore be supplied with plenty of nourishment within itself. Somewhat fleshy parts, preferably inclucling a bud are desired for the best results.

\section{Uses and Examples.-} Green wood cuttings are extremely useful in the propagation of many of our potted plants. (Fig. 28.) Geraniums and begonias have already

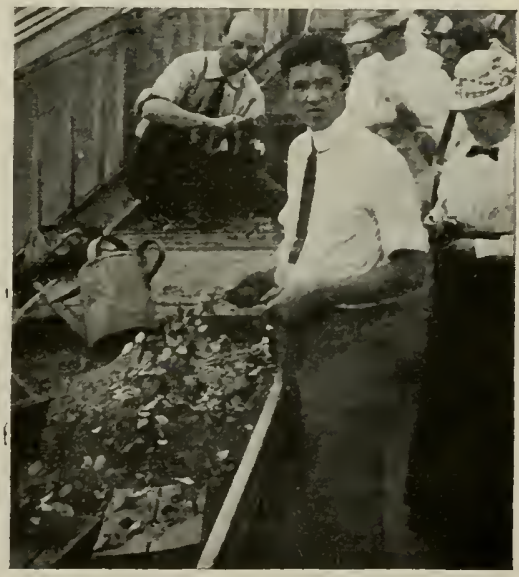

FIG. 2s.-Making beds of cuttings of reses and other indoor plants.

been mentioned. Chrysanthemums and carnations are commonly propagated in the early spring for the fall and winter crops of blossoms. Many of our foliage plants grown in borders and ornamental beds are propagated in-doors during late winter and early spring months. Many roses are propagated almost entirely by cuttings of the immature wood. Numerous other examples are common. 
Management after Rooting.--For best results the cuttings are watched closely during the rooting period, and as soon as they establish plenty of root surface they are lifterl out with a small portion of the sand or soil adhering to them. They are then potted or transplanted to bels or boxes. Good garden soil containing plenty of black loam is best for them at this time. They are then kept well watered and given other good conditions to force the growth somewhat rapidly.

\section{PROPAGATION BY LAYERING}

When plants are propagated by layering they are certain to produce the same kind as the parent plant, as they are really a part of it. They are also much more certain to grow than in the case of cuttings because they remain attached to the parent plant and may obtain circulation and nourishment from it until new roots are formed at the point of layering.

There are several kinds of layering: (1) vine layering, mound layering, (3) tip layering, (4) pot layering.

Vine Layering.-A great many vines may be propagated by layering. Among these are the different varieties of grapes, clematis, and Virginia creeper. There are two types of vine layering, one called the serpentine form, in which the vine touches the ground at several points, but is bent into the air between these points. The second type is simple vine layering. (Fig. 29). The vine is somewhat covered with earth throughout its whole length and may send up buds at the nodes and send down roots at any point along the stem. In the serpentine layering roots are formed at the points where the vine is covered with soil, and the stem in the air serves as a shoot without the formation of a new shoot. In either of the types the parent vine is cut in parts between the points of rooting, and each part will form a separate plant.

Rooting and Transplanting.-The vines used for layering should be vigorous and well supplied with nourishment. They are best started during the height of the growing season, which is after the spring growth is well started. At least there must be enough time left during the summer for the plants to root well before autumn. The new plants may be taken up either during that autumn or early the following spring. They are transplanted to their new locations and given the same care that is required for good growth of shrubs and trees. 
Tip Layering.-When the tips of certain woody plants are bent over and covered with soil they may form roots and new shoots. Then when the parent branch is cut off a new plant is left growing at the point where the rooting took place. Black raspberries are most commonly propagated by this method. (Fig. 30.)

Plan with Raspberries.-After the crop of berries has been picked is the best time to begin the propagation by tip layering. Cultivate the soil between the rows thoroughly so that it is mellow and moist and free from weeds. In a rather straight row by the side of the parent plants bend down the longest canes, slightly break them on the under side a few inches from the tip and cover them with some soil at the wounded points. Scores or hundreds of tips may be thus treated in a short time. If necessary clods of

F1G. 29.

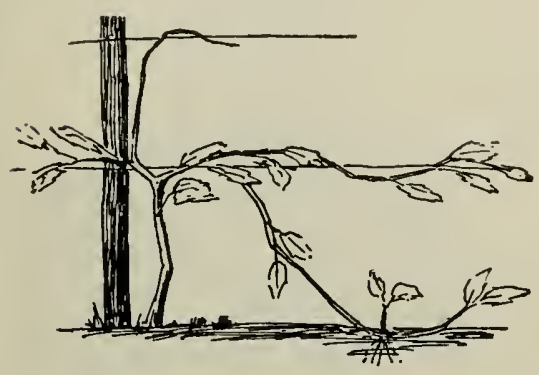

FIG. 30.

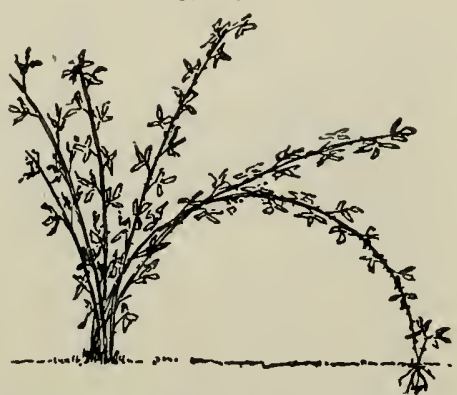

FIG. 29.-Vine layering; an easy method of propagating certain varieties of grapes or other vines which do not grow well from cuttings.

FIG. 30.-Tip layering of canes of the blackcap raspberry.

earth may be placed on them to hold them down. In light sandy loam it is sometimes necessary to hold them with pegs thrust deep into the soil. In a few weeks these may be examined and found to be provided with roots. The tips of the twigs which were not covered will form fresh leaves or new shoots. When new growth is thus established, cut off the parent canes connected with the old plants. This may be done with a spade or pruning shears. The new row of young plants may be left in place until late autumn or early spring. They are then taken up and planted in the new berry patch where they are to remain.

Other Plants Grown by Tip Layering.-There are a number of plants which naturally propagate themselves by tip layering. Indeed, many of our ornamental shrubs may be induced to form 
new plants by this method. The golden bell, or Forsythia, very naturally multiplies by this method. Plants which are not commonly propagated by layering may be induced to do so if the twig is wounded at the point where it is covered with soil, and if the weather conditions are favorable. Willows, poplars, dogwoods and others will easily form new plants in this way.

The Strawberry has a special plan of propagation. Its runners take root at the nodes. (Fig. 31.)

Mound Layering.-This method obtains its name from the fact that the soil is mounded up among the lower stems or branches. The method is resorted to because of the fact that root division is

FIc. 31 .
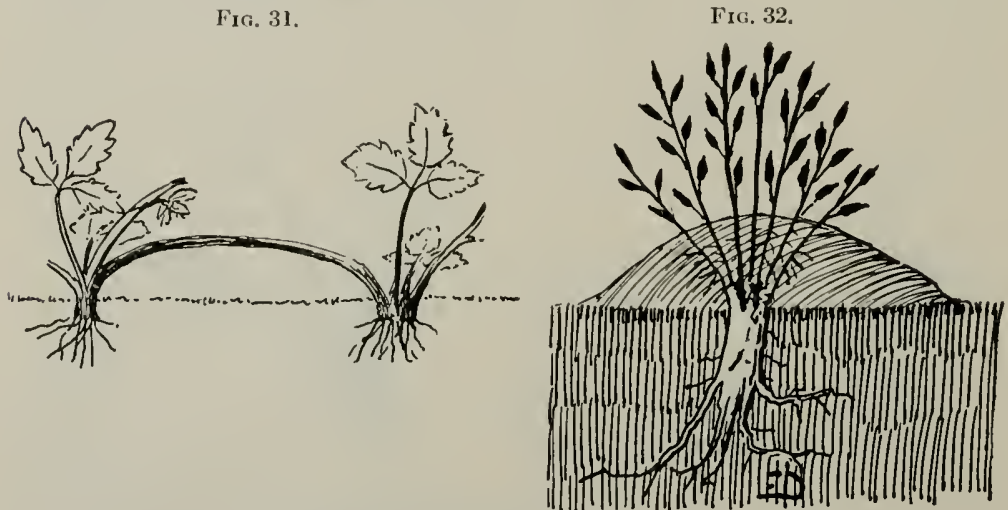

FIG. 31. - Strawberries and many other plants naturally multiply by means of runners which take root at the tip or at nodes.

Frg. 32.-A mound of soil among the stems of the gooseberry will eause roots to form in this soil. Plants may then be multiplied by division.

too slow, or may not be possible because of there being only one stem arising from the ground.

Wren the soil is mounded up among the lower branches for a season, roots will be sent from the lower branches into this soil. (Fig. 32.) At the end of the growing season the whole plant may be taken up and divided by cutting these newly rooted branches away from the others. These may be planted as separate indivictuals.

Common Examples of Mound Layering.-The lilac, gooseberry, quince, althea and others may be easily propagated by this method. Indeed, the method is a very sure one, as it does not in any way endanger the life of the parent. 
Analogous to Root Division.-There is but little difference between mound layering and root division, except that in mound layering the gardener finds it necessary to mound up the soil among the lower branches to induce more roots to be formed on the stems already bearing buds or branches. Propagation by root division was explained in Chapter IV.

Pot Layering.-In some indoor plants, such as the India rubber plant of greenhouses, propagation is effected by means of pot layering.

A flower pot is split open and the two halves are tied around an upright branch and the pot is filled with sand or soil, or wet moss. If the branch be wounded at the place, a cluster of roots will be formed in the pot. After this the branch may be cut off below the pot and we have a separate plant already rooted. The young plant is then repotted in good soil in a larger pot for further growth.

\section{HOME PROJECTS AND NURSERY EXERCISES}

1. Root Cuttings.-Propagate blackberries, dewberries, or Loganberries, by root cuttings.

2. Types of Cuttings.-Make cuttings from grape, or other available plants, showing each of the four forms.

3. Grapes from Cuttings. - In early winter make many cuttings of grapes. Tie the cuttings in bundles of twenty-five each, and label properly. Store these as directed. Plant when danger of frost is over. Give them proper care for one year and sell plants or transplant to a vineyard. Continue this project as long as desired.

4. Trees and Shrubs from Cuttings.-During the dormant season make cuttings of currants, gooseberries, privet, golden bell, Japanese barberry, Japanese rose, spirea, syringa, or any shrubs that may be available. Try some that you are doubtful about propagating by this method. This exercise may be continued as a project by storing, planting, and earing for the cuttings for a season or more.

5. Green Wood Cuttings.-Propagate geranium, fuchsia, begonia, rose, or other house plants, using methods suggested for green wood cuttings. After rooting, these may be cared for and the plants sold when brought to flowering age. This is a project suited to indoor work.

$6,7,8$. Layering.-Conduct projects similar to the above with vine layering, tip layering, and mound layering, using such plants as are suggested in this chapter.

\section{QUESTIONS}

1. What are the differences between true stems and roots?

2. Describe root cuttings. Give directions for making and using them.

3. What are the four forms of hardwood cuttings?

4. Give directions for making, storing, and planting hard wood cuttings.

5. Make a list of trees and shrubs grown from hard wood cuttings. 
6. What are the principles involved in the successful growth of green wood cuttings?

7. How are green wood cuttings managed after rooting?

8. Deseribe vine laying.

9. Describe the method of tip layering as applied to blackberries.

10. Why is mound layering resorted to?

11. Describe the steps in mound laycring.

12. Describe pot layering.

References.-U. S. Farmers' Bulletins: 157, Propagation of Plants; 471, Grape Propagation; 643, Blackberry Culture. 


\section{CHAPTER VI}

\section{BUDDING AND GRAFTING}

BUDDING is really a form of grafting in which a single bud is used. On the other hand we may say that grafting is a form of budding in which a twig bearing several buds is used. In each case the bud or twig is inserted upon another stem or root where it will grow and form a complete union. In grafting, the twig is called a scion and the stem or root to which it is attached is called a stock. The stems on which buds are placed in the budding operation are also called stocks.

Reproduction by Budding or Grafting.-There are several principles to be kept in mind when plants are to be propagated by budding or by grafting.

1. Good varieties of peaches, plums, cherries, apples, pears, etc., may be propagated by using buds from them to grow on suitable stocks.

2. The buds will grow if properly inserted on stocks closely related to the kind from which the buds were taken. Peaches and plums may be grown on peach or plum stocks. Apples and pears may be grown on apple or quince stocks.

3. The stock does not influence the character of fruit borne by the tree resulting from this budding or grafting. The fruit is like the kind from which the bud was taken.

4. The stock may influence the character of growth and size of the tree resulting from the union. Thus quince stocks will cause pears and apples to be dwarfed in size, or the Paradise apple, when used as stocks, will dwarf the trees. The stocks may also influence the power of resistance to disease.

Shield-Budding.- There are many methods of budding but the one which is rather more common than all the rest is shield-buddling. It is named from the shape of the piece carrying the bud as it is cut from the plant to be propagated. A T-shaped cut is made in the stock and the two corners of bark are raised and rolled back slightly The shield bearing the bud is inserted just under the flap of bark so that the growing layer, called the cambium layer, just under the bark will rest against the wood of the stock. (Fig. 33.) The bark is then placed snugly against the shield to hold it in place. This 
leaves a slight opening for the new bud which will begin growth at the proper time. The bark and shield are held in place by wrapping with waxed cotton or raffia.

Propagation of Peaches.-Improved varieties of peaches are propagated chiefly by budding. The actual budding is done either in June or September. In the extreme southern states, June budding is quite commonly practiced. The buds used for the June buddings of penches are saved from the dormant season in cold
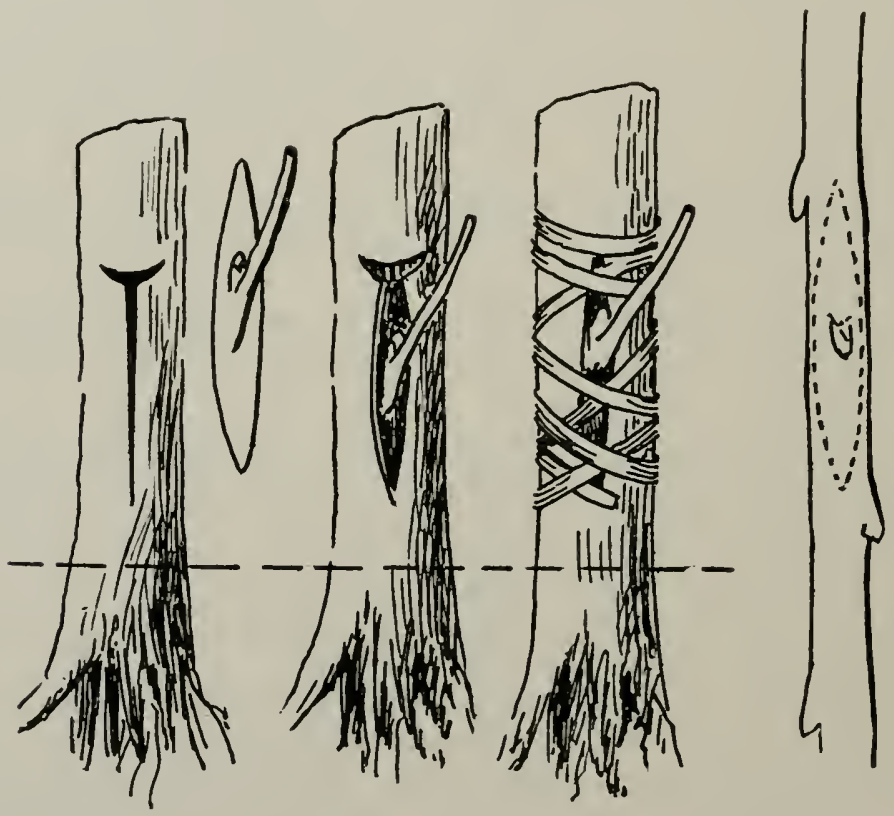

FIa. 33. - Three steps in shield budding. At the right is a scion or budding stick from which the buds are cut as shown by the dotted line.

storage or in cellars. They are inserted on young growing seedlings started from seed early that spring.

For September budding of peaches the buds used are from the current year's growth on good varieties. They are inserted on seedlings started from seed in the spring of that year. In this case, they do not start growth in the same fall that the budding is done. They became calloused in place and remain dormant until the following spring. At that time, the top of the seedling is cut off above the 
new bud and the whole strength of the sap from the root is thrown into the development of the new shoot from the new bud. All other shoots are pruned off with the fingers and none but that growing from the improved bud is retained.

After the budded seedling has grown one season, it is ready to be transplanted to the orchard. In the case of June budded peaches, the new buds begin growth almost immediately after they are inserted. The seedling shoots are then removed and all the growth is thrown into the new shoot. The budded peach tree is left in the nursery row until fall or the following spring when it is ready for transplanting to the orchard.

Propagation of Plums.-Plums are grafted or budded in much the same ways as described for propagation of apples and peaches. The stocks are of several kinds for the different types of plums. For the European (Domestica) and Japanese plums probably the most popular are the Marianna plum grown from seeds and the Myrabalan plum grown from cuttings. American wild plum seedlings are much used as stocks for the buclding and grafting of improved varieties of American plums, particularly in the middle and western states. Peach stocks are well suited for use in growing plums for light soils and for southern localities.

Propagation of Cherries.-Grafting and budding are both practiced in the propagation of cherries. Budding is more common. This may be done on stocks suited to the different types of cherries. The time of budding may be in June or in August and September as in the case of peaches. Preference is usually given to September budding. (Figs. 34 and 35.)

Securing Materials for Budding.-Seeds for growing stocks are usually taken from the seedling trees. They are what nurserymen designate as "native" seeds. As the stocks do not materially influence the fruit of the orchard, it is not absolutely essential that native seeds should be used but seeds from improved varieties are considered less suitable for the growing of stocks as the growth may be poor and seeds may fail to germinate.

Scions from which the buds are to be taken are cut at the proper season from trees of bearing age. If the limbs are taken from peach trees, for example, for August budding, they would be taken only a few days before the budding is to be done. The leaves are cut with knife or scissors leaving the leaf stem attached beneath each bud. This protects the leaf scar and gives the operator a handle for use in placing the bud. These fresh scions should be kept wrap- 
perl in wet paper or wet sawdust until used. They may be sent by express or by parcel post long distances if clesired.

Seeds for apple stocks are usually taken from cider presses disregarding variety or source of the seeds. The pomace is separated from the seeds in tubs of water as the best seeds will sink and the pomace will mostly float when the water is stirred.

Other Types of Budding.-Besides the shield-budding already described there are several other methods in use for special purposes.

Prong-budding is a modification of the common shield-budding as it uses a short prong or spur instead of the simple bud. This is

FIG. 34 .

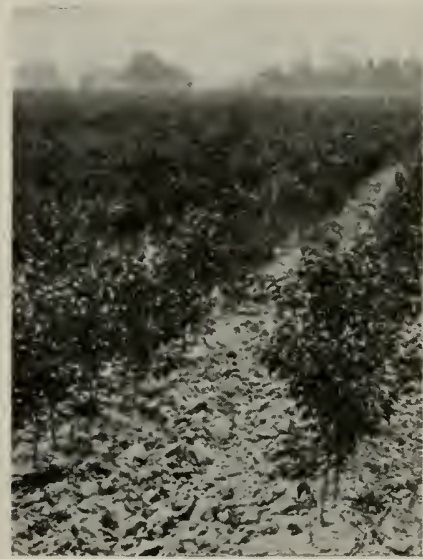

FIG. 35.

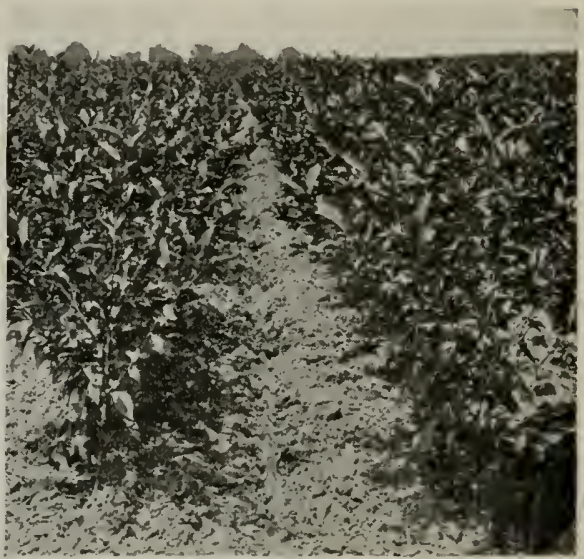

Fro. 34.-Buds of sweet cherries set in stems of Mahaleb cherry seedlings in July and August. These buds remained dormant until the next spring, when the seedlings were cut to the new bud near the ground. See the growth from these buds in figure 35 . (U. S. D. A.)

Fia. 35. - One season's growth of sweet cherries budded in July and August on Mahaleb cherry stocks. See figure 34 . (I. S. N. A.)

commonly used in the propagation of nut trees on the Pacific coast. The English walnut is thus budded during the domant season. The shield shaped bud is tied in place and also waxed. The operation is somewhat like grafting and is often named twig-budding.

Plate-budding differs from shield-budding in having a rectangular cut made in the bark or the stock. This piece of bark is turned down and a patch of bark of the same size and shape is cut from the scion. This bears a bud and is fitted into place on the stock. The flap of bark is brought back somewhat into place and tied. The 
flap of bark may be divided into two parts in which case the bud is placed near the center and is not likely to be covered by the flaps when returned to place. The olive is sometimes propagated by this method of budding.

Flute-budding differs from plate-budding in having a larger area of bark cut away entirely. The bark from the scion bearing the bud is of considerable size cut to fill the entire area.

Chip-budding is so named because the piece from the scion bearing the bud includes a piece of bark and wood. It is beveled in mortise shape above and below and is dove-tailed into a cut in the stock made just to receive it. It should be waxed and tied in place.

\section{GRAFTING}

Tongue-Grafting.-The particular form of grafting known as tongue-grafting or whip-grafting may be practiced either in the top working of trees or in root grafting young trees. The method is illustrated in figure 36 . First a long sloping cut is made on the lower end of the scion, then a sloping cut somewhat resembling a split is made as shown. The upper end of the stock is cut in exactly the same manner. The two tongues formed are slipped under each other and the union is pressed together as closely as possible. If the scion and stock are of the same diameter, the growing layers of cambium just uncler the bark are adjacent to each other and will grow together. This forms a perfect union between the scion and stock. The grafted portion is wrapped with waxed knitting cotton or with waxed bands of old muslin. The wrapping is to hold the parts together and also to aid in excluding the air. The wax also aids in keeping out surplus water.

Propagation of Apples by Grafting.-If apples are to be propagated by root grafting, the work may be done in the winter and much time of the nurseryman is saved. The roots are obtained from seedlings started from seed the preceding spring. These seedlings are dug in the fall with the entire tap root. They are tied in bundles of about one hundred each and stored in wet sand or wet sawclust in the cellar or storehouse where they will not freeze.

The scions for winter root grafting are cut from

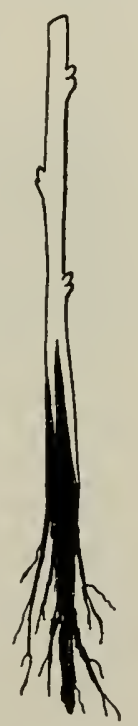

Frg. 36. - A root grafted apple using the tongue method. The scion and root arecut about alike then slipped together tightly and wrapped with waxed knitting cotton. 
improved varieties of apple trees, preferably of bearing age. These are of the list season's growth and bear shoot buds rather than fruit buds.

The roots may be cut in pieces about four to six inches in length or they may be left entire. Of course the top of the seedling is cut off and discarded. Grafting of the scion and stock is then performed as already described. Bundles of root grafts, containing from twenty-five to fifty each are tied securely around the point of union. These are labeled with wooden labels written in black lead pencil. If painted labels are used the writing will not be obliterated by mold or discoloration of the wood. The labels should indicate the variety of the scion, the number in the bundle and

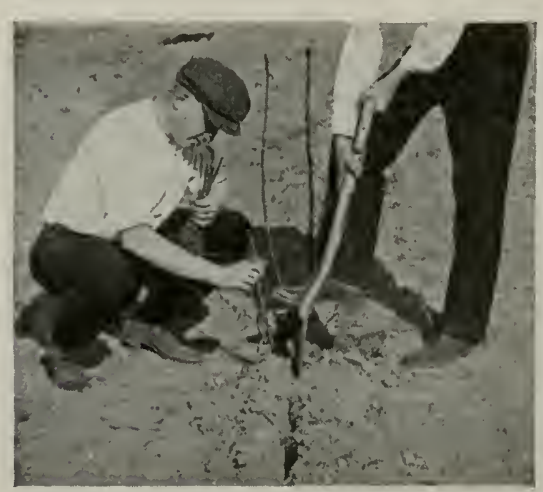

Fra. 37.-Root grafts and cuttings are rapidly set out by thrusting them back of a spade which makes a narrow opening. (N. J. Station.) the date of the work. The scions and roots should be trimmed somewhat evenly at the top to make a neat bundle. Three, four, or more buds should remain on each graft.

'The young root grafts should be stored in the same manner as the scion, in wet sawdust, in well drained boxes in a cool cellar or storehouse. In warm climates they are sometimes stored on thenorth sides of buildings or merely put into the ground until planting time.

Setting Out Grafts.- In the middle or late spring, grafts are set in rows far enough apart to allow of cultivation. An opening is made with a spade for each graft (Fig. 37.) If the trees are eight to twelve inches apart and the rows three and a half feet apart, thorough tillage can be given them through the growing season. After one or two years growth in the nursery, they are ready to be transplanted to the orchard. Trees may be more suitably shaped to suit the ideals of the orchardist if they are transplanted at the end of one year's growth. The period is counted from the time the young root grafts are set in the nursery.

The depth of setting a young graft is important. Only one or two buds should be left to show above ground. The soil should be well firmed with the foot around each graft, but care must be exer- 
cised to avoid breaking off the buds when the tramping is being done. Apple trees will grow well in rich, mellow, black loam. All damage to the trees must be avoided during the growth in the nursery.

Cleft-Grafting.-This form of grafting is usually performed in the top of trees but may be used nearer the surface of the ground. Branches one-half inch in diameter or larger are cut across and split with a heavy knife or chisel. Two wedge-shaped scions are cut and inserted at the edges of the split twig in such a way as to bring one cambium layer of each in contact with the cambium layer of the cleft branch. The wound is then thoroughly waxed with rather hard grafting wax to exclude rain and prevent drying out. (Fig. 38.)

Top Working Fruit Trees.-There are several reasons for desiring to top work fruit trees.

1. The grower sometimes finds that the variety he has does not suit his purpose.

2. He may find the variety is not the kind he supposed he was purchasing when the trees were obtained from the nursery. Labels are often misplaced and mistakes are apt to occur.

3. He may desire to insert a new kind on the tree which is already in bearing. He may then place a new variety on one or more of the limbs to quickly test a new kind as they will bear earlier than if started on young trees.

4. If he has a large block of trees of one variety that have proved to be self sterile, he may be getting plenty of blossoms with little or no fruit. He may then find it advisable to top graft a number of trees in the block with another variety which blossoms at the same season. The two kinds will furnish pollen to each other and fruit will be produced.

5. Young orchards are sometimes set with well known varieties. The next year these may be top grafted or top budded with scions taken from the owner's orchard of bearing trees. The orchardist thus gets buds started which he is absolutely sure are true to name. He also has saved something on the purchase of his trees by selecting cheap varieties from nursery catalogues.

Top Working by Cleft-Grafting.--If apple trees are top worked for any of the above reasons, the method used may be either cleft-grafting or budding. If the cleft-grafting method is to be used, scions of the desired varieties may be saved from the preceding dormant season by storing them in wet sawdust in a cool cellar. 
These may then be inserted in the spring after growth has started, or a little before that. Care must be used to prune away competing branches and allow the new graft to have room, light and air for growth. After the new grafts are well established more pruning away of the old sort may be done.

Budding of Old Trees.-Many orchardists find much difficulty in top grafting old trees. The stocks and scions may fail to grow uniformly in size or the union may be incomplete, particularly in the heart wood. The result of an incomplete union may cause them to break during wind storms. For these reasons budding is
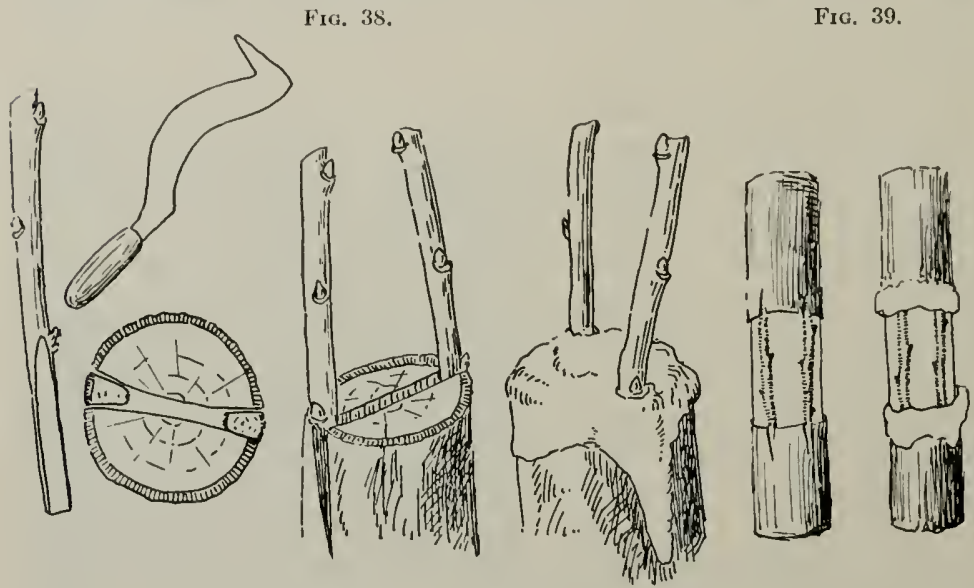

Fig. 38-Cleft grafting. Scions are cut beveled both ways as shown at the left, so as to fit closely at the cambrium and inner bark. The tool or cleaver shown is used to split the stock. Grafting wax is used to protect all the wounds as shown at the right.

Fig. 39.-When trees are girdled by mice, rabbits, or farm implements, they are sometimes saved by bridge grafting. Two stages of the process are here shown.

quite commonly practiced in top working of orchards whether the trees be young or old. When a shield bud is inserted on the side of the stock, the uneveness of growth will make no perceptible difference. As little or no wood is present under the bark, there will be no weakness to cause trouble in the future.

There is one serious difficulty, however, in top working orchard trees by the buclding method. A single bud is inserted in each place and much more work is required to insert a sufficient number of buds than by the cleft-grafting or tongue-grafting methods.

Top budding of orchard trees may be practiced with practically all kinds of orchard fruits. The work may be done at any time 
during the growing season provided buds suited for the season are available. If the work is done in the spring or the early summer, dormant buds held over from the winter season are used. If the budding is to be done late in the summer or early fall, buds of the current year's growth may be inserted and allowed to start into growth the following spring. Practically no time is gained by the fall method and it is less common.

Other Types of Grafting.-For special purposes there are several forms of grafting much less common than the cleft-grafting and tongue-grafting already described.

Splice-grafting is fairly well described by its name. Two sloping cuts are made on the two pieces and these are laid together and tied.

Saddle-grafting is so named because the scion is split and set upon a wedge-shaped cut made at the top of the stock. This method is sometimes used near the surface of the ground in the propagation of some grapes. A mound of earth may be thrown around the grafted point after it has been tied.

Veneer-grafting is so named because an incision just through the bark is made on the stock. This is about an inch long. The base of the removed piece is cut off with a downward stroke leaving a little pocket. The scion is bevelled on one side slightly chiselled at the end to fit in this pocket and against the cut area of the stock. The graft must be very thoroughly tied to hold it in place. This method is much used in the propagation of ornamental and potted plants. It may be used when the scion and stock are of different sizes. A very small scion may be made to fit against the veneer cut on a large stock.

Side-grafting.- Several forms are in use. A thin, wedge-shaped cut on the scion will fit under an opening in the bark of a large stock and the top of the stock neer not be cut off until later. Bridge grafting (Fig. 39) may use this form of graft.

The side-grafting cutting method differs from the last in having a wedge-shaped cut made on a small stock. This wedge is inserted under the bark of the scion or cutting. Careful tying is absolutely necessary. Waxing may also be used. Some grapes are grafted on roots by this method.

Shield-grafting is similar to prong-budding and may be called scion budding. A beveled scion is fitted under the T-shaped cut on the bark of the stock. It is then well tied and waxed.

Inlaying is so named because the wood of the scion is cut in exactly the same shape as the piece of wood removed from the 
stock. If a trough-shaped cut is made in the side of the stock then the scion is cut to fit this trough. It is then tied in place and waxed.

Grafting Wax.-There are three main ingredients in most grafting waxes, (1) resin (2) beeswax or paraffin (3) tallow, lard, linseed oil, or wagon grease.

A good formula is four parts by weight of resin, two parts by weight of wax, and one part by weight of grease. This makes a wax of medium hardness. For greenhouse work or for use in hot weather, a harder wax may be desired. This is formed by using more resin and less grease. For outdoor work in cold weather a softer wax may be made by using less resin and more grease. If linseed oil is used in place of the heavier forms of grease, the wax is softer.

Directions for Making Grafting Wax.-Take an old ean which is not soldered. Melt the resin in this ean, add the wax and lastly add the grease or oil. After thoroughly stirring, pour the melted mixture into a bucket to cool. Grease the hands and pull like taffy. It should be pulled until it is all uniformly light in color. Then lay it on greased paper to cool.

When desired, a mass of the wax may be dipped into warm water and thus warmed for use. It is commonly carried in a mass on the back of the left hand during grafting operations.

Number 18 or number 20 linitting cotton is commonly purchased in balls. This may be wound off in skeins about eight inches long by wrapping on a board or book. The skein is cut at both ends and the strands tied by a cord around the center. This may be dipped into melted wax. Waxed knitting cotton may be softened to suit the desires of the grafter at any time by dipping it in warm water.

\section{NURSERY PROBLEMS}

Rabbits and mice often girdle trees or scar them badly and must be kept out of the nursery. The rabbit trap shown in figure 40 will help to reduce the number of rabbits. Mice are present only when there is litter in which they may hide.

Growth of trees is very important and the trees must be kept growing rapidly throughout the growing season. Have them culcultivated often and very carefully to avoid damaging the trees. Feed the trees well. The effect of fertilizer is shown in figure 41 .

Inspection of Nurseries. - State laws provide for the inspection of nurseries at least once a year. The nursery is examined for inju- 
rious insects and diseases and a certificate of inspection is furnished. A copy of this is printed on the tag used in shipping each lot of trees and shrubs, either within the state or across lines. The forms for these certificates vary somewhat in different states. That used in Tennessee is typical (Fig. 42.)

FIG. 40.

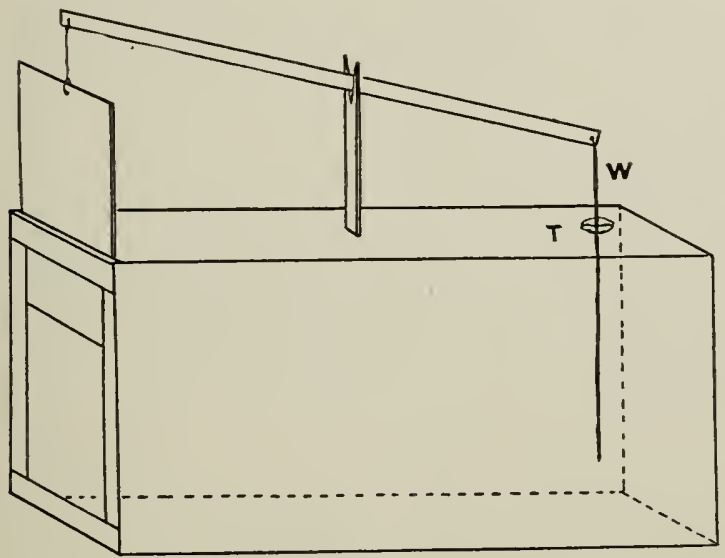

FIG. 41.

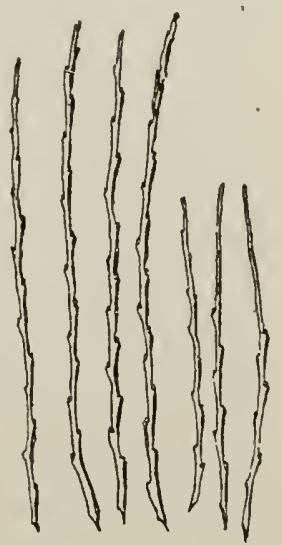

FIG. 40.-A box trap for rabbits is easily "set" by catching a notch in the wire, IF, on a tin strip tacked on the box at $T$. The rabbit "snaps" the trap by touching the wire.

Fig. 41.-Twigs of one year's growth; left were from fertilized trees; right not fertilized.

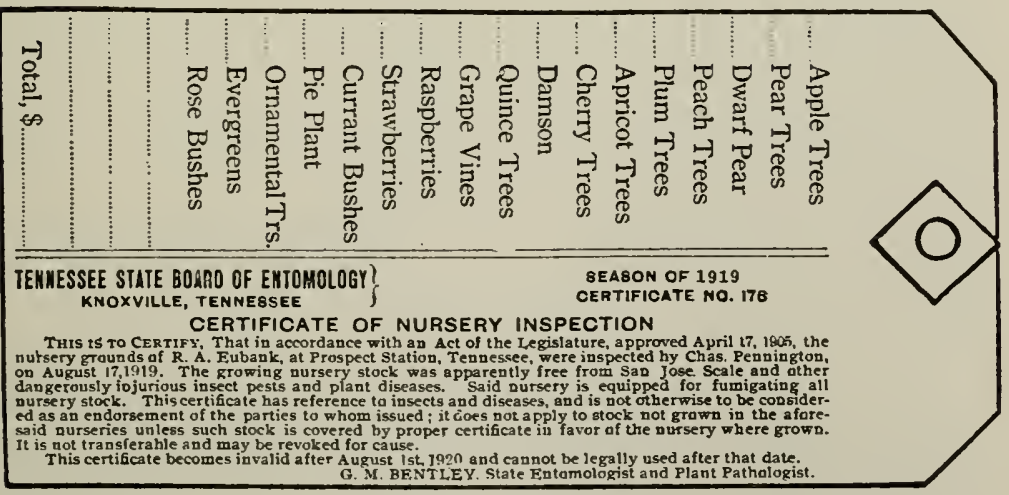

FIG. 42.-Inspection form. This shipping tag may have the name and address on the other side. 


\section{NURSERY AND ORCHARD PROJECTS AND EXERCISES}

1. Methods of Budding. -With any suitable twigs make five or ten specimens of each of the methods of budding.

2. Methods of grafting should be practiced in like manner until each method is well learned by crery one.

3. Grafting wax should be made by students. Also wax a supply of knitting cotton after winding it into skeins eight or ten inches long and cutting the ends.

4. A peach nursery should be started as a home project. Follow the methods outlined in this chapter. Grow the stocks, bud them, prune the trees, cultivate and care for them for a season after the budding time. They may then be transplanted to orchard rows, or may be sold if the project is to close.

5. A plum nursery project, including the three main types of plums, may be conducted in a similar way.

6. A cherry nursery project should be planned by some students. Let it be conducted as suggested in No. 4.

7. A nursery of apple and pear trees may be made interesting by using the root grafting method of propagation. Stocks may be purchased from large nurseries to save a year in growing them. Carry the project to completion as suggested in No. 4. Careful attention should be given to labels and records.

S. Top working apple or other orchard trees is good practice. Use the budding and the cleft-grafting methods. When: new varieties are thus inserted on trees of bearing age, note the success of the different methods used. Also note the time required to secure fruit on the new twigs.

\section{QUESTIONS}

1. Compare budding with grafting.

2. State several principles of propagation by these methods.

3. Describe shield-budding.

4. Outline the plan for propagation of peaches by budding.

5. What stocks are used for propagation of plums?

6. What are the problems involved in securing stocks for budding?

7. Describe prong-budding and plate-budding.

S. Describe flute-budding and chip-budding.

9. Describe the process of making a tongue-graft.

10. Outline the plan of propagation of apples by root-grafting.

11. How are materials and grafts stored during winter?

12. How are the root grafts set in nursery rows?

13. Describe cleft-grafting. What are its chief uses?

14. Give several reasons for topworking apple trees.

15. How does splice-grafting differ from tongue-grafting?

16. Describe saddle-grafting and veneer-grafting.

17. Describe side-grafting. How does the side-grafting cutting method differ from this?

18. How does shield-grafting differ from budding?

19. Describe inlaying.

20. Give directions for making grafting wax.

References.-U. S. Farmers' Bulletins: 157, Propagation of Plants; 710, Bridge Grafting. Nursery Manual, Bailey, Macmillan Company; Produc. tive Orcharding, Sears, J. B. Lippincott Company; American Apple Orchard, American Peach Orchard, Plums and Plun Culture, Waugh, Orange Judd Company. 


\section{C'HAPTER VII}

\section{THE HOME VEGETABLE GARDEN}

Maxy rural surveys have been made touching upon the subject of home gardens in rural districts. It has been found that in many sections of America many farmers as well as many city and village people do not have their own home gardens. The excuse for this often is found in specialization. Farmers grow cotton, wheat, or other single crops and neglect the garden. Even truck farmers sometimes fail to have their own home gardens because they grow a few special crops, such as melons or tomatoes for market, and do not have a variety of crops for their own tables, or to be preserved for winter use at home.

Importance of Home Gardening.--When comparisons are made between conditions found in small countries of Europe and in those of America the results are startling. In small areas we find the Europeans making a large part of their livelihood from their own gardens, while in America we find far too many of the people depending upon the nearby grocery store for their fresh vegetables in summer and for their canned goods in winter. This accounts very largely for the congestion in transportation by freight and express. Much time and labor are involved which should be used for better purposes.

Home gardening is a healthful, rejuvenating occupation for old people; it is good training and occupation for children (Fig. 43); it offers diversion for overtaxed minds; it is a good occupation fer women of all classes. Gardening, in the early morning hours, is pleasant and attractive to many who know from experience that it is not irksome.

Economy of Time and Labor.-The home garden should be so planned as to save as much time and labor as possible. This can be done by laying off the garden so that horse labor may be used wherever it is possible. Wheel hoes (Fig. 44) will save an immense amount of hand labor, but to use these the rows must be long and not interrupted by small beds of vegetables. With a horse or a wheel hoe one person may cultivate ten times as rapidly as with other garden tools. The work is done better and production is increased. But little work should be left to be done by hand or by 
the hoe. Make the work easy so that all will want to increase the size of the garden next year instead of diminish it. A labor-saving marker is shown in figure 45. If much hand weeding is required because the plants are put in small beds the garden work will become irksome and tedious. The gardener soon begins to figure how much time he is wasting and how limited is his reward for the labor expended. On the other hand, if large areas are used and good yields come from the least labor the results are encouraging.

The Door-yard Garden.-In providing for a handy garden either in the country, village, or city (Figs. 46 and 47), there are a number of principles which should be borne in mind. Try to

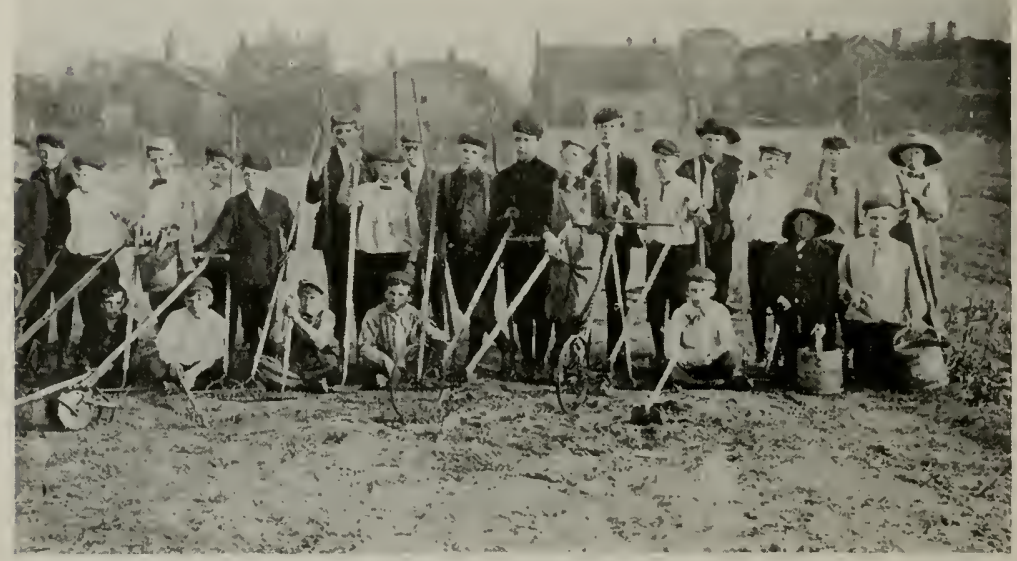

Fig. 43.-Boys of the Cleveland training garden, and the tools they learn to use. (Photo from U.S.D.A.)

have an early spring garden, a good midsummer garden, and a good fall garden. There are crops suited to all of these seasons, and they should be selected with an aim to have fresh vegetables of different kirrds at all these seasons. The crops suited to different seasons are classified in the next chapter.

A succession of plantings of a number of these, such as beans, corn and others will provide freshness and permanence in the garden.

Do not aim to have everything grown in the garden, but try to have a good assortment so that vegetables enjoyed by different members of the family will be available in their seasons. 
Do not try too much to have vegetables out of season. We should be content to have fresh vegetables at the time they are due in the garden. A little forcing, however, is sometimes desirable.

Make good use of hotbeds and cold frames so as to have plants which require transplanting ready for the open garden when warm weather comes.

A Suggestive Plan.-In planning the garden all local conditions should be held in mind, the likes and dislikes of the family or

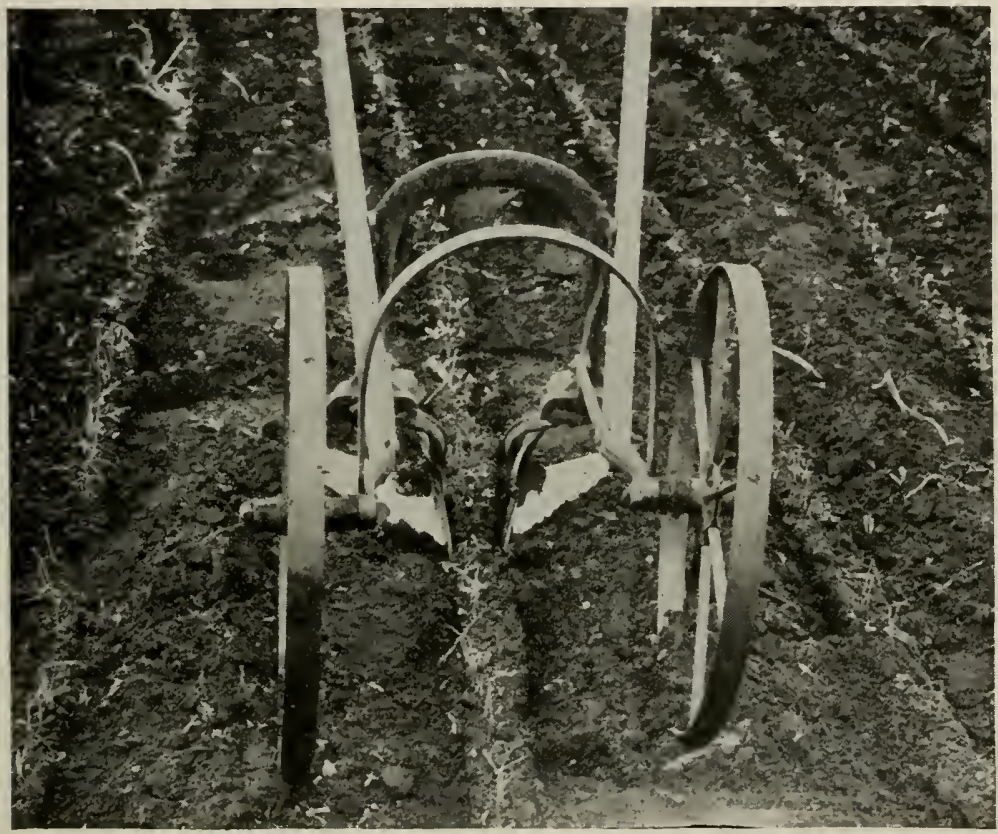

F19. 44.-A double wheel hoe may save much hand weeding in gardens. (Indiana Station).

the market, the experience of the gardener, necessity for economy of space, time of frosts in spring and fall, richness of soil, irrigation facilities, etc.

The accompanying plan from Cornell Extension Bulletin 14 is given with dates for New York state assuming the time for the last spring frost as early in May. These dates may be varied according to latitude for the whole country.

The rows should run the longest way of the garden. 
Plan for a IIome Garden

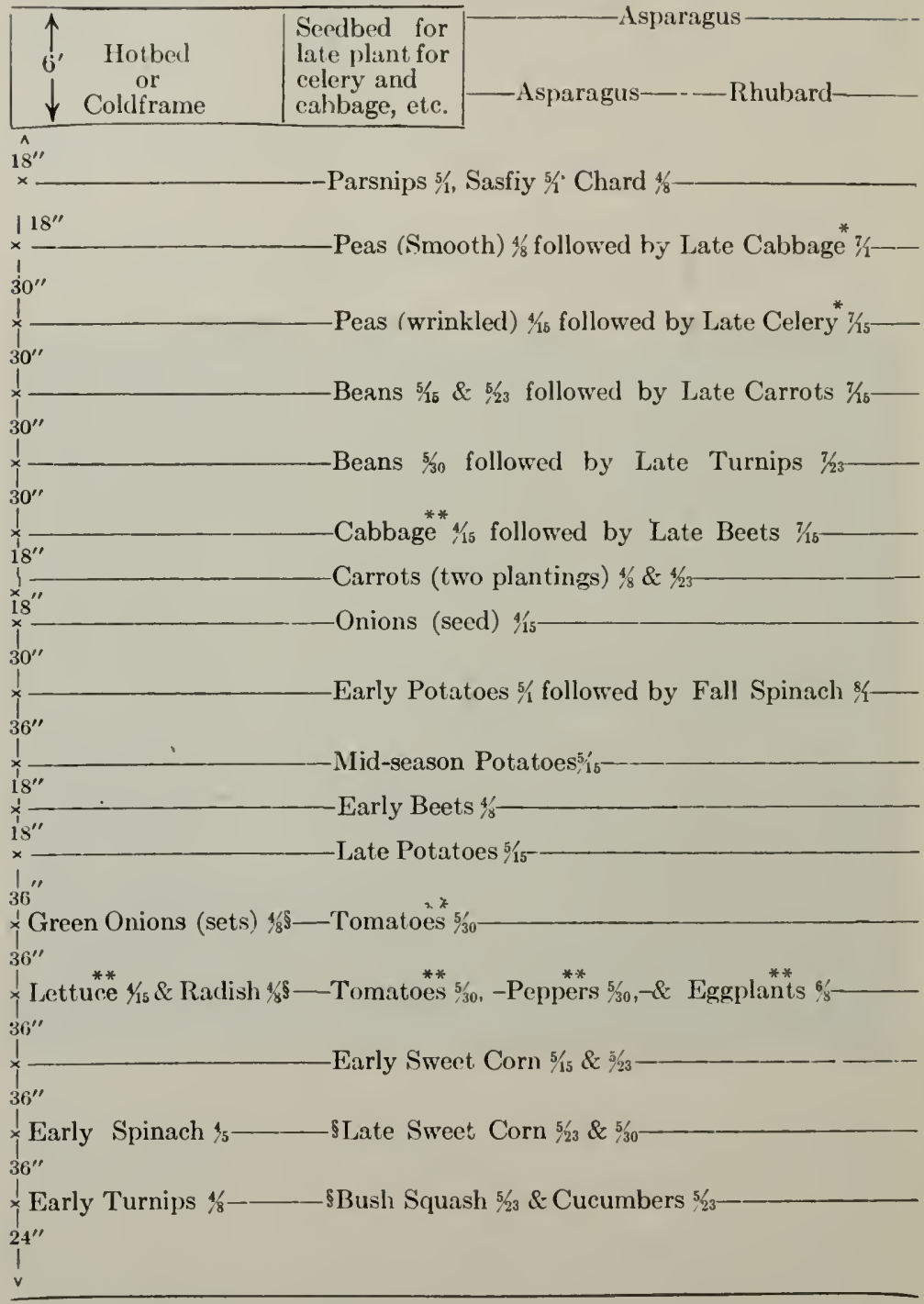

*Transplants grown in seedbed.

**Transplants bought, or grown under glass.

\$Remove only enough of the first crop to make room for planting. 
A City Garden.--The following plan for a square rod garden, published by the extension division of the University of Minnesota, is well suited to many village and city back yards. The figures at the right indicate the inches between rows.

$$
\text { Plan for a Square-Rod Garden. }
$$

Radishes and carrots followed by tomatoes ...............

. Early peas

.Early peas

Radishes and carrots followed by tomatoes

Early peas

. Early peas

.Lettuce followed by tomatoes

String beans

String beans

.Spinach followed by tomatoes

Early beets

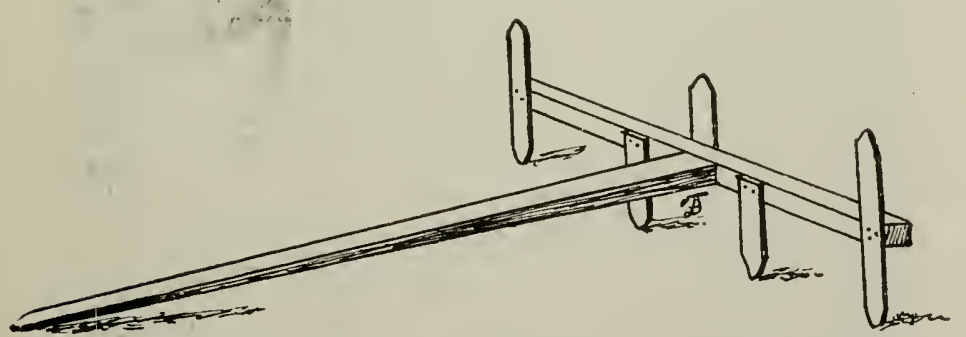

Fig. 45.-A handy home made marker for garden rows. As it stands in the drawing four rows are marked two feet apart. If it be reversed three rows are marked three feet apart. One may be made for other widths of rows. This one may be pulled by hand.

The Vegetable Border.-It is well to establish a permanent vegetable border along one side of the garden, either in the country or in the city. This border may contain such plants as would not require an abundance of cultivation, but which would require an abundance of mulching and manuring. This border may be located 
along the fence at the side of the yard and may be several feet in width. Here we should find such crops as rhubarb, asparagus, horse radish and other perennial herbs. Heavy applications of

FIg. 46.

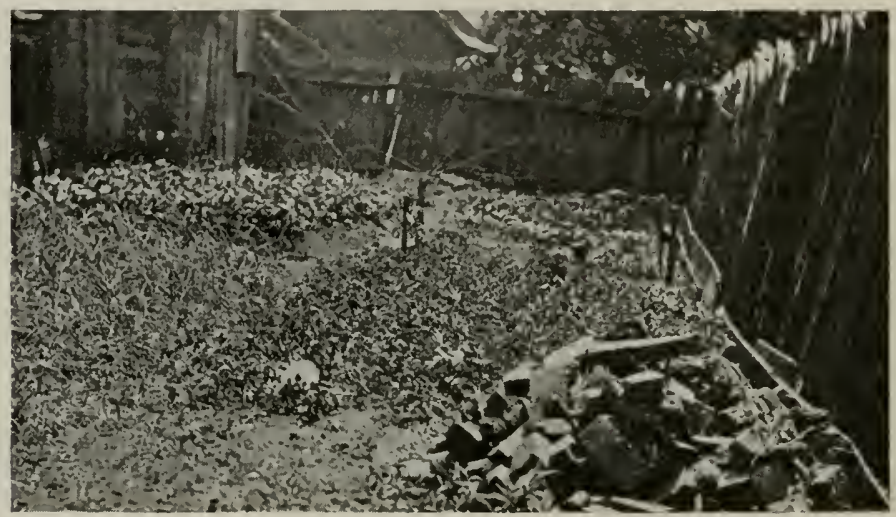

FIG. 47 .

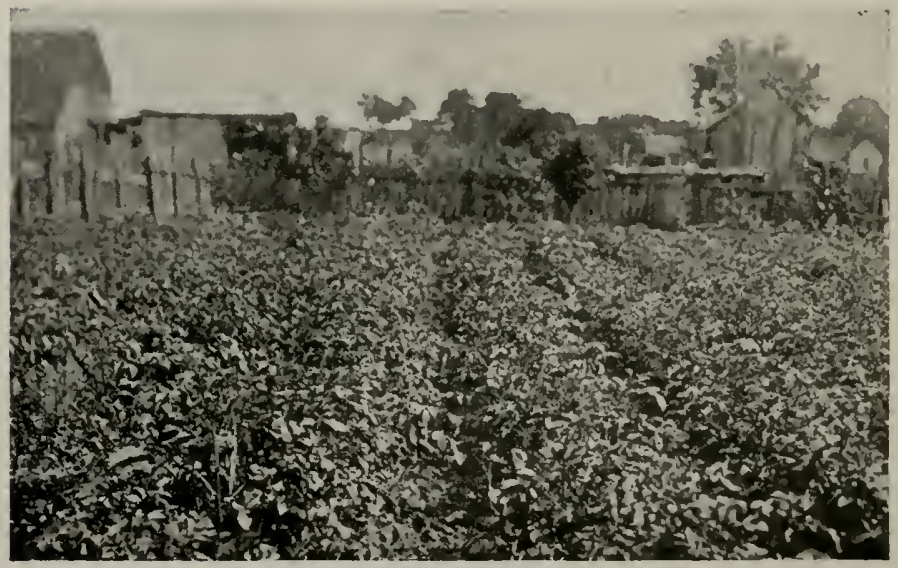

Fra. 46.-Gardening in back yards and vacant lots is good home project work. It is sometimes conducted under difficulties.

Frg. 47.-The home project gardens in villages help to transform unsightly lots into productive, healthful places.

manure can be put on this border in the fall and the ground can be thoroughly mulched in the early spring with straw or other 
coarse litter. The mulching may be done after the plants have come through the ground. It serves the purpose of conserving moisture, keeping the ground mellow and smothering weeds.

Do not make the mistake of having the vegetable border shaded by trees. Let it be at the opposite side of the yard rather than under large shade trees or fruit trees.

If the vegetables here referred to are to be planted in the regular garden they should be along one side rather than through the center. If they are at a distant side of the garden from the house they will allow the gardener to give more attention to the crops which require frequeit planting and frequent tillage.

Horse-culture Gardening.-The annual crops in the garden make up by far the largest area. They should be planted in rows far enough apart to allow the use of a horse cultivator between the rows. This would mean about three or three and one-half feet, depending upon the amount of land available. A little room should be allowed at the ends of the rows for turning with a horse and cultivator. It is plainly evident that the rows should be as long as convenient, and should at least run the length of the area. Less space will be wasted at the turning ends, and less time will be required for turning.

Some gardeners will raise the objection that they do not care for long rows of some of the crops in the garden. In that case half rows, quarter rows or less can be planted and several crops will be found growing in the same row.

There are some crops which would be easily covered with a horse cultivator unless great care is exercised. An adjustable cultivator may be used so that the teeth or shovels will be some distance from the plants. (Fig. 48-B. C.) Another remedy for the difficulty is to have growing with the small vegetables a few plants of some larger kind. For example, when carrots, parsnips or salsify are very young they need something along with them, such as radish or turnip to show the location of the row. This makes it possible to go through with the cultivator much more easily, and thus prevent the smothering of the crop by growth of weeds. Weeds should not be allowed to get ahead of the crop while waiting for the crop to become large enough to cultivate. Some gardeners go through ahead of the cultivator and sprinkle lime dust along the row so that the cultivation can be done with less danger of covering.

A Farm Garden.-The accompanying plan of a garden 100 by 200 feet from Circular 198, Illinois Station, is arranged for horse 
cultivation. A wheel hoe could be used in a garden of this size. Always change size, kinds of vegetables, etc., to suit your conditions: 'The dates of planting may need to vary considerably.

\section{Plan for a Farmer's Garden $100 \times 200$ Feet}

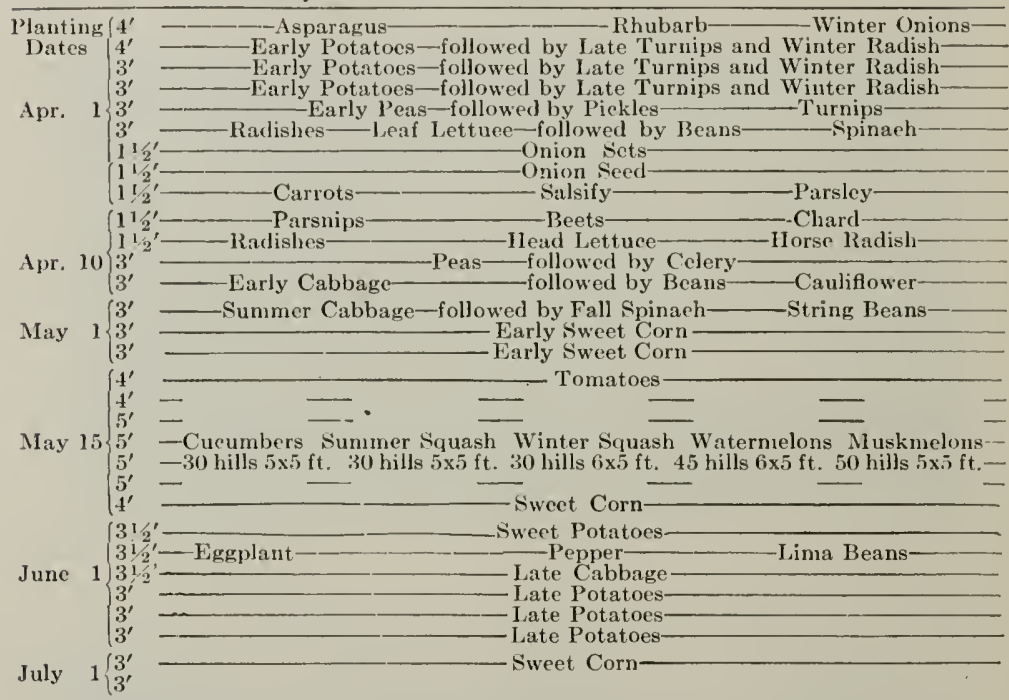

Small Market Gardens.-Almost any garden may have a surplus of some of the erops at any time of the year, but the market garden must be distinguished from the home garden by having something in the garden available for market at nearly all times in the growing season.

It is even more important with the market garden to have the plans well made regarding size, direction of rows, distance between rows, succession cropping, companion cropping, etc.

If much hand work is required in the market garden the profit to be derived from the crops is entirely lost. It is essential that the horse methods of tillage and planting be employed in the market garden even more than in the home garden. Hand planters are used for rapidly dropping the seed and covering it.

Extreme diligence must be exercised to keep the garden full of the crops which are going to make a financial return to the gardener. When a (rop) is too old for harvesting it must be turned muder or otherwise clestroyed to make room for a more profit- 
able crop. The ground must be used to its best advantage at all times.

Another Farm Garden Plan.-The garden plan 90 by 240 feet is taken from Circular 14 of the Kentucky Station. The space between rows will allow for horse tillage in most of the garden.

Farm Garden Plan, $90 \times 240$ Feet

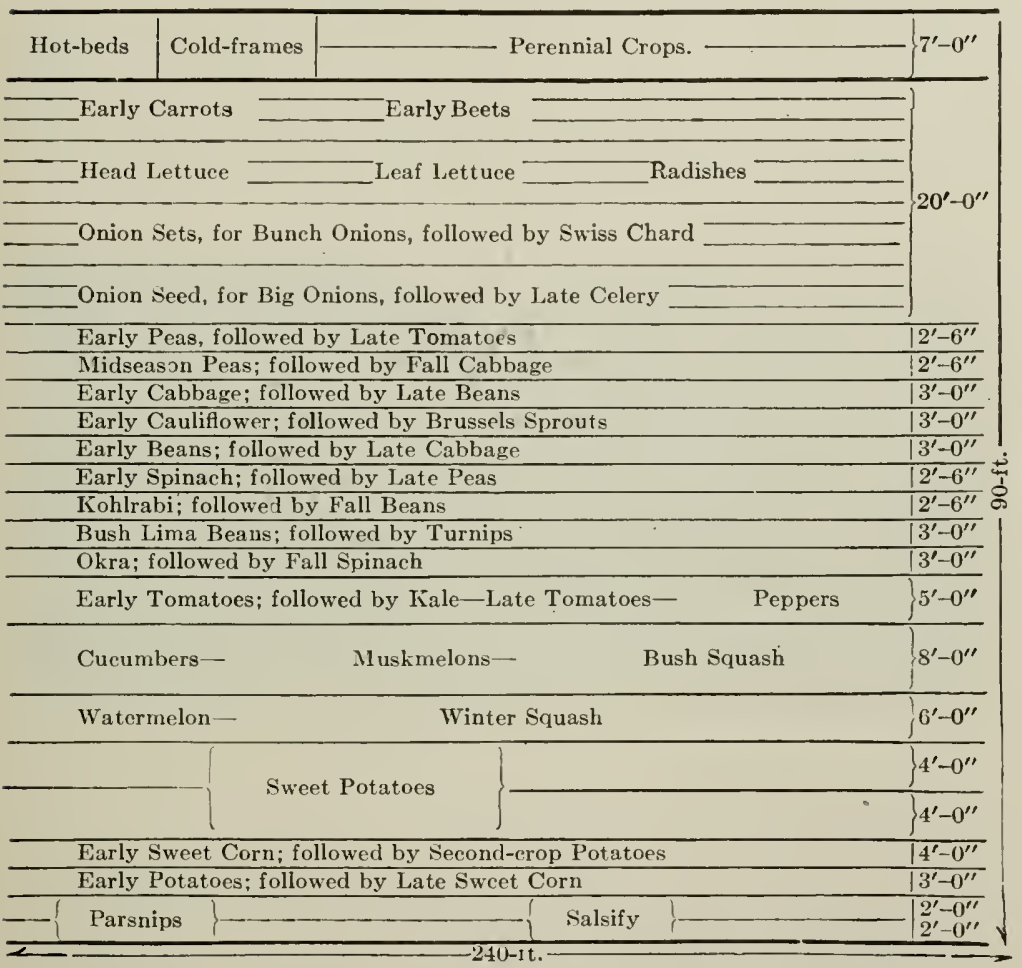

The Truck Garden.-Crops grown in the truck garden are usually produced on a larger scale than in the small market garden. They are usually found within a reasonable distance of very large markets so the products can be shipped or hauled directly to markets which are not easily overstocked even if the crops are very large. Truck growing may be extended hundreds of miles away from such markets if the number of kinds of crops is limited. Truck farmers may produce melons, sweet potatoes, Irish potatoes, sweet 
corn and other special crops which will stand shipping for long distances.

The planting plan to be follored depends entirely upon the latitude, soil and other conditions of the region. The planting should be timed so as to meet a favorable season in the markets which are to be supplied. Growers in the extreme north should not try to produce extra early erops, but should strive to meet the late advanees in price; those through the middle latitudes should have their crops ready to meet the demands in the large markets after the more southern growers have exhausted their erops. In the most southern latitudes earliness is of prime importance. It is the early market which the growers here must meet. Their reward is

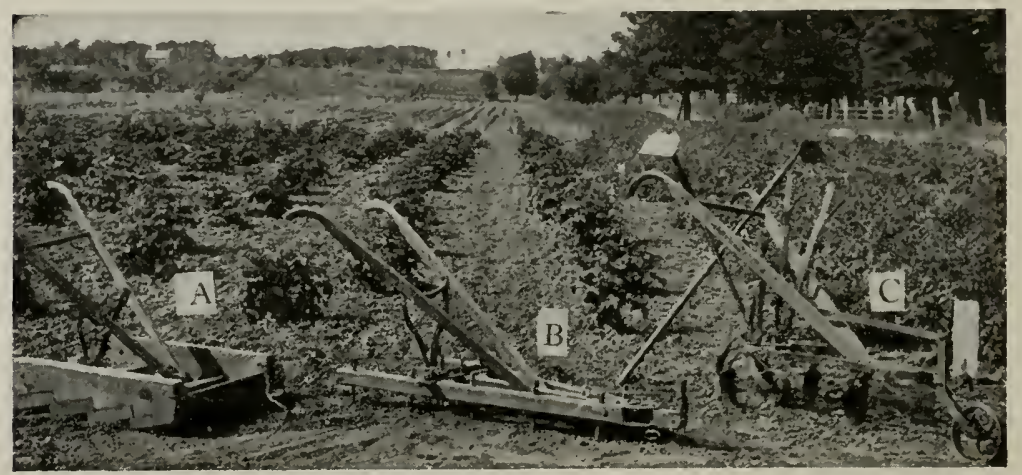

Frg. 48.-Three good one-horse implements for garden culture. A, planker for crushing clods and smoothing the surface. $B$, spike-tooth cultivator for producing a loose mulch. $C$, shovel cultivator for more thorough and deeper tillage. $B$ and $C$ are adjustable in width. (Indiana Station).

found by having their crops so early that they find no competition from other sections farther north.

Gardens for Different Seasons.-The early spring garden should contain those crops which have withstood the winter cold and are ready to harvest in early spring. In some latitudes this would include turnips and kale for greens and winter onions. The spring garden should also include the crops which can be grown in a very short time, such as loose leaf lettuce, head lettuce, radish, asparagus, rhubarb, English garden peas, spinach, ete.

Soon after the early spring garden we should find such crops as carrots, beets, white turnips and second crops of many of the earlier spring vegetables. 
Along through the summer there should be fresh supplies of early cabbage, snap beans, sweet corn for roasting ears, okra, if desired, later growths of beets, carrots and turnips. There should be plenty of cantaloupes, water melons, cucumbers, peppers, tomatoes and new Irish potatoes.

Later in the fall we should have supplies of the summer vegetables for drying or canning. A number of the vegetables already mentioned can be ready at this time. We should have winter cabbage, sweet potatoes, Irish potatoes and celery ready to go into storage, and there should be late plantings of English garden peas, lettuce, radish, spinach, and others.

As winter comes on we may find the number of fresh vegetables greatly roduced except in the extreme southern states. However, there may be green winter onions grown from shallot bulbs, turnips, kale and rape for greens, a number of vegetables in the coldframe, such as turnips, lettuce, beets, carrots, etc. Celery transplanted to boxes in the cellar may be fresh throughout the winter season. An abundance of coldframe space or deep pits will add greatly to the winter possibilities.

\section{GARDEN SOILS}

The home vegetable garden should have the best soil on the place. Rich black loam is best. Any soil can be made rich and black by the addition of enough vegetable material. This may be applied in the form of barnyard manure. A number of applications of manure well turned under will improve almost any soil and make it better for gardening.

Best Type of Soil.-For most vegetables soil which has considerable sand in its makeup is better than soils which are largely made up of clay. Sandy loam is a soil which contains a larger proportion of sand than clay loam.

Sandy soils are more easily- warmed, are better drained, will respond to modifying treatment more quickly and produce earlier crops of vegetables.

Clay loams are colder, hold moisture better, hold plant food better, are less responsive to liming and manuring, produce crops later, but on the whole produce as much of most of the crops as do the lighter soils.

Modifying the Soil.-On farms where the most ideal garden soils are not found they can be amended and made suitable for gardening by the addition of organic material, by thorough, deep 
tillage, by discing the surface well, and by close attention to the best methorls of handling them at the proper time. (Fig. 49.) A sanciy soil, for example, can be plowed when rather wet or rather dry without injury; a clay loam, on the contrary, must never be plowed when too wet or too dry.

Liming.-One of the best methods of improving a garden soil is to thoroughly lime it. The application of 500 to 1000 pounds of burned lime, or twice this amount of ground limestone will make a marked difference in the physical character of the soil. Lime will make sandy soil more tenacious by bincling the particles together. This tends to make it more retentive of moisture and plant food.

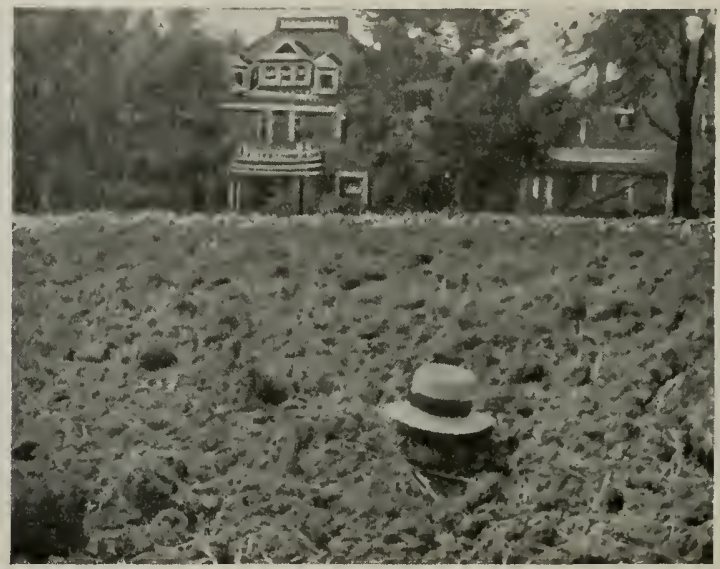

FIG. 49. - When the soil for a new garden is first plowed the prospect for a good garden may be very discouraging. The clods may be crushed by a planker drag or an acme harrow. This should be done immediately after plowing, before the clods become hard.

Lime added to clay soils tends to make them more porous, lose water more rapidly, unlock the plant food more readily, and they are warmed more easily. Many of our garden crops are much improved by the addition of lime. It is best, however, not to add lime of a caustic nature to those portions of the garden which are to be used that year for the growth of Irish potatoes and other root crops. The liming for those portions of the garden should be at least one year in advance of the growth of such crops.

Adding Humus and Manure.-One of the best ways of adding organic matter to soils is to grow green crops of rye, vetch, crimson clover or other crops which will grow during the late fall, winter 
and early spring. After these have produced a few inches of growth in the spring they may be turned under and the ground well disced, rolled and harrowed. If enough lime is present even a heavy application of such green manure will not make the soil sour. The humus obtained from the rotting of green manure produces remarkable results in the increase of crops of all kinds. Green manure is much cheaper than stable manure if time can be allowed for its growth.

Many garden crops will stand heavy applications of barnyard manure without injury. If manure can be obtained without too great an expenditure of money and labor it is the quickest way of improving our garden soils. Applications vary all the way from three tons to twenty tons per acre, depending upon the crops to be grown. If very heavy applications are to be made the manure should be thoroughly incorporated with the soil by very deep plowing, cliscing, rolling and harrowing.

One of the greatest dangers from the use of heavy applications of green manure or stable manure is that a parl or layer of organic matter may be placed on the bottom of the furrow, and the moisture supply shut off during the growing season. This condition must be avoided. Thorough spreading of the manture and thorough harrowing and discing after the plowing will tend to incorporate the soil with the organic matter and thus allow capillary moisture to continue rising as it is needed by the growing crop.

Gardeners using commercial Fertilizers always find it profitable. It is best to study the special needs of each crop and supply the particular forms of fertilizer which are needed in each case. A complete fertilizer is one which contains all three of theso-called fertilizing elements, nitrogen, phosphoric acid and potash. If the ingredients are purchased for supplying each of these three chemicals they can be mixed by the gardener in proportions best suited for each crop. It is not good practice to buy a complete fertilizer for all kinds of crops because the same mixture will not suit them all equally well. The dealer or manufacturer who does the mixing usually applies unnecessary filler, which requires the expenditure of money and labor in shipping and hauling.

Tillage.-The preparation of a good seed bed is one of the marks of good gardening. Deep, thorough plowing, harrowing immediately after plowing, planking or rolling to fine the surface, harrowing the surface to maintain a loose mulch, all are valuable practices in the garden (Fig. 48). Never let the soil become cloddy, hard or 
crusty. Frequent, shallow tillage is infinitely better than crusty soil followed by deep plowing. Spring tooth cultivator's which are adjustable are excellent for garden tillage.

Cover Crops.-Much of the garden will not be oceupied during winter by money crops or other strictly garden crops. All vacant spaces should be covered with a green growing crop sown as early as the regetables are taken off, or the cover crop may be sown between the rows of tomatoes, corn, and similar crops, after tillage is over. If the cover crop is sown in August it will make a green covering throughout the winter, and will produce an abundance of green manure for the addition of humus the following spring. Among the best crops for growth in the winter are different forms of winter grain, crimson clover and hairy vetch.

Drainage.-Under-drainage is not as expensive as the begimner is likely to think. If the soil tends to wash under-drainage will tend to prevent it. If water stands on the soil under-drainage, of course, will help to remedy the diffieulty.

One of the essentials of successful market gardening or truck gardening is to have crops produced at the right season of weather conditions. Drainage will help better than almost anything else in overeoming climatic and weather difficulties. Soils that are well under-drained will be warmed more quickly and are therefore much better for gardening.

Irrigation.- Watering garden crops at the right season is highly important. In the average country home garden this may be impossible. Rainfall must be depended upon. In such eases frequent, shallow tillage is to be recommended. This will conserve the moisture from one rain to the next. Some have called this "horse-leg irrigation." Frequent use of the horse cultivator saves much expense for artificial irrigation.

The overhead system of irrigation is not as expensive as some might suppose. Water pipes placed on rows of posts running through the garden are provided with special nozzles along one side of the pipes. These nozzles are three and one-half or four feet apart. The lines of pipe are forty or fifty feet apart. Of course these must be connected with a water supply pipe which may run in the ground and rise to each of the lines of pipe. Special unions are required to allow the rolling of the water lines so as to throw the water as desired to either side (Fig. 50.)

The water supply for irrigation may be from wells, ereeks or other sources. The water may be supplied through pipes either 
from an overhead tank, a reservoir on a hill or by direct pressure from a pump running all the time the irrigating is being done.

In the extended regions of the arid West where irrigating projects are in use, irrigation is so well understood that this need not be described here. Under such circumstances water is supplied in great abunciance at stated intervals, and may be applied to the crops either by the flooding and furrow methods or otherwise.

Garden Tools.-Hand tools of various kinds for the garden are shown in figures 51 and 52 . The garden rake is one of the best hand tools, as it will help in preparing the seed bed, destroy clods, remove

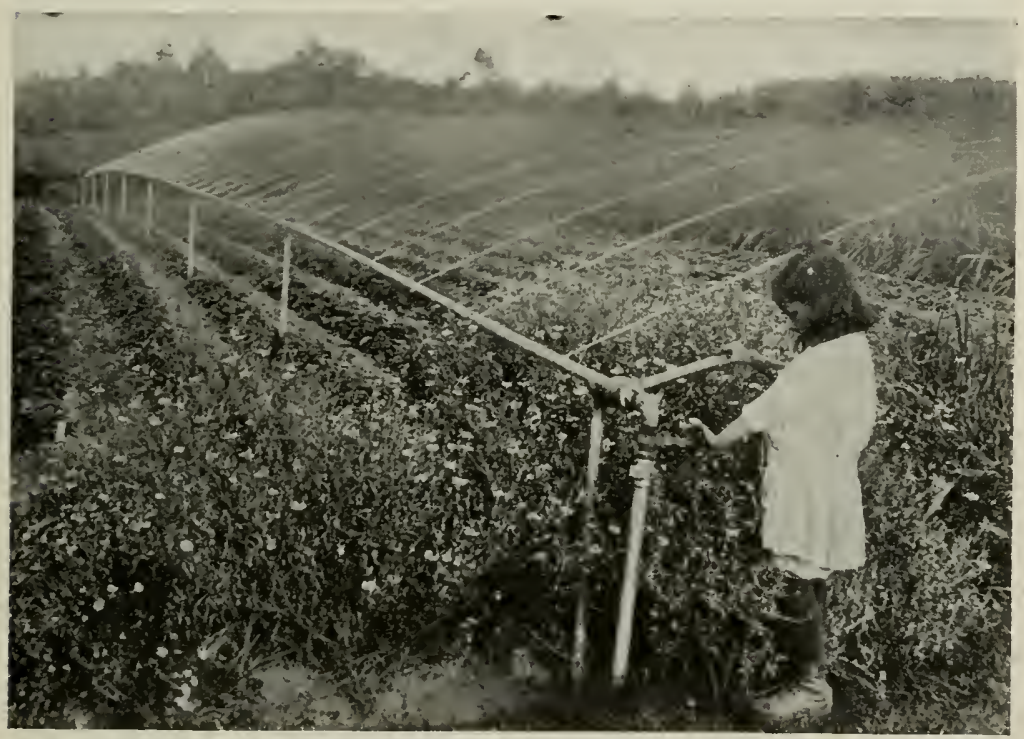

Frg. 50.-Irrigation with spray pipes can be easily operatel. The nozzles are about three feet apart. The hand lever rolls the pipe to spray in any direction. (Skinner Irrigation Co.)

rubbish, etc. (Fig. 53.) The rake is useful in planting as shown in figure 54. Later it is the best tool for conserving moisture and killing small weeds when they are germinating from their seed coats, even before they show above the surface of the ground.

The hoe, although a very common garden tool, is less valuable than the rake. At planting time, however, it is very useful, and if weeds are allowed by careless gardening, the hoe is an efficient tool for destroying them.

As gardeners learn to use the level culture system of gardening 
the hoe is no longer needed for hilling up the plants. Numerous small garden tools such as twine winders, hand dibbers, hand weeders, (Fig. 51) seed droppers, pruning shears and others need not be specially described; their names indicate their use well.

Combination wheel hoes and planters are very desirable implements for the home garden. (Figs 44 and 55). At planting time, after the ground is prepared for the seed the planter will save enough time to repay for the purchase. After much of the plant-

FIG. 51 .

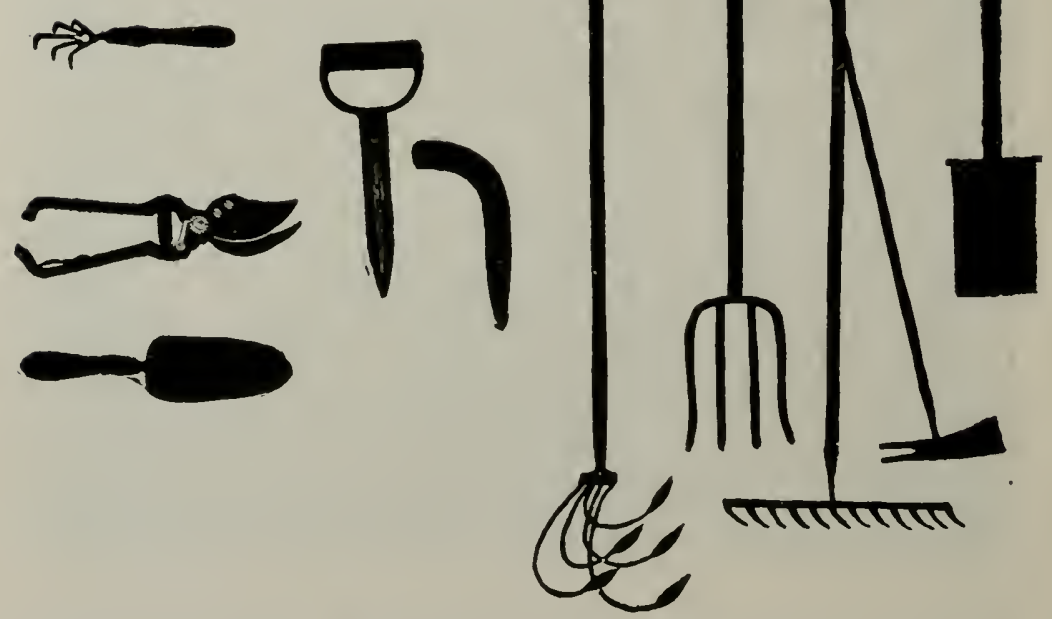

FIG. 51.-Handy tools for transplanting plants, and weeding beds; pruning shears at left.

Frg. 52.- Most necessary hand tools for garden work.

ing is done only a few minutes are required for transforming the implement into a good garden eultivator. Some wheel hoes have no seed attachments; these are much cheaper and are always ready for use as cultivators. (Fig. 44.)

So much lias been said regarding the use of a horse in the garden that we should give special attention to the suitable horse cultivators. Two main kinds may be recommended. 


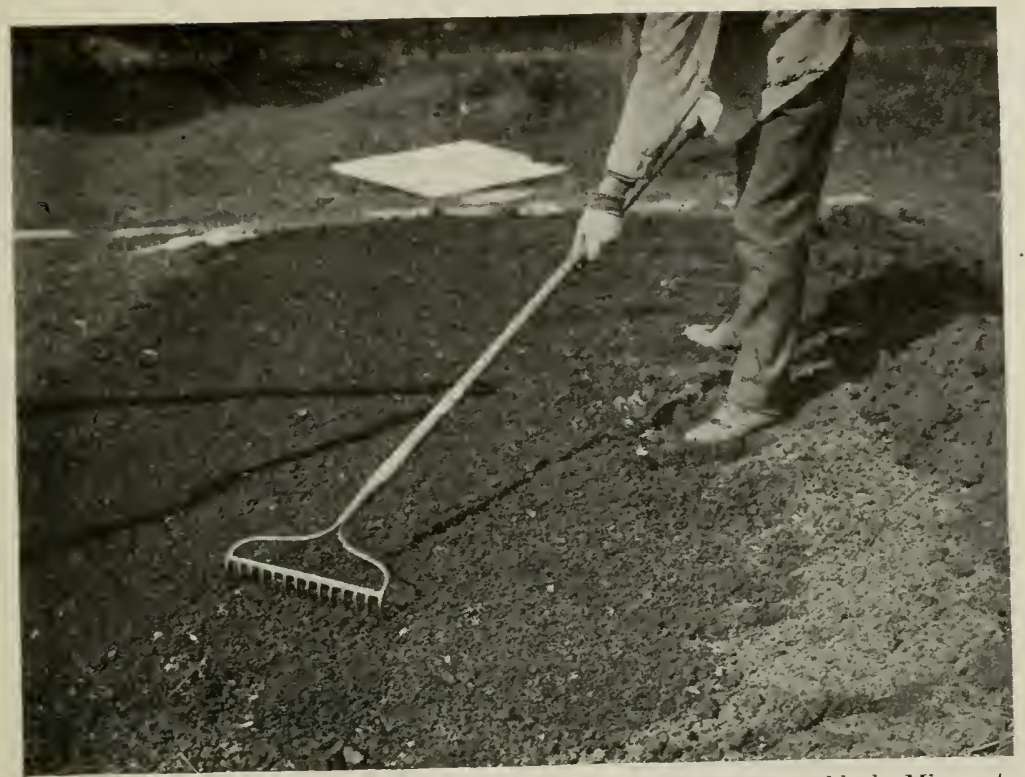

Fia. 53.-The garden rake is the best tool for the final preparation of a seed bed. (Minnesota Station.)

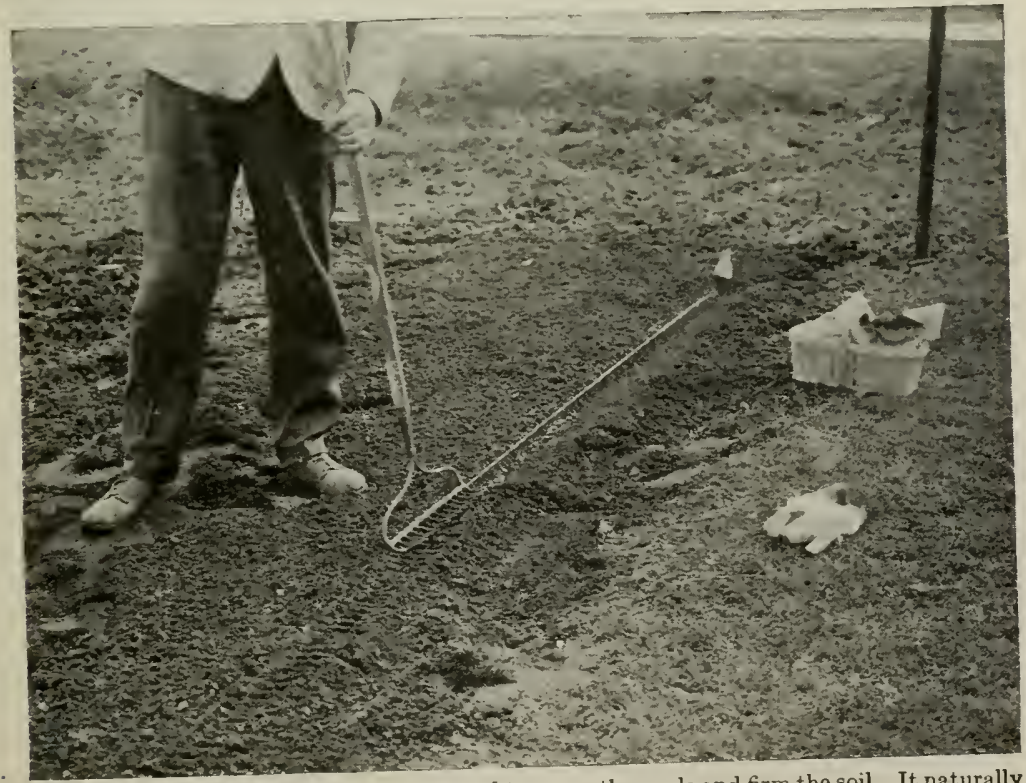

. The rake is used to cover the seeds and firm the soil. It naturally leaves a mulch of loose soil on top. (Minnesota Station). 
The spike-tooth cultivator which is quickly adjusted by the use of a central lever is well suited to gardens having loose, friable soil. (Fig. 48). This may be made so narrow as to go between the rows of sugar beets or other plants which are planted only twenty or twenty-four inches apart. On the other hand, this may be set wide enough to till the whole middle where the rows are fully three feet apart.

The spring tooth cultivator, having about seven two-inch teeth, is a less expensive implement. This form of cultivator is adjustable so as to suit rows of different width, and so as to throw the surplus earth either from or toward the row as desired.

Judging Home Garden Projects.-It is well for the gardener to know on what points his garden may be scored by instructors or others who visit it from time to time. The following score card is suggested by the U. S. Bureau of Education. It may be modified to suit local conditions.

\section{Score Card for Judging Home Gardens}

A-General appearance Arrangement of rows Freedom from weeds Cultivation and eare Proper thinning

$\mathrm{B}-$ Choice of vegetables

For home use

For marketing

For canning

C-Freedom from pests

Spraying for insects

Spraying for disease

Other remedial measures

D-Evidences of

Continuous cultivation

Companion eropping

Succession cropping

E-Care of Tools

$\mathrm{F}$-Value of produce

Used at home

Sold in the market

Used for canning 


\section{SURVEYS, EXERCISES, AND PROJECTS}

1. Garden Survey.-Plan a garden survey of your community. Let it cover the conditions for the last year or two. Size of garden. Number of kinds of vegetables grown. Chief products. Uses made of products. Number of people in each family. Whether horse culture was employed.

2. Review the facts obtained in above survey, or conduct independent survey to determine the profits or income from gardens having a surplus to sell.

3. Determine from the facts obtained how many families produce most of their vegetables for (1) summer use, (2) for winter use. Also find methods of storing, preserving, drying, etc.

4. Calculate the total amount of money saved to the community by home gardening instead of buying products needed.

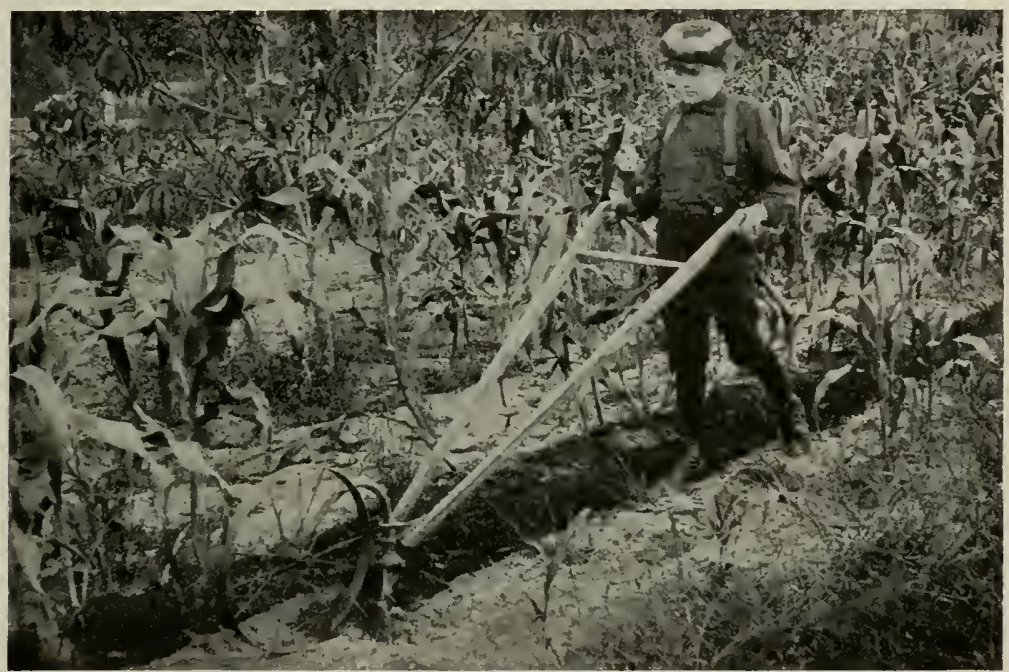

Frg. 55.-One attachment of the wheel cultivator is a small turning plow which may be used to cover grass and weeds. This boy makes good use of it. (Bateman Mfg. Co.)

5. Determine approximately the time and amount of labor lost where horse culture is not used.

6. Garden Plans. - Draw several of the best garden plans found in the community. Then draw several of the poorest plans, where beds are chiefly used. Contrast these and replan the poor ones.

7. Study vegetable borders found in the community. What crops are grown in them? What methods of mulching and culture are used?

8. Make some ideal home garden plans to include all vegetables which should be grown in the spring, summer and fall gardens.

9. Truck Gardens.- Visit market gardens and truck gardens, and study the system of rotation, succession, companion cropping, harvesting and marketing.

10. Tools and Implements.-Make a list of the garden planters, wheel hoes, other kinds of cultivators, and other kinds of garden tools and implements found in the community. Determine if possible why some people have these and others do not. Are they purchased because of fads, or for their actual benefits?

11. Garden Soils. - If two or more types of soil are found in the com. 
munity, determine which is best for gardens in general, and which for special erops, such as lrish potitoes, sweet potatoes, peanuts, and others.

12. Make inquiry to find what gardeners in the community have attempted to modify their soils to improve the yields of garden products. What methods have been most suceessful in this respect?

13. Liming.-Conduct a project of soil improvement through green manuring and liming.

14. Manuring and Fertilizing.-Conduct experiments in home gardens or on the school grounds, to compare the benefits from (1) green malluring, (2) use of barnyard manure, (3) commercial fertilizer containing considerable nitrogen. Crops for these experiments may be corn, potatoes, cabbage, or other erops grown on rather extensive seale.

15. Tillage.-Compare by experiment, (1) deep and shallow plowing (2) fall and spring plowing. Also compare deep and shallow cultivation of eorn and other garden crops.

16. Cover Crops.- Some students should conduct home prejects in improvement of soils through cover crops, using them in the spring as green manures. Comparison should be made with plots left bare during the winter.

17.-Drainage.- If gardens with under-drainage can be found in the community, make a study of the benefits resulting therefrom.

18. Irrigation. - If any system of irrigation is in use in the vicinity, cooperate with the owner in determining the benefits derived from irrigation. Make a list of the items of expense for installing and operating.

19. Some student may find it possible to conduct a projeet of installing and operating overhead irrigation, (Fig. 50), or some other inexpensive system. Records should be kept of the cost of installing, cost of operation, and results obtained. Yields should be compared on irrigated and nonirrigated plots of the same crops.

\section{QUESTIONS}

1. Enumerate the benefits of home gardening.

2. In what ways may time and labor be saved by the home gardener?

3. What are some of the elements of success with the door yard garden?

4. What is meant by the vegetable border?

5 . What plans are necessary if horse-culture is to be used?

6. Distinguish between the home garden; the small market garden, and the truck garden.

7. Make a list of garden crops to be started at different seasons.

8 . Describe a good type of soil for suecessful gardening.

9. What are good ways of adding humus to soils?

10. What are the effects of liming sandy soils? Clay soils?

11. Give some directions regarding the use of commereial fertilizers.

12. What are the advantages of deep plowing? Of shallow cultivation?

13. What are some good winter eover erops for your section?

14. When should they be sown? With what fruit or garden crops can they be used?

15. What are the advantages of under-drainage for gardens?

16. Deseribe plans for irrigation with which you are familiar.

17. Make a list of garden tools which you consider essential for good results.

References.-U.S. Farmers' Bulletins: 218, School Garden; 839, Canning by Cold-Pack Method; 853, Home Canning of Fruits and Vegetables; 856, Control of Diseases and Insects ; 879, Home Storage of Vegetables; 881, Salting, Fermenting and Piekling; 916, Community Drying Plant; 934, Hone Gardening in South; 936, City and Suburban Gardening; 937, Farm Garden in North; 984, Farm and Home Drying of Fruits and Vegetables.

Productive Vegetable Gardening, Lloyd, J. B. Lippincott Company; School and Home Gardening, Davis, J. B. Lippincott Company. 


\section{CHAPTER VIII}

\section{HOTBEDS, COLDFRAMES, AND FLOWER PITS}

THE chief purpose of hotbeds is to start plants early enough to have them mature in time for market or in some cases to get them to mature before fall frosts kill them. A secondary purpose of hotbeds is to grow vegetables of edible maturity out of their natural season. Examples of crops started early in hotbeds are tomatoes peppers, eggplant, cabbage, kohl-rabi, cauliflower, and others. Among the erops that may be grown to edible maturity in hotbeds are those which mature quickly and which do not require great heat. Examples are lettuce, radish, spinach, and sometimes carrots, beets, and turnips.

Frames for Hotbeds.-The standard size of hotbed frames is six feet from the low side at the south to the high side at the north. In length east and west there is no limit. They are however commonly made into a length which is some multiple of three feet, that is, either three, six, nine, twelve, ete. The low side of the frame should be about one foot above the soil inside. The high side should be about eighteen inches above the soil inside. The difference in height gives a slope to the glass covering toward the south so that the rays of the sun will enter the pit better.

How Frames are Made. - If a piece of two by four is placed in each corner of the frame and the boards nailed to these, the frame may be easily eonstructed. The iwo end pieces must be cut at a bevel to agree with the sloping of the bed. If a six-inch slope is to be given as suggested, a board six feet long and six inches wide may be marked diagonally from one corner to the other and sawed on this mark. This will give the two pieces needed for the two sloping ends.

Glass for Hotbeds. - Sash made especially for hotbeds may be easily constructed. These have the supporting strips for the glass running from end to end vithout any cross piece except at the head of the sash and under the glass at the foot of the sash. These two hold the long strips in place. The glass may be of any desired length and of a width to fit the distance between the strips. There are two methods of placing the glass in the sash. (1) The glass may be "butted," that is, placed edge to edge. (2) The glass may 
be lapped about one-fourth inch so that the water will shed off as with shingles on a roof. The lapping is usually preferred as heavy rains will not leak into the bed so badly.

Improvised sash may be used on hotbeds, that is, windows from any old building may be placed end to end, fastened together by two strips along their edges inlaid or screwed so as to hold the two halves. The entire window is thus used as one sash on the hotbed. In case such glass is to be adapted for this use, it may be necessary to make the frames so as to fit the glass instead of making them of standard size.

Placing the Hotbed Frame.- It is best to dig a pit a little larger than the hotbed frame. This may be one to two feet or more in depth. Put about one foot of fresh horse manure in the bottom of the pit and tramp it thoroughly. Six or eight inches of good garden soil should be placed on the manure. A part of this may be put in place before the frame is lifted on the manure but some of the soil should extend up into the frame after it is placed. Compare these features in figures 56 and 57 . Soil or manure should be banked up well around the outside of the frame to exclude all possible drafts of cold air. The glass may now be put on and after a few days the first extreme heating of the manure will be over. Then the soil is smoothed and watered if necessary, ready for planting the seeds (Fig. 58).

How the Hotbed is Heated.-There are two ways in which the hotbed receives heat. (1) The chemical change due to the rotting of manure gives off a great deal of heat. This being under the plants forces growth somewhat rapidly. If this heat is lacking the bed is called a coldframe. (2) The sun heat is trapped by the glass and held in the bed. This is made clear by the statement that sunlight goes through clear glass without heating it, but when it strikes the soil or other objects inside, the light is changed into heat which cannot get out through the glass readily.

Using Flats in Hotbeds.-Boxes about twelve by eighteen inches or larger, and four inches in depth, will be of use in growing seeds in the hotbeds. Fill the flats with three inches of soil and after planting the seeds in them place them on the soil in the hotbed. When transplanting time comes these are easily lifted out and taken to where the transplanting work is done. In cold weather the transplanting should be inside to prevent chilling the plants.

Ventilation of Hotbeds.--On warm sunny days the beds will become too hot and ventilation is necessary. (Fig. 59.) A ther- 
mometer in the corner of the bed will serve as a guide to the gardener in this matter. Cool season crops should not be required to stand a temperature of more than eighty degrees in the day time, and seventy degrees would be better. Warm season crops, such

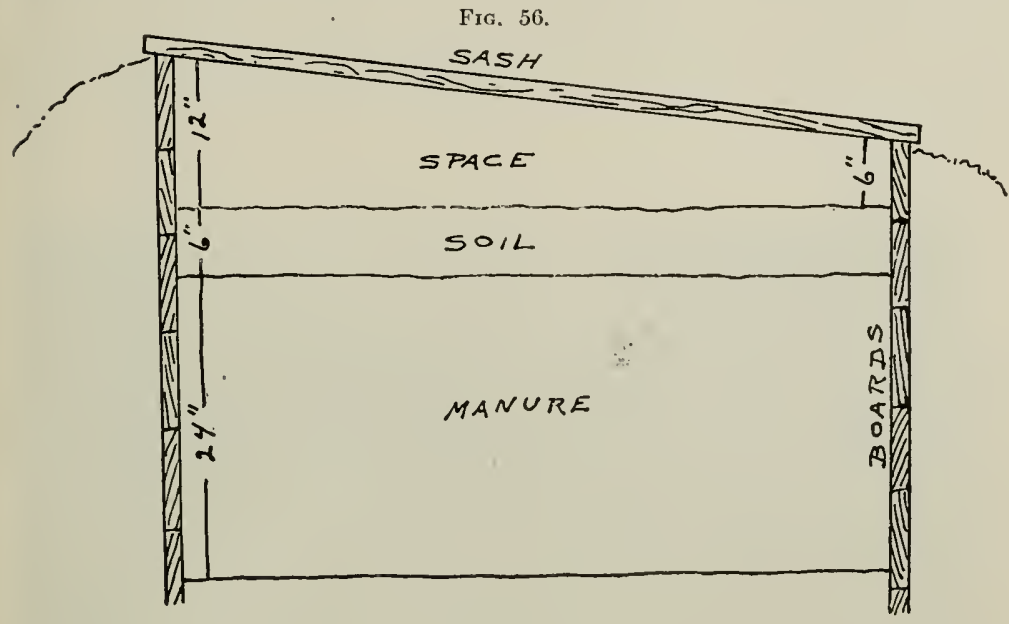

FIg. 57.

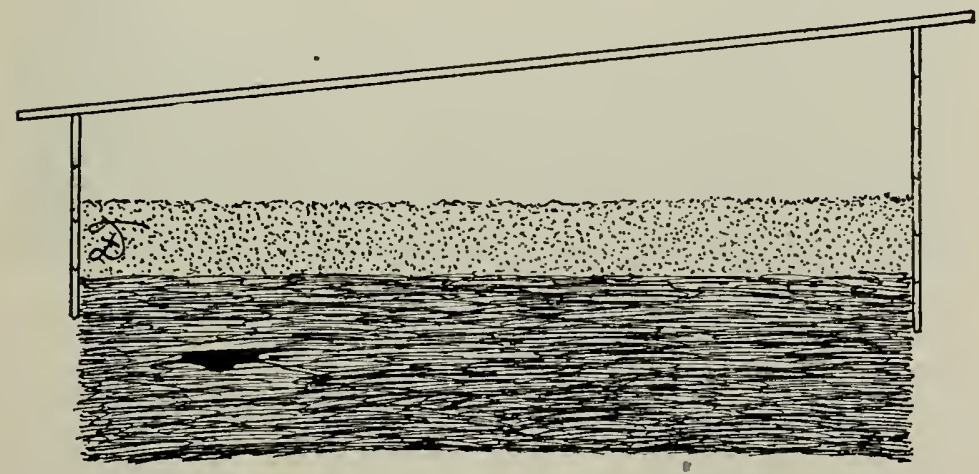

Fra. 56.- Plan of manure hotbed. The sash is six feet long and slopes to the south.

FIG. 57.-Cross section of a six-foot hotbed. The bottom of the frame is placed a little below ground and a pit is dug about 18 inches deep. This is filled with fresh horse manure, on top of which is placed 6 inches of rich garden soil. The glass sash on top slopes toward the

as tomatoes, peppers and eggplant may stand a temperature of eighty to ninety degrees.

Ventilation is accomplished by raising the sash at the north end 
and supporting it with two sticks at the corners of the sash. When the weather becomes very warm, the sash may be removed entirely during the day.

Ventilation not only controls the temperature of the bed but also supplies the necessary fresh air and helps keep surplus water vapor from accumulating inside. Too much heat and too much water vapor is certain to cause damage to the plants. Dampingoff fungus is a common trouble in hotbeds and poor ventilation is apt to help start it.

Watering.-As the plants are growing under the cover, water-

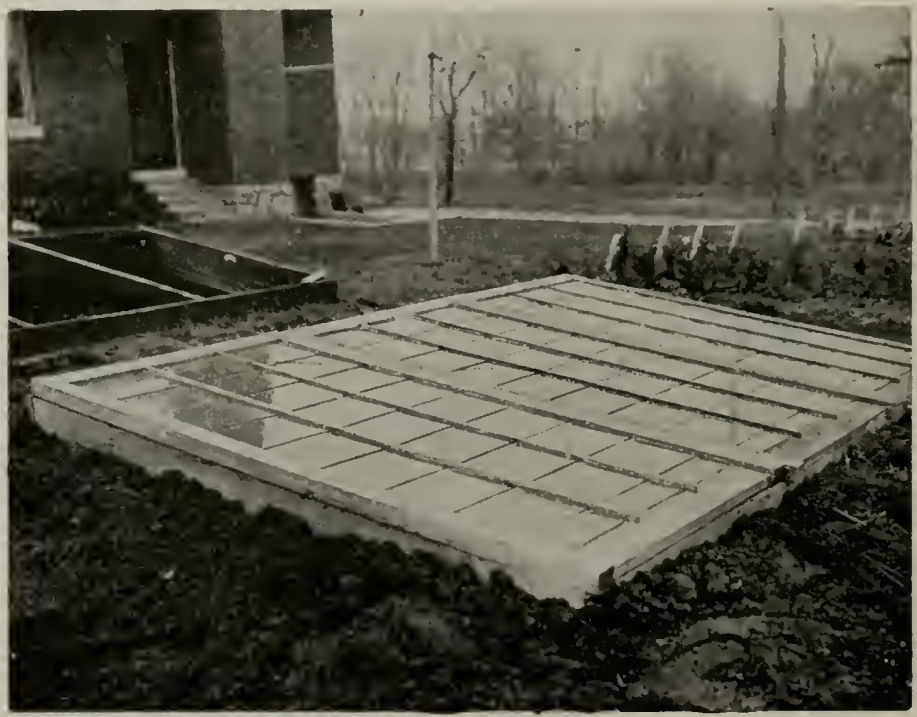

FIG. 58.-A three-sash hotbed ready for use. (Kentucky Station).

ing is a matter which must be given close attention. If too much water is applied, the soil will become soggy and the plants will turn yellow and suffer for want of air in the soil. If the bed is properly ventilaterl, considerable watering is necessary beeause the heat of the bed will dry out the soil. If the bed is filled with water, the manure underneath may stop heating. Light applications of water nearly every day is the best plan with the hotbed.

The Hotbed Becomes a Coldframe.-After some weeks the manure in the hotberl will fail to give out heat because the rotting is advanced so much. In this condition it may be considered merely a coldframe as it gets its heat only from the sun through the glass. 
Hotbeds which are started in late winter or early spring may continue their heat from the rotting manure long enough to last until the warm spring weather has come. The plants in the bed may no longer need artificial bottom heat.

Coldframes Compared with Hotbeds.-The chief difference between a coldframe and a hotbed is the absence of bottom heat in the coldframe. In many cases, however, the coldframe has no glass but has in place of it a covering of muslin.

The muslin cover of the bed may be stretched and tacked on

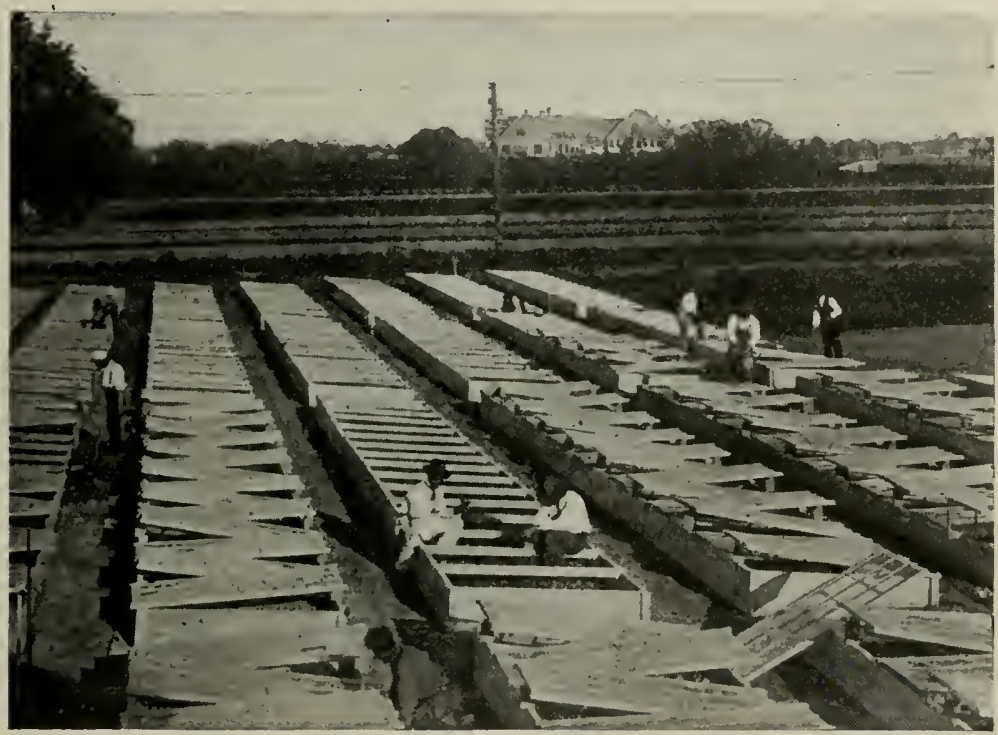

Fig. 59.-Students of Hampton Institute working in hotbeds and coldframes. Methods of ventilating are here shown. (U.S.D.A.)

frames which are fastened in place by wooden buttons or may be merely laid upon the bed. In many cases the muslin may be tacked directly to the frame along the upper side. The other edge of the cloth is tacked to a strip of wood or pole which serves as a roller. To remove the cloth, the roller winds up the cloth as it is rolled toward the upper side of the frame. The bed is quickly covered by merely unrolling the cloth and letting the pole hang over the lower side.

Frames for Beds.- Sloping frames are not always constructed for coldframes. Boards are placed on edge and nailed together 
at the corners and the eloth or glass is placed over the bed. It is not desired to have very much heat but the frames may be merely to protect the plant from the frosts or other extreme ocld at night.

Uses of Coldframes in the North.-In the colder latitudes one use of the coldframe is to harden off plants which have been forced in the hotbed. Another use is to protect early spring crops which mature in short time, such as lettuce, radish, spinach, carrots, and others. As these plants are hardy and can endure some frost the

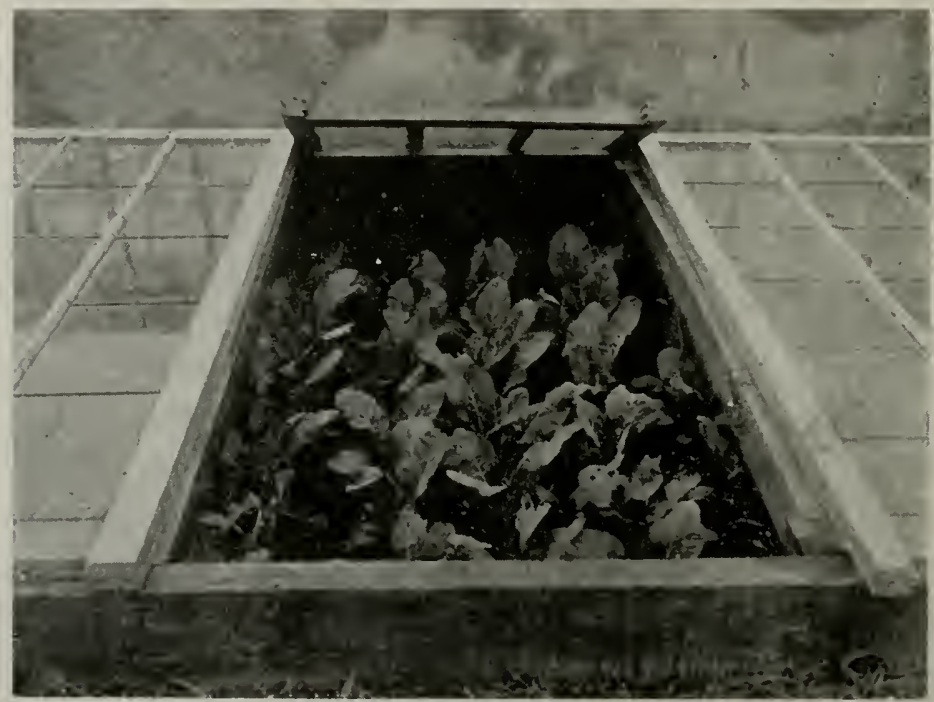

FIG. 60.-Cabbage and cauliflower plants may be grown in coldframes in winter for early spring setting. (Kentucky Station.)

frame merely serves as a protection from snow and cold blasting winds which would eheck the growth somewhat.

In the northern latitudes, coldframes are usually covered with glass so they will eateh consiclerable heat from the sun.

Extensive Use of Coldframes in Southern States.-Besides the uses of coldframes mentioned for northern latitudes, another very extensive use is in the growing of rather hardy vegetables luring the fall and winter season. In the Gulf States the weather may be mild enough to grow certain crops almost to maturity out of doors in the fall. Only a little protection is needed and the coldframe will serve this purpose. 
Another use in southern states is the forcing of vegetables in spring. (Fig. 60.) Enough heat from the sun may be obtained through the glass cover of the coldframe to start such tender crops as tomatoes, sweet potatoes, peppers, and eggplant. That is to say, in many sections no bottom heat is required for the forcing of such plants in time for transplanting to the garden.

Pits for Flowers and Vegetables.-Many gardeners construct pits two feet or more in depth for keeping vegetables over winter. Sometimes these pits are four or five feet deep and are walled up with brick, wood, or other material. They may be covered with glass over which is placed straw mats, old carpets, or other protective material. In favorable weather all the cover is removed except the glass and the plants are stimulated by the light and air. They are protected from the extreme cold by being below the surface of the ground and well housed.

Some Special Uses of Deep Pits.-As winter approaches, the flower gardener may take up a number of choice specimens which he desires to keep active through the winter season. Among such plants would be violets, or pansies placed in boxes, chrysanthemums or carnations transplanted to pots or boxes, and many others. House plants which may be desired for later use in propagating new flowering crops may be stored throughout the winter in such pits. For example, this might be an ideal place for storing old geranium plants from which cuttings are to be made later.

The vegetable gardener often uses deep pits of this kind for storing and perhaps blanching crates of celery transplanted into shallow soil in crates or old orange boxes. Even in the northern states, flats of growing head lettuce and other crops may be finished in deep pits provided they are located in sumny exposures.

Deep pits are sometimes used for the first starting of bulbs, such as Dutch hyacinths, and others which do not require much heat. The bulbs are placed in pots of wet sand or soil and covered in the bottoms of these pits. This will save cellar room which might otherwise be used for this purpose.

Management of Transplanted Plants.-The plan for shifting and final transplanting to the open garden of vegetables is often a puzzle to the beginner. The number of shiftings in the beds of the different kinds of plants is shown in the accompanying table. The dates are those published by the Illinois Station (Circular 216) for Central Illinois, and allowance must be made for localities farther north or south. 
Directions for Growing Transplunted Plants

\begin{tabular}{|c|c|c|c|c|}
\hline Crop & Dates of sowing & $\begin{array}{l}\text { No of of } \\
\text { shifts } \\
\end{array}$ & $\begin{array}{l}\text { Distances in flats or } \\
\text { beds, or size of pots }\end{array}$ & $\begin{array}{c}\text { Dates for } \\
\text { transplanting } \\
\text { to the open } \\
\end{array}$ \\
\hline Onions. & Feb. 1 & 0 & Not shifted & April 10 \\
\hline Beets.. & Feb. 20 -Mar. 1 & 0 & Not shifted & 1. 10 \\
\hline Head lettuee. & " 20 " 1 & 1 & $21 / 2$ " pots & 10 \\
\hline Early cabbage. & " $\quad 20-\quad$ " 1 & 1 & $2^{\prime \prime}$ in flats & 10 \\
\hline Early cauliflower. & " $20-$ " 1 & 1 & $2^{\prime \prime}$ in flats & 10 \\
\hline Kiohl-rabi....... & " $20-"$ " 1 & 1 & $2^{\prime \prime}$ in flats & 10 \\
\hline Tomatoes.. & March 1 & 2 & $2^{\prime \prime} \& 4^{\prime \prime}$ & May 15 \\
\hline Peppers... & " 11 & 2 & $2^{\prime \prime} \& 4^{\prime \prime}$ & " 15 \\
\hline Eggplants. & 15 & 2 & $2^{\prime \prime} \& 4^{\prime \prime}$ in pots & June 1 \\
\hline Celery.... & " 15 & 1 & $2^{\prime \prime}$ in flats & "6 15 \\
\hline Summer cabbage. & " 15 & 1 & $2^{\prime \prime}$ in flats & May 1 \\
\hline Sweet potatoes.... & April 20 & () & Not shifted & June 1 \\
\hline Muskmelons. & " 20 & 0 & Not shifted & May 15 \\
\hline Cucumbers... & “ 20 & 0 & Not shifted & " 15 \\
\hline Late cabbage. & " 20 & 0 & Not shifted & June 15 \\
\hline Endive...... & " 15 & 0 & Not shifted & Aug. 15 \\
\hline
\end{tabular}

\section{EXERCISES AND PROJECTS}

1. Types of Beds and Pits.-Study the different types and sizes of hotbeds, coldframes, and deep vegetable and flower pits in your region. What coverings are used? Note the advantages of the various ones. Also study the special uses made of them by gardeners.

2. Construction.- Make a hotbed and a coldframe and run them for a seasols. Grow such plants as mav pay best in your locality. Record all cost of material, labor, and seeds. Also record value of products and thus determine the probable profit through a series of years.

3. Pits.-Conduct a project in a way similar to that suggested in No. 2 , in the construction and use of a vegetable and flower pit, or several of them.

4. A contest between students may be started in connection with Nos. 2 and 3. Let history or story of the work count 20 per cent, records 20 per cent, methods 25 per cent, and financial results 35 per cent.

\section{QUESTIONS}

1. What are the chief purposes of hotbeds?

2. Describe the making of wooden frames for hotbeds.

3. What are some of the ways of providing glass and sash for hotbeds?

4. Explain the two ways by which a manure hotbed is heated.

5. Cive directions for the ventilation of hotbeds.

6. Give eautions regarding watering.

7. Compare coldframes with hotbeds.

8. Finumerate the uses of coldframes.

9. Describe a good flower pit.

10. What are the chief uses of deep winter pits?

Reference.-U. S. Farmers' Bulletin, 460, Frames as a Factor in Truck Gardening. 


\section{CHAPTER IX}

\section{TENDER AND HARDY VEGETABLES}

The students of gardening often find much difficulty in deciding what plants may be best grown at the different seasons. A classification of garden crops, showing which ones can endure frost in the spring or autumn, which can endure summer heat, etc., will be of great help to young gardeners.

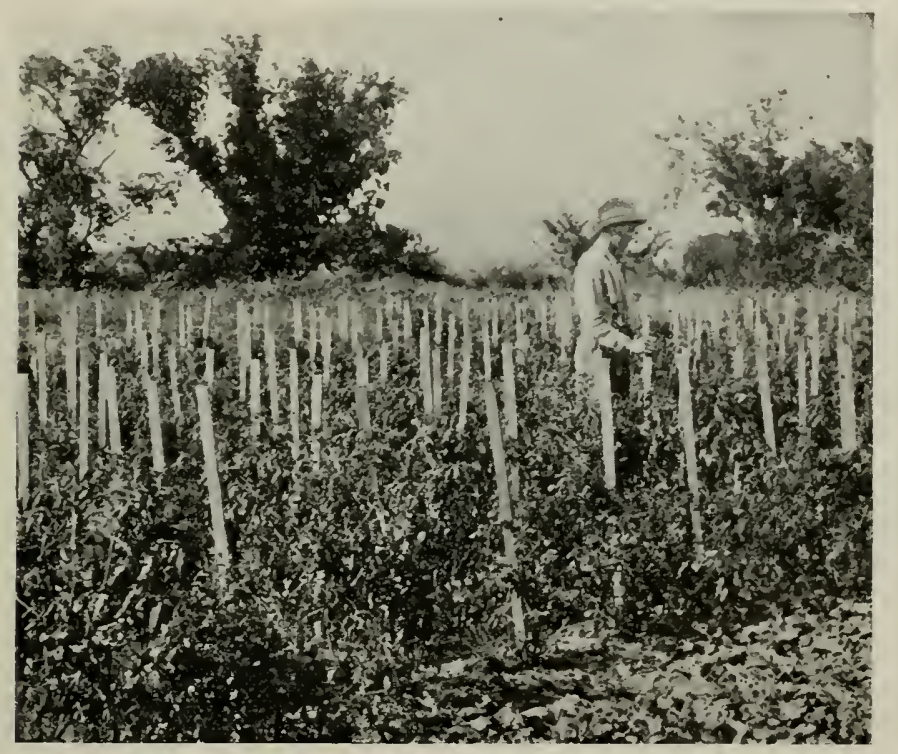

FIG. 61.-Tomatoes belong to the very tender group. Varieties will mature their crops quickly and the crop has a wide range of climate.

Warm Season Crops, Usually Transplanted.-Those crops which we start early indoors, or in protected places because they are easily injured by frost are (1) tomatoes, (Fig. 61) (2) eggplant, (3) sweet and hot peppers, (Fig. 62), (4) sweet potatoes. These require transplanting. In our temperate zone the season is too short to grow them after hot weather comes unless they be started much earlier than this. 
Warm Season Crops, Not Transplanted.-The following hot weather erops are usually not transplanted from hotbeds or coldframes. They are usually planted in the open garden when summer weather comes. (1) Pop corn, sweet corn and field corn; (2) beans of all kinds including limas, snap beans, green and dry shell beans, also soybeans and cowpeas; (3) the vine crops of the melon group, including water-melons and citrons, cantaloupes and other musk

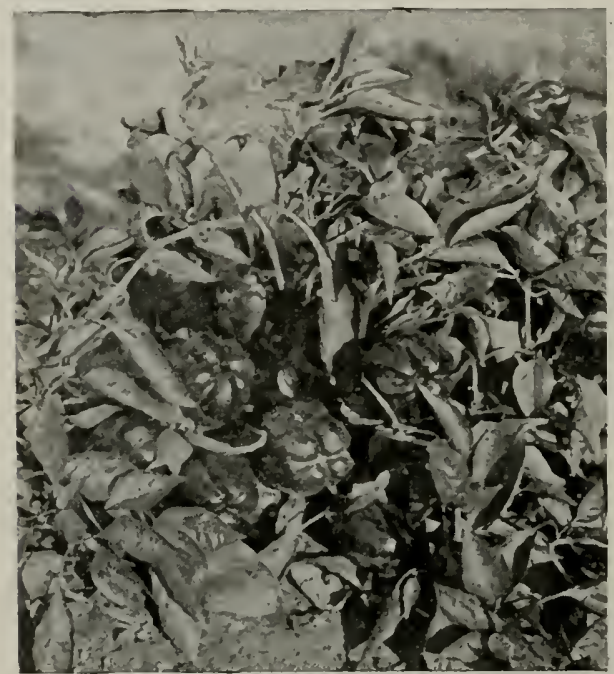

Fra. 62.-Sweet peppers represent the tender vegetables. They are productive, easily grown, and have few enemies.

melons, squashes and pumplins, cueumbers and gherkins; (4) okra or gumbo.

In northern states it is more or less common practice to start cantaloupes in individual boxes in hotbeds or coldframes, during the spring season. They are thus foreed somewhat earlier and are of good size when set in the summer garclen.

\section{Early Spring Crops,} Usually Transplanted.There are four crops that are started in early spring and should mature before the summer heat becomes intense. (1) Early cabbage (Fig. 63), (2) head lettuce, (3) Cos lettuce or romaine, and (4) early cauliflower.

These do not endure summer heat well and will not head up well nor be erisp if dry summer heat strikes them for a long period.

They are best started in protected beds as in window boxes, then transplanted to coldframes for a short period and are later transplanted to the open garden in very early spring.

They endure the late spring frosts.

Cool Autumn Crops, Usually Transplanted.-Several crops of the cabbage and celery groups are best suited to make their main growth in the late autumn weather. They may be started in beds where there is cool shade and where they may be easily watered. 
In middle or late summer they are transplanted to the open garden during favorable weather, when the soil is very moist.

They will endure a considerable amount of autumn frost and may remain out until the ground begins freezing.

Included in these groups are: (1) celery, (2) celeriac or turniprooted celery, (3) late cabbage, (4) Brussels sprouts, (5) broccoli, (6) late cauliflower. In the southern states late head lettuce may be treated in like manner.

Spring Greens that Endure Summer Heat.-A number of salad plants and greens may be started in very early spring and yet will endure summer heat fairly well. (1) Endive, (2) parsley, (3) upland cress, (4) Swiss chard, (5) borecole or kale, (6) collards, (7) New Zealand spinach, (8) dandelions.

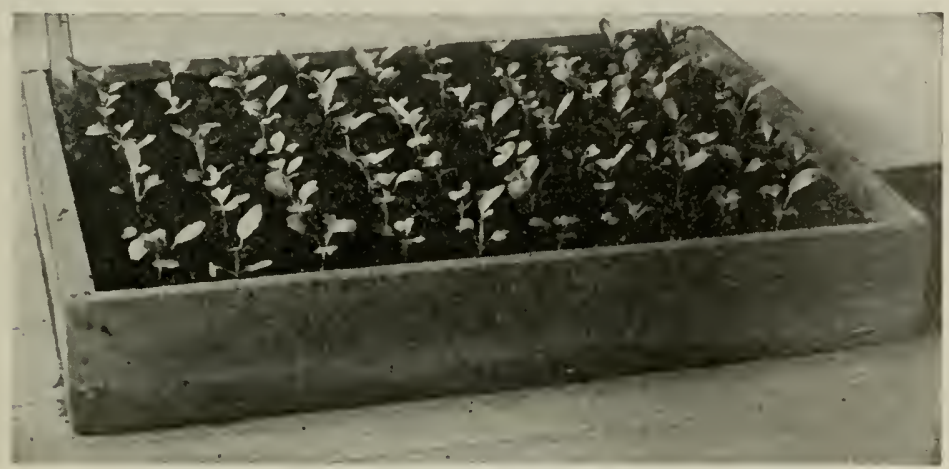
Fig. 63. - A flat of young early cabbage plants one week after transplanting. (1llinois
Station.)

Root Crops and Tubers.-These are of three classes: (1) Those which can be grown in a very short time in early spring, as radish and white turnip. Kohl-rabi and rutabaga may also be considered in this group, but they will extend more into the summer which they endure rather poorly.

(2) Those that endure spring cold and summer heat very well, as beets, sugar beets, mangels, carrots, Irish potatoes, and Jerusalem artichokes.

(3) Those that endure spring cold, summer heat, and also stand the winter freezing of the mature crop, as salsify, parsnip, and horse-radish.

The onion group will stand the spring frosts and also the summer heat. This group includes true onions, garlic, leeks, and shal- 
lots. In regions having moderate winter weather a few of these can withstand the winter freezes. Shallots are often grown as winter crops.

Perennial Crops.-These are required to withstand the cold of spring and winter and also the heat of summer. The common garden perennials are rhubarb and asparagus. Others less common are globe artichoke and sca-kale. In very cold climates they are mulched in winter to prevent heaving and injury of the crowns.

Short Season Spring Greens.-Leaf Lettuce, corn salad, garden cress, spinach, mustard, and turnip greens will do best in early spring. They will mature their leaf crops for the table before summer heat is on. In the southern states nearly all of these may be started in late autumn and will withstand some winter freezing, particularly if mulched a little with straw or waste materials. Mustard and turnip crops for greens are most commonly grown by this plan.

Early Peas are best grown in very early spring. They enclure frosts well and should mature their crop before hot weather. In southern states they may also be grown as a late fall crop if there is enough rainfall.

Planting Table.-The accompanying planting table will serve as a rough guide in planning and planting the home garden. Experience is a better guicle. In the hardiness column, $\mathrm{T}$ means tender, killed by frost; VT, injured by cool weather; $\mathrm{H}$, hardy, stands frost; $\mathrm{VH}$, stands freezing of the soil. The table is largely adapted from Cornell Extension Bulletin 14.

\section{SURVEYS AND EXERCISES}

1. Early Spring Crops. - What vegetables of this group are most grown in your community? 'To get this information make up a list of all hardy spring crops and have them checked over by each family indicating the amount grown in each case.

2. Warm Season Crops.-A similar survey should be made for warm season crops.

3. Cool season crops that endure summer heat should be completely listed and a similar survey made.

4. Transplanting plants is a good garden or greenhouse exercise. Use as many kinds as possible of those listed in this chapter. A number of exercises of this character will be profitable practice. "'se "flats" if desired. Have good garden soil in each and water the plants well before and after transplanting.

5. Making flats is another good exercise for early spring or any other season. Use boxes from shoe stores or grocery stores. Cut them down or use the lumber to be made over into shallow boxps of convenient size to handle (Fig. 64.) Four inches is a good inside depth. Nail them well but leave some drainage cracks in the bottom of each. Also make transplanting boards and dibbers. 
Planting Table for a Home Vegctable Garden

\begin{tabular}{|c|c|c|c|c|c|c|c|}
\hline & $\begin{array}{c}\text { Hardi- } \\
\text { ness }\end{array}$ & $\begin{array}{c}\text { Time } \\
\text { to first } \\
\text { maturity } \\
\text { (days) }\end{array}$ & $\begin{array}{l}\text { Distance } \\
\text { between } \\
\text { plants } \\
\text { (inches) }\end{array}$ & $\begin{array}{l}\text { Distance } \\
\text { between } \\
\text { rows } \\
\text { (inches) }\end{array}$ & $\begin{array}{l}\text { Number } \\
\text { of seeds } \\
\text { to sow } \\
\text { per foot }\end{array}$ & $\begin{array}{l}\text { Amount of } \\
\text { seed to buy } \\
\text { for } 100 \text { feet } \\
\text { of row }\end{array}$ & $\begin{array}{l}\text { Depth } \\
\text { to plant } \\
\text { (inches) }\end{array}$ \\
\hline 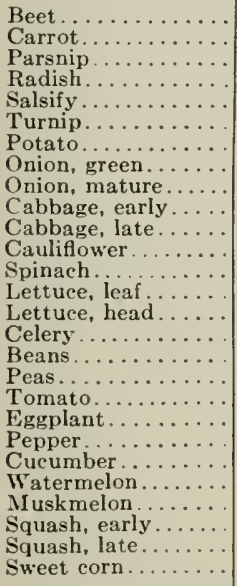 & $\begin{array}{c}H \\
H \\
\text { VH } \\
H \\
\text { VH } \\
H \\
T \\
H \\
H \\
H \\
H \\
H \\
H-V H \\
H \\
H \\
H \\
T \\
H \\
T \\
V T \\
V T \\
T \\
V T \\
V T \\
T \\
T \\
T\end{array}$ & $\begin{array}{c}40^{5}-90 \\
60-100 \\
120-150 \\
25-40 \\
120-150 \\
50-90 \\
80-140 \\
25-40 \\
100^{5}-140 \\
60-110^{5} \\
90-130^{5} \\
70-100^{5} \\
30-60 \\
305-70 \\
40^{5}-90 \\
70-100^{5} \\
60-80 \\
50-70 \\
60-90^{5} \\
90-140^{5} \\
90-120^{5} \\
65-80 \\
90-110 \\
90-110 \\
65-80 \\
70-100 \\
70-100\end{array}$ & $\begin{array}{c}2-4 \\
2-4 \\
3-4 \\
1-2 \\
2-3 \\
2-4 \\
14-18 \\
1-2 \\
2-4 \\
12-18 \\
18-24 \\
15-24 \\
2-4 \\
3-8 \\
6-15 \\
4-6 \\
2-5 \\
1 / 2-1 \\
18^{2}-48 \\
24-30 \\
18-30 \\
12^{3}-36^{4} \\
48^{4}-724 \\
12^{3}-48^{4} \\
30-48 \\
18^{3}-72^{4} \\
18^{4}-36^{4}\end{array}$ & $\begin{array}{r}12-30 \\
12-30 \\
18-36 \\
6-15 \\
18-36 \\
12-30 \\
30-36 \\
8-15 \\
15-30 \\
21-36 \\
30-36 \\
21-36 \\
12-30 \\
10-15 \\
10-15 \\
24-48 \\
24-36 \\
24-36 \\
30-48 \\
24-36 \\
24-36 \\
42-60 \\
60-84 \\
48-60 \\
42-60 \\
60-84 \\
30-42\end{array}$ & $\begin{array}{r}20-40 \\
30-60 \\
20-40 \\
30-60 \\
20-40 \\
30-60 \\
1 \text { piece } \\
8-15 \\
20-40 \\
5 \\
5 \\
5 \\
20-40 \\
5 \text { or } 25 \\
5 \text { or } 20 \\
5 \\
10-20 \\
18-30 \\
5 \\
5 \\
5 \\
4^{3}-10^{4} \\
4^{3}-10^{4} \\
4^{3}-10^{4} \\
4^{3}-10^{4} \\
4^{3}-10^{4} \\
4-8^{4}\end{array}$ & $\begin{array}{l}1 \text { ounce... } \\
1 / 2 \text { ounce.. } \\
1 \text { ounce... } \\
1 \text { ounce.. } \\
1 \text { ounce.. } \\
1 / 2 \text { ounce. } \\
1 \text { peck... } \\
1-2 \text { quarts } \\
1 / 2 \text { ounce. } \\
1 \text { packet. } \\
1 \text { packet. } \\
1 \text { packet. } \\
1 \text { ounce.. } \\
1 / 4 \text { ounce.. } \\
1 / 4 \text { ounce. } \\
1 \text { packet. } \\
1-2 \text { pints. } \\
1-2 \text { pints. } \\
1 \text { packet. } \\
1 \text { packet. } \\
1 \text { packet. } \\
1 / 2 \text { ounce. } \\
1 / 2 \text { ounce. } \\
1 / 2 \text { ounce. } \\
1 / 2 \text { ounce. } \\
1 / 2-1 \text { ounce } \\
1+1 / 2 \text { pint }\end{array}$ & $\begin{array}{c}1 / 2-1 \\
1 / 4-1 \\
1 / 2-1 \\
1 / 2-1 \\
1 / 2-1 \\
1 / 2-1 \\
3-4 \\
1 \\
1 / 2-1 \\
1 / 4-1 / 2^{6} \\
1 / 4-1 / 2^{6} \\
1 / 4-1 / 2^{6} \\
1 / 2-1 \\
1 / 46-1 \\
\frac{1}{6}-1 / 4^{6} \\
\frac{1}{8}-1 / 4^{6} \\
1-2 \\
1-2 \\
\ldots \ldots \ldots\end{array}$ \\
\hline
\end{tabular}

- For earth blanching.

+ Hills of 3 or 4 plants.
2 For single stem training.

5 From transplants.
3 For single plants.

6 In seedbed.

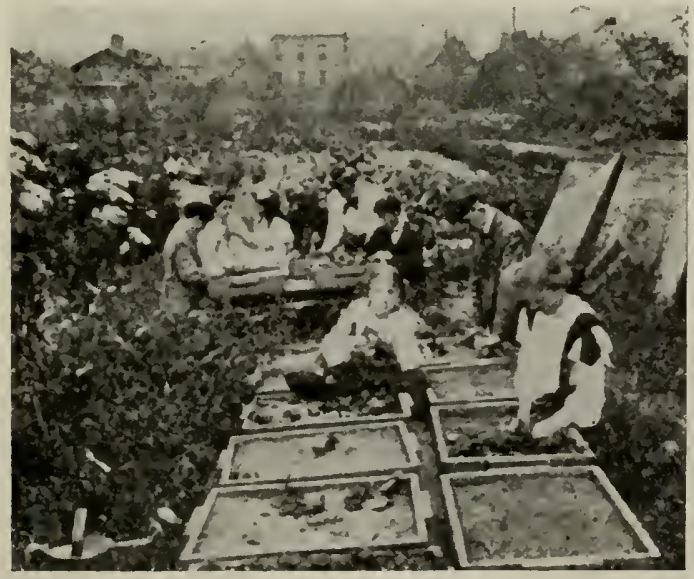

FiG. 64.-Young people transplanting plants into flats made by themselves, 


\section{QUESTIONS}

1. Give a list of warm season crops that are usually transplanted.

2. List the warm seison crops that are not transplanted.

3. What are the early spring crops usually transplanted?

4. What cool autumn crops are usually transplanted?

5. What spring greens endure summer heat?

6. Give a classification of root erops and tubers with reference to season and time of maturity.

7 . What can you say of the hardiness of the onion group? What are included here?

8. Name four perennial garden crops.

9. Give a list of early spring greens and salad crops that will produce a crop before the heat of summer.

10. What is the best season for garden peas?

References.-U. S. Farmers' Bulletins: 201, Cultivation of Mushrooms; 218, The School Crarden; 232, Okra; 254, Cucumbers; 289, Beans; 354, Onion Culture; 434, Onion Seeds and Sets; 553, 554, Popcorn; 559, Corn, Kafir and Cowpeas; 642, Tomato Growing in South; 934, Home Gardening in South; 936, City and Suburban Vegetable Gardeu; 937, Farm Garden in North. 


\section{CHAPTER X}

\section{COOL SEASON VEGETABLES OF EARLY SPRING AND FALL}

THe gardener can easily adapt to his own special needs, simple directions for growing the special crops. Soils differ considerably in their character, and variations in the different methods of prepparing the seed bed are necessary. Depth of planting varies according to the soil moisture. Seeds may be planted deeper in dry soils, and shallower in very moist soils. The depth of planting also varies with the proportion of sand in the soil. Deeper planting is allowable in very sandy soils. If the depth is too great in clay soils the sprouts may not push through the soil. The number of plantings is also influenced by the character of the soil, the time of year, the frequency of rain and other factors.

Plants of this group do not thrive well in very warm weather. They grow best in early spring and cool fall weather.

Radishes.-Any good garden soil is suitable for radishes. The depth of soil may be less than in the case of other root crops. They mature quickly and must be tender and crisp to be relished. Many gardeners plant radish seeds with other seeds so that the young plants will show the row quickly, and thus allow earlier cultivation. The radishes are later pulled out from among the other plants and used on the table. The best crops of radishes may be grown if they are in rich soil with plenty of manure, and are supplied with an abundance of moisture. The crop is very hardy, and should be planted as early in the spring as the soil can be worked. A succession of plantings may be made about ten days or two weeks apart. Thinning is not necessary, except as the largest roots reach edible size they may be pulled to make room for others.

Fall crops of radishes are as much relished as the spring crops. They thrive in the long cool season of the autumn. The earliest fall sowings may be made in August, and the latest sowings may continue to grow until time for the ground to begin freezing. At this time of year weeds are less troublesome, and the seeds need not be sown in drills, but may be sown broadcast on a well prepared soil and covered with the rake. A pound of seed will sow onetenth of an acre. In drill rows allow an ounce of seed to fifty feet. 
Lettuce.- Leaf lettuce is much easier to grow than is head lettuce. Both require very rich garden soil; it should be moist and loose. The edible qualities of lettuce depend upon its being very crisp and tender; rapid growth is therefore necessary. Sow head lettuce in flats in the window or hotbed. Transplant the little seedlings once or twice. Several plantings may be made later, particularly in cool elimates. The erop does well in partially shaded places, provided enough moisture is supplied. Head lettuce does not endure as much summer heat as many other garden crops. Leaf lettuce will also become tough and send up seed stalks when the weather becomes hot and the soil is dry. The late summer or fall erop may be stored by sowing seeds in beds or a protected place. These may be transplanted about the first of September and mature a nice erop of heads before freezing weather. If winter comes on too soon, eover the plants with eoarse litter and let them continue their growth during warm spells which may follow.

In the extreme southern states lettuce plants may be covered and left out all winter; in the northern states they can be transplanted into coldframes under glass or cloth and continue to grow and make heads for winter use.

Romaine.-A type of lettuce known as Romaine, or Cos lettuec, is becoming more popular in America. It is more ereet than eommon leaf lettuce, and the leaves are rather firm, as in head lettuce. Unlike the other forms of lettuce, it requires blanching for the best flavor. In the southern states Cos lettuce is becoming more popular because it endures more summer heat than other types of lettuce.

English Garden Peas.- 'There are three main types of garlen peas, according to the height of growth. The dwarf varieties are the earliest and require no staking; the medium and tall varieties require supports of some kind. As the expense of staking is less in the home garden than in large commercial plantations the tall varieties are more used. Peas may also be classified aceording to the eharacter of seed produced, being smooth or wrinkled. The wrinkled varieties are sweeter in flavor and are considered of much better quality, but the smooth peas are hardier, and are planted in large fields for eanning purposes.

Peas do not withstand summer heat. They must be grown in the cool part of the year. They endure winter cold fairly well. If sown upon the earliest approach of spring they will endure con- 
siderable freezing of the ground and severe frosts. Successions of plantings are seldom made in the southern states because of the rapid approach of hot weather. In northern latitudes several plantings may be made. It pays to soak the seeds before planting, but too much soaking may be harmful, as the seeds may split open and be destroyed. The rows should be far enough apart to allow of cultivation, and the distance will vary according to the height of the varieties. They may be planted in double drills and a support placed between these drills. Two bushels of seed will plant an acre. The depth of planting may be one to two inches. In the region of large canmeries grain drills are used for planting the seeds.

When the crop is ready for harvest it is mowed with a hay mowing machine and raked as hay. The vines are not allowed to cure on the ground, but are hauled immediately to the threshing machines at the camneries. The vines and other waste may be put into silos as feed for cattle. The vines from the home garden make good forage for stock.

Spinach.-This plant belongs to the beet family, and the seeds resemble garden beet seed. The plants are very hardy, and will endure severe spring frosts. When hot weather comes seed stems are sent up and the crop is lost. Rich garden soil is preferred. The crop is grown exclusively for greens, for which it is one of the mildest flavored plants. The crop may be matured in six or eight weeks from the time of planting. In the southern states it is frequently grown as a late fall crop. With a little protection of straw or other litter it may stand the severe winter weather and make an early spring growth for the table or the market. It is not, however, quite as hardy as mustard and turnips grown for the same purpose. The spinach crop is drilled in rows twelve to eighteen inches apart and may be tilled with a wheel hoe or garden rake to prevent the crusting of the ground. The fall crop may be sown broadcast, as there is less trouble from weeds. Allow one ounce of seed to one hundred feet of drill for spring planting. (See New Zealand spinach in Chapter XI).

Mustard.- When this crop is grown for greens it may be planted in early spring or in the fall, in the northern states. In the southern states it is commonly sown broadcast in the fall and may withstand the winter and produce an early cutting of greens in February, March and April. It is more commonly sown broadcast than in rows. One ounce of seed will sow about one-fifth of an acre. There 
are two main types known as the white and the black mustard. White mustard has dark green, smooth leaves and is preferable to the black mustard, which is strong in flavor.

Corn salad is drilled in close rows in very early spring. The clusters of leaves are ready to use in forty to fifty days. The uses and treatment are like those for garden cress. A fall planting may be made just in time to harvest before the ground freezes. Or in regions of mild winters the leaves may be mulched with leaves or straw and the salad used during winter or early spring.

Garden Cress has a burning flavor and is likened to pepper grass. The seeds are drilled in very early spring, in rows just far enough apart to allow the rake or wheel hoe to pass between. The plants may be thimned by pulling out some for use. The crop is produced very quickly, and is used for garnish or flavoring sandwiches and salads. The plants run to seed if the weather becomes warm before the crop is used.

Cabbage.- In both the northern and the southern states this crop is grown in two ways. (1) An early variety planted in early spring maturing, before the hot, dry weather of mid-summer, (2) the later crop, or main crop, planted by mid-summer or earlier and maturing in late fall. Both crops endure frost and thrive best in cool weather. The fall crop is preferred for use for making sauer kraut and also for storage through the winter.

Early Jersey Wakefield (Fig. 65), Charleston Wakefield and Succession are good varieties for early spring planting. The heads are smaller and are formed earlier than in the case of later varieties.

Late Flat Dutch and Drum Head are good main season or late varieties (Fig. 66). The heads are large and firm and will keep well in storage if buried in trenches or if stored in frost proof cellars.

Two forms of planting are practiced. One is to sow the seeds in beds and pull the plants after they are a few inches high. These are then set in the open garden where they are to grow.

The other plan is practiced for the late crop in some sections. The seeds are dropped in hills about two feet apart in rows three feet apart. A little powdered lime is dropped in each place to indicate the location so that cultivation may be begun immediately after planting, as weeds are very bad at that time of year.

Fertilizer should be applied abundantly to the cabbage crop. It is almost impossible to overfeed the plants. Lime is very helpful, particularly if the crop is grown in rich bottom land or bog land. 
The late crop of cabbage may follow a crop of early potatoes or some other early garden crop. Sometimes cabbage plants are set between the rows of potatoes, in gardens, and the digging of the potatoes can be done without injuring the cabbage plants.

As soon as heads are formed and have become somewhat solid they may be used for cooking or for salad. If the heads tend to burst in the garden they should be bent over or partially pulled to check the growth. They may remain in this condition in the garden for some time without injury.

Cabbage should not be grown on the same ground for several ycars in succession. The disease called "yellows" may soon infest

FIG. 65 .
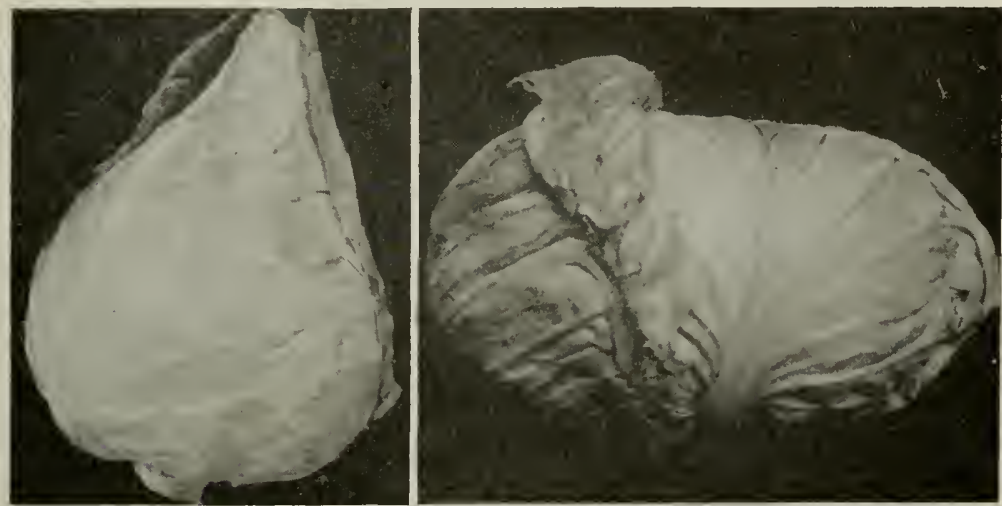

FIG. 65.-Typical form of the earliest varieties of cabbage.-Early Jersey Wakefield. (Ohio Station.)

Fig. 66.-Allhead is a rather early variety but has the broad, flat form of later varieties. (Ohio Station.)

the soil where continuous cropping is practiced. If the disease is present resistant strains should be used if possible. (Fig. 67.)

Turnips.-This crop is extremely hardy, and in the southern states will grow throughout the winter. In all the states the cropmay be sown in very early spring in a well pulverized soil. The turnips are ready for the table in sixty to ninety days from seeding time, and the greens from the tops may be used much sooner than this.

There are two main types of turnips in common use, the white turnip and rutabaga. The latter has a yellowish flesh. Good varieties of white turnips are Purple Top, White Flat Dutch and White Globe. 
Turnips prefer cool weather, and may be grown as an early spring crop or as a fall crop. The fall planting may be protected from extreme cold weather by a covering of straw or other litter. Two plans of sowing the crop are in use. Drill rows are more commonly planted with the rutabaga, but any turnip may be drilled in rows. Clean culture is given between the rows. The second plan is to sow the seed broadcast on a well prepared soil. The latter plan is more common with the fall crop.

The use of turnips in the garden should be increased. Those

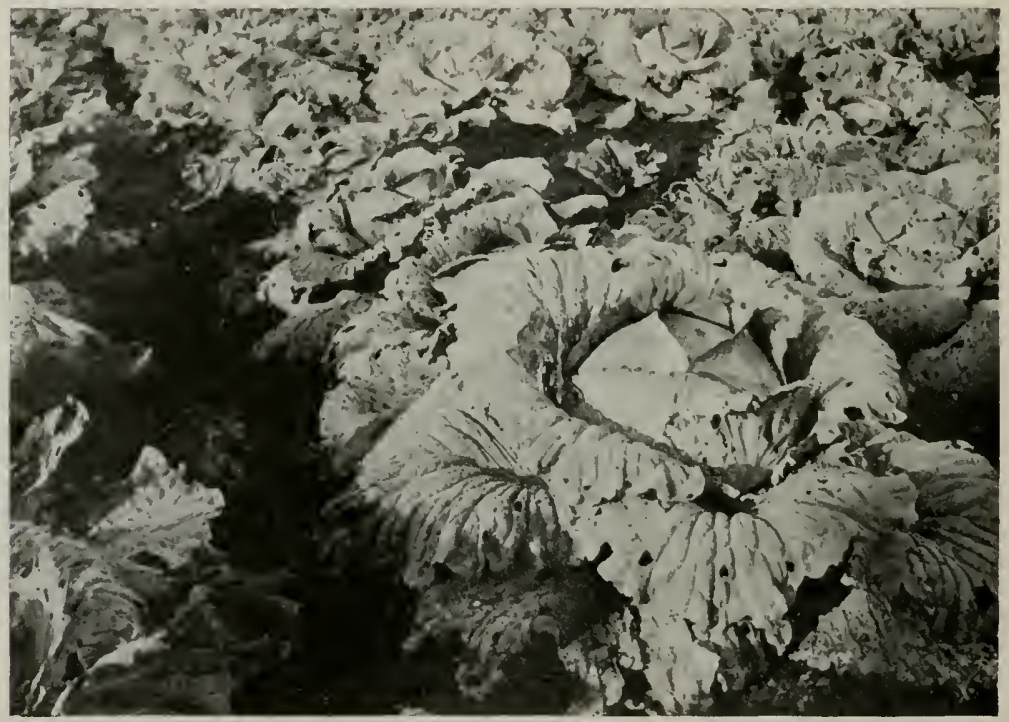

F1G. 67.-Strains of cabbage resistant to yellows, variety Wisconsin Hollander. (Wisconsin

not desired for table use may furnish feed for stock, such as hogs and sheep. The turnip roots may be stored in deep pits, in cellars, or may be covered with soil in piles in the garden. They should not be allowed to freeze, and it is best to have them available for use during freezing weather.

Probably the worst garden enemy of the turnip is the green plant louse. The lice attack the leaves of the fall crop much worse than they do the spring crop, but in some cases are bad at both seasons. As the erop is not expensive the most economical plan is to pull the turnips and feed them to hogs or other stock as soon as 
the attack is seen. Spraying with kercsene emulsion on the under side of the leaves will destroy the lice to some extent, but this is a very difficult task because the leaves lie on the soil.

Cauliflower.- This plant belongs to the cabbage group and the culture methods are similar. The quickly grown cauliflower is preferred for table use. Two plantings are therefore desirable, one in early spring and the other in late summer and fall. The plants may be readily transplanted, and are commonly first grown in beds and then transplanted to the open garden. The rows may be two or three feet apart and the plants one to two inches apart in the row. Good cultivation and careful attention should be given the plants from setting time to maturity. When the heads have reached a size of two inches across, the outer leaves should be tied up over the heads to protect them against the sun and weather and to blanch the heads. If this is not done the heads will become bitter and discolored. As the heads become large enough for table use they may be harvested, and cabbage plants or other crops grown in their place. For market or show the leaves may be trimmed as shown in figure 68 .

The worst enemy of cauliflower and cabbage is the green cabbage worm, produced by the white cabbage butterfly. Dusting the small plants with wood ashes, tobacco dust, road dust or air-slaked lime will aid in keeping away this pest. Paris green mixed with lime is good. The butterflies prefer to lay their eggs on weeds or other plants where dust has not been applied. The use of poison in the lime is important where the worms have begun eating. The dust is applied while the morning dew is on the plants.

Kohl-rabi.--This is another plant of the cabbage group. It may be compared to a turnip above ground. The solid fleshy head is very palatable when cooked in a manner similar to that of cooking turnips. As the crop becomes rather old the peeling becomes strong and should be removed before cooking. Even with the young heads it is desirable to remove the peeling. The transplanting, cultivation, harvesting and storage are similar to those for cabbage.

Broccoli.-This crop makes its chief growth in cool weather, and is commonly grown in autumn for late harvest. If grown as a spring crop the plants should be started early enough to be transplanted as soon as the soil in the garden can be worked. The plants need the same care and management as cabbage and cauliflower.

Brussels Sprouts.-The young plants look like cabbage plants, and belong to the cabbage group. The stalk is supplied with many 
very small heads which are pickerl off and boiled either as a vegetable dish or to accompany meat dishes. The crop matures best in late fall weather. The heads do not form during hot summer. The seed is sown in the open in mid-summer, and the row is marked with a little lime dust as with late crops of cabbage. The plants may be readily transplanted, and can be started in beds where they are easily watered. As the plants are very tall they are given a litthe more space between rows, particularly if horse cultivation is to be used. Two or three feet should be allowed with one or two feet

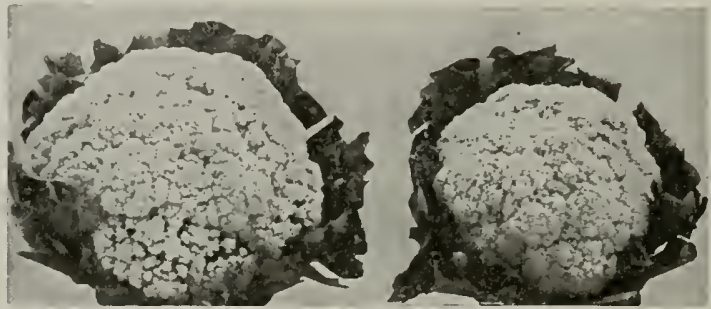

Frg. 68.-Heads of cauliflower with medium trin for show in market. (Cornell Station.)

between plants in the row. The delicious heads are improved in flavor by allowing them to be frosted a few times before harvesting.

Celery.-This crop thrives best in the cool days of late fall. The plants are readily transplanted, but are very slow to develop. The seeds are difficult to germinate and should be soaked before planting. In the northern states the plants should be ready to transplant to the garden by June or earlier, but in southern states transplanting to the open garden may be done as late as August or September. Set the plants six to eight inches apart in rows about four feet apart. Rich black loam is best. An abundance of humus in the soil is of great importance. When the transplanted plants reach a height of three to five inches they are topped by pinching to cause them to become more stocky. They should have frequent watering and frequent tillage.

The stalks only are palatable when they are thick, crisp and tender. They should be blanched as winter approaches. This is done in several ways. A simple method is to bank up the dirt on both sides against the plants, with the top leaves projecting, (Fig. 69). Another method is to set a piece of agricultural tile four inches in diameter around each plant. Another common method is to set a board on edge at each side of the row. (Fig. 70.) These 
are held four inches apart with pieces nailed across the top edge. The boards are held in place at the bottom by pegs driven into the ground. Leaves or other litter may be filled in between the plants to help exclude the light. Celery will stand considerable frost and may be left in the garden until the ground begins freezing.

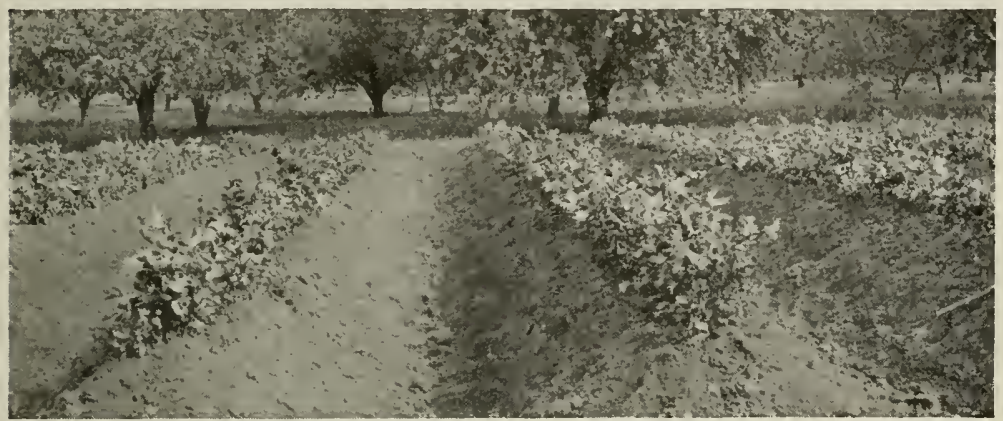

FIg. 69.-Celery well "hilled up" with soil for blanching. (Illinois Station.)

The crop may be stored in a number of different ways. One method is to dig the plants and put the roots in four inches of soil in the bottom of crates. The plants are packed closely together in

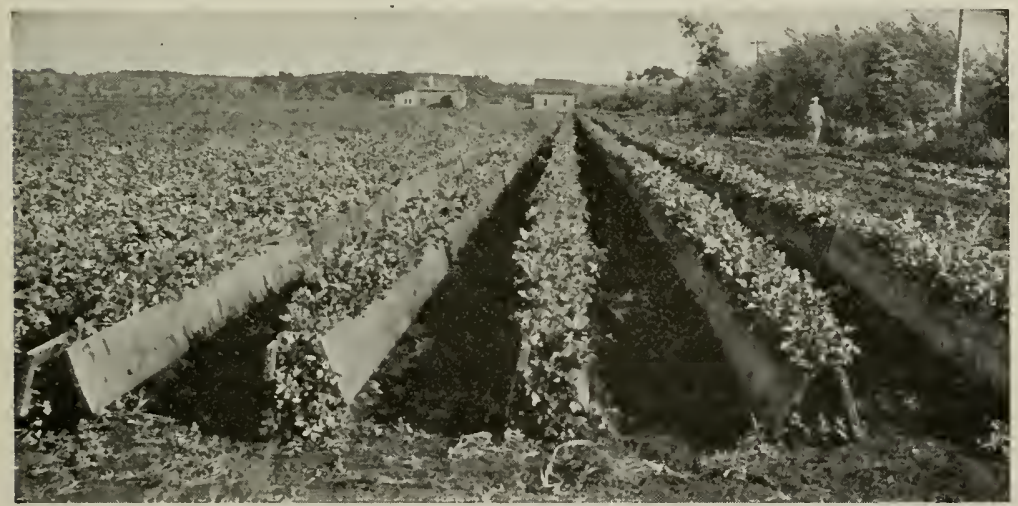

FIG. 70.-Blanching celery with boards. (Lloyd's Production Vegetable Growing.)

the crates and the soil is kept watered without wetting the stems. The crates are stored in a cool cellar and allowed to continue their growth and blanching until used. Another method is to store the celery in rather dry sand with the top plumes projecting above the 
sand. A little moisture may be added by setting the bottom of the crates in shallow water for a few minutes. Celery is sometimes held in cold storage in shipping crates without any sand or soil.

The winter (rop of celery which reaches northern markets in spring is produced in Florida and other southern states. It grows throughout the winter in the open garden where the ground does not freeze. Good varieties for the home garden are Golden Self Blanching and Giant Pascal.

Celeriac is turnip rooted celery. The seed is planted and started much the same way as with celery. The roots are the edible portion. These are used for vegetable soups and contain the same medicinal qualities as found in the celery plant; these properties make both of these crops valuable articles of the diet. They are considered nerve tonics. As the stems are not to be used for food, blanching is not required.

\section{EXERCISES, SURVEYS, AND PROJECTS.}

1. Varieties.-Obtain several garden catalogues and study varieties of the crops included in this chapter. Determine which varieties are most used in your section and why.

2. New Crops.-What crops of this chapter are not commonly grown in your region? Get seeds of these and grow the crops to edible maturity.

3. Uses of Vegetables.-Get recipe books and government bulletins to learn new ways of using the different vegetables. If possible let some of these dishes be prepared and served at home or at school.

4. Cultural Methods.-Make inquiry regarding cultural methods used in your region, for each of these crops. Include rate of seeding, time of planting, transplanting, distances between rows, depth, cultivation, and special treatment. Record these in tabular form and note the variations. Indicate by special marks with colored pencil, which you consider best for each crop, considering soil, climate, and everything.

5. Head Lettuce is of ten difficult to bring to perfection. Discover what difficulties are encountered if any. Give the best methods to those who are not successful with this crop. Consider the best variety for the region and soil, temperature at time of heading, watering, fertility of soil, shade and any other vital points.

6. Garden peas should be tried in the fall. Grow the crop at home and report results.

7. Turnips of several varieties including both the yellow and white, should be grown in comparison with each other to determine the rate of growth, qualties, winter hardiness and other points.

8. Resistance to freezing may be tested as a home project by growing winter radishes, spinach, mustard, corn salad, garden cress, cabbage, and others of this group. Start them at suitable times in the fall and allow a part of each crop to remain in the garden over winter. Protect them with leaves, straw, or other light litter. Do not smother them too much if the winter is mild.

9 . Celery may be grown as a special home project to make trials of different methods of setting, culture, blanching, storing, etc.

10. Sauer kraut may be made as a home project. Test its keeping quali- 
ties. Record amount and value of cabbage and salt used, time for making and care given while fermenting, and value of product in winter.

\section{QUESTIONS}

1. What types of radishes are most grown in your section? Which variety is most popular?

2. Is leaf lettuce or head lettuce better suited to your section?

3. What difficulty is encountered in growing head lettuce during warm weather?

4. What advantage has Cos lettuce over other forms?

5. Describe good methods of training pole beans.

6. Which are usually earlier, the pole or dwarf varieties of peas?

7. Why is spinach more popular in the market than greens of the mustard and turnip group?

8. Describe management of the mustard and turnip crop to supply greens in the late fall and early spring.

9. What are the special advantages of growing late cabbage in preference to early cabbage in the home garden?

10. Which of these would bring the best price in your market?

11. Compare white turnips with rutabagas in color of flesh, time of growth, keeping qualities, and market value.

12. Give directions for growing and blanching cauliflower.

13. What can you say of the value and use of kohl-rabi?

14. Are broccoli and Brussels sprouts grown by any gardeners in your section? What use is made of the crops?

15. At what season would you transplant celery plants to the garden, in your region?

16. Give directions for care, management, blanching, and storing of celery.

17. What use is made of celeriac?

References.-U. S. Farmers' Bulletins: 766, The Common Cabbage Worm; 925, Cabbage Diseases. Productive Vegetable Gardening, Lloyd, J. B. Lippincott Company; School and Home Gardening, Davis, J. B. Lippincott Company. 


\section{CHAPTER XI}

\section{COOL SEASON VEGETABLES THAT ENDURE SUMMER HEAT.}

The crops included in this group will thrive best in cool weather of spring and fall. They are all hardy and will stand considerable frost of either spring or fall. Some will eren live through the winter. The special advantage which members of this group have over the crops included in Chapter $\mathrm{X}$, is their ability to withstand the heat of mid-summer. Most of them will grow reasonably well throughout the summer if enough moisture is provided.

Onions.-As already suggested, the onion group includes the true onions, leeks, garlic, challots and chires. The main crop of onions to be harvested in late summer or fall and to be stored as dry onions over winter is grown from seed sown in early spring in very rich black loam as free from weeds as possible. If the soil is somewhat sandy and well drained it will warm up earlier and the seed will sprout better. An abundance of organic matter in the soil aids drainage, as well as helps preserve the moisture during the dry season. If horse tillage is to be used during the growing season the rows are to be drilled about eighteen to twenty inches apart. If wheel hoes (Fig. 72) are to be used instead of horses, a little less space is required. The seed is drilled thick enough to make the plants stand about two inches apart in the row (Fig. 71), but usually thinning is required. If a little radish or turnip seed is planted at the same time the rows will be more quickly seen and cultivation may begin before the weeds become so thick as to smother the crop. Thorough cultivation to preserve moisture and stimulate growth is required. A commercial fertilizer containing considerable potash and phosphoric acid with a small percentage of nitrogen is commonly used. This can be applied soon after the crop is up and cultivated into the soil with a wheel hoe or garden rake. Continuous rapid growth is desired. This is attained by frequent cultivation (Fig. 72.) When the growing season is about over they should not be cultivated. A second growth should not be allowed by late cultivation or by late rains. The bulbs may be pulled and dried to prevent the second growth. Pulling is usually done when the tops begin to die. If the weather is dry and hot the 
onions may be left exposed to the sun for several days (Fig. 73). They are usually gathered in shallow boxes or open crates, and should be handled very carefully. The shallow crates may be piled one upon another in the wagon to avoid the onions being bruised. They should be stored in a dry place. As cold weather approaches they may be placed in a cool but clry cellar. At no time should they be piled up. If dry air can get to them readily they will keep for many months.

There are three main types of seed onions, and a number of varieties of each type (Fig. 74). A popular variety of each type

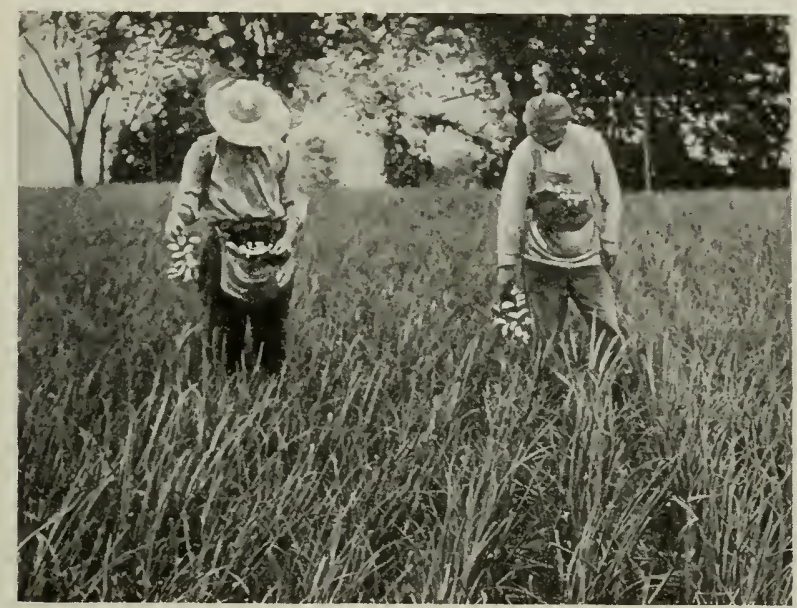

Fig. 71.-When large weeds are pulled from the onion patch they may be put in weed sacks and carried from the field. (Michigan station)

is here given. (1) Yellow Globe Danvers, (2) Red Wethersfield, (3) Southport White Globe. The Bermuda type of onion is grown somewhat in the Gulf States. It is milder than any of the other onions, and is popular on the market. Three varieties are Red Bermuda, White Bermuda and Crystal Wax.

Green onions such as are commonly sold in bunches in the markets are easily produced in one of two ways.

1. Onion sets may be planted an inch apart in rows about one foot apart. This may be done in very early spring, or if shallot bulbs are used in the southern states the sets may be started in the fall. The first growth from the onion sets may be eaten within a few weeks. 
2. In the southern states seel of silver skin onions or some other hardy variety, may be sown in September or later and will survive the winter with little or no protection. Along the Great Lakes and the Atlantic and Pacific coasts they may also be grown during the winter, particularly if a little mulch of clean straw is provided. The crop requires less cultivation than the main erop of onions. There is little trouble from

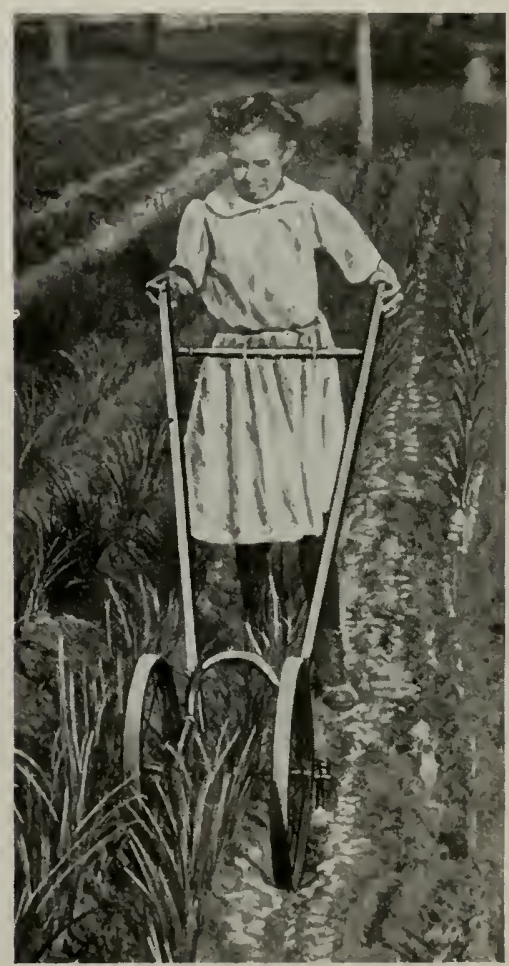

FIG. 72.-Ten year old girl with double wheel hoe. Cultivating onions in the lome garden. (Bateman Mlfg. Co.) weeds at this season, and the soil usually contains plenty of moisture. Green onions should be ready for pulling early the next spring.

Garlic.-The advent of our foreign population particularly from the Mediterranean region has eaused this crop to become more popular in America. Garlic has a very strong flavor and odor which has tended to restrict its popularity. It may be used for flavoring salad dishes or for adding flavor to meat and vegetable soups. The crop is easily grown from small bulbs or sets and need not to be grown from seeds. The crop is easily stored if handled carcfully and kept in a diy place.

Leeks.-Soups are sometimes flavored with leeks instead of onions. The crop of so-called "wild-onions" so common in many parts of America, belongs to the leek group. The soil requirements are similar to those for the true onion. Growers sometimes prefer to blanch the necks by hilling up the rows on each side during the last eultivation.

Shallot.-The bulbs are formed in clusters which are easily broken apart and planted separately. This is the best means of propagation of the erop instead of by seeds. As the shallots are 
very hardy they are commonly planted in September in the southern states. They will produce a good growth and may remain in the garden all winter without injury. This gives a crop ready for use during the open winter or early spring. In northern latitudes the bulbs are planted in very early spring and will develop a crop similar to green onions from onion sets in a few weeks after planting.

Chives.-This crop grows in dense tufts forming clusters resembling a grass sod. The green growth is eut and used for flavor-

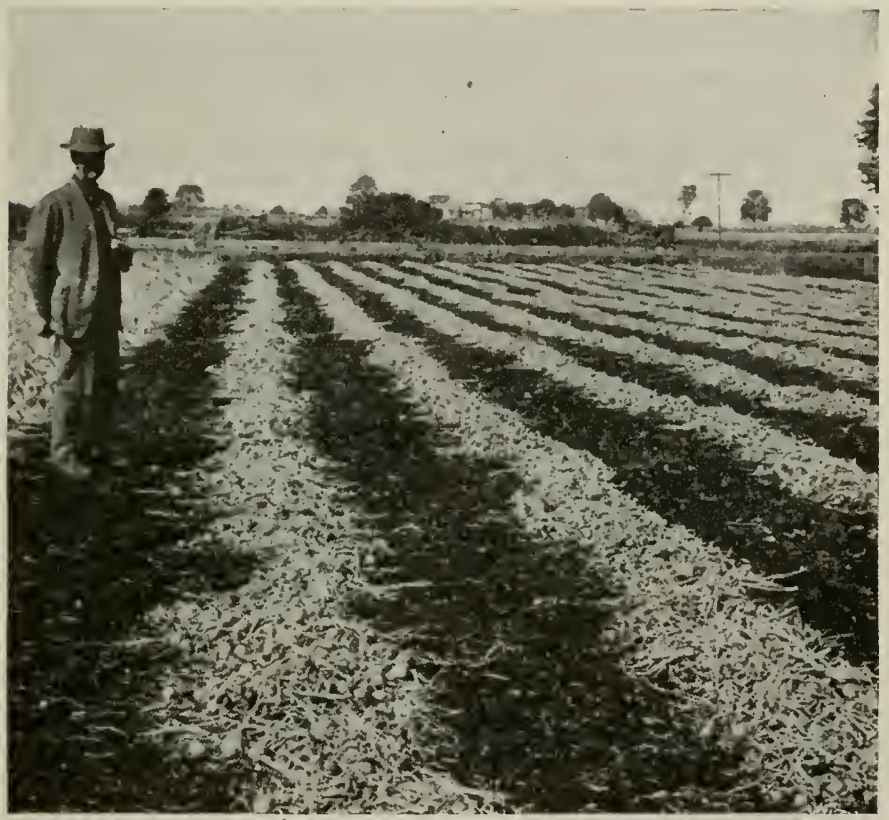

Fig. 73.-Well matured onions curing in wind rows before topping. (Michigan Station.)

ing and is followed by renewed growth. The plant is so easily propagated by division of the mass of roots that growers find it rather a serious pest in the garden.

Swiss Chard.--This plant belongs to the beet family and has a leaf somewhat resembling the sugar beet, but with long fleshy leaf stems. These stems may be cooked and served with cream dressing in a manner similar to serving asparagus. The leaves themselves are used as greens, and are as mild as spinach for this purpose. There is no fleshy root as in the true beet. 
The seeds are sown in rows about fifteen or twenty inches apart to allow of tillage between the rows, with the plants six to twelve inches apart in the rows. This planting should be done as early in the spring as the ground can be prepared. The crop enclures hot weather well and will also endure both late spring and early fall frosts. As the leaves become large enough they may be pulled off, the outer ones being used and the central ones allowed to continue their growth. In this way the same plants will continue to supply a crop throughout the entire season. If given thorough tillage and enough moisture and conditions are favorable, the crop will not become too fibrous for table use. An immense yield may be ob-

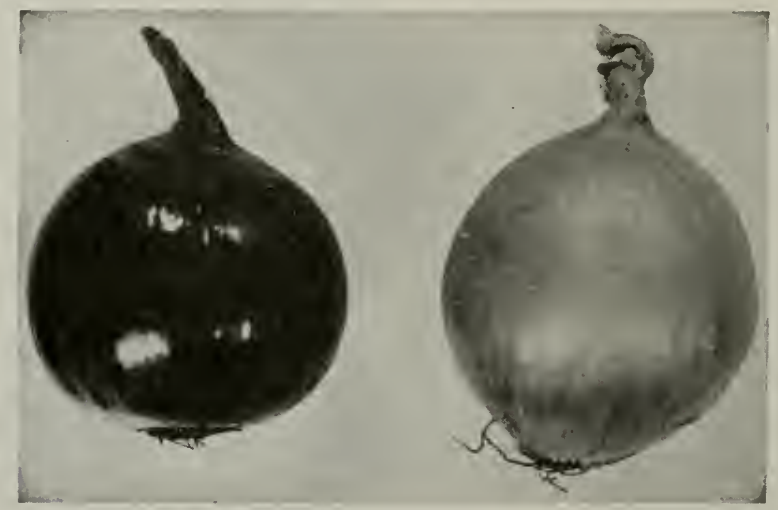

FIg. 74.-Types of globe onions. Michigan ideal ou left. Longer form on right, preferred in many markets. (Michigan Station.)

tained from a very few plants. If thinning is required the plants pulled out may be used for greens.

This crop is becoming more popular for home use in America because it is one of the few garden crops which will endure both extreme cold and summer heat. As the plants are easily transplanted the seed may be sown in hotbeds to get an early start. Transplanting would then take place in very early spring.

Collards may be called non-heading cabbage. Like other members of the cabbage group they are able to withstand a great deal of frost in spring and fall. They will stand summer heat better because they do not form heads. The tender leaves forming a rosette at the top of the tall stem are especially fine for salad after the first fall frosts. 
The plants may be started from seeds sown in beds and later transplanted to the garden rows. Set them one foot apart in rows about two feet apart. If the seed is drilled in the garden rows the plants will require thinning. One-half inch of soil is en ough over the seeds. An ounce of seed should produce about three thousand plants. Give the growing crop clean culture all the season. Take off the leaves near the top for use, and new leaves will continue to form if the top bud is not destroyed.

New Zealand Spinach.-This crop endures hot weather. Instead of sending up flower stems it will continue to grow in hot weather; watering, however, adds much to its qualities. If the new growth is harvested by cutting or breaking above the ground the same plants may continue to yield during the entire season. The seed should be sown in rows far enough apart to allow of some form of cultivation. The plants should be thinned to several inches or one foot apart if they are to be used for continuous cropping and growth through the season. (See spinach in Chapter X.)

Parsley is used for garnishing meat and salad dishes and for seasoning soups. It may be grown in the open garden all through the spring, summer and fall and in a window box during the winter. The seeds may be sown in window boxes or in hotbeds or coldframes. The plants may be readily transplanted, and as they will stand considerable frost they may be set in the open garden in early spring. Sometimes the plants are taken from the garden in the fall and transplanted to boxes for storage in vegetable pits or for continued growth in doors. For the winter house plants it is better to sow the seeds in a bed in August or September, watering them well and taking them up before the ground freezes. By picking only a few leaves they will thrive throughout the season. A few plants in the window during the winter will supply a family. Dried leaves from the summer growth may be preserved for flavoring soups during the winter.

Upland Cress.-This crop is not extensively grown, probably because its merits are not well known. Leaves may be gathered from the growing crop and the plants will continue to form new leaves throughout the season. It is one of the crops which will endure summer heat as well as extreme cold in spring and fall. It is used very much the same way as water cress, that is for salads and for garnish. The seed may be sown in the open garden in very early spring. The drill rows may be about eighteen to twenty 
inches apart. In the southern states a fall crop may be started about the micldle of August or even later.

Kale.-This is also called borecole and belongs to the cabbage group, but produces no heads. It is extremely hardy, and will endure both frost and summer heat. In the southern states it will continue its growth throughout the winter.

Good varieties are Curled, Dwarf Siberian and Tall Scoteh. For the spring crop sow as soon as the soil can be worked. Plant the seeds in drill rows or broadcast. A half ounce of seed is enough to plant 100 feet of drill. Cover about one-fourth to one-half inch. If drill rows are planted allow space for tillage between the rows. As soon as the plants are large enough begin thinning and use them for greens. The young leaves are most tender.

For the fall crop the seed may be sown broadcast over a well prepared seed bed and covered with a rake. This may be done in August or September, or even later in the southern states. Kale is not subject to common garden enemies, and the crop will grow with very little care and attention.

If plants of the spring crop are left in the rows eight inches apart they may continue to yield leaves for greens throughout the season. Only a few leaves are picked from each plant at a time and more continue to form in the center.

Endive.-This curly-leaved salad will form dense heads like head lettuce. The crop is grown in much the same way as lettuce, but the leaves need to be tied up to cause them to blanch, which removes the bitter taste. Two or three weeks are necessary for this process. Care should be taken that no dew or rain is on the leaves at the time of tying, as rot would start. If the leaves are left tied too long rot may be started. For home use only a few heads are tied at a time. The young plants can be readily transplanted, and if this plan is followed they are set about one foot apart in rows cighteen inches or two feet apart. The main crop may be harvested in the fall, and a few plants may be transplanted into crates containing a little soil. These crates may be stored in cellars or deep pits, as in the case of celery.

Carrots.-Good varieties are Half-long Scarlet, Early Scarlet Horn, and Chantenay. The seeds of carrots are very small and germinate rather slowly. They are usually soaked in water a day before planting. They should be covered very shallow, as the seedlings are weak and camnot break through the thick crust. A few seeds of radish scattered in the row at planting time will 
help to break the crust, and will also mark the row more plainly so that cultivation may begin early. The soil should be very fine and somewhat sandy to prevent baking. The addition of humus is very helpful to the crop. The seed bed should be very thoroughly prepared and very level. The seed is drilled in rows 18 inches apart, or double rows may be placed two feet apart. An ounce of seed will plant one hundred feet of row. As the carrots need thinning the larger specimens may be pulled for table use. Careful, close tillage is important at the very start. The crop will stand considerable frost, and planting may be done in very early spring. The later plants may be left in the garden during the fall or until needed on open winter days. Freezing of the ground will injure the crowns somewhat, but many of the roots will endure this ordeal. The roots may be pulled in the fall and piled in heaps covered with sufficient soil to make them easily accessible during the winter season.

Parsnips.- This is a very hardy crop; indeed it will stand much freezing of the ground in the fall and winter. The edible roots are made sweeter by some freezing. The seed should be planted in the open garden in very early spring. Parsnips do not transplant readily. The seed is slow in sprouting and should be soaked before planting. Very old seeds should not be used. Scatter in the row a few seeds of radish or turnip to help break the crust of the ground for the parsnips and also to mark the row before the parsnips begin to show. The drill rows may be eighteen to twenty inches apart, or double rows may be two or three feet apart if horse tillage is to be used. A row of parsnips with a row of salsify a few inches apart from it is a good form of double row, as both of these crops can be left in the garden until winter. One ounce of seed will plant one hundred feet of drill.

Good varieties are Early Round, Guemsey, Yellow Crown. The plant is a biennial and should not be used after growth begins the second year. A poisonous product is apt to form which injures some people. The second year's growth may be left in the garden to form seeds if desired. Give the crop clean, deep thorough cultivation and keep it growing throughout the whole summer. Thinning is usually necessary; this should be done when the plants are forming their third and fourth pairs of leaves. Leave the plants at least two inches apart in the row. It is best to plant the parsnips at one side of the garden where they will not be in the way of the summer succession of quick-maturing crops. 
Salsify.-The common name of this plant is vegetable oyster, becuatuse of its flavor. It is commonly used in regetable soups, or may be served with eream or eream gravy as a side dish. As suggested under the head of parsnips the salsify may be grown in companion rows with parsnips. The seeds are slow in germination and should be soaked before planting. The use of turnips or radishes to help break the erust and mark the row early is desired. Thin the plants to at least two inches apart. Clean deep cultivation should be given throughout the whole season. The crop may be used in about 100 days after planting, but may be allowed to remain in the ground the remainder of the season or until winter or the following spring. The roots may be dug at any time when the ground is not frozen. Freezing gives them a better flavor.

Beets.-A rich sandy loam is the best for the red garden beet. Any deep, good garden soil will produce the erop well. Two other types of beets should be considered under this head: the sugar beet, from which a large portion of the sugar of the world is obtained, and the mangel wurzel which is used ehiefly for livestock.

Good varieties of the red garden beet are Egyptian, Early Eclipse, and Early Blood Turnip. The seed should be drilled in the garden in rows early in the spring, twenty inches or more apart. If horse tillage is to be used two feet or more should be allowed between rows. Two ounces of seed are sufficient to plant 100 feet of row. When the plants are forming their second and third pairs of leaves they should be thimned to a few inches apart. The plants from the thimning may be used for greens; they are as good as spinach.

The sugar beet and mangel may be drilled a little later than the garden beet, and should be thimned to about eight inches apart. With all of the beets clean, deep cultivation is best. The garden beet should be planted several times to get the most tender roots. They suffer more from the summer heat than the other types. Frequent watering will help to prevent checks in the growth. Suspended growth causes the roots to become woody and unfit for table use.

Garden beets may be stored by piling them in the open and covering well with soil over which is placed corn staiks or other litter to prevent the soil from being washed off by rain. Mangels and sugar beets may be stored in like manner. Sugar beets may be sliced and boiled to extract the sugar in early winter and storage is 
not necessary. The pulp from the making of sugar may be fed to cows or other livestock. Storage in deep pits or cellars is better suited to northern climates, as these plans make the product more accessible during freezing weather.

The mangel wurzel is very productive, 20 tons per acre being possible under favorable conditions. The roots are much prized by stock feeders as they furnish much mineral matter and succulence as well as other feed ingredients during the season when pasture grass is not available. The roots may become large, being six to eight inches in diameter with most of the root projecting above ground. They are easily harvested and storage is not difficult.

The practice of growing sugar beets for home use is not common. The crop is abundantly grown near large beet sugar factories. However, the beets can be used at home. The crop is very productive of sugar, yielding fifteen to twenty per cent of refined sugar. A small garden patch will yield enough sugar and syrup for one family. The roots are sliced with a kraut cutter or otherwise about the time the ground begins freezing. The pulp is boiled until the saip is well extracted. The juice is then drawn off and boiled down as in the case of sorghum juice and maple sap. The home made product is not white as in the case of refined sugar. The refining process with charcoal and linıe is not difficult for those who desire to practice it.

Horse-radish.-This is an appetizer or condiment made from the roots of the plant. They are grated and stored in vinegar, very little vinegar being used. Grated horse radish is used with meats and other foods. A few plants at one side of the garden will persist indefinitely and furnish enough product for any family. Very little cultivation and attention is required. The plants are usually started from fingerling roots taken from the side of the older plants at harvest time. These may be set in the fall or spring, and will begin growth as spring weather comes on. Bury the crowns about two or three inches deep in rich black garden soil. Keep the weeds away and no other enemies will disturb the plants. Dig the roots in late fall, wash and grate with a common kitchen vegetable grater or grind them with a meat grinder. Put this product in bottles, and enough vinegar to moisten, but not enough to fill all the space in the bottle. Turn bottles over a few times after stoppering them well, to wet all the mass with the vinegar.

Rhubarb.-This crop furnishes palatable leaf stems for early spring use when other vegetables are not in season. The high per- 
centage of oxalic acid and other acids in the sap gives it certain properties which other vegetables do not have. The name pieplant is given to the erop because of its special use in making pies, as well as in making sauce.

Rhubarb prefers a rich black loam, and is much benefited by the addition of quantities of barnyard manure. The crop does best when not disturbed for a number of years. The stalks die to the ground each fall, and new leaves grow in early spring.

The erop is seldom grown from seed because of the long time required for the young plants to become large enough for table use. It is therefore usually propagated by division of roots, and each part planted must bear a bud formed at the crown or near the surface of the ground. Division is made either in late fall or early spring. The crop is usually planted at one side of the garden where plowing for other crops will not disturb it. The crowns should be planted a few inches below the general level of the soil and a mulch of manure may be placed above them. Extra manuring is usually given the plants each fall, and the new spring growth comes through this with much more vigor and increased size.

As the leaves are pulled each spring, care should be exercised to not destroy the central crown bud in the center of each whorl of leaves. Pulling the outer leaves may continue for several weeks. After that the plants are allowed to renew their vigor by retaining their leaves the remainder of the season. Unless seeds are desired for propagation the flower stalks sent up by any of the plants are cut off before they exhaust the strength of the plants.

Starvation of the plant is indicated whenever the leaf stalks become puny in size. Sometimes a similar result is noticed when the roots become crowded. In this case a division of the roots is necessary. Some of the crowded roots should be dug out and moved to another place. Additional manure may be added with favorable results.

Asparagus. - This is another crop which should be planted at one side of the garden, as it is a perennial and should not be disturbed for many years. The roots may be divided or the crop may be started from seeds sown in small beds where the plants may be given close attention for one or two years.

A good method of starting a permanent bed is to dig a ditch either with a shovel or by plowing out furrows to a depth of fourteen or sixteen inches. Fill the trench with rich black soil containing an abundance of manure well mixed with it. The asparagus 
crop needs very rich soil. In this trench plant one or two rows of two-year-old roots with thick, strong crowns. Leave the plants twelve to eighteen inches apart in the row, with the same distance between the rows. Plant the roots deep enough so the crowns will be covered two or three inches. This should be done in very early spring or in late fall. During the winter the rows should be covered with several inches of barnyard manure. The shoots will come up through this each spring and after the first year or two from planting time may be cut for table use.

Another plan is to plant a single row in a deep furrow and cover by throwing the soil back over the plants. The rows in commercial planting may be 4 feet apart. The depth of soil over the crowns of the plants may be greatly increased if the soil is somewhat sandy. The space between rows is given thorough cultivation throughout the growing season, and the plants are forced to make all growth possible from spring to fall. As the season closes the tops are mowed and raked off. The ground is all plowed with a turning plow, and heavy applications of manure are made along the rows.

Cutting the crop is to be done carefully. Injury to the crowns by careless use of asparagus knives is far too common. As the shoots come through the soil and manure over the rows the knife is thrust at an angle through the soil to cut the shoot at its base, or just above the other buds. This must be done without cutting other shoots which are to appear later.

There are two forms of product from this crop. The most popular is the white asparagus produced in the manner already described. The shoots in this case have not been exposed to the sunlight and have not turned green. The other form of product sometimes desired by growers is the so-called "green asparagus." In this case the buds are near the top of the ground and the shoots are allowed to grow to some height before they are cut. This gives a much stronger flavor to the product and is usually not preferred by the consumer.

The annual management consists in cutting for a period of four to six weeks in the spring, depending upon the strength of the plants. Then the crop is allowed to grow vigorously throughout the remainder of the season. Cultivation is given to encourage this growth and to keep out weeds. In home gardens it is well to cut out any stems which are about to bear seeds unless a seed crop is desired. The flowers are diœcious, that is, the staminate flowers 
are on some plants and the pistillate flowers on others. The staminate plants are preferable because no strength is lost in producing seeds. A heavy application of manure is given in the fall and winter after the tops have been mowed and removed. The manure is allowed to remain until after cutting season is over.

Beds should remain undisturbed for many years. If properly manured and cultivated they will continue to increase the amount of cutting furnished each year.

Asparagus rust is a serious disease of this plant which sometimes destroys the crop in certain sections. Thus far the best remedy is to propagate from plants which are immune to the disease. Although spraying with Bordeaux mixture will help control the rust, efforts by this method are not considered economical.

Globe Artichoke.-The edible portion of the globe artichoke is the undeveloped flower bud. These buds are sold in the large markets. They are cooked in somewhat the same way as asparagus, being served with cream or other dressing. The crop is propagated largely by seeds sown under glass in hotbeds or coldframes. Plants started in February or March may be transplanted to the open garden in two months. Rich black soil is preferred. They are set three or four feet apart each way, and should be given clean tillage. The plants will yield some buds the first year if started in very early spring.

The crop is chiefly grown in regions where the winter is not severe. During cold winters the plants should be covered with soil or coarse litter, as the stem must live over winter.

Many side shoots or suckers start from the plants each spring, and these are sometimes used to start new plants. A portion of the cluster of flower bucls should be taken with each shoot. Plant the crop at one side of the garden along with other perennials, as the plants will live for three or four years.

Sea Kale.-This is another crop which is used as a substitute for asparagus. The succulent leaf stalks are cooked in much the same way. The crop is even earlier in its spring growth. The plants are propagated either from seeds or from cuttings. They are set in rows three or four inches apart with the plants about two feet apart in the rows. No leaves should be cut until the plants are two or three years old. As in the case of rhubarb the seed stalks should be cut to prevent taking the strength of the plants. Heavy applications of manure should be made each fall to aid in producing strong, succulent growth. As the stems are to 
be blanched before using they are covered either with coarse litter, or may be covered with crates or boxes to exclude the light.

Jerusalem Artichoke.-This product resembles the Irish potato. The plant itself belongs to the sunflower family and the flowers and leaves resemble other sunflowers. The tubers are not much used for human food, but are palatable and nutritious. Fields of the crop are grown by planting the tubers or the seeds. The crop is sometimes utilized by allowing pigs to root out the tubers and feed upon them. As many of the tubers are left in the ground and will grow the following year they should be started at only one side of the garden or in a remote place where they will not injure annual crops or become serious weeds.

\section{EXERCISES, SURVEYS, AND PROJECTS}

1-4. Read Nos. 1 to 4 given at the close of Chapter $\mathrm{X}$. Now use the crops included in Chapter XI.

5. Resistance to freezing should be tried by growing crops started in the fall. Plant the different crops of the onion group, including garlic, leeks, shallots, and chives; also use young and old chard, collards, parsley, upland cress, kale, endive, mature carrots, mature parsnips, mature salsify and young beets. A part of each crop left in the garden for winter may be protected with different amounts of litter. Note when each lot begins to die, if at all. Record the minimum temperatures each night.

6. Endurance of summer heat should be studied by growing crops included in this chapter. Start them in early spring and note the effect on each as hot weather comes. The effects of drouth should be noted in each case. Do the products become strong in flavor, tough, woody, or do the plants run to sced, or stop growth, or do they thrive well?

7. Onions of several varieties should be grown to determine which are best for use in producing ripe onions from seed, to be stored or marketed. Also make a trial at the same time to see which are best for producing onion sets to sell or to plant at home. Soil and season often influence the growth of onion sets.

8. Storage of special crops such as beets, carrots, and onions for winter should be tried at home. Use several of the best plans known and compare them. Also store parsnips and salsify by placing them in pits, cellars, or deep in the ground and compare with some left to freeze in the garden rows. Which are sweetest? Which keep best?

9 . Drying vegetables for winter use is a good home project for both young men and young women. Use the plan suggested in U.S. Farmers Bulletin 841, or elsewhere. A number of the vegetables in the home garden should be dried. Compare the results with other methods of saving them.

10. Canning vegetables for market and for home use is also suitable for home projects for garden students. Read the methods given in U. S. Farmers' Bulletin 853 and in other bulletins. Containers of different kinds, different methods of packing, etc., may be tried. Calculate the profits after selling or using.

11. Horse-radish harvested in late fall may be grated or ground in a meat grinder and preserved in bottles with a little clear vinegar. The bottles may be neatly labeled and sold or used during the winter. 
12. Forcing asparagus and rhubarb is a good winter exercise or project. Dig the largest roots and let them freeze. Later take them into a hotbed or to a cellar window and wet them with water slightly warmed. Do not force the growth too rapidly. Record the cost of labor and the value of products secured.

\section{QUESTIONS}

1. Give directions for growing onions from seed.

2. How do garlic and leeks differ from true onions?

3. Compare slrallots with true onions. What special advantage have they?

4. What two uses are made of Swiss ehard?

5. What advantage has New Zealand spinach over true spinach?

6. What are the chief uses of parsley? Of upland eress?

7. Why is kale a good greens crop for all the year? How could you save it for winter?

8. Give the culture and use of endive.

9. What erops in this chapter should have marker crops, as radishes or turnips, planted with them?

10. Which crops in this chapter mav be readily transplanted?

11. Why ought parsnips and salsify to be planted at one side of the garden instead of in the middle?

12. This is best for what other crops in this chapter?

13. Give full directions for the growing of asparagus.

14. Give the same for rhubarb.

References.-U. S. Farmers' Bulletins: 354, Onion Culture; 567, SugarBeet Growing Under Irrigation; 568, Growing Sugar-Beets under Humid Conditions; 772, Control of the Sugar-Beet Nematode; 823 , Beet Syrup; 829, Asparagus; 837, Asparagus Beetles and their Control. 


\section{CHAPTER XII}

\section{WARM SEASON VEGETABLES}

Crops of this group thrive best in the summer months. They are injured or killed by frosts in spring and fall.

Sweet Corn.-This is an important table vegetable in all sections of the country. It may be grown in all home gardens, except the very small ones. The product is good for use in the summer, and may be dried or canned for winter use.

Rich, black loam or clay loam is best for corn. Spade or plow the soil to a great depth, pulverize it thoroughly and allow it to stand several weeks before planting, if possible. During this time it should be raked or harrowed several times to keep a soil mulch, preventing crusting, hasten the sprouting of weed seeds, and help to admit the warm air.

Good varieties for the earliest product are Golden Bantam Peep-of-day, and Adams Early; for the medium season crop Country Gentleman is highly prized; for the latest crop Stowell's Evergreen is probably the best.

A pint of seed is sufficient for 200 feet of rows. Plant four or five kernels in a place, making the places two or three feet apart. The rows may be three and one half feet apart. The plants may be thinned to leave only two or three stalks in each place.

The ground should be kept thoroughly stirred to maintain a good loose mulch and prevent the loss of moisture. No weeds should be allowed to grow.

When the silk on the cob begins to dry the corn should be about ready for table use. Kernels should be full of milk. It should be used immediately after picking.

To dry the corn for winter use it should be cut from the cob and the kernels well seraped out with the back of a knife just after cooking for table use. Dry the kernels over the back of the stove or in an open oven. This drying may be continued during the preparation of several meals without use of extra fuel. When thoroughly dried the corn may be placed in paper hags or breakfast food boxes, which are then sealed by pasting paper over the opening. This keeps the weevils and other insects out. It should be stored where mice will not disturb it. For table use in winter it is soaked 
for an hour, then cooked a little and served with cream as in the summer time.

Field Corn for Roasting Ears.-In the southern states field corn has a sweeter taste than in the northern states. It is therefore much used as roasting ears. When used for this purpose it should be selected very carefully and should be prepared for the table when the kernels are very young. Freshness is also more important with field corn. Sweet corn is to be preferred to the other varieties for winter use as dried corn.

Pop Corn.- This erop is very easily grown in any home garden. The so-called rice pop corn is the best type for planting. The season and methods are similar to those for other corn. The cropshould be allowed to mature thoroughly before harvesting. When the ears are gathered they should be stored in a dry attic where there is some warmth from a chimney or some other dry place. Be careful about mice attacking it.

Never plant pop corn too near other kinds of corn which will tassel at the same time. They are sure to cross and injure each other. If the tasseling is at different times no crossing will take place.

Beans.-This is a warm weather crop and should not be planted before warm spring weather comes. A number of varieties of beans may be planted in succession, that is, several plantings of one kind may be made so that a fresh crop is developing through the long summer season.

A rich sandy loam is preferred, and some phosphoric acid and potash may be added in the form of commercial fertilizer.

Good varieties of snap beans are Stringless Green Pod, Refugee, Kidney Wax, and Rust Proof Wax. A good pole bean to be used either as "snaps" or as a dried product is Kentucky Wonder. There are many other good pole beans, such as Pole Horticultural.

Lima beans are of four different types. The bush limas include the small prolific bean of the Henderson type and also the large fleshy bean of the Burpee or Dreer type. The pole types are also of the two sizes but the large seeded kinds are the more popular.

The soil should be deeply and thoroughly worked, and should be somewhat loose at planting time. If the soil can be plowed or spaded several weeks before planting time it should be kept stirred throughout the whole interval. This warms the soil and causes the seeds to sprout readily when planted. 
Bush beans (Fig 75) should be planted three or four inches apart in rows about two feet apart. Bush limas are given more space between the rows and also in the rows. One pint of seed is usually enough for planting 100 feet of row. Cover to a depth of one to two inches, depending on the moisture in the soil.

Cultivate the plants well to maintain a good soil mulch and prevent the growth of weeds. Frequent shallow tillage will do this. Climbing varieties may be planted near. stalks of corr, or may be planted with the corn at corn planting time. Poles or stakes must be provided when pole beans are planted alone. One common practice is to lean two rows of stakes together and tie them at the top, allowing the vines to climb and form an arch. Chicken wire

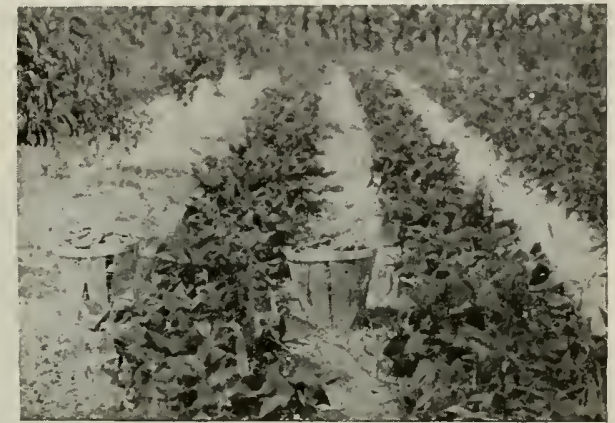

FIG. 75.-Bush limas are less productive than pole limas, but they mature their crop in less time and labor of staking is saved. (New Jersey Station.) and strings are used in different ways for supporting the vines.

Many varieties of beans may be dried for winter use. The snap beans in pods are usually canned for winter use.

Tomatoes.-This crop is usually grown from plants started in the house, hotbed or coldframe (Fig. 76). They should not be planted in the open garden until warm weather, and when all danger of frost is over. As a long season is required for the crop, much time is gained by having the plants well developed in beds or in-doors before time for transplanting to the garden. The best plants are produced by transplanting at least twice from the seed bed to trays or pots.

Set the plants about two feet apart in rows at least three feet apart. If the garden is large more room should be allowed. A rich, well manured soil is best. Set the plants very deep and give the stem plenty of opportunity for forming new roots. This may be done by laying it somewhat horizontally in the furrow at planting time. The top must be allowed to extend a few inches above the soil.

When growth is well started drive a stake near each plant and later tie the plant well up on this with raffia, coarse twine or strips 
of cloth (Fig. 77). Some pruning of the plant is desirable. Reduce the number of stems as desired and remove the lower suckers. To induce a few plants to mature their crop extra early, the late blossoms may be pinched off to force all of the strength of the plant into the earlier fruits. Clean, thorough tillage is necessary for the best growth.

Good varieties of the early season are Earliana, Early Jewel; medium and late varieties are Livingston Beauty, Ponderosa, Acme, Stone, Baltimore. For eanning purposes the Stone variety is popular.

Tomatoes should alwars be sprayed with Bordeaux mixture

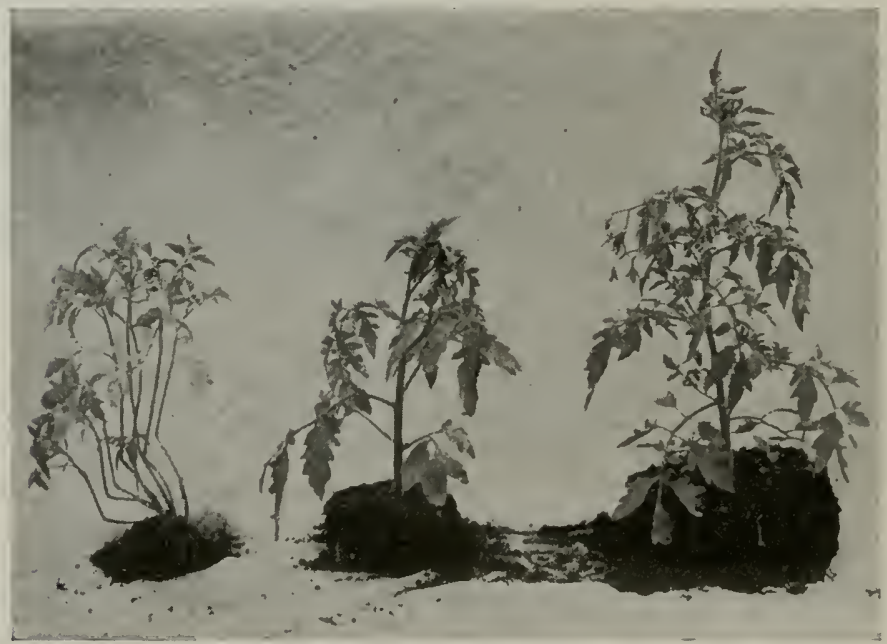

Fig. 76.-Tomato plants all of the same age. From left to right; not shifted, shifted oner, and shifted twice. (lllinois station.)

containing some arsenate of lead. The combined spray material described under the head of Irish potatoes is well suited to the tomato crop. There are several fungous diseases which attack the tomato plant, and these are largely prevented by Bordeaux mixture if it is applied early. Some poison is included with Bordeaux mixture for the sake of fighting tomato worms or other leaf eating insects.

Peppers.-This is a warm scason crop. The plants are started indoors or in hotbeds, as in the case of tomatoes. They require similar treatment, but usually are not staked. 
Good varieties of the sweet pepper are Golden Queen, Bull Nose, and Chinese Giant (Fig. 62). Hot peppers used for pickle sauce are Cayenne and Red Hot.

Eggplant.-This is a warm season crop, and the plants are started in-doors or in hotbeds or coldframes. At least two transplantings of the young plants should be made. If they can make their last growth in tin cans or pots before setting in the garden they will be much stronger. The crop should have rich black soil, well prepared before setting in the garden.

Good, thorough tillage will help the plants to attain large size and yield abundant crops. (Fig. 78).

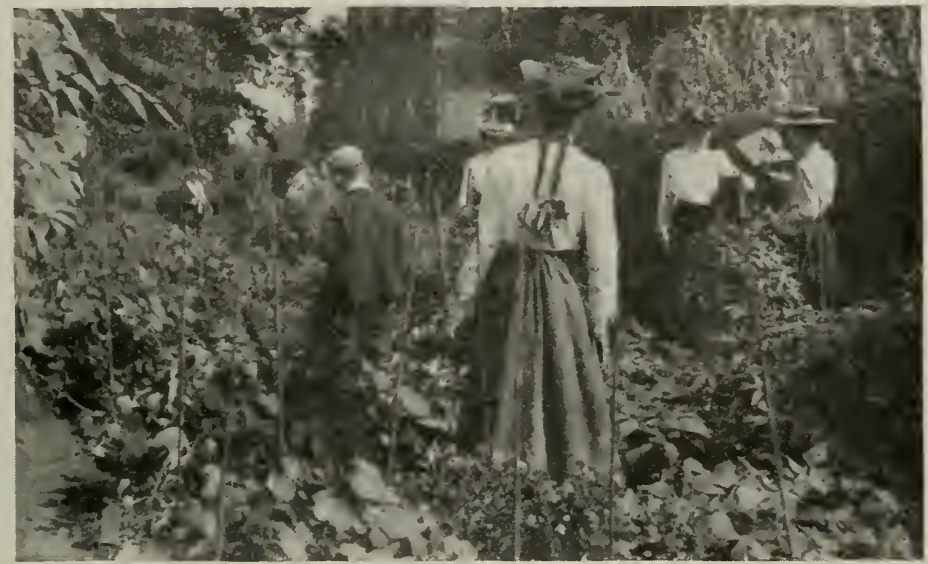

FIG. 77.-Tying up tomatoes. Girls of the high school take a deep interest in school and home gardening. (U.S.D.A.)

Good varieties are Black Beauty and Improved Purple. A very common enemy of the eggplant is the flea beetle, which eats holes in the leaves and may seriously injure the crop. To prevent this the plants are dusted with tobacco dust or sprayed with a solution of nicotine sulfate. Arsenical poisons, such as arsenate of lead, are sometimes used.

Okra.-This crop is grown abundantly in the southem states. It requires a long warm season. It is used for cooking alone or with tomatoes. Its chief use is in soups. It may be canned or dried for winter use.

Good varieties are White Velvet, Lady Finger, Long Podded, and Perkin's Mammoth. The early varieties will form edible 
pods in about forty days but will continue their growth until frost if properly cared for. Prepare the land by deep plowing and good thorough harrowing. Give a heavy dressing of barnyard manure either before or after harrowing. Plant the seeds three inches deep in drill rows about four to five feet apart. The plants after thinning should be one to two feet apart in the rows. 'Two ounces of seed is enough to plant 100 feet of row. Give clean, shallow tillage throughout the growing season. If the pods are kept picked as fast as they are large enough for table use the crop will

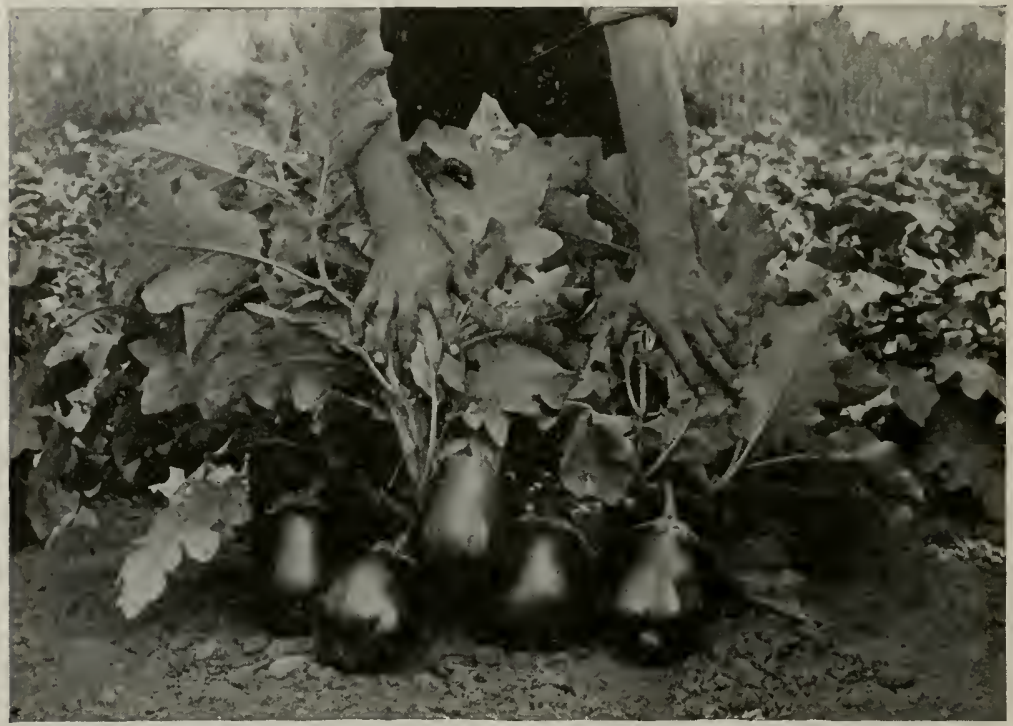

Fig. 78.-Good specimens of eggplant. (1llinois Station.)

continue bearing much longer. Do not let any of the seed ripen on any plants except those that are wanted for seed purposes.

Cucumbers. - This is a very tender erop and should be grown only in warm weather. The soil should be rich and mellow. When the danger of frost is past make places for the plants by opening the soil a foot deep and two feet across. Fill each hole two thirds full of barnyard manure, mixing in some soil. Cover this with soil and plant eight or ten seeds over this circle. The seeds may be soaked before planting. Cover them about one inch deep. The elumps may be five or six feet apart each way. After the 
plants are up and begin to crowd each other a few may be removed if necessary.

Good varieties are White Spine, Davis Perfect, and Emerald.

If an early crop is desired the plants may be started in a hotbed or coldframe in pasteboard boxes or berry boxes. These are transplanted to the garden after clanger of frost is over.

After the vines begin to run they should be made to take root at a number of places by covering a little with some soil. This will help to control injury from vine borers. Cultivate the crop thoroughly until the vines cover the ground. Protect the plants while young in the home garden with box frames covered with mosquito bar. These are to keep off cucumber beetles which eat the leaves and destroy the plants. These beetles may be killed by spraying with arsenate of lead. After the cucumbers begin to form, continue to fight the beetles by dusting the vines with tobaceo dust, lime dust, or by spraying with nicotine sulfate.

Inter-cropping with snap beans of the bush varieties should be practiced. Plant the snap beans as early as the cucumbers are planted. As soon as the vines begin to need all of the ground these beans will have produced a crop and may be removed.

Muskmelons.-This crop should be grown some distance from cucumbers and squashes. They are apt to cross-pollinate with them and the fruits will be seriously injured.

The best varieties of the canteloupe group of muskmelons are Rocky Ford, Jennie Lind, Netted Gem and Paul Rose. There are many other good varieties offered in garden catalogs. (Fig. 79). Muskmelons may be forced in hotbeds as described for cucumbers. In the field they are given more space, the groups of plants being six or seven feet apart each way. They will respond well when thoroughly manured. Each group of plants should be thinned to not more than four or five plants. In large fields they are planted by opening furrows six feet apart. Seeds are dropped in the furrows and covered and later the plants are thinned to about two feet apart. The manure may be placed all along the furrow.

This crop is also attacked by cucumber beetles and vine borers. See remedies mentioned under the head of cucumbers.

Watermelons.-This crop is particularly favored by rich sandy loam. It thrives best in very warm climates where the moisture conditions are favorable. Here the melons reach their largest size and best qualities.

Good varieties are Florida Favorite, Tom Watson, Georgia 
Rattlesnake, and Kleckley Sweet. The Ice Cream variety is grown in northern states because it will mature in less time than others. The melons are small in size.

Besides for eating in the usual way during summer the crop is valuable for the rinds which are sometines preserved as sweet pickles for use in winter.

Plant the seeds after soaking for a few hours. Make the rows ten feet apart and the plants eight or ten feet apart in the rows. Two or three plants in a place may be allowed. Rich soil about the plants is necessary for the best growth. A fork full of manure, or more, about the hills will pay. The watermelon vines are less likely to be attacked by cucumber beetles and vine borers. If

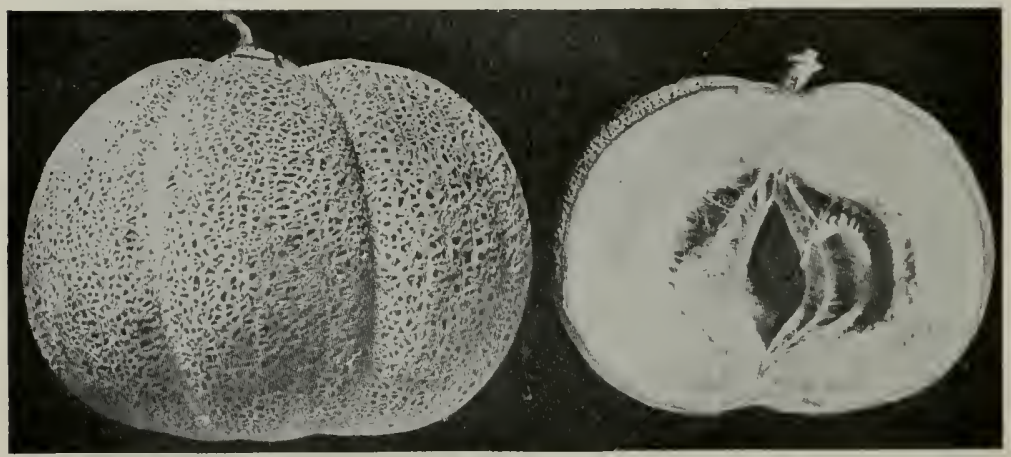

Fig. 79,-Large type of oblate muskmelon, with deep flesh, edible clear to the rind. (Vermont Station.)

good cultivation and plenty of manure are provided the growth is so rapid that these enemies are seldom noticed.

The crop is frequently grown in large fields because of requiring so much space in the garden. It is best when grown in the garden to use other plants, such as snap beans near them until the watermelon vines have grown enough to need the whole space.

Squash.-Remember to plant this erop where it will not mix with cucumbers, muskmelons, or pumpkins. There are two main types of squash, the bush variety and the running variety. Much more space is required for the running varieties. In selecting seed from the catalog note carefully which type is chosen. The running varieties are much more prolific and a fewer number of them will be necessary to supply the needs of the family.

In the matter of season, there are two types. The summer , 
squash is harvested green during the summer season. Popular varieties of this type are Patty Pan and Summer Crook Neck. The winter squash forms a harc rind when mature. Popular varieties are Delicious, Hubbard and Boston Marrow. Cushaw is one of the crooknecks. The winter squash may be stored in collars until mid winter. In harvesting for storage they should be very ripe with firm rind, and should be handled carefully.

Prepare the soil as thoroughly as possible. Plant the bush varieties in places about four or five feet apart each way. The rumning varieties should have space of about eight or ten feet each way. Two or three plants may be left in each place. The crop grows best in hot weather, and will not endure frost. Plant two or three weeks after earliest corn planting time. Soak the seeds before planting and cover them one inch deep. The crop is sometimes grown in rows of corn as the plants will endure shade almost as well as do pumpkins. If grown with.sweet corn of the early or medium varieties the corn stalks may be cut as fast as the roasting ears are removed. The squash vines then have the entire area. The corn will help somewhat in preventing too much crosspollination with cucumbers and melons, though it will not insure this. After the summer squash crop is harvested the vines may be removed and late corn crops may be planted.

Pumpkins.-There are two main types of pumpkin grown chiefly in corn fields. The small pie pumpkin is sweeter than the large field pumpkin. The latter is used chiefly for stock. The pumpkin endures shade well and thrives well in growing fields of corn. The seeds may be planted in every third row and covered about one inch deep. Two or three seeds are planted in each place. This is done after the corn is about ready to tassel, or a little earlier than that. The corn cultivation may be over by the time the pumpkin vines begin to run too much. The crop is often harvested after the corn is cut. This may be done either by hauling in the crop after frost or by turning stock into the field. The table varieties may be stored in cellars or pits which do not freeze.

Mushrooms. - This crop is seldom thought of as a garden crop. It can be grown in a cellar or in a vegetable pit where there is little light and where rotting manure may form enough heat to warm the soil. The crop is sometimes grown under beds of green houses, or under benches in cellars. Some half rotted manure may be incorporated with the soil, then some spawn of mushrooms may be scattered over this and watered thoroughly. If warm 
water is used it will start the growth and the heating of the manure more promptly. Experience is necessary to make a success of the mushroom bed. With favorable conditions results are very gratifying. Even when the best rules are followed carefully the results are sometimes discouraging. Conditions must be studied closely. The average gardener without experience is not willing to study the conditions enough. The temperature must not be too warm nor too cold. Most of the light must be excluded. Plenty of water must be in the soil without drowning it. The spawn must be fresh and must not be killed during the starting period.

Mushrooms are coming more into favor. They are fried in butter or other fresh grease and are served as beef steak. They may be made into stews or used in soups. They are not only polatable, but have considerable nutritive value.

Mushrooms found in the woods or garden may be gathered while fresh. Care must be exercised to distinguish the edible ones from the poisonous kinds.

\section{EXERCISES, SURVEYS, AND PROJECTS}

1-4. Suggestions Nos. 1 to 4 at the elose of Chapter $X$ should be applied to the present chapter.

5-6. Suggestions for drying and canning given in Nos. 9 and 10, Chapter $\mathrm{XI}$, should be considered here with reference to the hot weather erops. Dry or can corn and beans, can tomatoes, (make preserves of small ones). Dry or can egg-plant, peppers, squash, pumpkin, and okra.

7. Salting and pickling a cueumber crop may be a part of a project in cucumber production. See directions in U. S. farmers' Bulletin 881. Keep record of cost and profits. Use watermelon rinds also for sweet pickles. Snap beans may be brined or pickled.

8. Home garden projects may be carried on by all students. Each projeet may include all the general garden crops or may be confined to special crops grown on a larger scale, as cantaloupes, watermelons, sweet corn, etc. Each project should include production, management, harvesting, storing, use, marketing, etc. Records should be kept in each case of the cost, value, profits, or labor income.

9. Exhibits of garden products should be made once a year to which the people are invited. The products should be judged whether premiums are offered or not. Inelude fresh specimens shown in attractive market conditions, and products stored, canned, dried, salted, and pickled.

\section{QUESTIONS}

1. How would you produce a continuous supply of roasting ears for home use during the season?

2. Give cultural direetions to maintain the supply of moisture for corn and similar garden crops.

3. What varieties of beans are best for winter use as a ripe product?

4. What varieties for snap heans?

5. Diseuss the different types of lima beans. 
6. How would you produce a succession of fresh green beans?

7. Give directions for pruning and staking tomatoes.

8. Give directions and purposes for spraying tomatoes.

9. Give directions for growing eggplants.

10. What are the chief uses of okra?

11. Give directions for the successful production of cucumbers for pickling and for table use.

12. How are cantaloupes produced ahead of the main crop of the region? Give details.

13. Describe soils and conditions for economical production of watermelons.

14. Same for squash and pumpkin.

15. Describe a good method of mushroom culture.

References.-U. S. Farmers' Bulletins: 232, Okra; 254, Cucumbers; 318, Cowpeas; 414, Corn Cultivation; 431, The Peanut; 537, How to Grow an Acre of Corn; 553, 554, Popcorn; 642, Tomato Growing in the South; 668, Squash Vine Borer; 707, Commercial Cantaloupes; 886, Harvesting Soy Beans for Seed. 


\section{CHAPTER XIII}

\section{POTATOES}

IN northern states the word "potato" almost invariably refers to the Irish potato. In southern states, however, the meaning is less definite and the name "potato" would cause some to first think of the sweet potato. Because of this uncertainty, we should refer to these two erops with their more definite names, "Irish potato" and "sweet potato."

\section{IRISH POTATOES}

This crop originated in America. Later it was introdured into Ireland and was grown so extensively in that country that the name "Irish potato" clung to it. It is grown in nearly all parts of the civilized world and leads all other crops in total tonnage. In production recent statistics show the order of maximum tonnage in the following countries: Germany, European Russia, Austria Hungary, France, United States, United Kingdom of Great Britian. The average yields vary from one to two hundred bushels of sixty pounds each. In the United States, the eight learling states are placed in the following order: New York, Michigan, Wisconsin, Maine, Pennsylvania, Minnesota, Ohio, Iowa. Maine has the honor of producing the largest average in bushels per acre.

Soils for Potatoes.-Crops of the best quality are produced on rich sandy loams rather than on heavy soils. Rich sandy loams also produce earlier crops than the heavy soils. Long-season varieties, which are intended for keeping over winter, may be grown very successfully in the medium and clay loams provided enough organic matter is present. The best method of adding organic matter to the soil for potatoes is by using green manure. Barnyard manure if applied to the soil several months or a year in advance will add much humus but it is not a good practice to apply the barnyard manure just before the planting of the crop. It tends to increase the seab disease and does not benefit the soil for that crop.

Under-rlrainage will greatly improve heavy soils for the potato crop. The soil will be better aërated and will not become puddled. 132 
Fertilizers for Potatoes.-In the most intensive potato growing districts, commercial fertilizers are used in growing the crop. A mixture containing four per cent of nitrogen, six per cent of phosphate and eight per cent of potash will suit the average Irish potato soils.

Much can be saved by "growing" nitrogen instead of buying it. If an annual crop of green manure is plowed under each year, the nitrogen supply will be abundant. This is particularly true if the green manure is composed of clover, vetch, or some other legume. Barn yard manure will help also to take the place of the nitrogen. Heavy soils are likely not to need as much phosphoric acid. It is also true that application of potash is more important on sandy soils than on heavy soils. Where early potatoes are grown for market, commercial fertilizer will aid materially in producing the crop quickly. The amount saved in getting the crop in to market at a high price will probably pay for the fertilizer used. Growers often use as much as five hundred to one thousand pounds per acre, or more.

The use of lime on potatoes is apt to cause scab disease but if it is applied on the crop preceding the potatoes in the rotation, the residue in the soil will help the potato crop. If this plan is followed, the best form of lime is ground limestone.

Preparation of Soils for Potatoes.-Plowing should be very deep. The crop should have a loose open soil. For this reason it is not necessary to have the plowing done long before planting time. It does not need to be repacked as it would be for corn, wheat and other small grain. The so-called deep tillage machines where one disk follows behind the other in the same furrow are best for the preparation of heavy soils for potato growing. Judgment should be exercised so that too much of the subsoil will not be turned to the surface at any one time. If, however, it is done with the disk plow, the subsoil brought up will be so very thoroughly incorporated with the other soil that little or no damage will be done in deepening the soil considerably at one season.

If a plow is run rather shallow, a subsoil plow which stirs the the bottom of the furrow but does not bring the loose soil to the top will deepen the root bed for the potato crop. If the ground is plowed in the fall as in the northern states, deep disking before planting is very desirable. This is also true if the sod has been turned under in the spring. The disk harrow will cut the sod to pieces and mix the organic matter with the soil. The smoothing harrow used after the disk harrow will prepare the ground well for 
planting. Hand methods of preparing soil for planting are laborious and expensive for large areas.

Varieties of Potatoes for Different Seasons and Sections.-In northern states, one crop only is grown in the season. For the home garden a small quantity is planted of some early variety. This may be Irish Cobbler (Fig. 81), Early Red Triumph, Early Ohio, or some other crop which grows quickly. The yield is always comparatively small for the early crop.

The main crop to be used for winter storage or for winter marketing is planted in rather early spring and occupies the ground throughout the growing season. Suitable varieties are Rural New Yorker, Burbank (Fig. 80), Carman No. 3, and many others. In each section there are certain varieties which become popular partly because of their special adaptation to the soils of the region.

In southern states two crops are commonly grown. These may not both occupy the same soil but the late crop is planted after the early crop is harvested. In all states southward from Virginia and Tennessee, the late crop may be planted as late as July 15 or August 1. The spring crop is started in February or March, or as soon as the ground can be safely worked. For winter storage the fall crop is the best, but where storage facilitates are very favorable, the spring crop harvested in July may be kept over for winter use. The varieties commonly used for both fall and spring crops are the same. They include Irish Cobbler, Early Triumph, Green Mountain, and others.

The long season crops are seldom grown in southern states. The long hot summers are not particularly favorable to their growth and the yield is less than where two crops are grown in one season.

Seed Potatoes.-It is a very common practice for the northern states to supply southern growers with seed potatoes. To some extent this practice is founded upon a false belief that southern grown seed potatoes are not so productive. Probably another cause for this practice is poor storage facilities in southern states. Potatoes kept over winter under unfavorable conditions may rot or sprout too soon. Cold storage facilities rather tend to remedy this difficulty.

In northern latitudes seed potatoes are kept over from the preceding year and are seldom shipped from cold storage plants. They may be stored in cellars free from frost. In an earlier chapter methods of improving seed potatoes have been described. 
Cutting Seed Potatoes.-Under "Propagation by Tubers," a method of cutting potatoes through the stem-end and eye-end into long fingers has been described. It is quite common to cut potatoes into pieces containing one or two eyes or buds. When seed

FIG. 80 .

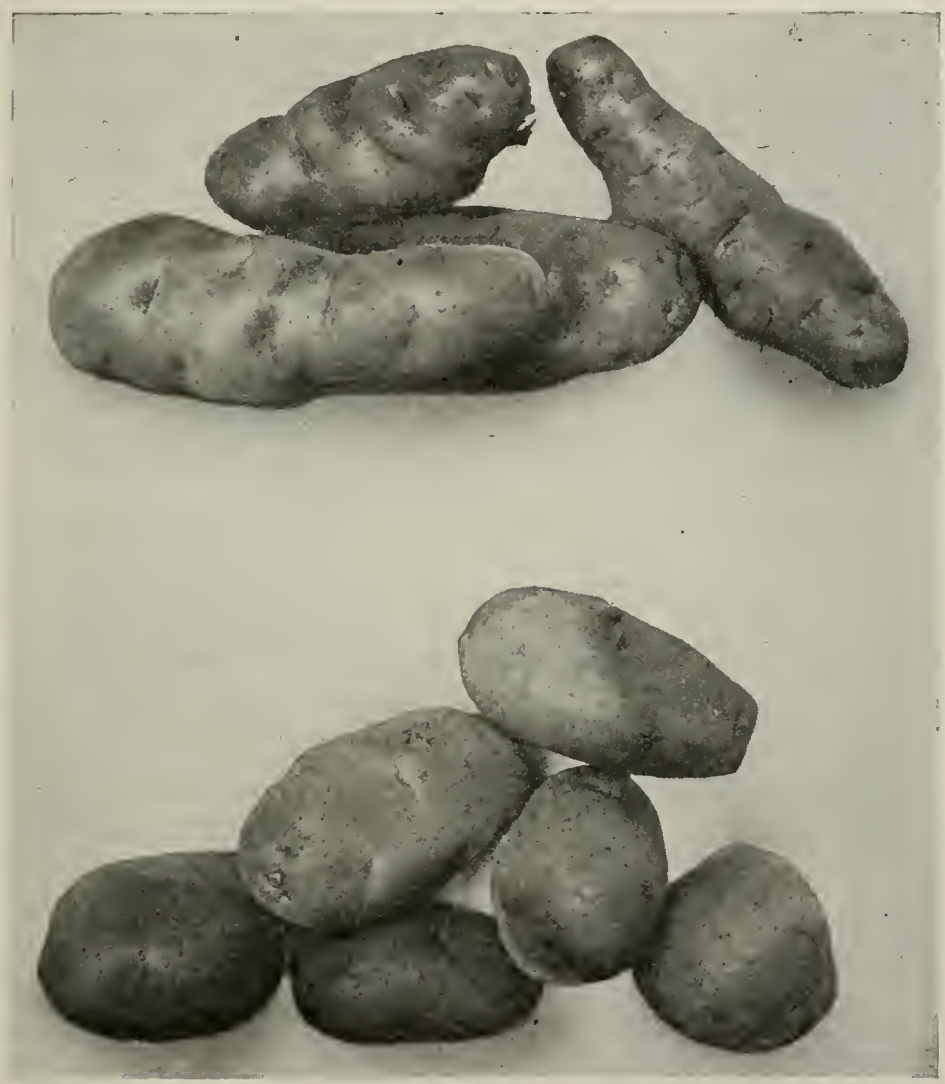

F1G. 81.

FIG. 80.-Long slender Irish potatoes of the Burbank type.

FIG. 81.-Roundish, smooth potatoes of the Irish Cobbler type.

potatoes are high in price, this is probably the best plan. When seed is not so expensive larger pieces will pay, giving larger yields.

Rate of Planting.-A trial at the Ohio Station on the number of eyes to the piece and bushels of seed potatoes to the acre showed 
the results in the accompanying table and chart. With the variety Carman No. 3 the most profitable rate of seeding was with half tubers using twenty-five bushels per acre, when the price was fifty cents a bushel. With the Bovee variety shown in the chart, the greatest profit was with two-eye pieces using fifteen bushels per acre.

Results of Using Different Quantities of Bovee Seed Potatoes per Acrc. Average for Two Years

\begin{tabular}{|c|c|c|c|c|c|}
\hline Size, ete. & $\begin{array}{l}\text { Bu. sced } \\
\text { per acre }\end{array}$ & $\begin{array}{l}\text { Yield per } \\
\text { acre, bus. }\end{array}$ & 50 & 100 & 150 \\
\hline One eye........ & 10 & $\begin{array}{lr}\mathrm{M}^{*} & 146.6 \\
\mathrm{U} \dagger & 32.7\end{array}$ & & & \\
\hline Two eyes... & 15 & $\begin{array}{lr}\text { M } & 159.1 \\
\text { U } & 45.5\end{array}$ & & & \\
\hline Half tubers......... & 25 & $\begin{array}{rr}\mathrm{M} & 131.7 \\
\mathrm{U} & 73.5\end{array}$ & & & \\
\hline Whole tubers........ & 40 & $\begin{array}{cr}\text { M } & 168.7 \\
\mathrm{U} & 99.4\end{array}$ & & & \\
\hline Small or 2 oz. tubers. & 22.6 & $\begin{array}{cr}\text { M } & 150.1 \\
\text { U } & 73.5\end{array}$ & & & \\
\hline
\end{tabular}

* M, marketable yield; $\uparrow \mathrm{U}$, unmarketable.

Treating to Prevent Scab.-Before the seed potatoes have been cut they should be soaked for an hour or two in a solution of formalin composed of one pint of formalin (40 per cent strength) in thirty-two gallons of water. The scab disease (Fig. 82) is likely to be introduced into any garden soil if the seed potatoes lave not been treated by some method to kill the scab spores. The method here given is very inexpensive and is not a dangerous one.

Sprouting Seed Potatoes.-Either before or after the potatoes are cut for planting they should be spread on the barn floor or in direct sunlight. If they are left there for a week or so, strong, heavy sprouts will form which will turn green and be ready for rapid growth as soon as the potatoes are planted. (Fig. 83).

Planting Potatoes.-The distance between rows is usually about three feet. The distance between plants in the rows may be from eight inches to two feet, depending on the soil and the variety. 
In the home garden a simple method of planting is to open the furrows with the plow and drop the seed pieces in by hand and cover them with the hoe or with the harrow.

In commercial planting, machines are commonly used which open the furrow, drop the potatoes and the fertilizer, and cover the furrows all in one operation. This makes the work very rapid and inexpensive.

Culture.-One of the secrets of success in the cultivation of the growing crop is to keep the soil very loose. For the first few weeks the tillage should be very deep. The soil should be stirred very thoroughly.

The plan of cultivation called level tillage is usually best for this crop. The most successful growers sometimes throw a little dirt towards the vines at the times of the last cultivation. Very much ridging, however, is certain to cause the soil to dry out. This is extremely detrimental to the growing crop. The soil should be kept moist and cool

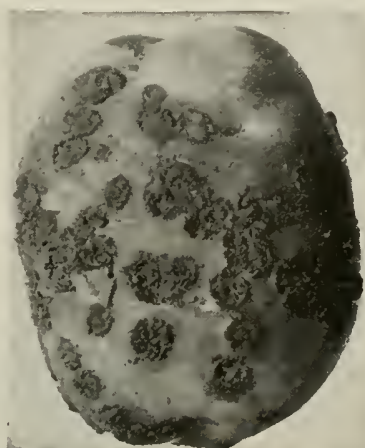

FrG. 82.-Common potato scab reduces the yield, causes waste in peeling, and infests the soil for future potato crops. See methods of control in the text. (Minnesota Station.)

and the vines should be allowed to spread out over the ground to shade it as soon as cultivation is stopped. Growers usually stop the cultivation at the time the plants are in full blossom. The
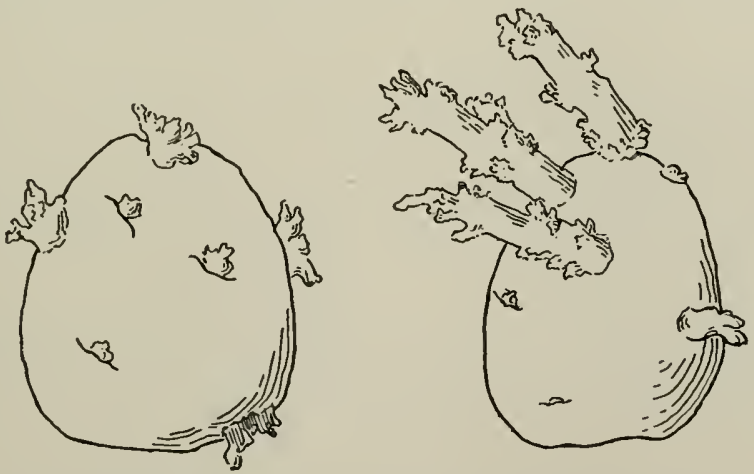

F1G. 83.-Seed potatoes exposed to the light before planting will develop stubby, green sprouts instead of tender, white sprouts. Strong plants are developed rapidly when those with the green sprouts are planted. Left tuber in light four weeks; right, ten weeks. (After Ohio Station.) 
tubers should be of large size at this time and further use of the cultivator is apt to disturb them or dig them out of the ground.

Spraying for Blight and Beetles.-The two-worst enemies of the Irish potato crop which can be controlled by spraying are late blight (Fig. 84) and the Colorado potato beetle. The blister beetle and the black flea beetle are sometimes serious pests. These however can be controlled by the same methods as are used for the Colorado potato beetle.

Spraying with the combined spray will control these enemies fairly well. Bordeaux mixture used before the blight begins will very largely prevent its attacks. Poisons applied when the beetles

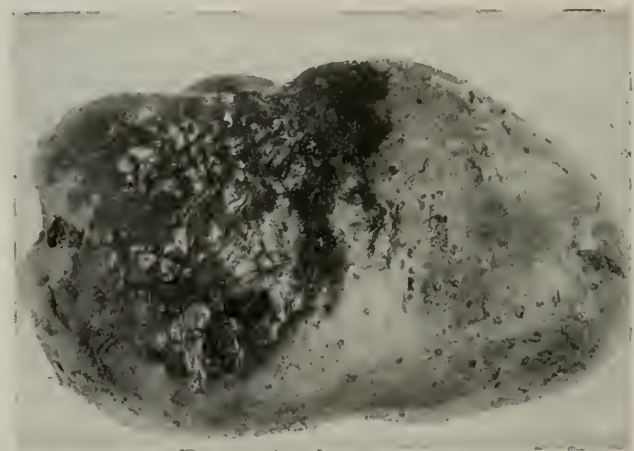

Fig. 84.-Late blight disease of potatoes showing the shrunken. rotted area. Avoid planting affected tubers and spray the growing crop with Bordeaux mixture. (Ohio Station.)

are at work will kill them. For this purpose arsenate of lead or Paris green may be used.

A combined spray material is made by mixing arsenate of lead or Paris green with Bordeaux mixture. The amount of poison used with the Bordeaux would be the same as with a like amount of water. (See Chapter XXV.) Make up the desired amount of Bor: deaux mixture and add as much poison to it as if it were merely water. When this combined spray is applied to the potato crop the beetles are killed, better than when the poison is used without the Bordeaux because the spray material is not so easily washed off by rains. The plants are not so likely to be injured by the arsenic in the poison because the lime in the Bordeaux takes up the free arsenic and prevents injury.

As the plants form new growth another spraying is required to 
cover the new leaf surface. If the spray material covers the entire plant the beetles will be destroyed first and the blight will be prevented.

Time for Harvesting the Potato Crop.-Irish potatoes are not mature until the vines cease growing. They are frequently dug and used at this time as "new potatoes." Those intended for storage for winter use should be allowed to mature as much as possible in the soil.

The fall crop does not need to be harvested until nearly time for the ground to freeze. Fall frosts do not injure the tubers and a slight freezing of the ground will do no harm unless it prevents the grower from harvesting the crop.

Digging the Tubers.-There are several methods of digging Irish potatoes from the ground.

1. The potatoes are sometimes dug by the use of hand tools such as a spading fork, potato hook, or common hoe. This method is slow and laborious and would be used only in the small home garden.

2. Plowing out the tubers with the common turning plow is more rapid and is well suited to the crop raised for winter use for the entire family. A modification of this method is to use a special plow with two or three prongs on each side of the double moldboard. This does not cover so many of the potatoes with the soil. They are more easily picked up after the plow throws them out.

3. Special potato diggers pulled by three or four horses are used in commercial fields. The machine has a large broad shovel which goes entirely beneath the row of potatoes and lifts the whole mass of dirt, tubers and vines up on a travelling carrier. This carries them over the axle of the machine and drops them on a series of bars which will let the soil through and drop the potatoes on top of the ground, a little at one side or behind the machine. This leaves them out of the way of the machine when taking the next row.

Potatoes are picked up in baskets, crates or bags and are hauled in for sale or for winter storage.

Storing Irish Potatoes.- It is important to have a cool cellar, pit, or special storehouse for saving potatoes during cold weather. Cellars warmed with furnace heat are not suited to this purpose. The tubers are not hard to keep but they should not be warmed or dried too much. If frozen, they acquire a sweetish taste which is not palatable. This may later change to a bitterness which renders them unfit for table use. 
Good vegetable storehouses are frequently made detached from the dwelling. A rellar is dug six or eight feet in depth and walled with concrete, brick, stone or lumber. A roof is placed over this and a stairway is provided at one end. If the surface drainage is good, the cellar may serve as an ideal storage place for Irish potatoes and a number of other root crops.

\section{SWEET POTATOES}

The sweet potato plant is believed to be a native of South America. Thus three of our most important food crops, the Irish potato the sweet potato, and Indian corn, were discovered in America.

The sweet potato erop is grown in nearly all states but is produced chiefly in the southern states where the climate is mild, the season long, and where moisture conditions are favorable.

Relationships.-The sweet potato belongs to the morning-glory family and is therefore closely related to the morning-glory of the flower garden and to some of our worst weeds in the field.

Soil.-The sweet potato prefers a rather sandy loam and unlike the Irish potato is not much helped by the addition of organic matter. When soils are rather too poor for the Irish potato, they are often planted with sweet potatoes.

Feeding the Crop.-As sweet potatoes are not much improved by the addition of stable manure, the best way to feed plants is to apply commercial fertilizers. From five to seven hundred pounds per acre of the general fertilizer may be used. Mix three hundred pounds tankage, one hundred pounds dried blood, four hundred pounds acid phosphate and two hundred pounds muriate or sulfate of potash. This would have a formula of about two and one half per cent nitrogen, nine per cent phosphate and ten per cent potash.

Starting the Plants.--Sweet potato plants are commonly called slips. The seed potatoes are spread out in a clense layer in the hotbed or coldframe. The potatoes are covered with a few inches of light sand or soil. The bed is then covered with muslin or glass. The potatoes are kept well watered and in about six weeks pulling of the slips may begin. The larger plants are best for setting in the garden but second and third pullings from the same roots may be used if necessary. The best plants have a good supply of roots, vigorous crowns and strong stems A good supply of leaves is best. 
In northern sections considerable heat is required in the beds. In the regions where freezing weather is likely to occur during the bedding season, artificial heating is provided by stoves or fire places with long flues running somewhat horizontally under the bed.

In the southern states, the plants can easily be sown early enough for garden use by using coldframes covered with cloth or glass. (Fig. 85.) These are located in sunny places protected from the cold, strong winds. In middle latitudes manure heated beds are most commonly used.

Transplanting to the Garden.- The plants are usually removed from the propagation beds by first watering them well and then

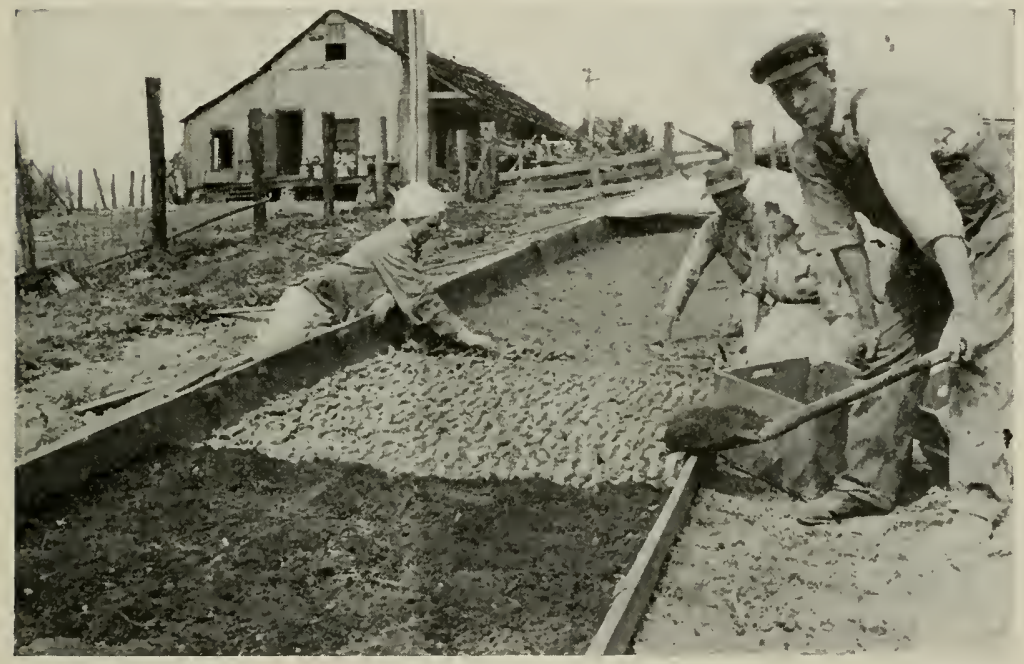

FIG. 85.-Bedding sweet potatoes in frames to be covered with cloth. The roots are covered with one or two inches of soil. (Illinois Station.)

pulling by hand. (Fig. 86.) They are then sorted if necessary and the roots are put in buckets containing muddy water.

After the soil has been well prepared by deep plowing and pulverizing, the plants are dropped in open furrows about two feet apart.

It is common to throw up a slight ridge by throwing two furrows of soil together and then open a furrow on this ridge by using a shovel plow.

After the plants are dropped in place, the planting is completed by hand. Fine soil is drawn around the roots and stem, leaving 
about one half the stem projecting from the ground. In dry weather watering at the time of setting is very helpful. Barrels of water may be hauled and a pint of water may be poured on each plant and a little dry soil used to cover over the wet soil to form a mulch.

Transplanting machines (Fig. 87) are used in many large fields. These machines are operated by two or three persons. A furrow

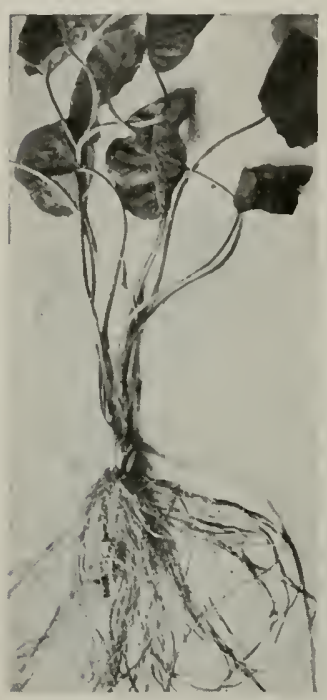

Fig. 86. - In sweet potato beds, thin the plants often to produce short stems and many leaves as here shown.

is opened, the plant set and watered, and the dry soil filled over the watering all at one time.

Cultivation.-The sweet potato requires a very loose open soil. To attain this, deep tillage is practiced at least during the early part of the growth. Several cultivations are necessary, and one hoeing to remove any weeds is best.

At the time of the last cultivation the soil is thrown toward the plants to leave it in slight ridges. As the potato vines begin to run, cultivation will be necessary. The ground is well shaded by the vines and is less likely to bake.

Enemies and Their Control.-Probably the worst enemy of the sweet potato is the stem-rot. This is sometimes very serious and affects much of the crop. Recent experiments indicate that the best methods of combatting the disease is to select seed potatoes from a field free from the disease. Some immunity to the disease is supposed to exist.

The propagation beds should be watched closely and if any of the disease shows there none of the plants should be set in the garden.

Harvesting Sweet Potatoes. - The crop is very sensitive to fall frost. With the first heavy frost which lills the vines, harvesting should begin. The vines may be cut away immediately after the frost and the potatoes may be then dug if the weather is favorable and the soil is in good condition.

In bright weather the potatoes may be left on the surface of the ground after digging and allowed to dry before hauling them into storage. Methods of digging are similar to those used for the Irish potato. (1) By hand tools. (2) By plows. (3) By machine diggers. 
Storage of Sweet Potatoes.-The principles of storage for sweet potatoes are very different from those for Irish potatoes. The roots should be put in the sun or in a warm room to thoroughly dry the surface before they are put away for storage.

Storehouses are sometimes built where the crates of potatoes are placed in narrow tiers from floor to ceiling. Somewhere in the room a stove is used to dry the air thoroughly. If there is free circulation of air through the crates, the potatoes will soon be dry enough to avoid rotting. The same room may be used to keep the potatoes during the cold weather providing they are well insulated from the outside cold.

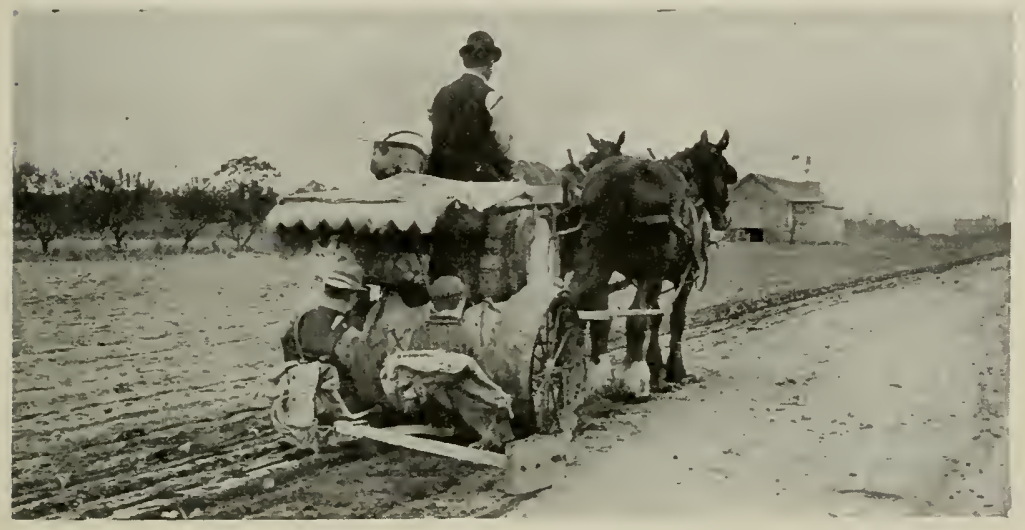

Fig. 87.-A transplanting machine for cabbage, tomato, tobacco, cauliflower, sweet potato and others grown on a large scale. The furrow is opened, the boys place the plants, some water is dropped from the barrel, and the soil is pressed against the roots. (U.S.D.A.)

Conditions accompanying the world war have taught many people to thoroughly dry sweet potatoes instead of storing them in the usual ways. In the dry condition they may be kept several months and there is no waste from rotting.

\section{EXERCISES, SURVEYS, AND PROJECTS}

1. Potatoes.-A home project in the improvement of seed potatoes should be started. Use the hill-row system. That is, select seed entirely from the best hills at harvest time. Plant the potatoes from each hill separately. Indicate these by numbers on stakes and on a record. Compare the yield of each and again select the best hills for seed.

2. Potatoes of several different varieties may be grown in comparison with each other. Compare them as to yield and judge each by the score card. 
3. Fertilizing potatoes with different kinds and amounts of commereial fertilizer is a good feature in a projeet of growing sweet potatoes or Irish potatoes. Vary the proportions of nitrogen, phosphate, and potash.

4. Storage of Potatoes. - Find what methods of storing Irish potatoes for the winter are in use in the region. Compare these as to results, expense, and labor.

5. Calculate the losses during storage by the best methods and determine the profits resulting from storage of potatoes for home use and for winter or spring inarket.

6. The storage of sweet potatoes may also be studied as suggested for Irish potatoes in 4 and 5 .

7. Seed potatoes.-Compare these two plans for your region: (1) Saving Irish potatoes for seed or (2) purchasing those shipped from another region at planting time. Which of these methods do you find in more eommon practice?

8. Growing Sweet Potato Plants. - Make a comparative study of the methods practiced in your region, of growing sweet potato plants. Include time and method of bedding, heating, sterilizing, watering, ete.

9. Planting. - If a machine planter for Irish potatoes is in use in the neighborhood, study the rate of planting, saving, cost, and profit as compared with the hand methods. How large would the field need to be to warrant the use of a machine planter?

10. Make a similar study regarding the use of a transplanting machine for sweet potatoes.

11. Methods of Cultivation.-Compare the level eulture with slightly ridged and highly ridged rows for (1) Irish potatoes, (2) sweet potatoes. These may be home projeets.

12. Compare shallow cultivation with deep cultivation for either sweet or Irish potatoes. Cultivate a number of rows by each method. Have the plots alike in other respects.

13. Treating for Scab.-Plant some seed potatoes infested with scab without treating them to prevent the disease. Near these put others that have been treated as direeted. Compare results in the crop.

14. The dusting and spraying methods of fighting potato beetles should be eompared in the same garden. Note the difference if any in control of the beetles, cost, labor, effeet on plants, etc.

15. The value of spraying with Bordeaux mixture against late blight may be earefully tried by thoroughly spraying one plot with this mixture (eombined with poison for beetles) and leaving another plot untreated with Bordeaux mixture. In other matters the two plots must be treated alike. The number of sprayings with Bordeauxımixture necessary to control the blight disease may be tested at the same time.

\section{QUESTIONS}

1. What can you say of the origin of Irish potatoes and of their name.

2. What are the best types of soil for this crop?

3. Give important points in fertilizing Irish potatoes.

4. Describe the preparation of soil for a potato erop.

5 . What varieties of potatoes are used in your section for the early and late erops?

6. What ean you say of the production and sources of seed potatoes for different sections?

7. Give directions for eutting potatoes for planting.

8. How are they treated to prevent scab?

9. Give method of sprouting them.

10. What are the advantages of this? 
11. Discuss methods and rate of planting.

12. Give directions for best cultivation.

13. What spraying is usually necessary?

14. What are the advantages of using a combined spray material?

15. Discuss methods of harvesting.

16. How may Irish potatoes be stored for winter use?

17. Contrast the storage of sweet potatoes with that for Irish potatoes.

18. Discuss soils and fertilizers for sweet potatoes.

19. Describe the construction and management of seed beds for starting sweet potato plants.

20. What are the chief methods of transplanting to the main field?

21. How should the crop be cultivated?

22. Discuss the time and methods of harvesting.

References-U. S. Farmer's Bulletins: 324, Sweet Potatoes; 533, Seed Potatoes, How to Produce Them; 544, Potato-Tuber Diseases; 714, Sweet Potato Diseases; 753, Commercial Handling of Potatoes; 847, Potato Storage and Storage Houses; 868, Increasing the Potato Crop by Spraying; 970, Sweet Potato Storage. 


\section{CHAPTER XIV}

\section{'SUGGESTIONS FOR GARDEN WORK BY MONTHS FOR NORTHERN STATES}

IT may be helpful to beginners as well as to others to arrange a number of suggestions regarding the eare of the home garden and home grounds in the form of a monthly calendar. This may as well begin with January as with any other month.

The calendar for northern states may differ materially from that for southern states. The latitude to be considered here is about that of New York, Chicago and westward.

January.-Look over the supply of stored seeds and see that they are not being ruined by mice or weevils. Make plans for the spring planting and write for seed catalogues.

Examine the flower pits and the vegetable pits and see that the winter weather is not injuring anything. A little extra covering may be necessary.

Hardy plants stored in coldframes should be examined to see that drainage is still good and that no harm is coming to the plants. Protect all places where wind is finding its way into the frames. Bank up with a little more manure or soil for extra protection.

Watch the storage cellar and see that no injury is done by cold weather.

See that plenty of manure is applied to the rhubarb and asparagus rows if this has been neglected in the fall.

Indoor plants may be propagated at this season of the year. Make leaf cuttings and green-wood cuttings and start them in boxes of clean moist sand. Bulbs may be potted early in January and put in cold places to start their roots slowly.

February.-Make all preparations for an early hotbed. See that the frame is in repair and the sash in good condition. Plans should be made for good horse manure at the time it is needed. Examine garden tools and implements and see that the metal parts are well oiled or covered with wagon grease to prevent damage from rust.

Test seeds. Order the spring supply of seeds.

The hotbeds should be started at least by the end of the month. Plant in them seeds of cabbage, cauliflower, beets, carrots, parsley, 146 
onions, lettuce, spinach, and radishes. Mushrooms may be started in the cellar during February.

If rhubarb roots were dug for forcing in the fall, they should be pushed along during January and February. Place them in a warm corner in the cellar and water them well. Strong succulent shoots will be very palatable now.

Hardy annual flowers and others may be started, such as pansies, dahlia seeds, gaillardia, China aster, cobea, and canna.

March.-Watch for a chance to prepare the soil in the garden this month. Many hardy plants may be started, such as onion sets, lettuce, radishes, hardy cabbage, potatoes, spinach, and peas if the weather proves to be favorable. Prepare the garden in every way possible. Think of all the things that have to be done and get ready for the spring rush. Drain the wet places in the garden, add manure here and there and add lime and wood ashes where needed. Have sand ready for starting nursery seeds.

Make extra plantings in the hotbeds. Give the hotbed close attention and avoid burning out the plants. The weather is very changeable and much attention is required.

The window boxes should be filled this month with transplanted plants such as tomatoes, cabbage, cauliflower, peppers and others. Perennial plants, such as asparagus, rhubarb and horse-radish may be transplanted this month.

This is a good month in which to start a wild-flower garden. Many plants begin to show in the woods and can be taken up before they make too much growth. Ferns and other plants can be placed on the north side of buildings or in other shaded spots where other plants would not thrive.

Bulbs of narcissus, tulips, and others started in January or February may be planted out this month. Sow hardy annual flowers out of doors. Plant pansies, sweet peas, and gladiolus seed.

April.-This may be a good month for the general plowing and harrowing of the garden. Make additional plantings of the hardy vegetables mentioned last month. Plants of head lettuce, cabbage, cauliflower, and spinach may be transplanted to the open garden when the weather is favorable. The hotbed can be emptied enough to start seeds of cucumbers, squash, and melons in berry boxes or paper boxes for transplanting in May. Vines, trees and shrubs should be planted early this month if not before. It is also a good time for transplanting evergreens.

The surplus products should be marketed if possible. Sell 
surplus plants from hotbeds, herbaceous plants from the flower garden, vines, trees, shrubs, and harvests of asparagus, rhubarb and winter onions this month (Fig. 88).

The permanent flower garden should be given much attention. Divicle the large clumps of such peremial plants as phlox, larkspur, golden glow, and others. Trim out the dead tops of the old plants and give the bed a good cleaning up. After spading all bare spots, apply some manure as a mulch to keep the ground mellow and enrich it.

May.-Probably the last spring frost will oceur during this month. After that almost any of the vegetables mav be risked in

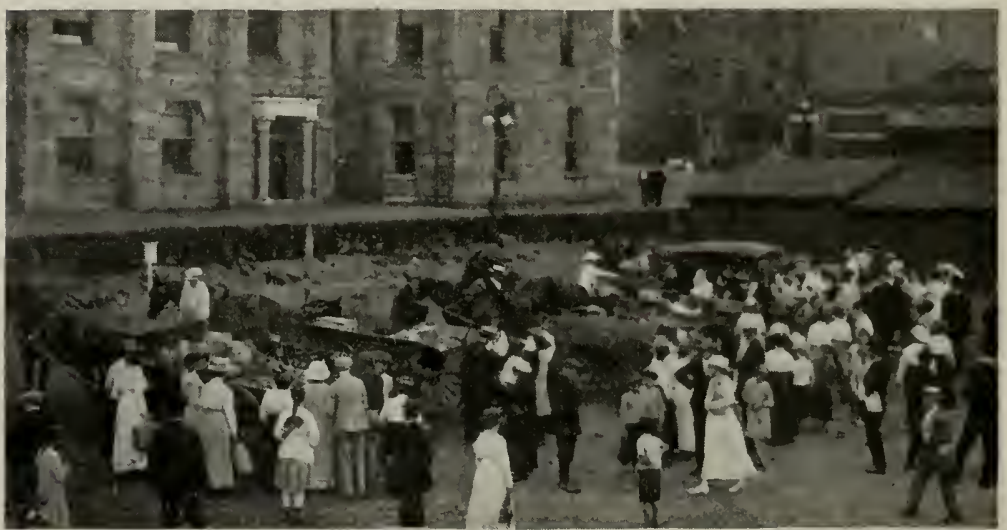

Fic. 88. - The surplus produets from the home garden and orchard should be marketed frequently directly to consumers in the town market. First day of Holyoke market. Compare with verify. (Massachusetts Agricultural College.)

the open garden. Do not plant many hot weather crops until the soil is warm. Additional plantings should be made of such hardy erops as beets, peas, onions, lettuce, radish, and transplant more cauliflower, cabbage, and kohl-rabi to the open garden early in the month.

The last of May is soon enough to risk tomatoes, peppers, corn, and beans in the open garden.

Apply nitrate of soda or other nitrogenous fertilizer to the asparagus bed early in the month. Set forcing frames with glass tops over clumps of asparagus and rhubarb if they have not begum growth before the first of May. Fight eut-worms that are working abundantly in May. A paper collar around all transplanted plants 
will keep them away. Watch for strong broods of plant-lice and spray with kerosene emulsion or with nicotine sulfate.

Spring flowering shrubs may be pruned after the blossoming season is over. The sod on the lawn should be well rolled and the grass should be mowed as early as it is high enough. House plants may be removed to the open garden late this month and plunged in the ground or transplanted. It may be necessary to cover them if there is danger of frost.

June.-All the hot weather crops, such as tomatoes, peppers, okra, cucumber, melons, pumpkin, squash, and all kinds of beans should be out this month. Make successive plantings every two weeks of snap beans, corn, and other vegetables which should be fresh for the table later in the summer. Work the garden thoroughly to prevent weeds and to retain soil moisture. Provide stakes for the early tomatoes, prune them, and tie them up well.

Spray potatoes with poison and Bordeaux mixture. This combined spray should also be applied to tomatoes and perhaps to the beans. Cucumbers and other vine crops may be sprayed likewise. Cover the joints of the vine crops with soil about two feet from the central roots so they will make extra rootings. This keeps them from suffering from the vine borers. Provide stakes for beans, tomatoes, and other plants requiring support.

After the last cuttings of rhubarb and asparagus, make heavy applications of barnyard manure to start the growth well for next year. Spray the currant bushes if they are attacked with currant worms. Use Paris green or arsenate of lead. Watch for insect attacks in trees and shrubs everywhere. Fruit trees should be given their second spraying with Bordeaux mixture and arsenate of lead to prevent scab and rot.

Carnations and chrysanthemums that have been started in-doors may be transplanted early in June to the open garden for their summer growth. Stake the tallest flowering plants to prevent them being broken by the wind.

Tender annual flowers and also perennials may be started from seed this month. Annuals started in the coldframes, hotbeds, or window boxes should be transplanted to the open garden in June.

The transplanting of potted plants, such as coleus, geraniums and many others should be attended to early in June if not before.

July.- Insect pests must be watehed closely. See if the melons, squash and cucumbers are free from their attacks: Remember to plant successions of wax beans, sweet corn, beets, carrots, and 
others. This is a good month to set out celery plants for the fall crop.

July is apt to be a dry month and watering must be attended to. Flood the ground with water rather than sprinkle it on top. Flower beds should have their share of water in dry weather.

Keep the garden growing by frequent cultivation. Allow no weeds to take moisture and plant food which should go to the garden crops. (Fig. 89.)

Keep the garden walks free from grass and weeds. (Fig. 90.)

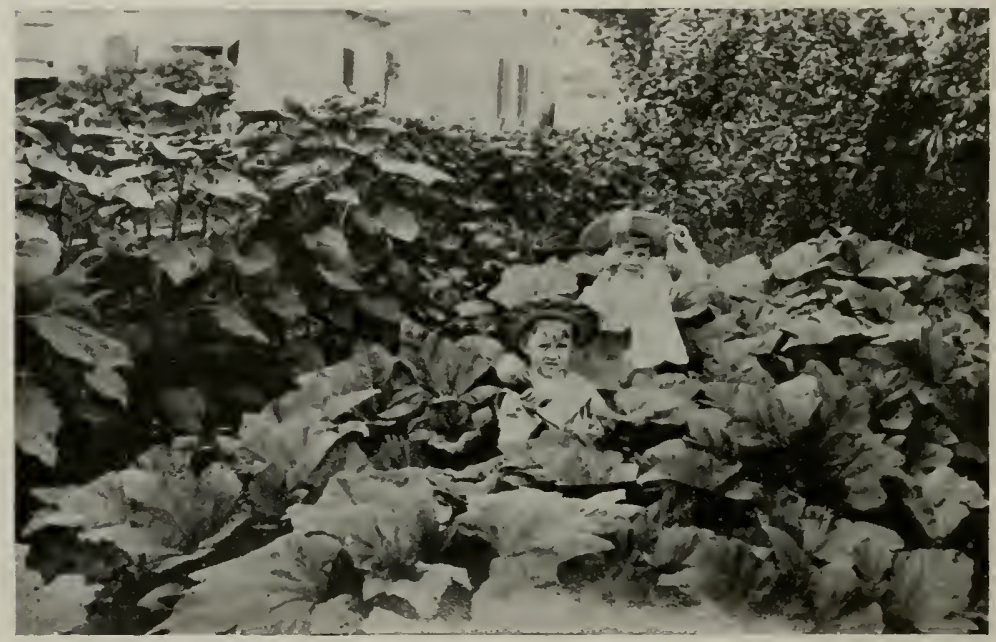

FIG. 89.-After the squash vines begin to cover the ground there is little use of trying to cultivate the soil. Pull out any tall weeds by hand and the small weeds will be smothered by the vines. (U,S.D.A.)

August.-If any celery was planted in June it may be ready to begin blanching now. The early varieties should soon be ready for the table. See "Methods" under the head of "Celery Culture."

Seed onions planted in early spring will probably be ready to harvest this month. When the tops begin to die the roots may be pulled or loosened. They may be left on top of the soil to dry for several days if the weather is favorable. Handle them carefully as you would eggs. Usually trays are good for this purpose. After they have thoroughly dried they are ready for long storage.

Watch the cauliflower patch and tie up the heads that are ready for blanching. Try laying some broad leaves over the heads instead of tying up the leaves. You may prefer the tying method. 
If you wish to force a few of the tomatoes to ripen earlier than the rest pinch off all blossoms after the first of August. Let only those that have set fruit remain on the plant. When tomatoes have reached their full growth they may be allowed to ripen in the shade instead of on the plants. Try a few this way.

Remember you can plant fall crops this month. Quick growing vegetables such as peas, early cauliflower, spinach, head lettuce, radishes, kale, turnips, beets, and others may be planted early in August. If the fall proves to be short or a dry season, a number of these will not pay well but they are worth trying.

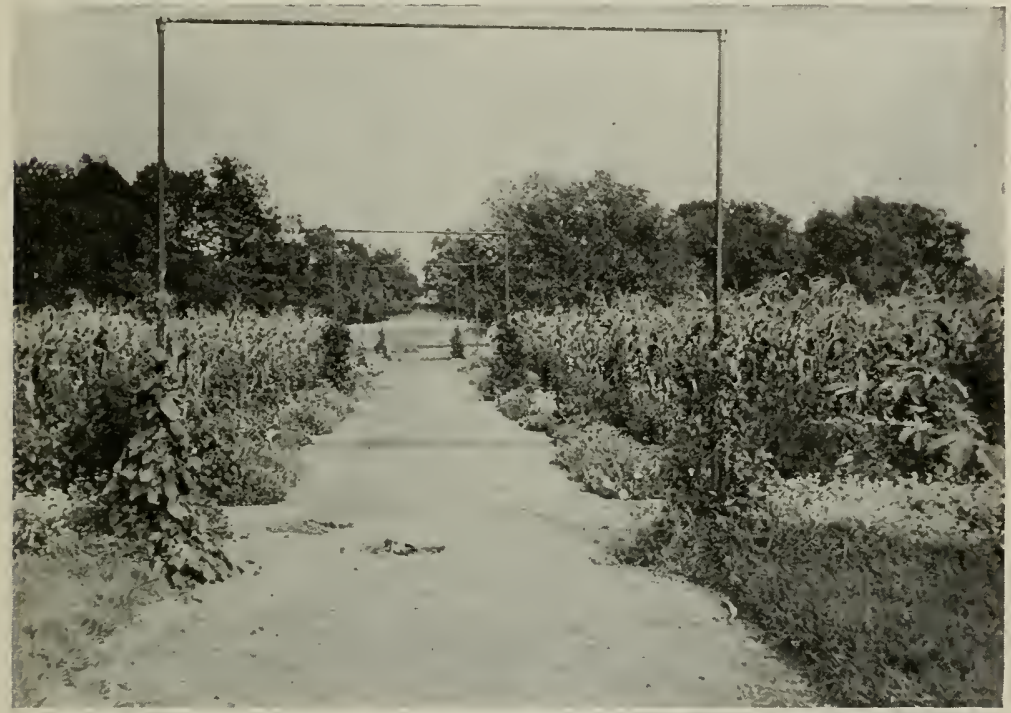

FIg. 90.-A school garden with a wide central walk showing arches for vines. (Rhode Island Station.)

September.-Remember this is likely to be the first frost month. Watch the vegetable garden and remove all tender vegetables before they are killed by the frost. Some vines may be allowed to die from frost and the crop harvested later. This is true of squash. pumpkin and sweet potatoes.

Save some tomatoes by pulling up the vines laden with green fruit and hanging them in a shed or barn. The fruit will continue to ripen for several weeks. Green fruits may be covered and saved for future ripening. There are many uses of green 
tomatoes. Try making some "mince meat" with them. A number of fall crops may be started early in September such as head lettuce, spinach, kale, winter onions, radishes, and others. Other short season varieties of garlen peas may be started september first.

Hotbeds and coldframes should now be put in order for use a little later. Start crops in coldframes by the end of this month.

While celery is going through the process of blanching, its growth should continue. The plumes project above the soil and if enough water is added the growth will make the crop much more tender.

September is probably the best month for fall exhibitions of garden products (Fig. 91). This should be planned early so that all may be preparing for it during the summer. Prizes may be solicited and awarded at the exhibition.

This is a good month for the sowing of grass on the lawns. If it does not germinate immediately, it will probably make enough growth before freezing weather to stand the winter. A little mulch may be necessary later on.

Look over the hardy border of wild flowers. Do such transplanting as is necessary to prevent crowding and to improve the stand. This is a good month to search the woods for more perennial roots for this border.

There are many perennials in the flower garden that need thinning and the fall is a good time for this work. Now they can be identified from the stems that remain standing. Look over the columbines, golden glow, perennial phlox, larkspur, dahlia and others. Do all planting of seeds of perennials which are recommended for fall sowing.

October.-The late crop of cabbage will need attention. Many of the heads tend to burst. To prevent this, bend over the tops to thoroughly check their growth. The late cauliflower heads may continue blanching if the heads are tied up. They stand the fall frosts well. On frosty nights protect the tender vegetables that still remain in the garden. The coldframes and hotberls should be kept full with growing crops. Start more winter vegetables late in October.

The asparagus bed should have its fall attention now. Mow off the stems, and plow the whole area with the turning plow. Apply six inches of manure over the rows. This is not a bad time to start new beds from seed sown last spring. Rhubarb may also be transplanted now. 

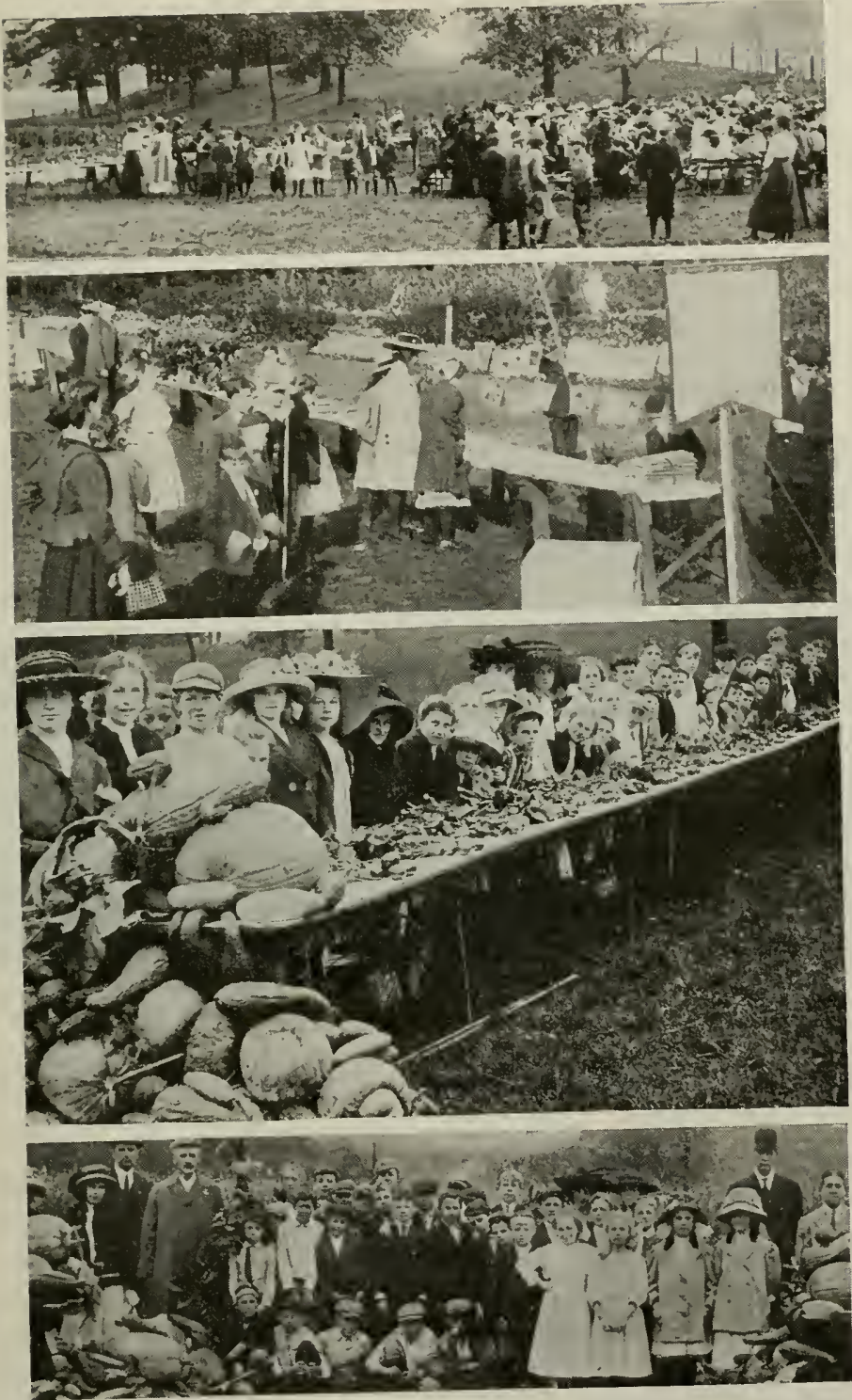

FIG. 91.- Scenes on exhibition days, out of doors. Garden products, and school work, are often combined. Prizes are awarded for exhibits and best gardens. The prizes may conare often combined. books, gold, silver and bronze pins and cash. (Rhode Island State College Extension Department.) 
Beds of winter onions may be set early in October. Give them a little protection with straw or leaves as the winter advances.

The sweet potato crop should be thoroughly dried by this month for storage through the winter. Parsley may be taken from the garden to continue its growth in coldframes or window boxes.

Many of the garden flowers should be taken in before they are killed by frost. House pots and winciow boxes should be filled with carnations, chrysanthemums, and others that have spent the summer out of doors. Plant lily-of-the-valley, delphinium, hollyhock, iris and other hardy perennials. Ferns from the woods

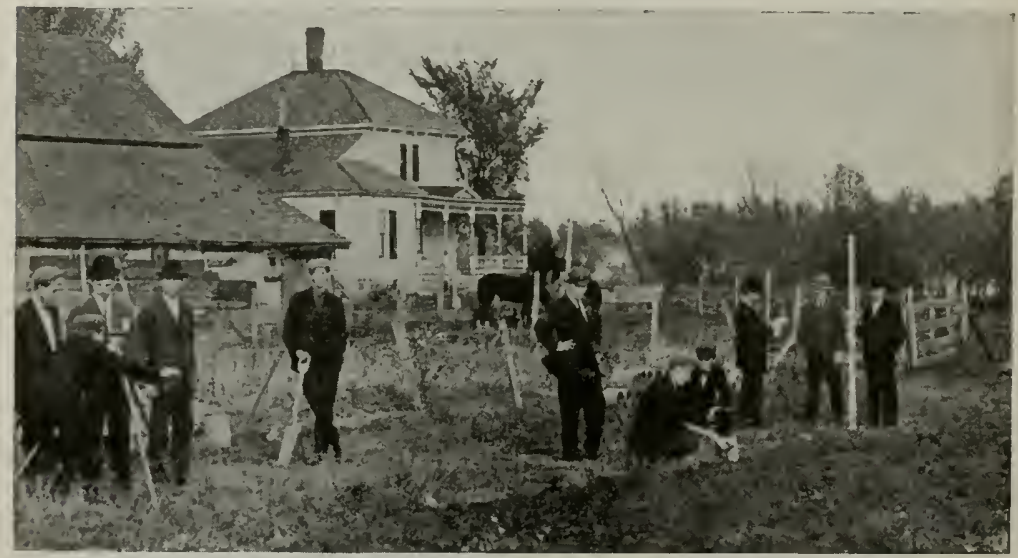

FIG. 92.-Students in a Minnesota high school doing the engineering work preliminary to tile drainage. (Minnesota Station).

may be identified now and may be transplanted later but before the ground freezes. Label each kind and then remove the top entirely.

Fall is the best season for draining land (Fig. 92). Begin the work early enough to complete it before the rainy season begins.

November.-This is the best month for harvesting the fall crop of potatoes. A deep pit or vegetable cellar that does not freeze will keep them well. Bury potatoes, carrots and turnips after they have been piled in heaps on the ground. A foot of soil thrown over them and a heavy covering of straw or corn stalks may save them nicely. Parsnips and salsify may be kept in the same way or left in the garden rows to freeze. Their flavor is 
improved by freezing but they are less accessible while the ground is frozen. The horse-radish may be harvested this month. Select the small fingerlings for planting the next bed. The large roots may be grated and put in glass cans or bottles with a little vinegar.

If the rhubarb and asparagus beds have not had their fall coating of manure, attend to it this month.

Celery should be taken in just before the ground freezes. It can be transplanted to shallow layers of soil in the bottom of crates and packed tightly. These crates are set in cold cellars and blanching will continue if the soil is wet without wetting the stems. Rubbish from the garden including vines, stems, and other waste should be added to the compost heap. A layer of sod, then a layer of manure, repeated, and the layers kept flat will make an excellent compost. Prepare it this month if possible. By spring it will be rotted enough to make a good ground soil for enriching the flower beds perennial shrubs and other places.

Fall plowing should be done before the ground freezes. Heavy portions of the garden may thus be exposed to the winter frost and much improved for garden use. Any places that need unclerdrainage should be attended to in the fall. The soil is drier now than in the spring. Drainage work is therefore much easier.

Do not leave dirt on the implements and tools. Clean them up well. Wash them if necessary to get them rlean. Rub wagon grease on the metal parts. A coat of paint on the wooden parts will extend their life perhaps several years. Store them all away for use next spring.

It is well to throw some litter over among all the perennials such as tuberoses, pansies and others. Manure over the beds of peonies, larkspur, and around the hardy roses and the climbing vines will protect the roots and add much nourishment for next year's growth.

Bulbs that are to remain out all winter may be mulched with manure or lighter material about the time the ground begins to freeze.

Did you ever plant sweet peas in the fall? Prepare a trench several feet long, make the soil very rich and plant the seeds about six inches deep. If this is done just before the ground freezes, no growth will take place until very early spring. They will be up ahead of spring-planted seeds and will be stronger because of the early start.

Transplant some beáutiful young evergreens into pots for the 
winter window. Also transplant cinerarias started from seed last summer.

For Christmas blooms, start some lilies-of-the-valley, Roman and Dutch hyacinths, and Chinese lilies. Pot the bulbs and control the temperature to suit the time you have left for forcing them into blossom. If they are kept cold several weeks before they are moved into a warm room they will be stronger but more time will be required to bring them into bloom. Give the carnations, chrysanthemums and other indoor plants close attention, loosening the soil at the top of the pots. Keep them well watered, guarding them as to temperature.

December.-Let some of the turnips be set in damp soil in the cellar to form succulent sprouts for use in salacls. They will be crisp as celery. Try starting some mushrooms in half-rotted manure under a bench in the cellar. Throw the spawn on the soil and water with warm water. The rotting of the manure will also help keep the soil warm and start the plants. If there should be enough cellar room, try keeping fresh plants for table use as they are needed. These may be growing in the south windlow in boxes of well watered soil. In this way we may have fresh grown onions, kale, cabbage, parsnips, carrots, salsify, rutabaga leaves, spinach, lettuce, and radishes. Do not try all of them at once. A few days may freshen up the plants for table use.

When the ground has frozen, out-door crops, such as winter onions, kale, spinach, and others should have an abundance of litter thrown over and among the plants.

If you are interested in forcing winter growth, the hotbed may be kept going and filled with many choice vegetables through the winter season. A deep coldframe with glass covering will serve the purpose for a number of the hardy plants above suggested for the cellar window.

Give close attention to the needs of the plants growing in window boxes, in the coldframes and hotbeds. Some liquid manure or solutions of such fertilizer as nitrate of sorla may be used when watering. For the plants which require less sunlight, provide a north window. Much sun is needed for geraniums, chrysanthemums, roses and some others. On the other hand, ferns, palms, dracæenas, vincas, begonias, and English ivy can endure more shade. 


\section{CHAPTER XV}

\section{SUGGESTIONS FOR GARDEN WORK BY MONTHS IN SOUTHERN STATES}

RuLEs for planting, harvesting, and other garden operations, are not so exact for the southern states because more time for each operation may be allowed. The seasons are longer except the winter season. More choice may be exercised in the matter of time for starting any of the crops.

For the suggestions given here the latitude of thirty-three to thirty-four degrees is to be kept in mind. For regions farther north or south the dates may be varied to suit the location. In regions south of the frost line there is really no true winter. Here many of the plants usually started in the spring farther north are planted in December. This makes them ready for market and table use before spring gardens farther north are started.

In many sections of the southern states, it is easy to grow vegetables out of their normal season. This may be done in the home garden as well as in the market garden. The surplus from the home garden may then be marketed with more profit.

\section{JANUARY}

Vegetables. - Sweet potatoes are sometimes bedded in coldframes or hotbeds by the last of January. In portions of the Gulf states they will be ready for the open garden in March or April. Make plans for the whole vegetable garden early in January. Let the garden work of all kinds begin as the season advances but never work without a plan. Remember the advantages of planting in long rows (Fig. 93) and make your plans that way. Get the soil in good condition before planting. If it is too wet, the use of the harrow a day or two in advance will cause it to dry out. Put a forcing box covered with glass on a few clumps of asparagus and rhubarb. The heat gathered from the sun may start them extra early. If the ground is not frozen much transplanting of perennials may take place this month. Set beds of rhubarb and asparagus. Some manure may be added to the asparagus beds with profit. The long sprouts coming through the thick cover will be stronger and whiter. 
If the weather is favorable risk a few of the less hardy garden crops out of doors. Garden pea seeds, onion seeds, parsnips, head lettuce plants, radish seeds, spinach seeds and plants, and turnip seeds and cabbage plants may all be tried out-doors near the last of January if the weather is at all favorable. Prepare the soil for the spring garden as soon as it is dry enough. The harrow will help warm it up and dry it out for the plowing.

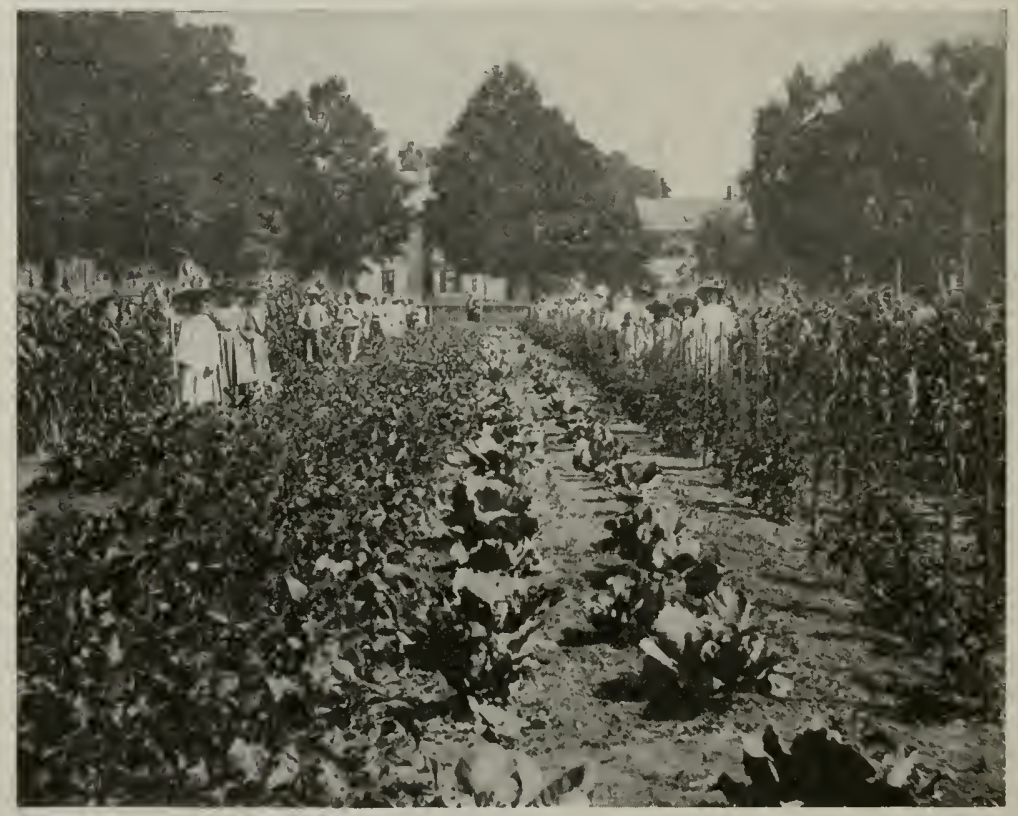

FIG. 93.-The long row plan used here, saves hand labor and economizes'space. Broad hats make the graden work more endurable, when the sun is hot. (R. I. State College, Ext. Dept.)

Flowers.-The house plants are the important part of the flower garden at this season. Give them all necessary care. Remove the dead parts. Water the plants well. Most of them will respond to watering with liquid manure. Soak some horse manure or cow manure in a bucket of water. Use the liquid on the plants about once a week. Keep off all insects. The red spider and plant lice may be noticed if you look closely. Wash the leaves with strong soap water for lice, spider, and scale, or use other remedies for the special insects. 
If the soil can be worked during this month, plant sweet peas where they will have plenty of sun. Make a trench and add some barnyard manure. Cover the seed about six inches deep. They will begin sprouting as soon as mild weather comes. Start dahlias of some of the new varieties or new colors from seed planted this month. They may be started in hotbeds or coldframes and transplanted when danger of spring frost is over. Such plants would blossom the same year. Try perennial phlox, pansies, violets and other hardy perennials in the same way.

A number of popular hardy flowers may be started in beds protected from the cold wind and exposed to the warm sun. Try poppy, candytuft, hollyhock, larkspur, fox glove, snapdragon and allyssum. If these are started in cold frames they will grow better and will blossom in late spring and early summer.

\section{FEBRUARY}

Vegetables.-Use the hotbed to start tender vegetables from seed. It is not too early to plant tomatces, eggplant, peppers, and others. The window boxes may be used instead of the hotbed for starting the seeds. Transplant them later to coldframes. Sweet potatoes may be bedded some time this month according to latitude. Irish potatoes should be planted in the open garden. Use an early variety and you may expect the harvest by the last of May or early June. Use Irish Cobbler, Early Triumph, or Early Rose.

Rhubarb and asparagus may be transplanted early this month. Use very rich deep soil with plenty of manure. Some fingerling roots of horse radish should be planted this month if not before. The perennial garden herbs may be started this month from roots or seeds. Sage, thyme and summer savory are worth having in the garden.

Plant small quantities of the earliest hardy garden vegetables some time in February. These include early garden peas, cabbage plants, cauliflower plants, parsnips, salsify, kohl-rabi, beets, radish and turnips. Celery seed should be started in the coldframe ready to set out later.

If you wish to force some melons and cucumbers they may be started in berry boxes or pasteboard boxes in the hotbed the last of February. They do not transplant easily unless the dirt is kept with the roots as in the boxes.

The area to be used for the late garden planting should be 
thoroughly plowed and harrowed. Keep the ground well stirred every week or two.

Flowers.-Make your plans for the flower beds for the season. Some embellishment of the home garden by the use of flowers along with vegetables is sometimes planned.

In the coldframes or hotbeds start seeds of a number of flowers such as petunias, pyrethrum, cyclamen, scarlet sage, Chinese primrose, verbenas, lobelias, heliotropes, and asters. Do not let the seedlings crowd too much. Several transplantings may be advisable.

Start in coldframes eannas, dahlias, tuberoses, gladiolus, and caladiums. These should be ready to transplant to the open beds as soon as danger of frost is over.

Hardy flowers started this month in the hotbeds may be transplanted to the open garden by the last of February. Pansies that have been covered all winter should be uncovered now. Dig the soil around them and add some fertilizer or manure. Make the cuttings of chrysanthemums and carnations if these have not already been started.

Start cuttings of coleus for bedding plants so they will be of good size for use in the garden after frost is over.

Be sure to plant sweet peas and perennial phlox this month if it was not done earlier.

\section{MARCH}

Vegetables.-Transplant to the open garden the cabbage and cauliflower plants yet remaining in the beds. If the celery plants are large enough they may be set out now. In favorable seasons a few of the tender vegetables such as tomatoes, eggplants, peppers, and sweet potatoes may be set out, with a venture, in the garrden now. Leave most of them until danger of frost is over.

Early in Mareh make arditional plantings of the hardy veget:bles, such as turnips, radish, lettuce, spinach, endive, garden peas, carrots, parsnips, mustard and salsify. More plantings of kohlrabi and Brussels sprouts may be made this month.

Before the ground begins to dry or become crusty the winter onions should be cultivated (Fig. 94).

If the early potatoes are not yet planted, plant Irish Cobblers early this month.

If the ground seems warm and the spring is early, try a few tender vegetables by planting ieeds of sweet corn, snap beans, 
and others. These may be cut by frost and more plantings should not be made until danger of frost is over.

Flowers.-Water the roses, beds of sweet peas, and other flowers that are out of doors. Rake the soil and keep it mellow. Work in some barnyard manure or water with liquid manure. This is the best month for planting many annual flowers such as marigold, nasturtium, petunias, phlox, poppy, cosmos, coxcomb, candytuft, balsam, alyssum, aster and verbenas.

By the last of March you may be able to set out the roots of caladium, canna, dahlia, gladiolus, and other tender bulbs. Put them in beds or borders where they are to remain during the summer. If late cold snaps occur, protect them well with coverings of leaves to avoid damage from frost.

\section{APRIL}

Vegetables.-If the season is not too dry nor too warm make additional plantings of peas, beets, spinach, lettuce, radish and early greens. This should be done early in April.

The tender vegetables may be put out now if danger of frost is over. Plant lima beans,

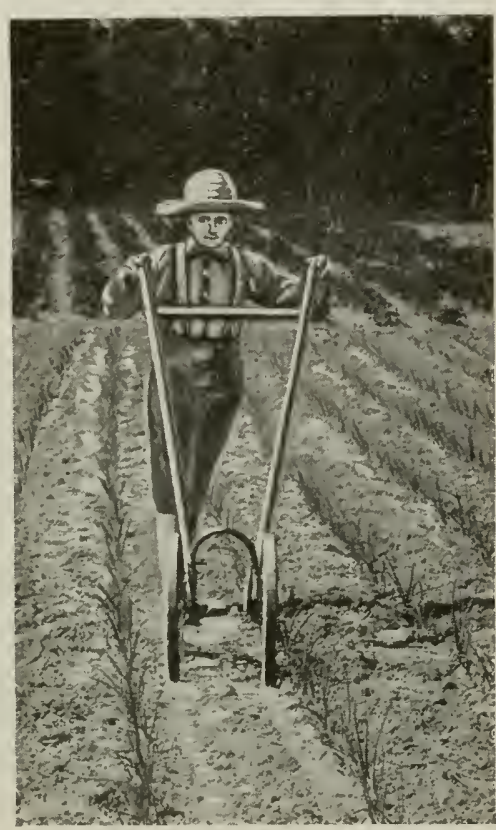

Fig. 94.-Cultivating the winter onions before the moisture escapes. The wheel cultivator makes it possible to grow the rows closer together. (Bateman Mfg. Co.) snap beans, pole beans, black-eye peas, and other tender vegetables. Risk a few tomatoes and when the weather becomes warm make the main plantings in the open garden.

Sweet corn should be planted every two weeks to get a succession of cropping. Country Gentlemen is one of the favored varieties of sweet corn. The latest plantings of the early varieties of cabbage and cauliflower may be set early this month. Late cabbage seed should be planted in beds ready for transplanting in May and June. They should not need protection in the beds but should be where they can be easily watered and cared for. 
Prepare the ground for the main planting of sweet potatoes which may be set late in April or early next month. (Fig. 95).

This is a good month for planting peanuts and other warm weather crops in small quantities. Try a few of the melons and cucumbers out of doors.

Flowers.-Rooted cuttings of chrysanthemums and carnations may be transplanted to the open garden. Put them in rows where they can be easily cultivated during the summer, with wheel hoes or horse cultivators. At least leave room for the garden rake between the rows.

Many of the bed plants such as the tender bulbs that have been

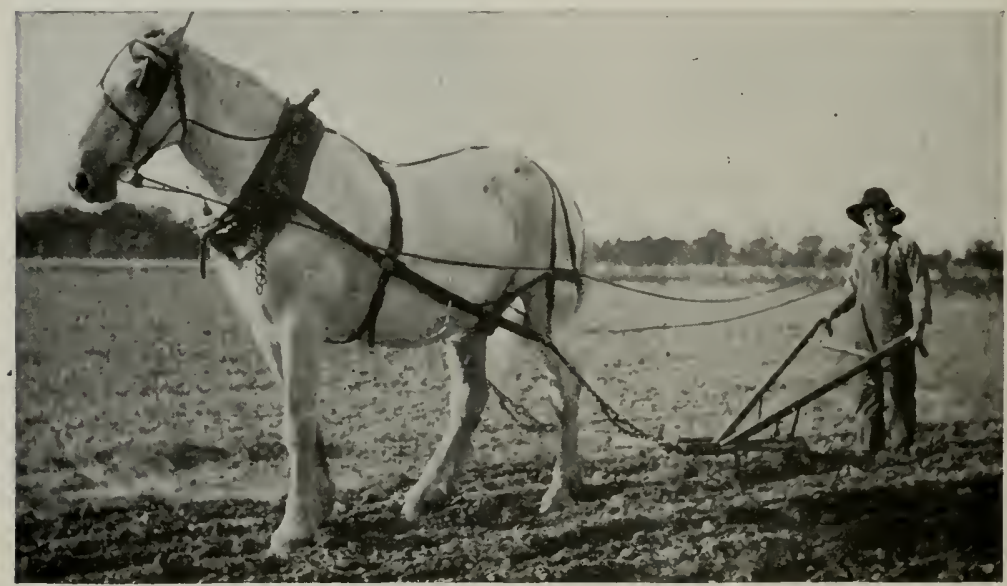

Frg. 95.-Cultivating the ground again before planting the crop. The soil was plowed in very early spring and harrowed frequently until planting time. This saved the moisture, caused weed seeds to sprout and be killed, and warmed the soil ready for the hc me project crop.

started in beds may be transplanted to the open garden this month when the danger of frost is over. Set out the cannas, caladiums, castor beans, dahlias, vincas, coleus, and others.

By the end of the month set out house plants and make the open garden assume its summer dress. Geraniums grown in the window during the winter may be used as bedding plants during the summer.

Plant more seeds of the flowering plants mentioned in the March group. Also start from seeds many of the vines such as morning glory, Japanese bean, moon vine, wild cucumber, gourd, velvet bean, and others. 


\section{MAY}

Vegetables.-Remember to keep up a succession of plantings of lima beans, bush beans, and Kentucky Wonder pole beans. Other hot weather vegetables should be planted now if not before. Cucumbers and melons may be started out of doors from seed. Plant also seeds of squash and watermelon. Remember these vine crops should be kept apart to keep them from crossing. If the pollen is carried from one to another by bees and other insects the flavor will be affected. Use plenty of manure in each place where the seeds are planted. The harvesting of early vegetables may leave vacant places in the garden. Fill these in with the summer crops.

Remember to keep a succession of plantings of corn for roasting ears. Sweet potato plants should be set out early this month.

Seeds of cauliflower, late cabbage, collards, and Brussels sprouts may be planted in the open garden. Put a little lime at each place where the seeds are planted to mark the spots. This will help in the matter of cultivation. Weeds grow so quickly that frequent stirring of the ground is advisable. Use a number of seeds at each place and thin the plants afterwards. Set out all plants from the hotbeds and coldframes that are to make their growth in the open garden through the summer. Eggplants, sweet potatoes and tomatoes should be set in the garden now.

The long season varieties of Irish potatoes may be planted early in May, such as Burbank, Carman No. Three, and Pearl or Peerless.

If you have not started seeds of celery soak the seeds in warm water and plant them now in the coldframe. They may be transplanted in July to the open garden for fall production. If you have large celery plants in the coldframe now they may be transplanted to the open garden for the earliest crop. The garden rake, the wheel hoe or the horse cultivator should be used very frequently through this month as well as later. Keep the soil well stirred. It prevents weeds and saves moisture for the plants.

Flowers.-Plant vines wherever they can be useful in hiding walls, unsightly places, etc. Seeds of all kinds of vines may be planted in the open now.

All of the tender annual flowers may be sown in the open garden this month. This will avoid the necessity of transplanting.

Use the rake around the flowers in all beds and borders. Never allow the soil to become crusty. A fine soil mulch is necessary for 
the best growth. If the weather should be dry at any time, remember to water the flowers abundantly. Vigorous growth now means big shows of flowers later this season. Flood the soil rather than sprinkle it. The water will penetrate to greater depth and the roots will go deeper as the result.

\section{JUNE}

Vegetables.-This month we may plant the late cabbage, rutabaga and collards from seeds in the open garden as suggested last month. Make at least two main plantings of sweet corn.

It may pay to plant a few more seeds of cucumbers, and cantaloupes. These will be bearing fresh crops when the early plantings are nearly dead from bearing heavy crops.

It is not too late to set more sweet potato plants. They will still produce a crop before frost. The same is true of tomatoes.

It is important to keep all weeds out of the garden this month. They rol, the crop of fertility and moisture. Frequent stirring of the soil will keep down the grass which tends to cover all the soil.

Flowers. - If the weather is not too dry or if facilities for watering are available, sow more seeds of asters, nasturtium and zinmias. Keep these well watered and they will blossom in the fall.

Make plans for the winter window boxes now. Pansies started from seed will be ready to transplant to the window boxes in the fall.

Cultivate the carnations, chrysanthemums and other plants which you are growing out of doors for fall and winter blooms. Keep the buds picked off and prevent the plants using their strength for flowering in the summer if you want them to use in-doors later. A little liquid manure will stimulate the growth now.

It pays to look over all the flower beds frequently and trim out the stems that are through flowering. It improves the appearance and saves the strength of the plants instead of ripening seeds.

\section{JULY}

Vegetables.-Early varieties of Irish potatoes such as Irish Cobbler, Green Mountain, and others may be planted in July. They will mature by the time the ground freezes and may be stored for winter use. If you have never grown a late crop of Irish potatoes successfully because of soils being too warm, try the straw mulch method. Plant the seed potatoes two or three inches deep in mellow soil and cover with four to six inches of straw, weeds, marsh hay, or other litter. This tends to keep the soil 
moist and cool and to prevent the growth of weeds. It saves all need of tillage.

Make plans for the late tall garden. Much of the early garden may be harvested, the plants pulled, the space cleared and prepared for the fall garden. (Fig. 96.) Some of the vegetables may be planted now, spinach, curled Scotch kale, Norfolk kale, Chinese and Japanese winter radishes, purple-top white turnips, rutabagas, dwarf Essex rape, English peas, beets, and others.

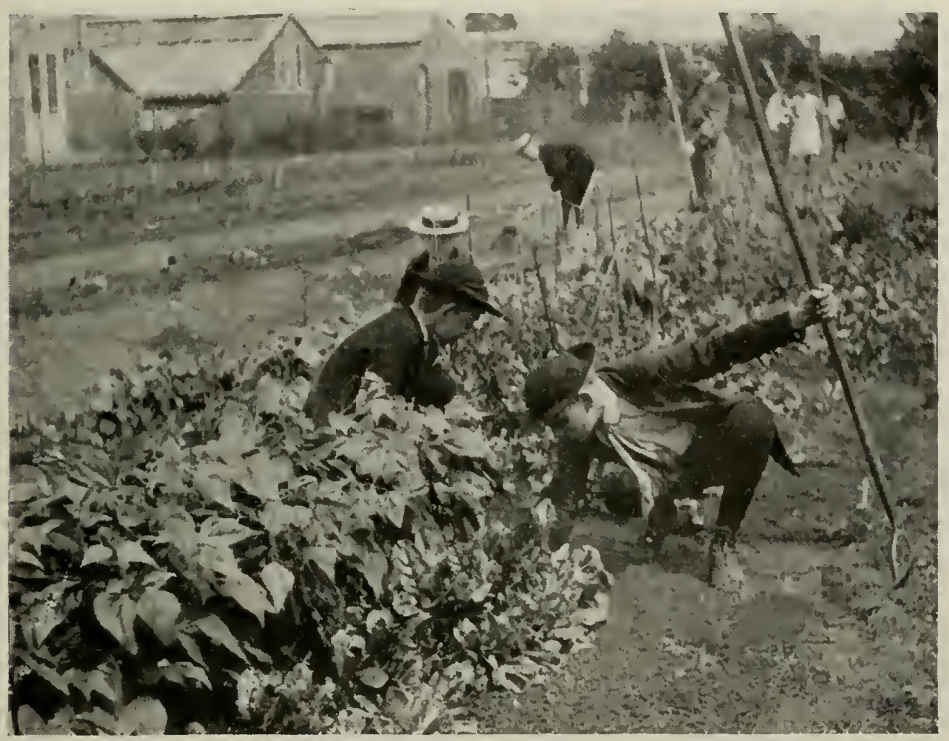

Fig. 96.-Learning the lesson of rotation of crops. Deciding what crops may be cleaned out from the early garden to make more room for the fall crops. (U.S.D.A.)

Late in July start seeds of Boston head lettuce to be transplanted later for fall heading.

This is probably the last month for the planting of snap beans. It is best to use the early varieties at this time. They should make their crop before the fall frost. Early in July plant a few more seeds of cucumber and muskmelon. If these are forced by good culture and water, they should produce a yield before the first fall frost. It is still not too late to plant out seeds of cabbage, cauliflower and other plants of that group. They will continue growth after frost until the ground begins to freeze. This gives them the long fall season for heading. For the fall and winter 
garden plant seeds now of parsnips, salsify, and carrots. Freezing improves the parsnips and salsify, and carrots will endure some freezing.

Did you ever start sweet potatoes by making cuttings from old vines? If not, try it this month. They will grow readily if well watered. They may yet produce a crop before frost.

If the late celery erop has not been transplanted to the open garden, this is a good time to do it. Make the rows about four feet apart and set the plants four to ten inches apart according to the variety.

Look over the whole garden for insect pests and plant diseases. Be sure to prevent damage from these sources. A hand sprayer with a few spray materials may be all that is necessary to save valuable crops.

Flowers.-This is a good month in which to enjoy the blossoms of many of the beds, but remember that work is necessary for future blooming. Keep the plants growing well for the sake of future blooms.

This is a good month to look for flower seeds. Save all kinds in a separate paper or envelope and label them properly. Seeds of cyclamen, primroses, and cineraria may be started in beds where they can be easily protected and cared for. These should be ready to transplant to the window boxes or pits for fall and winter blossoms in-doors.

Do not allow insect pests to defoliate the roses just because they are no longer blooming. Keep plant lice off the nasturtium, hydrangeas, and all other plants. Wash the leaves with soapy water, or spray with kerosene emulsion or nicotine sulfate.

\section{AUGUST}

Vegetables.-August is often one of the driest months. The heat is so intense that the little rainfall does not remain long in the soil. Considerable watering of the garden may be necessary. A good plan is to turn on the water at night and let the ground be thoroughly soaked. The deeper the water penetrates, the more the roots will go down into the soil.

Use the cultivator frequently. Someone has called this irrigation because it saves the moisture in the soil.

Considerable sweet corn should be pulled, cut from the cob and dried for winter use. Many other vegetables may be dried for 
winter. Among them would be lima beans, pole beans, okra pods, peppers, cowpeas, soybeans, and others.

Remember to save seeds for next year's planting. This month you can obtain fine specimens of many garden crops, such as tomatoes, sweet corn, okra, peppers, eggplant, watermelons, cantaloupes, and others.

If plants have not been started for the fall garden, plant them this month. The hardy plants that endure frosts may be planted in August to remain during the long fall season.

Flowers.-Geranium cuttings may be taken from the out-door plants and rooted in moist sand. After they are well rooted put them in rich soil, water them well, and they will be ready for potting at frost time. They should produce a show of blossoms during the winter in the windows.

Seeds of a number of perennials, such as hardy chrysanthemums, pansies, larkspur, columbine and many others may be started in the open garden early in August. It will save about one year's time in waiting for them to bloom. Most of them will show blossoms the next year.

Water the flowers that are to give a fall show, such as chrysanthemums, carnations, scarlet sage, and cannas. Give them special attention in every way to make their growth thrifty and increase their ability to bloom.

\section{SEPTEMBER}

Vegetables-Early this month is the last chance for setting plants of celery, cabbage and cauliflower. Early varieties should be used so they will mature before winter. Plant more seeds of radish, lettuce and onions. Shallot onion sets may be put out this month in time for fall and winter growth. Sow fall green crops, such as turnips, kale, mustard, and dwarf Essex rape. Early in September plant a few seeds of carrots and beets, using early varieties. It is rather too late to make more plantings of beans, corn and very tender crops. As fast as these are harvested remove the plants and sow a cover crop of crimson clover, rye, and vetch to leave through the winter. The place should be thoroughly cultivated before sowing seeds. If barnyard manure is available, a little of that may be applied at this time.

Flowers.-Hardy annual flowers may be sown this month for use in window boxes during the winter. Remember that bulb planting time is coming soon. Make up lists from the garden cata- 
logs. If you did not make plantings of the perennial flowers in August, do it this month. They may make enough growth this fall to blossom next year if you care for them well

This is a good month to transplant peonies, iris, Marlomna lily bulbs, and a number of others that are through blossoming for the year.

Late in September is not too early to start bulbs of hyacinth, chrysanthemums, and narcissus to be used in pots or winter boxes, during the winter. These should make some Christmas blooms.

\section{OCTOBER}

Vegetables.-Be sure to put out your winter onion sets and shallots this month. Sow more seed of winter greens such as spinach, kale, turnips and mustard. If the winter does not come on too soon, there may be time to mature another crop of lettuce and radishes. At least these may be sown in coldframes late in October. A number of crops may be started in coldframes this month. A little protection will keep them growing after severe weather stops the growth out of doors.

Late in October is a good time to transplant rhubarb and asparagus. It is a good time to take up horse-radish and transplant the fingerlings to new places.

If you wish to make use of the hotbed through the winter season, get everything ready. See that the sash is in good condition, repair the frame if necessary and have the manure ready to use late in October or in early November.

The fall show of vegetables and other farm products may be held this month. Select the very best of your products. Help make a good exhibit even if you do not expect to win any prize (Fig. 97).

Flowers.-Look over all the flower beds and select seeds for next year's planting. Put each kind in an envelope or paper and label it, showing the kind, color, etc. Plant more bulbs of hyacinth, tulips and narcissus. These will help form a succession of blooms next spring.

A number of flower clumps may be taken up before frost and put in the window boxes for winter. Some of them may be put in coldframes or flower pits to be held until wanted in the windows later on.

A number of the house plants that were set in the open last spring should be taken up now and repotted. Do not let them be 
killed by frosts if they are tencler. Trim them well, pick off the dead parts and give them the best soil you can find.

After the frost has killed the beds of cannas and caladiums, the mature bulbs should be dug and dried in crates or stored in dry sand in the cellar. They should be kept from freezing during the winter. This is a good month in which to transplant violets, pansies, lily-of-the-valley, tuberoses and many others. The tall flowering stems of many perennial border plants should be re-

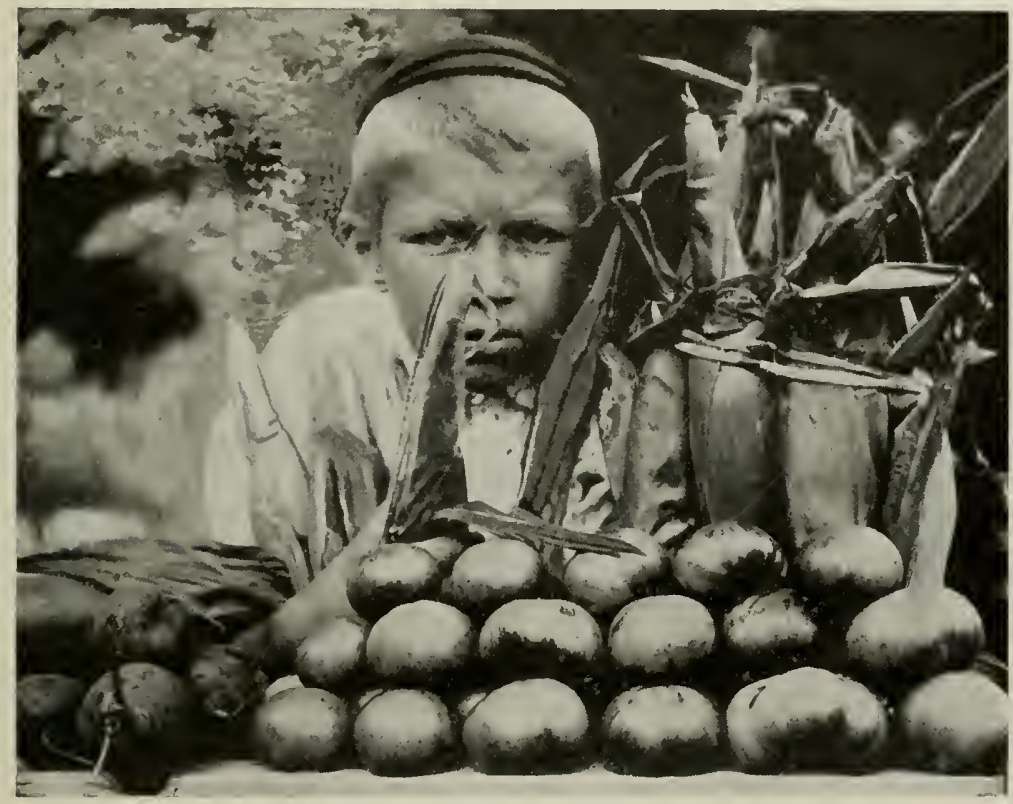

F1G. 97.-Prize winnıng exhibit of vegetables and the producer. This boy knows how to produce good crops, and is skilful in selecting the products for market or for exhibit. (R. I. State College, Ext. Dept.)

moved late in October. If you wish, transplant the roots at this time. Do not let them become too crowded. You can better remember what ones need moving now than you can next spring.

\section{NOVEMBER}

Vegetables.-If frost has not yet killed tender vegetables such as melons, tomatoes, late beans, and others, harvest their crops as rapidly as possible or protect them when the first frost comes. 
Tomato vines loaded with green fruit may be pulled and hung in the shade to ripen their fruits. Green tomatoes may be ripened off the vines if they are fully grown.

Give the asparagus bed good attention this month. Mow the tops and let them be piled on the eompost heap. Give the beds a heavy coat of barnyard manure to help the growth next spring. If this coating is several inches thick the new shoots will come through it and be large, long, well blanched, and tender. If you wish to transplant asparagus roots, this is probably the best time to do it. Rhubarb roots may also be transplanted now. If you are going to grow some cabbage, cauliflower and celery in cold frames, have the plants ready and set them now if possible. They like the cool weather of November and will thrive if the ground does not freeze in the bed.

You may yet plant onion sets but they may need protection of leaves or other litter when the severe winter weather is on. Lettuce, spinach, kale, and similar hardy plants may be stored in the hot bed or coldframe this month. They can be transplanted later to the hotbed as the winter weather becomes severe.

Give the whole garden a general cleaning up after the first heavy frosts are over and the tender plants are through their work. (Fig. 98). Trellis stakes from beans and tomatoes may be tied in bundles and stored for next year. No litter should be burned. Keep it in a compost to rot and make humus for next year. Rye may be sown in November as a winter cover erop on all bare spots in the garden.

Flowers.-Late this month sow seeds of sweet peas to remain dormant until spring. If they are planted six or eight inches deep they are not likely to sprout this fall. Make plantings of hyacinth, nareissus and tulip bulbs. These will not start this fall but will be ready for early spring blooming.

Protect the late flowering plants out of doors on frosty nights. Keep them beautiful out of doors as long as you can.

\section{DECEMBER}

Vegetables.-This is probably the best time to harvest the late garden vegetables such as Irish potatoes, cabbage, cauliflower, the main crop of celery, ete. Store them for winter use. Put cabbage heads with their roots upward in rows two or three layers deep and cover with soil about the time the ground freezes. Cover 
the soil with heary layers of corn stalks to keep the rain from washing off the soil. Transplant celery to shallow layers of soil in deep crates. Keep them well watered without wetting the stems. If these are started in the cellar they will continue growth and be nicely blanched and tender when wanted for table use.

Protect the winter hardy crops such as winter greens, winter onions, etc., and let them remain out of doors through the winter. A light coat of leaves or similar litter may be enough.

Plan to use the hotbeds and keep them well filled with growing crops. Seeds of cabbage, cauliflower, radish, lettuce and a number

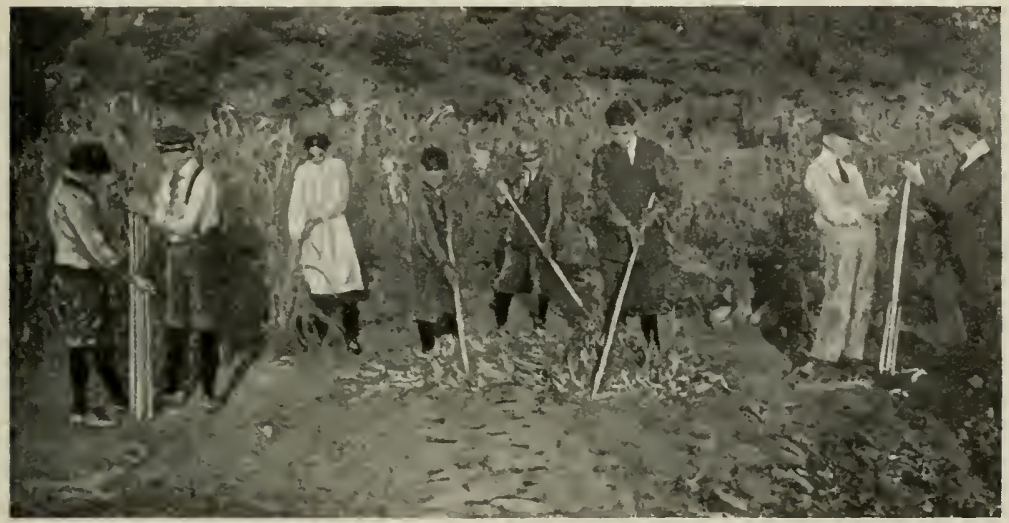

FIG. 98.- The cleaning up season is here. Tomato stakes are tied in bundles, old vines and stalks are raked together and left to rot in a compost. It is best to never burn the garden wastes. They will make good manure and humus in the soil. (Photo from R. I. State College, Ext. Dept.)

of greens may be started in coldframes now and transplanted later to the hotbed.

Parsley may be transplanted from the garden now and put into window boxes for use in the kitchen as needed cluring the winter.

Before the ground freezes, take up some large strong clumps of asparagus and put them in boxes in the cellar. Do the same with rhubarb roots. These can be used for forcing during the severe weather of January and February.

Flowers.-This is the latest month for the starting of winter bulbs. They will be late enough if started early in December. Some of the bulbs can be planted out of doors at any time when the ground is not frozen. 
Sweet peas may also be planted out of doors if the ground is in condition to be worked this month. This is the best month for a show of chrysanthemums. Stake the long stems well, water the soil and protect them from attacks of plant lice and red spider.

Cyclamen and cinceraria plants started in the summer nay be potted now for blossom in-doors.

Before the ground freezes take up a number of the beautiful flowers from the garden and put them in a flower pit or coldframe for storage until they are wanted for winter blossoming in the house. 


\section{CHAPTER XVi}

\section{THE HOME ORCHARD-APPLE, PEAR, QUINCE}

A GOOD home orchard is an attraction and material asset to any home, whether in the village or in the open country. We should think of the orchard as including the tree fruits, such as apple, pear, quince, peach, cherry, plum, etc. The last three are considered in the next chapter. In Florida and southern California we would include in the home orchard the grape fruit, lemon and orange. A study of the maps in this and the following chapters will be of interest (Fig. 99 and 100).

\section{APPLE}

Location and Exposure of the Apple Orchard.-The grower should not be discouraged if he has not the best location for the apple orchard. The exposure should not be toward the westerly winds if that can be avoicled. A north or north-east slope is better. This will keep the soil cool in the spring and prevent the warm days from forcing the trees into blossom so early as those on a southern slope. The earliest blossoms are in greatest danger from late spring frosts.

One of the most important considerations in the location of the apple orchard is the finding of a slope and putting the orchard near the top of it. This will give air drainage, which is the best protection against damage from late spring frosts. When frosty nights occur the cold air settles in the low places, and blossoms are often damaged here when those at the top of the hill are uninjured.

If possible, locate the apple orchard near enough the farm buildings so that it can be easily watched. Not only does the orchard need protection from human marauders at fruiting time, but it should be under the eye of the owner so that he will give it better protection against insect enemies and plant diseases. Fruit trees along the roads may satisfy those who would otherwise enter the orchard. They may also supply some fruit for home use.

Apple Soils.-In well settled regions the experience of the older residents will tell whether the soil is suited to the growth of apple trees. If trees have made a vigorous growth their size taken 
FIG. 99.

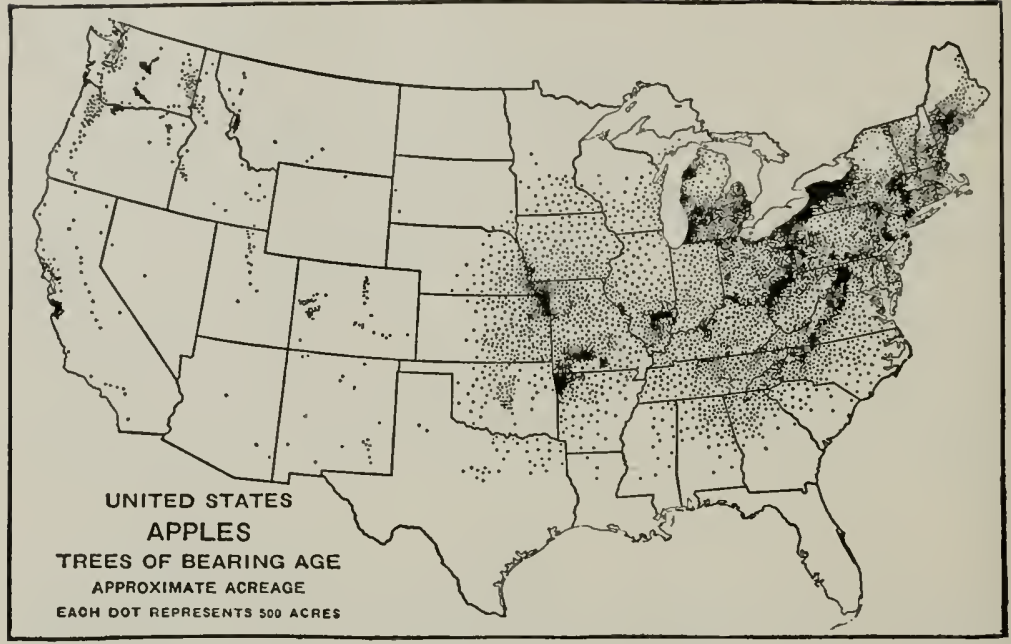

FIG. 100.

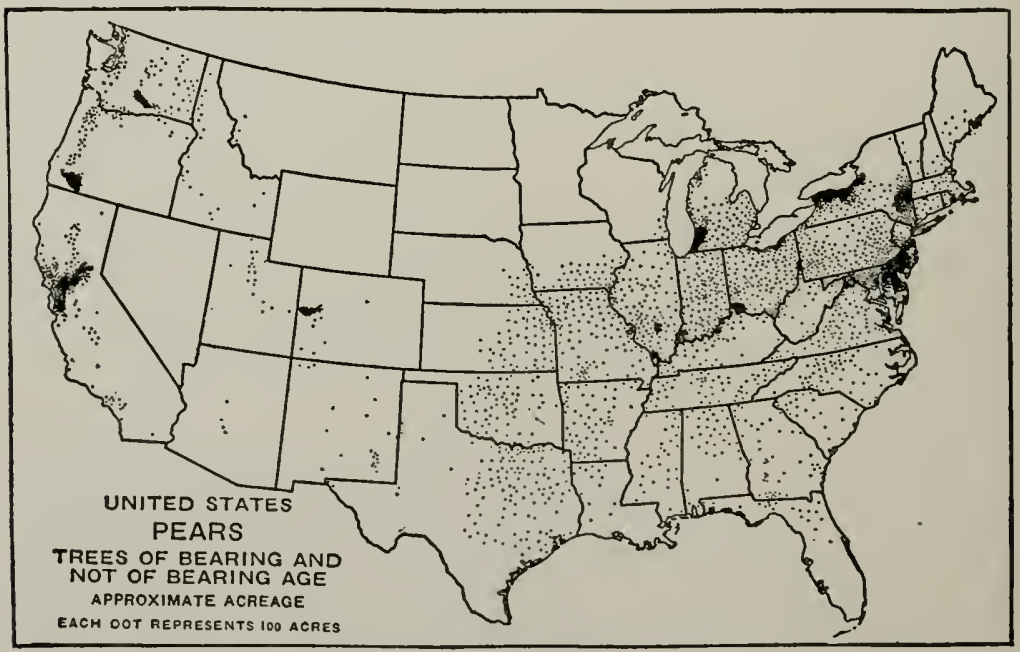

FrG. 99.-Apple trees of bearing age. Approximate acreage, 1910. Over 93 per cent of this acreage was in the eastern portion of $U$. S., the acreage in any one of the five leading states-New York, Ohio, Pennsylvania, Michigan or Missouri, exceeding that of the entire western half of the United States.

FIG. 100.-A pproximate acreage of pear trees in the United States. The largest centers of production are located in eastern Maryland, Delaware and southern New Jersey, in western New York, southern Michigan, in the Sacramento and Santa Clara Valleys, Cal., the Rogue River Valley, Ore., the Yakima Valley, Wash., and the Grand Valley, Colo. 
into consideration with their age will tell the tale. In poor apple soils the growth will be meager or poor. Soil also influences the length of life of apple trees. Medium loams and heavy loams are to be preferred to the light sandy soils for apples. The soil does not need to be extremely rich, but a moderate degree of fertility is desired.

Varieties for the Home Apple Orchard-Nurserymen speak of the varieties of apples under three heads, de pending on their season of ripening-summer, fall and winter varieties. If the grower intends to have a surplus of apples for market he ought to be careful to have enough of one or two varieties rather than a few of a great number of varieties. When the orchard comes into bearing one of the most harassing things which will confront the grower is to spray and otherwise care for varieties which blossom and ripen at different times. This task will be greatly simplified if he has only a few varieties to demand his attention at spraying time, picking time, etc.

In theory the home orchard which is not to have any fruit for market may have a great number of varieties with only a tree or two of each kind. This sounds ideal, because the tastes of different members of the family at different seasons will be gratified and fruits for all purposes will be produced.

On the other hand, apples of many varieties will shed their petals at different seasons and require spraying to fight the codling moth at as many different times. The close attention which this mixture will require may cause the spraying to be neglected or even abandoned in busy seasons. Another point about having too many varieties is that there may not be enough trees blossom during the same time to pollinate each other. A study of a table of blossoming dates at the time of selecting varieties should settle this point before the orchard is planted.

A good list of varieties for the home orchard will include one or two good standard varieties of summer apples, one or two of the fall varieties and the list should include good winter keepers. Perhaps three of the winter varieties of keepers will be enough. If we bring this plan down to its simplest form we might have one summer variety such as Duchess, one fall variety, such as Grimes Golden or McIntosh Red, and one variety of winter apple such as Winesap or Newtown Pippin.

In choosing the varieties for any region study the results of trials made by other growers. No general recommendation can be 
made which will include all regions and all soils. The glowing descriptions in catalogs, or those made by tree agents should not be taken to mean that the varieties are well suited to the region. There are many things to be considered in the choice of varieties: (1) Does the fruit hold on well? (2) Do they withstand bitter rot and other varictal diseases? (3) Do they grow to good size on these soils? (4) Do they keep well? (5) Do they yield well? (6) Do they bear regularly? (7) Does the tree make a thrifty growth? (8) Are the trees long lived? (9) Do the fruits stand handling? (10) Are the apples of good quality? The last point may be the sole subject of the discourse of a tree agent. If the variety falls down on all the other points, or any of them, the tenth point will not overcome the difficulties.

Write to your state experiment station and get a list of varieties recommended for planting in your region.

Planting the Apple Orchard.-Apple trees become so large when full grown that they must be planted at distances varying from 30 to 40 feet apart each way. If they are started at half these distances three-fourths of the trees will have to be cut out to prevent too much crowding. This thimning of the trees in an apple orchard is difficult because each tree is considered so valuable when it is large and is bearing fruit that the grower does not "have the heart" to cut the trees.

Inter-cropping with other trees such as peaches or pears or plums is sometimes practiced. If the apple trees are planted 40 feet apart each way and the peach trees are planted half way between them in the same rows and an extra row of peaches 20 feet apart is planted between each two rows of apples, this will make 27 apple trees per acre and three times that number or $\$ 1$ peach trees, making a total of 108 trees to the acre.

Plan of Planting.--The rectangular plan of laying out the orchard is most common. Two lines rumning from one corner are established with stakes. Enough stakes are placed along these two lines to establish the rows in both directions. By measuring with a pole from the stakes in these two lines it is easy to locate all of the balance of the trees in the orchard (Fig. 101).

If a stake is driven where each of the trees is to be planted it is easy to sight along these rows of stakes and straighten the row if necessary. As each stake is removed by the digger when making the hole for the tree it is necessary to mark its location before it is lifted out. This is done by using a planting board as shown in 
figure 102. Two stakes are placed in the line of stakes to suit the length of the planting board. The notch at its center is held on the stake where the trees is to be planted until the other two stakes are driven in place. Then the stake is removed and the hole may be dug. When the tree is planted the notch on the planting board will locate the trunk of the tree exactly.

Heeling in Trees.-When trees are received from the home nursery or by shipment from a distance, a trench should be dug in

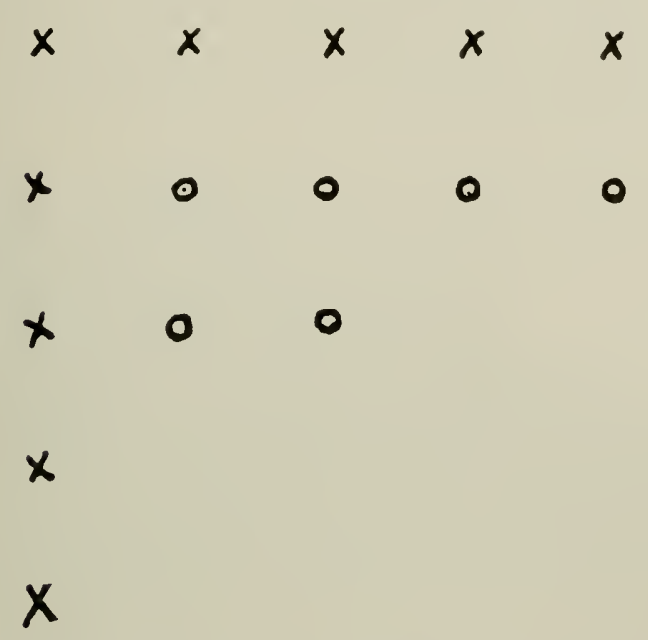

Fig. 101.-Plan for setting an orchard. X's are stakes set at right angles along two sides. The places for all other trees, $O$, are easily obtained by neasuring with two poles from adjacent stakes.

the orchard and the roots immediately covered with soil. The bundle should first be cut apart so that the soil will come in contact with all the roots well. Care must be exercised to avoid the labels being lost or the varieties mixed. If necessary each variety can be placed by itself in a separate trench or hole (Fig. 133).

Pruning before Planting.-The holes should first be dug, and when everything is ready for planting the trees may be taken up and pruned before planting. Cut off all the broken roots and trim away any diseased or injured parts. Prune the top somewhat severely so as to balance the loss of roots occasioned by the digging. One-year-old trees have buds throughout, and the pruning will be simply cutting off all the top down to a height of about two feet. 
Two-year-old trees are much more difficult to handle in this regard. The buds are on only the last season's growth, and good judgment must be exercised to decide which old branches should be left. It is often impossible to make a low-headed tree when twoyear-old nursery trees are being planted. Try to leave such branches as will balance the head of the tree when these become the main head limbs. If the branches are the same height on the main shaft of the tree they will tend to split, and the tree when loaded with fruit will be seriously injured.

Height of Head.- When the main branches start out near the. ground the tree is said to be low-headed. If the trunk is three or four feet below the main branches the tree is called high-headed. (Fig. 103.)

Many orchardists now head trees low at planting time. This

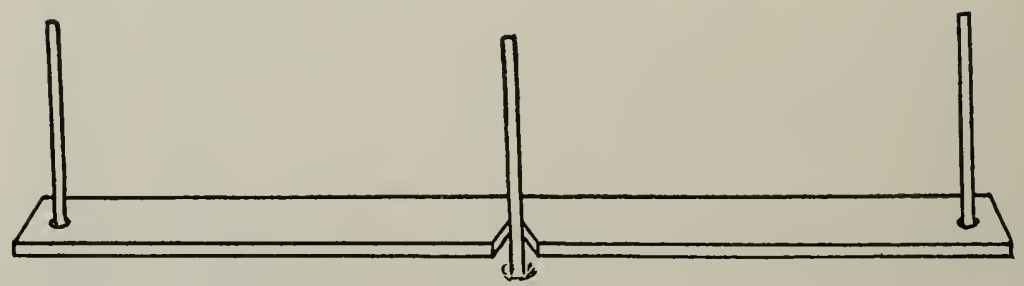

FIG. 102.-A planting board used as shown makes it eas $y$ to place the tree exactly where the stake was placed for it.

makes them easier to spray and prune; the fruit is easier to harvest, and the trees are less apt to split and break in heavy winds or when loaded with fruit. Cultivation near the trees is more difficult unless special implements are used. Compare the trees shown here as to height of trunks, figures 103, 104, 109, 110, 111.

Planting an Orchard Tree.-The hole for the planting of a tree should be considerably larger than the area covered by the roots. It should also be deep enough so that some of the best soil may be thrown back into the hole before planting. The tree should also be set an inch or two deeper than it was in the nursery. After getting the tree in its exact position throw some of the best soil over the roots and tramp this firmly in place. If any manure is to be added it should be put above this and not too close to the tree. Only a little manure for each tree should be used at planting time. When filling in the balance of the soil tramping occasionally is best. Leave some loose soil on top to form a mulch and prevent evapora- 
tion. It is necessary to have the soil well firmed against the main trunk so that it will not be blown over by the wind. A little manure may be used on top of the soil. It serves as a mulch, and the nourishment will be leached into the soil gradually by rains.

Culture of the Young Orchard.-If the orchard is on a hillside the soil may be plowed toward the rows so as to leave a terrace for each row of trees. This will require a reversible, or hillside plow. The soil between the rows should be thoroughly cultivated at least during the first half of its growing season. If the land is only slightly sloping a common turning plow may be used each

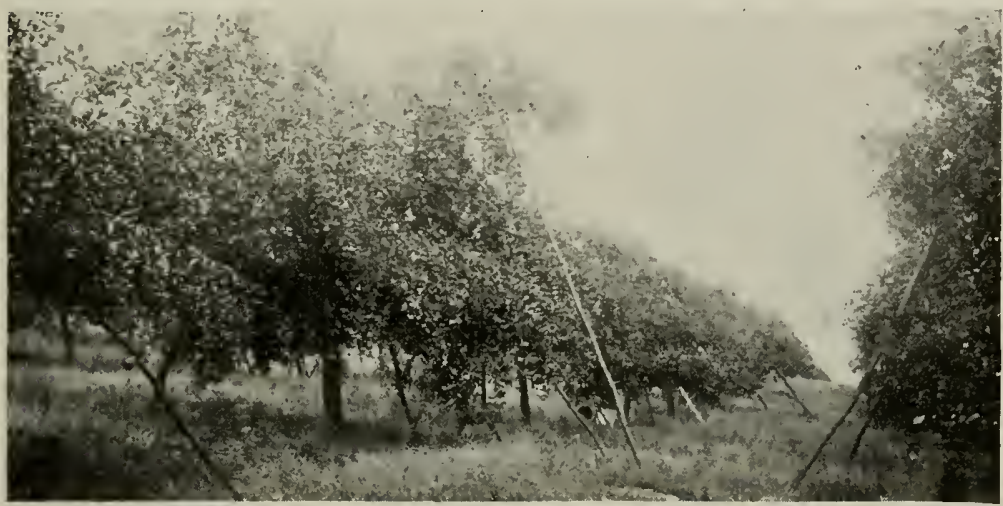

FIG. 103.-Trees with high heads and long trunks need propping more than do low-headed trees. Thinning the fruit would also save some of the propping.

spring. Follow with a disk harrow and spiketooth harrow. The latter may be used several times in the season.

Inter-cropping.-The most economical plan is to have crops growing between the rows, such as potatoes, beans, beets, or any garden crop which requires frequent tillage. These crops will make use of the land which the young trees do not cover, and their presence will require the grower to cultivate the trees sufficiently.

It is not good practice to plant young orchards on grass land without thorough cultivation. After the trees have become older and have produced a few good crops the plan of allowing a sod to form in the orchard is more excusable. Clean cultivation has proved to be the best method so far as yields and quality are concerned. 
Winter Cover Crops.-In the last half of the summer a cover crop may be sown, provided the inter-crop is out of the way. If early potatoes, for example, are grown between the rows this crop may be harvested and the soil then disked and sown with a cover crop. One of the best mixtures for northern states is rye and winter vetch. In the central and southern states crimson clover may be added to this mixture. Use one bushel of rye and one peck of vetch and one-half peck crimson clover per acre.

Green Manuring and Fertilizing.-In the spring after the winter cover crop has had time to make a spring growth the crop may be turned under as green manure. The soil should then be disked and the annual inter-crop may be planted. The best time to apply commercial fertilizer is just after the first spring plowing. The fertilizer then added will help the inter-crop and also help the orchard trees. A well balanced fertilizer may be mixed at home to suit the soil requirements. While the orchard is young some fertilizer rich in nitrogen should be used. After the trees are of bearing age, omit most of the nitrogen and add more phosphate and potash. The quantity to be added will depend on whether or not the soil is naturally fertile.

Pruning the Orchard.-Much of the vigor and health of the orchard depends upon the annual pruning. Most of this work will be done in the winter when other farm work is less pressing (Fig. 104). But some light pruning in midsummer is valuable, particularly with young trees. Pruning the orchard is as important as spraying, cultivating, or fertilizing.

Figure 105 shows the fruit spurs of the apple tree. In pruning old trees we should be careful not to remove such spurs. There are a number of points to be remembered by the operator while doing the annual winter pruning.

1. Remove all dead or diseased parts and burn these if affected with blight or other serious disease.

2. Cut out broken limbs.

3. Prune out all those twigs which strike across the body of the tree.

4. When two or more limbs extend along the same line or closely parallel each other, prune away the less vigorous.

5. Thin the head of the tree enough to admit plenty of light. and air to all parts. Never allow erowding in the tree top.

6. Cut back some of the new growth on young trees or on any that grow rapidly. A third or a half of such growth is often pruned back. 


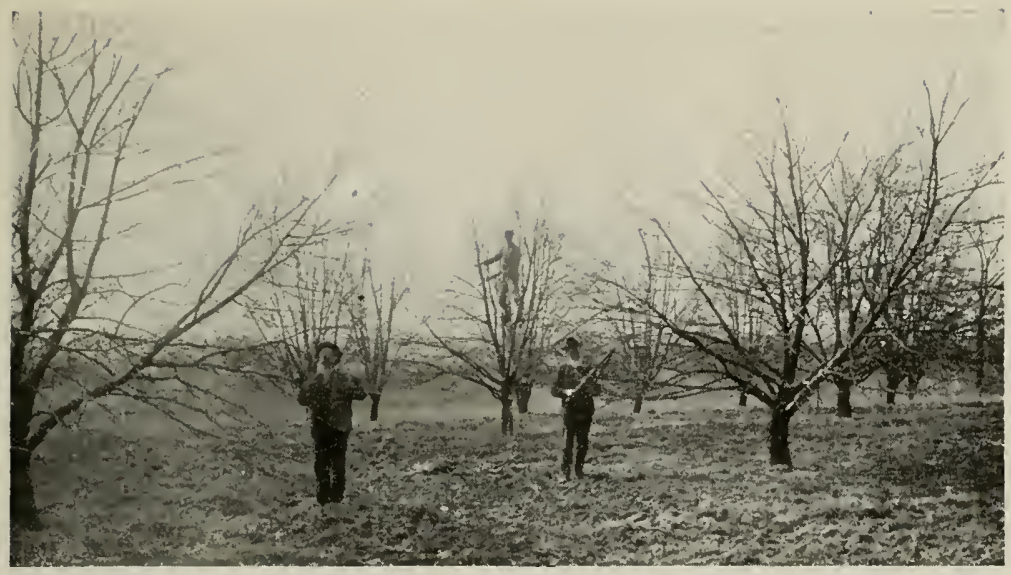

Fra. 104. - A light pruning each winter keeps the home orchard trees within bounds. The winter cover crop of rye makes the work more pleasant and benefits the soil. (Indiana Station.)

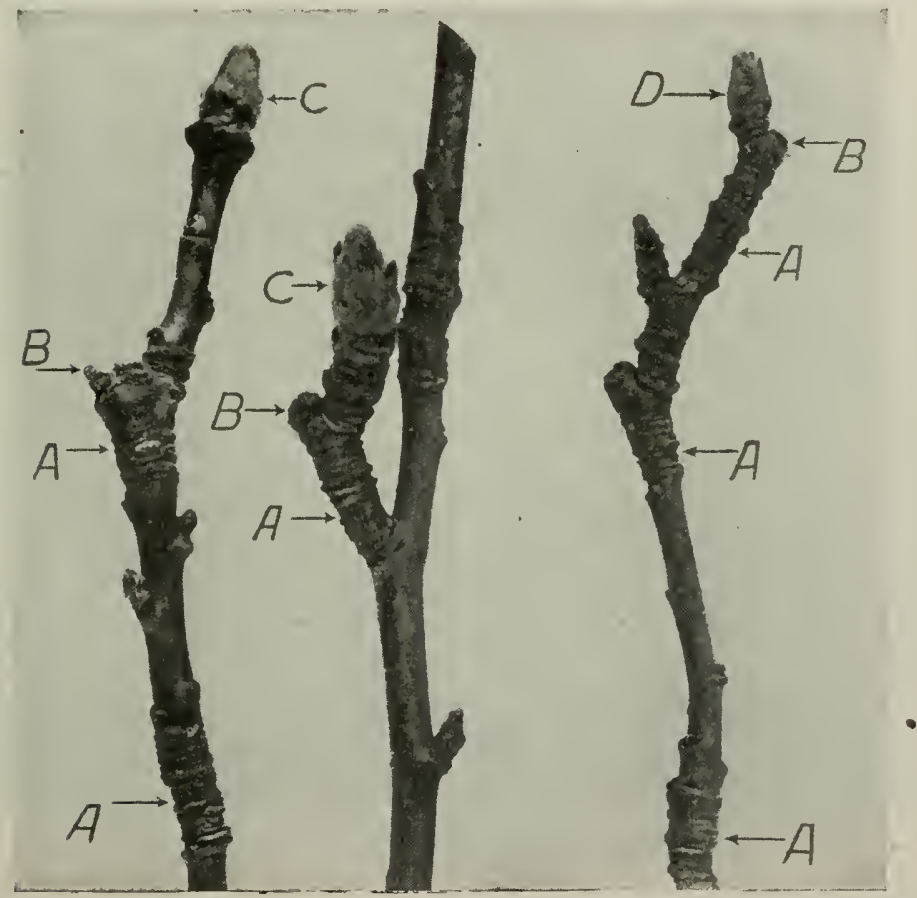

Fig. 105.-Fruit spurs of apple. $A$ to $A$, shows one year's growth marked by the rings or scars of the terminal bud scales. $B$, shows where fruit was attached; the number of crops may be counted. The fruit buds, $C$, are downy and are larger than shoot buds, $D$. (Indiana Station.) 

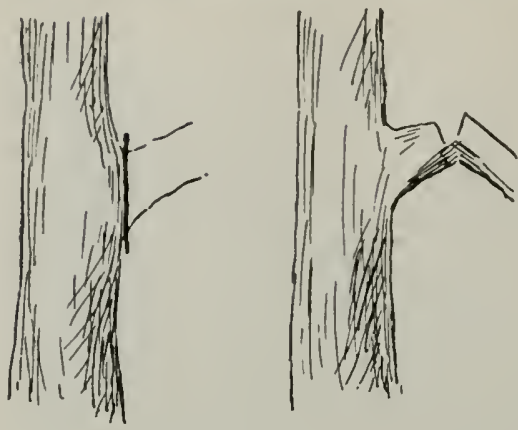

Fig. 106.-Good and bad pruning contrasted. Cut close when removing large limbs. Cut from the under side first to prevent splitting down the bark.

work is done when the fruit is quite small. The clusters are reduced to single fruits. Removed fruit may be dropped to the ground to be eaten by pigs.
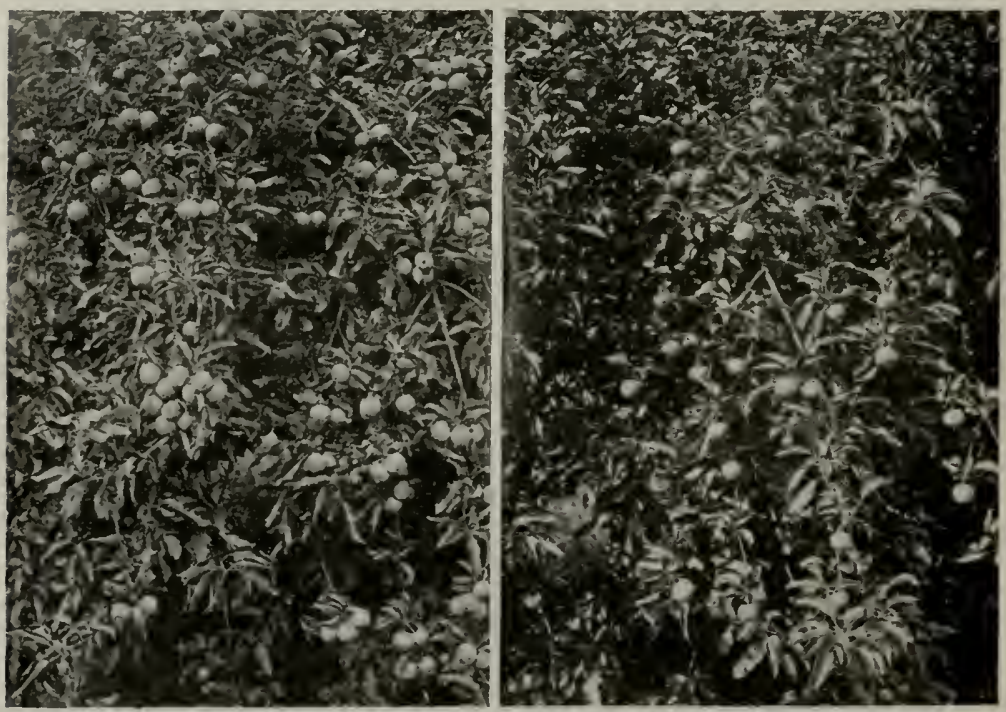

FIG. 107.-Gano apples, before and after thinning. It takes courage to thin fruit, but the size is increased enough to pay. (Ohio station, Newark.)

The objects of thinning are (1) to prevent the spread of rot or other disease of the fruit; (2) to increase the size and quality of the 
fruit left on the trees; (3) to induce the tree to bear a good crop annually instead of every other year; (4) to save work at harvest time in picking and sorting low grade fruit.

Dwarf apple trees are neither a fad nor a novelty. But they are not usually considered commercially profitable in America. Almost any variety of apple can be made to grow well on dwarfing stocks as Paradise or quince. The trees will then come to bearing much younger (Fig. 108). They may be planted as close

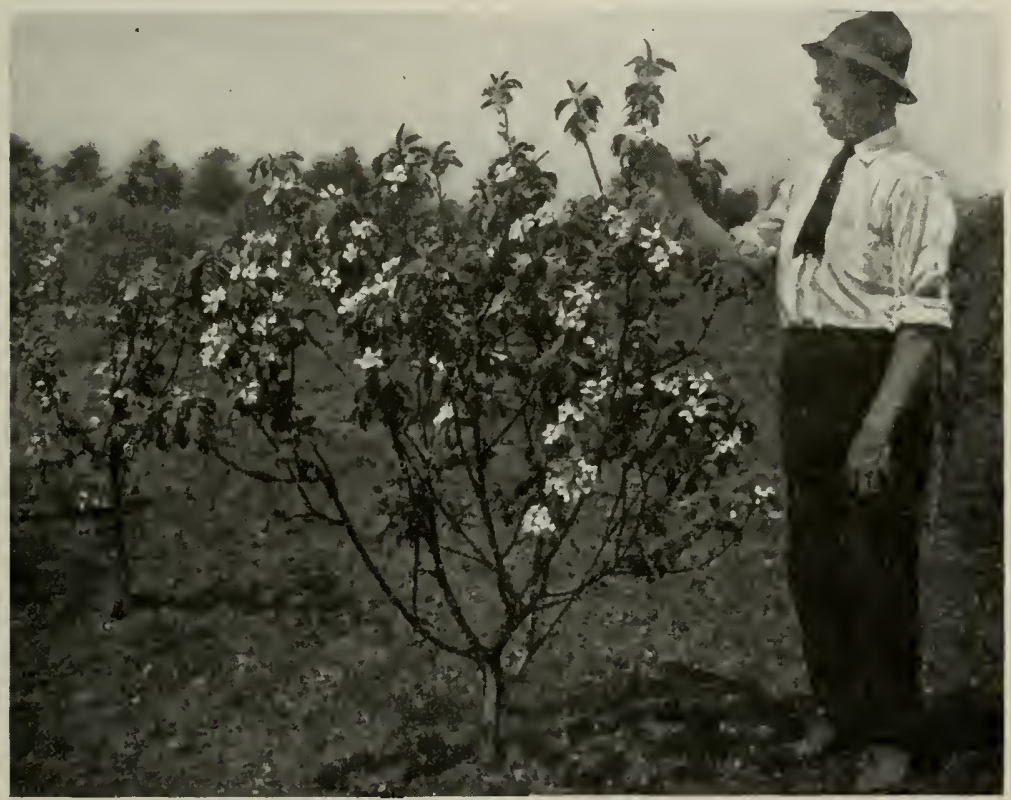

Fig. 108. - An orchard of dwarf apple trees four years old. (New Jersey Station.)

as seven to nine feet apart each way. The fruit is not changed in size or otherwise by the dwarfing. The trees are more expensive than standard trees and many more are required to set an acre. While the yield per tree is much less, the yield per acre is not as much reduced as might be expected.

Irrigation in Dry Climates.-In arid regions of the western states and elsewhere irrigation of orchards is necessary. Water may be applied to the soil in a number of ways. Far the most common method is to plow furrows between rows as shown in 
figure 109 or to have the furrows eross the orchard along lines that are nearly level. Water is turned into the furrows from head ditches as desired.

One day or a few days after watering, the soil should be tilled to conserve the moisture and to prevent baking and cracking of the surface. A harrow of some type to suit the texture may be used for this purpose.

The soil should be thoroughly watered several times during the growing season.

Renovating Old Orchards.-On many farms there are old orchards of apples and other fruits that should be renovated. If

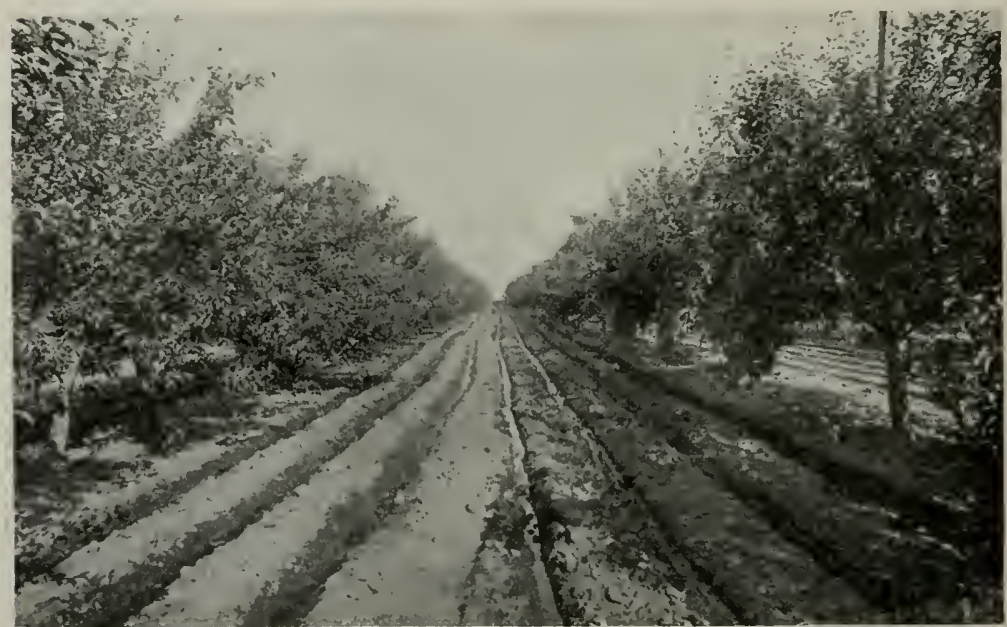

FIG. 109. - The furrow method of irrigating orchards and gardens, used in dry climates. (Photo,by Gagnon, Wenatchee.)

the trees are not too nearly dead, and if enough of them are still standing to fill the area fairly well, they may warrant some work and expense of renovating (Fig. 110).

Steps in Renovation.-Four or five steps are necessary in reviving an old neglected orchard.

1. Pruning is always necessary, but there is clanger in pruning too heavily at one time, for it may cause a very rank growth of new wood and thus delay the bearing of fruit for some years. No harm can come from cutting away all the dead or unhealthy parts (Fig. 111). Beyond this do not thin the limbs too much. 
2. Cultivate the soil by plowing shallow at first and deeper afterward. In orchards where such tillage is possible the effects will be very beneficial.

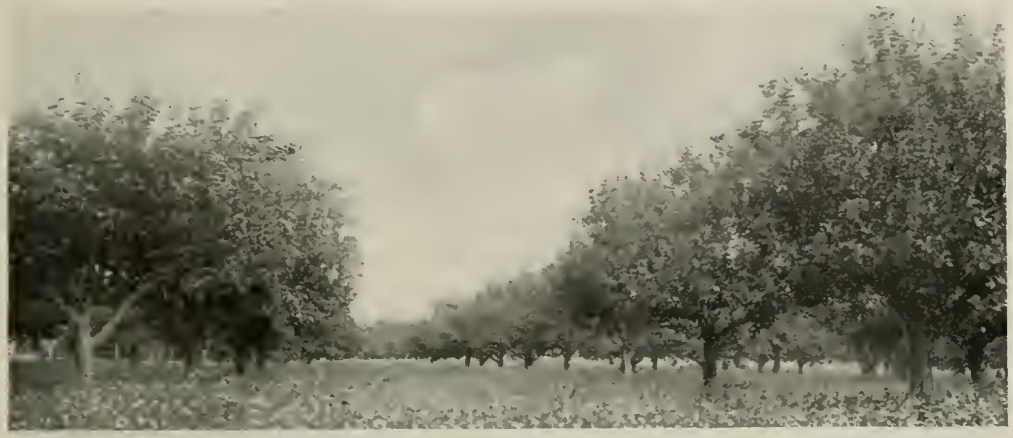

FIG. 110.-An old Baldwin orchard after being rejuvenated by pruning, spraying,, cultivating and fertilizing. (Courtesy of F. C. Sears.)

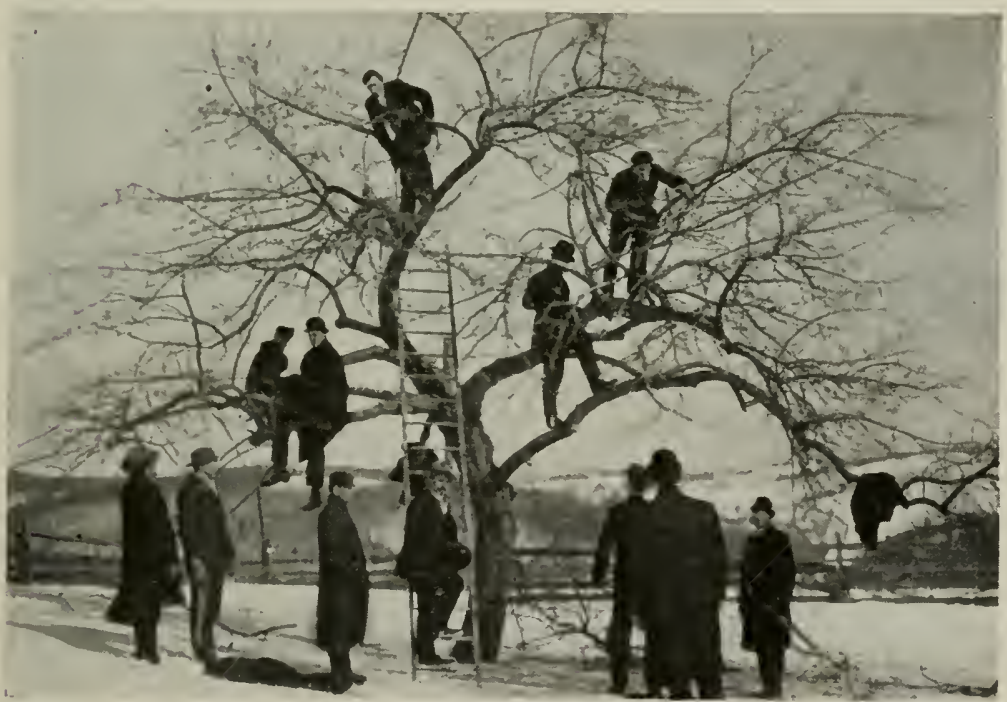

Fig. 111.-A lesson in rejuvenating an old apple tree. Such work is necessary only after much neglect. (New Jersey Station.)

3. Fertilizing the soil to feed the trees must be done with judgment. Use considerable stable manure or nitrogenous fertilizer if the growth of leaves and new wood show lack of vigor (Fig. 
112). If this growth is likely to be sufficiently stimulated by pruning and cultivation, omit most of the nitrogen but feed the trees with phosphate and potash.

4. Spraying is always necessary in a neglected orchard. Follow a good annual spraying campaign as given in a later chapter.

5. Working over the trees to change the variety to a more valuable kind is sometimes advisable. This takes more time and delays the results longer than the four preceding operations. For methods of grafting and budding old trees see Chapter VI. (Fig.113)

Harvesting the Apple Crop.-Some varieties of trees will bear after five or six years, while others will require several years more

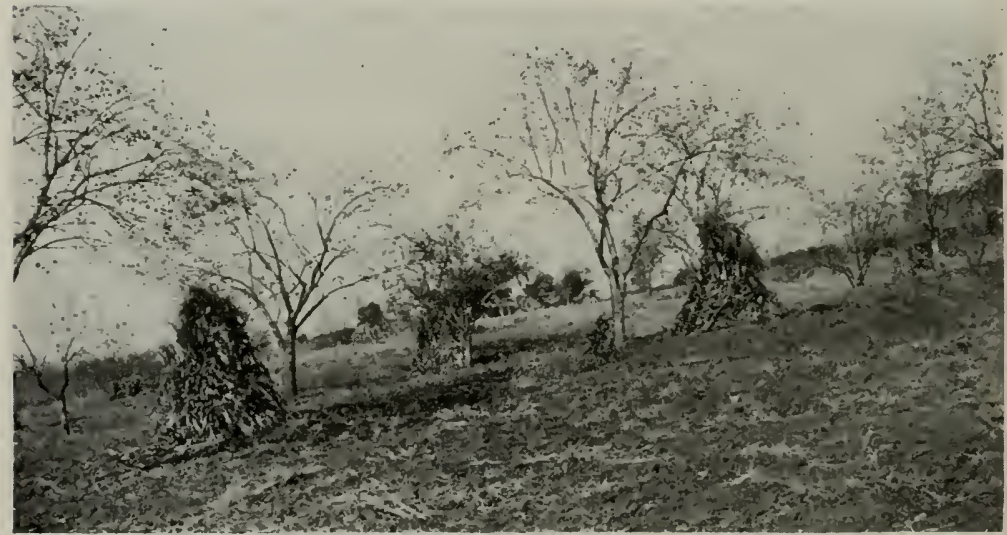

FIG. 112.-When corn or other crops are grown in old orchards the trees may be starved and diseases of foliage are commonly found. (Ohio Station.)

for their development. Too often the fruit is allowed to drop to the ground and is gathered after it has been injured by falling. On the market wind-fall fruits are considered as culls and are hardly worth handling. They are so badly bruised that they will not keep long and the bruised side at least has to be wasted by the consumer. The rot started by the bruising soon destroys the whole fruit.

Pick fruits from the tree when they are nearly mature, and keep them in suitable places until used or sold. A good plan for picking is to use a half bushel basket with strong, rigid handles which can be suspended on the left arm or may hang from a hook on the ladder. This basket should be lined with a heavy bag or cloth. 
As fast as the basket is filled the picker descends to the ground and carefully transfers the fruit to boxes or barrels.

The ladder used for picking from large trees may consist of a main shaft split open for the lower six feet. The rounds or steps are put through these two forks; where the shaft is single, the steps extend through it, and are curved upward to keep the man's feet from slipping. The top of the ladder rests against the outer branches of the tree and is more stable than a common

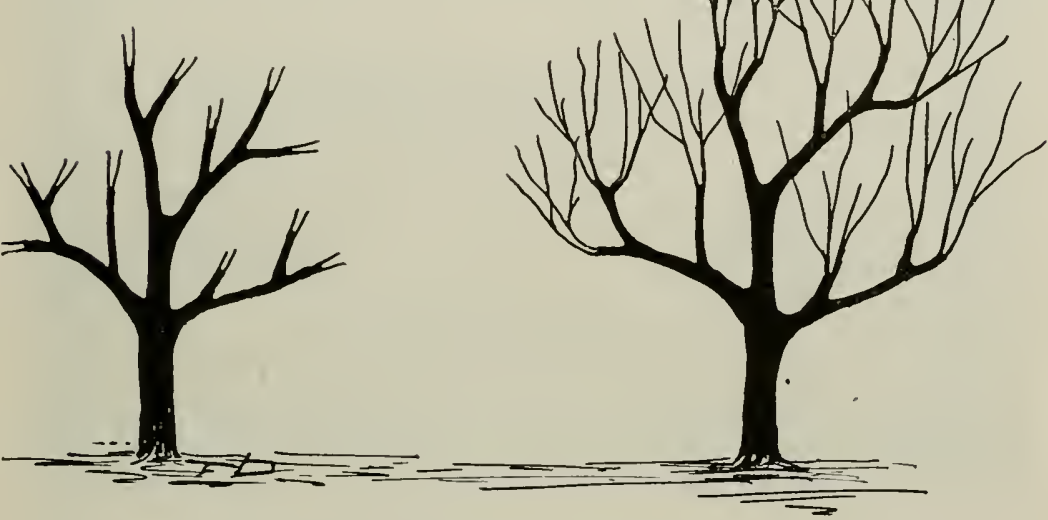

Fig. 113. - Two steps in working over an old apple tree by cleft grafting cions of a better variety. The success of this work depends upon an even growth and good union of the woods of stocks and cions. Budding on smaller twigs is more successful.

step ladder. For small trees a common step ladder eight or ten feet in length may be used.

The fruit should be removed from the tree twig by a twisting motion, or by placing the thumb nail at the end of the apple stem. Care should be exercised not to remove the fruit spurs with the fruit. It is a bad practice to allow the apple stem to be pulled cut from the apple cavity. This is likely to start fruit rot, and the fruit will not keep so well in storage.

Keeping the Crop.-Summer varieties are usually not held long. They are intended for immediate use, and the surplus should be 
sold as soon as harvested unless it is wanted for home use. The advantage of growing summer varieties is that the price may be better at that season and storage will not be necessary.

Fall and winter varieties are usually held for some weeks or months. The winter varieties are always better keepers than the fall varieties. The latter can not be kept long except in cold storage. One of the best home storage places is a cellar where the fruit will not freeze and where it will not dry out too much. The apples may be placed in barrels or boxes, closed up well and placed in the cellar until needed for market or for use. The barrels are opened and the fruit that is going to market is carefully repacked.

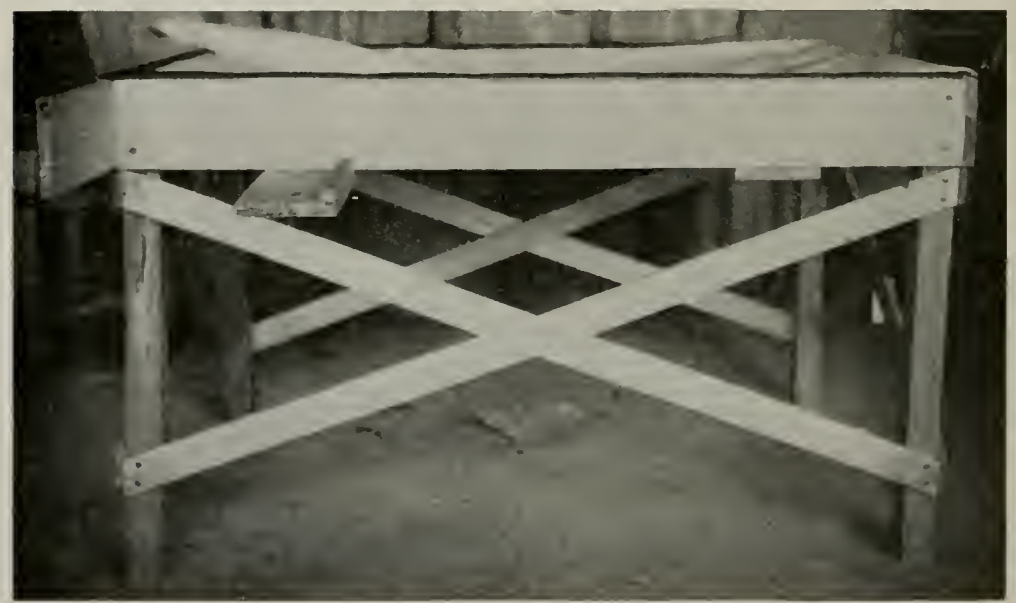

Fig. 114.-A convenient packing table with loose burlap bag top, used in sorting fruit and packing boxes. (Indiana station.)

Fruit stored in apple boxes will bring better prices than that stored in barrels. This must, however, be sorted well and be of uniform color and size. For systems of packing barrels and boxes for market see Sears' Productive Orcharding.

Figure 114 shows a good form of sorting table which may easily be made at home.

Figure 115 shows a compression elamp for use in closing apple barrels. Such a device greatly reduces the damage to apples in barrels when shipped by rail or by truck.

Figure 116 shows two methods of packing apples in boxes to secure uniform and good results. Figure 117 shows how the fruit is wrapped with stamped papers. 


\section{PEAR}

A number of points which have been discussed under the head of the apple will apply here. Nothing more need be said regarding the location and exposure or the culture of the pear orchard. The methods of planting and pruning are also similar.

Soils.-For the pear we would prefer to use the very heavy soils, at least the pear will enclure heavier soils than almost any other fruit.

Pruning.-Pear trees should be regularly pruned each year. Follow the general directions for pruning given for the apple. In many cases it will be necessary to cut back some of the new growth as shown in figure 118.

Varieties.-Pears differ widely in their keeping and eating qualities and in their resistance to disease. Those should be selected for planting which are most suited to the locality. Before planting considerable inquiry should be made concerning the varieties which stand blight in the local soils. Also find which ones will bear best and which trees live longest in the local soils.

Along with these matters should be considered the question of quality. Some pears, such as Seckel are of very high quality and are suitable for eating out of hand. The Bart-

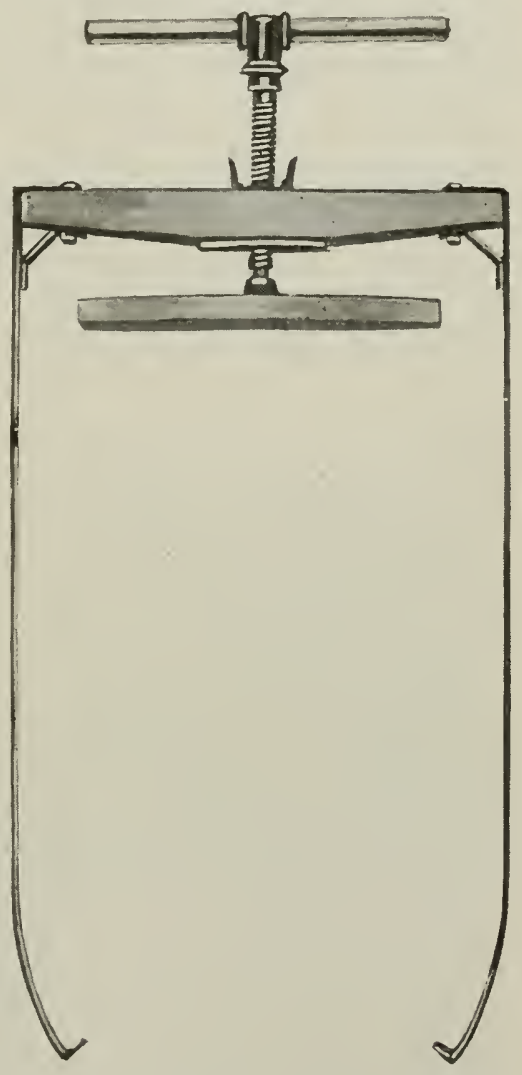

FIg. 115.-Press and clamp for "heading" barrels of apples. When fruit is packed with some pressure the damage from shipment is reduced. lett is of good quality and yet is often attacked by twig blight. The Kieffer is considered one of the poorest in quality, yet is one of the best keepers, and is often least subject to attacks of diseases. Select only one or two varieties of pears for the home orchard. 
Too often the surplus fruit is unmarketable. When the season is favorable other fruits such as apples will readily take their place on the market and the price of pears is comparatively low.

Harvesting the Fruit.-Pears are more subject to damage by bad handling than apples. The fruit should invariably be picked before it is soft. As soon as the pears are full grown they should be carefully removed by hand and laid in single layers in baskets lined with cloth. They should then be placed in single layers in crates, covered and kept in a dark cellar or similar place. They
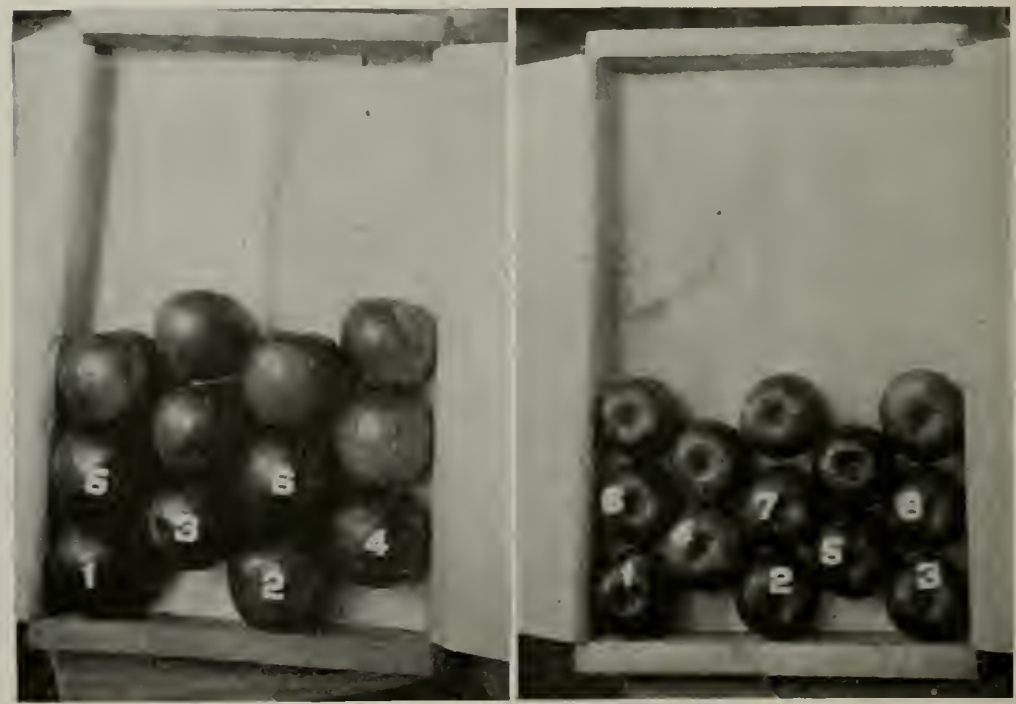

Fig. 116. Two methods of packing apples in boxes. At left, start of 2-2 diagonal pack. The box holds four layers of 24 apples each. At right, start of 3-2 diagonal pack, with smaller apples. The box holds five layers of 33 apples each. They are placed in layers in the order in which they are here numbered. (Indiana Station.)

will ripen readily in the dark and will attain highest flavor and best quality. When ripened in the dark they have less of the gritty tissue in the flesh of the fruit.

Many varieties of pears are not suitable to store, but should be consumed, marketed or canned as soon as they have reached their highest perfection.

\section{QUINCE}

This fruit is not commonly grown in the home orchard. A few trees will supply the needs of the family. 
The fruit is rich in jelling properties, but somewhat insipid in flavor. It is therefore usually mixed with other fruits for canning or jelling, but is seldom used alone.

Culture of the Quince.-The trees or bushes are small and may be grown at a distance of only ten feet or so from each other. The roots are very shallow and therefore the quince may be grown in soil where the water level is not very deep below the surface. The trees do not prefer wet places, but they will endure such places better than other orchard fruits.

The methods of planting are similar to those mentioned for

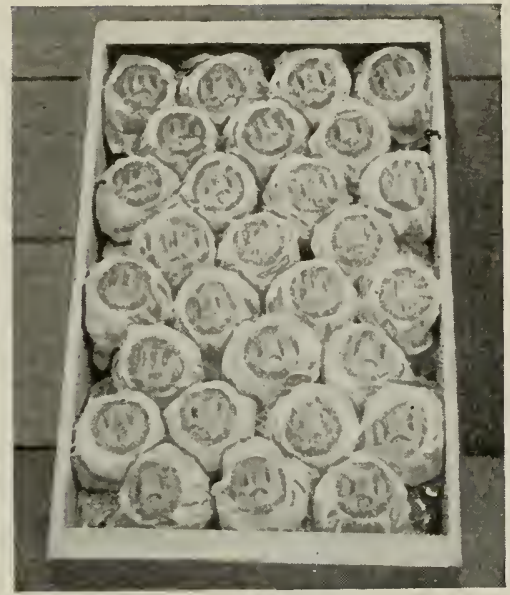

FIG, 117.-Fancy apples are of ten packed in boxes holding almost one bushel. The "3-4" pack here shown is used only for small apples. The " $2-3$ " is more common. Wrapping prevents bruising and makes the fruit keep longer.

the apple. In pruning, however, special methods are used. The quince is really a bush, as there are usually a number of main shoots or branches coming from or near the ground. This fact allows it to

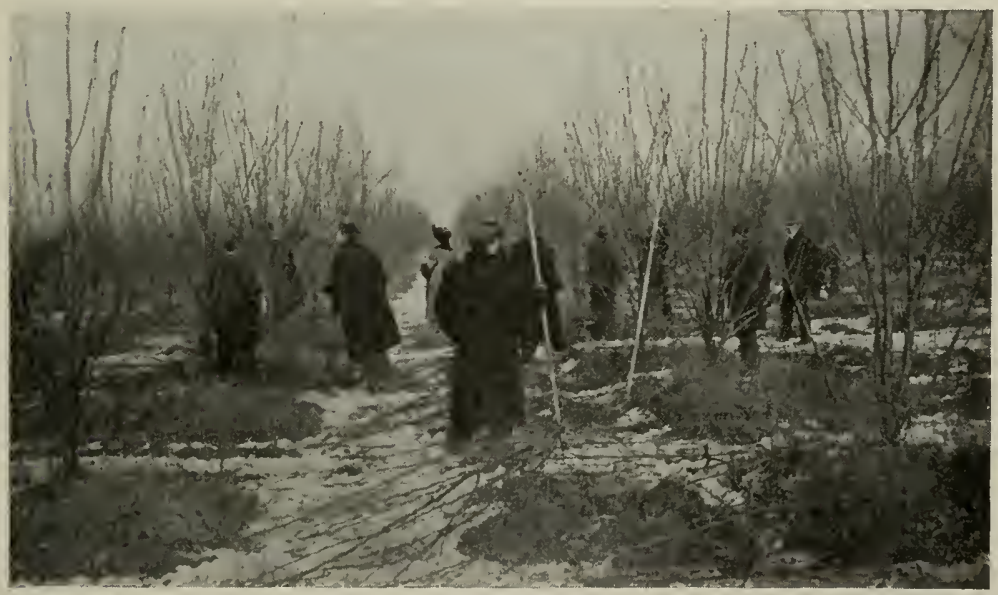

Fig. 118,-Winter pruning of Keiffer pear trees after they were neglected for a few years. (New Jersey Station.) 
be propagated by mound layering already described in an earlier chapter. The amnual pruning consists chiefly of removing any dead or diseased parts, thimning the head to allow the entrance of enough sunlight and remove the branches which tend to rub against each other. The general shape of the head should also be controlled by the proper pruning of the outer branches.

\section{SURVEYS, PROJECTS, AND EXERCISES}

1. Orchard Exposures. - Send a few questions to each home of the region to determine the size of orehard, direction of slope, height of ground above surrounding land, kind of soil, killing of blossoms by late spring frosts, etc.

2. Tabulate the results and compare the exposure with the frost damage.

3. Varieties of Apples and Pears. - Make up a list of these fruits grown in your region and indieate which are considered most successful in the features mentioned in this chapter. Classify the varieties according to time of ripening.

4. Inter-cropping in young orchards should be made a special study for your region. What crops are used? Which are best for the trees? How long is inter-cropping continued in young orehards?

5. A project in inter-cropping may be conducted by each student in his home orchard. Make plans and record forms to include each of the points to be observed and reported.

6. Orchard projects are rather long but they should be started. (1) Some ean deal with the starting of young orchards. (2) Others may include the management of the home orchard for a year or two. (3) The rejuvenation of old, negleeted orchards are good projects.

7. Harvesting, packing and marketing may be short projects pursued by young people.

8. Fruit Storage.-The above may be combined with winter storage of apples and pears. Trials may be made to compare results of (1) marketing from the orehard, and (2) storing and holding for winter prices.

9. Scoring Fruit Exhibits.-Fruit growing projects are made more interesting if the products are to be exhibited at school or some other central location. Figure 91 shows some good features of exhibits. Autumn is usually the best time for the show.

Let all know what points are to be scored when the fruit is judged. Publish or otherwise announce the score cards to be used. The points are here given by way of suggestion: Uniformity of exhibit, 20 points; size of fruit, 15; color, 15, form, 15; quality, 15; freedom from blemishes, 20; total 100 points. (See School and Home Gardening ehap. XXI.)

10. Fruit Descriptions. - When apples and other fruits are available, students should practice describing fruits. See plans and methods in Waugh's "Systematic Pomology." Also see descriptions of six varieties of apples given with figure 119. Secure typical speeimens from homes and markets. Compare different varietics as to form, eavity, basin, color, dots, skin, core, quality, flavor, texture, use. Describe each in these points.

\section{QUESTIONS}

1. Describe a good location for an apple orchard (on your place if possible).

2. What soils in your region (or elsewhere) are best suited for apples? For pears?

3. Name varieties of apples for summer, for fall, and for winter, which are recommended for your region. 

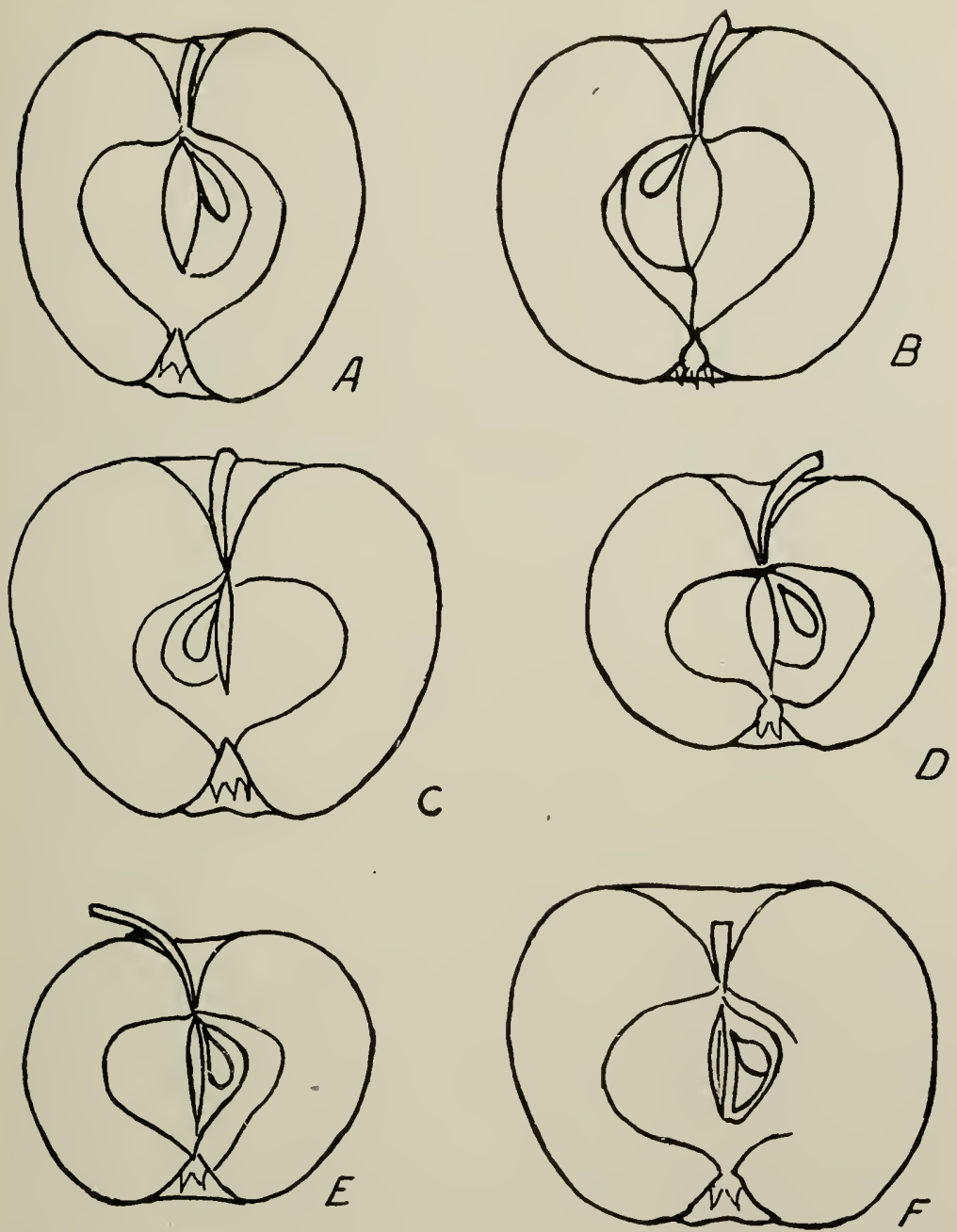

Fig. 119.-Typical forms of six varieties of apples. $A$, Chenango, oblong to ovate or egg-shaped; cavity large; basin shallow, core large, partly open. $B$, Winter Banana, globular, symmetrical; cavity wide, deep; calyx and basin very small; core large, open. $C$, Buckingham, roundish-conical; cavity wide, deep; basin wide, deep, furrowed; open small, closed. $D$, Lawver, roundish-oblate; cavity large, furrowed; basin and calyx medium; core large, open. E, Golden Sweet, oblate or roundish-oblate; cavity and basin medium; core medium, nearly closed. $F$, Sierra, roundish-oblate, inclined to conic, with broad base; cavity very wide, deep; basin very wide, rather shallow, furrowed; core small, closed. (After Ohio Station.) 
4. What distance apart is best for planting apple trees? For pear trees?

5. Describe a good plan for laying out the orchard for planting.

6 . What should be the pruning for young trees at planting time?

7. Describe the planting of a tree.

8. What crops are good to grow between the rows of young trees in your region?

9. What are the uses of a winter cover crop in the orchard?

10. What would you use for this? When? How started?

11. Give some cautions and directions for the harvesting of apples.

12. Same for pears.

13. Give best conditions for storing of winter apples.

14. Describe some methods used in your region.

15. Give several points regarding the management and growth of the quinee.

References.-U. S. Farmers' Bulletins: 482, Pear and How to Grow It; 727, Growing Fruit for Home Use in the Great Plains Area; 852, Management of Common-Storage Apple Houses in the Pacific Northwest; 903, Commercial Drying of Fruits; 984, Farm and Home Drying of Fruits and Vegetables. 


\section{CHAPTER XVII}

\section{ENEMIES OF THE APPLE, PEAR, AND QUINCE}

MANY of the insects and diseases which attack the apple orchard are also enemies of the pear and quince. These may well be considered in a group together.

Codling Moth.-One of the worst apple insects is the codling moth, or apple worm. It is the insect which makes apples, pears and other core fruits wormy. The adult moth lays eggs in early spring in the blossoms of the fruit. As soon as the eggs hatch the larvæe eat their way toward the center of the fruit, and when fully fed emerge from the surface and drop to the ground from a suspended web fiber. In many cases the apples drop to the ground with the larvæ in them. When the young emerge they go to the trunk of the tree and form cocoons or nests in crevices of the bark. Here they rest for a few weeks, or if the season is short they may spend the winter in this pupa stage. Where the season is long enough a second brood of moths lay eggs on the surface of the half grown apples, and the young do much damage by burrowing tunnels through the fruit. Wormy apples are almost worthless on the market.

Remedies for the Codling Moth.-The best remedy is to spray the trees just after the petals fall. Never spray when the trees are in full bloom because of danger to bees which are pollinating the fruit. The spraying should be done before the calyx cups close and before the young apples begin to hang downward (Fig. 120 and 121).

The spray materials used should all contain arsenical poison so that the young larvæ will be killed as soon as they begin to eat their way into the fruits. Arsenate of lead is usually preferred to Paris green. As the apple is subject to a number of diseases, Bordeaux mixture is usually applied at the same time. Arsenate of lead mixed with Bordeaux mixture at the rate of about three pounds of poison to fifty gallons of Bordeaux mixture is applied as a fine spray. This should be done not only just after the petals fall, but should be repeated again about two weeks later. This will counteract the attacks of the latest insects of the spring brood. 
Apple Borers.-The apple tree is attacked by several borers. The unost common of these is the so-called flat headed apple tree borer, which is the larva of a buprestid beetle. The larva lives in the tree about two years and burrows chiefly in the sap wood and
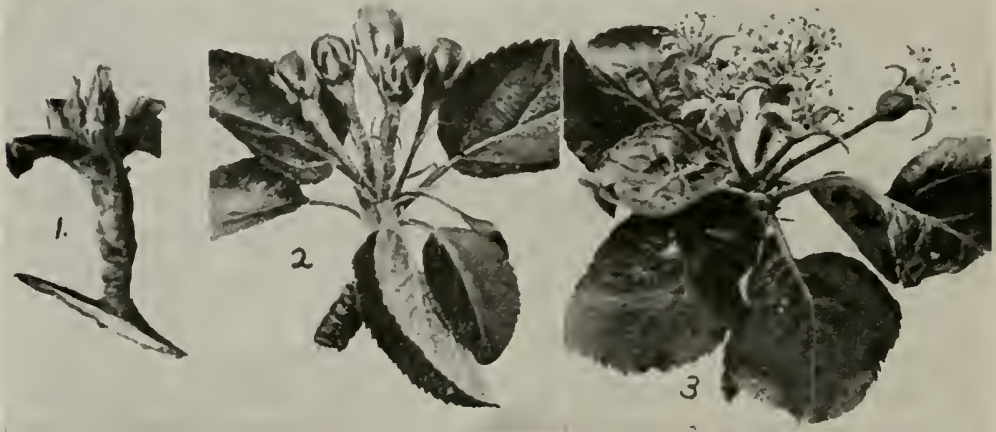

Fig. 120.-Three stages for spraying apple and pear trees. 1, winter buds open, spray for scab, aphids, and bud moth. 2 , pink or pre-blossom, spray for seab, bud moth, and leaf roller. 3, caly x spray for scab and codling moth. (Oregon Station.)
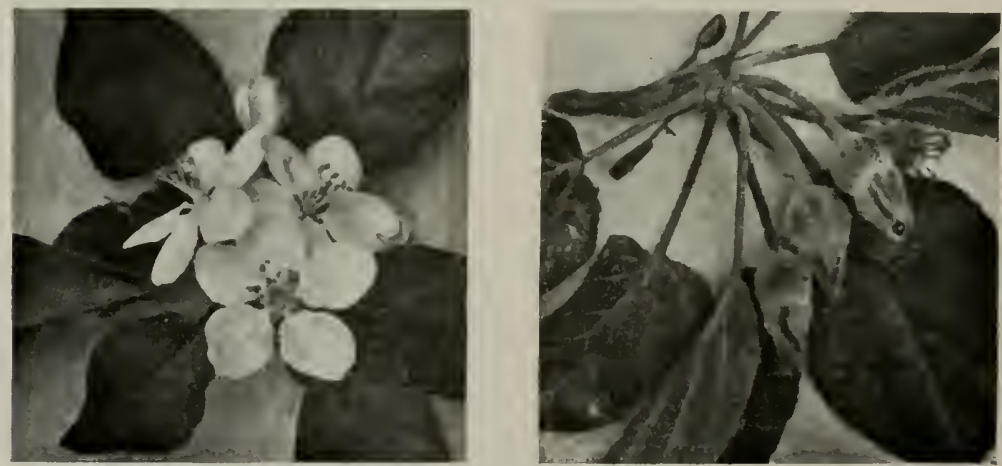

FIG. 121.-Two conditions of the apple or pear when a spray should not be applied. When blossoms are open pollen and bees would be injured. Just after the calyx cups have closed and the stems are hanging down a poison cannot be placed in the cups.

green bark. As it gircles around the tree it eauses much damage. and trees are often killer when attacked by several borers.

Another common apple tree borer is the so-called round headed borer, which is the larva of a beautiful long-horned beetle (Fig.122). It lives in the trunk of the tree about three years and burrows in the heart wood as well as in the sap wood. 
The remedies for these apple borers are mechanical. 'The larvie must be found and killed before they have done much damage. Cut away the outer bark with the point of a knife or wire and destroy the larva. The trunk of the tree may be protected from the adults by bands of paper or other materials which will keep the adult beetles from laying their eggs on the trunk. Netting shown in figure 123 may be fine enough to keep out these beetles. Repellent washes are sometimes used. One of the best of these is a heavy coat of lime-sulfur.

Canker Worm.-This is sometimes called a measuring worm, as the feet of the larvæ are at the two ends of the body, and the insect. seems to be measuring the distance as it travels. These occur in large numbers in the trees and destroy the leaves. As the leaves of a tree are its lungs and digestive organs it suffers greatly from the attacks of this insect. All biting insects can be readily destroyed by applications of poison. Arsenate of lead combined with Bordeaux inixture is applied whenever attacks are noticed.

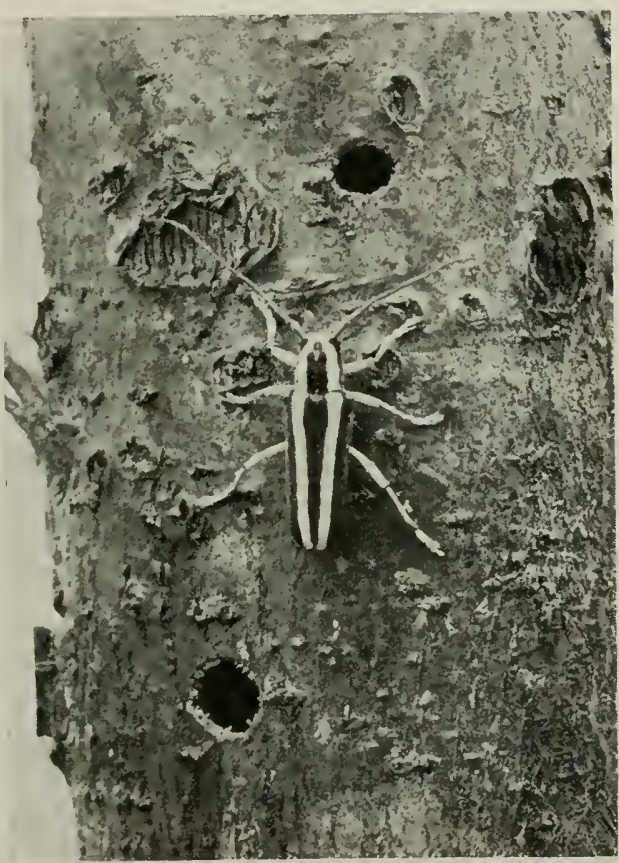

Fig. 122. - Adult beetle of the round headed apple tree borer. The holes show the wounds made by the insects. The larvæ are very destructive to apple trees. Watch the base of the trees and when borings are found follow the channels with a wire and crush the insects. (West Virginia Station.)

Tent Caterpillar.-There are two forms of tent caterpillar which commonly attack trees. The larva of the apple tent caterpillar has a row of yellow dots down the middle of the back instead of a yellow stripe found on the forest tent caterpillar. Both of these attack a number of kinds of trees, and as their work and remedies are somewhat similar they may be considered together. 'The egg 
clusters are formed around the twigs of the trees and may be seen in winter when there are no leaves on the trees. These may be pruned off and destroyed. In the spring when the eggs hatch the young soon form webs as homes, from which they make attacks on the leaf growth.

The web may be burned with torches of kerosene on long poles.

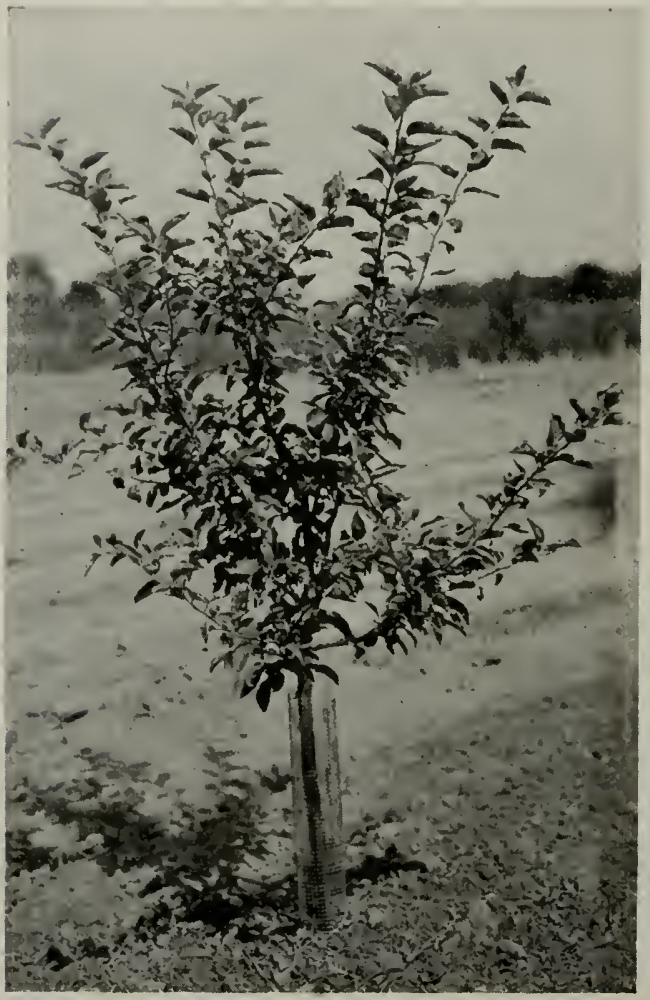

Fig. 123,-Netting around the base of tree to protect from nice, rabbits, etc. (Indiana Station.)

Many caterpillars may thus be destroyed with a minimum of injury to the tree.

Another remedy is to spray the tree all over with arsenical poison, such as arsenate of lead. This will poison the larvæ when they are seeking their food.

Apple Scab.--Probably the worst disease of the apple is apple scab. This fungous growth attacks the leaves, small twigs and the young fruits themselves (Fig. 124). The scabby appearance formed on the fruit gives origin to the name. The disease lives in the form of spores on the trees and in the rubbish under the trees from one season to another.

Remedies.-The winter spraying for San José scale described under the head of peach growing in the next chapter will destroy many of the winter spores of the scab disease.

The orchard should again be sprayed with lime-sulfur or Bordeaux mixture about the time when the buds are opening and before the blossoms are open. 
Twig Blight.-Pears, apples and quinces are subject to attacks of a bacterial disease known as twig blight. Small twigs of trees are seen to turn brown after the leaves have formed. This may prove very serious, as the attacks may extend into the larger branches and destroy nearly all the new growth each season. No satisfactory remedy for this disease has yet been found. Spraying with Bordeaux mixture for the control of scab and other diseases will doubtless aid somewhat in the control of twig blight.

Severe pruning is considered the most satisfactory remedy. The pruning instruments should be disinfected after every cut by dipping in an antiseptic solution, such as copper sulfate, or carbolic acid. Make the cuts about one foot farther back than the disease because of the probability that the disease extends downward in the sap farther than it shows on the surface. Burn the prunings.

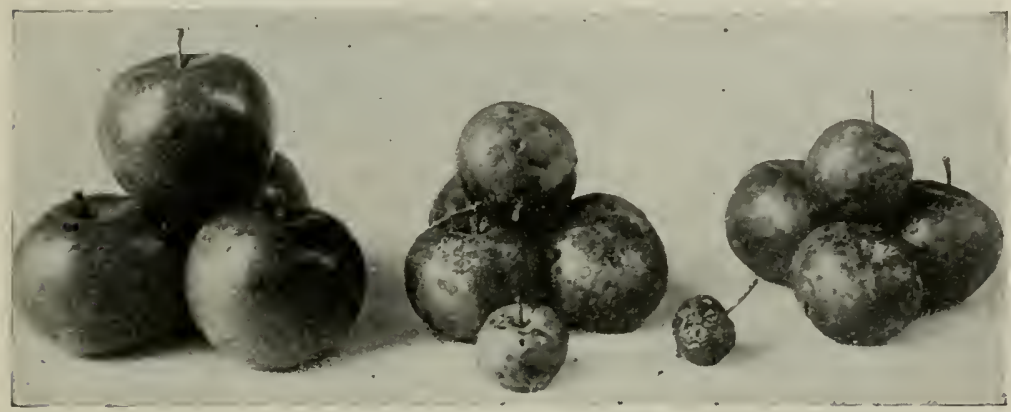

FIG. 121.-Scab disease and sooty blotch on apples compared with sound specimens on the left. (Ohio Station.)

Constitutional remedies are sometimes recommended. It is believed that the disease is more prevalent in heavy, rich soils. If this be true, robbing the soil of some of its plant food by cropping with millet, buckwheat and similar crops may be helpful.

Certain varieties are more immune to the disease than others. Further study along this line is yet to be made.

Bitter Rot.-The apple fruits are attacked by a disease known as bitter rot. The fungous growth starts in a small spot on the surface when the fruit is growing on the tree. These spots enlarge until they cover large areas and reach to the center of the apples. Several spots blend into each other and the whole fruit is finally destroyed. Certain varieties of sweet apples are more subject to the disease than others. Bentley Sweet, for example, is quite subject to attacks of bitter rot, 


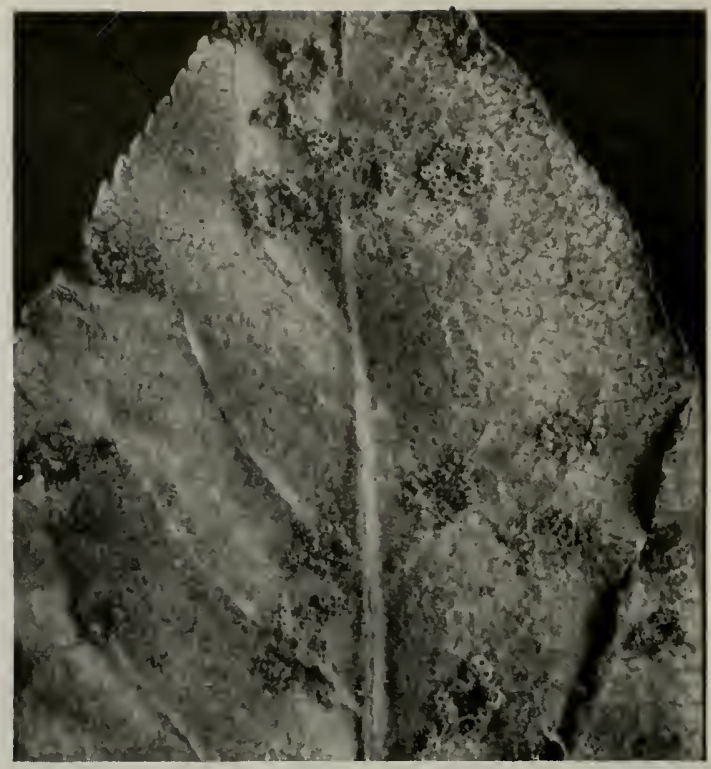

Fig. 125. -Rust on apple leaf somewhat enlarged, showing the cup-like fungous growth (Indiana Station.)

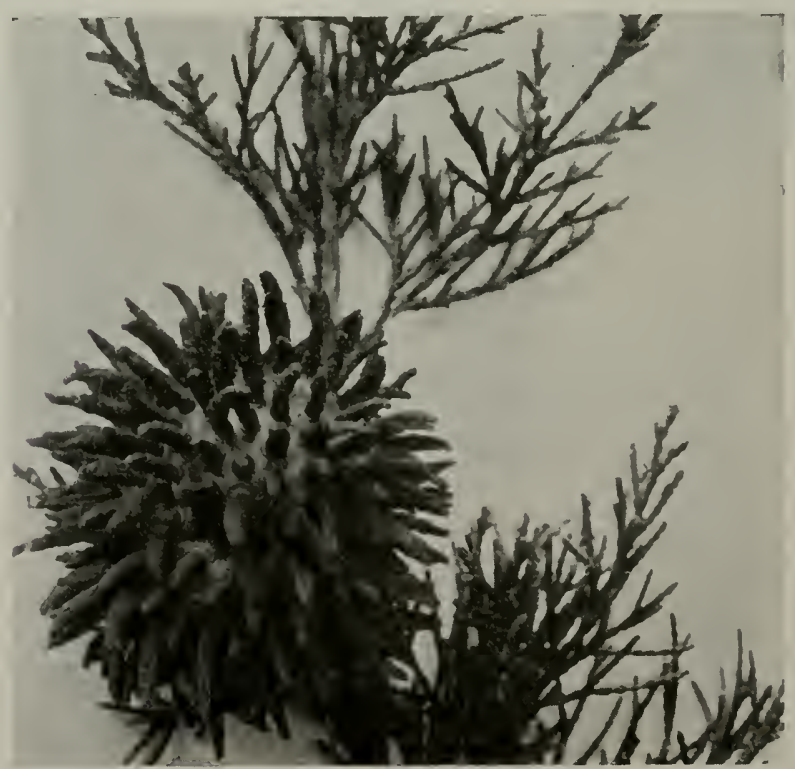

FIG. 126.-Apple rust fungus on the cedar, called "cedar apple." Spores from this generation infest the apple, as shown. (Indiana Station.) 
Spraying with Bordeaux mixture is considered to be a partial remedy for this disease. There is evidence that rich soils will cause fruits to suffer from bitter rot worse than where the trees are partially starved.

Apple Canker.- This form of attack is noticed on the large twigs and main branches, and sometimes on the trunk of trees. The best remedy is to scrape away and thoroughly cleanse the diseased parts. Wash with copper sulfate solution. Spraying thoroughly with lime-sulfur is believed to be helpful. Scraping and cleaning, however, should always precede the washing with antiseptics.

Sun Scald.-The appearance of sun scald is somewhat similar to the canker disease. The bark on the main parts dies and peels from an attack of sun scald. Scraping clean and washing with antiseptics are recommended.

In setting young trees care should be exercised to allow their own growth to shade their trunks. Trees are sometimes severely attacked by sun scald after a winter with much snow. It is supposed that the reflection of the sun from

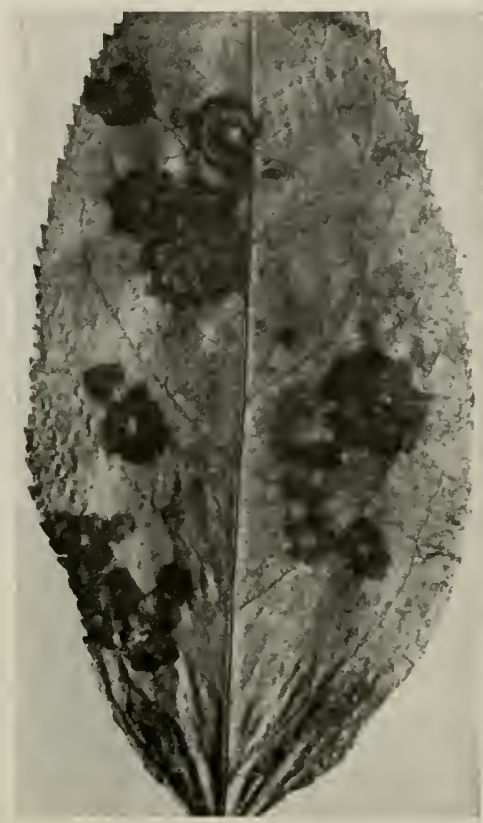

Fig. 127.-Frog-eye leaf spot disease on apple leaf. The usual spraying to prevent scab holds this disease in check. (Virginia Station.) the surface of the snow will blister the bark so openly exposed at that season of the year. Tying the trunks with paper will protect them in the winter as well as in the summer. This method may be easily practiced in the home orchard.

Apple rust is a fungous disease which seriously attacks the leaves, twigs and young fruits of pears and apples. The fungus has ail alternate generation in the form of a fleshy growth on cedar trees, known as the cedar apple (Figs. 125 and 126).

A remedy for the disease is to cut down all cedar trees in the vicinity of the orchard. Spraying with Bordeaux mixture, as for scab, will aid in controlling the rust. 
Frog-eye is a fungous growth forming round spots on the leaves (Fig. 127). It also attacks the twigs and fruit of pears and apples. The sprayings recommended for scab disease will usually control frog-eye.

Curculio on Core Fruits.-A species of curculio closely resembling the one which attacks peaches, plums, and cherries, is an

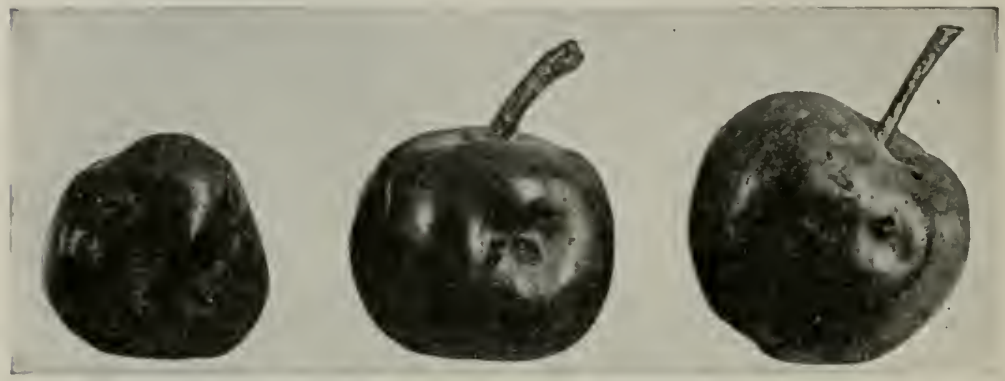

Fig. I28.-Apples deformed and stunted by attaeks of curculio beetles.

enemy of the apple and other core fruits. Figure 128 shows the bad effects of this insect. The wounds in the young fruits made by the insect in biting the skin, eause a deformity. This may make much of the fruit unfit for market.

\section{EXERCISES}

1. Losses from Orchard Enemies.-Ascertain to what extent the San José scale insect is injurious in your neighborhood. The same information should be learned regarding the other insects and diseases of orchards. Calculate the total loss due to these enemies.

2 . Collect specimens of insects and specimens of frait, twigs, etc., showing the damage done by various diseases and insects. Among these try to secure both apple rust and cedar apples. Keep these at school for future reference.

3 . Practice combating enemies by all the methods suggested for each. Determine which are the best remedies.

\section{QUESTIONS}

1. How can you prevent damage by codling moth?

2. How can you combat apple tree borers?

3. What remedies are used for canker worms?

4. For tent caterpillars?

5. For what troubles in the orchard are poison sprays combined with Bordeaux mixture?

6. Give remedies recommended for twig blight.

7. Describe the disease called frog-eye.

8. Describe the effects of curculio attacks on apples.

References.-U. S. Farmers' Bulletins: 662, Anple Tree Tent Caterpillar; 675, Round Headed Apple Tree Borer; 93S, Apple Bitter-Rot and Its Control. 


\section{CHAPTER XVIII \\ THE PEACH ORCHARD}

THE peach is probably themost popularorchard fruit in America, and yet the regions where it is grown commercially are much more limited than for the apple (Fig. 129). The largest peach orchards are found in the southern states and along the Atlantic and Pacific coasts where the climate is modified by large bodies of

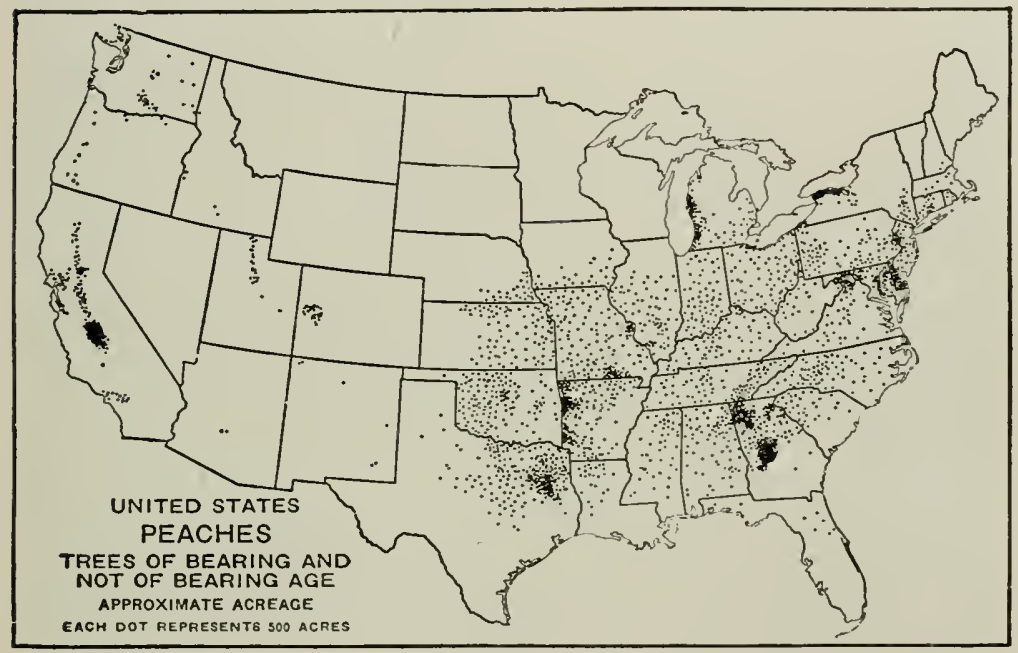

FIG. 129.-About three-fourths of the peach trees are south of the Ohio and Missouri Rivers and in California. Low winter and spring temperatures occur so frequently north of a line from Chicago to Cheyenne that the production of peaches becomes unprofitable.

water and along those shores of the Great Lakes where the prevailing winds tend to modify the climate enough. The peach is also grown commercially along the Allegheny Ridges, where the air drainage is sufficient to prevent serious damage to the blossoms from late spring frosts.

Location and Exposure.-In selecting the location for the peach orchard we must give the utmost attention to the question of air drainage. The peach tends to blossom so early in the spring that the late spring frosts will kill the pistils and ruin the crop for that 
year. The peaches planted at the top of the hill will be far less subject to spring frost than those in the valley. A very gentle slope as in figure 130 may be sufficient.

It is more important to have the peach crop grown on the northeast slope than with any other orchard trees. The first few warm days on a southern slope may warm the soil enough to force the trees into blossom. As the blossoms have no protection from the leaves, as in the case of the apple they are more easily killed.

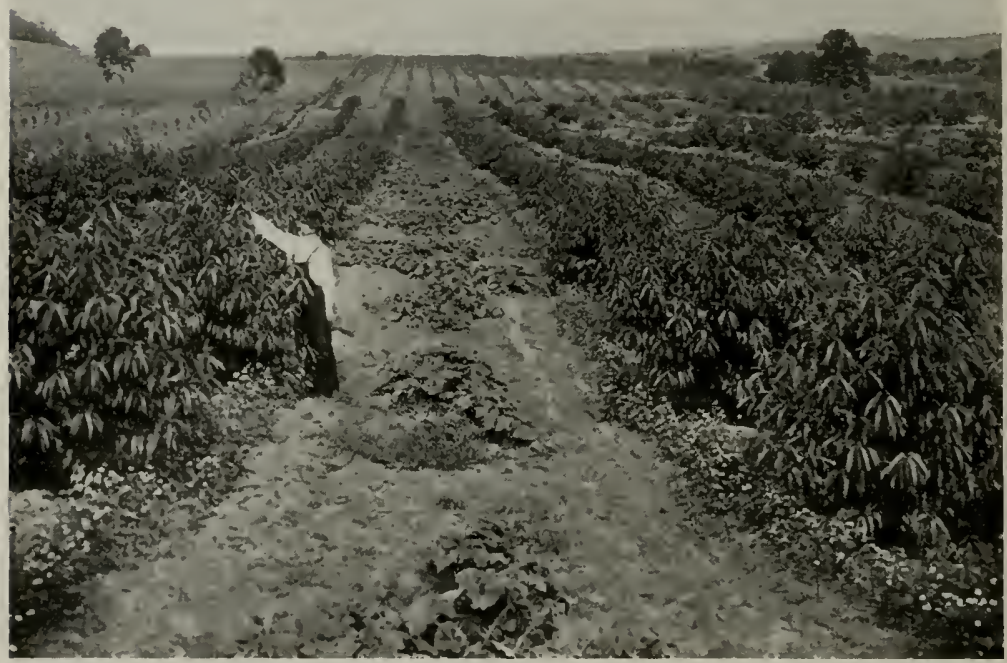

Fig. 130.-A peach orchard in Massachusetts, two years old. Eoston Marrow squash vines growing between the rows. Use inter-cropping only while trees are young. (l'hoto from F. C. Sears.)

In nearly all climates the peach tends to open its buds even with a few warm days in January, February or March before winter is really over. In northern exposures the soil remains cold and the sap is not forced into circulation through the tree enough to cause the buds to open. The fruit is therefore not so likely to be killed if the blossoms do not show before spring weather has come to stay.

Peach Soils.-The peach will thrive well on rather light soils (Fig. 131). Soils very heavy in clay are not well adapted to peach growing. The peach prefers soils that are warmed quickly and 
have good under-drainage. If the drainage is poor the leaves will turn yellow and the growth is slow.

High elevations will usually have sufficient drainage unless there be seepage water from the hillside. Apples, pears and plums would better be used where there is danger of the soil being too heavy for peaches.

Varieties for Planting.-Peaches ripen at different seasons, and a succession of ripening may be secured by selecting several varie-

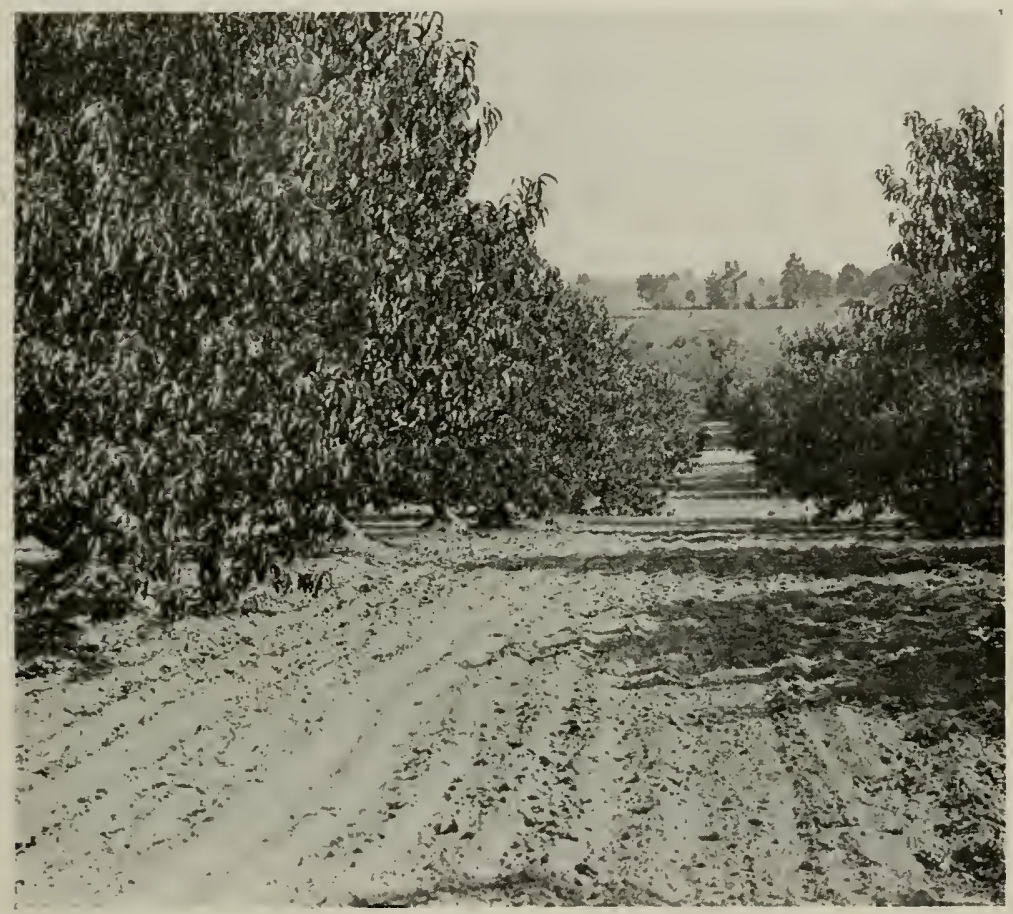

Fig. 131. - The light soil of the peach orchard should be kept well cultivated. (Indiana Station.)

ties with different ripening dates. The very earliest varieties are more subject to attacks of the brown rot disease, and as it is a very serious enemy the earliest varieties should not be planterl. Berries and other fruits may be made to take the place of early varieties of peaches. For the home garden start with Mountain Rose or Champion. Next would come Oldmixon Free or Stump-theWorld. Just after these will come Reeve's Favorite or Captain 
Ede. These all precede the Elberta in ripening. The Elberta is a yellow fleshed, free stone which is very popular, and many orchardists make their main planting of this variety.

Just after Elberta we can have Crawford Late or Fox Seedling. Then will follow Smock, Ford Late, or Picket Late. The next group will be Bonanza, Heath Cling and Leavy's Late Cling. If any later than these are desired plant Salway. Still later than this is Bilyeu, but it is hardly worth growing for home use.

Do not choose more than one of each of these groups. If we omitted the last this would make a selection of seven varieties. This may be too many. Probably the best three would be Mountain Rose, Elberta and Crawford Late. Ask your state experiment station to recommend varieties for your section.

Getting the Trees.-In selecting trees for planting the grower has a number of things to consider.

1. Whether to plant June budded or August budded trees is probably the first consideration. June budded trees are always cheaper when purchased from the nurseries. They are smaller, as they have made less than one season's growth.

2. Trees of June budding (Fig. 132) are much cheaper than those of September budding (See chapter VI.), but the cheapest in this case are not the best.

3. Whether to buy trees from the nursery or to grow them at home is another consideration. If large orchards are to be planted and the matter has been considered at least a year in advance it may pay to grow your own trees. Otherwise buy them from a nursery not too far away.

4. Never buy two-year-old trees. They are sure to make less growth than the younger trees; it is more difficult to make their heads form to suit; they cost more; the freight is more; a larger number of them will die.

5. Order trees several months in advance so that you will be certain to get your choice of varieties. If possible have them shipped to you before it is time to plant. Heel them in as shown in figure 133.

6. In ordering allow some latitude in choice of varieties. In eertain groups one variety is nearly as good as another. Allow the nursery to substitute trees for those they cannot supply in your list, provided they ripen at the same season.

Laying Out the Orchard.-The directions for laying out the apple orchard should be read again (Fig. 134). If peaches are to be 
plantea alone and not as fillers among apple trees they may be set twenty feet apart each way, or even as close as fifteen feet each way. The distance will depend upon (1) strength of the soil (2) type of head whether low or high, (3) system of pruning to be followed in the care of the orchard. Close pruning will allow of close planting.

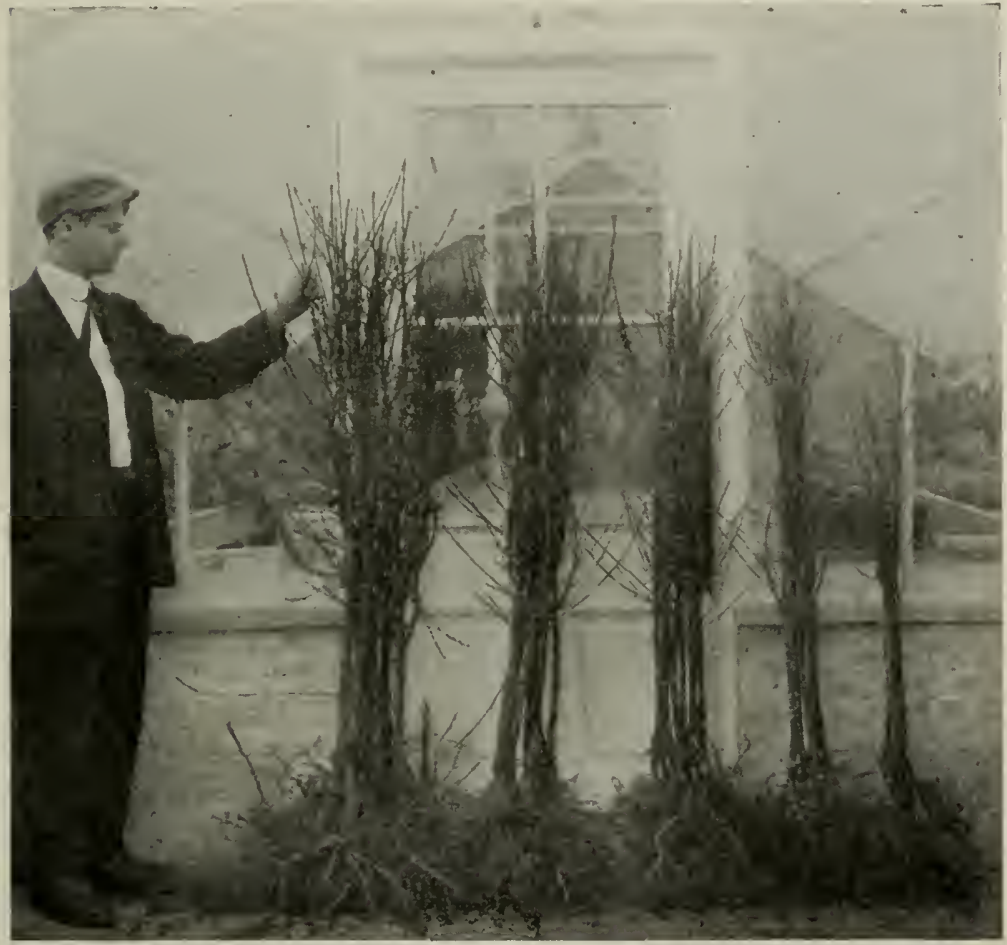

FIG. 132.-Peach trees just received from the nursery for planting in the orchard. At left are grades one, two and three of September budding. Next are two sizes of June budded trees. (New Jersey Station.)

Peaches as Fillers.-The peach tree comes to bearing age by the third or fourth spring after planting. Because of this quickmaturing feature the trees are often planted with apples, which mature more slowly. The plan usually followed in this filler system of planting is shown in figure 136 . There are three times as many peach fillers as there are permanent apple trees.

When the peach trees are about ten or twelve years old they 
may be cut out and the ground will be fairly well occupied with apple trees.

Inter-cropping.-The same principles regarding inter-cropping mentioned for the apple orchard apply here (Fig. 135). If crops which require thorough cultivation are grown between the trees, then the trees will receive the cultivation they need. Do not grow tall crops, such as corn or sorghum between the trees. This tends to shade the trees too much unless wide spaces are between the crops and the trees. Early varieties of Irish potatoes are suitable, if the soil is favorable. It is well to let the orchard have

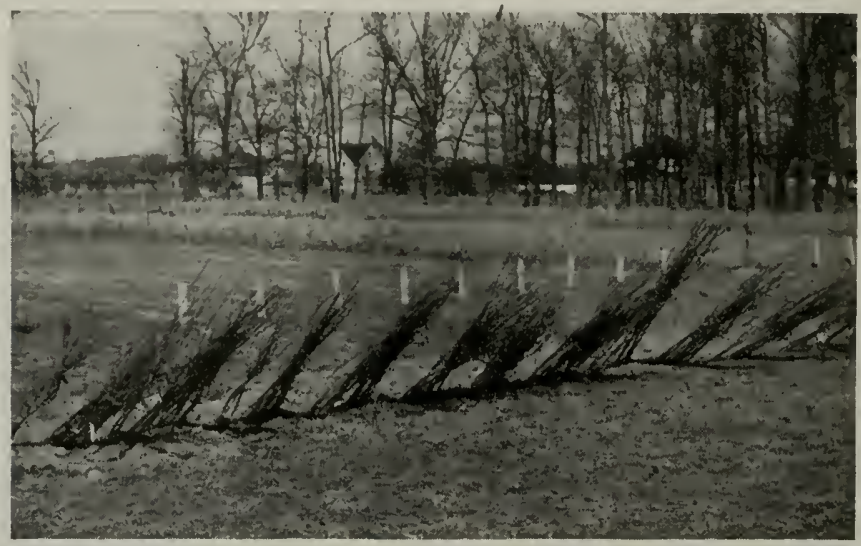

FIG. 133.-Fruit trees should be heeled in as soon as received or when dug from the nursery. Tramp the soil well about the roots. (Indiana Station.)

very little if any cultivation during the latter part of the summer and early fall.

Cover Crops.- It is more important, perhaps, with peaches than with any other orchard trees to have a cover crop sown late in July or early in August to remain during the fall and winter (Fig. 137). The growth of this crop will tend to check the growth of the trees in the fall, cause them to ripen their buds and bark in time for winter and prevent some winter killing. The cover crop will also take up and hold available plant food for the use of the trees the next summer. It will prevent leaching and washing of the soil. The cover crop also keeps a carpet over the ground which is much appreciated during the winter pruning and spraying operations.

For the cover crop sow rye, winter vetch and perhaps crimson clover where the winters are not too severe. 
Clean culture in a bearing orehard without an inter-crop is a good plan while the trees are young.

Pruning.--In starting a young orchard it is important to start the trees right. Low-headed trees make the spraying easier, the picking easier, and the pruning easier. The cultivation, however,

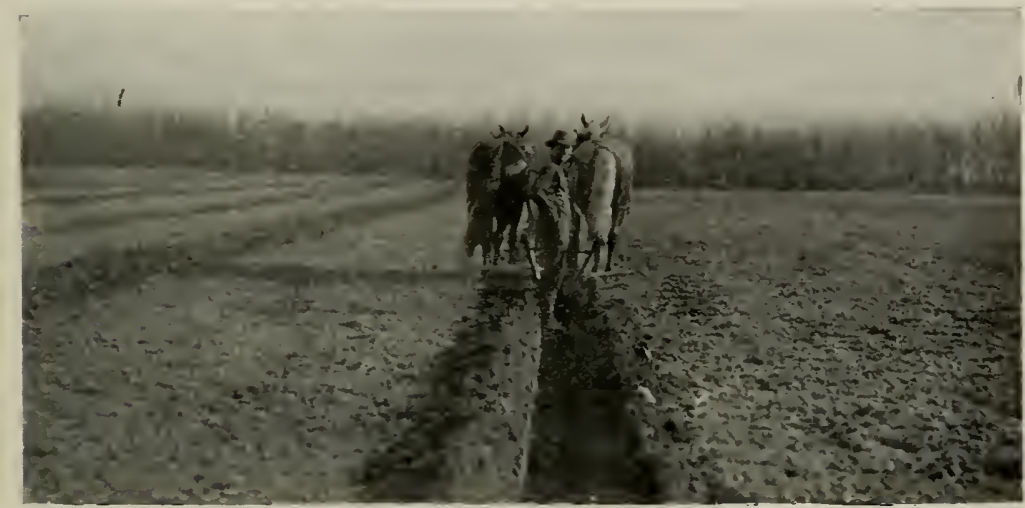

F1G. 134.-Laying off the rows for planting peach trees. If the furrows are very straight this method of laying out the orchard will save considerable hand labor in setting the trees.

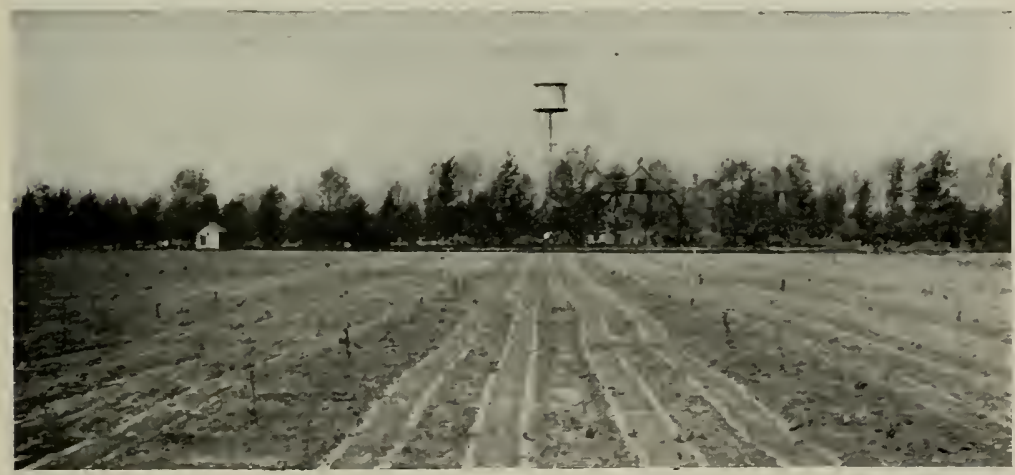

Fig. 135.-A young peach orchard with rows of garden truck planted between the rows of trees. (N. J. Station.)

is a little more difficult, as the limbs of the trees are more in the way of the implements and teams.

In selecting the side limbs when the orchard is young remember that these are to be the main limbs of the trees later on. They should be at different heights on the trunk so they will not split off 
so easily. They should extend in different directions so as to somewhat balance the tree.

The annual pruning (Fig. 138) of the peach orchard should include (1) the removal of all branches that are dead or diseased, (2) remove any twigs or shoots or large branches that tend to rub or cross through the head of the tree, (3) trim off twigs bearing mummied fruits, (4) trim away any parts that have been broken or injured by wind or otherwise, (5) thin the mainhead if needed to let in more light, (6) cut back the long growths. This may include

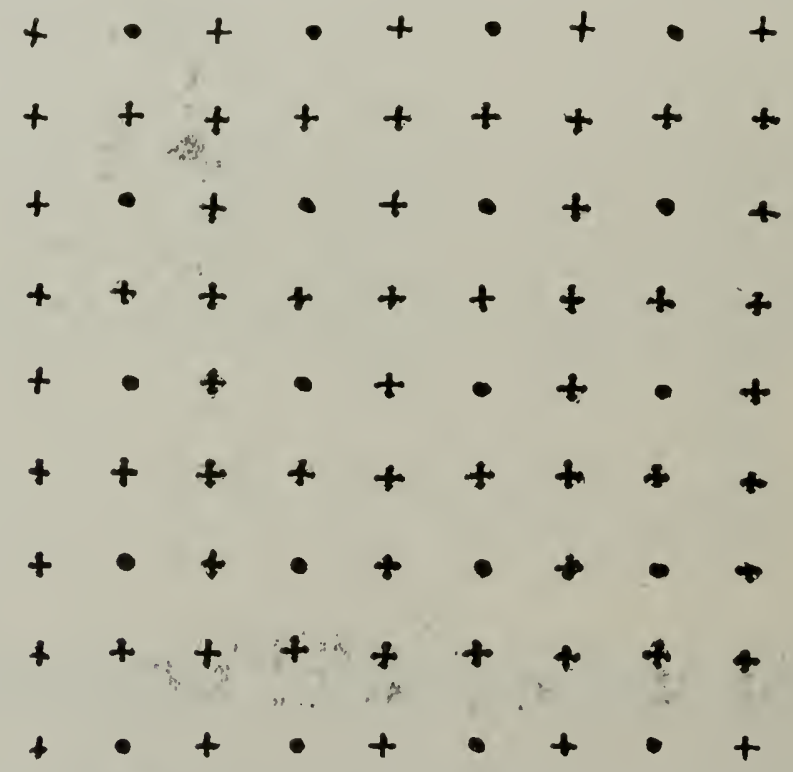

Frg. 136. -A plan of planting the orchard using the filler system. Black dots are the per manent trees; others are temporary.

the entire removal of some of the long shoots and cutting back one-third or one-half the length of many others.

Some study should be given to the location of the fruit buds at pruning time. They are located where two or three buds are found together on the twigs. If the fruit buds are numerous more severe cutting back of the new growth is allowable than when the fruit buds are scarce.

It is well to look over the trees each summer and remove small shoots starting at the base and inside the head where they are not 
needled. These may be pinched off or cut with a pocket knife. (Fig. 139).

Fertilizing the Peaches.--On light sandy soils considerable commercial fertilizer should be used, particularly in the growing of the young trees. In the early growth use a mixture containing considerable nitrate or ammonia (Fig. 140). As the trees reach bearing age use a larger proportion of phosphoric acid and potash and reduce the quantity of nitrogen. It is best to make the fertilizer mixture at home to suit the soil and the conditions of the trees.

The best time to apply commercial fertilizer is just after turning

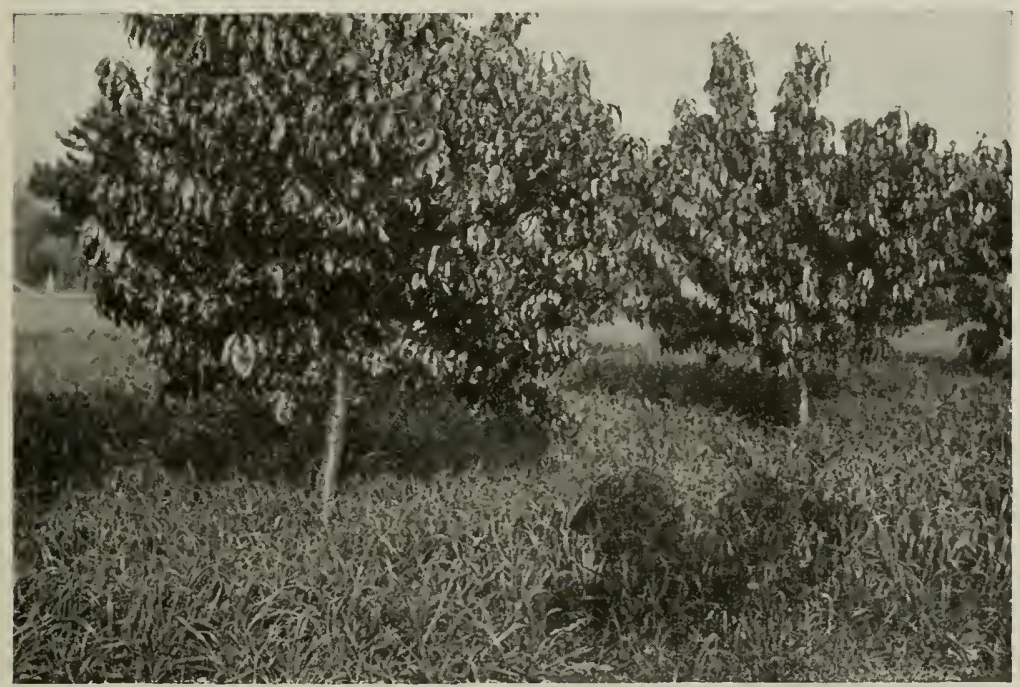

Fig. 137. - The cover crop is sown early to make a good growth before winter. (Indiana Station.)

under the green manure crop. Harrowing or cultivation which follows the spring plowing will help to incorporate the fertilizer with the soil.

If soils are heavy little if any fertilizer is necessary in addition to the green manure added by the plowing under of the winter cover crop.

Harvesting the Peach Crop.--For home use it is well to let the peaches become fully mature on the trees before picking. They should be watched enough to have them picked before they fall to the ground. For market purposes it is necessary to pick them 
much earlier than for home use. When the crop is to be marketed near by they can be more nearly ripe than if they are to be shipped some distance. Often the California crop is picked ten to fifteen days before it is sold on the eastern markets. During this time the fruit is becoming riper in packages. This plan, however, does not allow for as much derelopment of sugar, and the fruit is apt to have a bitter taste. The longer the crop remains upon the trees the sweeter and richer the flavor will be.

Always pick the fruit by hand; never allow it to be shaken from the trees and gathered from the ground.

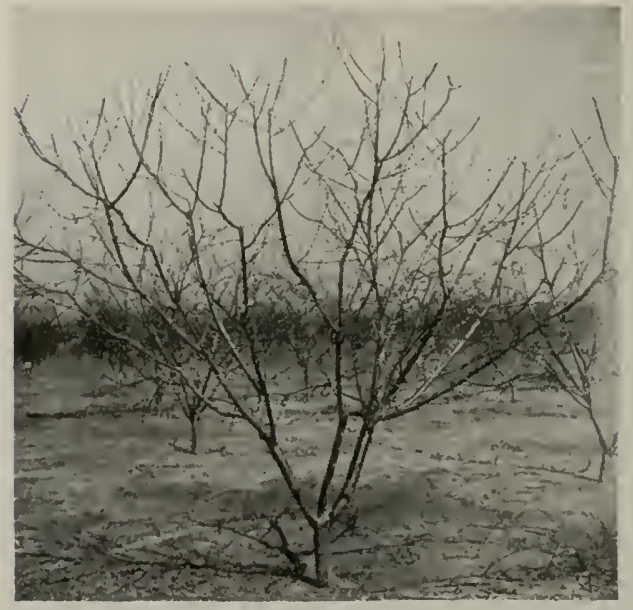

FIG. 135. - Some light pruning each year is the best plan. Note the amount of prunings under the tree. This tree might have the branehes thinned out a trifle more.
With low-headed trees small step ladders will enable the picker to reach all parts without climbing. (Fig. 141). On high-headed trees some climbing may be necessary, or longer ladders may be used.

If the crop has been thinned little sorting of the fruit will be necessary, as it will practically all be of first grade size. The thimning is done when the peaches are about the size of cherries. Only enough peaches are left on the trees at thinning time so that they will not touch each other when they become full size. They snould not be left closer than four inches. Enough improvement in size and quality is attained to greatly increase the value of the peaches produced. The cost of thinning is very little, and the crop brings a better price. Figure 142 shows bad effects of not pruning the tree nor thinning the fruit.

Peach Packages.-The best fruit for market is packed in crates containing six one-half peck baskets. This is called the Georgia ('arrier, or the Georgia crate (Fig. 143).

The next grade of fruit is quite commonly packed in Climax baskets with wood or wire handles over the center. The cover 


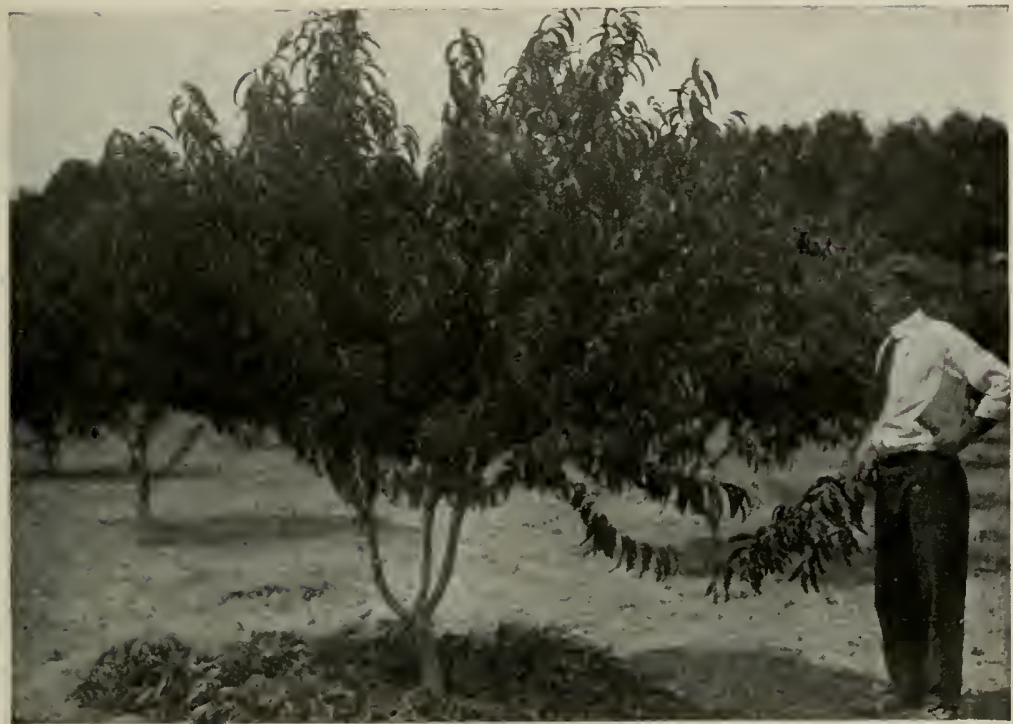

F1G. 139.- Summer pruning is chiefly done with a knife or merely with the fingers. Remove the small shoots inside and at the base, to direct the grow th where desired. (New Jersey Station.)

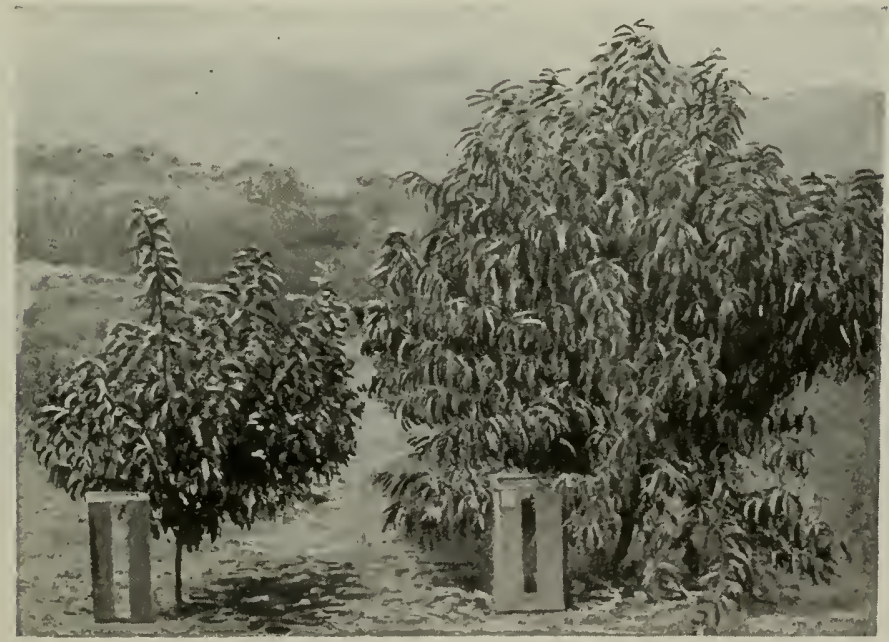

FIG. 140. - Orchard peach trees two years old. The one at the right has been fed liberally with much nitrogen in the fertilizer. The other has received no fertilizer. 
mily be either of wood or of mosquito bar. The handle should be rigid, and is usually not bent down during shipment. Fruit

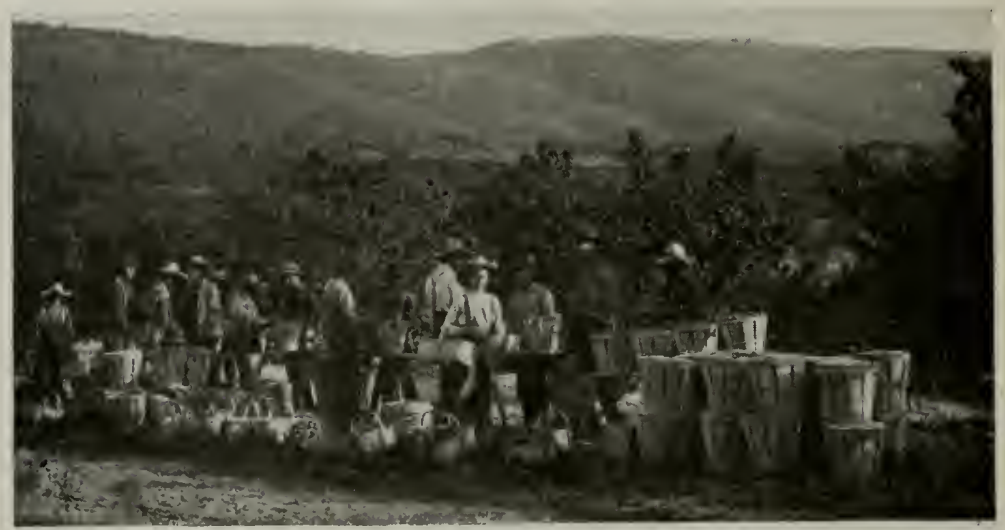

F1G. 141.-Picking and packing peaches for shipment.

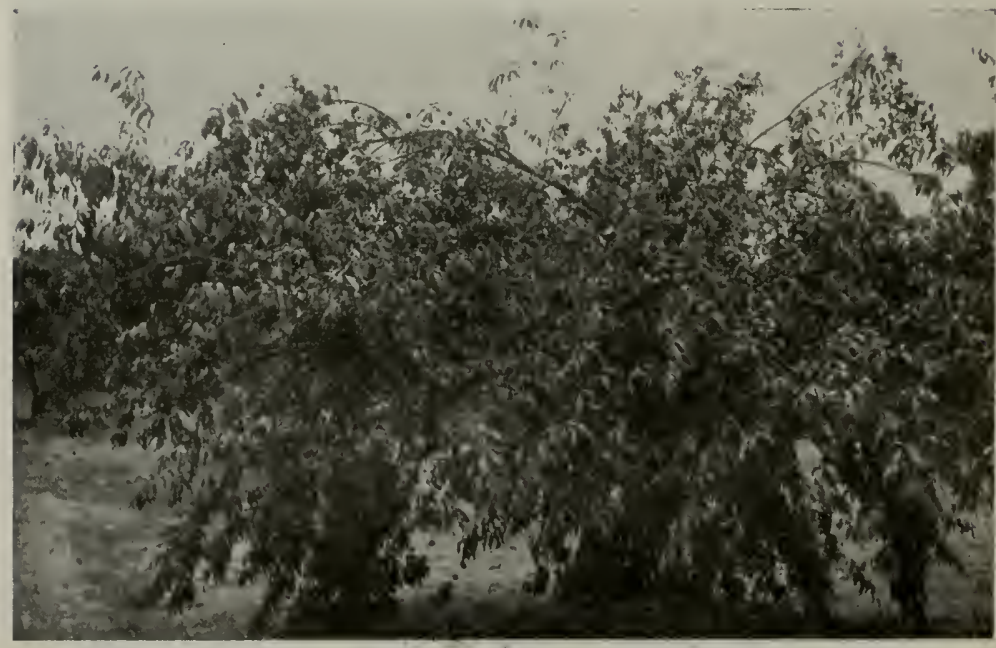

FIG. 142. - A peach tree breaking down with its load because the branches were not cut back, and the fruit was not thinned. (New Jersey Station.)

packed in Climax baskets is usually not repacked at the market, but the purchaser takes the package with him.

The Delaware peach basket holds one-half bushel or more, has 
sloping sides and is used abundantly for the bulk of peaches shipped to market from many peach sections. These are used by some growers for packing the third grade or poorest fruit. The covers are made of wood and protect the fruit well when shipped.

\section{ENEMies.}

The San José scale is very destructive to the peach orchard. It is prevalent in all parts of the country, and attacks nearly all kinds of fruit trees and shrubs, and is very serious on many forms of shade and ornamental plants. Figures 144 and 145 show the insect.

The pest is not so serious that it requires the destruction of the trees by man, as methods of control are now well understood. Thorough spraying in the winter with lime-sulfur or with miscible oil will usually keep this pest in check. We can never get rid of the insect entirely, but the annual spraying is beneficial for other purposes, and the extra cost of the battle due to the presence of the scale is rery slight. The trees should be sprayed very thoroughly

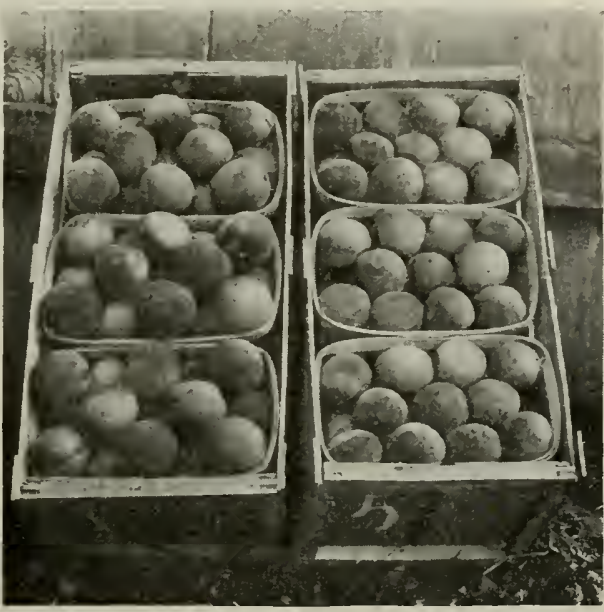

Frg. 143.-Two styles of packing peaches in Georgia carriers. Diagonal pack at left, popular with dealers. Flat and tight pack at right, fruit often bruised. (Michigan Station.)

just after the winter pruning is completed. Select a warm, bright day in winter and spray thoroughly from top to bottom of the tree. Let no spot be skipped. If the scale is very severe two sprayings may be necessary. The first spraying may be applied in the late fall or early winter just after the leaves have dropped. At this time use the miscible oil. See Chapter XXV. The next spraying can be with lime-sulfur. This should be completed before the buds begin to swell in the spring.

The peach tree borer is a serious pest in nearly all orchards. It bores in the soft wood near the surface of the ground, sometimes several inches underground, and sometimes as much as a foot or so above ground. It attacks trees of all stone fruits, 


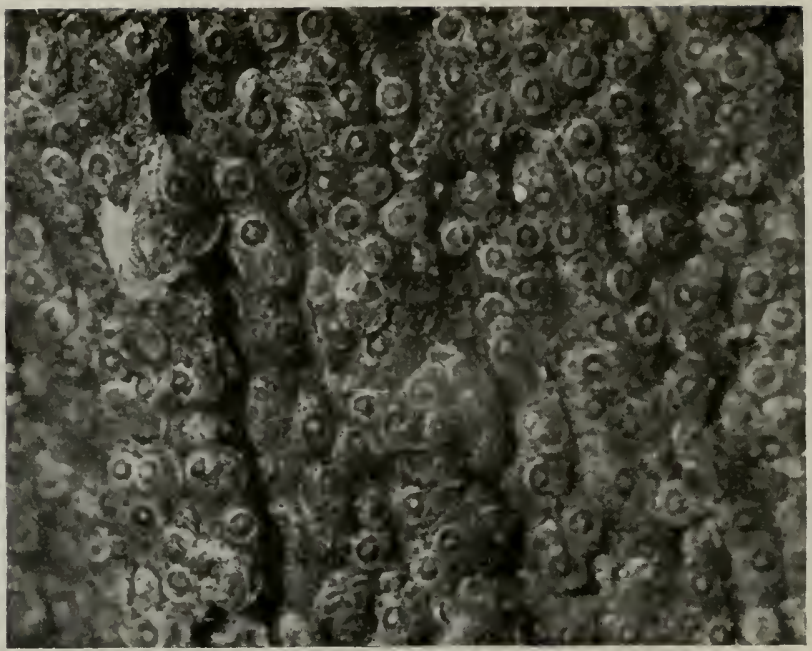

Fic, 144.-San José scale on twig, as seen under magnifying lens or microsenpe. (Kientucky Station.)

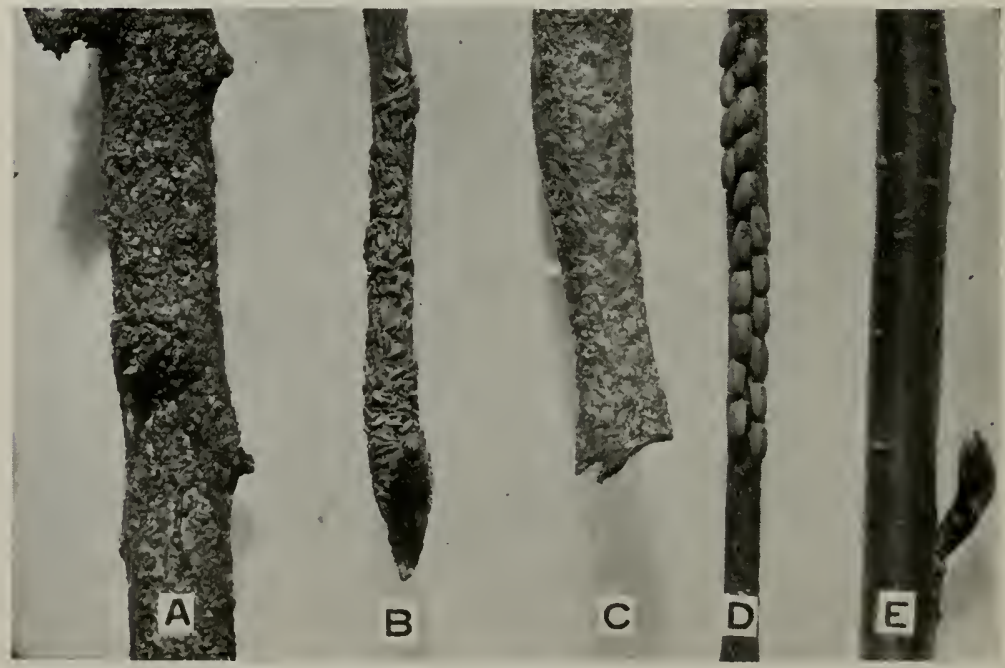

Fig. 145. - Three left twigs infested with scale inscets. $A$, San José scale; $B$, oyster-shell bark-louse; $C$, the scurfy bark-louse; $D$, eggs of grcen grass-hoppers, sometimes mistaken for scale; $E$, healthy twig. (Kentucky Station.) 
The adult insect is a moth with transparent wings (Fig. 146). She lays her eggs on the bark of the tree near the ground, and the larve when hatched eat their way inward.

There are several remedies. One is to keep the adult from laying her eggs on the trees by banding them with tar paper, veneer wood or other material (Fig. 147). Another remedy is to dig out worms and kill them with a knife or wire. To do this it is well to remove the soil with a hoe for several inches below the surface. In a few days the larvæ may be located by their borings or sawdust. When found they can be easily traced with a wire and killed. After this the soil is again thrown back to the trees and mounded slightly to make the work easier next time. This operation should be systematically followed every spring and fall.

The plum curculio is the worst enemy of the fruit itself. This little beetle lays eggs on the surface of the fruit when it is about the size of the garden pea. The young hatch and eat their way into the fruit at a wound made by the adult. The larva feeds on the flesh of the fruit, chiefly near the stone. This often causes the fruit

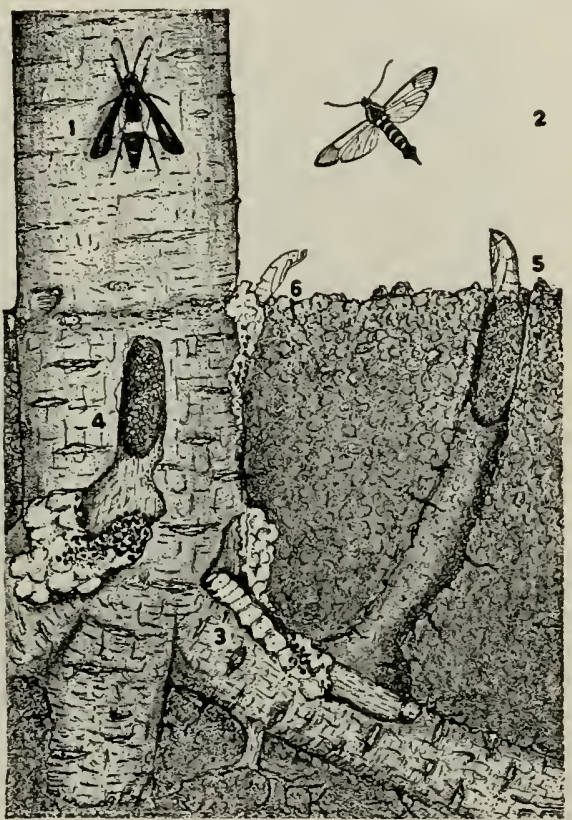

Fig, 146.-The peach tree borer: (1) female moth at rest; (2) male moth; (3) larva, or grub, feeding its burrow; (4) cocoon; (5) cocoon with pupa emerging; (6) empty pupal case protruding from a burrow. (Ohio Station.)

to fall to the ground, and entirely ruins it for market purposes.

As the adults lay their eggs chiefly in the morning twilight they can be destroyed by jarring the tree and catching the adult on stretchers made for the purpose. This method only partially controls the pest.

Another remedy is to spray the tree thoroughly with a poison containing arsenate of lead at the time the petals fall from the 
trees, or soon after. A second spray is usually necessary about ten days later. Use two to three pounds arsenate of lead in 40 gallons of water or in 40 gallons of Bordeaux mixture.

Brown Rot of Peaches.-This is probably the worst fungous disease of the peach (Fig. 148). It is most serious upon the early ripening varieties, but is found to some extent on nearly all varieties unless they are thoroughly sprayed with Bordeaux mixture. The best plan is to select varieties which are least affected by the

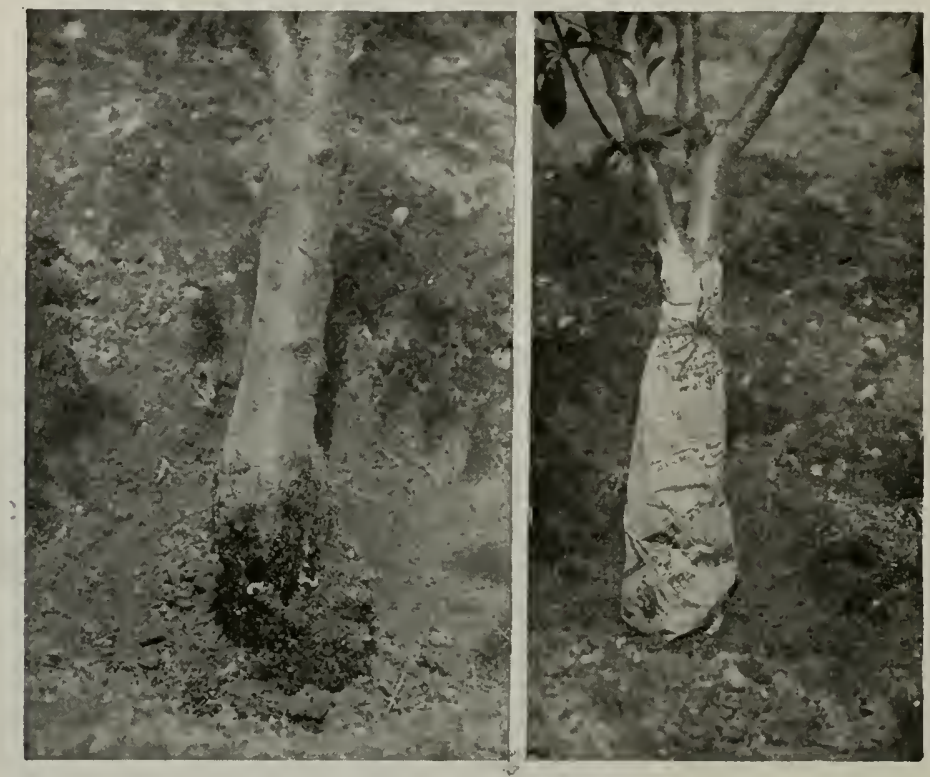

Fig. 147.- Peach borers have been removed from the left tree and lie in view. Right tree protected with paper so adult moth cannot place her eggs in the trunk. (New Jersey Station.)

brown rot and then to thoroughly spray them with Bordeaux mixture. The spray for scale with lime-sulfur in late winter or early spring will aid materially in controlling this disease. This should be followed with a spray of Bordeaux mixture at the time the buds are swelling before they show very much color. When the petals fall and we are spraying for curculio we should use Bordeaux mixture combined with the poison. This will control both the disease and the insect. Repeat the spray about ten days later, using about the same mixture. In severe cases it may be necessary to give an orchard a third spraying with the same mixture. 
Peach Leaf Curl.-This is a fungous disease which affects the foliage of stone fruits and often causes severe dropping of leaves

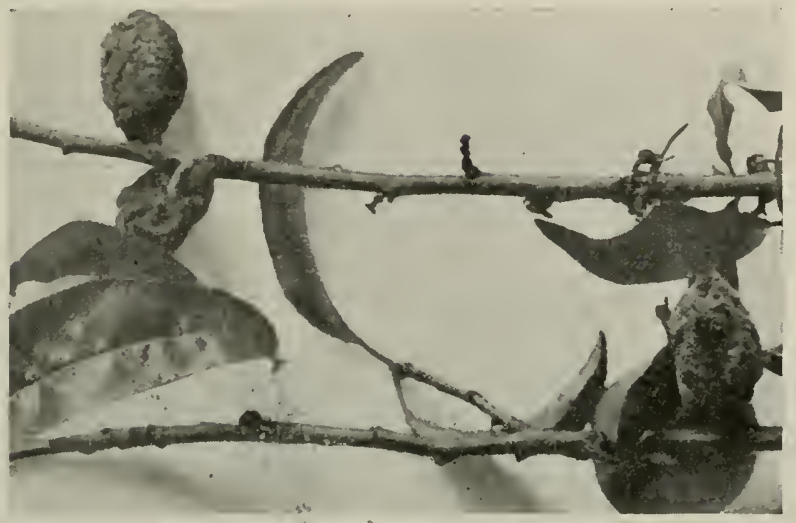

Fig. 148.-Brown rot (monilia) on peach and plum. It affects the fruit, twigs, and leaves of all stone fruits.

in early summer or later (Fig. 149). The trouble is usually controlled without special effort while spraying orehards with fungicides for other cliseases such as brown rot and scab.

Peach Scab is a serious disease of the peach in some sections. It affects the fruit and causes it to harden and split on one side, and the twigs turn brown. This makes them resemble an attack of twig blight on apples.

The campaign just described for the control of brown rot disease will be effective in the control of scab.

Peach Yellows.-This disease is difficult to recognize. Its cause is not known. Symptoms which indicate the disease are: (1) Red, spotted character of the fruit; the spots and red lines of flesh beneath them are scattered, and appear on one side before they do on the other. (2) Premature ripening and uneven ripeness of fruit. (3) Bitter and insipid taste of such fruits. (4) Tip growth of small yel-

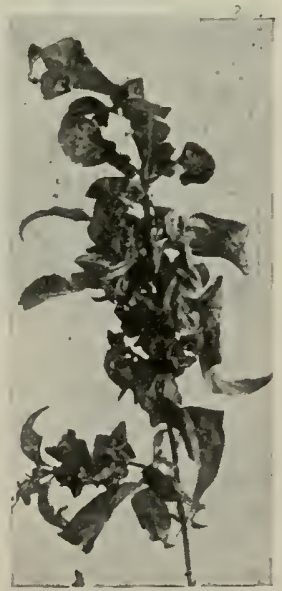

Fig, 149.-Peach leaf curl disease which attacks branches of cherry, peach and plum. lowish leaves from terminal buds. These leaves are stiff, narrow, and stand outward from the stem. These tip growths may appear 
late in the season. (5) Stiff-leaved, yellowish shoots from the body of the tree. These may become dense tufts. (6) Small, slender growth of all new wood (Fig. 150), with narrow, small leaves. These may be yellow or reddish in color. (7) Death in a few years.

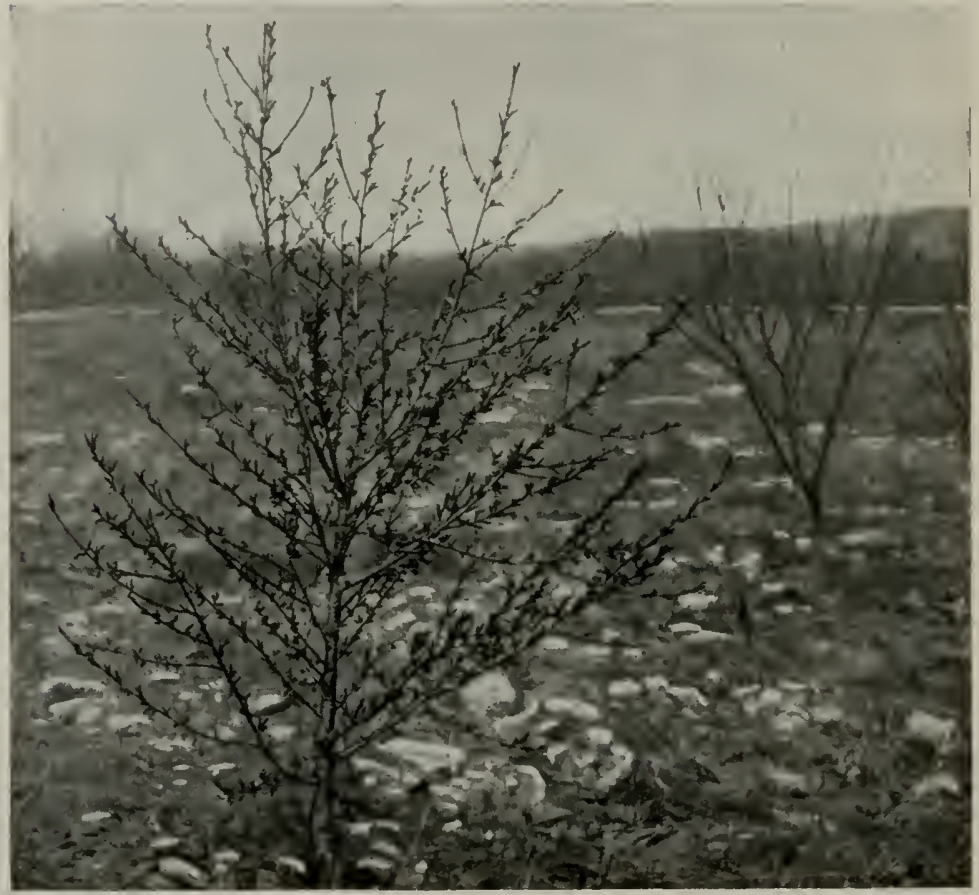

FIg. 150.-A pretty certain indication of the yellows disease. Numerous weak twigs and branches with premature starting of leaves in early spring. (New Jersey Ntatiou.)

Do not confuse attacks of borers or of starvation with the yellows disease. Rosette, little peach, and leaf curl are diseases which are apt to be mistaken for yellows.

The treatment, when yellows is positively found, is to take out the tree, roots and all, and burn it entirely. No spraying or other cure or prevention has yet been found. 


\section{SURVEYS, PROJECTS, AND EXERCISES}

1. Orchard Projects. - A student may manage the peach orchard for one season or more. Perform the pruning, spraying, cultivation, fertilizing, intercropping, growing the cover crop, fighting borers, harvesting, marketing, etc. Make directions and record blanks to suit.

2. A more limited project may include merely the inter-cropping in a young orchard. Plant, cultivate, harvest, and market these crops.

3. A short project may be made of the picking, packing and marketing of a crop of fruit.

4. Fertilizer trials may be made in the orchard to determine which are best for your particular soils, which hasten the ripening, which delay the ripening.

5. An Orchard survey should be made to determine what varieties are most successful, times of ripening, best exposures, loss from spring frosts benefits of spraying, damage from borers, scale, curculio, brown rot, scab; system of heading, picking, packing, and marketing.

6. Blossoming Dates.-Make a list of all the varieties of peaches grown in the region. Opposite each of these indicate the date of (1) first bloom, (2) full bloom, (3) falling bloom. From these tables determine what varieties could be used to cross pollinate others.

\section{QUESTIONS}

1. What regions of America are best suited to the growing of peaches?

2. Why is an eastern or northern slope best for peach orchards?

3. Describe best soils for peaches, plums, and cherries.

4. Make a list of varieties of peaches arranged according to dates of ripening.

5 . Give several points to consider in selecting trees for planting.

6. Give directions for laying out and planting the peach orchard.

7. Mention several good crops to grow between the rows of the young orchard.

8. Give several advantages of using cover crops in the peach orchard.

9. Give directions for pruning trees at setting time.

10. Give arguments for low heading and for high heading.

11. Discuss fertilizers for peaches.

12. Give directions and reasons for thinning fruit.

13. Give several cautions and directions for harvesting peaches.

14. Describe some good fruit packages for peaches.

15. How is the peach-tree borer kept in control?

16. The plum curculio?

17. Give directions for control of San José scale.

18. Same for brown rot.

19. Same for peach scab.

References.-U.S. Farmers' Bulletins: 685, The Native Persimmon; 900, Homemade Fruit Butters; 917, Growing peaches: Sites and Cultural Methods; 918, Growing Peaches: Varieties, Classifications, and Propagation. Read the peach article in The Standard Cyclopedia of Horticulture. 


\section{CHAPTER XIX \\ CHERRIES AND PLUMS}

MaNY of the lessons considered in the Peach chapter are of value in connection with the raising of cherries and plums. Each of these fruits are further discussed in this chapter.

\section{CHERRIES}

Cherries are chiefly of two main types: the sweet and the sour cherries (Fig. 151). These come from two distinct species, but

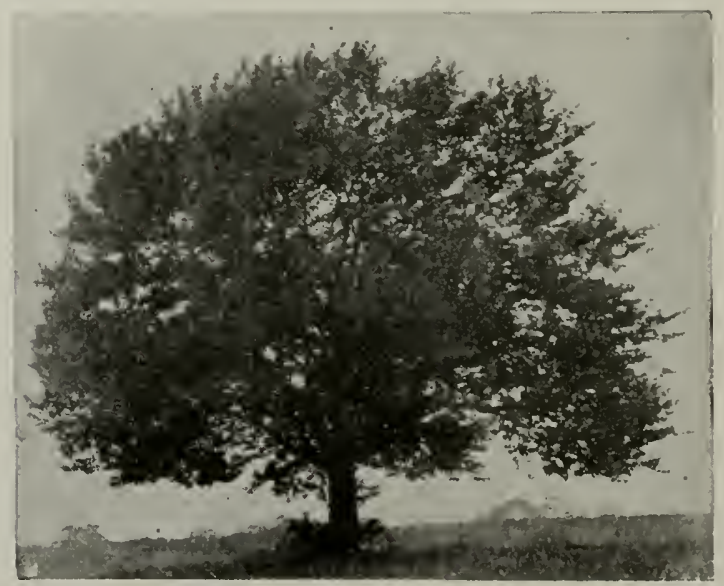

Fig. 151.-Black sour cherry trees sometime reach enormous size and live many years.

they have been greatly improved by close selection and otherwise. Those in cultivation have chiefly originated in the Old World, and our native cherries are little used. The cherry is grown successfully in all parts of the country, from Newfoundland to Florida and from ocean to ocean (Fig. 152).

Soils.-The sour cherry is grown in nearly all types of soil and in varied climates. They are considered much hardier than the others and less subject to enemies. The sweet cherry prefers rather rich black loam, and should be given close attention by the grower. 
Location.-As with the apple and peach, the cherry trees should be planted where there is plenty of air drainage. A good slope toward the east or north is desirable.

Varieties.-Growers who are unfamiliar with the varieties of sweet cherries should first grow only a few of them. The varieties of sour cherries may be grown with less care and with more assurance of success.

Varieties of Sweet Cherries.-The popular varieties of sweet cherries are the so-called Hearts, the Dukes and the Bigarreaus. Black Tartarian and Governor Wood are varieties of the Hearts.

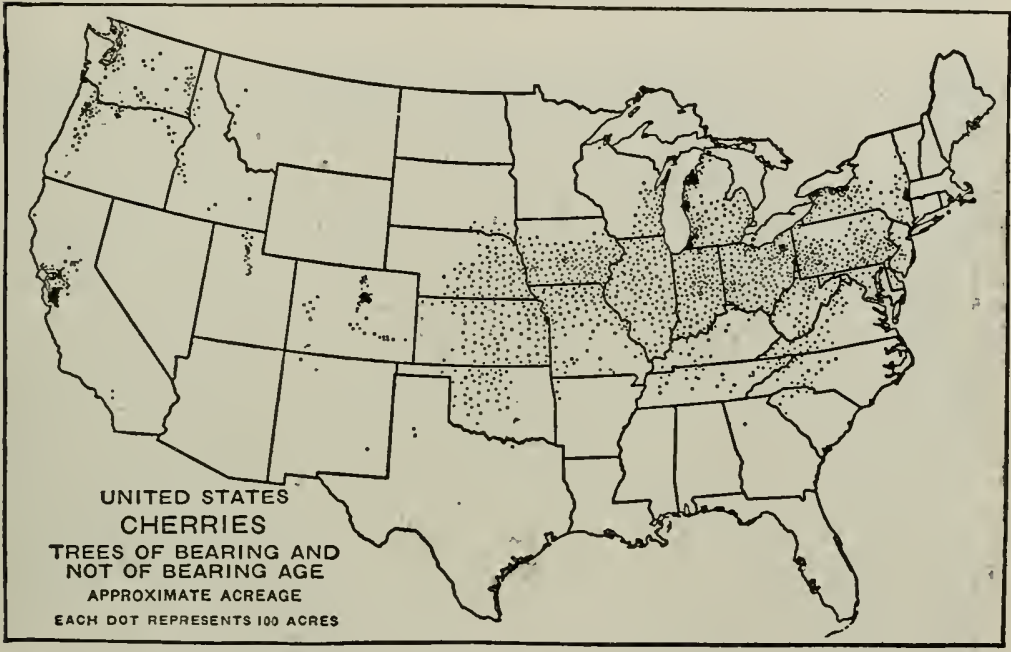

FIG. 152.-Approximate acreage of cherry trees in the United States. California, Oregon, Michigan, New York, Pennsylvania, Ohio and Wisconsin are the leading states in the production of cherries. The centers of commercial production are located in the Lake States and the valleys of the West. Very few cherry trees are found in the Southern States. (U.S.D.A.)

These are heart shaped and light colored. The Dukes are represented by May Duke and Rheine Hortense. These are smaller than the other sweet cherries. The flesh is very soft, and they are difficult to handle in shipping. The Bigarreaus are also heart shaped, but have firm flesh. The Yellow Spanish and Napoleon are light colored, and the Schmidt and Bing are dark colored.

Varieties of Sour Cherries.-The early Richmond and Montmorency are rather small, light colored, sour cherries with rather clear juice. The trees are somewhat upright in growth and branch while very young (Fig. 153). 
English Morello and Iouis Philippe are small sour cherries, dark in color with clark clear juice. The trees are characterized by having a drooping habit.

Propagation of Cherries.-Budding is chiefly followed in the propagation of cherries of all kinds. Mazzard and Mahaleb stocks are commonly used except in Japan. Russian sour cherries are sometimes used in the regions with rigorous winter. The budding is done in late summer more commonly than in June The buds

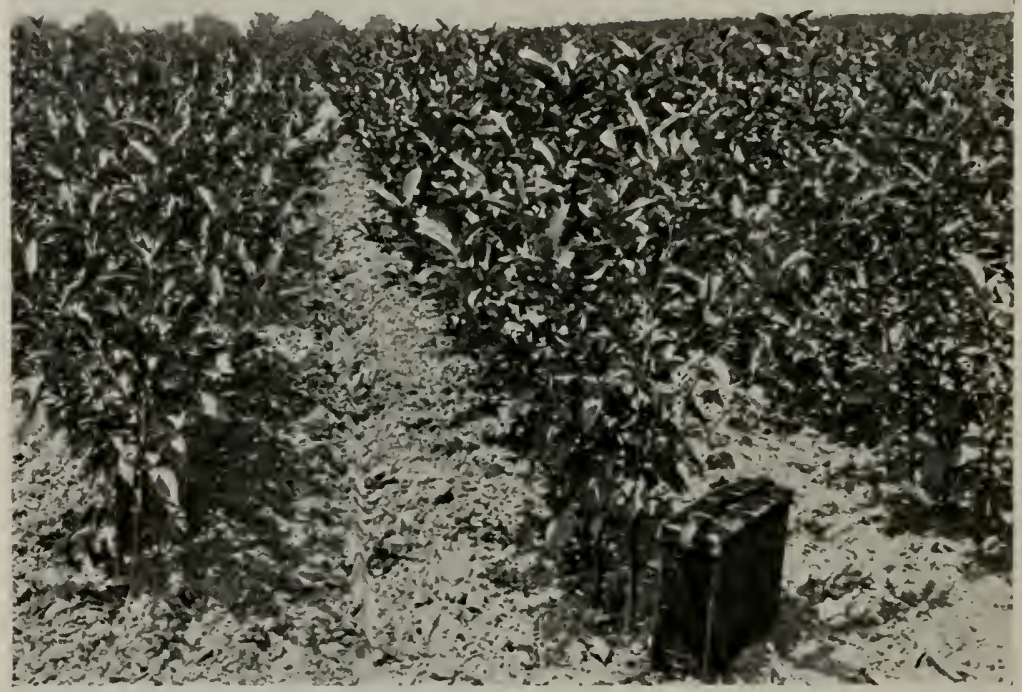

Fig. 153.-A block of Montmorency cherry trees during its first season's growth in the nursery. The sour varieties habitually branch the first season as shown here.

remain dormant until the following spring, when the stock is pruned off above the bud and a new top is formed by the shoot growing from the bud. Growers desiring fruit should select the trees budded on Mazzard stock, and should insist upon trees of this kind when purchasing from nurseries. The growth of the trees may not be so beautiful, but the bearing qualities will be much improved over those budded on Mahaleb stocks.

Starting the Cherry Orchard.-Trees are commonly planted at distances somewhat the same as peaches. The upright varieties if 
headed low may be grown as close as sixteen feet each way. If the trees are headed high, and if the soil is rich so that the growth will be large the distance may be twenty to thirty-three feet apart each way.

The planting may be done either in late fall or early spring. In the southern states winter planting may be also followed.

Only a few trees are necessary for the home orchard, but if a surplus can be easily marketed it is well to start a number of trees, as the fruit usually brings a good price.

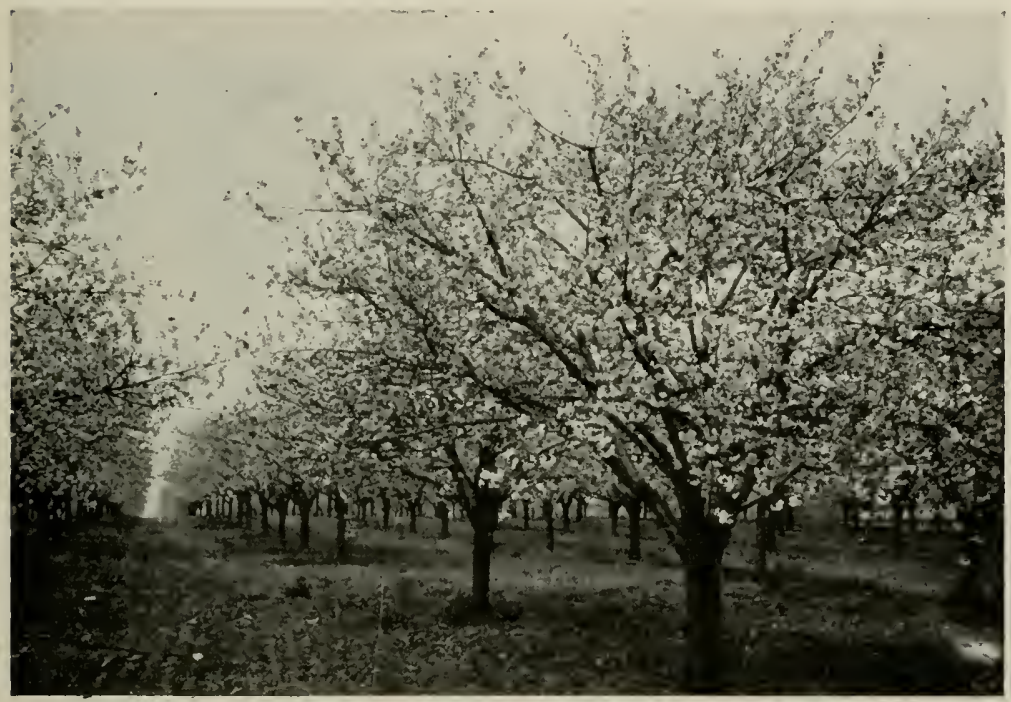

Fig. 154.-Well pruned cherry trees fifteen years old in a commercial orchard. (IT.S.D. A.)

Pruning.-Cherry trees may be headed two to three feet above ground, and sometimes lower heading is practiced. It is well to thin the branches annually, but we seldom practice as close pruning with the cherry as with the peach or apple. Cut away all injured or diseased parts and make the tree well balanced throughout the head. Figure 154.

Cultivation.-Clean culture between the trees is recommended. A winter cover crop may be sown in midsummmer to remain until late spring. This, if plowed under may have enough plant food so that fertilizer will not be necessary. The addition of manure or other forms of fertilizer may be used on light soils. 
Picking Cherries.-Cherries are usually picked with the stems on; this prevents the loss of juice and makes them stand up better during handling. They are usually picked in Climax baskets with handles or in smaller baskets holding one or two quarts. The fruit is usually repacked so that the stems are not conspicuous when shown on the market. Small trees may be picked from the ground and from small ladders, as shown in left corner (Fig. 155).

The cherries should not be picked until they show some degree of ripeness. Mere coloring is not sufficient. The flesh should be well developed. showing a degree of maturity.

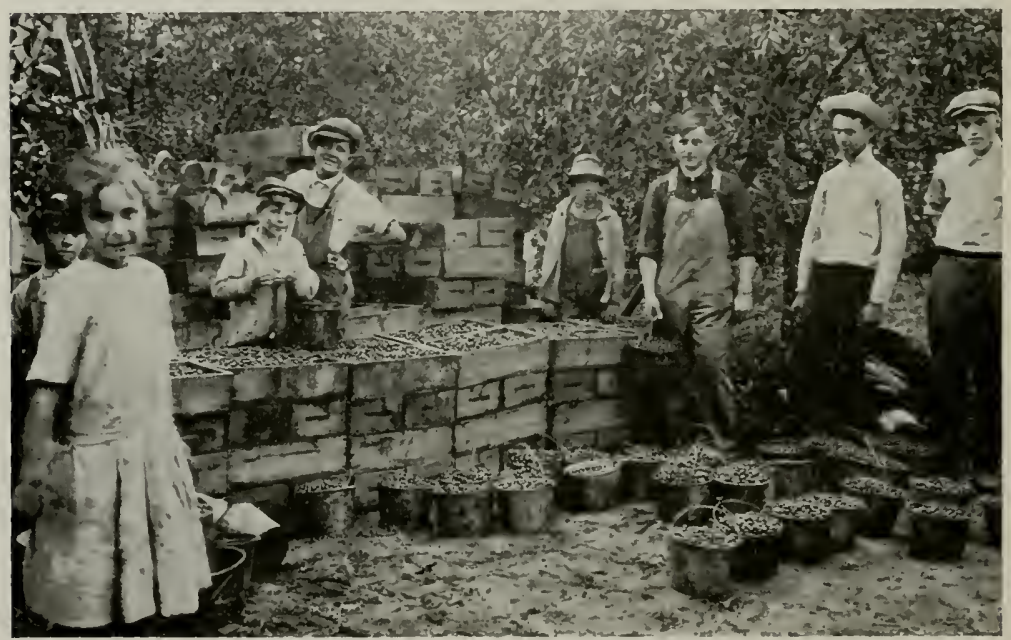

Fig. 155.-Packing Early Richmond variety of cherries in Ohio. The rigid metal buckets used in picking prevent serious bruising of fruit. (U.S.D.A.)

Uses.-For home use the cherry crop should be used abundantly while fresh for stewing, eating out of hand and for making pies. Much of the surplus erop may be preserved for winter use. Some varieties are easily dried, but all may be readily kept in the eanned form. They are less commonly made into preserves and jellies. Juice of other fruits added to the cherry juice will aid in jelling. The juice of the cherry alone may be kept in the unfermented form.

Insect Enemies of the Cherry.-The cherry, like other stone fruits is seriously attacked by cureulio insects which make the fruit wormy. The remedies suggested under the head of peaches may be used with the cherry as well as with the plum. 
Peach borers also attack the cherry trees, particularly of the sweet varieties. The remedies against borers have already been discussed under insect enemies of the peach.

San José scale is less serious on the cherry than on peaches and plums. The remedies, however, are the same.

Brown Rot on Cherries.-Probably the worst disease of the cherry is the brown rot. It seriously attacks the sweet varieties and is hard to control. Spray with Bordeaux mixture as suggested for the peach.

\section{PLUMS}

There are three main types of plums in common use. These are almost as different from each other as plums are from cherries,

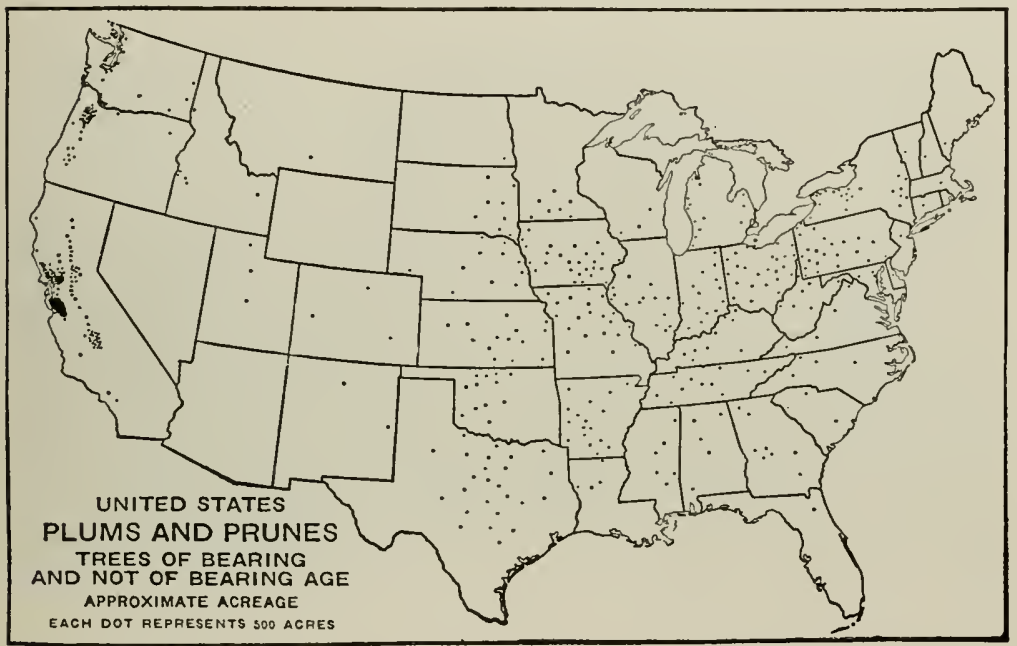

Fig. 156.-About one-third of the acreage of plums and prunes is in California. (U. S. D. A.) and yet they grade into each other in many ways. Their culture, soil and characteristics differ widely. Figure 156 shows the wide distribution of plum trees in the United States.

Soils for Plums.-The Japanese plums and the Domestica, or European plums, prefer rich, heavy soils. Many of the American types of plums endure well the light soils, while others of this group prefer the rich, heavy soils. In trying to select a type to suit the soil of any particular region it is well to consult the experiment station authorities in your state. Some varieties will do much better than others in any locality. 
Location and Exposure.-Plums, like peaches, should be grown on the northern and eastern slopes to help retard the blossoming season and prevent danger from late spring frosts. If such exposure cannot be secured for the plum orchard it should at least be planted where there is good air drainage, so that the cold air on frosty nights in the spring will not kill the pistils of the blossoms at the critical time.

Types and Varieties.-Three main types of plums grown in cultivation are (1) the Japanese group, including Burbank, Abundance, Satsuma and many others. This group is abundantly grown in California as well as in all other sections of the country.

(2) The domestica, or European plums, are represented by

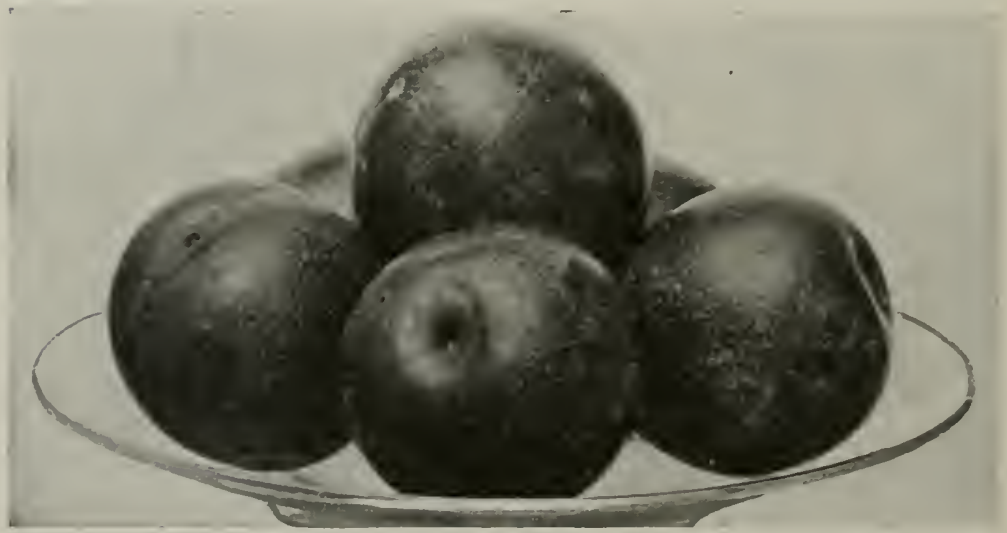

FIG. 157.-Miner variety of American plum. A good red fruit, and the variety is used as stocks for American plums. (Iowa Station.)

Lombard, Bradshaw, Yellow Egg, Green gage, Rheine Claud, Quackenboss and many others. Prunes and Damsons belong in this group. This group of plums is more popular in the northern and eastern plum growing sections than in any others.

(3) Plums of the American type are natives of America. They include the common wild plims and the improved varietal forms of several species. In this group are usually grown such varieties as Wild Goose, Wayland, Miner (Fig. 157), Golden Beauty (Fig. 158), Newman, Moreman, Lone Star, Caddo Chief, Milton (Fig. 159) and many others.

The Apricot or Simon plum is so distinct in character that it is often not classified as a plum at all. It is widely distributed 
throughout this country, but is chiefly grown in southern California and somewhat in the Gulf States.

Starting the Plum Orchard.-After preparing the soil as well as you would for a corn crop, lay off the rows at distances to suit the varieties. For most of the American plums the rows may be closer than with peaches. Fifteen feet each way is quite common. With Japanese plums and some of the European plums the distance is often a little greater. Some orchardists prefer to plant the rows closer one way than the other. In this plan make the distance between the rows eighteen or twenty feet and the trees the other way may be set eight to twelve feet.

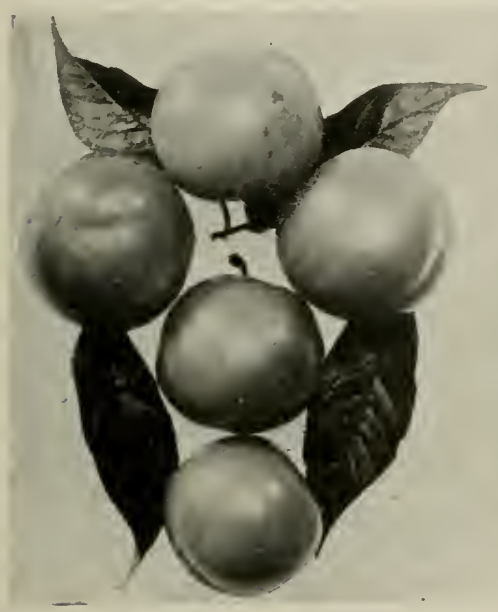

FIG. 158.-Golden Beauty plum.

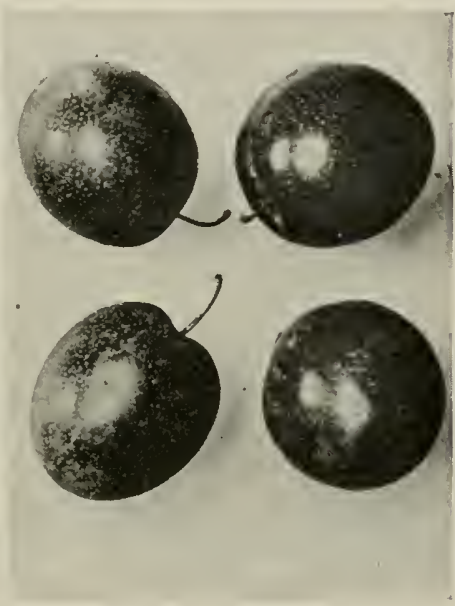

FIG. 159.-Milton plum.

Careful planting is advised. Do not expose the roots to the air any longer than necessary. When the trees are received from the nursery they should be heeled in until the holes are dug. Put them in a barrel containing some water and carry them in this way on a sled or on a wagon to the place where they are to be planted.

The roots are therefore wet when put into the hole and covered with soil. Firm the soil about the roots well, but leave a light mulch on top.

Pruning.-The low heading of plum trees is now usually practiced. It is well to give close attention to the choice of the main branches, particularly in those varieties which make large trees, 
such as some of the Japanese varieties. Avoid keeping branches that are opposite each other; this tends to cause more severe splitting when branches are loaded with fruit.

The annual pruning should consist of thinning out the head, removing dead branches, and cutting away diseased parts and removing all mummied fruits if any. Cut back the long leaders that have made too much growth. Keep the tree as symmetrical as possible without losing the other points mentioned. Never allow stubs to be formed by the pruner. Make all cuts as close as possible to the main branches so that the wounds may be easily healed over.

Cultivating the Orchard. - The first few years a crop should be grown between the trees which will require clean cultivation. Plant beans, peas, early potatoes, early cabbage or other similar crops. After the trees are old enough to bear, the inter-crop may be discontinued if the trees are large. Clean culture should be given the orchard if the best results are to be attained. A winter cover crop may be sown in midsummer to cover the soil, to prevent washing, to save the fertility for next year, and to make a carpet over the ground for the pruning and spraying operations of winter.

The cover crop may be turned under in the spring as green manure. This will serve as fertilizer for the trees that season. If the soil is well suited to the type of plums grown, probably no other fertilizer will need to be arlded. In case the soil is rather too light some commercial fertilizer or barnyard manure may be applied in addition to the green manure.

Harvesting the Crop.-With some varieties it is difficult to pick the crop at just the right time. So many of the fruits may ripen ahead of others that they will need to be watched and picked at intervals through several weeks. If they are for home use or to be sold on the local market they should be allowed to ripen as far as possible on the trees without dropping to the ground. If they are to be shipped some distance they may be picked much earlier and will usually complete their ripening fairly well after picking. Many varieties of Japanese and European plums will ripen more uniformly and fewer pickings will be necessary than with the American varieties.

The fruit is commonly picked in large Climax baskets, with wooden handles, hanging from the left arm. These will prevent the bruising of the fruit if the picker is careful. Small, round baskets holding from one peck to one-half bushel, made of rigid 
splints and having strong wooden handles, may be lined with cloth and used by the picker. The fruit should be sorted as to size and color when packed for market. The types of package in common use are the same as those mentioned for peaches, except that many of the smaller varieties are often marketed in quart baskets. Damsons and others when first found on the market are often shown in quart baskets. The large peach baskets are not commonly used for plums.

Home Use of Plums.-The larger varieties of plums are peeled and pared or cut in half, the seed removed, and then they are stewed for table use. The Japanese varieties and some of the large European varieties are often served fresh and eaten out of hand.

Methods of preserving for winter are canning, drying, preserving and making into jelly. The American plums are popular for jelly. Damsons are preferably made into preserves. Prunes are commonly dried or canned.

Insect Enemies.-The San José scale is very serious on the plum. This insect has been thoroughly discussed under the head of peaches.

Peach borers are usually as bad on plums as on peaches or cherries. The Japanese varieties are perhaps more frequently attacked by borers than are the trees of other types. Attention must be given to all plum trees to prevent danger from borers. Dig them out as described for borers on peaches.

The plum curculio will make all the fruits wormy if possible. Wormy fruits are absolutely worthless on the market or for table use. Spraying is the best method of preventing their attack. Follow the spraying campaign described for the peach.

Brown Rot on Plums.-This disease is the most serious enemy of the plum orchard. The early varieties are sometimes entirely destroyed by the brown rot. The rot starts on one spot or on one side and gradually spreads over the whole fruit. The spores become abundant over the surface and can easily be blown to other fruits or will spread to them through actual contact if the fruit has not been thinned. Many of the twigs are apt to turn brown and the new leaves are killed. A vigorous spraying campaign such as described for the peach should be followed. During the winter, many of the fruits which have been affected by this disease remain on the trees. These should be removed at pruning time so that they will be plowed under in the early spring. 


\section{PROJECTS AND EXERCISES.}

1. Orchard Projects.-Planting and managing an orchard of plums or cherries, or both, may be considered a valuable long-time project. It should include eare of soil, pruning and spraying of trees, inter-eropping, fighting borers, harvesting the fruit crop, marketing. Records should be kept of all the steps in the project.

2. Any point of this project may be pursued for a shorter time, as the care and management of the crops used in inter-cropping, growth of cover crops, fertilizing, cultivation, etc. The entire care and management of the orchard for one entire year would make a good project.

3. Variety Trials. - With project No. 1 a trial of different varieties may be made to determine which are best for home use or for market in your region.

4. Orchard Fertilizers.-Make trials with different fertilizers in either young orehards or in older ones. Determine which are best in your soils for producing large growths of young trees, which hasten or delay the ripening of fruit.

5. Cherry and Plum Surveys.-Repeat the orchard survey suggested at the elose of the preceding chapter. Apply it now to plums and cherries.

6. Blossoming Dates. - Make a list of all the varieties of plums and cherries that are considered successful in your region. Reeord for each the dates of blossoming and show what varieties could be grown together for pollenizing purposes.

7. Ripening Dates.-Opposite the names of the different varieties record the first and last ripening dates of fruit for your region.

\section{QUESTIONS}

1. How are cherries propagated?

2. Mention varieties of each of the two main types of cherries.

3. What cherries and plums are grown in your section?

4. What can youl say of the distribution of cherries in America? Of plums? (See maps).

5. Give directions for starting a cherry orehard; plum orehard.

6. Give instructions regarding the picking of cherries.

7. What are the three main types of plums? Give examples of each.

8. Why should mummied fruits be removed from plum trees?

9. What crops can be used for inter-eropping?

10. Compare these crops as to suitability for this purpose.

11. Discuss methods of pieking plums.

12. What are the chief inseets affecting the plum?

13. What are the plum's worst diseases.

References.-U. S. Farmers' Bulletin 776, Growing Cherries East of the Rocky Mountains.' See Waugh's book of Plums and Plum Culture. 


\section{CHAPTER XX \\ STRAWBERRIES}

The strawberry is grown in all the humid parts of the United States (Fig. 160). It requires considerable moisture and should not be grown where the rainfall is too light unless irrigation is provided.

Soils.- The best soils for growing strawberries are light sandy loams or medium sandy loams. The clay soils also produce the

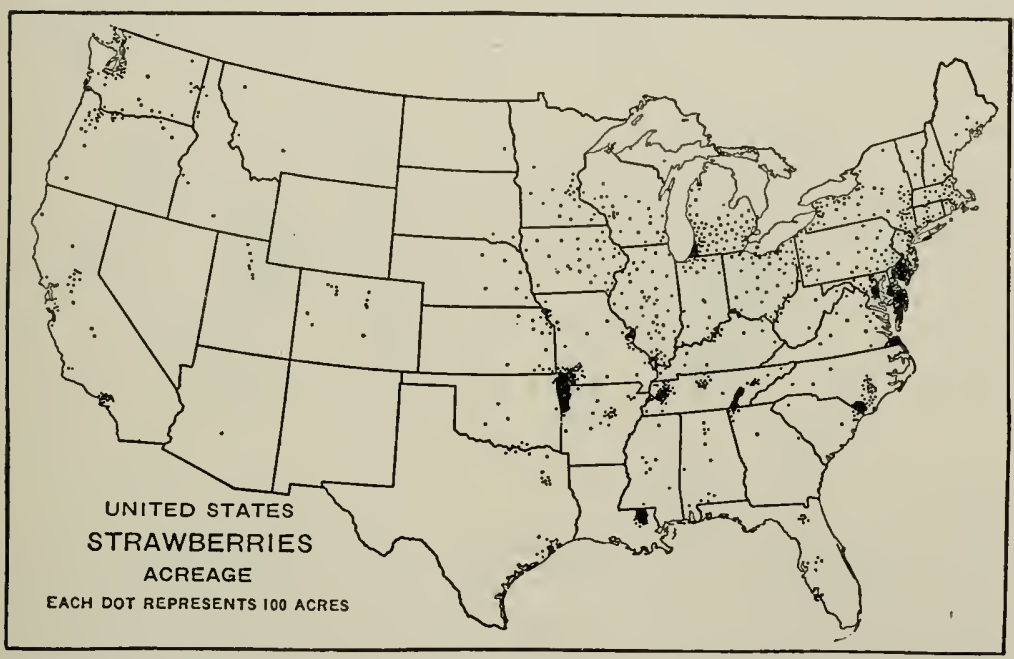

FIG. 160.- Strawberry acreage in the United States. Strawberries are intensively cultivated for shipment largely to northern markets in several localities along the Atlantic Coast and in the lower Mississippi Valley. Important centers of production are also located in the Pacific Coast States. (U.S.D.A.)

strawberry well, but if dry weather follows heavy rains, the soil will bake and the yield be greatly reduced.

The heavy soils may be made more suitable for strawberries by a heavy application of manure. This will add organic matter and loosen the soil. The addition of lime will also flocculate the soil and make it more porous. If lime and manure are both added to heavy soils, the results will be very favorable to strawberries.

Location.-It is well to have the strawberry plantation in a sunny exposure where there is no shade from trees. Near the main 
residence is a good place. The picking should be attended to often and a long distance might cause neglect. The crop is more easily protected from marauders if the patch is located near the home.

Varieties of Strawberries. - Each locality favors certain varieties of strawberries. It is easy to make a selection of several varieties that will thrive in a particular region.

There are two kinds of strawberry blossoms. Some varieties have only the pistillate blooms while others have perfect blossoms with both stamens and pistil. Those with perfect blossoms have the power to pollinate themselves and bear fruit without the proxinity of other varieties. Those varieties with imperfect flowers such as Black Beauty, Granger and Sherman, which have few if any true stamens and no pollen, must be grown near other varieties
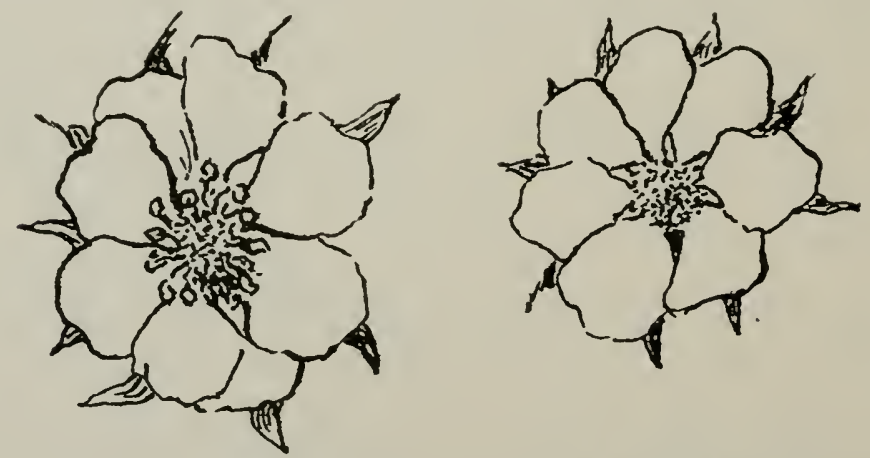

FIG. 161.-Two types of strawberry hlossoms. Left one has stamens and can pollinate itself and others. Right has little or no pollen and eannot bear fruit alone.

which blossom at the same time and bear perfect flowers. The pollen from the perfect flowererl varieties will fertilize the others and fruit is produced (Fig. 161).

The two kinds may be planted in alternate rows, or one row of perfect flowers to each three or four of imperfect flowers.

It would be a good plan to select such varieties for planting as are grown suecessfully by others in the same locality on the same kind of soil. Do not select new varieties until they have been reported favorably by the experiment stations or by other experimental growers. Write to the State experiment station for a list of varieties which are suited to your region. Popular varieties used in nearly all parts of the country are (1) Excelsior and Dunlap (2) Klondike and Missionary; (3) Chesapcake, Aroma, Sample, 
and Gandy. These groups are numbered in the order of their ripening. Others popular in many sections are Glow Mary, Brandywine, Warfield, Bubach, Marshall, Climax, Melinda, Jessie, Gold Dollar, Clark, Wilson, Americus, Iowa, etc.

The Indiana Station found the following varieties to be superior to others in their season:

Earliest

Gill

Excelsior

August Luther

Early

Texas

K'londike
Medium

Senator Dunlap

Haverland

First Quality

Grand Marie

Aroma
Late

Grays Dollar

Black Beauty

Columbia

Chesapeake

Sample

\section{Latest}

Gandy

Ohmer

Three Plans of Growing Strawberries.-Far the most common method of growing the strawberry is known as the matted-row system. In this plan the plants are set about twelve to eighteen inches apart in rows four feet apart. The runners from these plants are allowed to take root in all directions until a rather solid mat is formed two feet wide (Fig. 162). This leaves a space for cultivation between the matted rows of about two feet. The weeds growing in the matted rows are pulled by hand.

The hedge-row system (Fig. 163) is coming more into use in nearly all parts of the country where it has been tried. By this plan the plants are first set in rows about three feet apart and are allowed to set their runners only in a narrow row forming a dense "hedge." The runners extending outside this middle space are cut off by a wheel cutter, hoe, or spade. The entire middle is thoroughly cultivated and all of the strength of the plants is forced into the crowns, blossoms and fruit.

The hill-row system(Fig. 164) differs from the hedge-row system in not allowing the runners to reach out in any direction. The plants are set in rows both ways about three feet apart each way. Cultivation is given in both directions. The plants attain stronger crowns by this method than by any other. Of course the number of plants per acre is less.

The student should compare the advantages of the three systems. The principle should be kept in mind that plants which allow runners to form continuously will not make strong crowns nor bear 
as much fruit to each plant as others. The herge-row and hill-row plans allow of more mulching as the mulching of the matted-row must be removed in the spring to allow the crop to form. In the

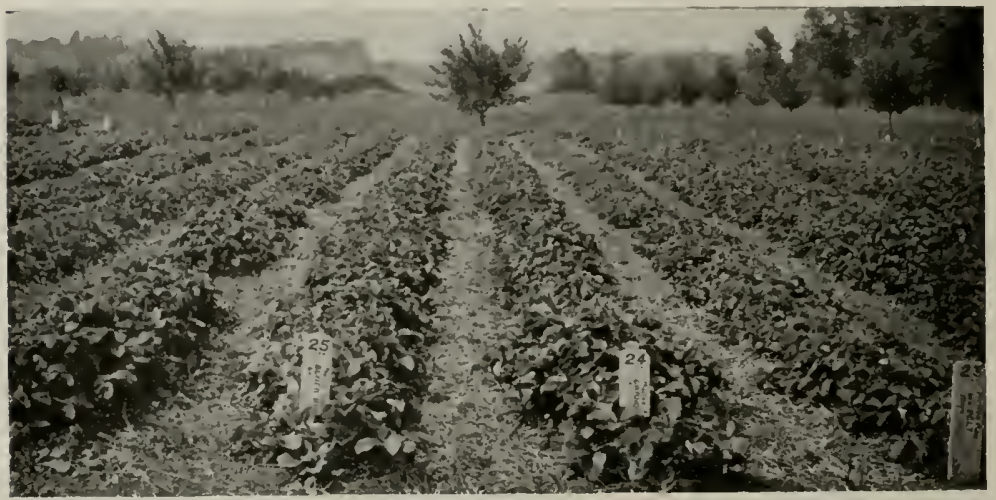

FIG. 162.-Strawberries grown in narrow, matted rows with straw mulch between. (Indiana Station.)

other two plans the mulch may remain between the rows until after picking. The fruit clusters may form upon it and are thus kept out of clirt. This mulch keeps down the wecds, conserves

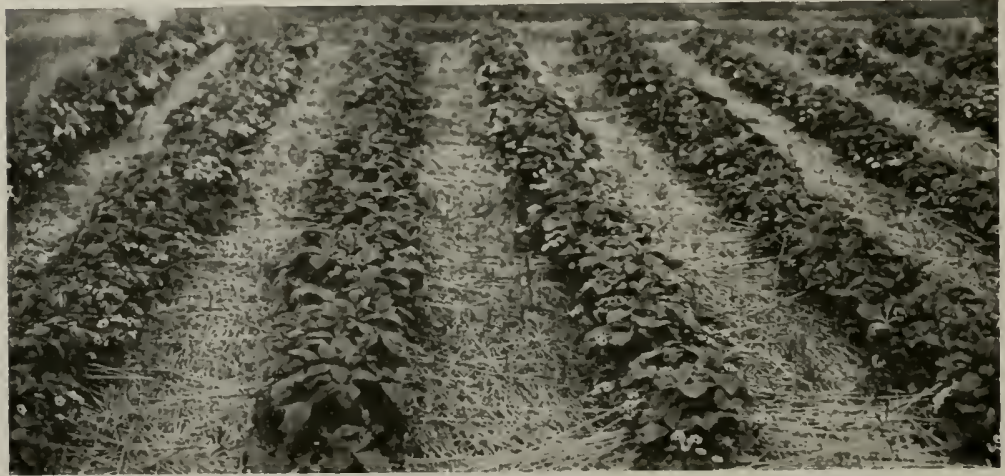

F:G. 163. - Strawberries in narrow hedge-rows three feet apart. The straw mulch saves moisture in the soil, keeps the berries clean, and keeps down the weeds.

moisture and makes picking more agreeable. After the crop is all gathered, the vines are mowed down, raked off with the mulch and put into the compost heap. 
Two kinds of mulching material, corn stalks and straw, are shown in figures 165 and 166.

Cultivation of Strawberries. - The plants respond readily to thorough cultivation. The more tillage given to the patch, the better the plants will grow and the larger will be the yield. Cultivation in the matted-row is very limited and does not come close to any plant but at the edges of the rows. The soil is apt to become hard and baked as the strawberry takes its moisture from the soil. In regions where grass tends to grow, considerable handwork and hoe work may be necessary. Clean cultivation with no weeds and grass should be the rule.

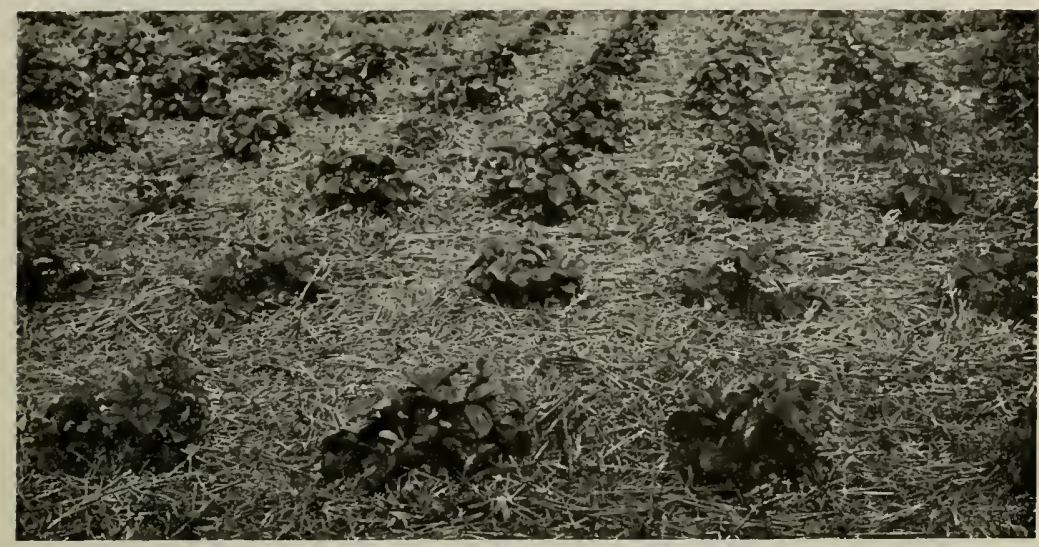

Fig. 164.- Strawberries grown according to the hill-row system. The plants in rows in two directions allow of cultivation on all sides of each plant. Cultivation takes place after harvest when the mulch is removed. (Indiana Station.)

Fertilizing.-The strawberry plant may be said to be a ravenous feeder. It requires a great deal of nourishment and will respond to heavy feeding. The best form of plant food is supplied by adding barnyard manure. Some soils can be fertilized as heavy as twenty tons of barnyard manure to the acre for the strawberry crop.

A good plan for applying barnyard manure is to plow it under at two different times before setting the plants. Apply one-half the manure, turn it under, then apply the remainder and turn that under by plowing crosswise of the first plowing. This will incorporate the manure in the soil well.

If commercial fertilizers are used, bone meal and tankage are good forms. Many growers give an application of nitrate of soda 
to the plants just after the picking season is over, after the patch has been eleaned up thoroughly.

Picking Strawberries. - The home patch should be picked frequently and no berries should be allowed to rot on the vines. This practice would take away too much of the strength of the plants. Most varieties of berries can be picked as soon as they show half color or a little more. The calyx and perhaps a portion of the stem should remain attached to the berries. This is the natural separation from the plant in most cases.

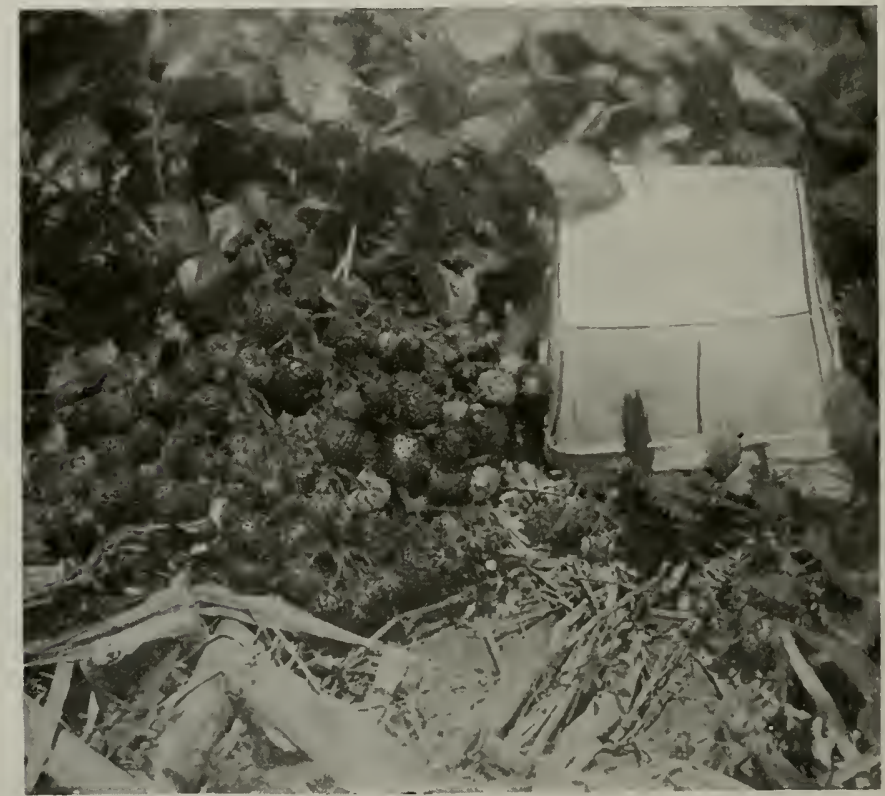

FIG. 165.-Corn stalks make a rather coarse mulch for strawberries, but will aid in keeping the berries clean.

(New Jersey Station.)

Never mass the berries in large vessels. They should be kept in light wooden berry boxes holding one quart. In commercial picking, each picker is assigned to his own row and required to pick it clean as he goes. The berry boxes are carried in shallow trays with strong handles. These trays hold from ten to twenty quart boxes. The grading and repicking is done at a central headquarters where the wagons load them for market. Each picker is given a ticket in the form of a tag tied to his crate or to his clothing. It is punched by the foreman as each lot of berries is delivered to him. The pay 
varies from one cent to two cents a quart in different sections and different years.

Insect Enemies of the Strawberry.-The strawberry weevil is one of the worst enemies of the plant. It is difficult to control. One of the best remedies is to mow the patch after picking, and burn the vines. The new growth following may be reasonably free from this insect.

Diseases of the Strawberry.-Several leaf diseases attack the plant. The leaf spot is probably the worst. Any of these are kept under control fairly well by mowing and burning the vines after picking. Instead of burning the vines they may be hauled to some

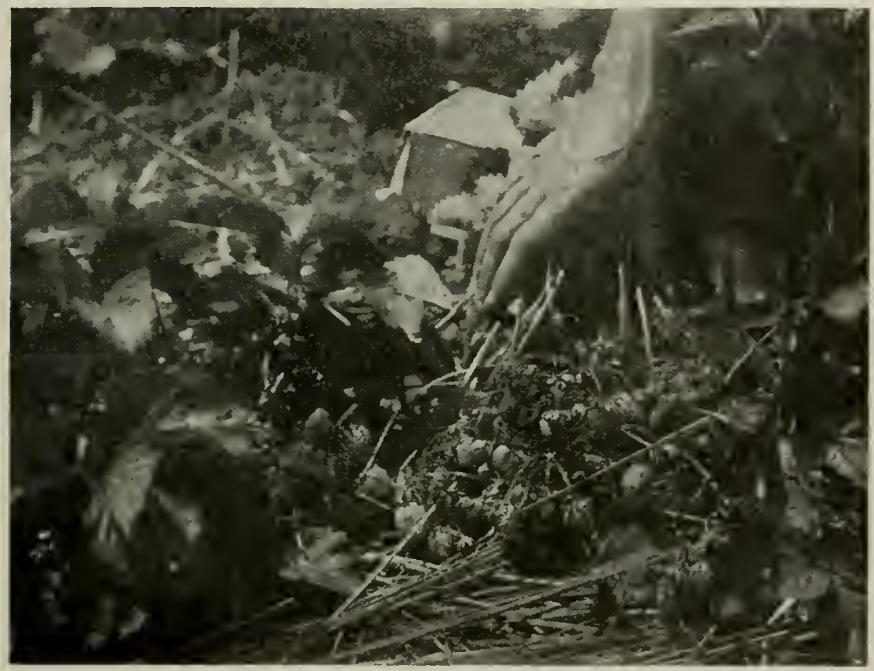

Fig. 166.-Coarse straw, weeds and marsh grass are ideal materials for mulching strawberries. (New Jersey Station.)

distance and put into a compost heap that is to be used on other crops. The rotting is destructive to the disease and if used on corn or potatoes no harm will come.

Renewing the Plantation. - Strawberries are expected to bear only two or three crops. If the vines are first set in August they may bear one light erop the next year and two heavier crops after that.

It is advisable to set a new patch every year or at least every two years. These plants should be put on fresh ground not infested with enemies of the strawberry. 


\section{STRAWBERRY SURVEYS, EXERCISES, AND PROJECTS}

1. Soils.-Study the soils of your region as to their suitability for strawberry growing.

2. Varieties for the Region.-Make a study of varieties grown in your region. Ask each grower for the best and second best varieties with perfect flowers, and pistillate varieties. Get the dates of ripening. Tabulate the results to show the popularity of each variety. Compare the varieties as to flavor, handling qualities, size, color, yields, disease resistance of plants, ete.

3 . Systems of planting should be studied in the gardens or fields. If the three main systems are practiced by any of the different growers of the community, a full comparison of the advantages and disadvantages should be made. Compare the yields, proportion of first grade berries, freedom from culls, costs of picking, etc. Compare them as to the adaptation to the annual mulching.

4. Projects with strawberries may be either short or long. (1) One form of project inay include merely the picking and marketing of one crop. (2) This may be extended to include the annual cultivation, management, mulching, etc. (3) A longer project may extend over two or three seasons from planting time to ending of the patch.

5. Judging strawberries of different varieties is a good exercise to aid in becoming familiar with different varieties as to size, shape, color, flavor, etc.

6. Planting strawberries by different systems should be practiced by all students.

7. Cutting off runners with different hand tools may be tried by each student until a good comparison can be made.

8. Starting plants in pots is a good summer exercise in the patch. Plunge small pots of soil near the strongest parent plants. Cause runners to take root in these. Later transplant the potted plants to new garden patches-say in August.

9. Forcing strawberries in-doors in winter from plants potted in early summer may be tried by those who have favorable conditions.

10. Strawberry growing contests may be organized among growers or among students. Have the areas and varieties the same in all cases. Let the individuals cxercise choice in the methods of planting, cultivation, mulching, etc.

\section{QUESTIONS}

1. What soils are best for strawberries? Second best?

2. Mention several perfect-flowered varieties of strawberries for your region.

3. How can you manage to get imperfect varieties to bear?

4. Describe the hedge-row system of growing strawberries.

5. Compare the results in this system with those in the matted-row system.

6. Give directions for and importance of thoroughly fertilizing strawberry plants.

7. Deseribe the annual mulching system for the strawberry patch.

8. Give suggestions regarding the harvesting and handling of strawberries.

9. What insects and diseases are apt to trouble strawberries?

References.-U. S. Farmers' Bulletins: 664, Strawberry Growing in the South; 854, Strawberry Culture in Tennessee, Kentucky, and West Virginia; 901, Everbearing Strawberries; 979, Preparation of Strawberries for Market. 


\section{CHAPTER XXI}

\section{GRAPES}

THERE are three main types of grapes grown in different parts of the country. They may nearly all be grown in the southern states but only the hardy varieties, or so-called northern grapes are successfully grown in the northern half of the country.

Soils.-The grape is not particularly partial to special soils though it will thrive much better on the medium sandy loams than in the heavier soils. Almost any good garden soil may be made to grow grapes successfully. The light soils may be improved by adcling organic matter in the form of green manure or barnyard manure. The heavier soils may be improved by the application of both these forms of manure and by the use of lime.

Location. - It is well to have the grapes near the house where they can be carefully watched from marauders, from birds, and from other natural enemies. For home use it is not a bad plan to have a grape arbor which is permanent in character and which will furnish a cover for a walk at least part of the year. If the grape is to be grown for market, a hillside is to be preferred. Good ctrainage is thus supplied and the vines may be set more closely if the sun can reach all of them.

The aspect should not be to the west but may be south or southeast. An east or north exposure is not objectionable. As the crop bears its fruit on shoots formed the same year, it is not usually affected by late spring frosts.

Varieties.-The so-called southern bunch grapes are suitable for growth through the southern states. Good varieties of this type are Headlight, Herbemout, Brilliant, and Bailey.

The great crops of muscadine grapes may be grown in states east of the Mississippi river and south of the Kentucky line. A trial nursery of muscadine grapes conducted by the United States Department of Agriculture in North Carolina has proved these varieties can withstand the winters in the warmer parts of that state. Probably the best muscadines named in order of ripening are Memory, Thomas, James, and Luola. The northern bunch grapes are suitable for growth in all parts of the country. They have been grown ever since colonial days and many varieties have 
been developed. These may be grouped into three classes according to their color: black, red and white (green). In the following list these are arranged by seasons of ripening:

Early Blach.-Champion, Early Daisy.

Early Red.-Delaware, Lutie, Wyoming Red.

Early White.-Diamond, Empire State, Winchell.

Medium Season Black.-Campbell, Eumelan, Herbert, Ives, Worden. Salem.

Medium Season Red.-Agawam, Brighton, Iowa, Jefferson, Lindley,

Medium Season White-Duchess, Niagara.

Late Black.-Norton, Wilder.

Late Red.-Catawba, Goethe, Woodruff.

Late White.-Noah, Triumph.

The Cornell Station gives the following list of the ten most important commercial varieties of grapes in order of importance: Concord, Delaware, Catawba, Niagara, Worden, Moore, Winchell, Campbell, Brighton, Diamond.

That Station also recommends the following list of varieties to use in home gardens:

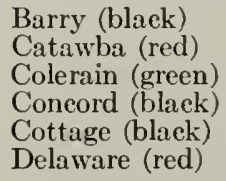

Barry (black)

Catawba (red)

Colerain (green)

Concord (black)

Delaware (red)
Diamond (green)

Downing (black)

Dutehess (green)

Empire (green)

Herbert (black)

Iona (red)
Kensington (green)

Pocklington (green)

Salem (red)

Winchell (green)

Worden (black)

Starting the Vineyard.-Grapes are chiefly propagated in America by ripe wood cuttings made late in the fall or winter. These are stored in wet sand or sawdust in a cool cellar and planted in the ground about the middle of the spring season.

After the cuttings are one year old, they may be transplanted to the permanent vineyard. Nurserymen supply one-year-old vines for growers in all parts of the country.

The northern and southem bunch grapes are usually planted in rows about eight to ten feet apart and the vines are about eight feet apart in the rows. Muscadine grapes are given about two feet more space each way. The vineyard is usually planted in the spring but fall planting is also successful.

Trellising.- Some systematic plan of starting the vines should be adopted. A number of plans are in use. Several of these have been given definite names. The high-renewal system is shown in figures 167 and 168. 'The four-cane Kniffin system is shown in figure 169. The Munsen system is shown in figures 170 and 171 . 
Three plans for pruning and supporting vines common in California and elsewhere are shown in figures 172, 173, 174 and 175.

Pruning.-Grapes should be pruned annually. The best time is in the winter when the sap is entirely dormant. If pruning is

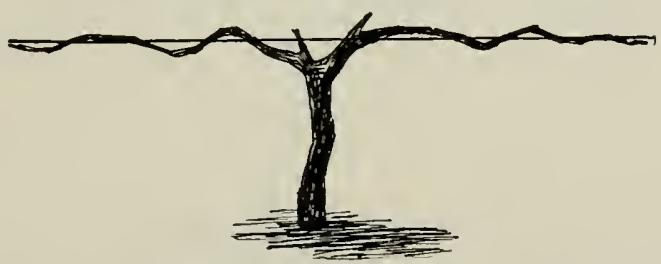

F1G, 167.-The upright or high-renewal system of pruning and training grape vines; after pruning. The fruiting shoots from these canes are trained upright and tied to the upper wires, as shown in next figure.

delayed until spring, the sap will flow from the wounds abundantly. This will take away the strength of the vine.

The system of pruning and the system of trellising should har-

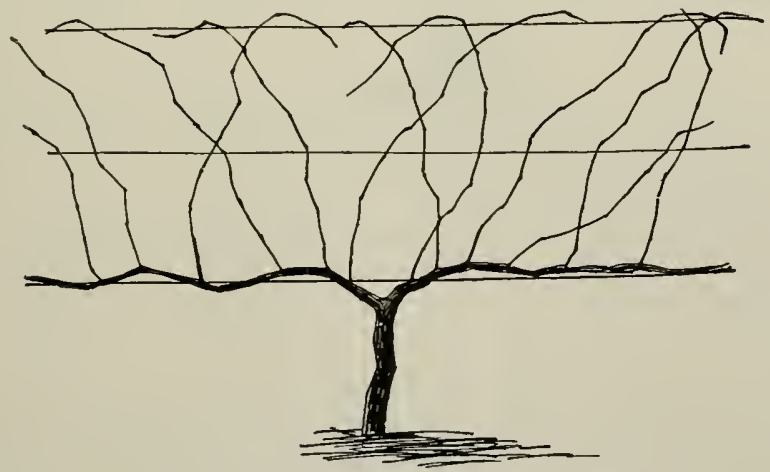

Fig. 168.-The high-renewal system of training the new fruiting shoots of grape vines. See the preceding figure. The wires are stretched at 24,40 and 56 inches from the ground.

monize with each other. Make the pruning rather close each year. Remember that the crop is borne on the new growth and not on the old at all. There is very little need of saving much of the old 
wood except to form a trunk and enough of the last year's growth to furnish the buds necessary for the main shoots of the next season (Fig. 170). An examination of the accompanying figures will give a clear idea of the great amount of wood that can be cut away each year. For example, if five or six buds are left to form as many more shoots, there will be as much new wood as the root system can support and bear a crop of fruit.

The effect of not pruning the vines each year is to so gradually divide the strength of the plant that the new growth in any one part is very limited and the possibility of fruit is thereby reduced. It is therefore difficult to allow vines to remain unpruned for the sake of

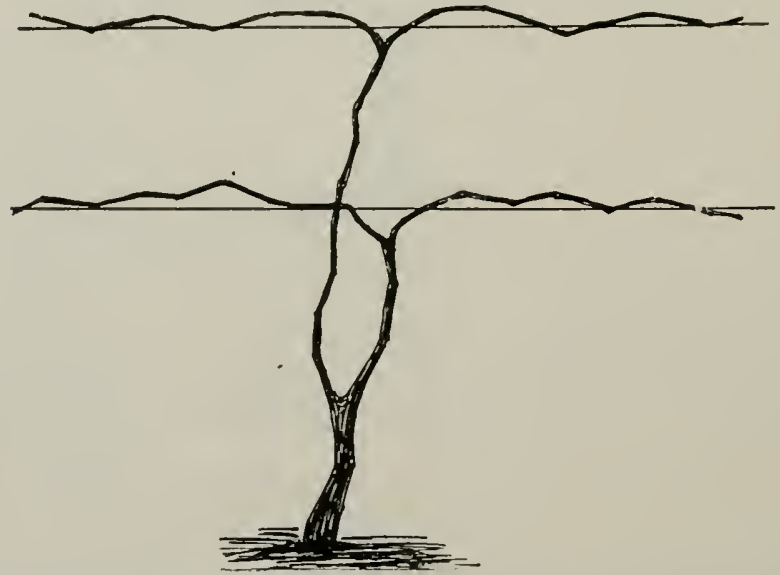

FIG. 169.-The four-cane Kniffin system of trellising grape vines, just after pruning. Two No. 10 wires are stretched. In the two-cane liniffin (or umbrella) system the right branch would be cut at the trunk, removing the two lower arms.

having an arbor well covered, without sacrificing fruit production. The best quality and yield is produced on well pruned vines. Arbors cannot be continuously covered with vines in close pruning systems.

Cultivation. - The annual care of the soil where crops are growing is important. There should be clean cultivation at least during the first half of the season and no large growth of weeds or cover crop should be allowed to form under the vines until the picking season is over. Rye, vetch (Fig. 176), crimson clover or some other crop may be sown about the middle of July or the first of August to form a carpet under the vines and remain cluring the fall, winter and early spring. 
Fertilizing.-The grape vine will not need heavy applications of fertilizer except on very light soils. The first year the vines are set they should have liberal applications of barnyard manure.

If commercial fertilizer is used it should contain a little nitrogen and a large percentage of both phosphate and potash. For soils

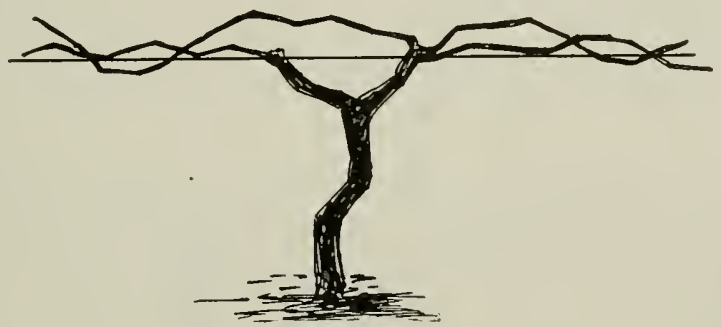

FIG. 170.-The modified Munson system of pruning grape vines. See the new fruiting shoots supported by the two upper wires and cross arms, shown in figure below.

needing heavy applications of commercial fertilizer, a good formula would be three per cent nitrogen, six or eight per cent acid phosphate, and four to six per cent potash.

Picking Grapes.-For home use pick grapes in strong baskets or trays with rigid handles. Spread a paper in the bottom and do

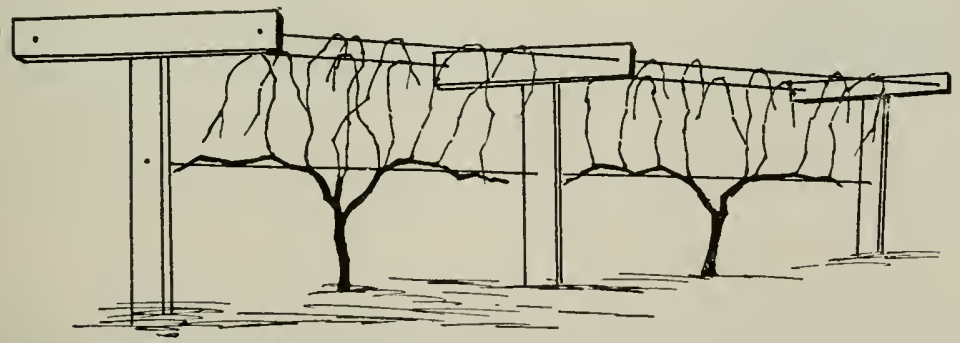

FIG. 171.-Munson system of training grape vines. The two wires on cross arms are tiwo feet apart. The new growth is not easily blown down. Spraying and picking are aided by this plan.

not pile the bunches more than one or two layers deep in the picking tray. Remove the bunches with a sharp thumb nail or a pair of scissors. Handle the fruit as gently and as little as possible.

A little study and experience will teach the picker just when to do the picking. Some varieties need to be picked as soon as 
they are well colored. Other's are much improved by remaining on the vines longer.

Marketing the Surplus.-Grapes are usually marketed in rigid Climax baskets with wooden covers. These are of several sizes, holding from three to ten pounds. In this form they are often shipped by express or in refrigerator cars long distances. If well protected and reasonably well handled, they may reach the consumer in first class condition and will usually not deteriorate before they have had ample time for consumption.

Insect Enemies of Grapes.-There are a number of insects which attack grapes. The chief enemies are discussed here.

FIG. 172 .

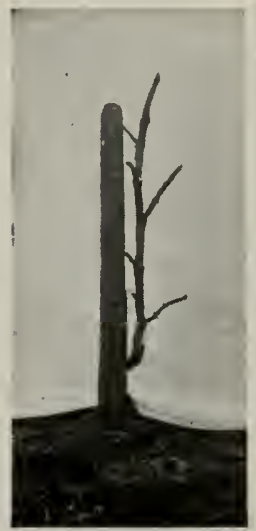

FIg. 173.

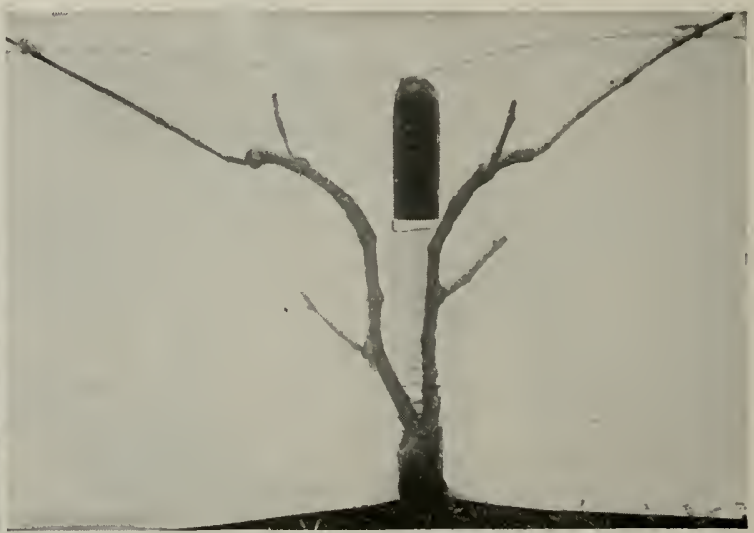

Frg. 172.-Pruning by the "vertical cordon" system. Vines about three years old niay have trunks three feet high with spurs at intervals up the sides. (California Station.)

FIg. 173.- Starting a double crown on a five year old vine. Finally, it will have two full units on each side if the lower arms are not weakened and fail to produce wood. (California Station.)

The grape leaf-hopper is perhaps one of the most common enemies of the grape. These are sometimes called "thrips." They feed chiefly on the under side of the leaves and suck the juice from them. Perhaps the best remedy is to thoroughly elean up the vineyard by plowing under in early spring all the leaves that have fallen. Hopper eages are sometimes used successfully where vines are not trellised. Resin sprays are sometimes used with nozzles which will strike the under side of the leaves.

The grape leaf-folder oceurs throughout the United States. Its damage is of less importance as it seldom seriously injures the crop. 
The larva folds the leaf over and fastens it with the web. From this house it does its feeding. If the attack is not serious the larva may be crushed by hand or the leaves picked off and burned. Where the attack is more serious, spraying with poisons is advised.

The grapevine flea-beetle is most injurious to the buds of the vines in the spring. Vines that are regularly sprayed with poisons are usually not troubled with flea-beetles. They are however

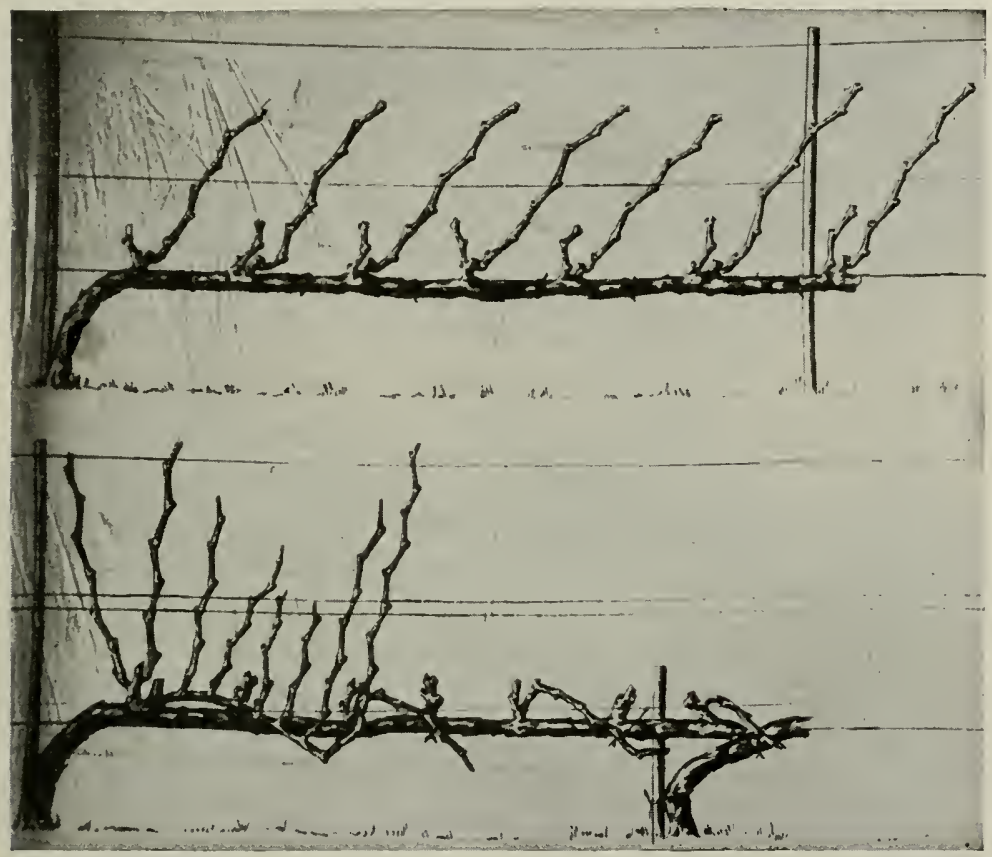

FIG. 174.-Grapevines pruned with single horizontal cordons, with spurs and half-long canes to start new wood. (California Station.)

more difficult to poison than most insects and eight pounds of arsenate of lead to forty gallons of water is advised.

Rose-chafers are often serious enemies of grapes, eating the surface from the leaves. When very abundant, the only successful method of control is to jar them off on stretchers of cloth from which they are collected and killed in kerosene. The stretcher may be somewhat funnel shaped and lead to the dish of kerosene below. 


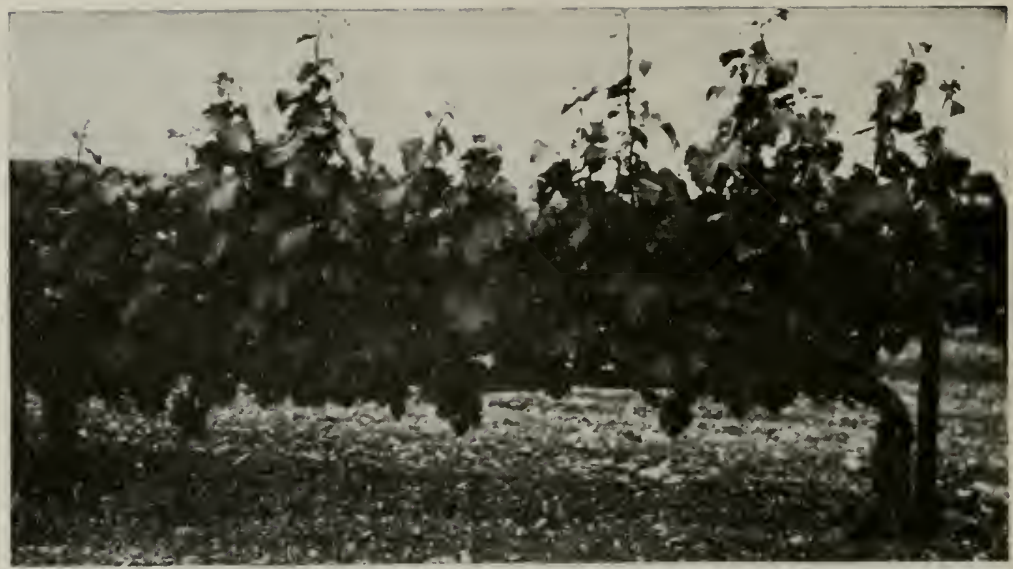

FIG. 175.-New growth on grapevine pruned to single horizontal cordon; variety Semillon. Compare with figure 174, (California Station.)

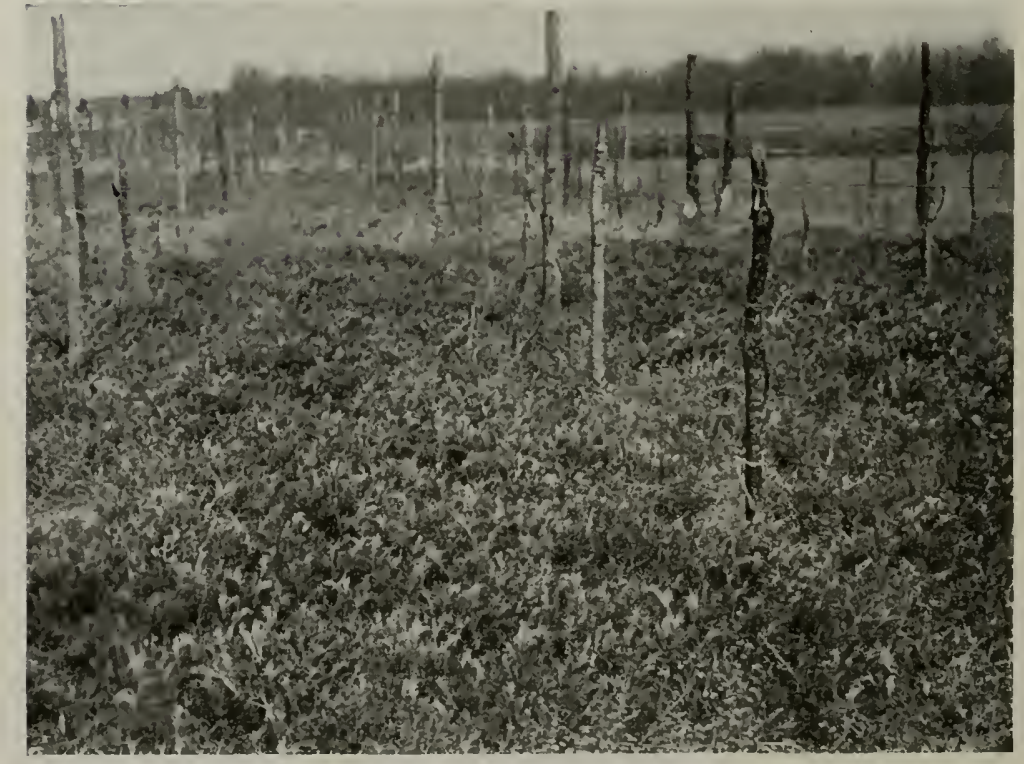

FıG. $176,-A$ winter cover crop of winter veteh in a young vineyard. 
The grapevine phylloxera attacks both the leaves and the roots of the grapes. It is seldom serious except in California and in foreign grape growing regions. This is true at least of the root forms. Leaf-galls are often found on American grapes in other sections. When the roots are seriously attacked, they are apparently poisoned by the insect and decay follows. The vines are

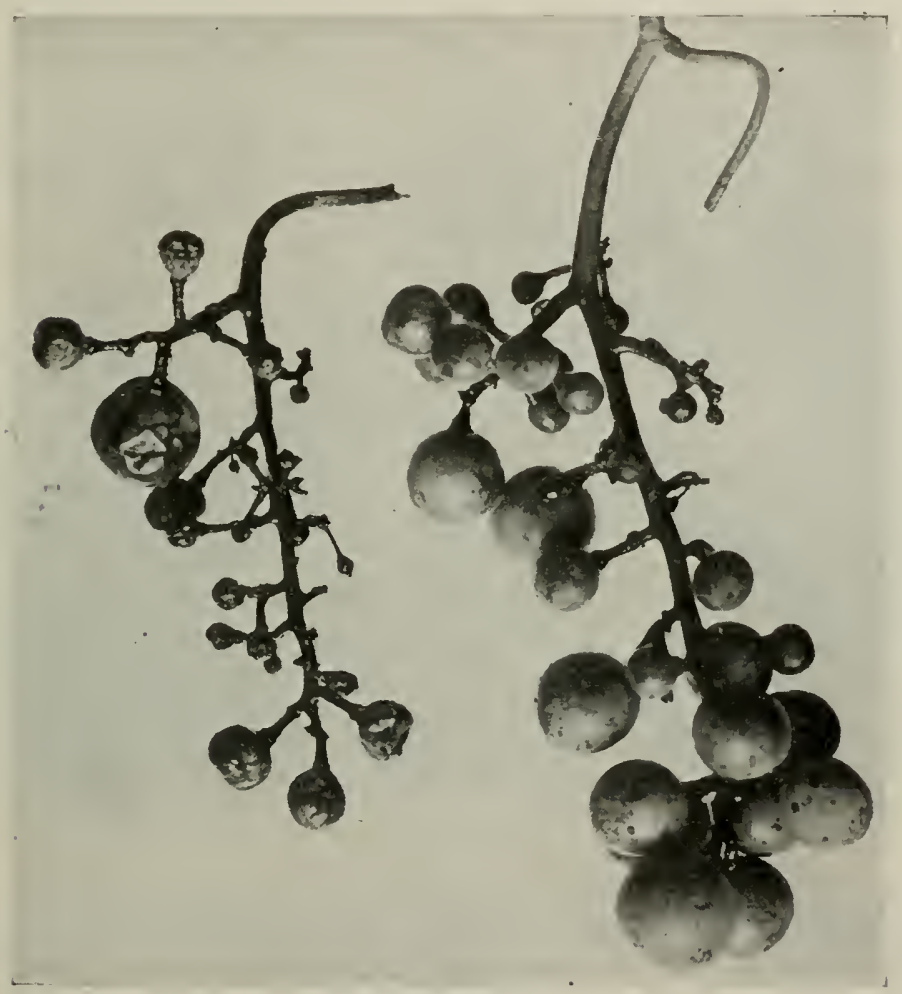

Fig, 17\%,-Downy mildew disease causes green fruit to become hard and dry; the riper fruits shrivel and turn brownish in color. (Minnesota Station.)

frequently killed. Resistant varieties must be used for stocks in order to control the root form of this pest. If European grapes are grafted upon American stocks, they are usually not seriously affected by this enemy.

The grapevine root-borer feeds on the roots of the grape some distance under the ground. Its work is not usually noticed until 
the vine dies or is nearly killed. It is believed that the muscadine group of grapes is not affected by this pest. It has been suggested that these vines be used as stocks for the grafting of other grapes where this enemy is serious.

Diseases of the Grape.-The black rot is doubtless the worst disease of the grape. Downy mildew (Fig. 177) is also very destructive in some sections. The methods required in preventing black rot disease will effectively control several other diseases which may otherwise occur. Spraying with Bordeaux mixture in the early

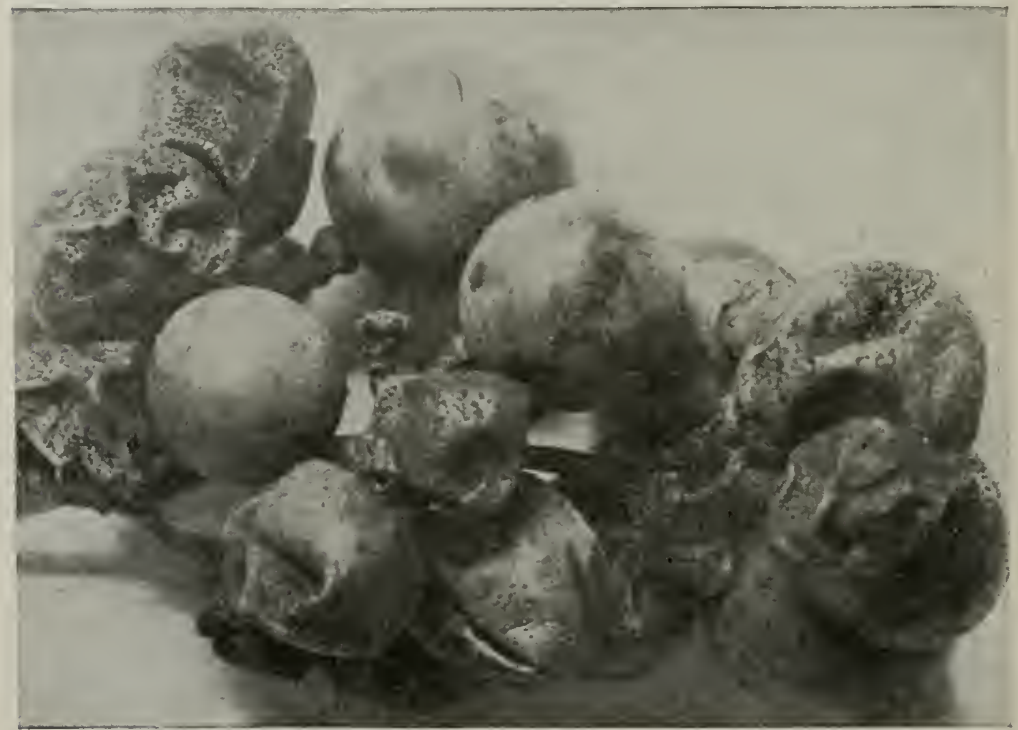

FIG. 178.-Grapes affeeted with rot disease. Courtesy Mel. J. Cook.

stages of fruit formation is recommended. This spray may be combined with arsenical poisons so as to control the disease and the leaf-eating insects at the same time. The first spraying should take place about the time the blossoming is over. It should be repeated every ten days or two weeks according to the weather conditions. With frequent rains and rapid growth, the spraying must be more frequent.

Figure 178 shows the first effects of rot disease. If the attacks of rot and mildew occur before Bordeaux mixture has been applied it may be impossible to control the diseases. However, unaffected parts of the vine may be saved if the work is done promptly. After 
the grapes are nearly full size, spraying with Bordeaux is not advised. It is difficult to remove from the fruit and some other material should be used which will wash off easily. There are two materials which may be substituted. Ammoniacal carbonate of copper is made from strong ammonia and carbonate of copper dissolved in water. Another harmless fungicide is livers of sulphur. For these formulas, see Chapter XXV.

The vineyard may be permanent if it is properly cared for. The vines are often known to reach the age of a century or more. In some soils, however, the life of the vines is much less. Frequently root-borers will affect the vines before the owner realizes their presence. Systematic spraying, annual cultivation, and close pruming will aid materially in making the vines permanent.

\section{GRAPE PROJECTS, EXERCISES, AND SURVEYS}

1. Care and management of the vineyard for a year or two should be made a home or school project. It should include pruning, spraying, tying, cultivation, fertilizing, bagging of fruit, harvesting, putting up products, and marketing.

2 . Setting, trellising, and care of young vines may be a project for the first year of the vineyard.

3 . Separate exercises may be made of each of the vineyard operations. These will give good practice to each student.

4. A questionaire may be made to determine the number of vines and amount of grapes grown by each family of the community. Ascertain best varieties of each color, order of ripening, worst enemies, remedies used, systems of pruning and of trellising. Ask for the amount and method of cultivation and of fertilizing in each case. The answers should be compared and the results tabulated under several heads.

\section{QUESTIONS}

1. From your own observation describe some good locations for the growing of grapes.

2. What varieties of grapes are most popular in your section?

3. Describe these.

4. What are the peculiarities and special uses of muscadine grapes?

5. Discuss the propagation of grapes.

6. Describe some good methods of trellising.

7. Give directions for the annual pruning of grapes.

8. What cultivation and fertilizing are required for grapes?

9. Give suggestions regarding the harvesting of grapes.

10. Mention the worst insect enemies and give remedies for each.

11. What diseases of grapes are found in your region? How are they controlled

References.-U. S. Farmers' Bulletins: 709, Muscadine Grapes; 758, Muscadine Grape Syrup; 859 , Home Preservation of Muscadine Grapes. 


\section{CHAPTER XXII}

\section{BUSH FRUITS IN THE HOME GARDEN}

THE term bush fruits as here used includes raspberries, the blackberry group, currants, gooseberries, blueberries, and cran- berries. The distribution of bush fruits is shown in figure 179 but the last three are not included in the map.

While these are considered chiefly from the standpoint of the

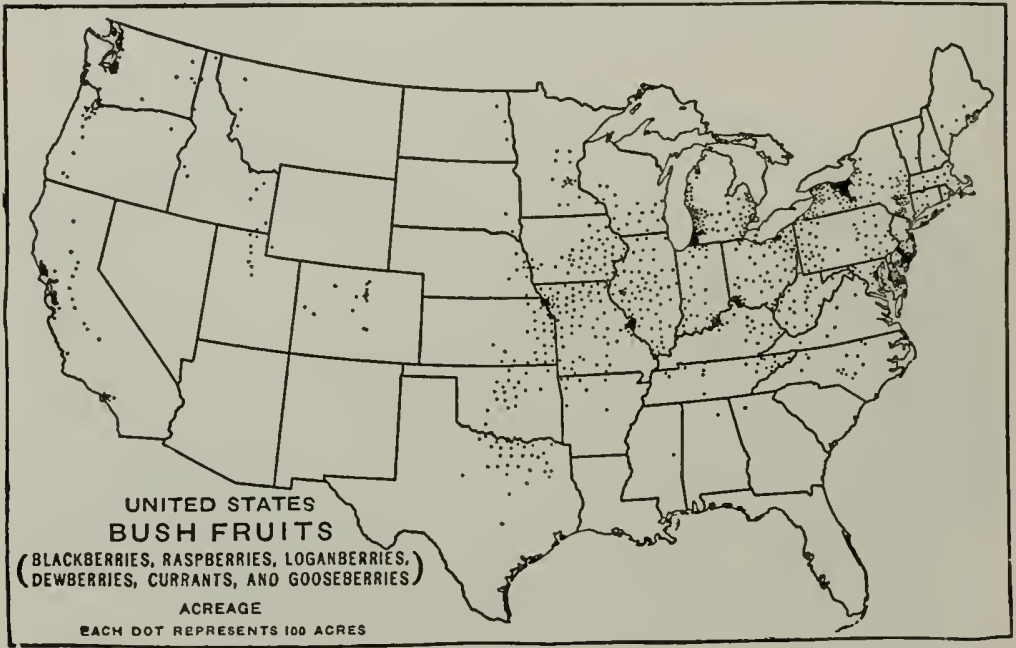

Fig. 179. - Acreage of bush fruits in the United States. The acreage is mostly in the Northeastern States, especially along the eastern shore of Lake Michigan and in the Lake Ontario and Finger Lakes regions of New York. Smaller but intensive centers of production are located in Sonoma County, Cal., around Salem, Oreg., and Puyallup, Wash.

home gardener, the methods are much the same as for the commereial grower. The surplus product should be properly marketerl.

\section{RASPBERRIES}

There are four main types of raspberries. (1) The so-called red raspberry group, including the red, purple and yellow berries (strigosus). (2) The black' cap group (occidentalis). (3) The European group with red and yellow berries (idæus). (4) Purple eaned varieties of the species Rubus neglectus. 
Soils.-Rich black soil is best for raspberries. They are not thrifty in light sandy soils. The vines respond readily to additions of fertilizers and manures.

Locations. - The raspberry patch for home fruit should be located at one side of the garden where the bushes may be left undisturbed for some years. Near the house is better than off at some distance because the fruit should be picked frequently. The vines should not, however, be placed in the shade of fruit trees or other trees. Give them an open exposure. The aspect of the slope is not an important consideration. Where hot west winds occur in the summer season, some protection on that side should be given.

Varieties.-For practical considerations, the third group mentioned above is not inclucled here. Among the varieties of black raspberries belonging to the American black caps (species $R$.

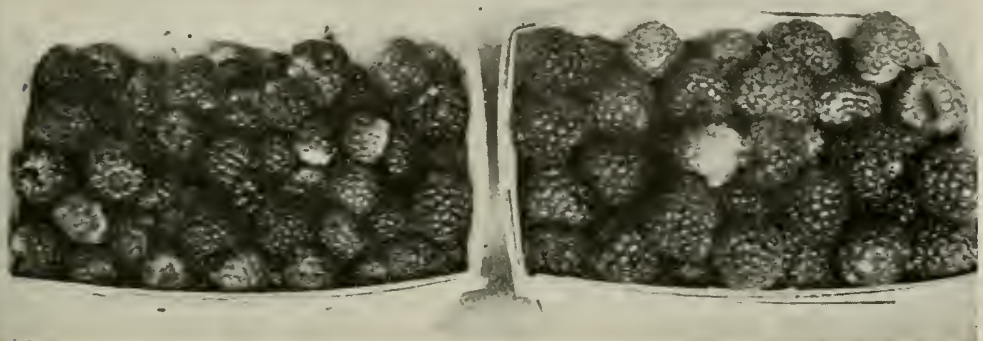

FIG. 180.-Pint berry baskets with two varieties of raspberries. Ruby at left, Empire at right. (U.S.D.A.)

occidentalis) may be mentioned Black Cap, Cumberland, Farmer, Gregg, Kansas, Ohio, and Palmer. The purple, red, or yellow berries belonging to this species (occiclentalis) are: Catawba (purple red), Columbian (purple), Golden Thornless (yellow), Purple Cane (red) and others (Fig. 180).

The red or purple varieties belonging to our native red raspberry group (strigosus) are Cuthbert, Herbert, King, Philadelphia, Marlboro, Ranere (or St. Regis) and Perfection. Yellowish varieties of this same group are the Caroline and the Flavus. Golden Queen is the chief yellow variety of the foreign species (idæus).

Planting Raspberries.-A good plar is to plant the raspberies in solid rows with the plants three or four feet apart in the row and the rows about six feet apart. Sometimes the hill system of planting is used, the plants being five feet apart each way. 
As the red raspberries (strigosus group) propagate readily by underground stolons or suckers, the solid-row method is best adapted to that type.

A good time for planting is in very early spring. Set the plants a little deeper than they were in the nursery soil and firm the dirt about the roots well.

Inter-crops such as cabbage, cauliflower, beans, peas, and other garden crops may be grown between the rows the first year. Allow room for thorough cultivation between these crops and the berries. Clean culture should be given not only the first year but every year.

Pruning.-The oldest canes should be kept cut out, and each summer the long canes should be cut back and caused to branch. This will induce more fruit clusters to form. The cutting out of old canes at the base may be done either just after the picking season is over or in the winter time. (Figs. 181 and 182).

Training.-Red raspberries are often so tall and slender that they require supports of some kind. If they are planted in the hill system, a single stake may be used to support each plant Fig. 183). If the bushes are grown in a solid row, a trellis may be made by stretching wires on posts (Fig. 184). The older canes are tied to this wire to keep them up when bearing their fruit. Two wires may be used, one above the other, with better results. Cross pieces are sometimes nailed on the posts and two wires at the same height are stapled to the same pieces. The canes are kept between these two wires and tied to one or the other.

A more common plan is to keep the canes so well cut back that no trellis is necessary.

Winter Protection.-Varieties are sometimes grown in the northern or western states which require special protection during the winter season. One plan is to throw a deep furrow of soil over from the plants on one side. Then the canes are bent down into the furrow and covered about two inches deep. In the spring they may be left covered long enough to prevent any danger from late spring frosts killing the blossoms. They are then uncovered and brought back to their original positions.

Harvesting Berries.-Care must be exercised in picking and handling the crop. If mashed at picking time they will not stand up well in the market and are soon wet with juice. The black cap varieties should be picked as soon as they show the least purple tinge and they will complete their ripening after picking. 


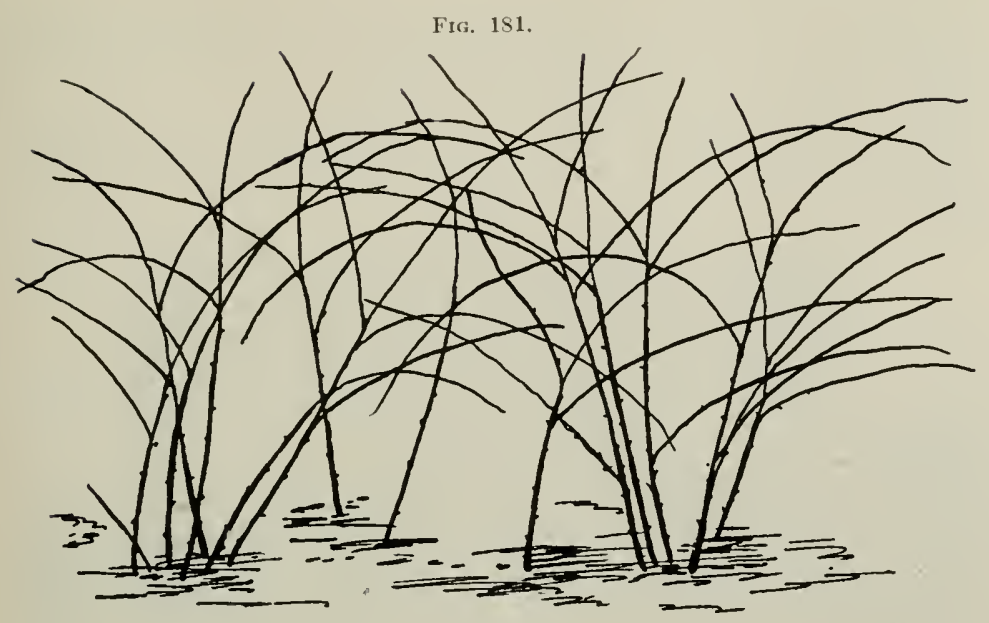

FIG. 182.

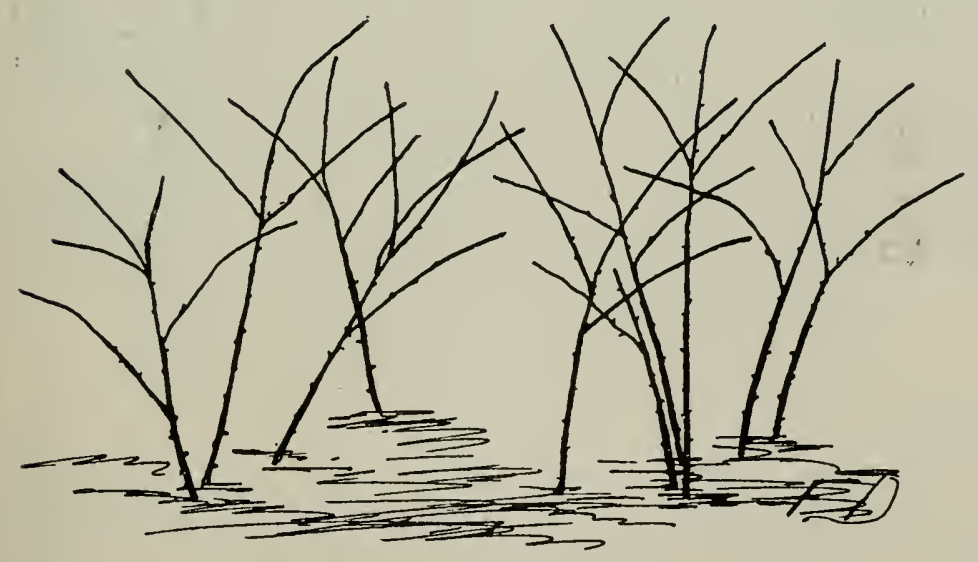

FIgs. 181 and 182 .-Black raspberry bushes before and after pruning. 
Over-ripe or injured berries should be discarded. If this is done by the picker it will avoid re-sorting of the fruit for marketing. The pint baskets are commonly used to pick into. The quart baskets may be used for the black and purple varieteies.

Home Uses.-For home use raspberries should be used abundantly in the fresh state, and the surplus if not marketable at good prices should be made up into forms for use during the winter. Both types of raspberries are excellent if camned by the cold-pack

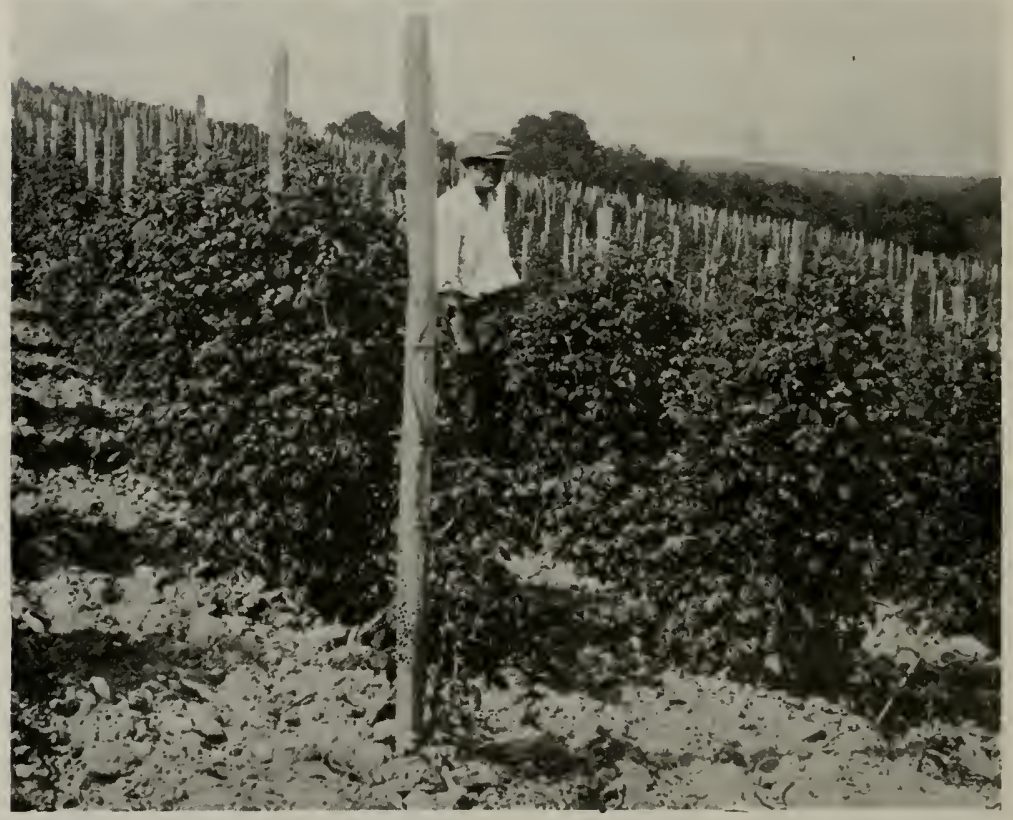

Fio. 183.-One-year-old raspberries grown by the hill system, supported by single stakes. (U.S.D.A.)

method. They may also be dried and saved without the use of cans. They are also made into jams and jellies.

Insect Enemies.-Cane borers are probably the most troublesome of the insect enemies of the raspberry. The eggs are laid by the adult in the tips of the canes and the larva when hatched will soon cause the tips to droop. When this is noticed, pruning off the tops will destroy them. Cut well below the drooping part and burn prunings. Eggs and larvæ in these tips are thus destroyed. 
Diseases. - Several serious diseases affect the raspberry. ('rown gall (Fig. 185) and orange rust are quite common. Anthracnose and eane blight are sometines quite serious. Great danger from these diseases arises from setting plants affected by them. Some varieties are more immune to the disease than others. Spraying remedies against these troubles are not commonly used. On the

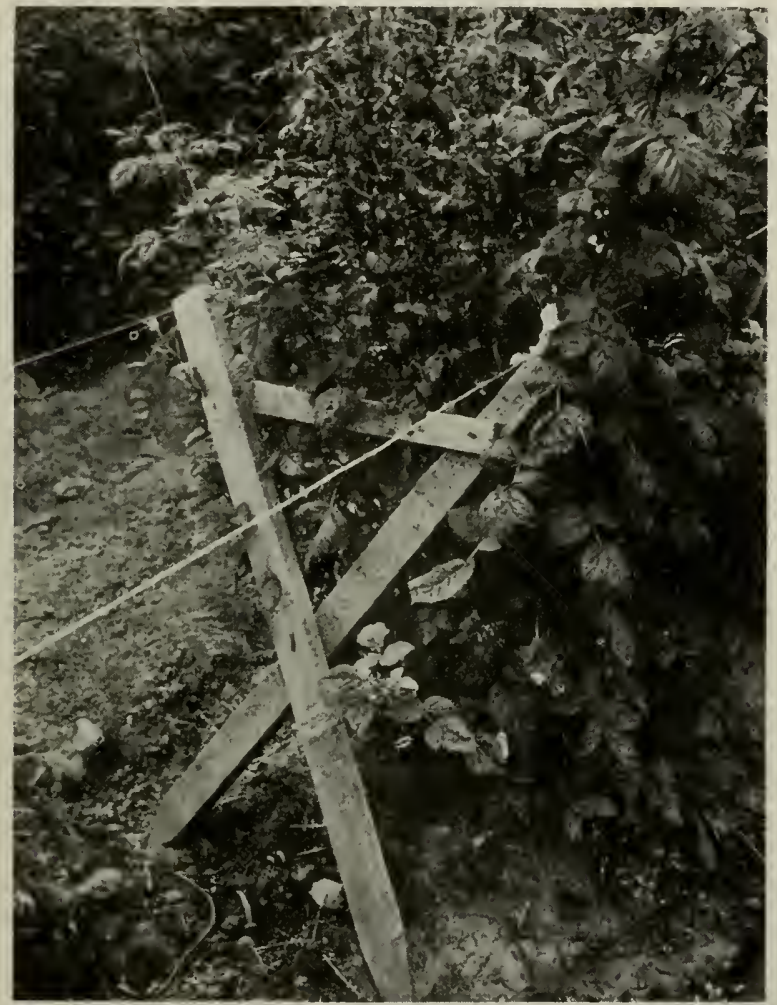

FIG. 184.-A form of wire trellis used for supporting raspberry canes. (U.S.D.A.) other hand, the chief means of control is to eradicate the plants when affected with orange rust or crown gall. Cut out the canes and burn the prunings when affected by cane blight or by anthracnose.

Permanency of the Raspberry Patch.-With both the red and the black raspberries it is necessary to avoid crowding of the plan- 
tation as it becomes old. Red raspberries, if allowed to spread by shoots from the ground, should be thinned out every few years. If black raspberries are cultivated close to the plants and are pruned as suggested by cutting out all the old canes annually, the plantation may last indefinitely.

\section{BLACKBERRIES}

As blackberries are native in such a large part of the country, they are less commonly grown in gardens than raspberries. They

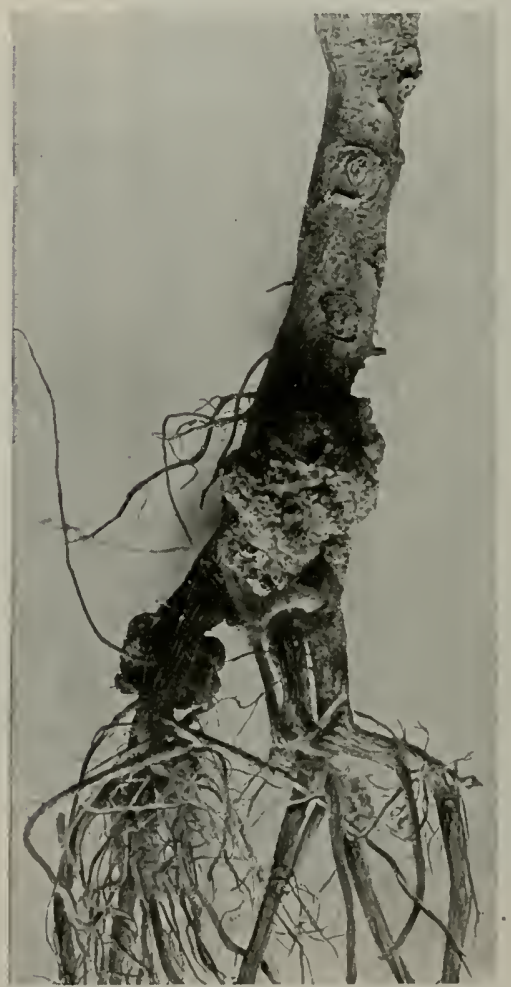

FrG. 185.-Raspberry crown gall. This disease may spread in the soil to peach trees. Do not set raspberries and peaches close together. (Minncsota Station.) are however grown in gardens with more profit and should find a place in more of our home gardens.

The best soils for the blackberries are rich, black loams. They are less thrifty on light soils. They respond well to additions of barnyard manure and green manure.

Location.-It is well to locate the blackberry patch where it will not be in the way of other garden crops. Along one side of the garden is a good place. The berries should be picked frequently during the ripening season and the patch should be located where it can be given attęntion at this time.

The Kinds. - The many forms of blackberries are difficult to classify. Bailey suggests the following groups: (1) The long clustered varieties are probably best known. The canes are tall and branching. The fruits are somewhat thimble shaped to cylindrical.

When ripe they are sweet and dull colored. An albino form of this group is white or amber colored when ripe. Taylor and 
Ancient Briton are common varieties of this group (Fig. 186). Mersereau probably belongs to this group. Iceberg is one of the albino varieties.

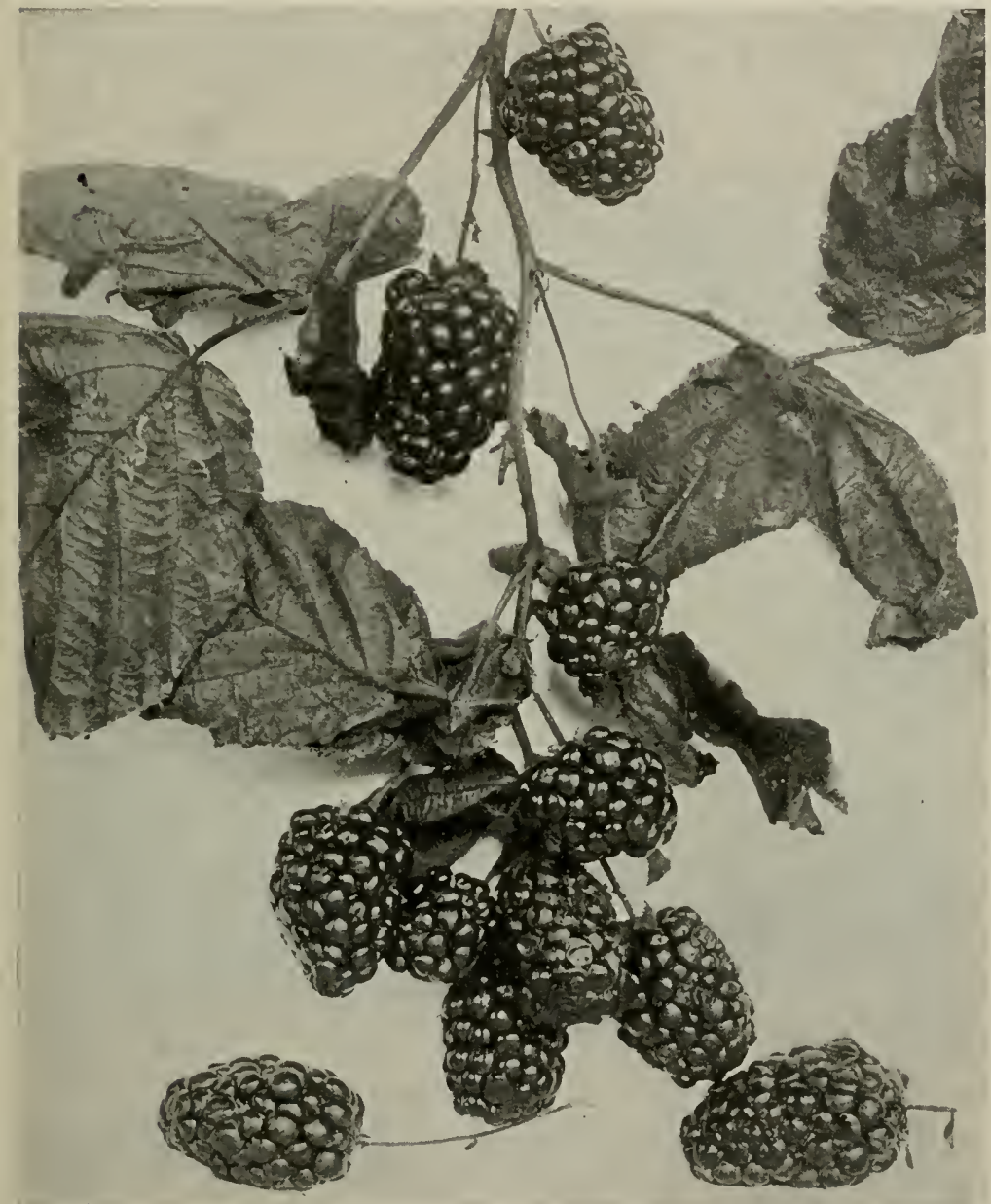

FIG. 186.-The Rathburn blackberry is a standard old variety which is still quite popular.

(2) The short-clustered blackberries are borne on smaller and weaker plants, with greenish canes, less thorny than the preceding. The clusters of berries are short and leafless. The berries are 
globose, a few in a cluster. The lobes of the berries are irregularly set. Popular varieties of this group are Snyder, Lawton, Kittatinny, and Agawam.

(3) The leafy-clustered blackberries have low, bushy plants bearing short elusters with leaves mingled with the flowers or berries. Early Harvest is the hest commercial representative of this group.

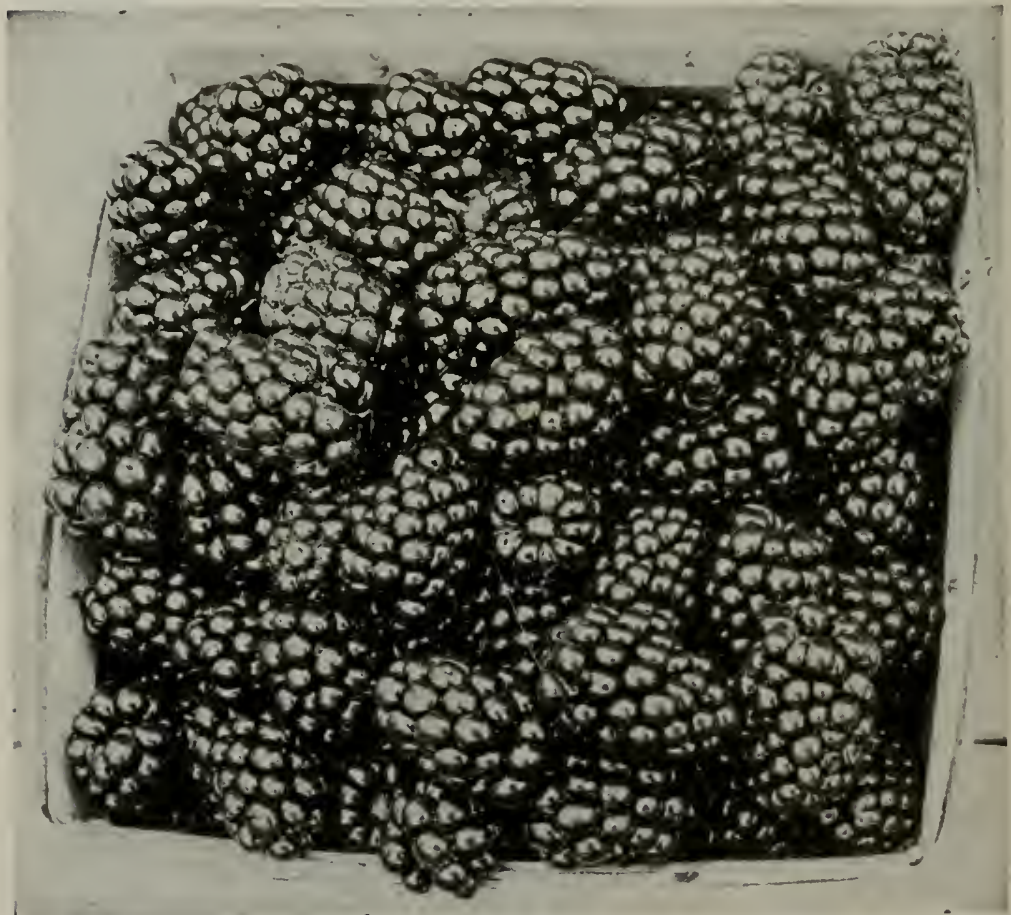

FIg. 187.-A basket of Lucretia Dewberries that taste as good as they look. (U.S.D.A).

(4) The loose-clustered blackberries have low spreading canes with broad notehed leaves. The berry clusters are large and the berries round, glossy and juicy with the lobes loosely attacherl. The so-called Wilson varieties belong to this group (Fig. 187)

(5) The sind blackberry is low and shrubby. The prickles are stout and are curved. The cluster's bear from one to four roundish berries. This is not of commercial importance. 
(6) The evergreen blackberries. The vines are clinging; the leaves are evergreen or nearly so. The berries are large, black, sweet, and ripen through a long period, sometimes lasting three months. The Oregon Evergreen is a common variety of the Pacific coast.

Planting Blackberries. - The most common plan of planting blackberries is to prepare the ground well as for corn and then lay out the rows about six to nine feet apart. Set the plants about three to four feet apart in the rows. This will leave room between the rows for the use of a horse, or team in cultivating or harrowing.

An inter-crop may be used between the rows to help maintain the cost of the patch until bearing time. Use a crop such as cabbage, beets, beans, or something which requires clean cultivation. Allow room between this crop and the blackberry bushes for a one-horse cultivator. The vines will begin to spread by means of shoots from the underground stems or roots. These should not be allowed to widen the row very much but the plants may become thicker in the row.

Pruning Blackberries.-The first year the canes may be allowed to grow to the height of eighteen to thirty inches. The top should be cut off and they will thus be forced to branch. Frequent pruning is therefore necessary during the growing season. If the bushes are kept low they will not require trellising. The fruit is borne on the canes produced the previous season. The old canes should be removed as soon as the crop has been picked. The easiest way to do this annually is to mow down the entire growth with a brush blade promptly after the picking is over. Very few young shoots will then be up enough to be injured by the blade. The work is much more rapid than trying to cut out and take away only certain canes and leave the rest. There will be enough time during the remainder of the summer for vigorous canes to be grown on which the crop is to be borne next year. Another advantage of mowing down the entire patch is the control of diseases and insects.

The old canes may be removed and burned, particularly if they are infested with borers and with rust disease. Canes started as late as midsummer will need less heading back, but if the season is favorable, attention to this must be frequent. Some heading will greatly increase the crop next year. More tips for bearing fruit clusters will thus be formed. The pruning of lateral shoots is sometimes necessary. A good rule is to keep the plants low enough to avoid the necessity of trellising. 
Winter Protection.-In cold climates winter killing may be prevented by laying down the canes in a furrow along one side of the row. Cover them with a light layer of soil or mulch of straw. Some varieties cannot be bent down very easily. In such cases the roots on one side must be loosened by digging. Very tender varieties are more heavily covered than others.

In the spring the plants are raised when the buds begin to burst. The cover may be kept on long enough to hold back the blossom season late enough to prevent damage from spring frosts.

Picking and Marketing the Crop.-Many varieties of blackberries change to the ripe color before they are mature. For home use they should not be picked too soon. For market they may be picked much earlier than for home use. The quality may not be quite so good but the handling will be much better. Picking is usually done in berry baskets holding one quart. Several of these baskets may be carried in a flat holder with a rigid handle, hanging on the belt or on the left arm. Pickers frequently wear gloves with the tips of the fingers cut away. This makes them less timid in getting berries that are somewhat protected.

Uses.-Blackberries are used for eating fresh with cream and sugar, or they may be stewed for immediate use. The surplus crop may be kept for winter use by preserving, canning, or drying.

The profits from the small patch are encouraging. If the surplus is sold, it usually brings a good price even in small markets. The crop is sometimes shipped long distances if necessary.

Enemies of the Blackberry.-There are very few enemies of the blackberry. The pithy gall-maker sometimes attacks the canes and may be controlled by cutting away the affected parts and burning them. The worst disease of the blackberry is bramble rust. The leaves are often badly affected and it may be considered a serious disease. The annual pruning which has been described is very effective providing all the canes are mowed down and burned just after the picking is over. This will usually keep the rust uncler control reasonably well.

Permanency of the Plantation.--Blackberry roots become too long and tend to spread badly. They should be kept within bounds and a wide strip for cultivation must be maintained. It may be necessary to turn the soil by plowing deep furrows near the plants and thus destroying the side suckers. The plants may also become too dense in the row so that they are virtually root-bound. In this case thinning out is necessary for success. This may be done by 
plowing out half or more than half of the row just after the mowing of the canes in midsummer. Those plowed out should be taken up and planted elsewhere, or they may be destroyed.

By avoiding the spreading and crowding of the roots, the patch may be maintained somewhat permanently.

\section{DEWBERRIES}

The wild dewberry has been domesticated and is now frequently grown in gardens. The fruit closely resembles the blackberry to which it is related. In fact the two are often hybridized, producing varieties resembling one or the other.

The plant has a trailing and climbing habit and is often grown upon the ground. In some cases the vines are supported on wires to protect the ripening fruit from being soiled by beating rains. Heavy mulches are sometimes used under the vines for this purpose.

There are at least five native species of dewberry. Probably the most popular cultivated variety is the Lucretia (Fig. 187).

Methods of propagation, planting, culture, and picking are practically the same as those given for the blackberry.

\section{CURRANTS}

Currants are grown chiefly for home use but are often sold in local markets. Their uses warrant their growth and they should be grown more abundantly.

Soils.--Rich soils are preferred by the currant. The roots require considerable moisture and the heavy soils retain moisture best. The roots are shallow and some mulching of the soil is advisable for protection during the winter and also to prevent drying out of the roots during the summer. If manure is used in the mulch, it will add considerable fertility to the soil as it rots and this will feed the plants sufficiently.

Location.-Plant currant bushes along the fence row of the garden but allow room for cultivation on both sides of the row. They may be given a place next to the raspberries and blackberries.

Types and Varieties.-There are two main species of the currant, the common red currant which has an albino variety, and the European black currant. There is also an American black currant somewhat similar to the other.

Varieties of the red currant are the Fay and the Cherry currant.

The currant is native of the colder climates, but has a wide distribution. 
Planting the Bushes.-Autumn is probably the best time to plant currants. They sprout so early in the spring that it is difficult to get the ground ready for them in time. Black varieties should be planted farther apart than the red varieties. Six feet each way for currants is a good plan. The rows of red currants may be five feet apart and the plants three or four feet apart in the row. Use strong one-year-old plants if they can be secured. Be sure to plant them deep as the roots tend to become too shallow. Firm the soil well by tramping it about the roots but leave a light mulch of soil on top.

Cultivation.-Give clean thorough culture, particularly during the first few years after planting. A row of garden truck may be grown between the rows of currants for one or two years.

Pruning.--Red currants produce their fruit on spurs which develop from the wood two or three years old. There should be a liberal supply of wood of this age. Therefore little pruning is desired. After the wood is four or five years old, some of it should be cut away each year. A little trimming may be necessary to give the bush the proper shape.

Black currants bear most of their fruit on wood of the previous season's growth. In pruning cut away the older wood as it is no longer of much value. This will help to keep the bush thinned out. Black currants tend to spread rather too much and may require shaping by pruning.

Mulching and Fertilizing.--The roots of currants are near the surface and should be well mulched with manure in the fall and early winter. This will prevent heaving of the soil by freezing. As the manure rots it will add fertility to the soil. It therefore would not need to be removed in the spring. Incorporate it with the soil by cultivation. On most soils the application of some potash in addition to the barnyard manure is helpful. Use at the rate of two hundred pounds of muriate of potash to the acre or apply wood ashes liberally. Currants will stand heavy fertilizing.

Picking Currants.-Currants are chiefly used for making jell and sauces. They are sometimes made into pies while fresh or from the canned product. In America they are seldom eaten out of hand.

Currants should be picked when they are in prime condition before they are too ripe. There is dangre of considerable loss if they are left too long. For winter use the crop is chiefly saved in the form of jell, but both black and red varieties are canned. 
Enemies of Currants. - The currant borer attacks the stem and sometimes kills considerable wood. Close pruning is a good remedy. Burn the prunings.

The currant maggot attacks the fruit about the time of ripening, causing the berries to fall to the ground. The attacked fruit is rendered useless because of the maggot inside the berries. The scratching of chickens about the bushes will help to control this pest. As the maggots crawl into the ground from the ripened fruit, they are picked up by the poultry. Give the chickens free run at this time, if the maggots are plentiful.

The Currant Sawfly.-This is also called the imported currant worm. This insect destroys the leaves by eating them. They are therefore easily kept under control by poisoning. This should be done as soon as the first attacks are noticed.

The oyster-shell scale is sometimes a serious pest on currants and other bush fruits. Winter sprays of lime-sulfur will help to keep the scale under control.

Leaf-spot disease is a rust which attacks both black and red currants, causing the leaves to fall early. Ammonia copper carbonate spray is probably the best remedy, if the fruit is nearly ready to ripen. After the picking season is over another spraying with Bordeaux mixture is recommended.

Renewing the Plantation.-One planting of currant bushes should last many years if they are properly cared for. The cost of starting a new plantation is very little as the plants are readily propagated by cuttings. Some time is required to bring them to full bearing and therefore the old bushes should be kept as long as they are vigorous.

\section{GOOSEBERRIES}

This crop has been given much more attention in European countries than in America. The fruit growing wild in America is often used for food.

Gooseberries are propagated chiefly by cuttings of ripened wood. Mound layering is also practiced.

Varieties of Gooseberries.-Popular varieties of American gooseberries are Downing, Pearl, Josselyn, and Hougton. European varieties are Industry and Whitesmith. Varieties grown in Canada and recommended because of their resistance to mildew are Companion, Eagle, Glenton, Green, Queen of Trump, and Snowball. 
Culture of Gooseberries.-The best soils for the gooseberry are those which will retain moisture well. Heavy black loam is probably best. Clay soils, if well drained, are very suitable. The moisture can be retained by mulching with barnyard manure. Set the plants in rows six feet apart with the plants about four feet apart in the rows. Use one-year-old plants if you can get them.

Clean culture is best. A row of cabbage, potatoes, or other clean culture crop may be grown between each two rows of gooseberries.

Prune the vines and give them a good shape. The first year leave five or six shoots for each plant. Prune out the oldest wood each year, leaving chiefly wood of the preceding season to bear the fruit. The oldest wood will bear some fruit on the spurs but these should usually be cut away and allow for more vigorous new growth.

Harvesting and Use.- Grooseberries in America are usually picked green when about full size. In European countries they are more commonly allowed to ripen and eaten out of hand or stewed in this condition.

The green fruit is used in making pies, sauce, and in flavoring other fruits. The surplus crop may be easily canned for winter use.

Enemies.-The sawfly or imported currant worm mentioned under currants is also sometimes serious on gooseberries, defoliating the bushes. Spray promptly with poisons.

The gooseberry worm attacks the fruit just before ripening. The worm lives inside the berries and renders the fruit worthless. The presence of poultry in the yard where the bushes are grown will render good service by destroying many of the larvæ. Hand picking of affected fruits may be advisable.

Mildew is a very serious disease of gooseberries. It has discouraged many growers by attacking the leaves, twigs and fruit. The disease spreads rapidly. The most promising remedy is the use of lime-sulfur wash to clean up the bushes cluring the dormant season. Use a weaker application when the buds first burst in early spring. Summer strength of this spray may be used later. If the attacks occur about the time the fruit is half grown, or later potassium sulfide, one ounce to two gallons of water, may be used.

\section{BLUEBERRIES}

Wild blueberries have long been abundantly used, but their growth in gardens is comparatively recent.

Plantations may be started by selecting the wild bushes and transplanting them. Choose those with largest and best berries 
and those which are most prolific. They may be propagated by mound layering and cuttings. Stump layering is successfully practiced. Cut off bushes in early spring, leaving the stumps at the surface. Cover these with a very sancly soil to a depth of two inches. Shoots will be sent up and by fall these will be rooted in the soil. They may be dug up, separated and transplanted early the next spring. These rooted shoots are grown for a season in pots of well-drained, sandy soil. Give them a shady place and avoid watering too much.

Soils for blueberries must be well drained and free from lime or limestone. Acid soils are preferred. Bog soil, if well drained, is excellent. Sand should be mixed with this.

Set the bushes three or four feet apart, in rows about as far apart. As they reach maturity they may be thinned if they are crowded.

Give the plantation clean culture. Cabbage may well be grown between the rows for a few years. The bushes will not bear commercially for four or five years.

Uses.-Eaten fresh with sugar, or cream and sugar, as a dessert, is the chief use. They are also cooked and used as sauce, and made into pies, puddings, and muffins. They are easily canned for winter use.

\section{CRANBERRIES}

The growing of cranberries is restricted by natural conditions, as the culture is limited to regions of cool climate, rich soil, and plenty of water.

The soil for cranberries should be deep, rich, and black. There should be a supply of sand near by to spread on top when the plantation is started. If an old bog is used for cranberries, it must be cleared of brush and roots as much as possible. Then plow and harrow it well. After the native growth has thus been subdued for a few months, the surface should be graded nicely. The plants are then set in a layer of sand spread a few inches deep all over the surface.

Flooding of the cranberry bog should be planned. This is necessary for several purposes: (1) to prevent the heaving out of plants by winter freezing; (2) to retard the blossom season and prevent damage from late spring frosts; (3) to protect the fruit crop from early fall freezes; (4) to prevent attacks of insect enemies; (5) to protect from fires; (6) to protect from drouth. 
A good plan is to have a dam holding a reservoir of water located a little above the level of the bog. The bog must be bordered by a bank of clay or solid earth to hold water when it is flooded. At any time desired the water from the reservoir and stream supply is turned on the bog and held any length of time needed.

Propagation and Planting.- The cranberry is increased from cuttings of the stems or roots, usually the stems. Mow the stems ten to fifteen inches long and gather them into baskets or ventilated barrels to transport to the new bog.

Mark off the sanded bog with rows of shallow furrows fifteen to eighteen inches apart. Cuttings may be dropped by hand along these furrows, or they may be gathered in bunches of five to ten, and these placed about one foot apart. The cuttings are then pressed into the soil with a broad, wedge-shaped dibber made like a spade, so that a man ean put his weight upon it. Heavy wheels are sometimes devised for pressing down two rows of cuttings at once. The furrows are then filled by raking in the sand, and the whole bog is then rolled with a heavy field roller.

After planting all the weeds and grass should be kept out and the cranberries given undisputed possession of the soil. During the first two years at least, the area should be kept comparatively dry at the surface, although it is best to keep the water level within four to six inches of the surface.

Each season it is necessary to go over the bog and pull out all large weeds and any tall grass which may appear. The vines will tend to keep out the weeds and grass after first year or two.

Gathering the berries is done by hand or by machines. They are picked in "measures" holding six to twelve quarts. From these they are poured into storage boxes, and kept from freezing in cellars until used or sold.

They are screened, fanned, and otherwise picked over in the winter before going to market. They are sold in bulk from barrels or in quart boxes.

Uses.-Cranberry sauce with turkey is a popular American dish. The fruit makes nice jell. The berries keep easily and do not need to be canned. Or they may be canned in cold, sterilized water, and will keep without cooking for a long time. 


\section{PROJECTS, EXERCISES, AND SURVEYS}

1. Raspberry projects.-Grow a patch of red or black raspberries using the best methods of setting, pruning, training, culture, harvest, etc. Market the crop and compare the income with the total cost.

2 . The patch may be taken into the project after it is already started. The financial results will be more satisfactory if each year's expenses are charged against its crop. Careful records should be kept.

3. Other Projects with Bush Fruits. - Projects should be planned and conducted in a similar way with blackberries, gooseberries, currants, and perhaps with blueberries or cranberries.

4. Practice in setting the different bush fruits should be provided each student. The work may be either at school, at home, or on some neighboring place.

5. Propagation of bush fruits of several kinds will furnish good practice to students.

6. Pruning bush fruits of all kinds is excellent work for short time exercises.

7. Picking berries and keeping records for large picking crews is good practice. This work may be accompanied with practice in sorting, grading, and preparing berries for market.

8. Surveys regarding bush fruits may be made in the region to determine a number of points: (1) best varieties of each kind grown, (2) distances of setting, (3) cultivation, (4) fertilizing, (5) methods of pruning and training, (6) yields, (7) disposal of crops, (8) age and duration of bushes.

\section{QUESTIONS}

1. What types of raspberries and what varieties are grown in your region?

2. Give directions for setting raspberries; blackberries.

3. What methods are used in propagating the young plants?

4. What inter-cropping is allowed in young patches of bush fruits?

j. Give the annual pruning and training for raspberries, blackberries, currants, gooseberries.

6. Is winter protection advisable for any of the bush fruits in your region? If so how is it accomplished?

7. Describe the harvesting of berries of each kind.

S. Give some ways of saving each of the kinds of berries or their products for winter use.

9. What are the chief insect enemies of the bush fruits in your region? Give remedies for each.

10. Give the same regarding the chief diseases.

11. Discuss the different groups of blackberries.

12. Describe the propagation of blueberries.

13. What are the purposes of flooding a cranberry plantation?

14. Describe the propagation and planting of cranberries.

References.-U. S. Farmers' Bulletins: 643, Blackberry Culture; 728, Dewberry Culture; 860, Cranberry Insect Problems; 887, Raspberry Culture: 900, Homemade Fruit Butters. 


\section{CHAPTER XXIII}

\section{NUTS AND SUBTROPICAL FRUITS}

IT should be of general interest to students in all parts of the country to learn of the fruits and nuts that are to be found in all our markets. For the purpose of giving general and horticultural information on nut culture and the subtropical fruits, these are discussed here.

Almonds have been grown commercially in California for many years (Fig. 194, E). The orchards extend into the irrigated regions of other southwestern states. The almond tree resembles the

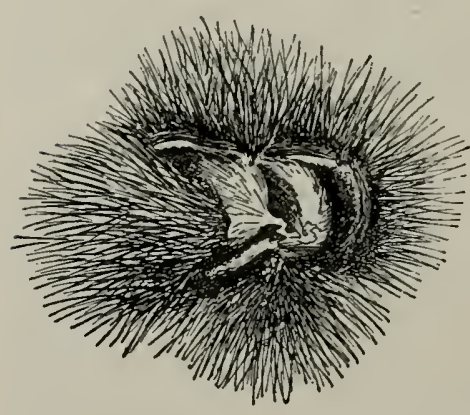

Fig. 1SS. - Native chestnuts are used for food. They are planted to produce stocks for propagation of the better sorts. peach tree in many particulars. The orchards are given much the same culture and care as peach orchards.

Trees must be protected from late spring frosts to avoid damage to the blossoms. Planting on hillsides to give air drainage is most practical. The use of orchard heaters is also resorted to.

Good varieties of California origin, named in order of popularity are: Napoleon, IXL, and Ne Plus Ultra.

Chestnuts.-These are both native and introduced. The native chestnuts (Fig. 188) of the northeastern part of this country are used for home consumption, but are seldom found in the markets. The rative stocks are used in propagating the improved varieties introduced from Europe. Cleft grafting and bark grafting are chiefly practiced in this work.

The Paragon and the Ridgely are good varieties grown somewhat easily on our native stocks. Japanese varieties may come into more general use when they are better known.

The chestnut blight has destroyed much of the chestnut growth of the East and may ruin the commercial growth of these nuts in Ancric'a. 
Native Walnuts.-Black walnuts are grown in nearly all states except the northern tier. They are used chiefly for home consumption or are sold in local markets. Few are shipped to distant markets. The large trees are readily grown from seed. They produce a fine quality of dark colored wood from which they derive the name black walnut.

Buttermuts or white walnuts, are similar to the above. The trees have a lighter colored wood. They have a more limited range and the nuts are not so generally used.

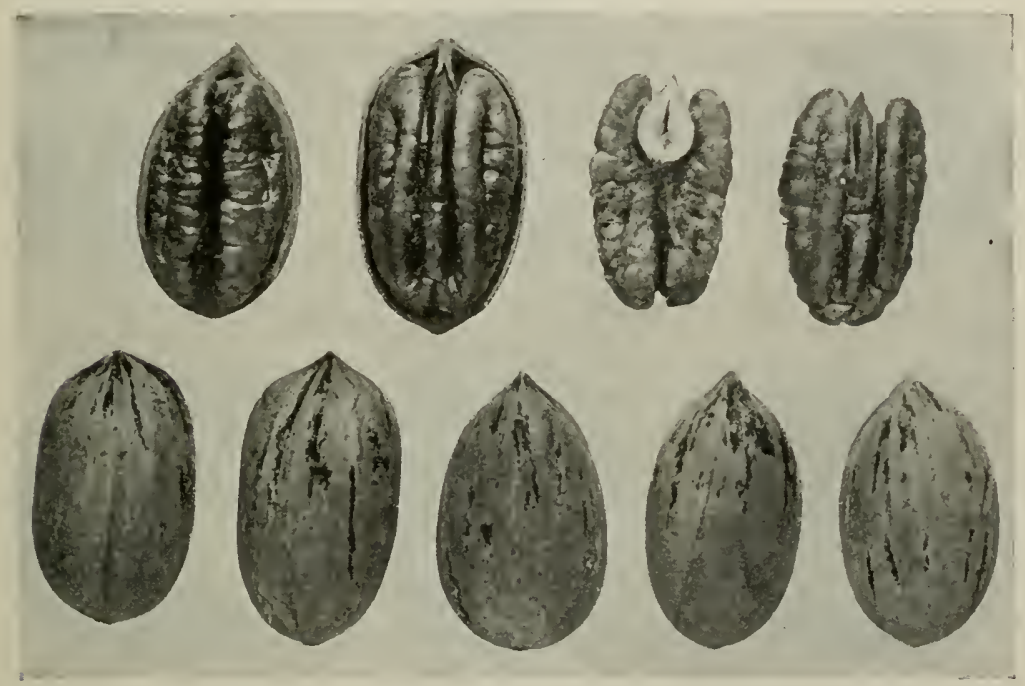

FIG. 189.-Thin shelled pecans of the Stewart variety. (U.S.D.A.)

Pecans are found native from Illinois and Iowa southward to the Gulf states. In the warmer regions they are grown commercially in orchards. There are a number of very fine varieties that are propagated chiefly by budding on seedling stocks. Large nuts with thin shells are much preferred in the markets (Fig. 189).

The wide range of soil and conditions under which pecans may be grown, and the prices for the nuts, should cause a more extensive planting of commercial orchards.

English Walnuts (Fig. 190 ) were early introduced from Persia to western Europe and the New World. The trees are grown for shade and for nuts in all parts of the eastern coast states south- 
ward from Philadelphia, and in the middle parts of the country. The commercial nuts come chiefly from the Parifie coast (Fig. $194, \mathrm{E})$. It is necessary to grow the trees in numbers to insure complete pollination. A few named varieties are propagated by budding and grafting, but seedlings are most commonly planted. The trees become very large and should be grown forty feet or more apart. The soil should be a deep loam with good under drainage of gravelly sub-soil. The usual orchard tillage is given

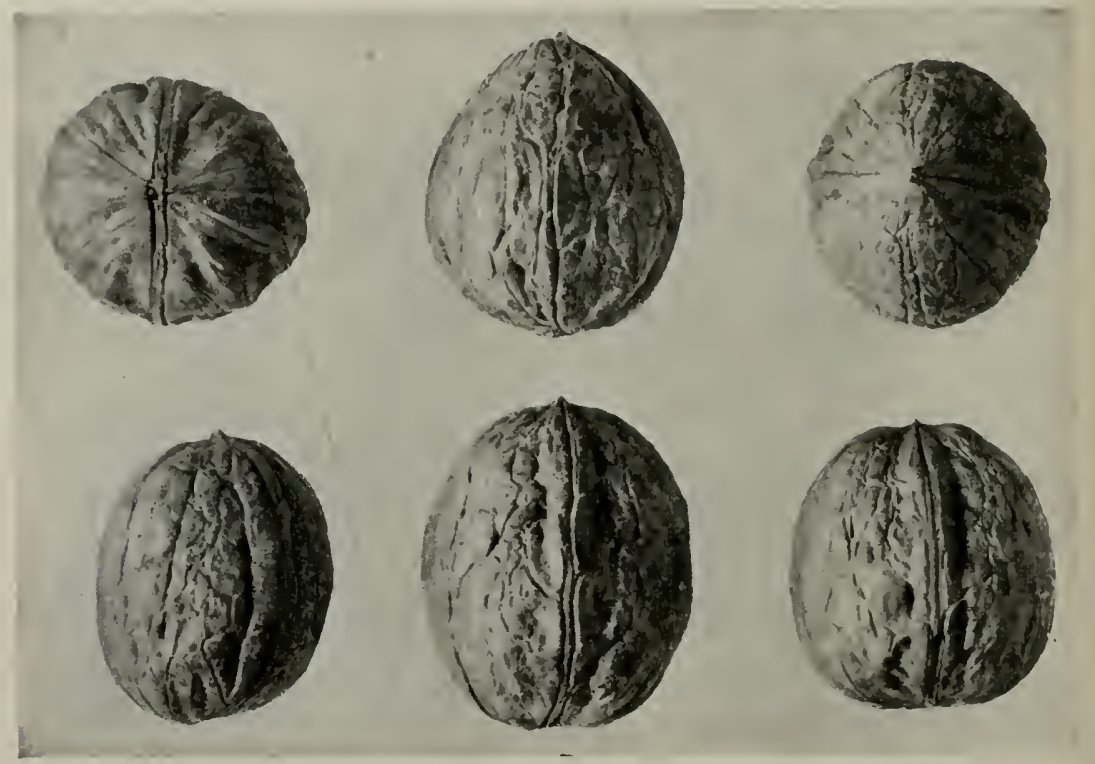

FIG. 190.-Concord variety of English Walnuts from budded trees in California. (U.S.D.A.)

the groves. The roots are deep, and deep plowing once a year is allowable.

Figs are grown for home use along the Atlantic coast as far north as Philadelphia, and in the lake region of Michigan. In the interior the trees must be laid down and protected in winter. Commercial orchards are grown along the coast southward from Norfolk and west to Texas. They are abundantly grown by irrigation in New Mexico, Arizona, and California.

The fruit is most generally known in our markets as dried figs, but the fresh fruit is becoming more popular. It is rich in sugar and is easily preserved in cans to be shipped to market. 
The bush forms are common in the southeastern states, the Brown Turkey variety being one of the smallest and hardiest. The Celeste is a little larger and about as hardy. It is used abundantly in orchard planting in the Gulf and Atlantic states. The Magnolia variety is grown in orchards of Texas southward from Beaumont. Trees are set from ten to fifteen feet apart in orchards.

In California the fig becomes a very large tree. Orchards are set thirty to forty feet between trees. The Suryrna figs are now abundantly planted in California, but other horticultural forms are still being used a great deal.

Figs are readily propagated from cuttings. The young trees are set in orchards at one to two years of age, and should bear in about the third season from setting. The yields are usually good and the results are encouraging to growers, as the trees are long lived and there are few enemies.

Caprification of figs is the name given to the work of insects which corresponds to the pollination of other fruits. This is important with the Smyrna fig industry. A few wild figs are grown in each orchard to serve as the homes of the special form of insects that do this work.

Olives.-This crop is mainly produced in the countries bordering on the Mediterranean. Olives were first grown in America by the Franciscan missionaries and others in California, Arizona, and New Mexico. They are now grown in those states (Fig. 194,D) and somewhat in Florida. One and a half million trees were reported in California in 1915.

Propagation of Olives. - The most common method of propagating olives is by tip cuttings of the current year's wood, four to six inches long. Remove all but a leaf or two and root the cuttings in sharp sand under glass with some bottom heat. They are then set in nursery rows for one, two, or three years, where they are cultivated and fertilized well.

Seedlings are also raised and planted in commercial groves. Many seeds are too hard to germinate and the ends must be clipped to aid in germination.

Grafting of seedlings after they are set in orchards is sometimes practiced.

The Mission variety is the oldest and most common in California orchards. Smaller varieties such as Chemlali and Redding are also propagated, but chiefly as stock for orchard grafting. Sevillano is a large-fruited variety used for pickling. 
Olive orchards are, set at varying distances between the trees, fifteen, twenty, twenty-four, or thirty feet are found in California. In some countries olives are grown as border trees along fences, roads, ete.

Thorough cultivation should be given the orchard each year until time to sow a winter cover crop. The green manure from the cover erop is plowed under each spring and other fertility added if neerled, particularly while the trees are young. Orehards that are irrigated are cultivated after each watering.

Pruning must be done each year. At first remove the lower branches to make a free trunk of about thirty inches. The head limbs should be eut back every year. Thin out one-third of the small limbs from the body of the tree. The fruits are improved by thorough pruning. It also aids in control of the olive-fly and scale insects. Olive-knot disease is also controlled by cutting away the affected parts.

Harvesting olives is a tedious task, as they should be picked by hand. They are allowed to all ripen on the trees as nearly as possible and then are all picked at one time, if the product is to be used for ripe olive pickles or for oil.

Oil is extracted from ripe olives by pressing, grinding, and re-pressing.

Pineapples. - This fruit is well known in all American markets. It is producer in Florida, southern California, Porto Rico Hawaiian Islands, the Philippines, and elsewhere.

Propagation is successful by several methods: (1) By crownsthe tuft of leaves at the top of the fruit. This method is not much used as the erowns are shipped with the fruits. (2) By slips, or buds produced in the angles of the leaves at the base of the fruit. These may be saved and planted. (3) By suckers from buds on the old stem above ground. These make several inches of growth and send down roots of their own. This is probably the most common method of propagation. (4) By rattoons, which are underground shoots from the main stem. These form roots and may be left growing when the old stump is taken out.

Soils and Culture.-Pineapples are partial to well drained soils. The soil need not be rich in organic matter, but it should be well supplied with plant food by means of commercial fertilizers. In Florida the spruce-pine lands are much used for growing this crop.

The plants are usually set in beds of several rows so they may be worked with hoes from the sides (Fig. 191). The rows vary in 
width from eighteen inches to three feet with different varieties.

Red Spanish is small and very popular. Queens and Porto Ricos are larger and more highly i)rized because of their qualities. Black Jamaica, Black Prince, and Smooth Cayenne are also good, large varieties. Blood, Sugar Loaf, and Enville are medium in size.

Pineapples are sometimes extensively grown under partial shade made of lattice work.

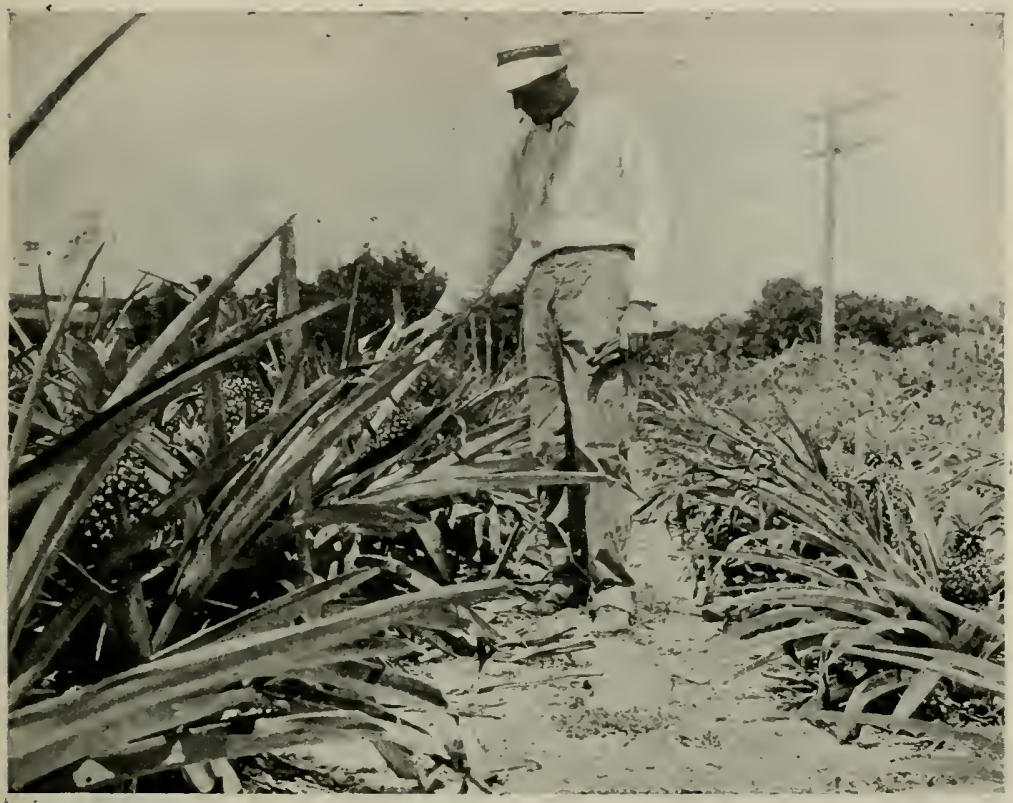

FIG 191.-Pineapples in the open field showing an aisle between beds. (U.S.D.A.)

Harvesting and Marketing.-For different markets the pineapples are gathered at different stages of ripeness, depending upon the distances to be shipped. They are twisted off by hand, conveyed to sheds, sorted as to size, ripeness, etc., and are packed for market. Each is wrapped in paper. They are usually shipped in half-barrel crates and the number contained in the crate is marked on the outside. Shipping may be either by freight or express.

Mangoes are of tropical origin. In southern Asia they are one of the most common fruits. In the subtropical regions of California 
and Florida some good varieties are grown, and many inferior seedlings are found. The fruits are variable in size and shape. Some are as small as plums and others many times larger, weighing as much as four or five pounds. The most common color is yellow or greenish yellow, with a possible blush of red. Good varieties have a skin as thin as the peach, and a juicy, mellow flesh that is delicious in aroma and flavor. The large stone is somewhat flattened and is either fibrous or free (Fig. 192). Some seedlings have a flavor suggesting turpentine, particularly in the skin.

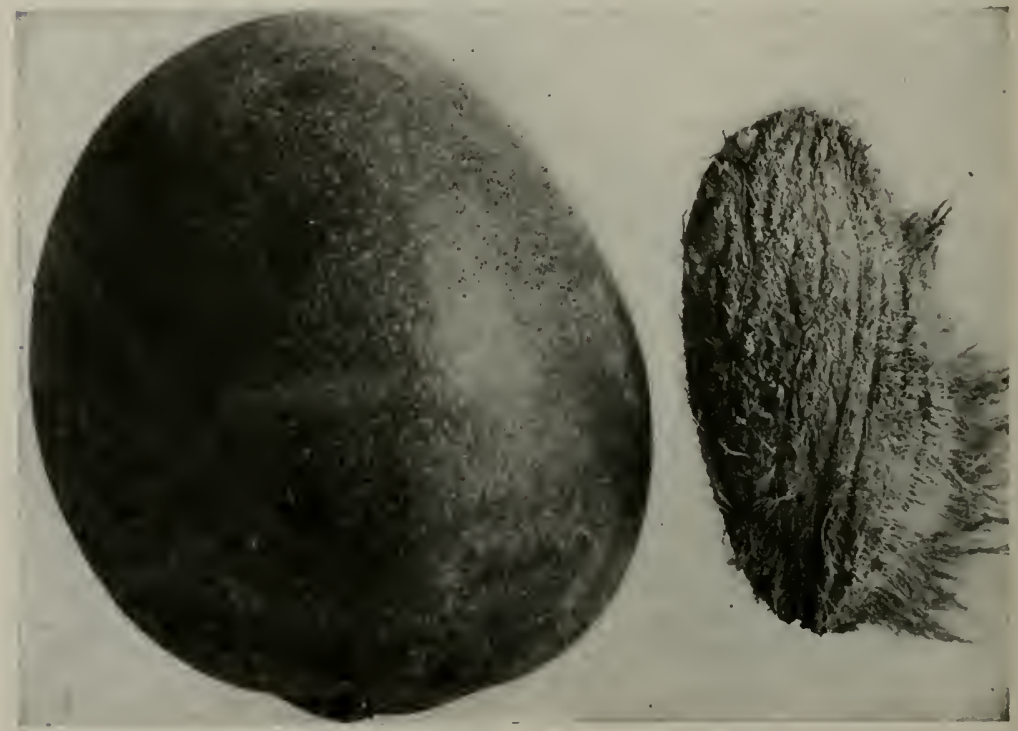

FIG. 192.-Fruit and seed of Haden Mango from the parent tree; one-third size. (U.S.D.A.)

Uses.-Bulletin 127 of the Florida Station gives recipes for preparing this fruit in a number of ways, as jelly, marmalade, preserves, sweet pickles, chutney, fries, ice cream, and sundae. The best fruits are eaten raw as a dessert.

Propagation.-The above mentioned bulletin gives details regarding propagation of improved varieties by shield budding, patch budding, inarching young and old trees, and striking cuttings.

Soils for mangoes should be well drained and well fertilizerl. Thorough tillage is very desirable. Mulches of litter over the surface during the dry season will aid in saving the soll moisture. 
Orchards.- Some distances between trees in different orchards are 35, 26, and 21 feet. Sandersha and Cambodiana are good varieties which are less affected by weather during blossom season. Mulgoba is a. standard variety of very high quality. Other good varieties are Harden, Amini, and Bennett. See description of these in the above mentioned bulletin. In the Standard Cyclopedia of Horticulture is a good account of mango culture.

Avocado.-This is a valuable fruit, grown extensively in many tropical countries. Certain forms are found native in Mexico and

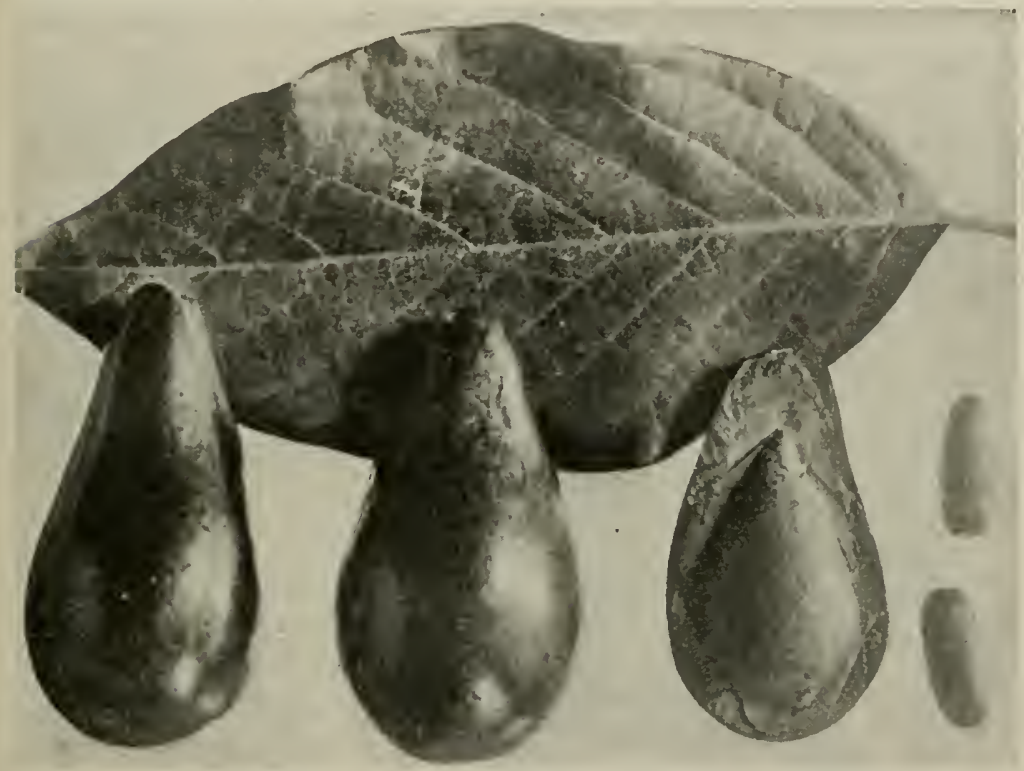

F1G. 193. - A good variety of Avocado averages over one pound in weight. The trees blossom in the spring, and the fruit is mature in a little over one year. It may be held on the tree several months longer. (U.S.D.A.)

Central America and are grown commercially as far north as Florida and Southern California.

The trees are large and produce fine shade. The pear-shaped fruits vary in size from one to six inches in diameter (Fig. 193). The skin may be soft and pliable or hard and shell-like. There is one large seed in a fruit which in some cases does not fill the seed cavity. The firm, yellowish pulp is rich in flavor, and is highly prized and nutritious. The large percentage of vegetable oil which 
it contains causes it to be used as a salad fruit; but it is used in many other ways.

Propagation of the Avocado.-Trees have been propagated chiefly by seed until recent years. They are now more commonly budded by shield budding on young seedling stocks. Improved varieties are thus perpetuated and the results are more satisfactory.

The Avocado Orchard.-Trees are usually transplanted to the orchard in early spring. If they then have many leaves these are sometimes partly stripped off to reduce the evaporation. A large ball of soil should be kept about the roots, or they may be carefully shifted into boxes which hold the soil to the roots while being moved.

Set the trees in rows twenty feet or more apart, in soil that has good drainage. The trees should be fertilized, cultivated, and in some regions irrigated, as is done with oranges and lemons. Try to "harden off" the trees for" winter.

Yields and Harvest.-Yields are very apt to reach thousands of fruits per tree in case of large seedling trees, but they are more apt to be counted by the dozens on trees of the large budded varieties.

The fruit is picked by hand and sorted before packing and shipping. The fruits vary in size, color, and shape. Each fruit should be wrapped in paper. For best shipping Georgia peach carriers are used. See figures in Peach Chapter.

\section{CITRUS FRUITS}

Under this hear are included such fruits as oranges, lemons, grapefruits and limes. None of these are grown in regions of severe frosts. All of them are grown in the warmer parts of Florida, California, and the borders of the gulf. They all find ready markets in all the states and elsewhere. The United States produces about one-third of the world's product (Fig. 194).

Oranges are by far the most important of the citrus fruits. There are three regions in this country where the crop is grown: The central belt of Florida; the western and southern slopes of the foothills of the Coast Range in California; along the Gulf coast from Florida to Texas. In the first two regions are grown ali types of oranges including the round and the Satsuma. The round oranges of both navel and seed types (Fig. 195) are here most grown for market. The Satsuma or flattened type, is the chief one grown along the north coast of the gulf. In Louisiana below New Orleans, and in the lower Rio Grande Valley and along the coast 

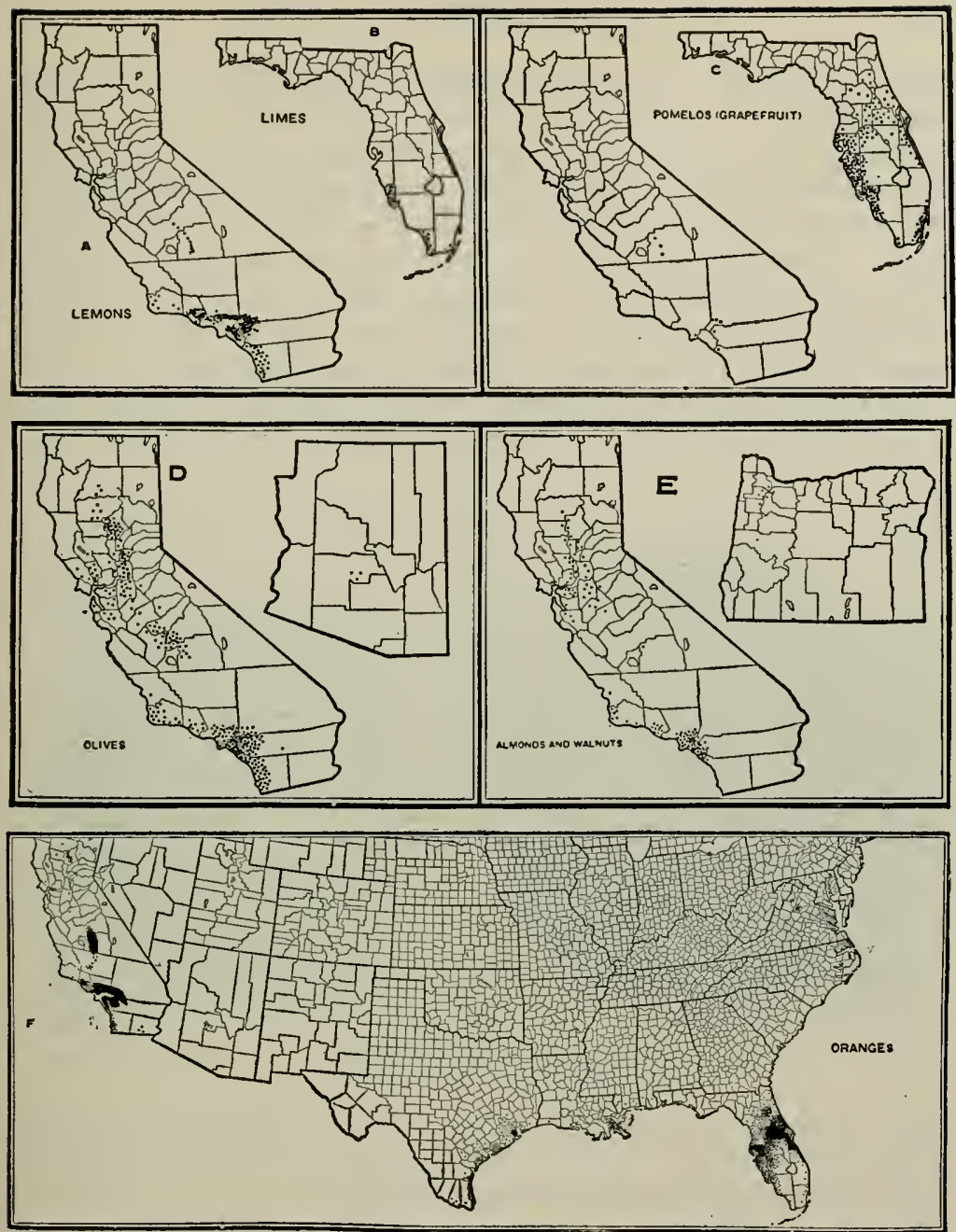

FIG. 194. - Maps showing trees of bearing age and younger. Each dot is for 100 acres of trees, except in $\mathrm{D}$ for 50 acres and $\mathrm{E}$ for 500 acres. Lemons are produced principally in southern California, where most of the crop is grown along the foothills on the western side of the Coast Range. Limes in the United States are grown commercially only in the southern tip of Florida and adjoining islands and keys. Grapefruit (pomelo) is grown in Florida, where the fruit attains excellent flavor. The industry is of increasing importance in California. Olives are grown mostly in southern California, west of the Coast Range, in the Great Valley, and in the valleys opening into San Francisco Bay. The commercial production of Persian (English) walnuts in the United States is practically confined as yet to California and western Oregon. The production of almonds centers in Contra Costa County, Cal., and extends up both the Sacramento and San Joaquin Valleys. The commercial orange crop of the United States is practically confined to California and Florida. California has nearly two-thirds of the trees and produced in 1909 about three-fourths of the crop. There are a number of long-established orange orchards in the lower Mississippi delta in Louisiana and in Arizona. (U.S.D.A.) 
in southern Texas, the round oranges are also grown on a commercial scale.

Propagation.-Almost all the old seedlings are giving way to plantations of budded trees. This is especially true in California. Stocks are produced by planting fresh seeds. In California the sour oranges and grapefruits are much used as stocks. In addition to these the rough lemon and the trifoliate orange are used in Florida and the Mississippi and Rio Grande regions. Oranges budded on the trifoliate stocks will endure frost the best.

Shield budding is commonly used for all the varieties. The budding may all be done in fall, winter, or early spring and summer.
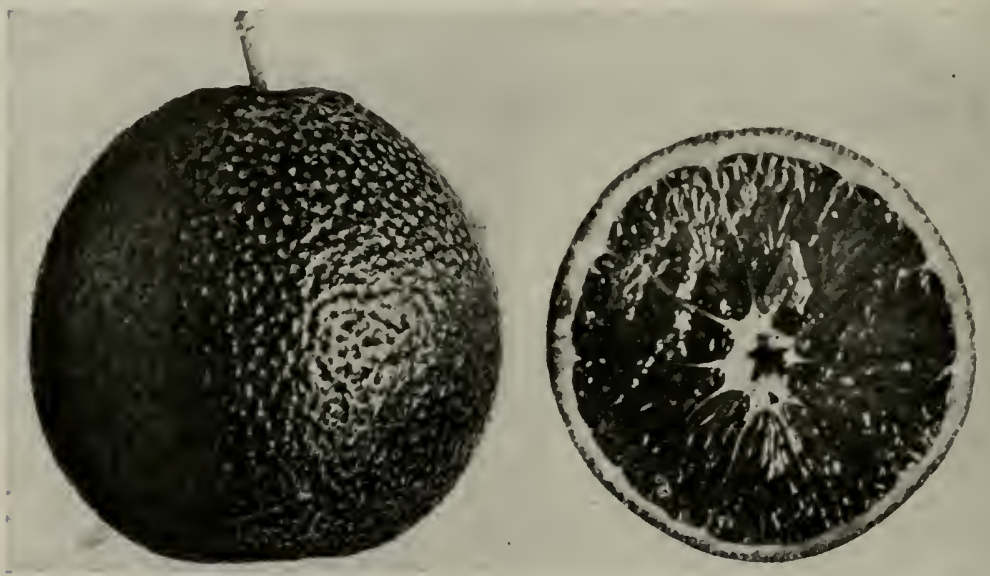

FIG. 195.-Valencia oranges of California are the most popular of the seed-bearing varieties. They are almost seedless. (U.S.D.A.)

The nearly dormant condition of trees is preferred in Florida. The buds are inserted about two to six inches from the ground. This is preferably done under lattice work.

Setting the Orchard.-Trees one or two years old from the budding are usually used in starting orchards. The distances between trees varies from 20 by 20 to 25 by 25 feet.

Soils used for orchards are quite variable in character. But the stocks on which the trees are grown should be adapted to the character of soil. Commercial fertilizers are commonly used in the best orchards.

Pruning.-When buds are well started the nursery trees are cut above the bud. The new shoots from the buds are cut at a height 
of thirty to thirty-six inches from the ground. This makes them branch and form the head of the future orchard tree. The sprouts below the buds must be removed persistently.

In the orchard the trees are "shaped up" and are pruned to keep down diseases, and remove injured parts. The pruned surfaces should be painted.

Culture.-Orchards are commonly cultivated the first half of the summer with disk harrows and other harrows. Then a winter cover crop is grown to be worked into the soil in spring. This green manure may be turned under by the only plowing given the orchard each year. In the irrigated orchards the dust mulch is re-established after each watering (Fig. 196). Cultivation is abandoned or

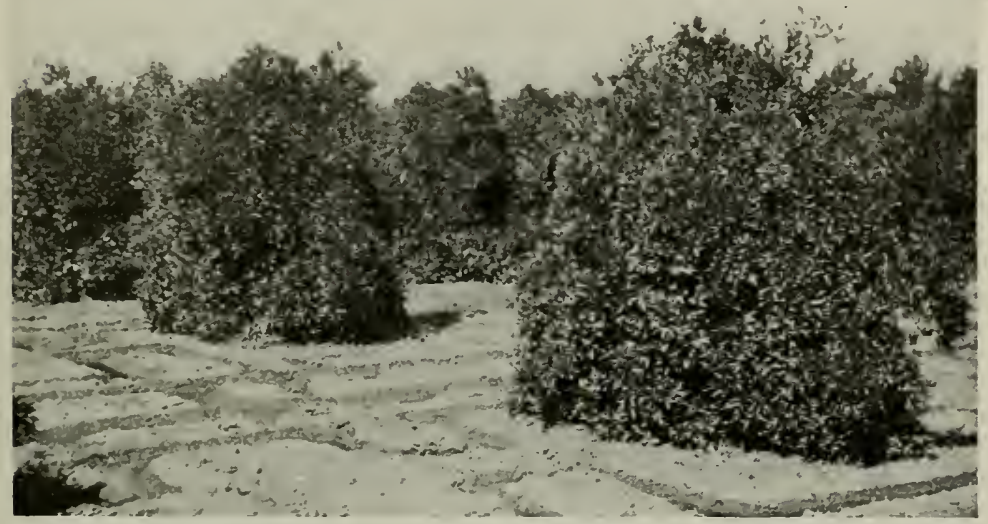

Fig. 196.-A California orange grove showing style of pruning trees and showing the irrigation furrows. (U.S.D.A.)

neglected in some orchards in both Florida and California, but this is not usually a good plan.

Harvesting and Marketing.-In California the Valencias (Fig. 195) are picked from June to October; navels from November to April, and seedlings in Spring. Most of the Florida crop is moved from October to May or June. Figure 197 shows an orange picking scene in California.

The bulk of the orange crop in America is handled through large associations that have central packing houses and market only well graded and wrapped fruits (Fig. 198). They are shipped in two-compartment boxes having a capacity of two cubic feet. Boxes half this size are used for the mandarin types. 
Enemies.-Many forms of scale insects attack oranges and other citrus fruits. There are also red spiclers, plant lice, rose beetles, and other insects attacking the orchards. The methods of control are spraying and fumigating under movable tents with hydrocyanic acid gas. Spraying in Florida and fumigation (Fig. 199) in California are the general rules.

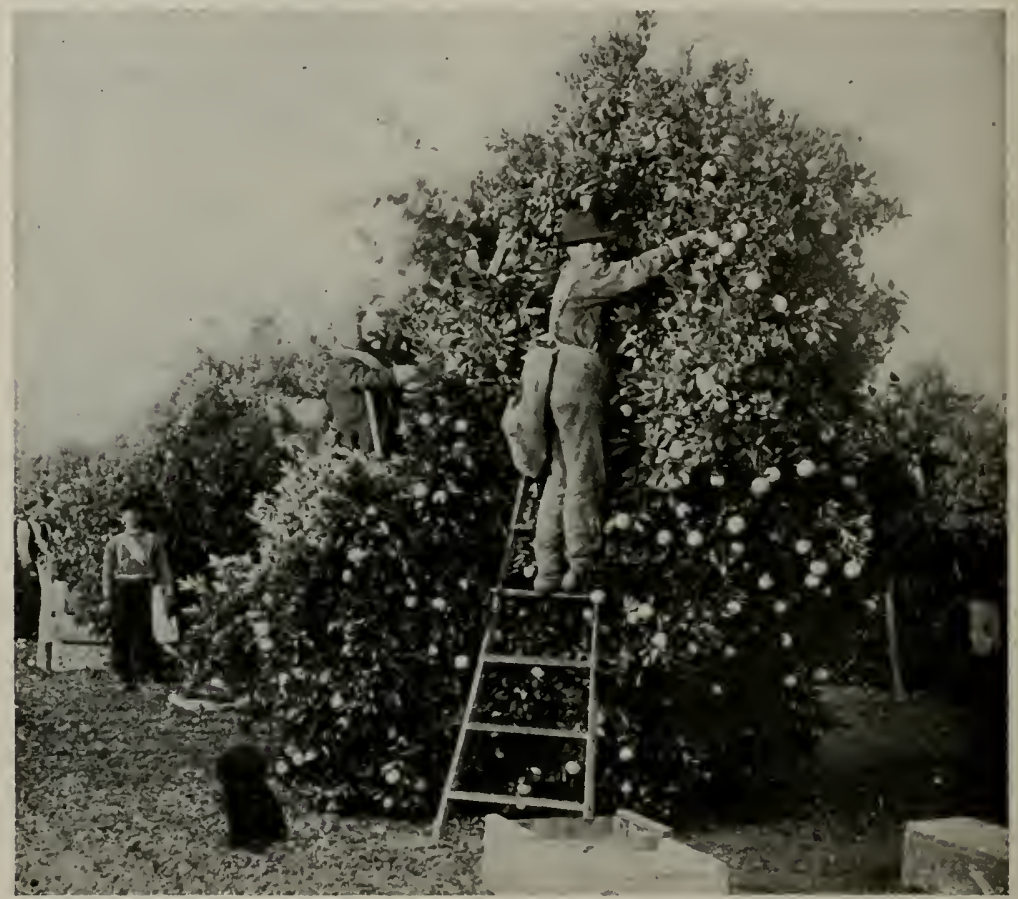

Fig. 197.-Oranges must be picked from the trees. Those which fall to the ground are considered worthless. (U.S.D.A.)

Common diseases of the trees are: gum disease, root-rot, trunkrot, wither-tip, twig-blight, melanose, and canker.

Frost is the most serious enemy of citrus fruits in America. The chief remedy is to have the wood well ripened up before winter. The use of orchard smudges is often very effective. Fruits are picked from near the ground first, to avoid frosting.

Grapefruit.-This is one of the citrus fruits of Florida, California, Arizona, and the West Indies. It is well known in all markets of 
America. It is slightly bitter in taste, and for this reason is not so popular as the orange for a breakfast or dessert fruit.

The name comes from the fact that the fruits may be borne in clusters resembling a bunch of grapes.

The trees are beautiful and symmetrical and bear fruit for many years. They are propagated by budding, the most hardy stocks

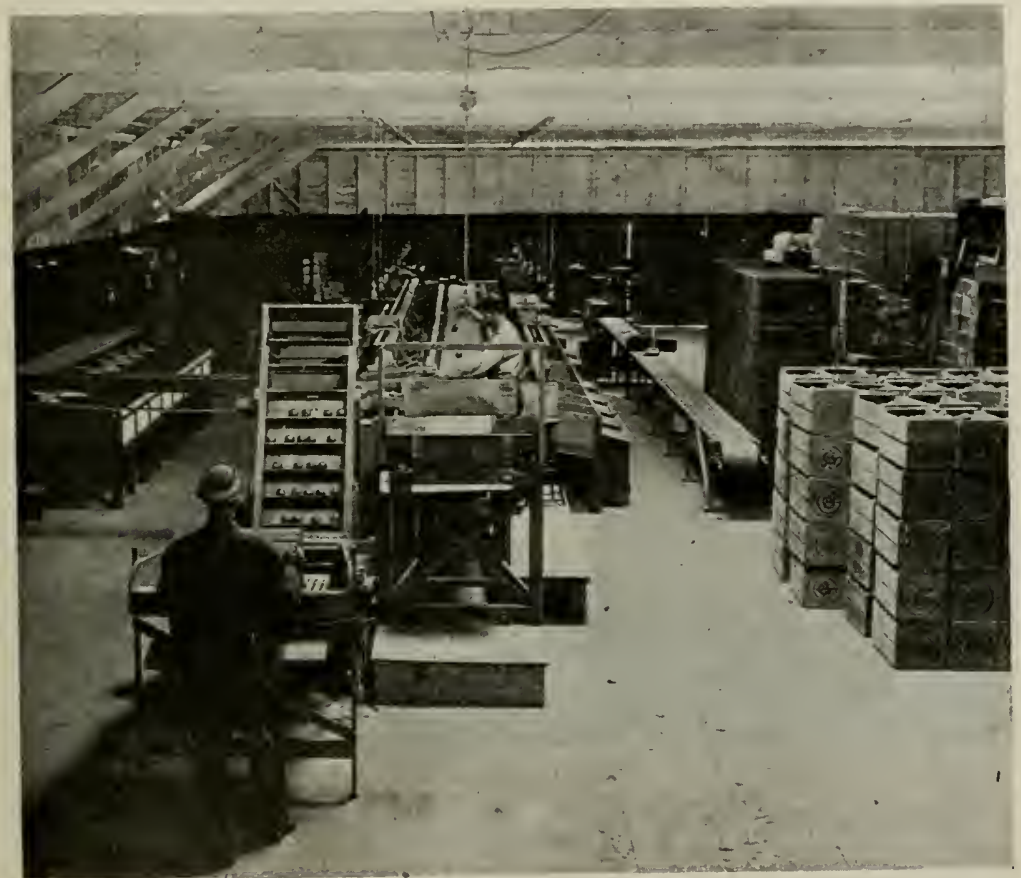

FIG, 19s.-Interior of an orange packing house, Highland, Cal. Hopper and brushes are used for dirty fruit. All fruit is graded according to size, quality, maturity, etc. (U.S.D.A.)

being the trifoliate orange stocks. Their own seedlings are also used as stocks for budding.

The trees are set eighteen to twenty-five feet apart each way in the orchard, depending on the kind of stocks used for budding. They are cultivated, sprayed, pruned, and fertilized with much skill and attention by commercial growers.

Duncan, Hall, and Pernambuco are probably the best varieties grown in Florida, Duncan being the most popular. In California the most popular variety is Marsh. 
Lemons.-This crop is much less grown in Florida than beiore the heavy killing of trees by frost in 1895 . The main erop of the United States is now grown in southern California near the coast. A period of low prices for lemons discouraged growers in both these states.

The fruit is picked a number of times each year. Prices are best in summer and regions that can produce good summer fruit have a decided advantage. Growers try to delay ripening from spring until summer. They also try to hasten the ripening of the fall fruit so as to get it on the summer market. Special processes

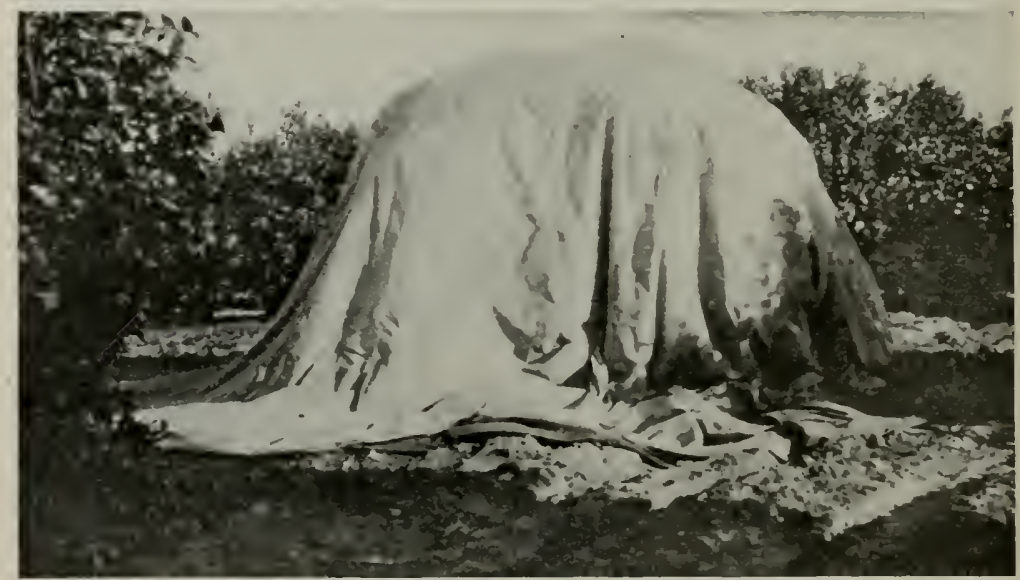

Frg, 199. - Tent over orange trees for fumigating with hydrocyanic acid gas to kill scale insects. This method is more common in California than elsewhere. (['.N.D.A.)

are sometimes resorted to in order that the fruit will assume a ripe color.

The culture and care of lemons is similar to that described for oranges. Much more attention must be given to the pruning of lemon trees.

There is more trouble from brown rot disease on lemons, and the cost of producing the lemon crop is greater in many particular's than the orange crop.

The sorting and packing of lemons is done chiefly by hand. The boxes are similar for the two fruits.

Limes.-These acid fruits are produced commercially on the extreme southwestern coast of Florida and the adjacent islands. 
The product used at soda fountains in America is brought chiefly from the West Indies and from Mexico. The management of orehards is similar to that of other citrus fruits.

\section{EXERCISES}

1. Specimens.-Find specimens in your markets or elsewhere of the different nuts and subtropical fruits.

2. Study these specimens as to market qualities and botanical structures.

3. Fruit Sources.-By inquiry from dealers and by reading, determine the source of each of these products. Labels on packages will aid in this.

4. Marketing Methods.-Learn all you can as to methods of packing, shipping, prices, and probable profits to the growers.

\section{QUESTIONS}

1. What kinds of tree nuts are sold in your markets?

2. What kinds grow in your state? Wild? Commercially?

3. Describe any nut groves you have seen or read about.

4. Describe the growing of pineapples.

5. How are they propagated?

6. What can be said of the value of the avocado as a market fruit?

7 . What are some uses of mangoes?

8. Tell what you can of the growing of grapefruits for market.

9. What are the different types of oranges and where are they produced?

10. Describe the work and tell of the value of a fruit growers association.

References.-C. S. Farmers' Bulletins: 29:3, Use of Fruit as Food; 674, Control of Citrus Strips in California and Arizona; 696, Handling and Shipping Citrus Fruits in the Gulf States; 700, Pecan Culture; 794, Citrus Fruit Improvement; S13, Pecan Insects and their Control· 923, Fumigation of Citrus Trees. 


\section{CHAPTER XXIV}

\section{LEGUMES AND FERTILIZERS-SOIL AMENDMENTS}

Four important plant foods are likely to be exhausted by cropping, leaching, and washing from agricultural soils. These are nitrogen $(\mathrm{N})$, phosphoric acid $\left(\mathrm{P}_{2} \mathrm{O}_{5}\right)$, potash $\left(\mathrm{K}_{2} \mathrm{O}\right)$, and lime $(\mathrm{CaO})$. Besides these four ingredients, another important factor is humus-a product from the decay of organic matter.

Nitrogen is the most important plant food in the soil (1) because it is most likely to be lacking; (2) because it is ordinarily the most expensive to replace by the purchase of eommercial forms; and (3) because its absence from the soil reduces the vigor of growth and also reduces the protein content of the plants.

The problem of supplying nitrogen for gardens and fields becomes more serious as the commercial sources of nitrogen become exhausted. Nitrate of soda from South America is already almost too expensive to be used by farmers. This is true of ammonium sulfate, dried blood, and meat scraps. The two latter and cotton seed meal are so valuable as stock feeds that they are no longer extensively used as fertilizers.

One important source of nitrogen still remains as cheap as it was before the world war, namely, atmospheric nitrogen. This is obtained by the growth of legumes, such as clovers, beans, peas, vetches and others.

Value of Legumes.-It has been known for hundreds of years that members of the clover family, when plowed under, would greatly increase the growth of the crops which follow them. It has been only a generation since the real reason for this has been known. Since this reason was discovered the use of legumes to improve the soils has greatly increased.

The power of plants of this family to obtain nitrogen from the air is not found in other plants. The gathering of the nitrogen from the air is dependent upon the presence of special kinds of bacteria to suit the various groups (Figs. 200 and 201).

Soils already containing these bacteria are said to be naturally inoculated. Others need to be inoculated by some artificial means to make the gathering of nitrogen from the air possible.

Methods of Inoculation.- Several practical methods of inocu286 
lation of soils for the growth of legumes are in use. When once inoculated thoroughly the soil will not need it again for the same group, unless long periods elapse between years when those legumes are grown on that soil.

The soil-spreading method is to get a little top soil from a place where the same plants have been very successfully grown, spread it on the new place and harrow it in before the hot sun has any chance to kill the bacteria. The rate of spreading the soil may be about 200 to 500 pounds per acre. The amount required will depend chiefly upon the method of spreading. More soil will be required if it is to be spread with a shovel. A rapid plan is to spread thesoil with a lime spreader or fertilizer drill. It may also be sown broadcast by hand, as seed is sown.

The aglutination method is to take a few shovels full of good, rich soil from a spot having plenty of the bacteria, and put it in a barrel or tub of water, add a halfpint of liquid glue and

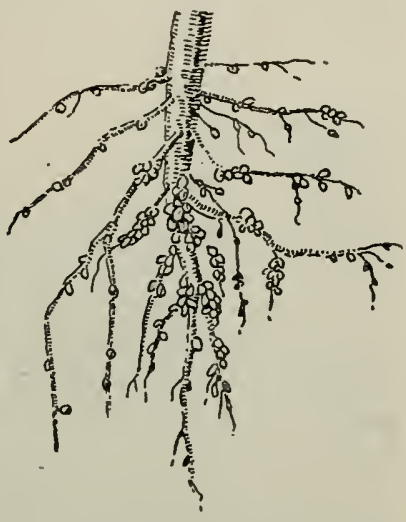

FIG. 200.-Soybeans, when well supplied with bacteria and nodules, will gather much nitrogen from the air and improve soils. a quart of lime water to ten gallons of the liquid. Stir thoroughly and wet the seeds with this liquid. Put the seeds in a box and pour the liquid over them and mix with a shovel or hoe until all are wet. Then spread the seeds on a smooth floor or canvas to dry in the shade. Sow them as soon as they are dry enough, and harrow them in very promptly.

The building-up method is founded on the fact that nearly all soils have at least a few bacteria for all of the groups of legumes. If some seeds of the legumes are sown with other crops for a few years they will naturally increase the number of legumes and rather complete inoculation may be the result.

Artificial cultures of bacteria for most of the legumes are furnished free by the U. S. Department of Agriculture and some state experiment stations. They are sold at about two dollars per acre by seed companies and others. In general the liquid or gelatin cultures are to be mixed with sterilized water and then the seed is to be wet with it and dried before planting. Special directions accompany each of the packages of artificial culture. 
Use of Legumes as Winter Covers and Catch Crops.-In gardens, orchards and fields there are many opportunities to grow some of the legumes either in summer or winter, between the times when the main crops are growing.

Winter annual legumes may be used for growth in winter seasons in all regions where the winters are not too severe. Winter or hairy vetch, Augusta vetch in the Gulf states, and crimson clover. These may be sown any time from mid-summer until about frost time. Frequently rye is mixed with them for seeding to help make a dense cover.

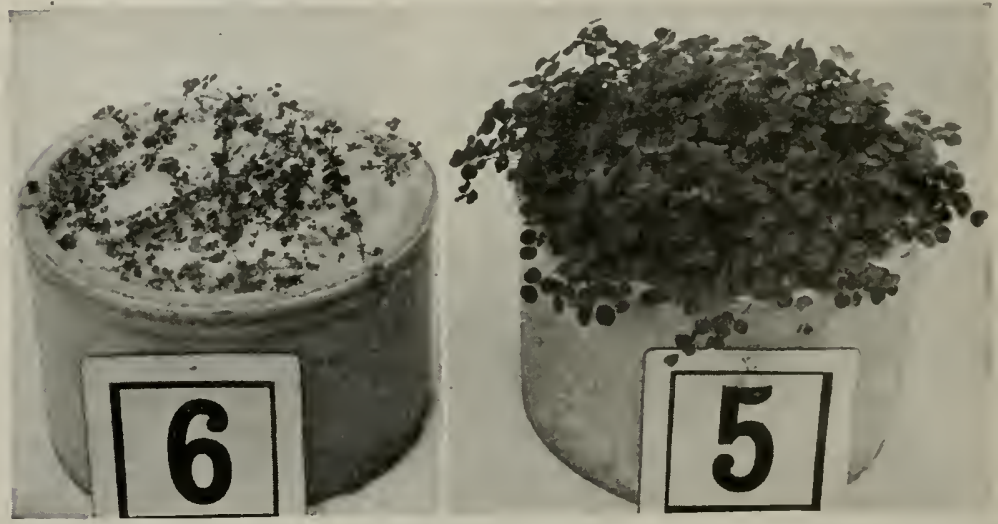

FIG. 201.-White clover, showing the effect of inoculation with nitrogen-gathering bacteria. The pot at the right was inoculated and that at the left was not.

Summer annual legumes may be grown after early spring crops, as after early potatoes, or after oats or wheat. Cowpeas and soybeans (Figs. 200 and 202) may be used in this way, and velvet beans may be grown in the southern states.

Spring annuals, such as spring vetch and Canada field peas, may be sown as early as the ground can be worked. They may precede corn, cotton, melons, beans and other summer crops.

Perennial legumes, such as red clover, alsike clover, white clover, (Fig. 201) sweet clover, and alfalfa, are good improvers of soil. They may be used in longer rotations of crops but are not so valuable for catch crops or cover crops, as they are too slow in their early growth.

Addition of Organic Matter and Humus.-When green manure 
and barnyard manure are plowed under, or otherwise mixed with the soil, the vegetable matter may be of very great benefit to the soil. As it rots humus is formed. All soils are improved by the addition of humus unless they are already well supplied.

It causes them to hold moisture in better form and longer between rains so that plants can use it. The presence of humus also makes a better home for beneficial bacteria; it helps to make plant foods available for the roots to use.

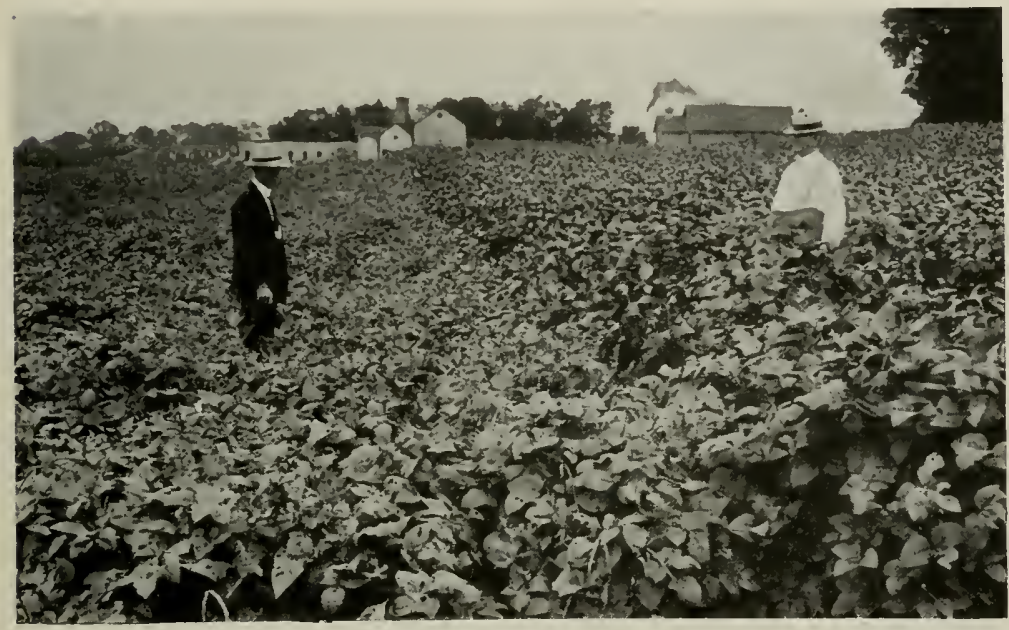

Fic. 202.-Cowpeas (left) and soybeans (right) used to improve soils for gardens, orchards, etc. (Tennessee Station.)

Besides the addition of humus the turning under of green manure will also add all the forms of plant food which they contain. If legumes are turned under the chief plant food is nitrogen, but with all forms of green manure some of all three important fertilizers are added, which soon become available for use of the growing crop. That is, nitrogen, phosphate, and potash are always present and as the manure rots it liberates these for the use of the crops.

Other Green Manures.-It is, therefore, very beneficial to most soils to mix green manure of any kind with them. When winter rye, for example, is grown during the fall, winter, and early spring, and then turned under, it takes from the soil the three main plant foods and saves them for the garden, orchard, or other crop. 
Barnyard Manure for Gardens.- One of the best ways of supplying both plant food and humus to garden and orehard soils is to apply barnyard manure. Manure is usually most abundant in the winter and spring scasons. These are also convenient and otherwise suitable times for adding manure to soils.

A good method is to spread the manure abundantly and evenly on the surface and then plow or disk it under. If plowed under it will be less in the way of cultivators or other tillage implements.

Manure is sometimes used as mulch on the surface of garden soils. This mulch may be applied during the growing season, between rows, after early cultivating. It is put on top of the asparagus and rhubarb roots after the tops are clead in the fall. It is put around bushes and shrubs as a winter covering.

In home gardens where manure is produced on the place there are two good plans to follow in the management of the manure. Fresh manure may be applied to some part of the garden as fast as it is produced. This is probably the best method of saving all the plant food in the manure. It is readily taken up by the soil and is then used by the growing plants.

Composting Manure.-Another good plan of saving manure for the garden is by means of a compost heap. It rots the litter and makes it finer. It kills weed seeds and many disease germs. It prevents danger when heavy applications are made to the garden. It prevents loss by leaching. If properly made the compost heap will not become too hot.

Making the Compost.-A good place to make a compost heap is at the edge or near one end of the garden, where it will be handy for use. On the ground spread a layer of barnyard manure about eight to twelve inches thick. Then put over this a layer of thick grass sods. Repeat these alternate layers until the compost is four to eight feet high. Keep the top somewhat level to catch the rainfall. If no rains occur at first the compost should be watered well. If there is not enough manure ready to make a large compost heap at one time the area and height may be easily increased afterward.

Potato vines, corn stalks, tomato vines, cabbage stems, weeds and many other garden wastes may be adcled to the compost heap from time to time. They will make good manure.

Composted soil will be valuable in hotberls, coldframes, seed beds, and for any spot where very rich soil is wanted. 
Cautions in Using Manure.-If too much manure is placed "under the row" or "under the hill" as sometimes practiced, the plants are likely to suffer from lack of moisture. This is worse in dry seasons. The pad of manure under the plants may prevent the rise of water through capillary action.

The remedies are to make light applications more frequently and to thoroughly mix the manure with the soil by tillage implements. When manure is well rotted it does not have this injurious effect.

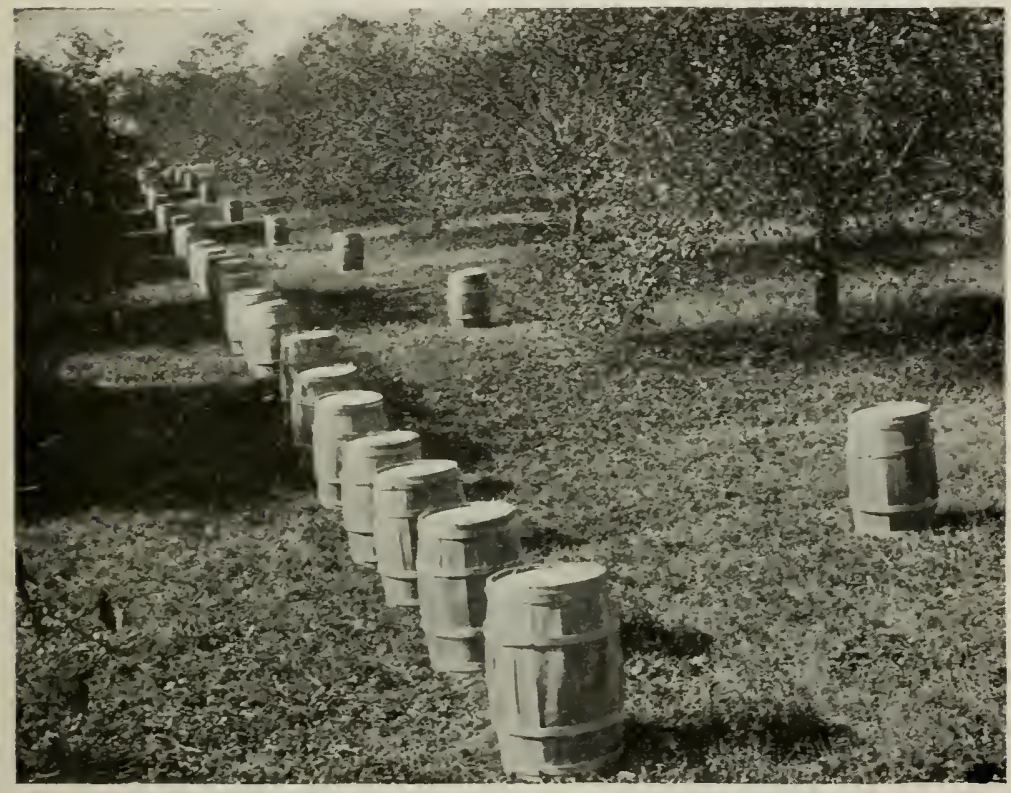

FIG. 203.-Effect of fertilizing a neglected orchard. Yield of fertilized row 46 barrels, unfertilized row nine barrels. (Ohio Station.)

\section{COMMERCIAL FERTILIZERS}

Orchards and gardens, as well as field crops, often need plant food supplied in the form of commercial fertilizers (Fig. 203). Conditions are so variable that no fixed formulas can be followed in all cases. Soils differ widely in composition, and plants differ in their needs.

Fertilizer formulas are expressions showing the percentage composition of the three main ingredients. It has nothing whatever to say about the source of the materials used. A formula 
good for Irish potatoes may be expressed 4-8-10, or 3-6-8. In most states of this country the first number inclicates the number of pounds of nitrogen (not ammonia) in each hundred pounds of the mixed fertilizer. The middle number refers to the amount of available phosphate. The last number, to the potash. The order is N-P-K. In Texas, Tennessee, and a few other states, the first number refers to the phosphate the second to nitrogen, and the last to potash. P-N-K. By inquiry find what the formulas mean in your state.

Home mixtures may be made to suit the conditions better than ready-made preparations. For example, soils are sometimes so rich in nitrogen that they will not produce good yields of Irish potatoes or sweet potatoes. These soils need to be balanced in their plant food by applying phosphoric acid and potash only. A complete fertilizer, containing the three main plant foods, would not remedy the difficulty.

In other cases nitrogen may be the very thing that is lacking. If so it would be best to use fertilizer that is not rich in phosphoric acid and potash, but is rich in nitrogen.

Needs of soils and crops are not very difficult to determine. Crops that are expected to make much leaf growth in yielding their crop need an abundance of nitrogen. This is true of lettuce, cabbage, cauliflower, celery and others.

Crops that produce seed crops or fruit require much phosphoric acid. Potash adds strength to stems and vigor throughout.

Indications of needs may be detected in the growth (Fig. 204). Root crops forming too much top and not enough storage in the underground parts, need less nitrogen and more potash and phosphoric acid. If the leaf growth of trees or any plants is limited or not of a good deep color, the indication is lack of nitrogen.

When crops fall down too badly in the wind, the indication is for more potash. Soils that have been farmed for a long time, sandy soils, and peaty soils are likely to need potash.

If the yield of vegetables or fruits is light as compared to what it should be, the soil probably needs more available phosphoric acid, and perhaps some more potash. In this regard watch the tomatoes, melons, cucumbers, okra, peppers, eggplant, corn, and other vegetables in which the crop is the real fruit of the plant.

Sources of Nitrogen.-In the commercial form nitrogen or ammonia may be purchased as nitrate of soda, containing fifteen to sixteen per cent of nitrogen, and sulfate of ammonia containing 
about twenty per cent of nitrogen. It is also abundant in meat scraps, dried blood and cottonseed meal. All of these materials are very expensive and should be used with great care and good judgment. Nitrate of soda is most likely to be wasted as it is soluble in water and may be washed or leached away unless the growing crop uses it up immediately. Plant the crop first, and

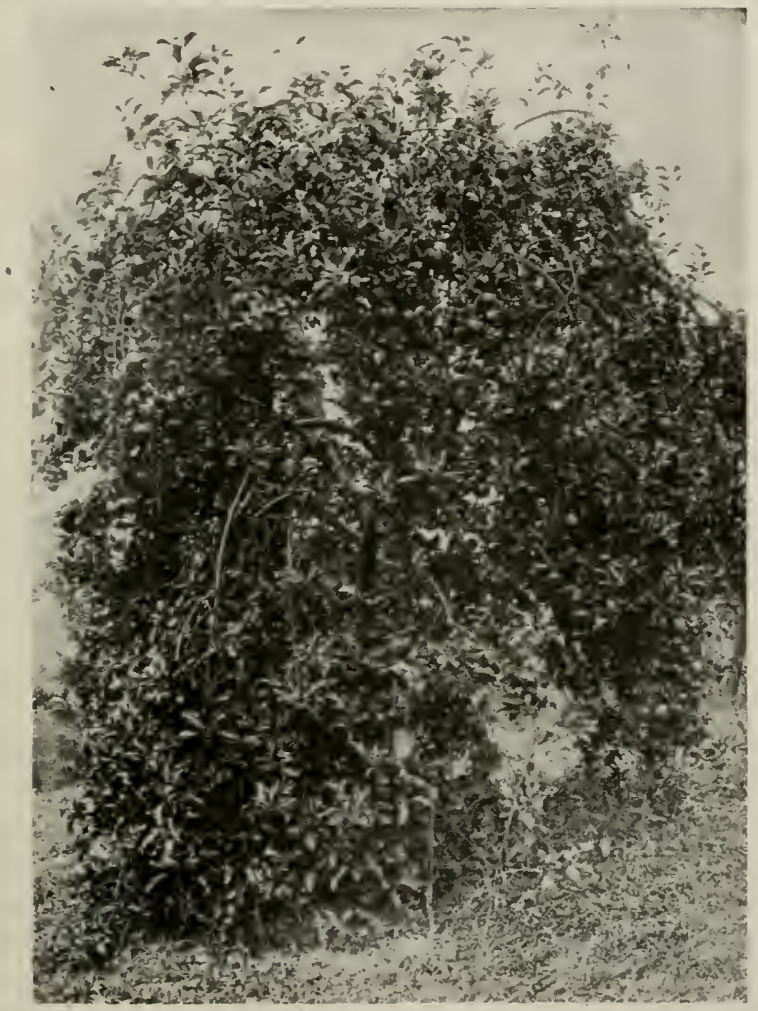

FIG. 201. - After being starved for years this tree was made productive by feeding with acid phosphate and nitrate of soda. (Ohio Station.)

after it is up and growing well the nitrate may be applied and cultivated into the soil. Some of the other forms in which nitrogen i. used are very slow in changing to available forms; some of these are garbage tankage, leather scraps, hair, etc. The source of nitrogen should be known to the user. This is a strong argument for the home mixing of fertilizers. The agricultural value is not 
based upon brand but upon the composition of the mixture and the sources of the elements.

The purchase of nitrogen-bearing fertilizers is least profitable because nitrogen can be so easily secured by the growing of legumes.

Sources of Phosphoric Acid.-Ground rock phosphate is the chief source of phosphate used in commercial fertilizers. It is a combination of phosphoric acid with lime and is mined abundantly in South Carolina, Temnessee, Florida and elsewhere. It may be applied to soils in the "raw" condition or may be treated with sulfuric acid. In the latter form it is called acid phosphate or superphosphate, and is much more available as plant food. It contains sixteen to twenty per cent phosphoric acid.

Ground bone is also rich in phosphate and may be used in the steamed form or may also be treated with sulfuric acid. When merely ground and steamed it is slowly available for plants and will last several seasons. It may contain twenty per cent of phosphoric acid and four per cent nitrogen. When treated with acid it becomes soluble and is more quickly used by plants.

Bone tankage is another source of phosphoric acid. It is obtained from packing houses, and is quite variable in composition.

Sources of Potash.-Wood ashes furnish potash for the home garden. Unleached hard-wood ashes contain from three to eight per cent of potash, with an average of about six per cent. They also contain some phosphoric acid and fully thirty per cent of lime. For use as fertilizer ashes may be either sprearl on the soil as made, or may be stored under cover till needed.

Saltpeter waste contains five to twelve per cent of potash. . It must be bought only on analysis.

Sea-weeds and similar plants are rich enough in potash to warrant burning them to secure this product. The ashes contain as much as five per cent of soluble potash.

Potash is obtained from burning or rotting tobacco stems, corm cobs, cottonseed hulls, straw, weeds, and other things.

Potassium nitrate contains about twelve to fourteen per cent of potash.

Potassium carbonate from the Caucasus region is often ninety per cent pure. It may be used as fertilizer when necessary.

The Strassfurt potash salts, known as car-nall-ite, kainit, and syl-vin-it, are ground and used as fertilizer, containing twelve per cent or less of potash. They are usually refined, yiclding two concentrated products: (1) sulfate of potash with forty-eight per 
cent actual potash, and (2) muriate of potash, with fifty per cent actual potash.

Potash is now obtained in commercial amounts from wastes in cement factories and iron refineries.

\section{LIMING OF SOILS}

Many garden, orchard, and field soils need liming. Our soils may be sour and need lime for that reason. Many legumes need lime (Fig. 205) so that their special bacteria can live in the soils.

Uses of Lime.-There are a number of beneficial effects resulting from the liming of soils.

1. Lime will correct the sourness of soils. Nearly all crops are less productive on sour soils. The application of lime will make these crops thrive if other conditions are favorable.

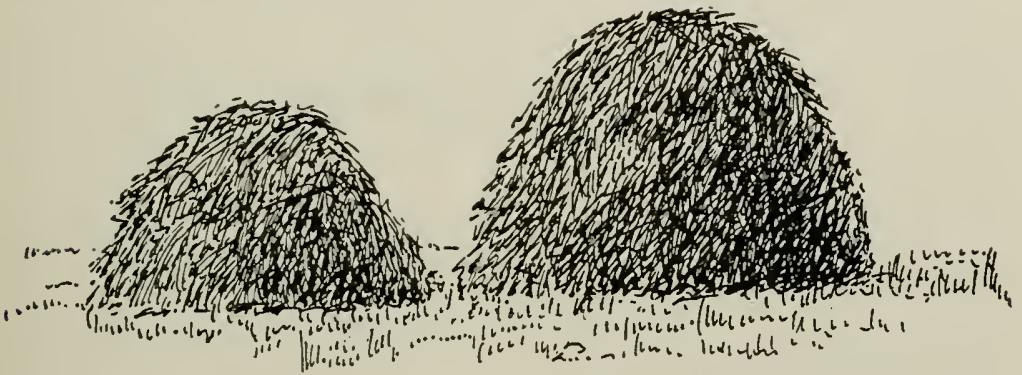

FIG. 205.-Lime increases the growth of clover and other legumes. Right from limed plot, left from unlimed plot. The clover improves the soil for other crops.

2. Lime tends to correct the stickiness of clay soils and makes them more loose and porous. They will then not bake and crack so badly as a result of heavy rains followed by dry weather.

3. Sandy soils are made firmer by the use of lime on them. They will plow better, hold moisture and plant food better, etc.

4. Liming of soils aids in the decay of vegetable matter which they contain. When green manure and barnyard manure are turned under lime should be applied soon after. The converse is also true. Organic matter must be applied to soils that are limed. Otherwise the humus matter would soon be gone and the net result would be detrimental.

5. Plant food in soils is made more available by the action of lime. At first the apparent result of liming would be much the same as adding a complete fertilizer to the soil. The growing crop is able to take from the soil more than it could without the action 
of lime. The eontinuous liming without the use of manure, will therefore deplete the soil.

\section{"Lime and lime without manure}

Makes both farm and farmer poor."

6. Nearly all kinds of beneficial bacteria in soils will thrive better in the presence of lime. This is notably true of the bacteria which aid legumes in obtaining nitrogen from the air.

7. Lime undoubtedly serves as a direct plant food for some legumes. This is most notable in the growth of alfalfa. Analysis shows that this plant contains considerable lime in its ash.

Forms of Lime.-There are several forms of lime used for gardens, orchards, and fields. These differ in their action, permanence, cost, ete. (Fig. 206).

Ground limestone is one of the best forms to use. In regions where it can be obtained it is cheaper than other forms of lime. Its action is not so rapid as the burned lime, but it is more lasting in its effects. It should be ground very fine and may be applied at the rate of one, two, or more tons per acre without any fear of injury to soil or crop.

Freshly burned lime is very caustic in its action. It burns out the organic matter from soils very quickly and has a very pronounced effect in aiding growth of elover, alfalfa, etc. Its effects are not so lasting as other forms of lime. It should be used in quantities ranging from one-fourth or on e-half ton per acre upward. Before spreading, it is usually put in a pile to air-slake. Some water may be added to help start the action. After it is in the form of fine powder it may be spread. It nearly doubles in bulk and weight during the process of air-slaking.

Hydrated lime is about the same in its action as the air-slaked lime already deseribed. It is the by-product of dealers and kilns where fresh lime is sold. It is sold either in bulk or in bags, and is in the form of fine powder. It usually becomes rather old and takes up more moisture than the freshly sla ked lime. The eost is often out of proportion to its value as compared with other forms of lime.

Ground oyster shell is similar in action to ground limestone and may be used at the same rates. The price may be low enough to warrant its use in regions near its source.

Hard-wood ashes contain, when not leached, thirty to thirty-five per cent of lime besides three to eight per cent of potash. When obtainable they should be used on gardens, about the bush fruits, and in orehards. 
When and How to Use Lime.-The best time to apply lime to soil is after plowing. It may be mixed with the soil by harrowing. It should not be plowed under. When soils are plowed in the fall, wait until spring to spread the lime, as too much of it would leach away during the winter.

Many methods of spreading lime are in use. Throwing it with shovels is rather slow and it is not very evenly distributed by this

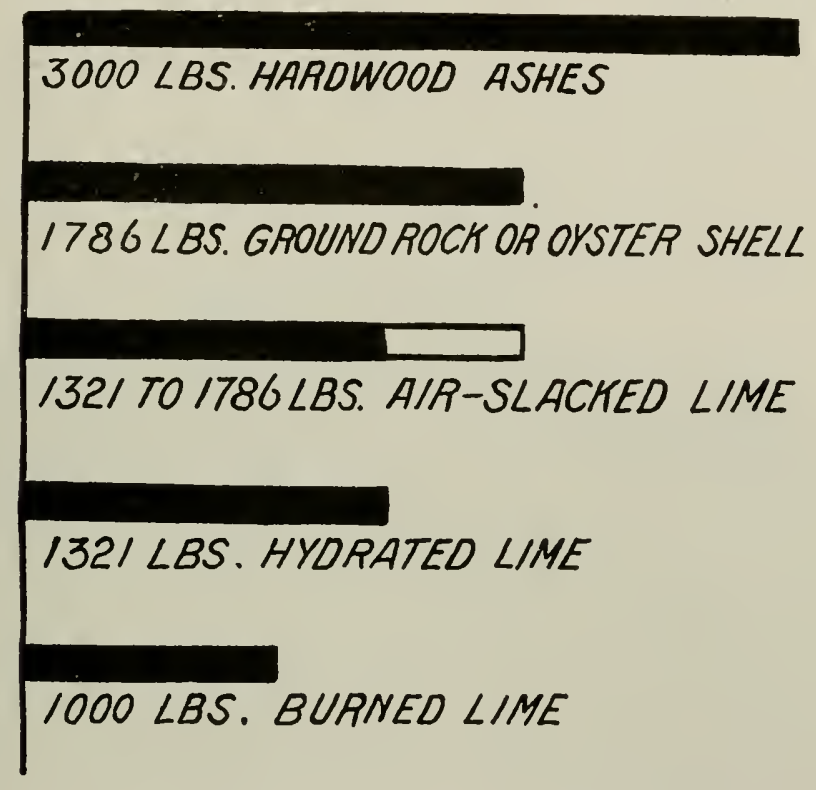

FIG. 206.-Chart showing the different amounts of materials required to furnish the equivalent of 1000 pounds of lime.

method. Special lime spreaders and lime hoods for manure spreaders are in use. It is sometimes hauled out and left in small piles to slake and is then spread by hand from these piles. It is better to do the slaking in one large pile and the hauling afterwards. Ground limestone and oyster shell are the most agreeable forms to handle.

\section{TILLAGE}

Soils may be improved both physically and chemically by proper tillage. Stirring the soil will greatly aid the growth of garden crops and fruits. 
Open or general tillage consists chiefly of plowing and harrowing the soil before the crops are planted. In gardens this may be done in either fall or spring, or both.

Deep plowing is necessary for root crops such as potatoes, beets, etc. The deep feeding crops such as trees and corn, also need the soil stirred to a great depth. Dynamiting (Fig. 207) will loosen the hard subsoil. This is often done before trees are planted.

Fall plowing is most beneficial for heavy soils. The winter

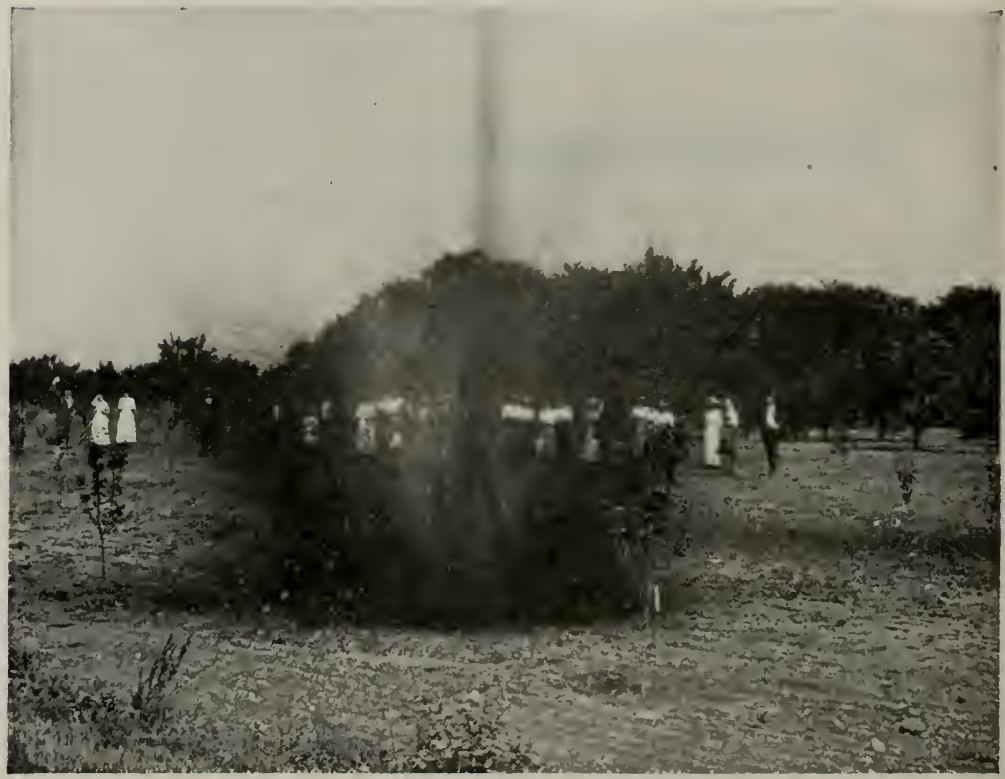

Fig. 207.-Blasting orchard tree holes is often very beneficial The growth of young trees may be greatly increased. (New Jersey Station.)

freezing of the turned soil will pulverize and aërate it. This renders it more friable and makes it better for gardening.

Spring plowing is necessary when a winter cover crop is grown and is to be turned under as green manure before the garden is planted.

Often it is a good plan to replow in the spring. If the fall plowing turned under sod land, this may be broken deeper in the spring. Plow cross-wise of the fall plowing unless the slope of the land prevents this. 
Repacking After Plowing.- - If land is broken only a short time before seeding time it should be repacked by the use of a harrow, planker, or roller. Much packing is not desired for potatoes, but for other garden crops the roller or other packer should be used and this followed by a spike-tooth harrow. If heavy rains come after spring plowing they will pack the soil enough, particularly if the soil is rather heavy.

Packing the soil establishes the capillary connection between the top furrow slice and the moist soil below. This will prevent much of the injury from drouth.

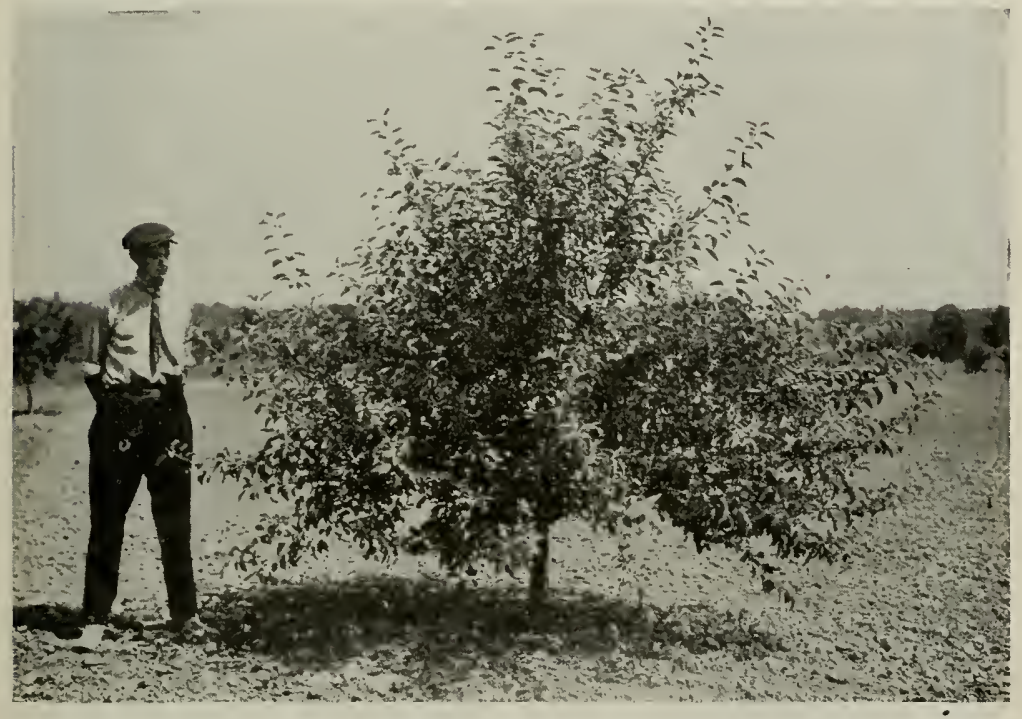

FIG. 208,-A young orchard grown under the clean culture cover crop system on rather level land. (Indiana Station.)

Keeping the surface loose is probably the most important factor in successful tillage of garden and orchard soils (Fig. 208). It prevents crusting and baking and large clods are not formed. The loose soil on the top will serve as a mulch and prevent the escape of moisture by evaporation.

Intertillage should be frequent, and in most cases it may be rather shallow in the garden. It may be done by use of smallshovel cultivators which are very sharp at the points. The use of wide shovels leaves the ground too much in ridges and allows it to become too dry. Keep the surface reasonably level and finely 
crumbled. Rains tend to spoil this mulch and the cultivator is again neederl.

For hand work the garden rake is good for intertillage. Wheel

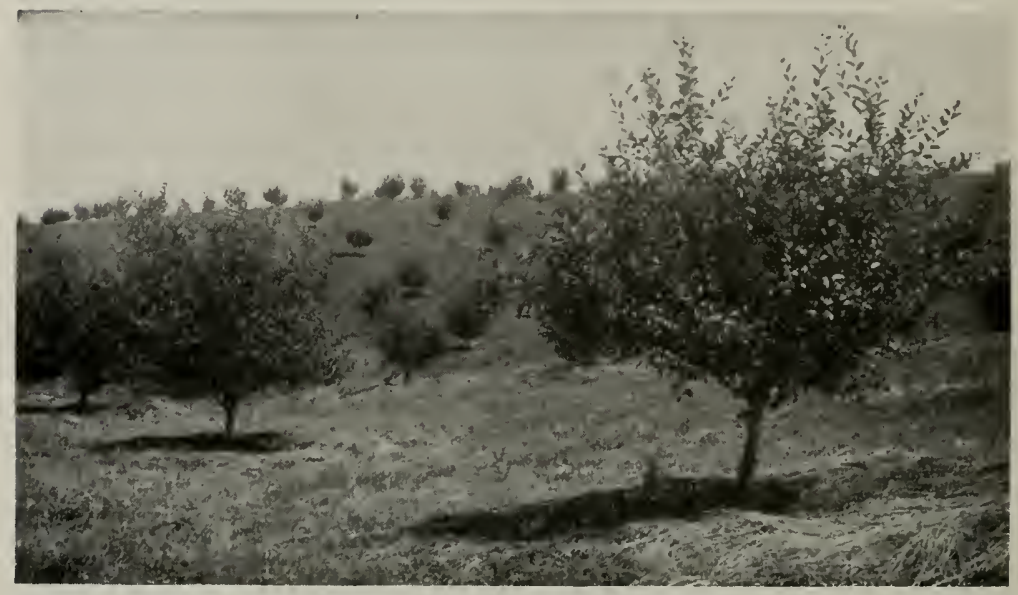

Fig. 209.-Six-year-old trees grown under the sod mulch system of orelıard inanagement. (Indiana Station.)

hoes are also useful in small gardens where a horse cultivator cannot be used.

The Sod-Mulch System of orchard management consists of growing a permanent grass crop, as timothy or orchard grass, in

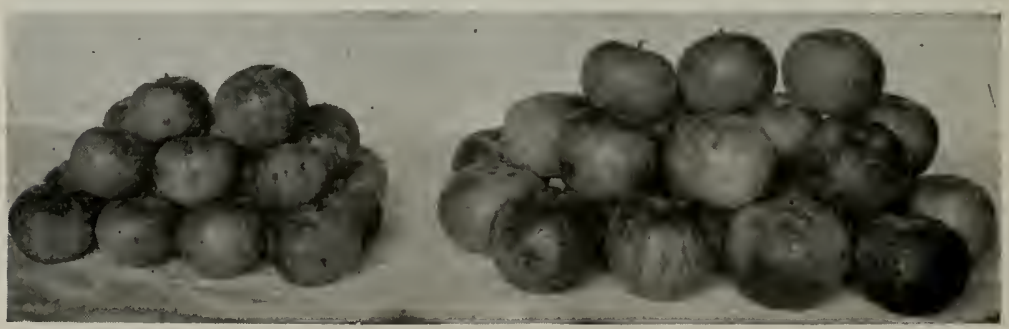

Fig. 210.-Cultivation increases size of fruit. These piles show relative sizes of the same variety treated by the sod and clean culture methods. (Indiana station).

the orchard as shown in the figure 209. This crop of grass is cut once or twice a year and left on the sod or spread under the trees. The mulch helps to protect the wind-fall fruits and to make the work of pruning and spraying more pleasant in the winter time. 
As compared with the elean culture method, the fruit is smaller (Fig. 210), the insects and discases are worse, drouth may be more harmful, and the growth of trees is less.

Orchard tillage may consist of three or four operations. Plow between the bearing trees in spring. Harrow soon after this to prevent the drying of clods. Dig around the trees if the plowing leaves the soil unturned. Watch the surface and prevent its becoming hard or crusty. Use the disk harrow or other orchard implement several times until midsummer. Then sow a cover crop to remain all winter.

Young orchards should be given such tillage as are required by cabbage or potatoes. Such clean-culture crops may be grown between the fruit trees for a few years.

\section{SURVEYS, PROJECTS, AND EXERCISES}

1. Manures.-Determine by a questionnaire (1) what legumes are grown in the region for eover erops, or green manuring; (2) which ones require artifieial inoeulation; (3) stage of growth at which they are plowed under; (4) other crops grown for green manure; (5) other sources of humus for soils; (6) amounts of barnyard manure used; ( 7 ) erops following these applications: (8) eare of manure; (9) composting; (10) results of manuring; etc.

2. Liming and Fertilizing.-Make similar questionnaires regarding the liming of soils, the use of commercial fertilizers, and home mixing.

3. Tillage practices may be studied by making an inquiry regarding fall plowing, spring plowing, depth of plowing for certain erops, rolling, harrowing, shallow intertillage, ete.

4. Growing crops as home projects may be so planned as to demonstrate the effect of certain practices. (1) Crimson clover as a winter cover erop with and without lime. (2) Special fertilizers on truck erops. (3) Deep fall plowing compared with shallow spring plowing for the garden. (4) Deep and shallow intertillage for potatoes, for corn, for the orchard. (5) Manure and no manure. (6) Barnyard manure compared with green manure. (7) Irrigation.

5. Exercises in the laboratory should be tried to show floculation of clay by liming; solubility of potash in wood ashes; alkalinity of wood ashes and lime; acidity of certain soil samples; the amount of organic matter in certain samples; solubility of acid phosphate; insolubility of rock phosphate; effect of sulfuric acid on the latter; solubility of nitrate of soda, ammonium sulfate, muriate and sulfate of potash, and other common fertilizers. (See details in the author's School and Home Gardening.)

\section{QUESTIONS}

1. What are the four mnst important plant foods in soils?

2. Discuss the sources of nitrogen for soils.

3 . How do legumes aid in supplying nitrogen?

4. Give several methods of inoculation for legumes.

5. Mention good legumes to use in the upbuilding of soils (1) summer annuals (2) winter annuals, (3) others.

6. What are some good methods of adding organic matter and humus to soils?

7. Describe the making of a compost heap. 
8. Give reasons for the home mixing of fertilizers.

9. How can you ascertain the kind of fertilizers needed by a soil?

10. What are the ehief forms and sources of phosphorie acid?

11. What are the chief forms and sourees of potash?

12. Enumerate the benefits from the use of lime on soils.

13. What other material should be added also? Why?

14. Compare the use of ground limestone with fresly-burned lime.

15. Tell when and how to use lime.

16. Give the benefits of deep tillage.

17. Give reasons for fall plowing.

18. Discuss repacking after plowing.

19. How is a soil mulch maintained?

20. What are its benefits in the garden and orchard?

21. What methods of soil maintenance or improvement are practiced in your region?

22. State which formula expresses the higher grade of fertilizer, 2-5-4 or 3-S-S. Give reasons for your answer.

References.-U. S. Farmers' Bulletins: 339, Alfalfa; 382, Seed Adulteration; 441, Lespedeza; 455, Red Clover; 515, Vetehes; 529, Veteh in S. Atlantic States; 550, Growing Crimson Clover; 579, Utilizing Crimson Clover; 646, Crimson Clover Seed; 690, Field Pea; 393, Bur Clover; 716, Management of Sandy Lands; 730, Button Clover; 757, Commercial Varieties of Alfalfa; 761, Management of Muck Land; 797, Growing Sweet Clover; S05, Drainage of Irrigated Lands; 820, Sweet Clover: Utilization; 836, Sweet Clover: Harvesting; 865, lrrigation of Alfalfa; 921, Principles oi Liming of soils; 931, Soy Beans in Systems of Farming in the Cotton Belt.

The Fertility of the Land, Roberts, Macmillan Co.; Crops and Methods for Soil Improveinent, Agee, Macmillan Co. 


\section{CHAPTER XXV \\ PRINCIPLES OF SPRAYING}

Too few who need to spray know the principles of spraying. It is necessary that the grower know what to spray for, and what and when to spray (Fig. 211). There are several purposes in view when a spraying compaign is conducted. (1) To prevent disease, (2) to fight insects which suck juices of plants, (3) to kill insects which eat the leaves or other tissues of the plants. The material

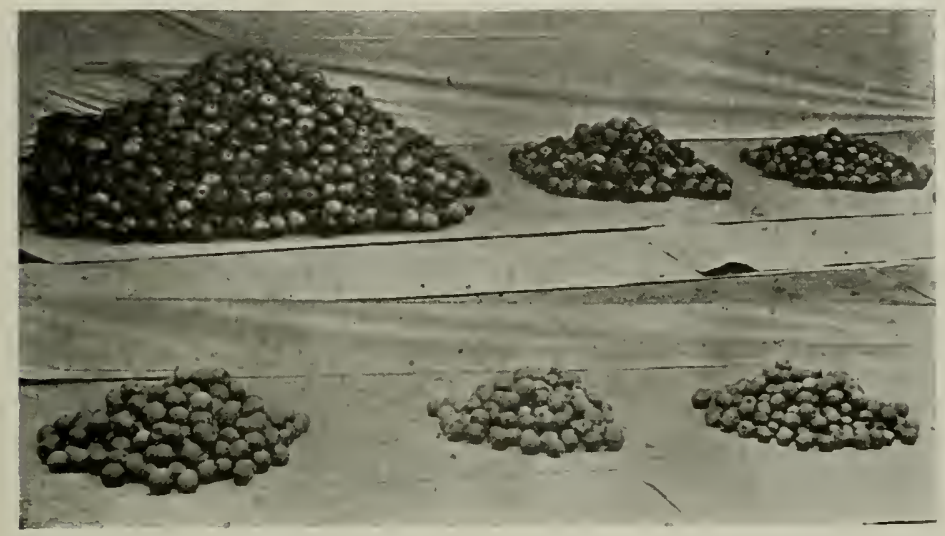

FIG. 211.-For spraying apple orchards lime-sulfur and arsenate of lead (shown above) are better than Bordeaux mixture and arsenate of lead, (shown below). Upper and lower lots each from a tree sprayed three times. (Illinois Station.)

used for these three purposes are of different character. One should not be used for the other, but sometimes the poison sprays for chewing or eating insects may be combined with the materials used to prevent disease.

Spraying pays in dollars. The best orchardists spray intelligently. They spray for definite purposes, with suitable materials at proper times. Spraying will then improve the quality of the product and increase the yield. This is true of both fruits and vegetable crops (Fig. 212).

Spray Materials to Provent Disease.-Nearly all of the plant diseases are caused by fungous growth. A few, however, are from 
bacteria attacks. The chief spray materials used to prevent disease are Bordeaux mixture, lime-sulfur, ammoniacal carbonate of copper, and livers of sulfur. The first two mentioned are more permanent and are not easily washed off by rains when once dry on the plants. The other two materials are used in cases where it is necessary to wash the fruit or other product before being eaten by people. They may be used to spray fruits that are nearly mature. Another fungicide is copper sulfate used on the dormant form of
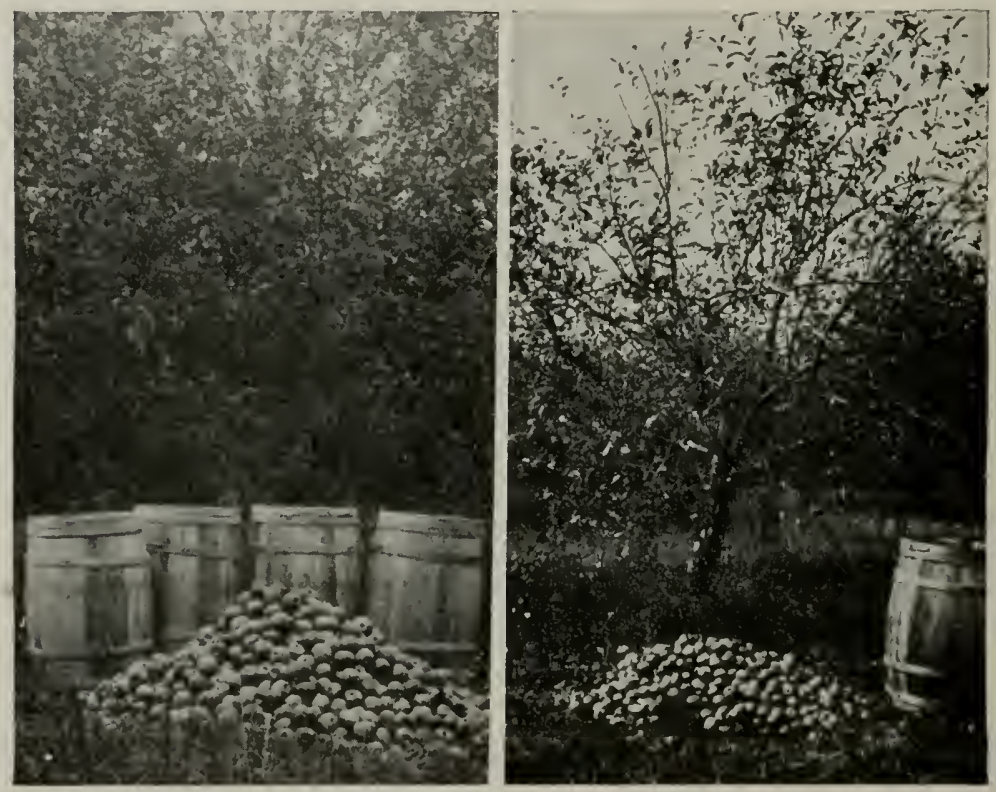

FIG. 212.-Spraying improves quality and increases yield. Sprayed tree at left bore four barrels of apples, 87 per cent marketable. Unsprayed tree at right bore one barrel, only 13 per cent marketable. Note also the difference in leaves. (Missouri Station.)

the plants. Lime-sulfur is also used to control scale insects chiefly during the dormant season of the plants. Each of these will be discussed in this chapter.

Bordeaux mixture is made of three materials: copper sulfate, fresh lime and water. The standard formula is 4 pounds of copper sulfate, 4 pounds of lime, in 40 gallons of water. This is briefly expressed as 4-4-40. The 3-3-40 formula is sometimes used where plants are tender, as on young tomato plants.

Dissolve the copper sulfate in hot water or hang the crystals in a 
cloth in the water near the surface so that the dissolverl part will settle to the bottom and cause other water not saturated to come in contact with the crystals.

Slake the lime in cold water by pouring on a little water at a time until some heat is generated, then pour on enough water to keep it from burning, or becoming dry from the heat. Do not smother the lime during the slaking process. This will prevent the formation of lumps. As the lime becomes completely slaked more water may be added, and stirring should be vigorous and for some

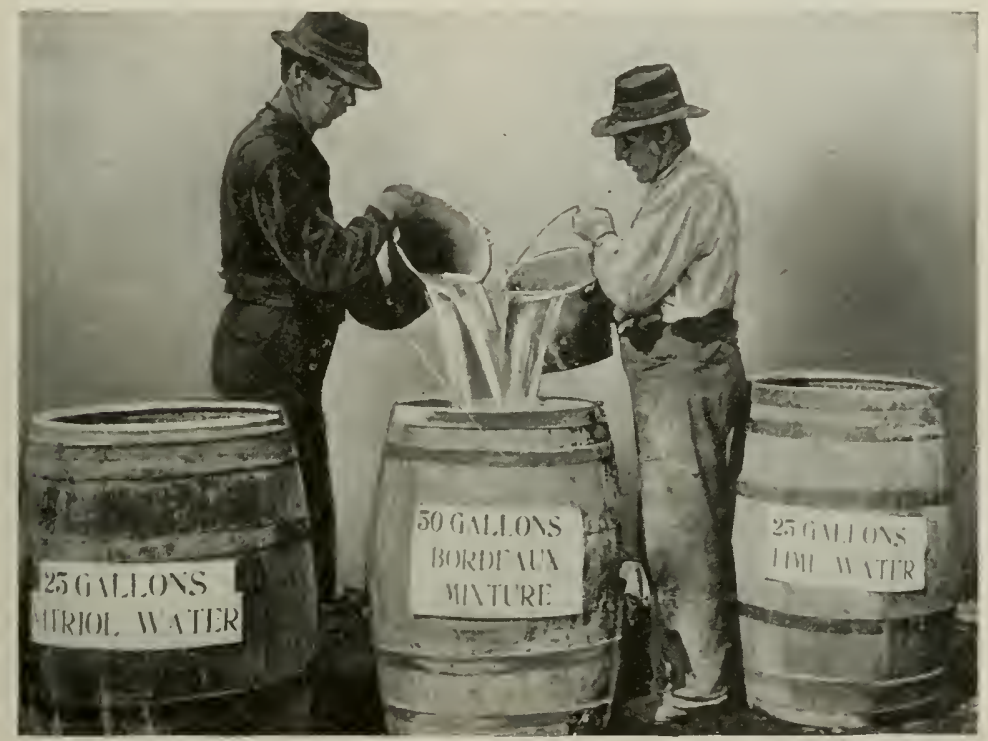

Fig. 213.-Bordeaux mixture is best made by pouring the two diluted stock solutions together into a third vessel, letting the streams mix in the air. (U.S.D.A.)

time. When the whole mass has been made of a creamy consistency strain it through a cheese cloth to remove the grit or other particles which will not pass through a fine sprayer.

These two stock solutions may be kept separate for any length of time. As they are used they should be thoroughly stirred or shaken before mixing. In mixing them dilute each, keeping strict account of the amount of water used, so as to attain the above formula as desired. When the two are diluted enough, pour them at the same time into a third vessel so that the streams will mingle. This causes a more perfect combination (Figs. 213 and 214). 
Ammoniacal Carbonate of Copper.-This is prepared by weighing out three ounces of copper carbonate. Make a thick paste with water in a wooden vessel. Measure five pints of full strength ammonia which tests 26 degrees on the Baumé scale. Dilute the ammonia by adding three times as much water. Then add this diluted ammonia to the paste mentioned. This will turn to a deep purple color. Then add enough water to make fifty gallons. It

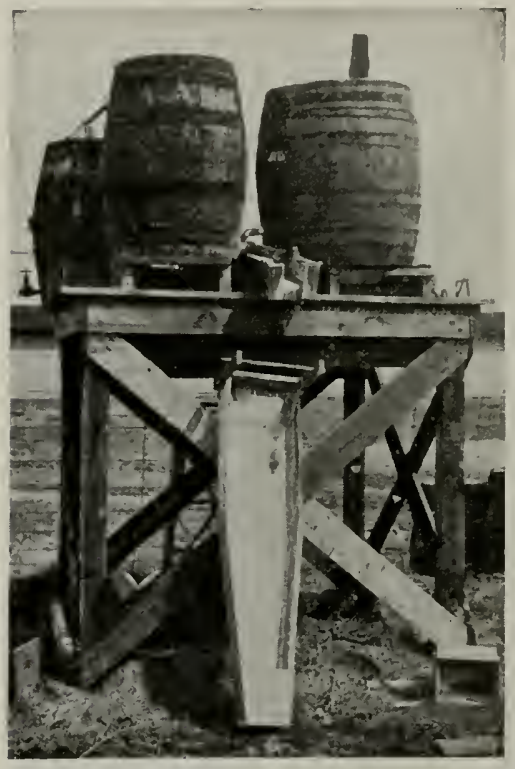

F1c. 214.-An elevated platform for mixing Bordeaux and other spray materials. Two barrels may be used for stock solutions and others for the dilute mixture. The extension trough aids in filling the spray tank which is hauled near the platform. (Indiana Station.) should be applied to the plants while it is fresh. It does not discolor the fruits and will remain on until washed off by rains. It is used chiefly on fruits that are nearly mature. It is also used on roses and other ornamental plants.

Copper Sulfate.-This material, when dissolved in water, as described in making one of the stock solutions for Bordeaux mixture, is a splendid fungicide to be used when plants are in the dormant condition. It will destroy many spores, and thus prevent much of the growth of the disease when spring arrives.

Dissolve one pound of the blue crystals of copper sulfate in about twenty-five gallons of water. This is particularly valuable in peach orchards to prevent peach leaf curl. It would be used in orchards which had been affected by this disease the preceding year. The spraying should be thoroughly done before the buds swell in the spring.

Livers of Sulfur.-The chemical name is potassium sulfide. Dissolve three ounces of the powder in ten gallons of water. The material should be well stirred before using, and may be used at any time desired. It is a specific against mildew on plants in green houses. Out of cloors it is often used on roses and other ornamentals. Water washes it off quickly, and to make it effective the spraying should be done after a rain, not just before a rain. 
Lime-sulfur--This preparation is used abundantly in the control of San José scale, either as a winter spray or as a summer spray. The spores of fungous diseases are largely killed when this spray is applied. If orchard trees, for example, are sprayed with limesulfur during the winter the spores with which the spray comes in contact are killed. This aids materially in the reduction of the disease during the following growing season.

There are several forms of lime-sulfur prepared. The home boiled concentrated lime-sulfur (Fig. 215), the commercial limesulfur, the self-boiled lime-suliur and the commercial dry powder.

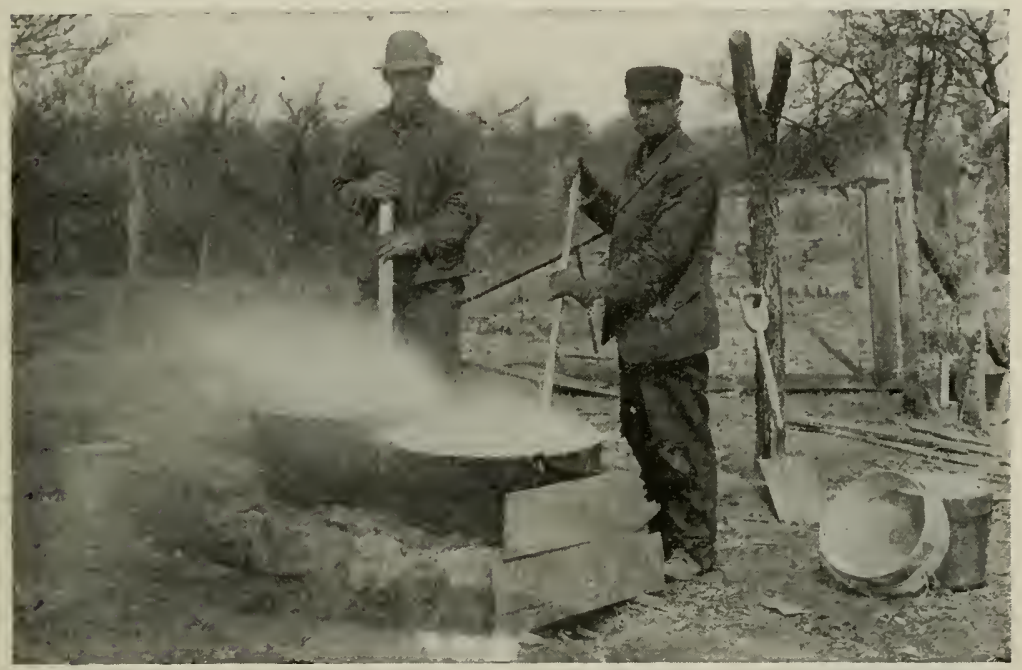

Fig. 215.-Home boiled lime-sulfur may be prepared as shown or may be boiled by a steam pipe leading into a barrel from a boiler. (Indiana Station.)

For spraying on a large scale the home made lime-sulfur may be prepared as follows: Use 38 pounds of fresh unslaked lime, 40 pounds of clean rolled sulfur powdered, and 50 gallons of water. Make a paste of the sulfur, using about 10 gallons of hot water. Then add the lime and let it slake. Add more hot water as necessary to prevent drying or lumping. When the lime has all slaked add the balance of the water to make the 50 gallons and boil, stirring thoroughly while boiling, for one hour (Fig. 215). As the water boils away more should be added to maintain the quantity.

A good method of boiling is to have the water in a barrel or tank and heat by means of a hose or steam pipe from a small boiler. A 
simpler method is to put the materials in a large iron kettle over a fire. The red liquid may be poured into barrels and covered with oil to prevent evaporation while being stored. This concentrated solution must be diluted before using. For example, if the reading of the hyclrometer is $35^{\circ}, 1$ part to 9 parts of

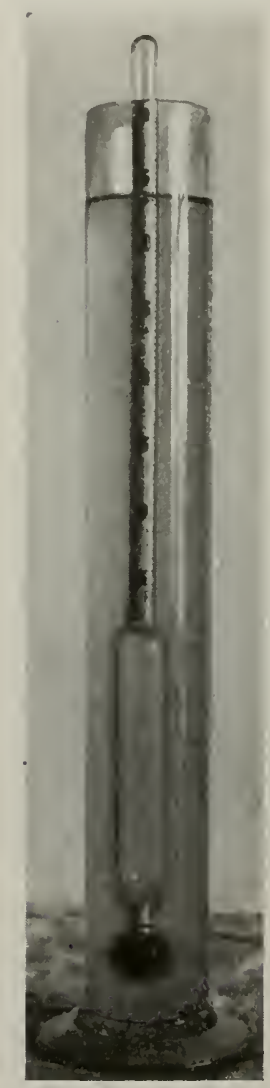

FIG. 216 .-Hydrometer and cylinder for use in testing the density of line-sulfur and other spray materials. It is scaled by the Baume standard. See table in

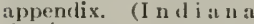
Station.) of boiling is allowable. If hot water is used, the solution boils more and a stronger preparation is the result. The formula may water may be used for the winter spray for sam José scale or as a winter fungicicle. 'Twelve parts of water to one part of this same liquid will be right for the blister mite. One part of this strength of liquid to 45 parts of water would be strong enough for the summer spray on apples when the trees are in full leaf.

Commercial Lime-sulfur.-This is sold in concentrated form by a number of manufacturers. It is a clear amber or red liquid, and will test from 32 to 35 degrees on the Baumé hydrometer (Fig. 216). It is ready to be mixed with water according to the proportions mentioned for the home made preparation. With this and powdered lime-sulfur directions come with the package showing the dilution for different purposes.

Self-boiled lime-sulfur is prepared by the heat formed in the slaking of the lime. Use. eight pounds of good fresh, unslaked lime. Add water to start the slaking gradually, but use sufficient to keep it from buming or lumping. When heat has begun to generate well, slowly sift into this eight pounds of the fine sulfur. Stir the mixture constantly and thoroughly. Add more water as needed. As soon as the boiling has ceased add the remainder of the cold water to make a mixture of 50 gallons. This requires thorough agitation while spraying. It is used as a special spray material against peach scab and brown rot of the stone fruits. Poison can be easily mixed with it for (ontrolling bud worms and other ehewing insecots. In making this prepalration any amomt 
also be raried by using a little more or a little less of the lime and sulfur in the 50 gallons of water. As a winter spray one or two pounds of copper sulfate is sometimes added to the 50 gallons of lime-sulfur. This is of special value against apple rust.

The use of poisons with a winter or summer spray of lime-sulfur is effective against chewing insects.

Principles in Using Fungicides.-It is important to remember that all fungicides should be used before the disease breaks out. After a serious outbreak little effect can be seen from spraying (Fig. 217). Plants that have not yet been affected may usually be protected by spraying after neighboring plants are diseased Use as strong a spray material as possible without injury to the
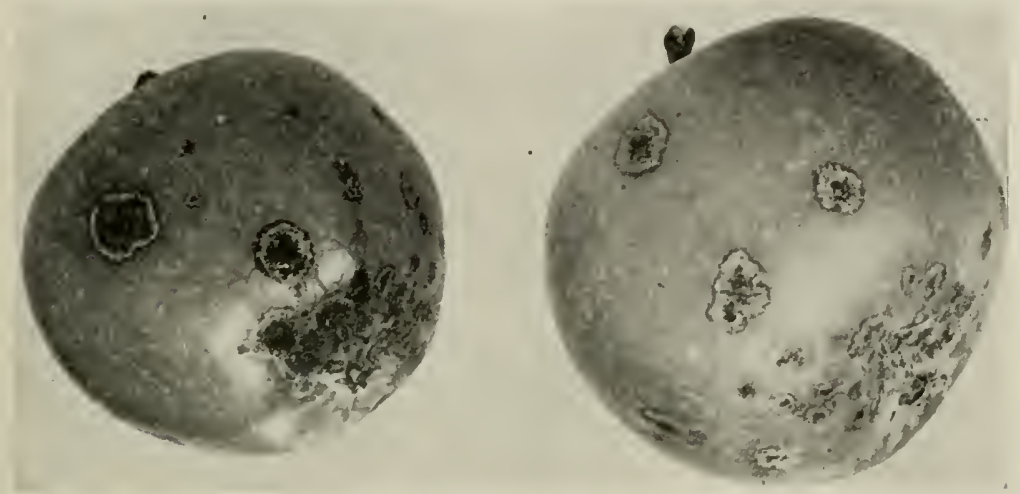

Fig. 217.-Apple scab is prevented by use of lime-sulfur as a winter spray, by the sumner strength of lime-sulfur when the petals fall, and the same two weeks later.

plants. Remember that young, succulent plants are more tender, and weaker solutions are necessary. A little trial will help to determine this point without depending absolutely upon formulas given in books or bulletins.

The principle involved in the use of fungicides is to use a material which is as permanent as possible without destroying the plant or any of its product, or to make it unfit for human use.

The spray must be strong enough and frequent enough to kill the spores of the disease before they enter the tissues of the plants. After they attain a good foothold it is difficult to control their growth.

Special directions for fighting the different diseases are mentioned in the discussion of the different fruits and vegetable crops. 
To Fight Biting Insects.-Many insects live on the surface of plants, eating twigs, leaves, fruit, etc. They bite their food and also obtain some of the poison material which, if strong enough, will kill them.

Poison Sprays.-Arsenic is the chief ingredient of most of the poison sprays. It is used in many different forms. The chief forms are white arsenic, Paris green, London purple, arsenate of lead, and arsenite of zinc. Hellebore is a native poison made from the plant by that name.

White arsenic is probably the cheapest form in which arsenic is sold. It is a white powder readily soluble in water, but is very injurious to the foliage, and can seldom be used successfully on plants when they are in leaf. It is used as one ingredient of spraying when combined with Bordeaux mixture. Prepare it by using two pounds of sal-soda in one gallon of water. Add one pound of white arsenic. When it is mixerl into the form of a paste boil until dissolved. Add enough water to replace that boiled away and make the gallon of stock solution for use with Bordeaux mixture. Use one quart of it with each 50 gallons of Bordeaux mixture for orchard trees. If there is enough lime in the Bordeaux mixture it will prevent the burning of foliage by the arsenic.

A similar stock solution may be made with half as much sal-soda. Then add to this mixture two pounds of fresh, unslaked lime. Add enough water to make two gallons of stock solution including the lime after slaking. Use two quarts of this stock solution to every 50 gallons of water. If the lime is good it should prevent most of the injury to leaves, as the lime takes up the free arsenic.

Paris Green.-This is a compound which is not uniform in composition. The national law requires at least 50 per cent of arsenious oxid. There must be three and one-half per cent of water-soluble arsenious oxid.

Paris green is abundantly used in spraying orchards by mixing one-half pound to 100 gallons of Bordeaux mixture, or one-half pound to 100 gallons of water, to which about one pound of fresh lime is added. The lime in either case is enough to take up the free arsenic and prevent burning of foliage. Paris green is also used as a mixture with lime-sulfur as a summer spray. It may be combined with the lime-sulfur for the winter spray, but is seldom used at that time as it is not needer. The use of Paris green as an arsenical poison is rapidly being replaced by arsenate of load. 
London Purple.-This was once a popular form of poison for use in gardens and orhards. It is now seldom used, as its composition is quite variable, the arsenic content running from 30 to 50 per cent. Use it, if at all, a little stronger than you would Paris green.

Arsenate of Lead.-This form of arsenic is used abundantly on potatoes, orchard trees and for almost all purposes in fighting biting insects. It is not so easily washed off the leaves by rains as are other forms of poison. Its composition is more uniform, and there is a less proportion of free arsenic present to injure the leaves. It is easily combined with the dilute forms of sulfur for summer sprays. It is sold in two forms, either as a thick paste or as a powder. If desired for spraying purposes the paste is to be preferred, as it dissolves more readily. The dust is sometimes used to mix with land plaster or air-slaked lime for dusting such plants as potatoes or low-growing vegetables. This is done in the morning when dew is on the plants. The land plaster helps dilute the arsenate of lead and causes it to cover more plants. It also helps to hold the poison on the plants, as it will harden when wet with the dew and cling, as whitewash does on a board fence. This saves making frequent applications if the weather is rainy.

There are several strengths in which the arsenate of lead may bə used, depending upon the insects to be killed, and also depending upon the danger of plants to injury. Two pounds in 50 gallons of water or Bordeaux mixture or lime-sulfur can be used on the peach against curculio and brown rot. It may be a little stronger for apples. On grapes for grape beetles or root worms and for fighting the rose chafer, four or five pounds may be used to each 50 gallons of the liquid.

The use of molasses with arsenical poisons such as arsenate of lead causes the insects to eat the poison more readily. This is important in the case of the flea beetles, rose chafers and others which are very hard to kill. Fruit flies may be attracted by the addition of molasses, and may be killed in this way.

Arsenite of Zinc.-This contains about 40 per cent arsenious oxid. It has come into more general use in recent years. It was first used abundantly in the Pacific states and in the trucking regions of the Atlantic slope. It is a good substitute for arsenate of lead. If used with lime-water or with Bordeaux mixture it is less injurious to the foliage, but it is less commonly mixed with lime- 
sulfur because there is no surplus lime to take up the burning form of arsenic. One pound of zinc arsenite is equivalent to about three pounds of arsenate of lead.

Hellcbore.-The roots of white hellebore plants are ground into a powder which may be applied either dry or in a water solution. After being ground it loses its strength rapidly, and should be kept in a closed vessel to prevent loss of strength. It may be dusted on plants in its full strength without injury. For the liquid spray use four ounces of powdered hellebore mixed with two to four gallons of water. An ounce of liquid glue added to this mixture will aid in keeping it on the plants.

Hellebore tea is sometimes made by boiling the roots in water. While fresh this may be sprayed on plants. Hellebore has its chief advantage in being much less poisonous than the arsenical preparations. It does not injure the leaves of plants and is less dangerous to crops that are to be used directly as human food.

Principles of Fighting Biting Insects.-There are a number of important principles to be borne in mind in fighting biting insects. First, make sure that the insects are of the biting kind. By observing their work, see what damage is being done. If the surface of the leaves is being taken by them, or if the leaves are being eaten in any way, or if the fruit is bitten, then you know that the insects are of this type. Poison sprays should be applied as soon as the work of the biting insects begins. Success depends upon getting them before they do much damage (Fig. 218).

The spraying material must be strong enough to poison the insects, and should be made attractive enough so that they will eat it. Usually the leaves will be attraction enough, but some sweetening is sometimes used.

Danger to foliage must be avoided. In nearly all cases this is possible by the use of lime added to the water sprays, or by using Bordeaux mixture containing plenty of lime.

Inseets which are soon to become imbedded in fruits must be poisoned at the very moment they are entering the fruits; for example, with apple worms and plum curculio insects this principle applies. It is necessary that the poison be on the surface ready for the insect to get his first mouthful, otherwise spraying would be too late.

To Fight Sucking Insects.-By sucking insects we mean those which take their food in the form of juices through sucking tubes which they inscrt below the surface of the leaves, fruit or stems. 
Plant lice are sucking insects which attack many plants (Fig. 219). It is evident that insects obtaining their food from the inside of the plants can not be poisoned in the same way that we would poison those eating the surface. An entirely different plan of combating such insects must be used. Contact sprays are applied. This means that the spray material must come directly in contact with the bodies of the insects in order to kill them.

Contact Insecticides.-Among the contact insecticides are the soluble or miscible oils, lime-sulfur compounds, soap mixtures,

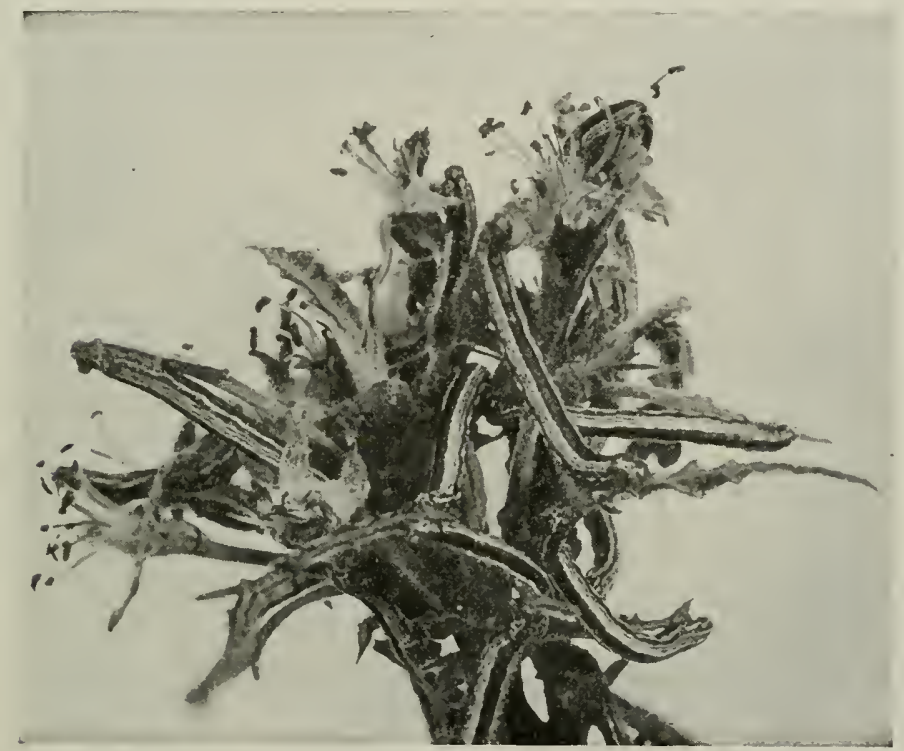

FIG. 218.-Canker worms feed on apple blossoms and on the leaves. Spray promptly with arsenate of lead. (Ohio Station.)

resinous emulsions, kerosene emulsion and crude oil emulsion. Sulfur and nicotime sulfate may also be used as contact insecticides. Pyrethrum, tobacco dust, road dust and other materials are sometimes used.

Kerosene emulsion is one of the oldest and one of the most effective home-made remedies for sucking insects. It is used commonly in fighting plant lice and all sucking insects with soft bodies,

Prepare a soap solution of kerosene emulsion by using laundry soap, one-half pound, two gallons kerosene and one gallon of water. 
Shave up the soap in the water while boiling hot. As soon as the soap is all dissolved remove from the fire and mix it with the two gallons of kerosene. Shake this mixture thoroughly for fifteen minutes. If you have a bucket pump use that in mixing, by spraying back into the same vessel. This soap solution may be kept in large bottles for use at any time. It should be shaken again each time before using.

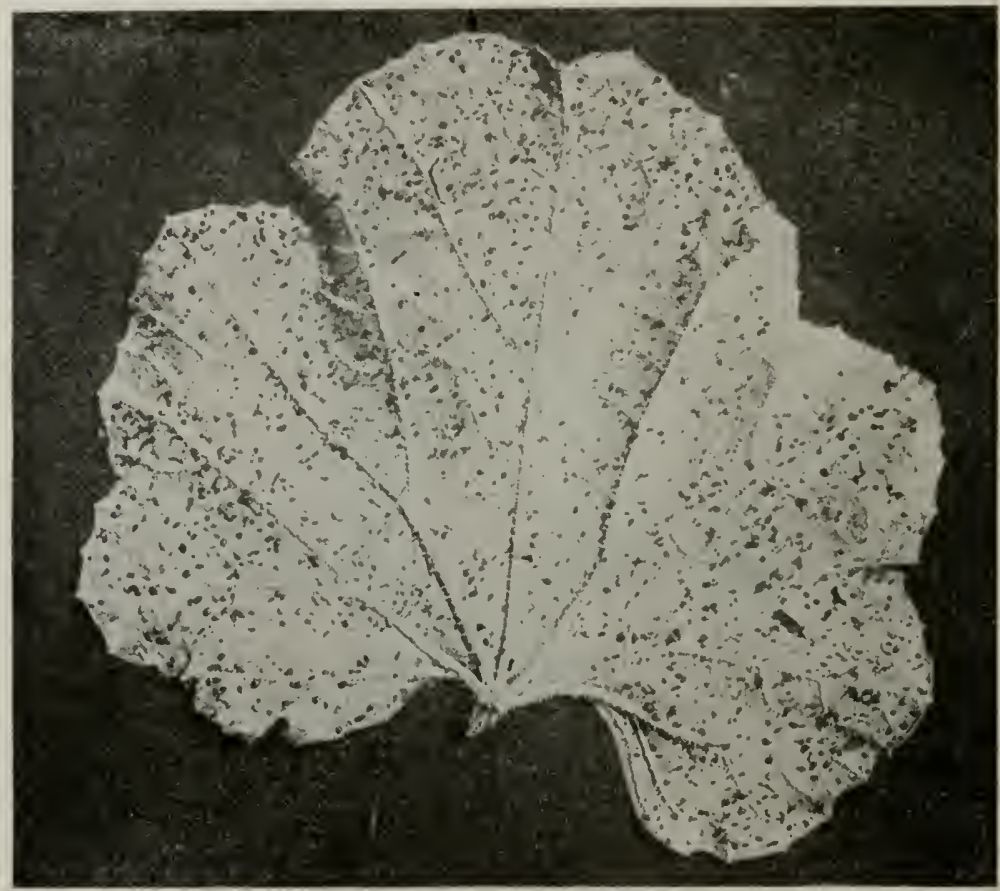

Fig. 219.-A melon leaf badly infested with plant liee. Spray with nicotine sulfate one part to 300 parts or 600 parts of water. (Illinois Station.)

On dormant trees and shrubs use one part of the soap solution to about seven parts of water. On plants in full leaf for plant lice, dilute it, using one part to about fifteen parts of water. Always make a trial to see if the plants are being injured, and also to see if the insects are being killed.

Crude Oil Emulsions.-The directions for making erude oil emulsions are practically the same as for making kerosene emulsion. The danger to plants is less than with the kerosene emulsion, 
but a large amount of water may be used for either the dormant spray or the summer spray. Its effect in killing insects is greater because of the greater amount of grease in the crude oil.

The strength of the emulsion is often indicated by the per cent of oil or kerosene present in the diluted material; for example a ten per cent emulsion would be indicated when the stock solution above described is mixed with twenty gallons of water.

Miscible Oils.-Soluble oils, or miscible oils are prepared and are on the market for ready use in making spray materials. A number of companies prepare such oils from crude oils or distillates.

The chief use of the miscible oils is in fighting the San José scale which is the worst of all sucking insects. For winter spraying against this insect about one part of miscible oil is used with fifteen parts of water. Usually directions come with each lot for making up the spray for different purposes and at different seasons. It is important to have the spraying done in dry weather and when there is iittle danger of freezing too soon after spraying.

Soaps.-Fish oil soaps have a disagreeable odor and are good repellants. They are often sold under the name of whale oil soap, but there is probably little on the market made from whale oil. Strong soap of any kind when dissolved in water is good to use on tender plants for destroying plant lice and other soft bodied sucking insects. Very strong soap suds should be used. Cottonseed oil and other cheap oils are used for making soaps to be used in spraying. A good formula for the home preparation of such soap is caustic soda, six pounds; fish oil or other oil, twenty-two pounds; water, one-half gallon. First dissolve the caustic soda in the water then add the oil gradually while stirring vigorously. If this work is done in a warm place boiling will not be necessary. 'The longer' the stirring is kept up the better the soap will remain in suspension.

Vicotine Sulfate. - This is an extract of tobacco containing about forty per cent of pure nicotine sulfate. It can be combined with other sprays as lime-sulfur, arsenate of lead and soap solutions. It is well to always add some soap to the whole solution to help make it spread better over the plants.

A commercial form of this preparation is known as "black leaf 40." This and the commercial nicotine sulfate are used in strengths varying from one part in 800 parts of water to twice that dilution.

Nicofume is a preparation of paper saturated with nicotine sulfate. It is used chiefly for fumigating green houses. The saturated paper is burned when dry. 
Tobacco dust is used both as an insecticide and as a repellant. Dusting this on plants to repel insects may drive them away (Fig. 229), or the nicotine extracted by the moisture of the dew or rain may kill some of the insects. Plant lice on the roots of apple trees or other plants are often destroyed by the use of tobacco dust. This is applied in the soil after digging away the earth from about the roots. Extract of tobaceo stems is used in much the same way.

Lime-sulfur solution is one of the best insecticides for use against San José seale and other forms of scale insects. The coating formed over the surface of the bark seems to smother the scale insects and they are killed whenever the spraying is done thoroughly.

Directions for making lime-sulfur solutions have already been given in this chapter. This may be applied in either the winter or the summer form according to the requirements; the strength is varied to suit the season.

Pyrethrum.- Persian insect powder is made from the heads of a plant belonging to the genus Pyrethrum, which we frequently find growing in gardens. It is a light brown powder which is somewhat dangerous to use in houses. It can be used if care is exercised to not breathe it. The powder loses its strength rapidly and must be kept in a closed vessel, or used when freshly made. It is commonly used in the powder form, but may also be dissolved in water at the rate of one ounce to three gallons. In the dry form it may be mixed with other powders such as lime dust, borax or flour. It may be used for fumigation by putting the powder on a shovel of hot coals.

Pyrethrum is sometimes dissolved in alcohol, one part to four parts of alcohol by weight. Shake this in a bottle and allow to stand for a week. This may be filtered through a cloth and used in an atomizer for house plants. Some water may be added if too strong for the plants. An extract of pyrethrum may be made somewhat in the manner of tea by pouring boiling water over the flower heads and allowing to stand for a few minutes.

Principles of Fighting Sucking Insects.-Remember that the spray materials must be strong enough to kill the insect by contact and must be applied when the insects are present. Oils and dust are both fairly good insecticides if they come in contact with the insects. Do not expeet the insects to be killed unless the insecticide does the work when the insects are present.

Future attacks of the insects are not affected by spraying or dusting done in advance of an attack. Soft bodied insects are much easier to kill by contact than are those of the scale group. 
Many of the so-called eating insects would be killed by contact insecticides if their bodies were soft enough to be affected.

It is well understood by students that all insects breathe through special breathing pores located on the body, and not through the mouth. Smothering is believed to be at least a part of the cause of the death of insects when killed by such insecticides.

Spraying or dusting against sucking insects can not be carried on in advance, but the work must be done at the proper time. This should be early in the attack of any kind of insect. Do not wait until the plants are seriously injured before fighting begins.

Special Ways of Fighting Insects. - Cut worms and other similar insects that eat plants are sometimes destroyed by poison bait. Bran mixed with Paris green or clover leaves dipped in some arsenical poison may be left where the insects may eat and be killed.

Grasshoppers are sometimes poisoned by the so-called "Criddle mixture." Mix one pound of Paris green with one barrel of horse droppings; add one pound of salt and some water so it will mix and spread nicely. Spread this well where the grasshoppers are abundant and where the poison will not do harm to birds or other creatures.

Kerosene torches are sometimes used for burning webs out of trees.

Lanterns burning at night over pans of water covered with kerosene form good traps for many insects. On warm summer nights the light attracts flying insects that fall into the kerosene, where they are killed.

Many insects are destroyed by hand picking and by pruning off parts on which they are feeding.

Banding of trees is sometimes used to trap the females of canker worm. This moth has no wings and must crawl up the tree to lay her eggs, where the larvæ are to find their food. A band of sticky fly paper will catch many of them.

Other trap bands such as brown paper or burlap are tied around the trunks of trees to trap codling moths and others that will form their cocoons under them. The bands may be removed and run through a wringer or burned to destroy the larvæ.

Farm and Garden Practices against Insects.-Among the best methods for combating insects and plant diseases are rotation of crops, fall plowing, using trap) (rops, thorough cultivation, burning and clearing the hiding places, the use of poultry and protection of birds. 
A spray calendar is a convenient reminder and guide in fighting insects and preventing diseases. The accompanying table was prepared by the Minnesota Station, (Bulletin 153). In almost every case an insecticide should be combined with a fungicide to save labor and accomplish two purposes at once. The calendar suits all parts of the country, but will always need to be varied in some particulars to suit the season or conditions.

\section{SPRAYING EQUIPIIENT}

One of the simplest garden sprayers is the hand sprayer which holds from one pint to one quart of liquid, shown in figure 220 . The liquid is forced out and upon the plants by the force of air blown by the pump. It is really an atomizer. This is perhaps the simplest and cheapest sprayer in use in small garclens.

Knapsack Pump.-A flattened oval vessel holding from thiree to five gallons may be easily strapped upon the back of the operator.

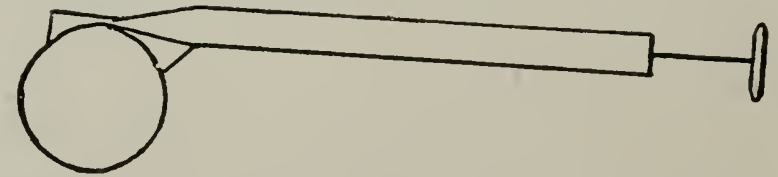

FIG. 220. - A small hand sprayer will be of much help in a small garclen.

A pump in the center is operated by a lever extending in front to either the left or the right side. In the other hand the operator holds the hose or short extension rod in spraying. The movement of the body will keep the liquid fairly well agitated. The operation of this sprayer is not tiresome, but unless care is exercised the slopping of the liquid may be disagreeable upon one's back.

Compressed air sprayers of the three gallon or five gallon size may be carried as shown in figure 221. The pressure pump in the top is operated before spraying begins. Agitation of the liquid is easy while carrying the vessel. This sprayer is well suited to work in small gardens.

A bucket pump is a very simple sprayer. Some forms are made to clamp on the side of a deep bucket holding 3 or 4 gallons. The pumping is clone with a lever by one operator who may hold the extension rod in the other hand and spray any plants either high or low.

Barrel sprayers are of several kinds (Figs. 222 and 223). Those using a barrel without a lread are most easily cleaned, and usually to 
be preferred. Some form of agitator is usually connected with the lever so that the liquid is kept stirred constantly. These may be provided with either one or two lines of hose and connection rods. If barrel sprayers are used on wagons or sleds drawn by a horse the man operating the pump may also do the driving. An assistant is required for handling each line of hose and rod.

Tank Sprayers of many sizes are used in large orchards (Fig. 224). The pumping may be either by hand or by engines of

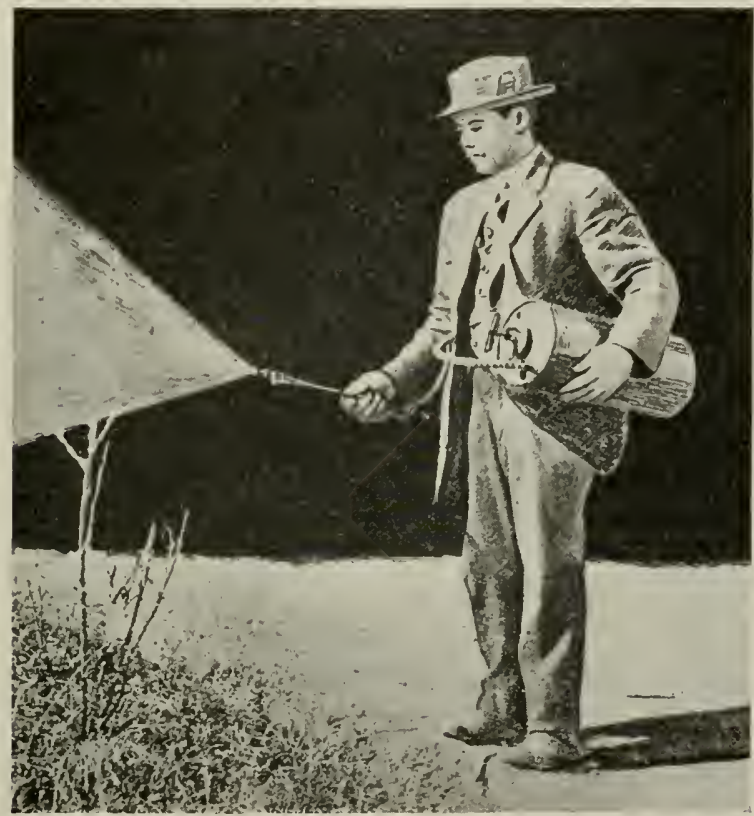

FIG. 221.-Compressed air sprayer, handy for garden use. (U.S.D.A.)

various kinds (Fig. 225). A suction hose leads from the tank to the pump and special agitators are usually required.

Gas sprayers are frequently used by orchardists. Gas tanks containing either condensed air, carbon dioxide or liquid air are used in connection with spray tanks which may be made air tight by screwing on tight covers after the spray material is placed in the tank. The gas tank is connected with the spray tank by a tight, metal-covered tube. The liquid is then forced out from the bottom of the spray tank through a pipe connected with the hose and extension rod. 


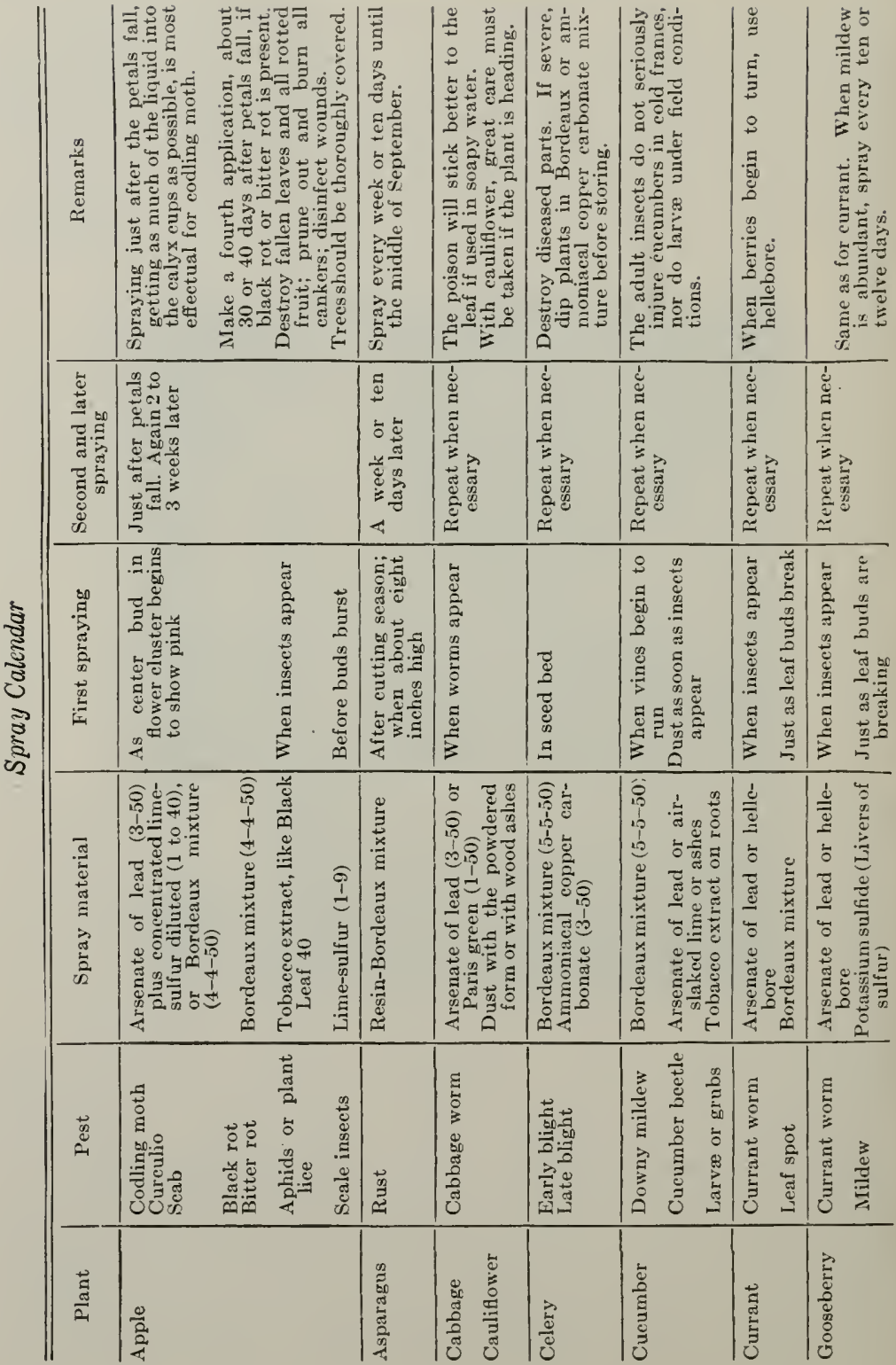




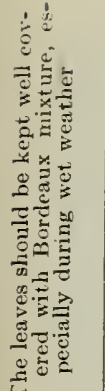

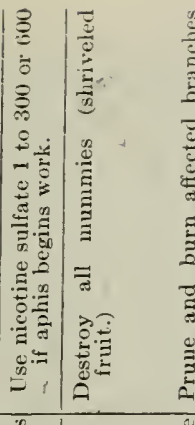
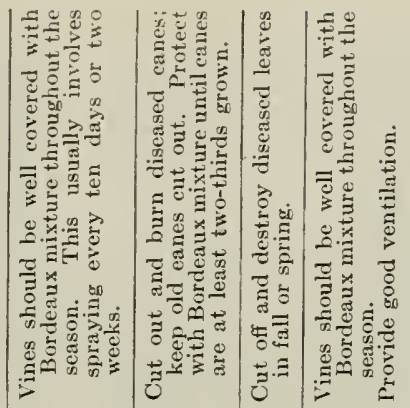

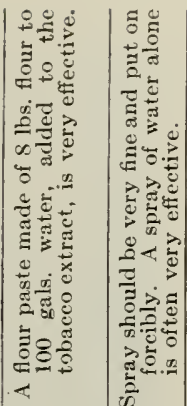

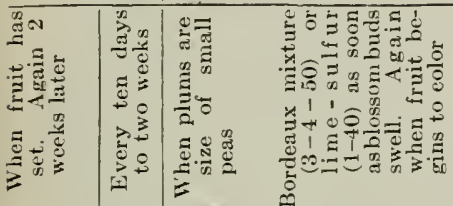

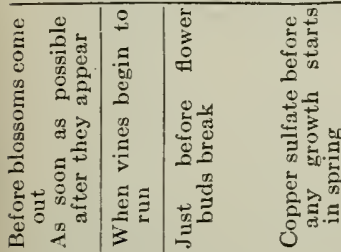

\begin{tabular}{|c|c|c|c|}
\hline 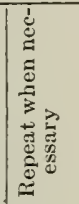 & 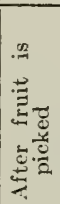 & 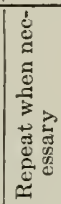 & 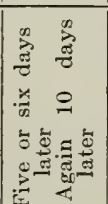 \\
\hline
\end{tabular}

(1)

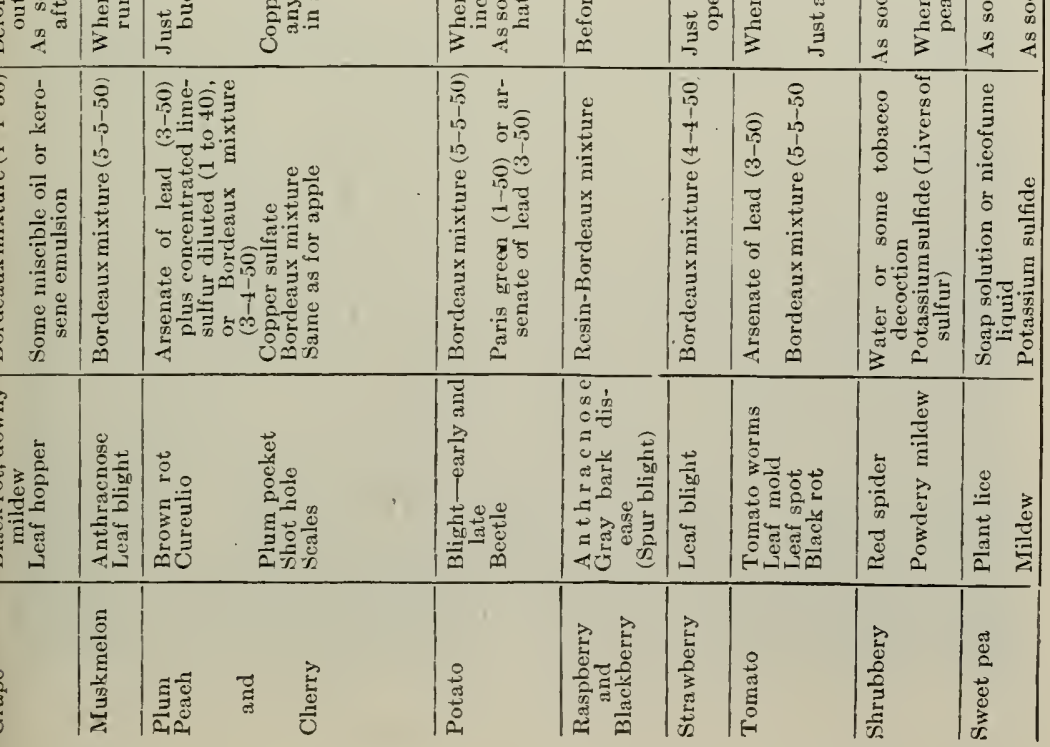


Fig. 222 .

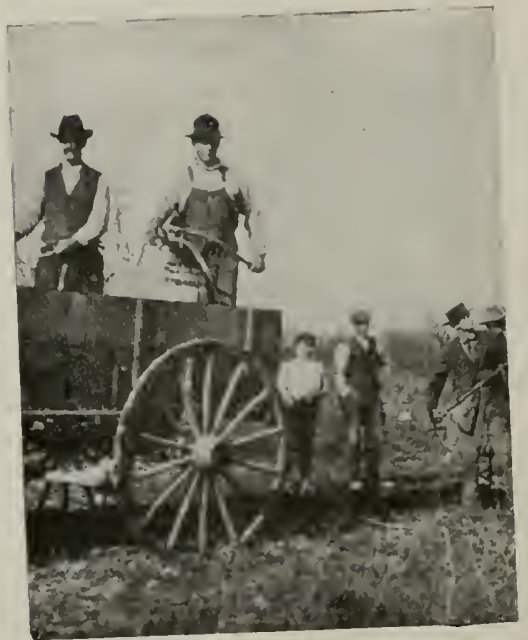

FIG. 223.

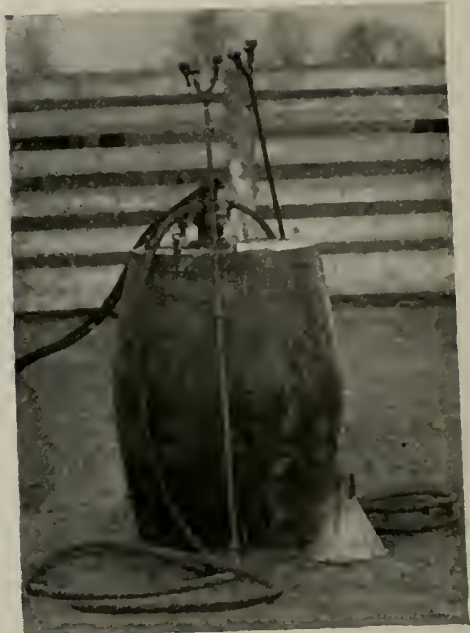

Fic 222 - C sing a barrel sprayer in a farm wagon. (Missouri Station.)

a bark nozzles FIG. 223.-A common form of barrel pump with two leads of This makes the barrel hard on each extension rod. The pump is bolted to the
to clean out after using. (New Jersey Station.)

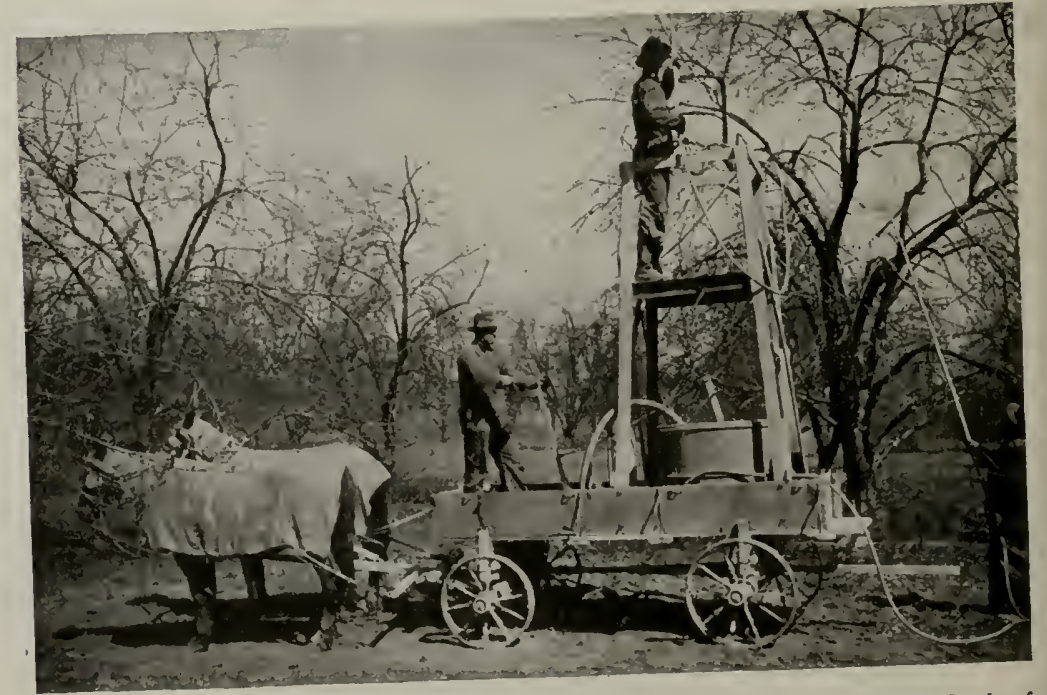

Fig. 22t - A double-acting hand pump and tank arranged to spray through two leads of hose from a farm wagon. From the tower platform the tops of orchard trees may be sprayed. (Indiana Station.) 
Elevated Towers.-Frequently trees are so high that the man using the spray lod needs to stand at a high elevation above the tank. Towers are then built on wagons holding the spray outfit. This plan makes it possible to reach the upper parts of the trees which might otherwise be missed.

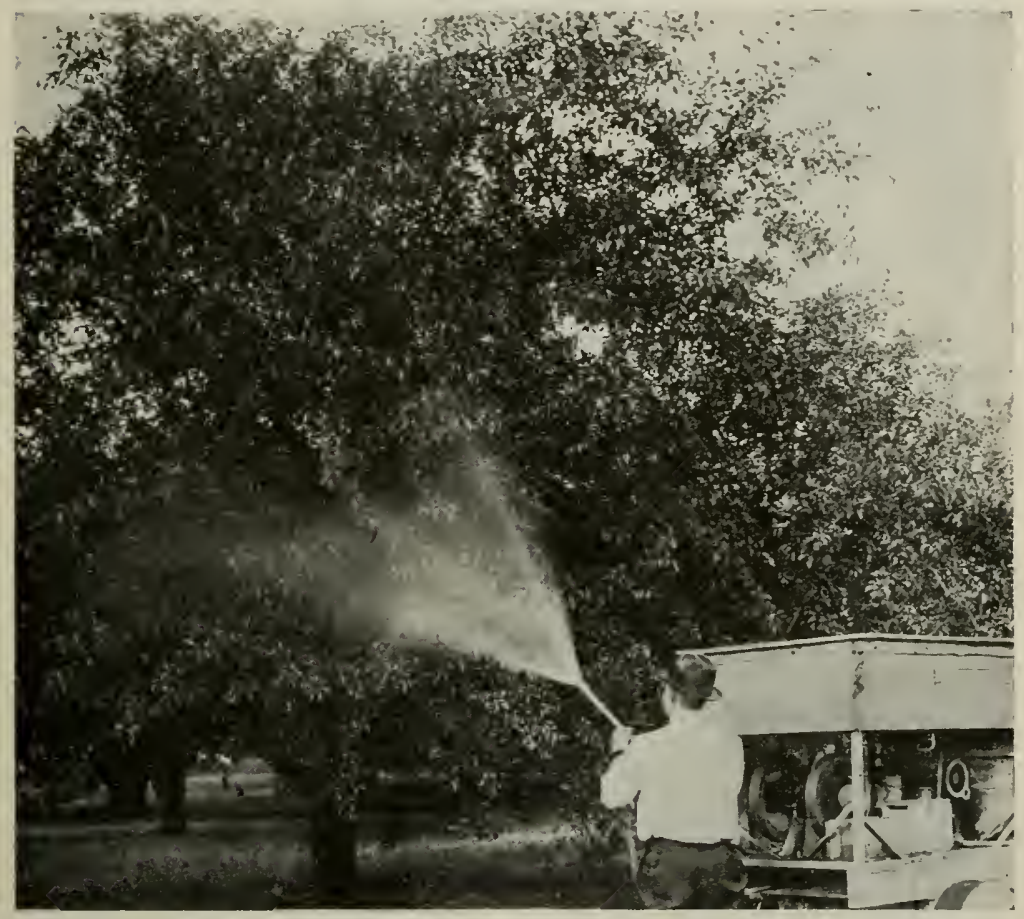

FIG. 225. - With a gasoline or oil engine a high pressure may be easily maintained. This makes a fine mist. (Michigan Station.)

Hose and Extension Rods.-The hose user in spraying should be strong and durable. On the other hand it should be easily handled and not too heavy.

Extension rods should be of lengths to suit the kind of spraying. For large trees, rods eight to twelve feet in length are sometimes used. At the base of the rod is a shut-off cock so that the operator in moving the rod from tree to tree, will not lose much material. The nozzle is attached to the end of the rod. Extension rods are usually made of thin brass surrounded by a bamboo tube. Some- 
times they are merely sections of gas pipe made of galvanized or black iron. The inside diancter may be about one-fourth inch.

Nozzles.- Spray nozzles are of

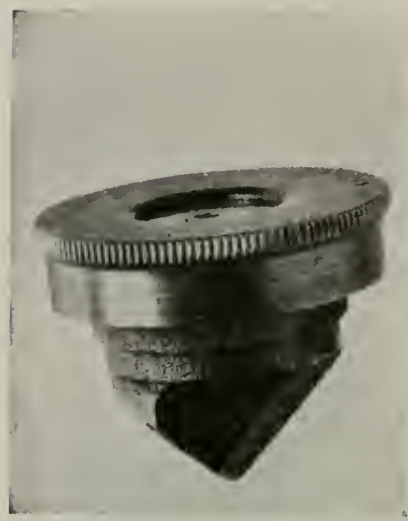

Fig. 226 . -The large disk nozzle gives a finer mist than the older ty pes. The angle eonnection, shown at the base, makes the spraying easier and more thorough. (Indiana Station.) many types. They can be used in comnection with any of the spray machines except the atomizer. Most sprays require that the liquid be made as fine as possible. Heavy streams of liquid are not usually desired. The best forms of nozzles now in use are those with large dises, sold as "dise nozzles" (Figs. 226 and 227).

The nozzle should be connecter with the spray rod by means of a 45 degree elbow, so that by merely turning the rod the operator can easily give a different direction to the spray. He can thus more easily strike all sides of the leaves and stems of plants.

Dusting instead of spraying is frequently practiced. It saves handling so much liquid and makes the work more rapid. Hand
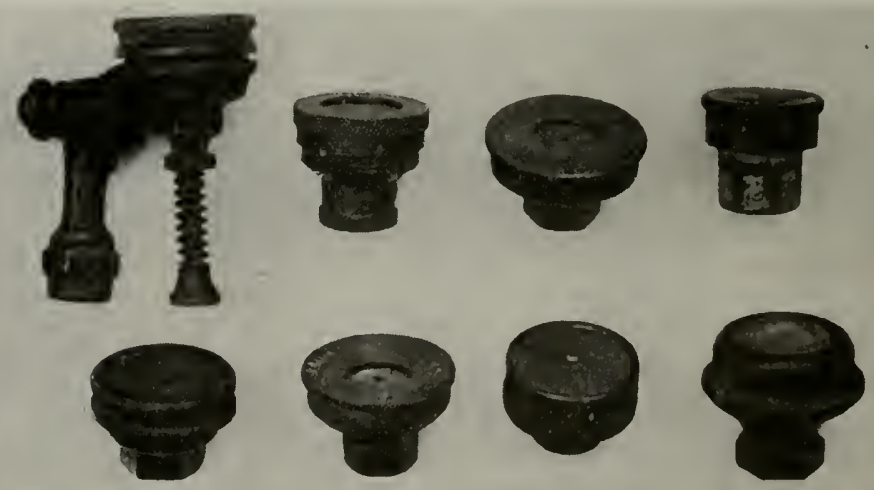

FIG. 227.-Several types of spray nozzles. All modern nozzles have a large disk in which the liquid is given a rutary notion before exit from the orifice. (New Jersey Station.)

clusters made of loose burlap are often used in potato fields and gardens. A marehine blower for dusting several rows at once is shown in figure 229. 

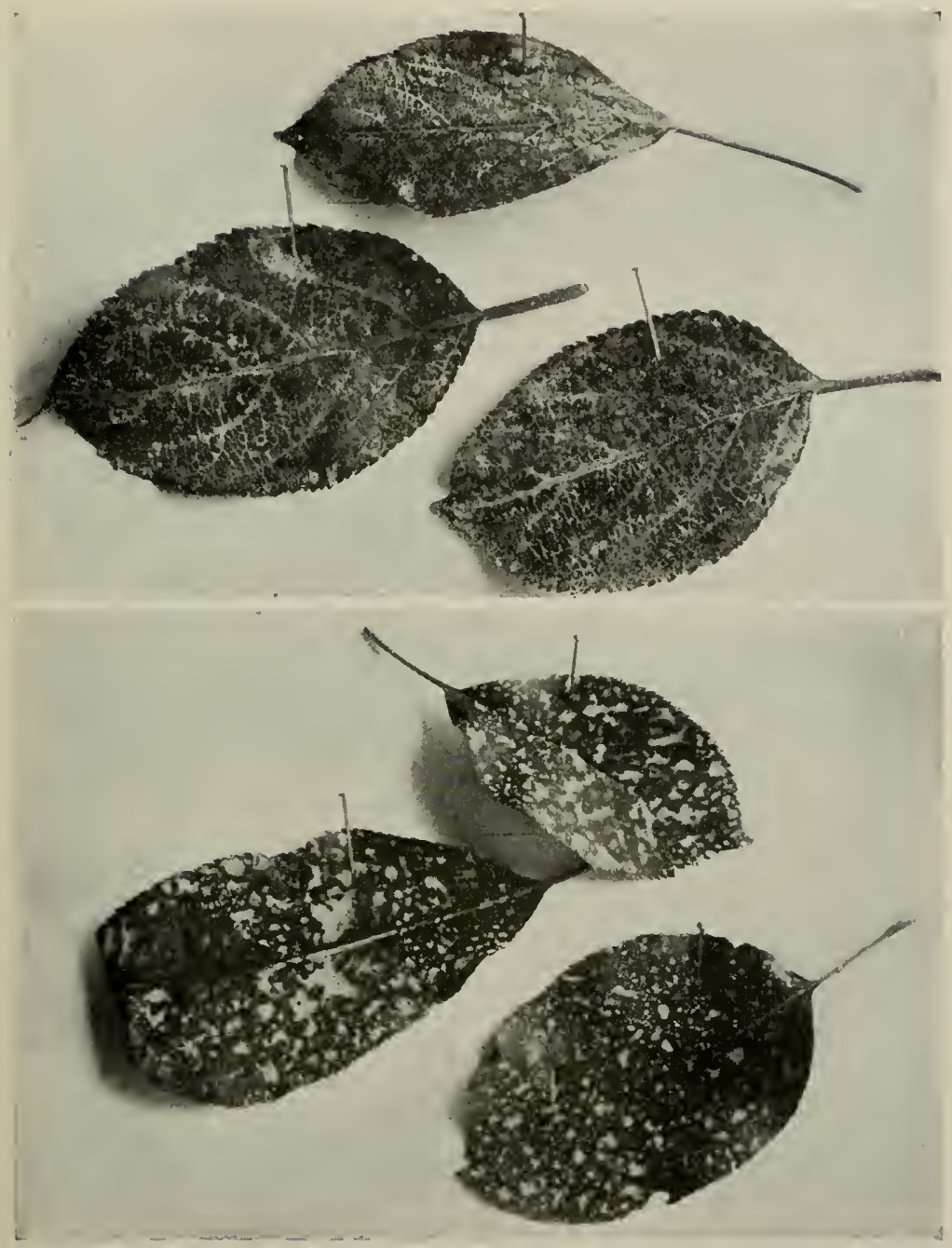

Fig. 228.-Upper figure shows an even coating of spray material with fine nozzle and high pressure. Lower figure shows the poor work of a coarse nozzle or low pressure. (Kansas Station.) 
Principles of Spraying.-Liquid sprays should usually be applied on a bright day to give the liquid time to dry before rain.

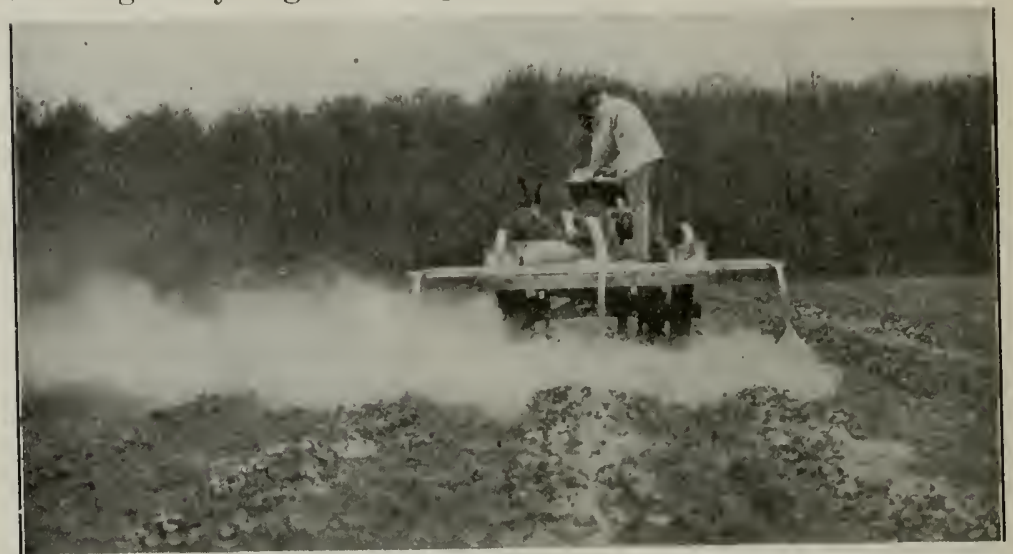

FIG. 229. - Three-row duster operated by gas engine; used on strawberries to combat weevils. (New Jersey Station.)

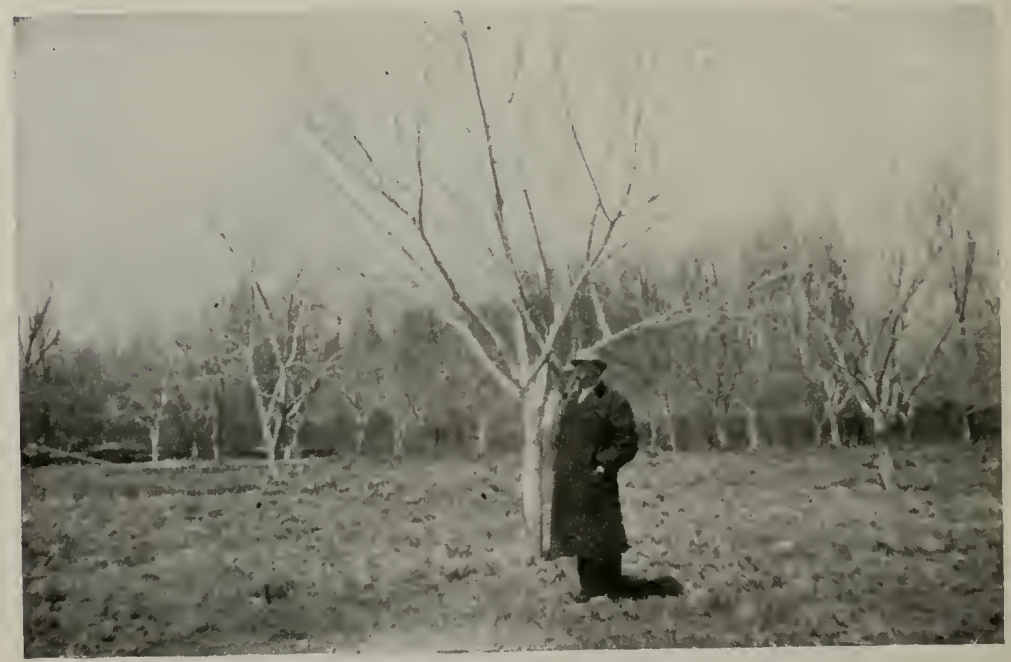

FIG. 230.-A Maryland orchard thoroughly sprayed with lime-sulfur. Every spot is coated with the spray material to snother the scale insects and to destroy spores of all diseases. (U.S.D.A.)

The finer the mist formed in spraying, the more even will be the spray on the surface of the plants. Damage to the plant is less likely to result (Fig. 228). 
Always make the spraying very thorough. Do not allow any part of the plant to be missed (Fig. 230). Insects feeding upon the parts not sprayed may afterward spread to other parts of the orchard or garden.

Never spray unless you know for what you are spraying. Use the material required for the purpose in hand.

Never drench the plants unduly. Damage is likely to result and material is wasted.

The cost of spraying is largely governed by the labor involved. If the spraying apparatus is handy, and the work is begun promptly, the benefits will usually far repay the cost of labor and material (Fig. 231)

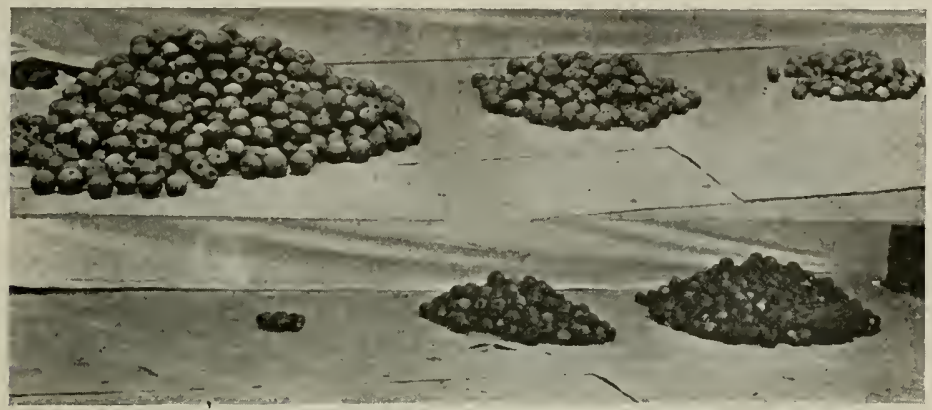

Fig. 231.- Spraying the apple orchard pays. Upper lot from tree sprayed three times; fruit mostly No. 1, at left, few culls at right. Lower lot from tree not sprayed, fruit mostly culls at right. (Illinois Station.)

Avoid making the spraying irksome. Protect your hands and face with suitable materials to avoid injury to the skin. By rubbing a little vaseline on the hands and face before spraying with Bordeaux mixture the material is easily washed off.

Poison sprays should be handled cautiously and not be left where children or dumb animals will be injured.

\section{EXERCISES, PROJECTS, AND SURVEYS}

1. Making Fungicides.-Prepare the stock solutions for Bordeaux mixture in quantities to suit your vessels. Make up some of the mixture and use it in the garden or orchard.

2. Make concentrated lime-sulfur solution. Then dilute it and use it in the orchard.

3. Make a solution of ammoniacal carbonate of copper, and livers of sulfur. Use each in suitable places.

4. Poisons.-Make up spray mixtures of arsenate of lead, of Paris green, of white arsenic, of London purple, of arsenite of zinc. Practice using each of these against chewing insects. 
5. Powders.-Make use of hellebore, pyrethrum, and tobaceo dust in suitable ways.

6. Emulsions.-Make up a stock solution of kerosene emulsion. Dilute and use some of this.

7. Make a similar emulsion using crude oil instead of kerosene.

8. Secure some prepared miscible oil, as "scalecide." Dilute this properly and use it as a spray.

9. Soap of several kinds should be made up into spray materials and each used on plant lice to test the effects.

10. Nicotine sulfate in the liquid form should be made up into a dilute spray and used on sucking insects, as plant lice, leaf hoppers, and others.

11. Cut worms should be fought in ways suggested.

12. Use banding methods to trap the larvæ of codling moths.

13. Use bands of sticky fly paper against canker worms, and against larvæ travelling up the trunks of trees.

14. Try hand picking of tomato worms, potato beetles, or other large insects.

15. Use of spray apparatus of several forms should enter into the preceding exercises. Use several forms of pumps, nozzles, and rods of different lengths.

16. Spraying campaigns against both potato bectles and blight tnay be it home project.

17. Similar projects may be planned in connection with the growth of any garden or orchard crops where the enemies are bad.

18. Community studies and surveys should be made to determine the most serious enemies in gardens and orchards and the most successiul methods of fighting them. Discover if possible, those that are spraying improperly as well as the successful ones.

\section{QUESTIONS}

1. Give the three chief purposes in view when spraying campaigns are conducted.

2. Mention several materials to use in preventing disease. Discuss each.

3. Tell how to make Bordeaux mixture.

4. Describe the making of concentrated lime-sulfur and tell how to dilute it for use.

5. Give directions for making self-boiled lime-sulfur.

6. What principles are involved in the use of fungicides?

7. Mention several spray materials to use in fighting the chewing insects.

8. What are the merits of arsenate of lead as compared with the others?

9. Mention several contact insecticides for use against sucking insects.

10. Describe the making of kerosene emulsion.

11. What are miscible oils? Discuss their use.

12. Discuss the use of nicotine sulfate; of tobacco dust.

13. What are the uses of pyrethrum?

14. What principles are involved in fighting sucking insects?

15. Give several special ways of fighting insects without spraying.

16. Describe a knapsack pump and suggest its best uses.

17. Same for the bucket pump; and the barrel pump.

18. Discuss the hose, extension rods, and nozzles.

19. Give some principles of spraying.

References.-U. S. Farmers' Bulletins: 440, Spraying Peaches; 595, Arsenate of Lead as an Insecticide against Hornworms; 648, Control of Root Knot; 650, San José Scale and Its Control; 662, Apple Tree Tent Caterpillar; 721, Rose Chafer; 722, Leaf Blister Mite; 723, Oyster-shell Scale and Scurfy Scale; 731, True Army Worm and Its Control; 737, Clover Leaf Hopper; 739, Cutworms and their Control; 763, Orchard Barkheetles and l'inhole Borers. 799, Carbon Bisulfict as an Inseeticide; 804, $\lambda$ phids Injurious to Orehard Fruits, Currants, Gooscberries and Grapes. 


\section{CHAPTER XXVI}

\section{WORK BY SEASONS IN THE ORCHARD, FRUIT GARDEN AND THE HOME GROUNDS}

THe beginner in orcharding may be helped materially by outlines showing the work to be done each season in the orchard.

Outline of the Year's Work in the Apple Orchard.-There are four main lines of work in the orchard which demand attention. In the winter the first task is to give the annual pruning which the orchard must have to be successful. Following this at any suitable time when the weather is favorable, the spraying campaign must begin. This will continue through the spring and early

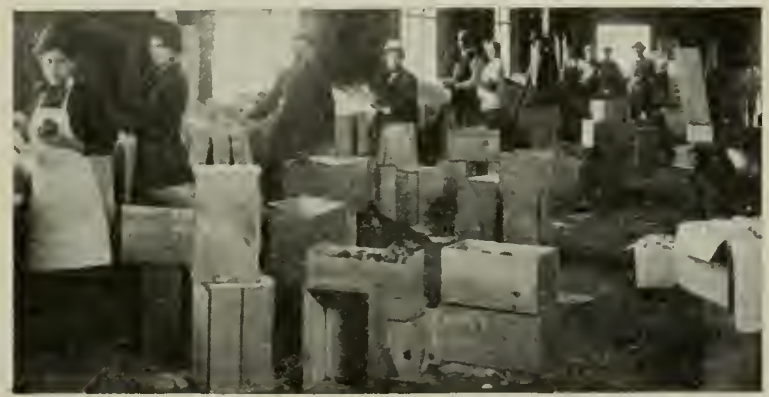

FIg. 232.-In co-operative fruit shipping associations the sorting and packing is often done on an extensive scale at a central station. (Photo by T. Gagnon.)

summer. Thinning is often necessary when the fruit is small. Probably before spraying is ended the annual cultivation must begin. This will be accompanied by fertilizing or feeding the soil to supply plant food to the trees and growing fruit. After the cultivation, picking will soon begin, and the fruit will have to be sorted and marketed or stored and later sold (Fig. 232).

There are special problems coming up from time to time during the year, such as the examination of trees for borers, and perhaps the fighting of codling moth by the banding methods. Protect the trees from sun scald, from attacks of rabbits, etc.

The Annual Campaign for the Stone Fruits--The operations in the peach orchard are about the same as for the apple orchard. 
1. Prune the trees in their winter condition.

2. Spray for scale and winter forms of fungous diseases.

3. Continue the spring spraying.

4. Cultivate during spring and carly summer.

5. Thin fruits when they are small.

6. Fertilize during the cultivation period.

7. Harvest the crop.

8. Sort, pack and market (Fig. 233).

9. Dig out borers each spring and fall.

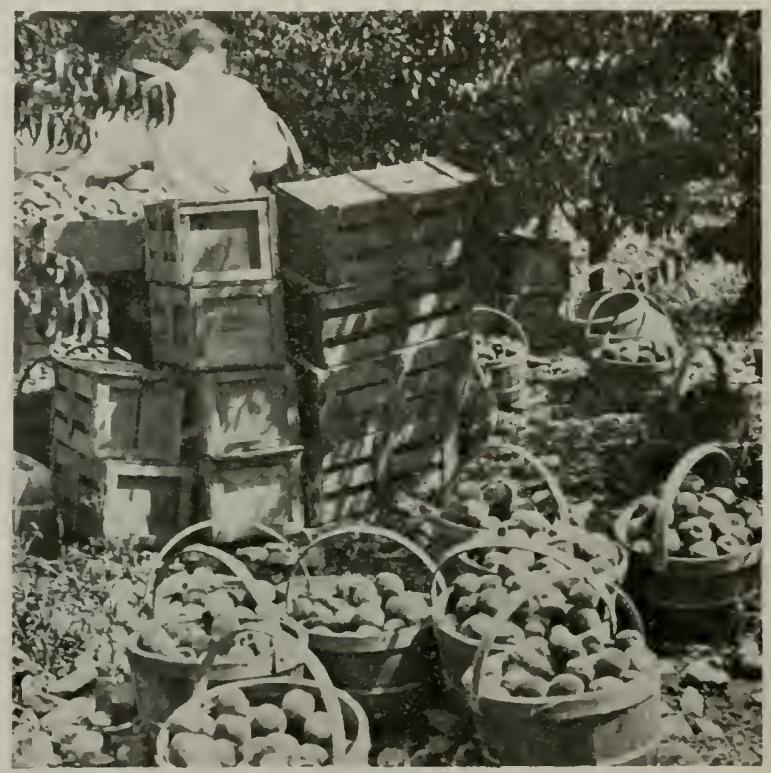

FIG. 233.-Picking baskets of this type help to protect the fruit from injury. Peaches are here being packed at an orchard station to start to market promptly. (New Jersey Station.)

The Year's Cultivation of Orchards.-Plow the ground by turning the soil with a turning plow in early spring. Let this approach as close to the trees as possible. If the slope of soil will allow it, tillage implements may be rum both ways. The small square near each tree can be worked up with hand tools such as grubbing hoes or mattocks. After plowing, the disk harrow or cutaway harrow (Figs. 234 and 235) should be used to crumble the soil and prevent loss of moisture. Some such implement should be used several times. It will prevent the baking of soil and will keep down the growth of 
weeds. Other tillage implements, such as the acme spike-tooth and spring tooth harrows may be used at short intervals after the first plowing and disking (Figs. 236 and 237).

By midsummer it is usually best to stop tillage. This will allow the trees to stop growing and ripen their wood and form the bud scales for winter protection. They are then less likely to be injured by winter freezing.

A part of the annual tillage should include the sowing of the winter cover crop at the time when the cultivation ceases. The seed may be sown just before or

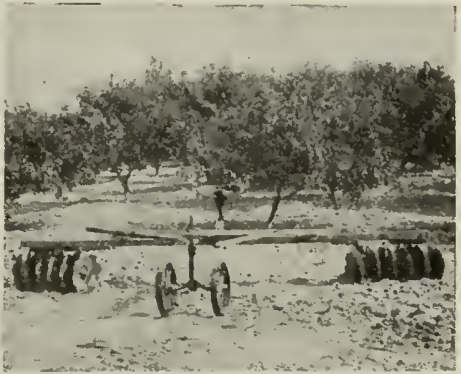

FIG. 234-A common disk harrow may be attached to the ends of an extension bar to cultivate under orchard trees. (New Jersєy Station.)

just after the last cultivation. A good cover crop mixture is one bushel of rye, one peck of winter vetch, and one-half peck of

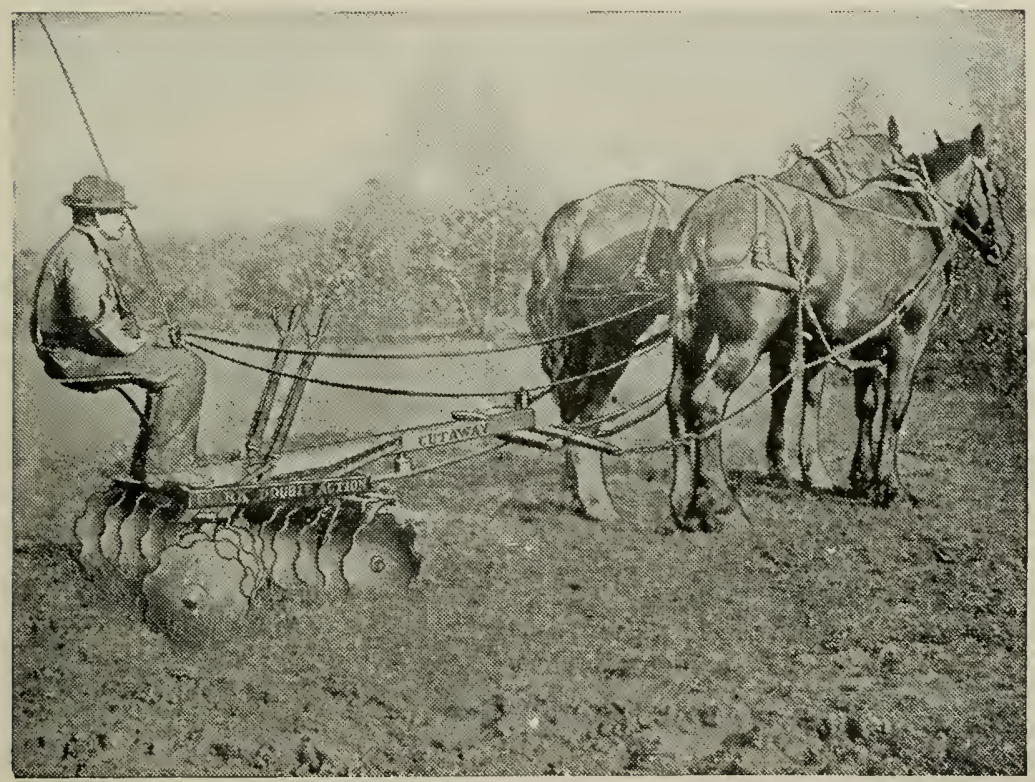

FIG, 235.- The cutaway disk harrow is well adapted to pulverizing the surface soil and preparing a seed bed for gardens. Smooth edged disks give similar results. 
crimson elover per acre. These can be sown in a hand machine or merely by hand. It is usually best to eover the seed with a

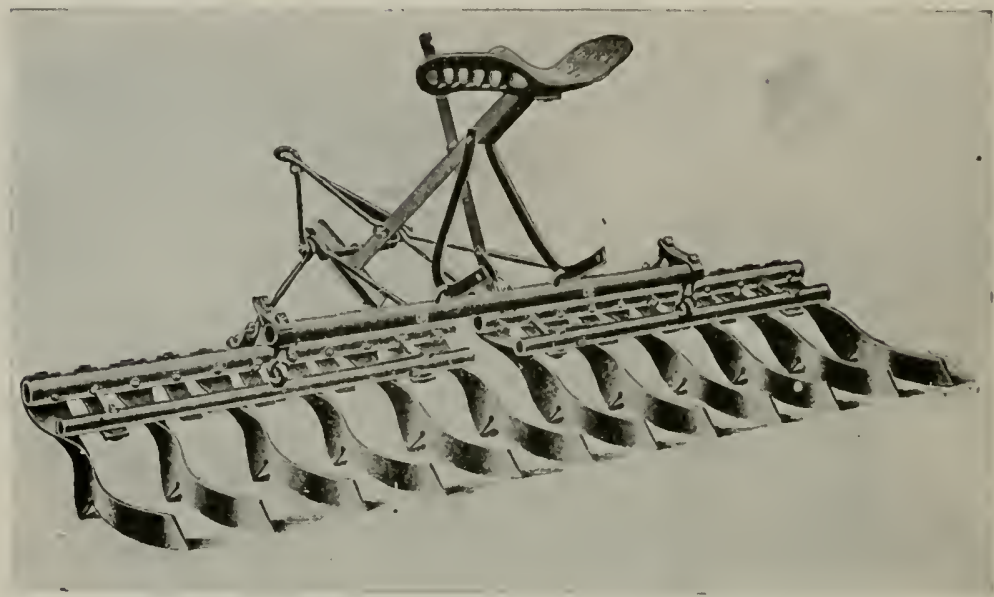

FIG. 236.-Acme pulverizing harrow used as a general purpose harrow. It is used for smoothing newly plowed ground or for the final preparation of a garden seed bed. It is a good orchard harrow.

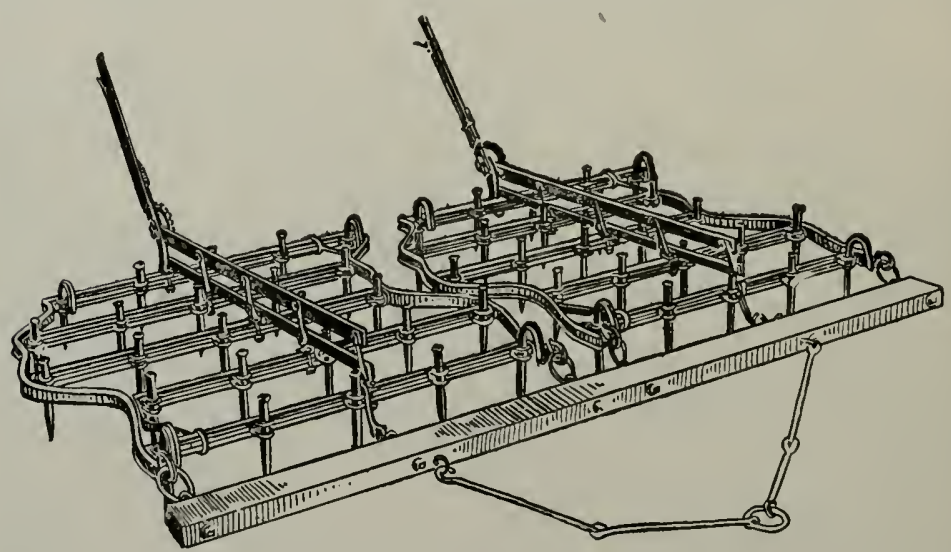

FIa. 237. - The spike tooth harrow with lever adjustments by which the slant of the teeth is controlled.

harrow. In northern latitudes the crimson clover may be omitted from this mixture and the quantity of the other seeds slightly increased. 
The spring plowing may be delayed until the winter cover crop has made a slight spring growth. The plowing will then turn under a good growth of green manure. This should supply an abundance of nitrogen, so that no other nitrate fertilizer need be used.

The only commercial fertilizer in that case which needs to be added would contain phosphoric acid and potash. If the trees are making a good growth and are not bearing much both of these plant foods are needed. On medium soils use about 150 or 200 pounds per acre of a mixture containing six to eight per cent of each of these plant foods.

Pruning Work of the Year.-The chief pruning of either the apple or peach orchard should come in the winter season. Special directions for this have been given in Chapters XVI and XVIII. The chief points to be borne in mind are that trees will need to have the branches thinned to let in more light, dead branches must be cut away, all injured parts must be removed and long branches should be cut back somewhat. The trees should be kept well balanced and somewhat symmetrical. At any time during the year when injury occurs by the wind or any accident, pruning should be resorted to immediately. Cover the wounded place or marks where large branches have been removed by painting them (Figs. 238, 239 and 240).

The spring thinning of the fruit maiy, in a sense, be considered pruning work, as it will aid materially in controlling the formation of fruit the next season.

It is well to practice some pruning in the summer season. Pinch off the little shoots that are out of place, particularly on the large branches and on the trunk of the tree. These can be removed with the fingers at that time without injury, and the growth during the remainder of the summer will be directed to better channels.

Another important part of summer pruning is to cut away diseased branches, particularly those affected with blight or, in the case of stone fruits, that are affected with brown rot.

The Spraying Campaign in the Apple Orchard.-The campaign here described applies not only to apples, but to all core fruits, including apples, pears and quinces.

In orchards affected with San José scale two winter sprayings are sometimes necessary. The first is with miscible oil applied in early winter. This loosens the scales and penetrates well into the rough bark.

Late in winter, after the winter pruning is over a strong spray 
of lime-sulfur solution is made to thoroughly clean up the trees of San José scale and spores of scab, rot and rust.

If the trees are not affecter with San José scale the winter spraying with lime-sulfur for the three classes of discases mentioned is necessary. In its place, however, copper sulfate could be used. It is not common, however, to find orchards not somewhat affected with the scale.
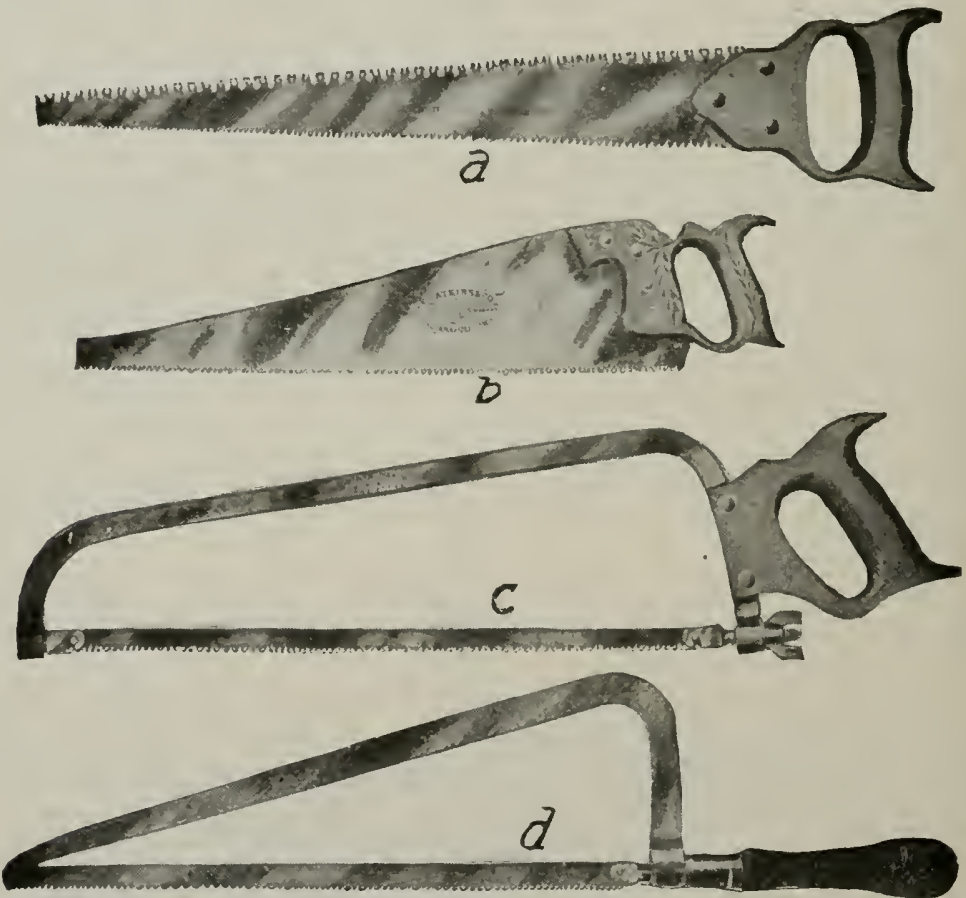

FIf. 238.-Four types of pruning saws. $C$, $d$, swivel bladed saws for use in close places; $b, 5$-point solid blade was for very large limbs; $a$, double edge saw often sold, but it may do much damage. (Nebraska Station.)

As the buds begin to swell, and before they show any color of green or white bloon, it is usually necessary to spray with poison to fight the bud worm. This may be added to a weaker solution of lime-sulfur to continue the fight against fungous diseases and San José scale. This sprayring ats the buds burst sometimes consists of arsenate of leal eombined with Bordeaux mixture. If at this time the buds are attacked by plint lice, the lime-sulfur will help to control this pest also. 
The next spraying should follow immediately after the petals fall from the blossoms. This should consist of arsenate of lead combined with Bordeaux mixture. The poison is to combat the codling moth which enters through the calyx cup of the fruit. The Bordeaux mixture is to combat scab, rot and rust diseases.

These same spray materials should be applied again in about ten days or two weeks. In special cases a third spraying with this material ten days or two weeks after the last may be made. Spray-

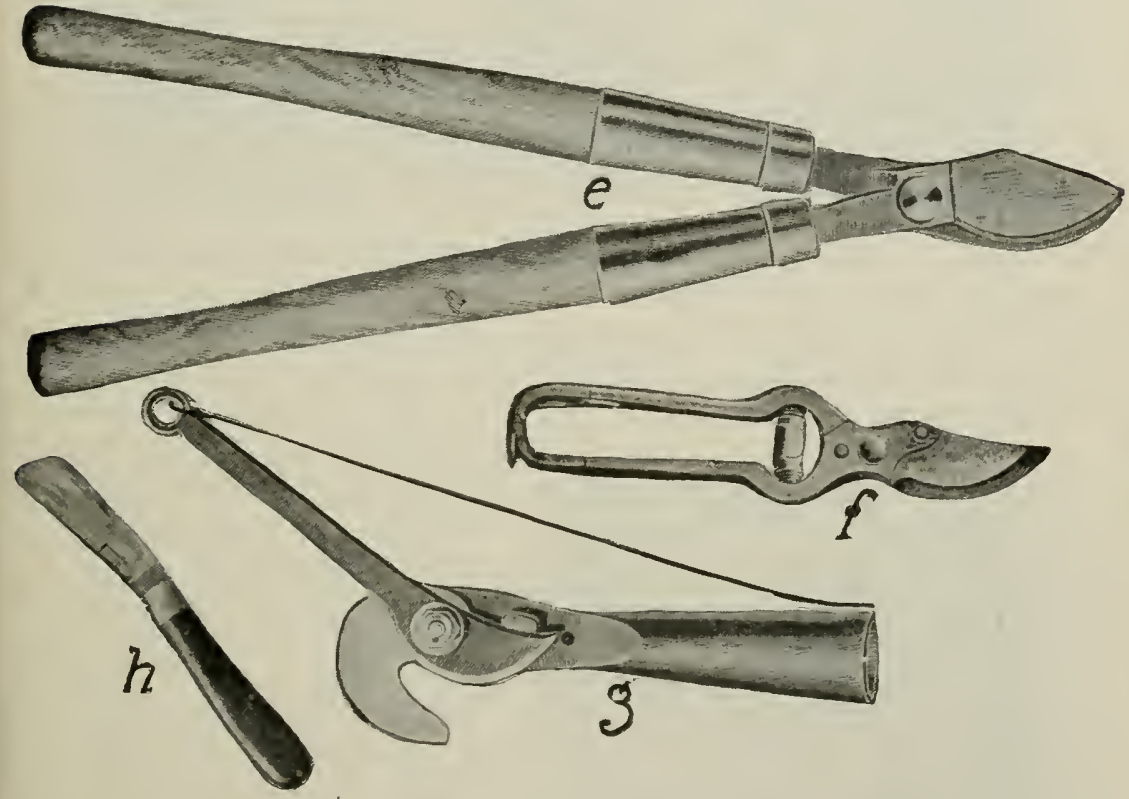

FIG. 239.-Large shears, $e$, will hasten the pruning work; hand shears, $f$, are necessary for small trees and twigs. The hole pruner, $y$, aids in the high tops. The heavy pruning knife with hooked blade is used on small limbs and for smoothing the saw work. (Nebraska Station.)

ing later than this will not be necessary except where bitter rot is likely to attack the crop. In that case a summer campaign may be necessary, spraying every two or three weeks according to the frequency of rainfall. This would be practiced only in special cases, and should be considered somewhat experimental. The material recommended is Bordeaux mixture made with four pounds of copper sulfate to six pounds fresh unslaked lime in 50 gallons of water. 
Spraying Campaign for Stone Fruits.-This campaign is very similar to that described for the apple orchard. In general the spraying is the sime for all the stone fruits, including peaches,
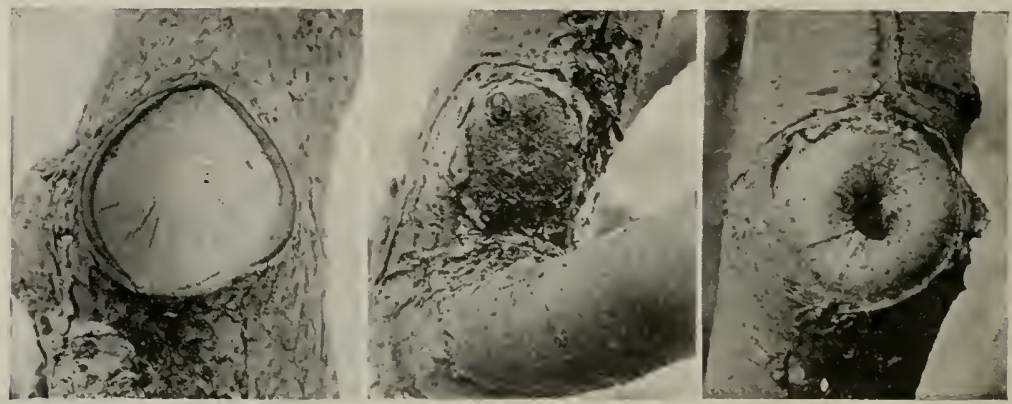

FIg. 240.-P'runing of large limbs should be as close as possible to allow the bark and live wood to cover the wound as shown in the central figure. Decay may begin before the new growth covers the wound, and a deep hole is formed, as shown at the right.

plums and cherries. The first winter spraying usually follows the heavy winter pruning. This consists of a thorough application of winter strength of lime-sulfur solution. It is the chief spray against San José scale and will aid

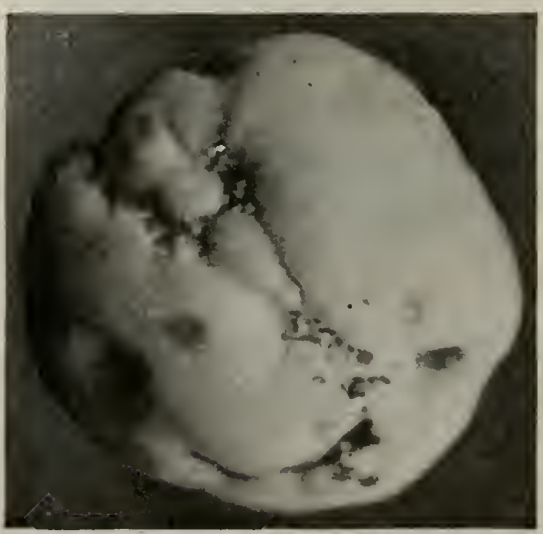

FIg. 241.-Curculio beetles in biting peaches and plums of ten cause deformed growth. (New Jersey Station.) greatly in the control of peach scab, brown rot, leaf curl and other fungous diseases.

At the time the petals fall the fruit is about the size of a navy bean. The curculio is then likely to make its first attack (Fig. 241). Spray with arsenate of lead added to the solution of self-boiled lime-sulfur or added to Bordeaux mixture.

The lime-sulfur and the Bordeaux mixture are good fungicides and will aid in the control of brown rot and peach scab.

This spraying is repeated two weeks later on all varieties that are most subject to brown rot. The poison is again added to the fungicide to control later attacks of curculio. 
This same combination spray should be used again about four or six weeks after the first curculio spray, and may be again repeated in about a month before the fruit is ripe.

\section{WORK BY MONTHS FOR SOUTHERN STATES}

January.-The last of January may be suitable for the transplanting of all kinds of shade trees and fruit trees. Tines and shrubs may also be transplanted if the ground is not frozen, and if the soil is not too wet. Before taking up the plants prepare the ground well and dig the holes.

Favorable days may be selected for the pruning of trees, shrubs and vines. All the orchard trees should be pruned this month if the weather will permit. By the end of the month spraying may be begun, or perhaps completed.

Remember that the dormant season is the time to make cuttings of woody plants for use in grafting or for growth as cuttings. Consult the propagation list and if you are not familiar with the methods of propagation study it for the desired shrubs, vines, etc. Make a trial of the cutting method. The cuttings should be taken early enough to allow time for callousing in storage before they are set in the ground in the spring to be rooted. Try grape vines currants, gooseberries, dwarf barberry, golden bell, spirea, syringa, and many other ornamentals.

Try to complete all of the indoor work, such as making of root grafts, making new labels, etc.

The lawn grass should be dressed with stable manure if this was not done in the fall. Liine may be used along with the well rotted compost to invigorate the growth next spring.

February.-If the weather is suitable this is a good month to begin the search for borers in peach and apple trees. After removing the soil to a depth of 3 or 4 inches around each tree watch for the borings, and then dig the "worms" out, using a wire or sharp pointed knife. Then the earth may be leveled back to the trees.

If danger of severe freezing is over strawberry plants may be set this month. Get the ground in good condition, open the marks well, and then set the roots deep enough to avoid danger when dry weather comes. Do not cover the growing crown with soil.

The old strawberry beds that were mulched in the fall should be slightly uncovered, or at least some of the plants may be allowed to start by the last of February.

For strawberry beds which were not mulched in the fall the 
cultivator may be used at once, then a mulch applied around the plants to protect the berries, save moisture and prevent weeds until the erop is picked.

If the spring is late some pruning and spraying will still be in order. Also push the planting this month. The planting of trees and shrubs should not be delayed until the transplanting would seriously check their growth.

February is one of the best months for sodding banks or other places where you want grass to take root quickly.

This month the hedges should be pruned and the ground raked and cultivated about them.

Re-dress the driveways by raking the surface, fill in the washed places with new material, give the edges a careful trimming and let them have a "dress-up" appearance.

March.-Begin to clean up the lawn grass by removing the winter or fall dressing with a sharp rake. If moles or frost have raised the soil in places it should be rolled well so that the roots will take hold again.

Much of the spring spraying will come in March. Look over the spraying campaign directions and follow them closely.

The bush fruits must be given some attention. Do not expect fruit crops without some effort. Cultivate the ground about them and supply more plant food by the use of manure or commercial fertilizer. Use wood ashes, if available, around the currant rows.

The main portion of strawberries should be opened up from their winter cover sometime in March if the season is favorable. A slight mulch over the hedge-rows of strawberry plants will allow them to come through and form their spring flower clusters. This should be done as soon as all danger of frost is over, but not before. Leave the mulch about the plants until the crop is picked.

April.-Sometime this month you can raise your own strawberry plants by allowing some of the runners to take root in plunged pots. If attention is given to these, strong plants can be produced which can be set out and bear a crop next year. Surplus runners from strawberry plants should be taken off except where the young plants are desired. The more runners you cut the more crop you can pick from the older plants.

Watch for insect pests and diseases everywhere this month. Use the remedies suggested for each as early as you notice the trouble.

April may prove to be a dry month, and watoring the lawns, strawberries and bush fruits may be necessary. Flood the ground 
at night and let the water soak into the soil well. Extra seed and some nitrate of soda may be sown where the lawns are poor. Rake in the fertilizer and seeds to cover them with soil.

May.-Use the cultivator frequently about the bush fruits. As soon as any patch of strawberries is picked, remove the mulch, mow vines and take them to the compost heap. Then start the cultivator immediately.

This may be the best time for the thinning of fruits on such trees as the peach, apple, pear and plum. Leave only enough to make a good crop. Do not let the fruits touch each other. You will get larger and better fruit if you thin early.

Pinching off the small shoots may be advisable on the main limbs and trunks of peach, plum, and apple

June.-Continue the summer pruning work so as to direct the growth where it should continue. Keep the lawns well mowed, and do not let the grass form seed-heads. Cutting grass makes better sod. Water the grass well if the weather is dry.

Blackberries and raspberries may be about through bearing before this month is over. The raspberries should be cut back and the old canes removed as soon as picking is over. With the blackberries use a brush hook and cut the vines to the ground. Remove them with forks. If they have been attacked by rust or by borers the vines should be burned; otherwise they may go to the compost heap to rot.

July.-As soon as the bush fruits have been pruned they should be cultivated thoroughly. Keep up the clean culture until frost. This is good practice also for the strawberry patch.

Prune the hedges again to good form and cultivate the soil near them. If the growth is poor in places, feed with manure or commercial fertilizer.

If the grapes are in danger from attacks by poultry or birds the bunches may be bagged as soon as they begin to show any ripening color.

This may be the month for pruning the blackberries.

Go over all the shrubs and see if there are any dead or dying parts. Prune out the dead rose heads and give all a trimmed appearance.

This is the month for sowing winter cover crops in the orchard. Use crimson clover, vetch and rye so the growth will continue all winter and early in the spring. This will make a good supply of green manure for use in improving the soil the next year. 
August.-Watch the lawns elosely. This may be a hot, dry month and ruin the lawns. Give plenty of water. Keep the growth clipped close to prevent evaporation and improve the looks. If the ground is cracked badly, harrowing the surface may help it. Some nitrate of soda sown over the grass just before watering will stimulate the growth at this season.

This is a good time to plant strawberries. Strong plants should be secured by taking those which have been rooted in pots plunged near the parent plants, or the strongest plants may be dug from near the old plants. These should be set in the new bed and watered well. If they are made to grow enough this fall before frost comes they will bear a fairly good crop next season, saving practically a year's time.

September.-This should be one of the best months in the year for a beautiful show of the home grounds. Keep everything in trim, going over the shrubs, mowing the lawn and checking all attacks of fall web worm or other insects.

If it is still necessary to sow a cover crop among the bush fruits or in the orchard, use rye chiefly. Vetch will also start this late. It is now rather too late for crimson clover unless sown early in September.

October--Grass seed may be sown profitably early this month. As soon as fall rains begin grass seed should be started, so as to give as much time for growth as possible before winter.

Prepare fruits for the fall apple show if one is to be held in your community.

Evergreens may be transplanted this month. Put a good mulch over the soil after the planting is clone. The work must be clone carefully to a void exposure of the roots.

Much of the planting of shrubs and trees shculd be done this month. Fall is a good time for much of this work in the southern states. Look over the catalogs, and order trees and shrubs early. Begin the transplanting as soon as the leaves have fallen.

November.-Transplanting should be pushed in earnest. Whenever trees and shrubs are moved, prune the roots to remove broken or injured parts. Always prune the top to correspond to the pruning of the roots caused by digging.

You can begin the manuring and mulching of the bush fruits, the hedges, and the shrubs this month. Deep litters may cause damage by field mice. This ean be prevented" by tramping or rolling the mulch down occasionally until the ground freezes, or the work may be delayed until freezing time. 
The fall sodding of lawns and banks may be done this month The wet season of the winter will keep it moist until spring when growth will begin. Sod moved carefully before the ground freezes is almost sure to grow.

This is a good time to plant hardy roses including bushes and climbers.

December.-As soon as the ground freezes mulch the shrubs, trees and strawberry patches. Lawns should be dressed with a winter covering of half-rotted barnyard manure. This can remain until growth starts next spring. A little lime with the manure will help.

Try forcing some strawberries in the hot bed. Use thrifty, potted plants. Water them well and put them in a fresh hot bed for growth. The work is at least interesting if not profitable.

Late in December is a good time to spray for San José scale on those trees which are worst affected.

Pruning the orchard trees should be done this month if the weather is favorable. Select good days for the work and begin as soon as the leaves are off. If the pruning can be completed before the spraying begins it will make the work of spraying more effective and save expense.

\section{WORK BY MONTHS IN NORTHERN STATES}

January.-This is a good month for pruning trees, vines, and shrubs. Winter spraying may be commenced on bright days late in this month.

The strawberry bed should be well mulched, or if this were done in the fall, see that the wind has not opened the mulch and exposed the bed anywhere. Replace good litter on the bare spots and cover with boards or brush to keep it from blowing away.

If there are scions and stocks available, this is a good time for making root grafts of plums, pears, and apples. Scions may be taken from the trees at this season, and kept in wet sawdust in the cellar until used. Stocks may be purchased from large nurseries. Store the grafts when made, as you would the scions.

February.-Get catalogs of nursery trees and bush fruits. Select the varieties and make your order early for the spring shipment.

Fruit trees and bush fruits should be sprayed with lime-sulfur solution to control the San José scale. This will also destroy spores of disease lurking in the bark. Barnyard manure should be applied to the garden during the winter months.

All outdoor winter pruning should be completed this month. 
March.-As soon as the frost is out of the ground begin transplanting bush fruits and trees. The earlier this work is done the better.

Prune out the oldest canes of currants and gooseberries, but leave some that are three years old.

Spade or plow among the bush fruits as soon as the frost is out of the ground, if the soil is not too wet. Applications of manure should be made among the bush fruits before the first cultivation.

A heavy dressing of well-rotted manure may be applied to the lawn grass early this month to be raked off in April. This is also a good month in which to sow grass seed.

Spade around shade trees and apply some suitable manure or let that be spaded in.

April.-Look at the instructions for spraying and watch the development of fruit trees carefully. Try to spray at exactly the right time.

April should be the month for the heaviest planting. Trees and shrubs planted later than the last of April are less likely to thrive.

The first cultivation of orchard trees should be completed in April.

Set out root grafts made during the winter. This may be done at any time after the warm spring weather begins.

May.-Strawberry beds may be started early in May. If the old bed has a winter mulch, part it a little over the plants and let them come through. This should be done just after the latest killing frost of the region. If mulching was not done in the fall, apply a clean mulch of straw or other coarse litter around the plants to hold the berries off the ground, to serve as a mulch for holding moisture, and to keep down the weeds.

This is one of the most important months for spraying. If peach, apple, pear, and plum blossoms are beginning to shed their petals, begin to spray for the curculio and the codling moth. Look out for currant worms and other leaf eating insects. Tent caterpillars and similar enemies may begin their work early.

Estimate the rields of fruit and order the necessary boxes, baskets, crates, etc. (Fig. 242).

June. Treep the bush fruits and orchards free from weeds and keep the ground well mulched by cultivation.

Summer pruning may be done in June. Pinch off the shoots that start on the main limbs where you do not want them. Careful direction of the growth of trees is worth while. 
As soon as the strawberries are picked, mow down the vines and rake off the mulch and vines. This litter may be rotted in the compost heap to destroy insects and diseases.

Start the cultivator among the strawberry plants immediately after cleaning up. This should continue thrcughout the season until the ground freezes.

Early in June is usually the best time to give attention to the thinning of peaches, plums, pears, and apples. Remove fruits when quite small. Leave them far enough apart to avoid touching each other when full grown. (Fig. 243).

July.-The bush fruits should be pruned after picking is over. Prune back the heads and long canes of blackberries and raspberries.

This is a good time for propagating black raspberries by tip-layering.

If bearing trees have not had their crops thimned before this, do it early in July. Thinning pays well in improving the quality of the fruit.

The last cultivation of the orchard trees may be made late in July. Plant

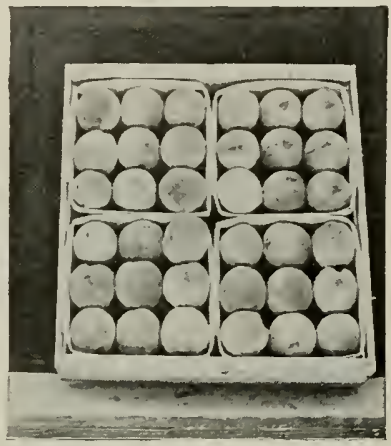

FIG, 242.-Paper-lined be r r y boxes sometimes used for marketing plums. a cover crop at this time consisting of rye, winter vetch, and perhaps some crimson clover if the climate is not too severe for it.

Remember to keep the runners well pruned from the strawberry plants unless you are practicing the matted-row system.

August.-Remember the currants, gooseberries, raspberries and blackberries. Give them all thorough cultivation during this month. They should be forced in their growth until the end of August. It will help next year's crop.

This is a good month in which to start a new strawberry bed. It is well to start a new bed every year as the old plants will not bear well more than two crops. Take the strongest plants started from runners near the old plants. Set these in new rows. Try the hedge-row system if you have never tried it before. See Chapter XX. Plants started in August should be ready to bear a light crop the next year. For this they must be forced to make a good growth the first fall.

Prune the privet hedge and all shrubs and give them good shape and let them strengthen the buds they are to form for next year's 
growth. Hips of roses and ripe seed of other flowering plants may be saved for future planting.

Evergreens can be fairly well transplanted in August if plenty of soil is taken with the roots. Slip a box with one end removed under the roots as you dig them. Take dirt and all to the new location.

September.-Stop cultivating the orchard by September first. No growth should be stimulated in the fall. The cover crop, if not planted in August, should be planted now. It will help check the fall growth, and will help save the nourishment in the soil for use of the trees next year. It will prevent washing of the soil and will form a carpet for the fall picking of fruit.

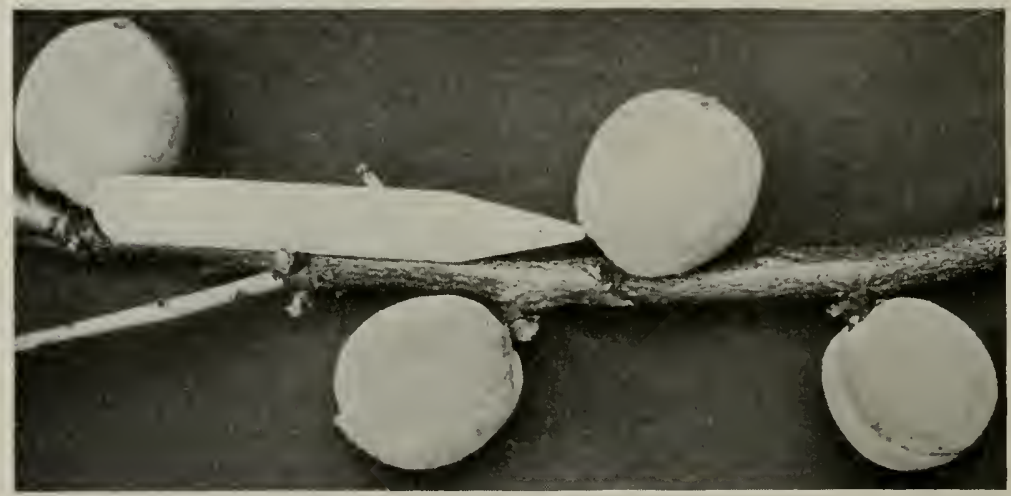

Fig. 243.-Thin peaches, apples and other large fruits to give then room and strength for growth. The fruits are enlough larger to pay for the work. (New Jersey Station.)

The bearing orchard should have the closest attention during the fall. All fruits that are ready for harvest should be taken from the trees by hand before they fall to the ground.

Order your trees and shrubs for fall planting. Those who get their orders in first have them filled with the best stock.

October.-It is well to mulch between the rows of raspberies, blackberries, currants, and gooseberries. Do this late in October after it is too late to stimulate growth this season. The mulch will protect the soil from packing, protect the roots from winter, and enrich the soil for the next year's growth.

If manure is not applied in the fall, sow a winter cover crop between the rows of bush fruits early in October or before.

If you have a cranberry "bog" clean it up now for winter. Pull 
out or mow off the rank growths of any sort. Get the dams and gates ready for flooding a little later.

Try to arouse interest in a fall apple show in your section. Much good may result from an exhibit of fruits.

Secure peach and plum pits for growth of stocks for next season. Do not put this off until the supplies are exhausted. Stratifying of these seeds may be postponed for a month or two.

As soon as the leaves have clropped from the fruit trees or bush fruits they may be transplanted with safety. If the winters are severe always apply a good mulch around fall-planted trees and bushes.

Ornamental shrubs of all kinds may as well be transplanted now as in the spring. This is the best time in the year for planting rhododendron, laurel, and other broad-leaved evergreens. If the old leaves are removed at planting time, new ones will form in the spring.

November.-All the bush fruits, such as blackberries, raspberries, currants and gooseberries, should be well manured in the fall. The strawberry bed should be covered entirely with several inches of straw mulch or similar material.

If you are planning any propagation of peaches, plums or cherries get the pits ready for the seedling stocks and put them in layers with sand this month, or as soon as freezing begins. This stratifying of the pits out of doors will allow them to become moist, freeze, and crack open ready for spring growth.

Strawberry beds may be mulched for winter late in November. It is well to let the ground freeze some before the mulch is spread over the plants. Use straw, marsh grass, leaves, corn stalks, pine needles or other cheap material that is free from weed seeds.

Continue planting fruit trees and bush fruits till the ground freezes. Fall planting will save time next spring when other duties are pressing.

December.-Orehard trees may be pruned in the fall as soon as the leaves are all off. The weather may be more agreeable in December than later in the winter. As pruning should always precede the spraying of orchard trees, the sooner the annual pruning is done the more time will we have for choosing good spraying weather.

Such broad-leaved evergreens as rhododendron and laurel should be given some winter protection. Shake straw or leaves among the plants and almost cover them with it. 
Just after the ground freezes, put a top dressing of "short" manure over all the lawn grass. If it is allowed to remain all winter the result will be gratifying next year.

\section{EXERCISES, PROJECTS AND FIELD STUDIES}

1. Pruning is good practice work for students. Prune fruit trees of as many types as possible. Also prune ormamental shrubs and vines.

2. Trips to neighboring orchards should be made from time to time, to study the bush fruit and orchard practices of different growers. 'Study the methods of spraying, pruning, cultivation, and fertilizing in use by each grower. Afterwards write up the plans and emphasize the good and bad points in the practices.

3. Projects in the care and management of an orchard of any type, carried on for a year or more, may require special attention to trials in different ways of cultivation, different amounts or kinds of fertilizer, methods of fighting borers, etc. The special problems assigned with the project should be in harmony with the particular needs of the orchard to be used. For example, if codling moth has been extremely bad, use all the known remedies and compare the results.

\section{QUESTIONS}

1. Give an outline of the year's work in the apple orchard.

2. Same in the peach or plum orchard.

3. Give a good plan for the year's cultivation of orchards.

4. Give a number of points regarding the pruning of apple trees; of peach trees.

5. Describe the spraying campaign in the apple orchard.

6 . Give the spraying campaign for stone fruits.

7. Give some suggestions for work in the orchard, berry patches, and lawns, for your region, by seasons: $a$, winter work; $b$, spring work; $c$, summer work; $d$, autumn work.

References.-U. S. Farmers' Bulletins: 181, Pruning; 440, Spraying Peaches for Brown Rot, Scab, and Curculio; 494, Lawns and Lawn Soils; 887, Raspberry Culture.

Productive Orcharding, Sears, J. B. Lippincott Company; Productive Small Fruit Culture, Sears, J. B. Lippincott Company; Beginners Guide to Fruit Growing, Waugh, Orange Judd Co. 


\section{CHAPTER XXVII \\ CONTROL OF WEEDS}

THE noxious weeds are of three main types. (1) Those which grow from seed each year and die in the winter; these are called annuals. Examples: purslain (Fig. 244), pig weed, rag weed, etc. (2) Those which grow continually year after year from the same underground parts, but may die to the ground each year; these are called perennial herbs. Examples: dock, Canada thistle, quack grass, Johnson grass, plantain (Fig. 245), dandelion, etc. (3) Those which grow one year from seeds and store nourishment in the underground parts and die to the ground the first winter. During the second growing season they make a rapid growth from the nourishment in the underground parts and produce flowers and seeds, after which they die completely the second winter, the only live part remaining being the seeds. These are called biennials. Examples: burdock, wild carrot, and many others.

Relation of Type to Methods of Control.-As annual weeds die each year it is not difficult to eradicate them. All that is necessary is to keep them from going to seed. In that case they will all be dead by winter. They spreal each year by seed, and if the seeds are allowed to form they will not be injured by winter. They will spread, and the weeds will become more numerous and more widely dispersed each year.

Annual weeds are usually found in cultivated fields where the seeds find a good seed bed for germination. Gardens are much more troubled with annual weeds than with perennials.

Perennials and biennials are more common along fence rows, road sides and in orchards or other places that are not regularly cultivated.

Such weeds store nourishment in the underground parts and live from year to year if their roots are not destroyed by tillage. The most successful way of destroying perennials is to plow and cultivate thoroughly. Nearly all perennials are easily destroyed by this method. There are a few with runners or rootstock that are difficult to cut with tillage implements; among them may be mentioned quack grass, Johnson grass (Fig. 246), Canada thistle and Bermuda grass. Weeds of the wild onion type which have 
bulbs that will grow in any position are also difficult to get rid of by a limited amount of tillage. 'Thorough and frequent cultivation however, will destroy weeds of this type.

Weed Dissemination.-All three classes of weeds bear seeds and are spread by this method for long distances. Weeds that form their seeds in burs, such as burdock, cockle bur, sand bur, bidens, Spanish needles and others are often carried on the coats of animals for long distances. They literally catch rides to their new homes.

Tickle grass, tumble weed, and a few others of that type spread by the whole body carrying seeds, rolling in the wind for miles and miles. Occasionally these are carried high in the air, but usually are found rolling on the ground. Many seeds, such as
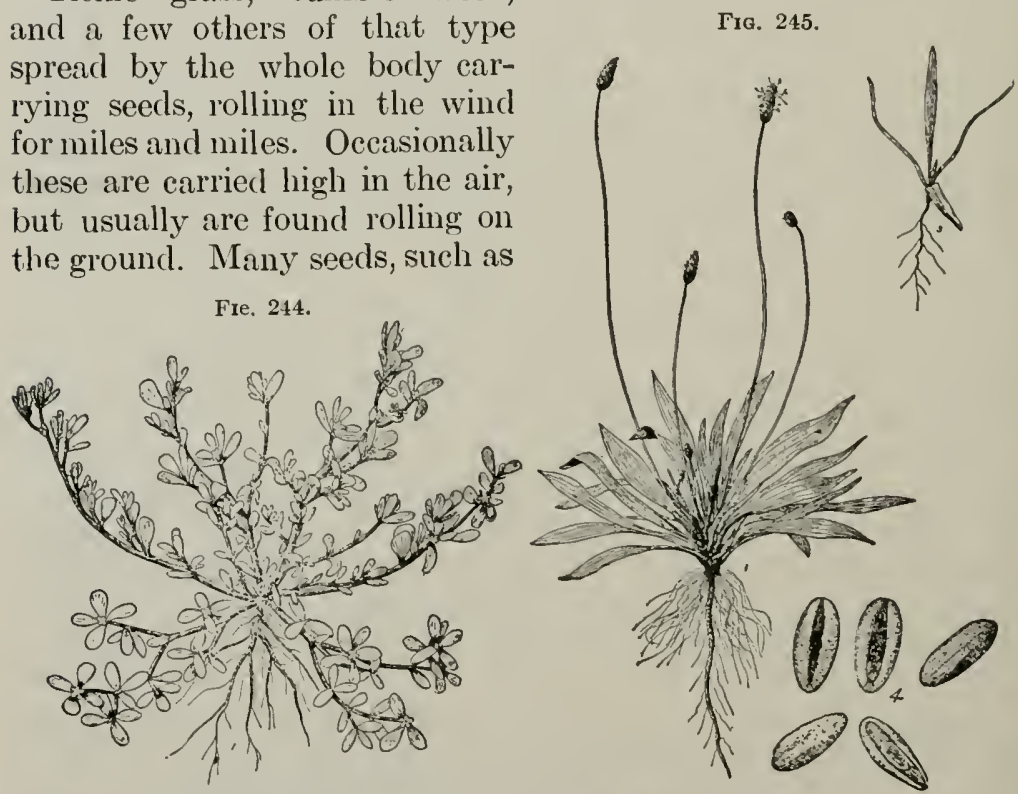

Fig. 244.-Purslane; entire plant. (Minnesota Station.)

FIG. 245.-Buckhorn Plantain; 1, entire plant; 3, seedling; 4, seed enlarged. (Minnesota Station.)

milkweed, dandelion, thistle and others may be carried by strong wind to distant places. Still others, such as the dock and wild carrot, may be blown somewhat by the wind and will also float upon water, where they are carried by either waves or currents to new fields.

Many perennial weeds have other means of spreading than by seeds. The underground stems, runners, etc., will spread weeds. Some of the worst grasses, Canada thistle, sheep sorrel, toad flax and many more are thus spread. Frequently such sceds are 
spread by means of tillage implements which merely transfer them from place to place. The more quack grass is cultivated the more it may be spread.

Principles of Weed Control.--It is important to study the life of a weed if you wish to eradicate it. Learn its habits and then you can control it. It is easy to cletect a weed that stores nourishment

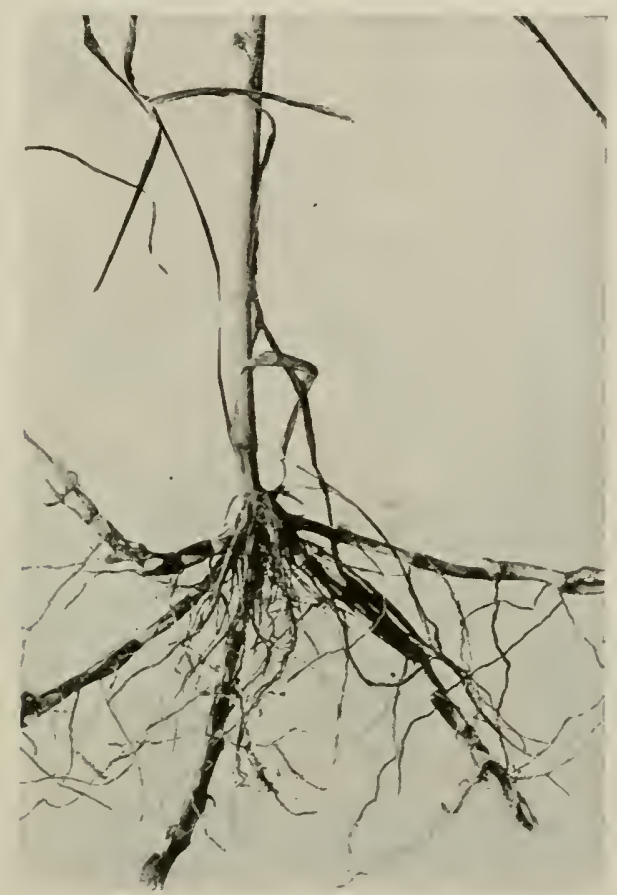

FIG 246. - Base of Johnson grass showing the joints on the underground stems or "roots," from which numerous grass stems arise. This makes it a serious weed.

in the underground parts. One can find the mass of stored material by pulling it up. Then you know it is not an annual.

If weeds have abundant rootstocks, as quack grass and Canada thistle, you cannot hope to find all of these numerous growths ramifying the soil. The control methods recommended in each case are to smother the plant.

Remember that plants cannot live if they do not have leaves exposed to the air during a part of the growing season. In chicken yards and pig pens where the leaves are continually eaten off the 
roots and underground stems are killed. Light and air are necessary for the successful growth of any chlorophyll-bearing plants, whether they are weeds or not.

Smothering plants by means of tar paper, covers of manure, straw or even with the growth of crops which over-shadow them are methods resorted to in special cases. For example, such weeds as persistent as Bermuda grass are sometimes killed by the growth

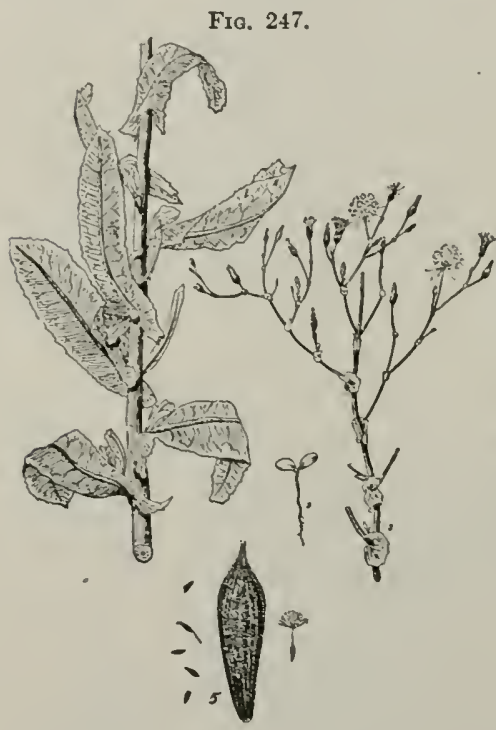

Fra. 248.

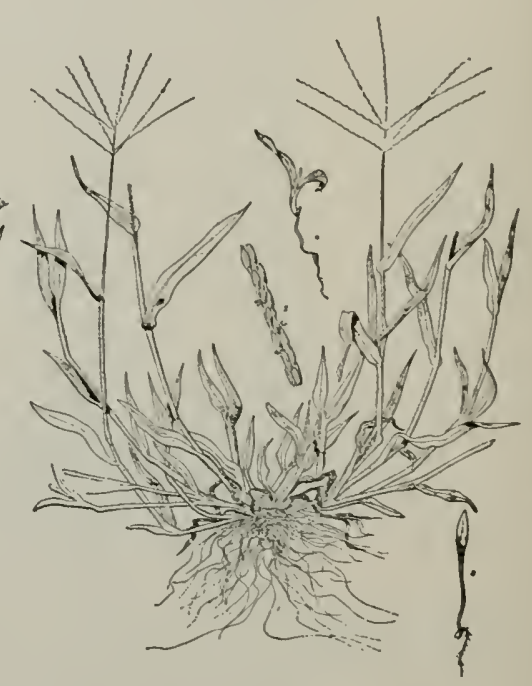

Frg. 247,-Prickly Lettuce; 1 , section of plant showing leaf arrangement; 2, tog of plant; 3 , seedling; 5 , seed natural size and enlarged. (Minnesota Station.)

Frg. 248.-Crab Grass. 1, Entire plant; 2, enlarged flower spike; 3, seedling; 4, seedling somewhat older. (Mlinnesota Station.)

of a smothering crop such as alfalfa, millet or wheat. The smother crop must be seeded densely to accomplish this end.

Seed Laboratories to Control Weeds.--Seed laboratories have been established in nearly all the states for the control of the weed nuisance. Regulations and laws are published which fix the standard for purity of seeds sold in the state, as well as standard for germination. Samples are examined in the laboratories and bad lots of seed are condemned.

Farmers and gardeners are able to choose seeds which have been tested for both purity and gemination. Too often the sower 
is the chief cause for the spread of weed seeds. Much care must be exercised to prevent spreading weeds.

Losses from Weeds. - There are several sources of loss due to weed growth. (1) They rob the crop of the plant food which it needs; (2) they use the moisture which the crop should use; (3) they crowd and strangle the crop; (4) they often poison soils and make them unsuitable for the crops.

FIG. 249

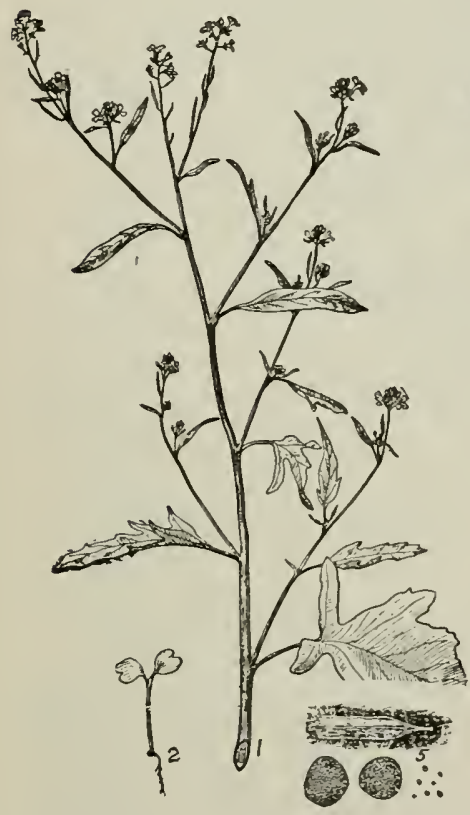

FIG. 250,

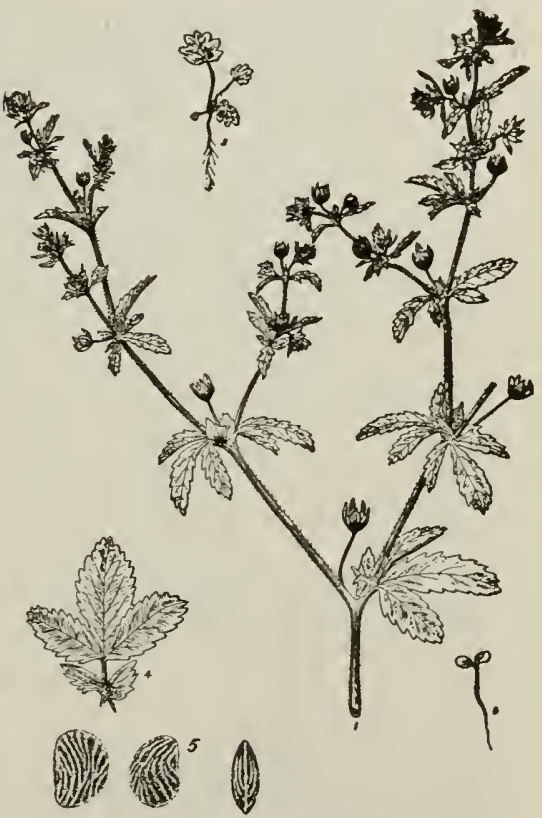

Fig. 249.-Black Mustard: 1, top of plant; 2, seedling; 5, seed small and enlarged. (Minnesota Station.)

FIG. 250.-Five-Finger; 1, top of plant; 2, seedling; 3 , seedling somewhat older; 4 , separate leaf; 5 , seed enlarged. (Minnesota Station.)

It may be said that weeds are beneficial in some respects. They cause the owner to till the soil when otherwise he might neglect it. Some are good for feeding pigs or other stock, prickly lettuce (Fig. 247), pig weeds and others are relished by swine.

Weeds and Grasses in Orchards. - It has already been shown in this volume that orchards should have a cover crop started about the middle of July or first of August. The purpose of this is to check the wood growth of the trees and cause them to ripen there 
wood and buds ready for winter. Weeds and grasses will appear in the orchard soon after tillage stops. Crab grass is often very persistent and will spring up quickly after cultivation ceases (Fig. 248). If the owner does not sow a cover crop at this time weeds will, to

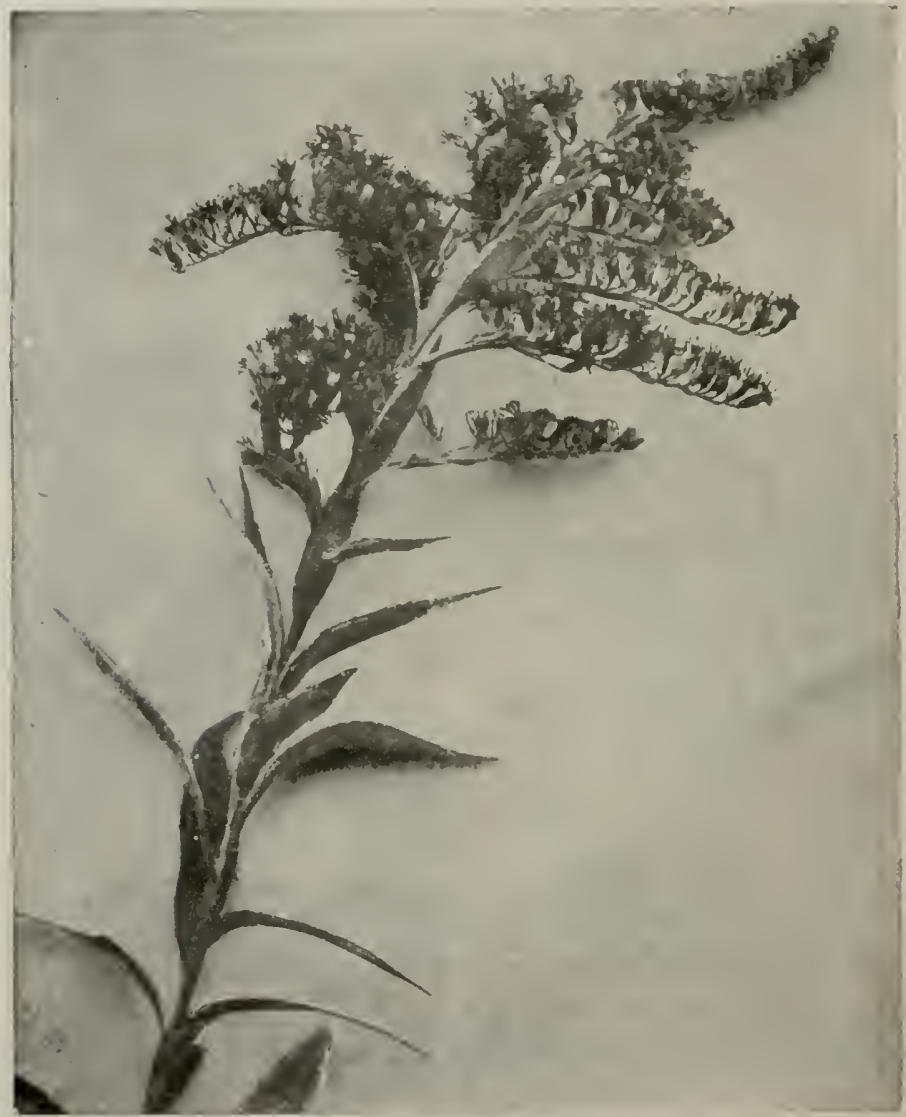

FIG. 251.-Golden rod is often abundant along fences, roads, and in pastures. It is a perennial weed easily controlled by rotation of crops.

some extent, form a natural cover crop. The growth of the weeds will fulfill a number of the benefits of the cover crop which the owner should have sown. However, most of them do not persist through the winter, as a winter crop should do. WVeeds which start in midsummer are likely to prove to be amnuals which are 
killed by_winter. Crab grass (Fig. 248), tumble grass, and similar annual grasses are of little benefit as winter cover crops. The orchardist should not excuse himself from sowing a good winter cover crop by thinking that the weeds will do as well. The amount of plant food collected by the growth of orchard weeds will not form a very valuable green manure crop the next spring. It is

FIG. 252

FIG. 253.
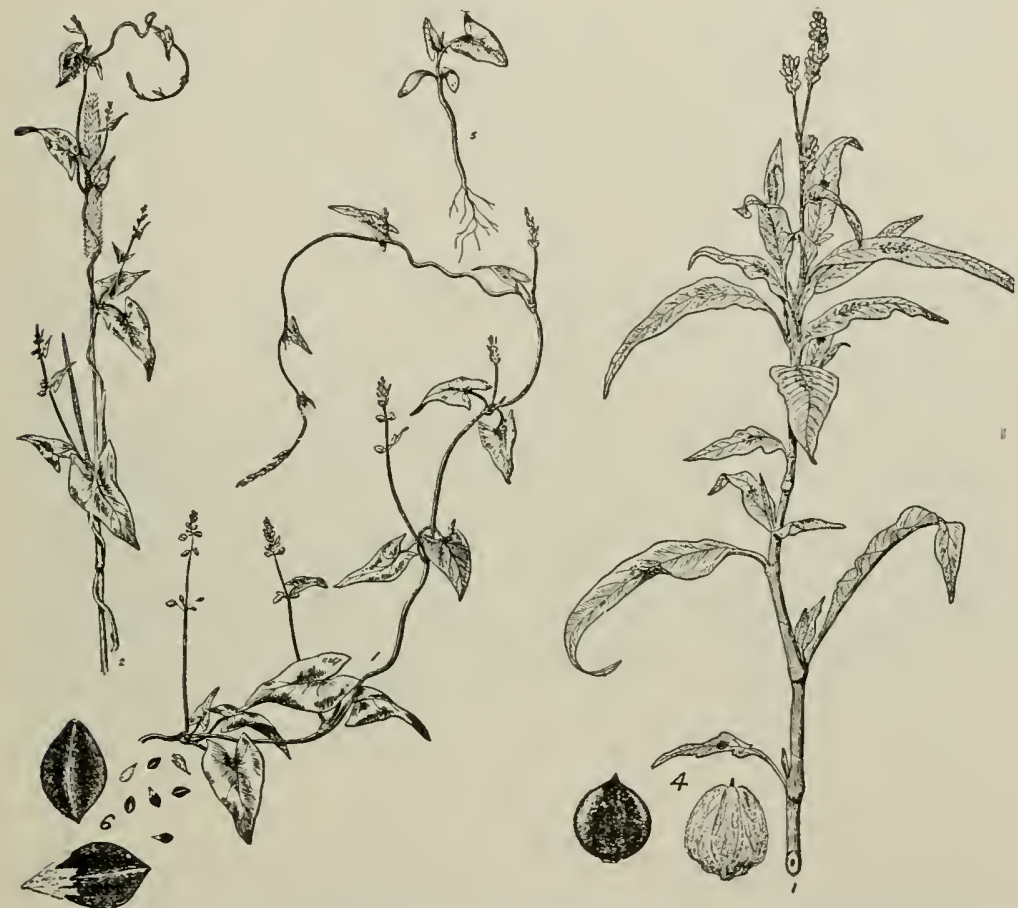

FIG, 252,-Wild Buckwheat; 1, entire plant; 2, plant winding around a stalk of timothy; 5 , scedling somewhat older; 6 , seed small and enlarged. (Minnesota Station.)

Fig. 253.-Pennsylvania Smartweed; 1 , top of plant; 4, seed enlarged. (MIinnesota Station.)

far better to sow a crop of winter grain mixed with some winter legume, such as vetch or perhaps crimson clover, which will make a green carpet over the soil for pruning and spraying work of the winter season. A cover crop which grows through the winter and early spring will prevent leaching away of much plant food. It will also prevent erosion. Best of all, it will form a valuable manure crop when turned under the following spring. 
Escaped Weeds.-Some plants are grown for human food or for stock feed and are allowed to escape from cultivation. 'The black mustard (Fig. 249) and the dandelion are familiar examples of this class of weeds. The bulbous buttercup and others with beautiful flowers have escaped from gardens in the Old World and in America. Five-finger (Fig. 250) is perlaps a weed of this character.

\section{EXERCISES, PROJECTS, AND FIELD STUDIES}

1. Identifying weeds of different kinds is best done in orchards, gardens, ete., where live specimens are seen in their growing eonditions. Not only learn names of the different kinds, but also the group as to length of life. Learn their methods of spreading seeds, study root systems, and decide whether they are ealled "noxious" or not. Also learn to know the weeds of fence rows, such as asters and golden rods.

2. Weed collections may be made to press, dry, and mount for future reference in each home and at school. Be sure to collect all the weeds shown in the figures of this ehapter and many others of your region.

3. Weed seeds should be collected in envelopes and bottles. Each kind should be labelled. These will aid in identifying bad weed seeds mixed with garden and farm seeds.

4. The worst weeds, such as wild onion, quack grass, Johnson grass, and Canada thistle, should be studied earefully. 'Their methods of spreading under ground and their storage of food, should be learned well.

5. Special methods of fighting these should be tried in a number of places. Special methods may sometimes include using salt, smothering, frequent tillage, plowing at stated seasons, use of hogs, close grazing by sheep, mowing, burning, oiling, speeial ehemieals.

6. The fighting of noxious weeds may be assigned as a special feature of eertain produetive projects in gardens and orchards.

7. Efforts of Neighbors. - On various neighboring places study the efforts to eradieate weeds by rotations, plowing, cultivation, ete.

8. Group of Weeds. - Study weeds by groups as (1) the bad grasses, (2) the joint-weed group (Figs. 252 and 253), (3) the pig weed group, (4) the sinflower group. Relationships will be seen by notieing the similarity of nembers of the same group.

\section{QUESTIONS}

1. Mention the three classes of weeds. Give examples of each which you know at sight.

2. What relation has the type to methods of control?

3 . What are some of the notable methods of weed dissemination?

4. What methods of dissemination of weed seeds have you observed?

5 . What are some of the prineiples of weed control?

6. Enumerate the chief kinds of losses from weeds.

7. Discuss the presence of weeds and grasses in orchards.

References.-U. S. Farmers' Bulletins: 279, Eradicating Johnson Grass: 610, Wild Onion; 660, Weeds. R. I. Exp. Station Bulletin 133, Woeds, their Eridication and Control.

Manual of Weeds, Georgia, Macmillan Company; Weeds of liarm and Garden, Pammel, Orange Judd Co. 


\section{CHAPTER XXVIII \\ THE HOME WOOD LOT}

THE farm home is not complete without a wood lot or shelter belt of trees (Fig. 254). Homes in the prairie states, as well as those in the naturally wooded regions, should have a block of trees permanently growing for the shelter and products which it yields. The densely populated countries of the Old World find the principles of forestry worth following in the maintenance of wood lots. Wood products are so valuable that we ought not to continually

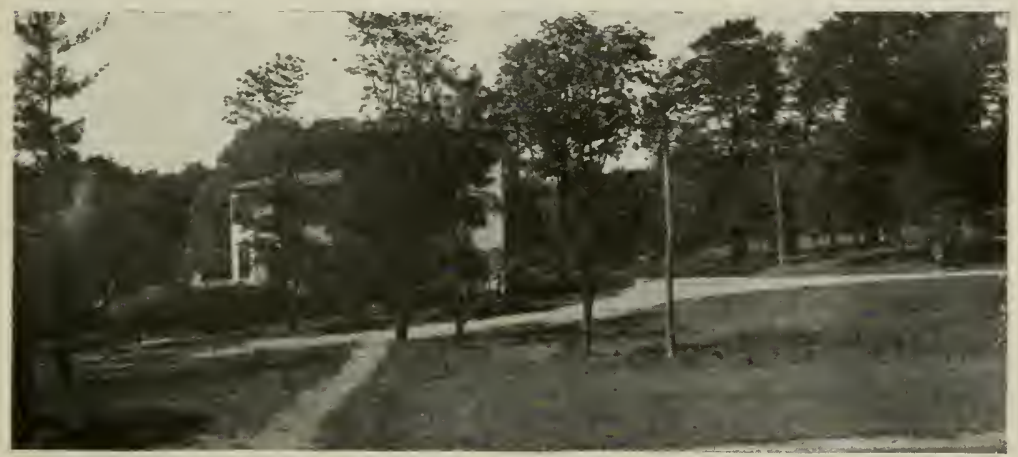

FIG. 254.-Trees, vines and shrubs not only add to the beauty of the farm home but the shade insures comfort to people and livestock.

neglect their production and ruthlessly destroy our native forests without doing something to conserve and replenish the products which we need so much.

Products of the Wood Lot.-Wood lots in general yield many products valuable on the farm, in the manufactures and in commerce. The following products have been enumerated: Nuts and fruits, sugar and syrup (Fig. 255), quinine, salicin, oils of sassafras, eucalyptus, beechnut and olive, matches, tooth picks, clothes pins, pencils, penholders, handles, baskets, shoe pegs, wooden dishes, wood alcohol, acetates, wood tar, potash, turpentine, resin, creosote, pitch, cork, tannic acid, charcoal, spruce gum, lamp black, excelsior, lumber, posts, poles, ties, fuel, and pulp. 
The Farmer's Needs.-From the farmer's own point of view it is worth while to have a rood lot. His home fuel supply is needed, wood for poles, posts, rails and other articles is also needed. This surely is enough to warrant his keeping a good wood lot perpetually on his place.

Location and Soils.-If possible, the wood lot should be made to occupy a place not valuable for other crops. A hill side too steep for cultivated crops may be used. A stony field where tillage imple-

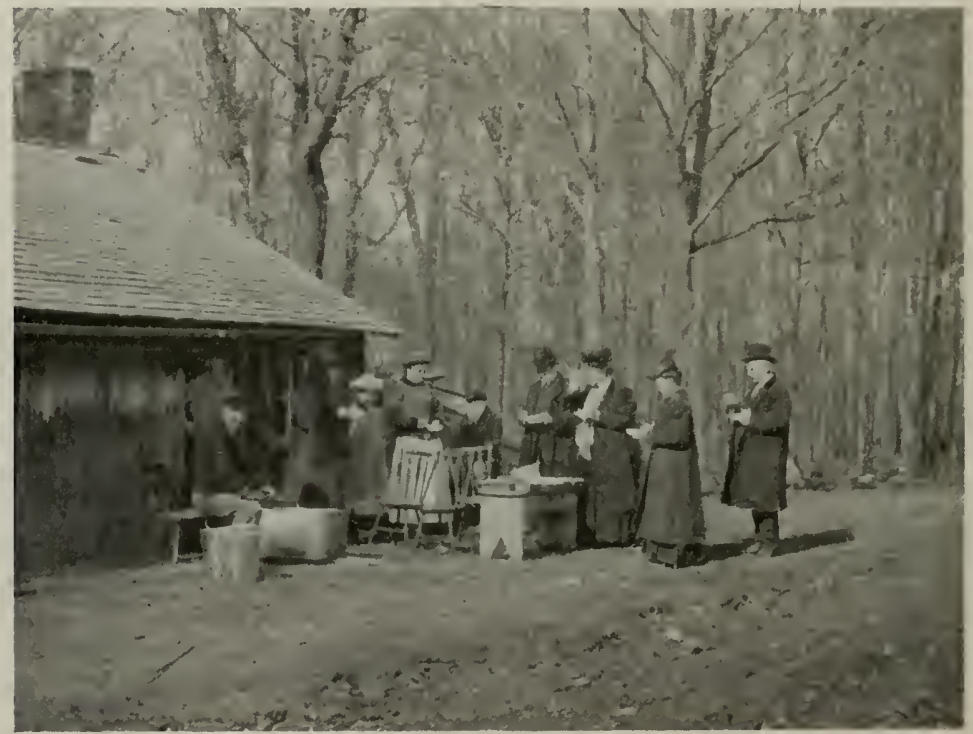

FIG. 255.-The home wood lot of maples may furnish a supply of sugar and syrup.

ments cannot be used will grow forest trees (Fig. 256). Low, wet lands flooded during the wet season may be made to grow those those kinds of trees which endure such conditions. Denuded hill sides (Fig. 257), or gullied old-fields may be planted to locusts and other trees which will thrive there.

Many hill sides and worthless lands have been cleared of native woods with no excuse whatever. The owner merely robbed Nature of her timber wood supply, without trees with which to reforest the place.

Wind Breaks and Shelter Belts.-The Midclle West, including 


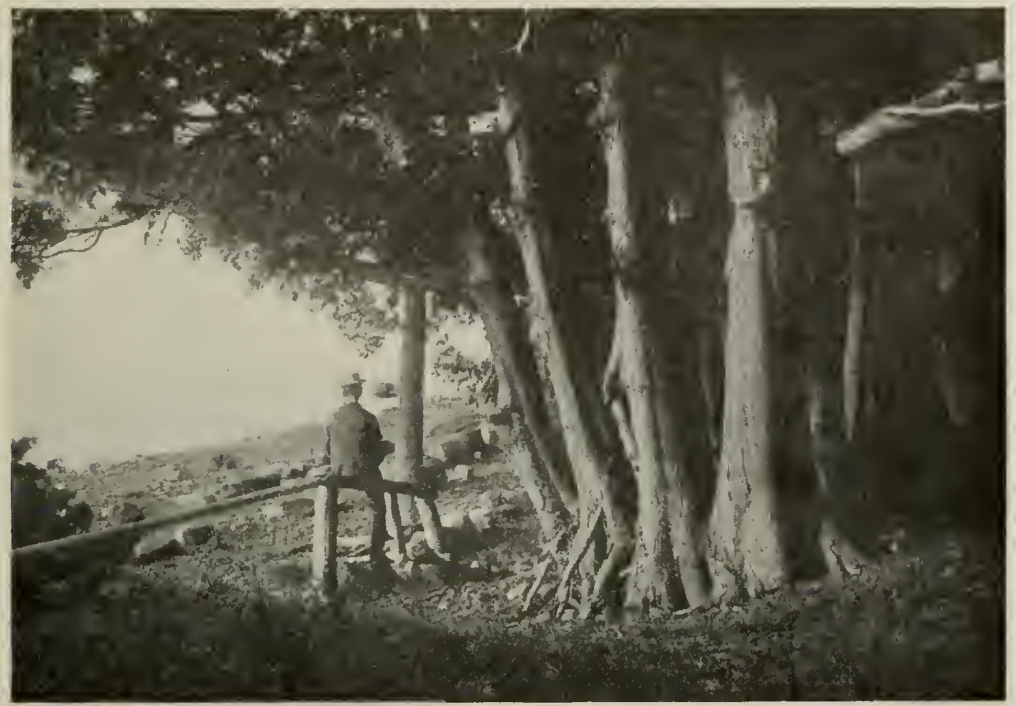

FiG. 256.-Why not let the entire rocky areas of the farm grow dense crops of timber? (Photo by Waugh.)
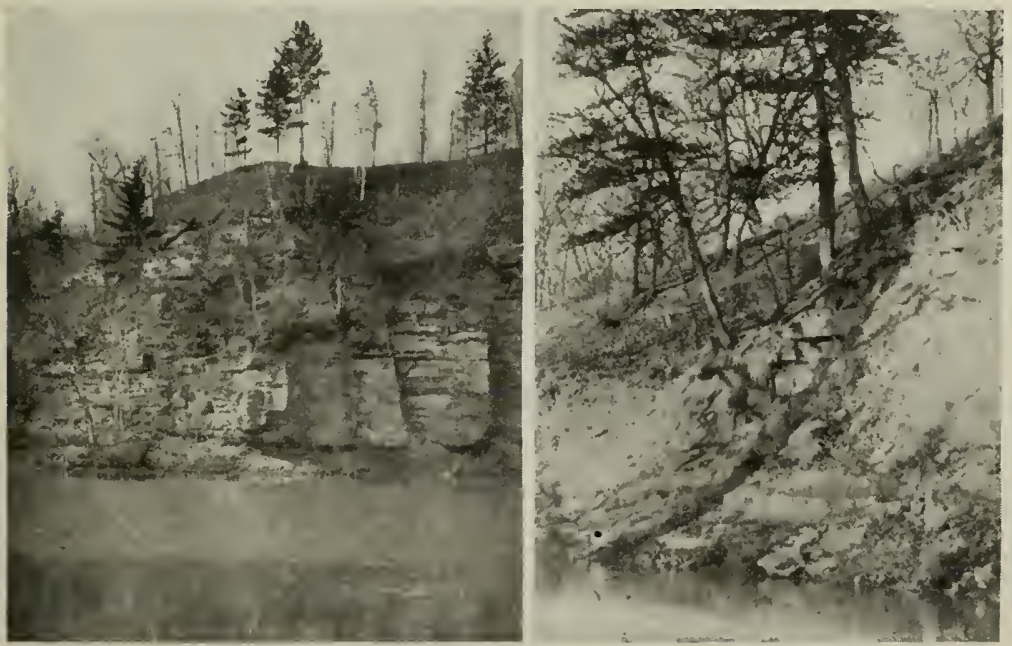

Fig. 257.-1'he rugged banks of streams may well be used for the growth of posts, ties, fuel, etc. (Photos by Waugh.) 
the prairie states would be greatly inproved by having a number of wind breaks and wide shelter belts on every farm. A shelter belt differ's from a wind break in the width of the area planterl. Thereare objections to growing trees near productive fields because of plant food 'which the trees take from the soil near the crops. A

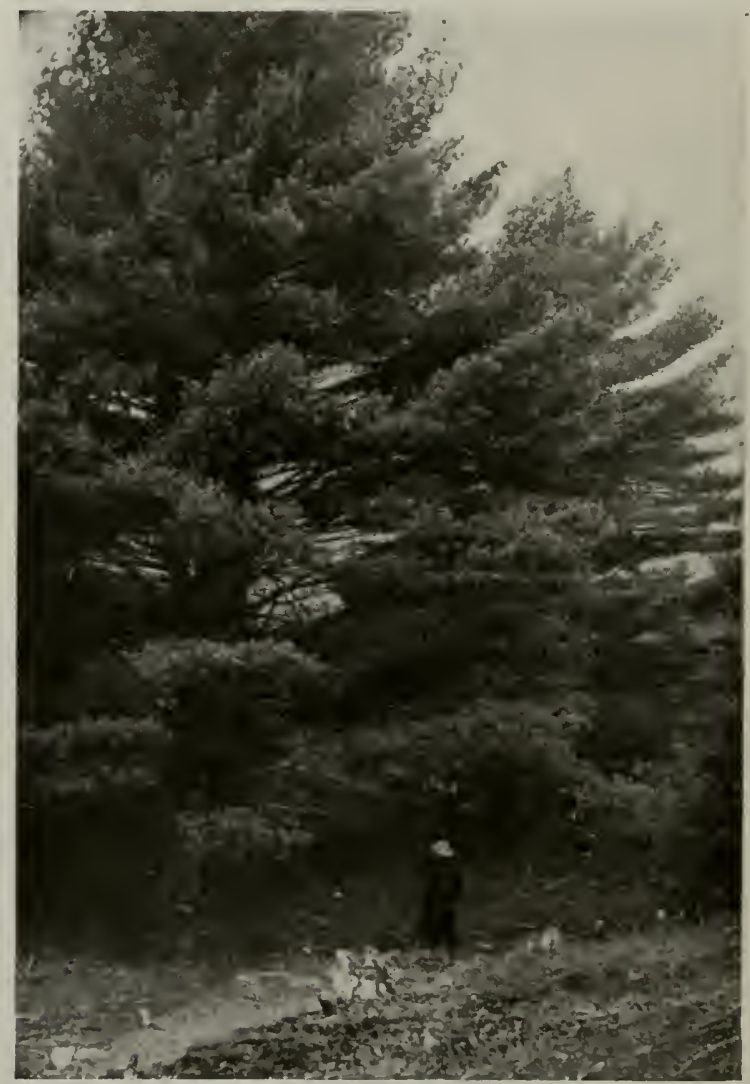

Fig. 258. - White pines make rapid growth of wood valuable for lumber. Thev must be grown in dense plantations for best results. (Photo by Waugh.)

shelter belt will do no more damage to the adjoining field than the narrow wind break, and will on the other hand produce far more timber products in proportion to the amount of land used.

The timber grown on a wide shelter belt is of better quality than 
that grown in a narrow wind break. Trees grown in wide plantations will grow straight, and have fewer knots than those having open ground on both sides. Compare the trees in figures 258 and 259 as to number of limbs and timber knots. The denser the trees are grown the taller and straighter will be the timber, and the freedom from knots and side limbs is remarkable.

Shelter belts should be planted with trees that are suited to the region. In the Middle West walnuts, hickories, elms and other hardwoods are usually thrifty and successful (Fig. 260). The

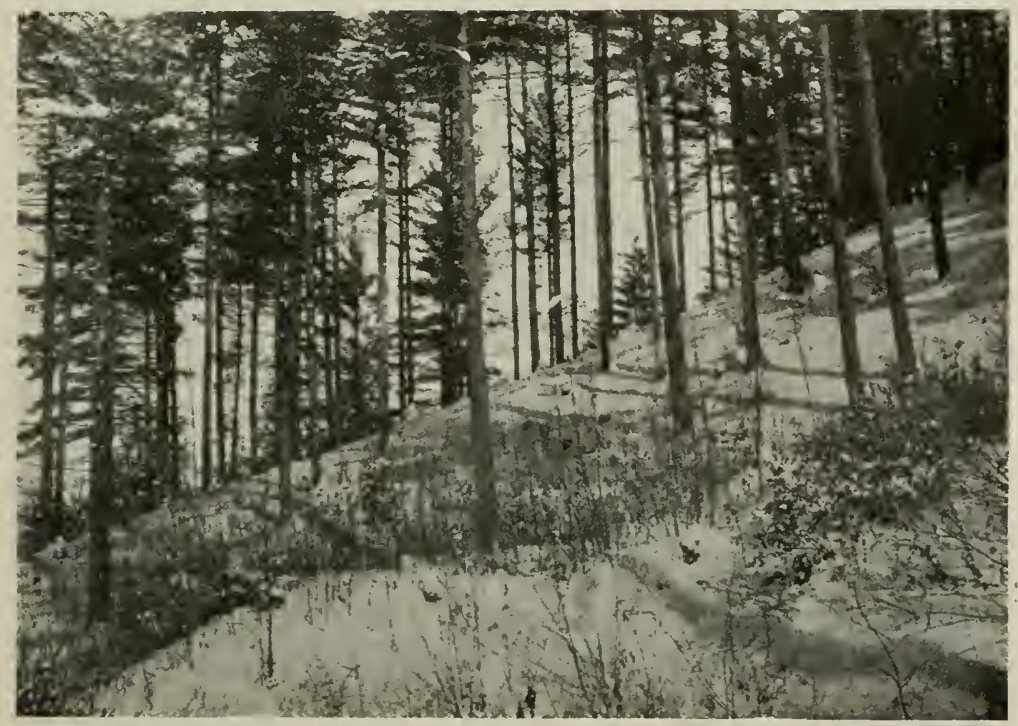

FIG. 259.-Spruce, cedar and pine will grow well on rocky hill sides. (Photo by Waugh.)

cone-bearing trees, such as pines, hemlocks, and spruces would not endure the dry seasons of much of the western prairie region. Select those trees which you find by the experience of others have proved themselves suitable to your section.

The width of the shelter belt may be made to suit the desires and conditions of the owner. Plant the trees about six to eight feet apart each way and ningle the varieties rather than plant all one kind in solid blocks.

How to Get the Trees for Planting.-Forest nurseries are maintained in nearly all states. When very young the trees may be 
bought by the thousand at nominal prices. Owners may also grow their own trees by buying or gathering seeds and planting them in nursery rows and giving proper attention and tillage.

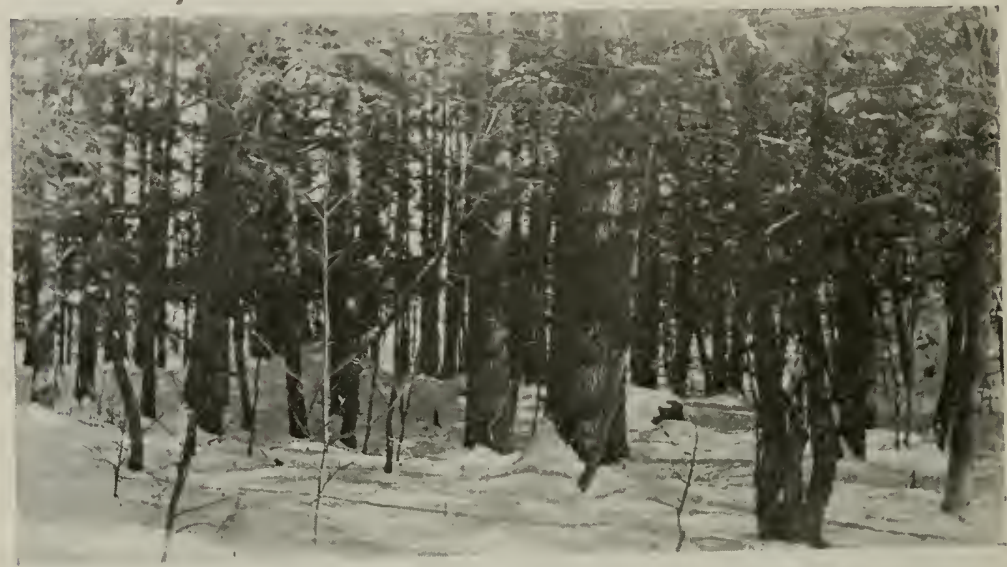

FIG. 260.-A mixture of hardwood and evergreens is most successful in the farm woodlot. (Indian Rock Farm.)

Some kinds are much more thrifty than others, while young, and these are best for home growth. Hardy catalpa may be grown

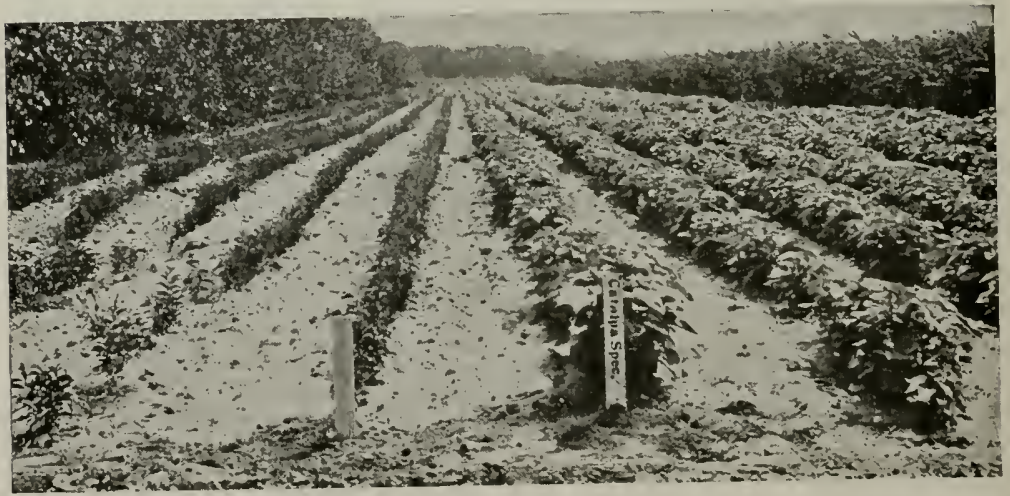

Fio. 261.- Seeds of catalpa and many other trees may be drilled in rows so that the young trees may be eultivated for a year before transplanting to the wood lot or shelter belt.

from seeds in rows to be cultivated with horse cultivators (Fig. 261). They are large enough in a few weeks after germination to allow of thorough cultivation. 
Planting and Care.-When the trees are transplanted to the shelter belt it is well to plant them in some wholesale way after the ground has been thoroughly prepared. Do not expect the trees to thrive if smothered by grass, weeds or other wild growth. It is better to give the plantation thorough tillage for a year or two. Plant inter-crops, such as potatoes, cabbage or any crop which requires thorough cultivation. They help pay for the work and will induce the owner to cultivate the trees. Damage from tillage instruments must be guarded against.

After the trees are large enough to reasonably fill the ground tillage and the growth of inter-crops may cease. Nature will usually do her own pruning. As the trees become crowded the side limbs will drop off, except at the top. There is no objection to pruning off the lower limbs in places where they become large and would tend to form large knots in the timber. The prunings should be gathered and used for fuel. Never allow them to rot on the ground. They would encourage attacks of bark beetles and other forest insects which first begin in dead twigs and then spread to the live trees.

Scientific Harvesting.-The modern principles of forestry teach scientific harvesting (Fig. 262). This means that the products from the wood lot or shelter belt may be secured without injuring it or in any way destroying the future growth of products in the plantation. A number of principles of forestry should here be considered.

1. Cut trees only when they are mature. Those which are still giowing rapidly and increasing their wood from year to year should not be harvested.

2. In cutting trees make them fall in such a way as not to injure undergrowth or to ruin the saplings near by. This may require more effort on the part of the woodsman, than careless falling of trees. They may need to resort to the use of pulleys and ropes to remove some of the top before the tree falls. This, however, is not always necessary.

3. Use all parts of the fallen trees, not leaving anything which can be of use to man. Too often we find this rule violated. Not more than half the product of native woods has been used; the remainder has been lost or worse than lost; it has even been left to decay and caused the breeding of millions of forest insects that have afterward attacked the live trees and destroyed millions of feet of lumber. 
4. When harvesting whole blocks or sections that have been started at about thesame time and arematuring somewhat together always leave enough seed-bearing trees to roforest the area. Siperimens for this purpose may be selected that are less valuable for lumber or other purposes and will bear an abundant supply of seeds for reforestation.

5. Growth from stumps, called coppice growth, should be used

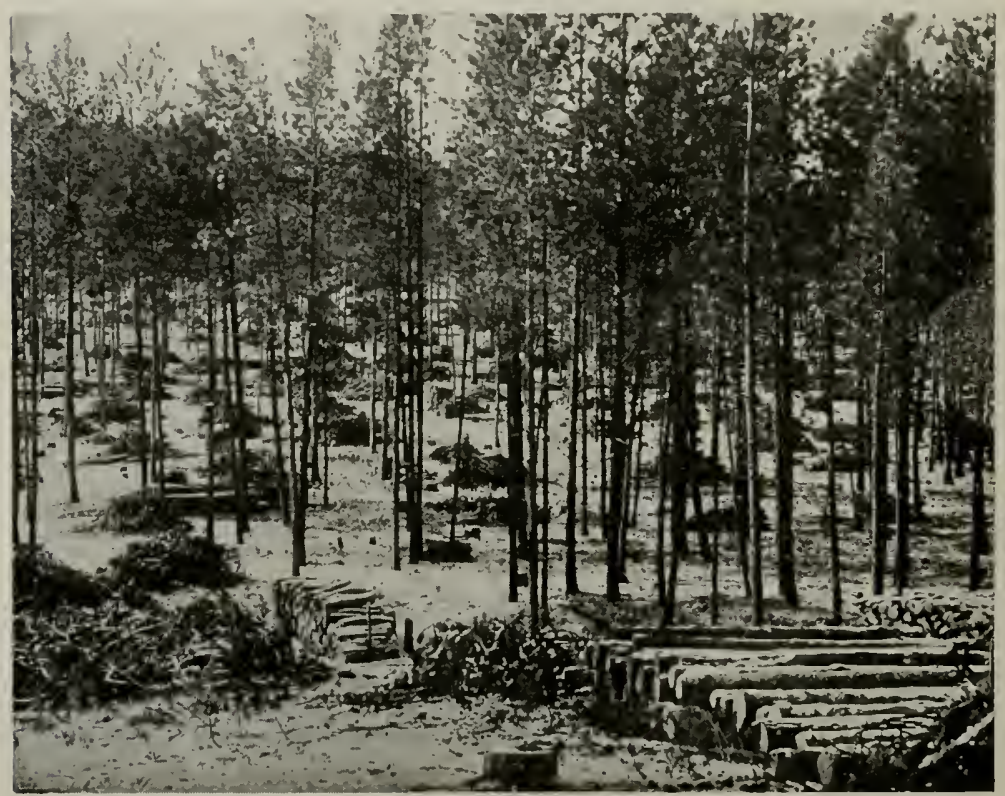

Frc. 262.-Careful harvesting of the wood crop will make the wood lot permanent. (U.S.D.A.)

as far as possible to reforest the area. Clean out the growth not desired.

6. Remove dead and injured trees regardless of their size to help control forest insects.

7. Prevent forest fires by never allowing fires to be kindled in them, by plowing, by burning back-fire strips around the forest, by keeping the brush well cleaned up, by watching constantly during dry seasons, and by posting up notices to warn all campers and hunters against starting fires. Replant all areas that have been swept by fire or by sevore storms. 
Profits from Forests on Poor Land.-- Mention has already been made of the kinds of places most suited for forest planting. Wo woukl scarcely expect a famer to plant a very large area with forest trees unless the land were unsuited to agricultural purposes. Of course, where the trees produce a shelter belt, more valuable land may be used because the belt will be placed where it will shelter the farm buildings and the farmstead in general.

The income from poor land (Figs. 263) may be greatly increased by its use for growing forest products. The growth of catalpa wood, or walnut and locust posts, chestnut poles and other valuable products, are well worth considering as a resource of the farm.

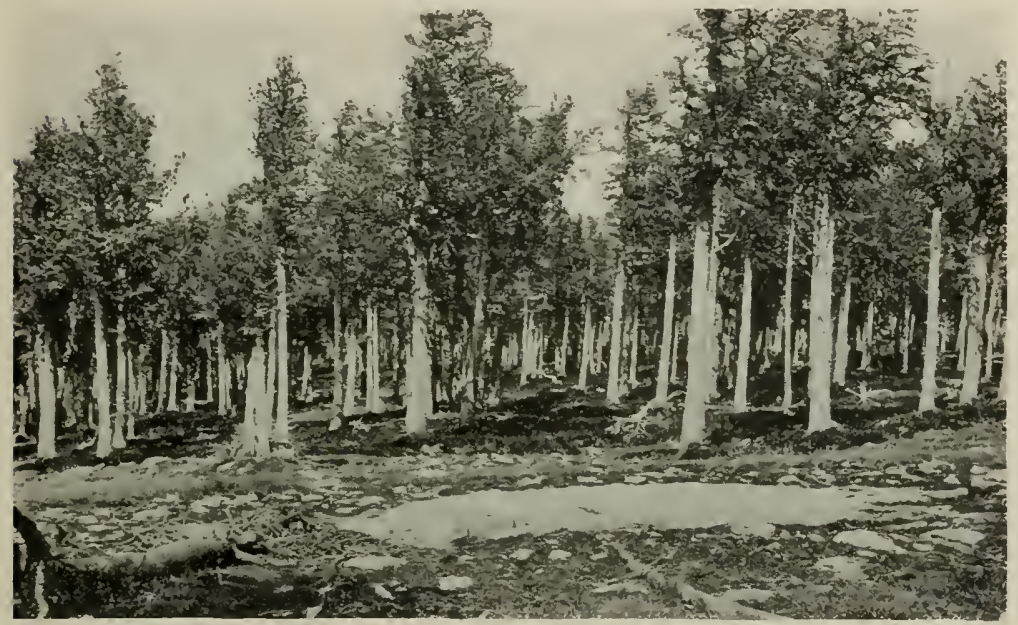

FIG. 263.-Rocky places should be used for growth of forest trees. The Lyall Larch here shown has very shallow roots. (Montana Station.)

The profits are slow in being realized, but when the yield begins the annual income may be calculated by dividing it by the number of years required to produce it. After the harvest begins an annual income may be produced. The present price of railroad ties, fence posts, telephone poles and logs for lumbering warrant the use of poor lands for their production.

Relief from Taxation.--The laws of several states are such that lands devoted to scientific forestry are relieved from taxation for a period of years. Reports may be made to the assessors and the areas may then be relieved of taxes, perhaps long enough to grow a crop of posts, poles, ties or saw timber. 
Benefits to the State.-The reason for these laws is that the state is benefited in a number of ways.

The forest carpet of twigs, leaves, ete., prevents the rapid run-off of water and thus springs and streams are kept constantly supplied from the rainfall of such forested areas (Fig. 264). Where forests have been cut off strems frequently go dry during the summer. The water power of mills and factories is thus weakened or exhausted. The water supply of homes, villages and cities is often reduced to the danger point. Large streams which should be navigable the year round are too low in dry weather, and too high in wet weather.

Forests often break or interrupt heavy winds and thus prevent

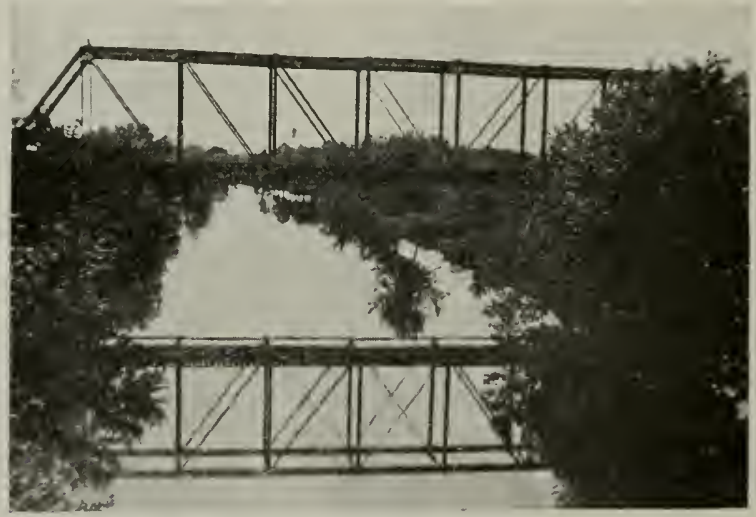

FIG. 264.-Where streams are bordered by trees and the fields covered with grass or other protection the water is elear and soil is not being eroded.

serious damage to property. The drying out of soil is prevented by the mulch of leaves and twigs, and the soil is not badly beaten down by heavy rains. The flow-off from such areas is very gradual and freshets are prevented.

The temperature of the soil is controlled and somewhat equalized by forest growths. At night and during cold snaps trees retard the loss of heat from the ground under them. The shade of the trees also prevents the intense heat of mid-clay.

Wind breaks tend to conserve the water in the area near them. Of course the trees take considerable water in the soil reached by their roots, but the breaking of the wind saves soil water in wide strips on the lee of the trees. 


\section{PROJECTS, EXERCISES, AND FIELD STUDIES}

1. A forest nursery project should include (1) preparation of soil, (2) planting of seeds or setting of plants from seed bed, (3) cultivation, (4) digging, sorting, counting, bunching, (5) sale or transplanting to wood lot. Keep records of expenses, varieties, numbers, sales, ete.

2. Starting a wood lot or slielter belt may be a home project. It should include (1) planning, (2) selection of site, (3) preparation of ground for the young trees, (4) setting the trees, (5) inter-cropping if possible, (6) all care for at least one growing season.

3. Collections of wood and forest seeds should be made for homes and for schools. Mount woods to show cross-sections and longitudinal views of the grain. Also show the polished and varnished surfaces of those that are suitable for this. Samples of bark may be placed with each. Seeds may be placed in bottles and labelled.

4. Forest products of other kinds may be assembled. Include as many as possible of those mentioned in this chapter.

5. Wood products of many kinds may be assembled for special exhibits.

6. Study of gullying should be made on a field trip. At the same time note the influence of tree growth in holding soil and preventing floods from starting gullies.

7. Streams, wells and springs should be studied in both wet and dry seasons. If possible take the actual rate of flow at each season, and note the influence of wooded areas on these flows in different localities.

$\mathrm{S}$. The forest carpet and the amount and source of leaf-mold should be examined in several places. Compare these in young and old woods.

9. Effects of Forest Carpet.-Tilt a small table at an angle of about thirty degrees. Place on this a large sheet of blotting paper. At the upper side slowly pour a glass of water on the blotter. Note the time required for water to flow to the lower edge of table. Now remove the blotter and repeat the trial on the bare table. How does the experiment show the effects of a forest carpet? How does a forest prevent serious floods?

10. Learn to know the trees of the region in both summer and winter conditions. The trees with deep tap roots, and those with shallow roots may be listed.

\section{QUESTIONS}

1. What can you say of the need of a wood lot for each farm?

2. What are the chief products of the woods in your region?

3. Describe some good locations for the farm wood lot.

4. What is the need for wind breaks and shelter belts in prairie states?

5. Suggest ways of obtaining trees for planting.

6. What care will the young plantation require?

7. Give important points in scientific harvesting.

8. Discuss the profits from forests on poor land.

9. How do forests influence floods, wells, springs, streams, and drouth?

10. What observations have you made along these lines?

References.-U. S. Farmers' Bulletins: 516, Production of Maple Syrup and Sugar; 700, Peean Culture; 711, Care and Improvement of Wood Lot;715, Measuring and Marketing Wood lot Products; 745, Waste Land and Wasted Land on Farms; 788, Windbreak as an Asset; 843, Important Pecan Insects and Control. 


\section{CIAPTER XXIX}

\section{BEAUTIFYING HOME GROUNDS}

Too often the country home gives the appearance of neglect. Some owners seem to think that a well kept place is only for city people. On the other hand, the country home should be beautified. Improvements should be made by planting of shrubs, shade trees, care of lawns, painting buildings, using vines to cover unsightly objects, laying out of walks and roads, surfacing these with good wearing material, terracing slopes, proviiding proper drains where wilter washes, ete.

Educational Value of Beautifying.-C 'hildren need to be trained in the sense of appreciation of the beautiful. If they are surrounderl by unsightly objects they are unconsciously trained to like such things. If, however, they are surrounded by beautiful grounds and their attention is called to the beauties of flowers, shrubs and trees, they will always love them and wish to have them on their own premises. Compare figures 265 and 266.

Financial Benefits.-The financial argument is one which usually strikes the farmer most forcibly. His place may be enhanced in value by the use of paint, and growing trees, shrubs and flowers. A well kept farmstead will attract buyers, and cause neighbors to remark frequently of the value of the place (Fig 267). A neglected home seems to be out of consideration by buyers, and the neighbors will sneer when the place is mentioned.

The small cost of planting trees and flowers is far more than balanced by the enhanced value of the place. A few vines may be started with a few cents' worth of seeds. These may be caused to cover unsightly buildings, shade porches, or cover stumps and fences. A few trees will cost so little that they will pay for their value in shade they furnish (Fig. 268).

Plans for Planting.-Before doing any extensive or permanent planting a drawing of the grounds should be made. On paper you can change the lines of roads and walks in a moment; not so after they are made in reality. Compare the pairs of plans in figures 269 to 271. Make the plan suit your ideals, but be practical in all this work. Do not try to make roads up steep places. Let them wind atround a gentle grade with beautiful curves and angles in roads 366 
and walks; let shrubbery be grouped in masses rather than scattered about the ground) (Fig. 271).

Choose permanent plants rather than annual plants. When you set a clump of shrubbery you should feel that it is permanent rather than temporary. Do not let this interfere, however, with planting of annuals for quick effect at first. You can hide an unsightly corner and give a beautiful effect with such annual

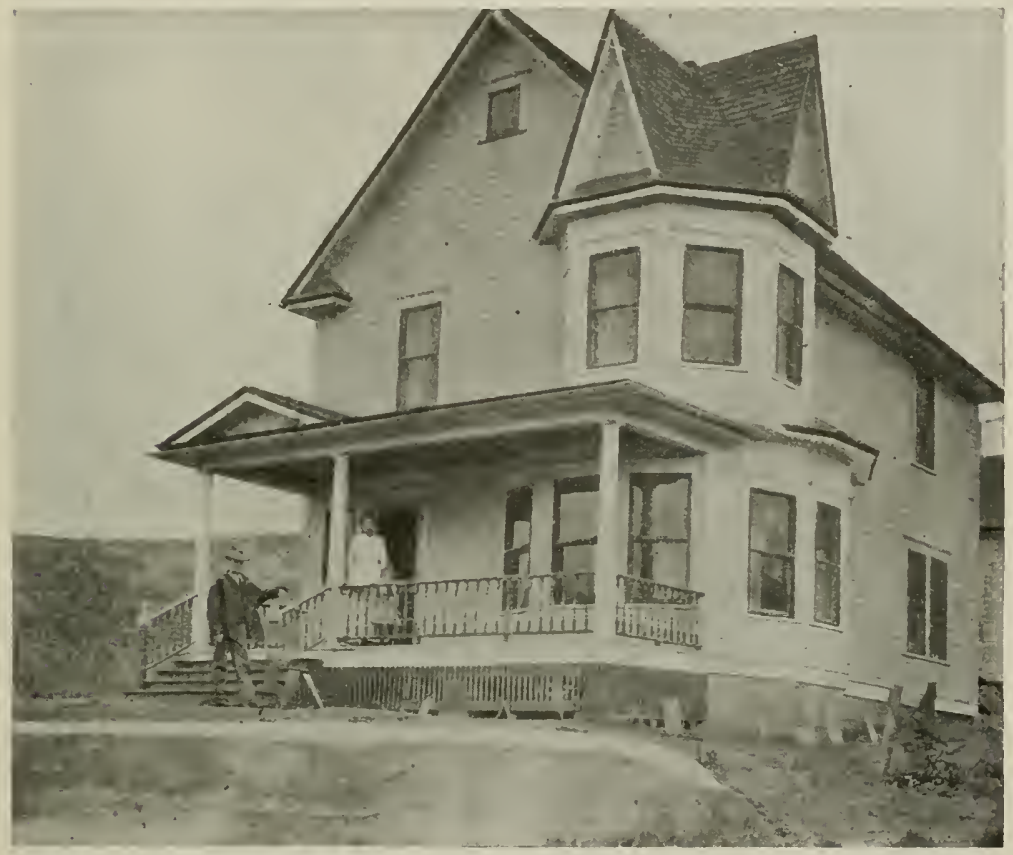

Fig. 26j.-This tall house would be much improved by groups of trees, shrubbery, and vines. (Productive Bee Kieeping.)

plants as sun-flowers, scarlet sage, annual hollyhocks, castor beans and others (Fig. 277).

Planting to Suit Buildings.-If the house or other building is tall, do not put a Lombardy poplar tree or other slender growth near by. Plant broad-headed trees to balance the stilted effect of the building. If the house is low and spreading, the tall slender growth may be used with better effect. Notice the harmony of residence and large trees in figure 272. Massing shrubs has already been mentioned. This plan helps to blend the lines of buildings 
with the smooth liwn surface. Evergreens for example, can be left unpruned to the ground. Their lines of beaty will blend harmoniously with their surroundings. Never leave any bare corners unprotected by shrubbery. Some one has said that when

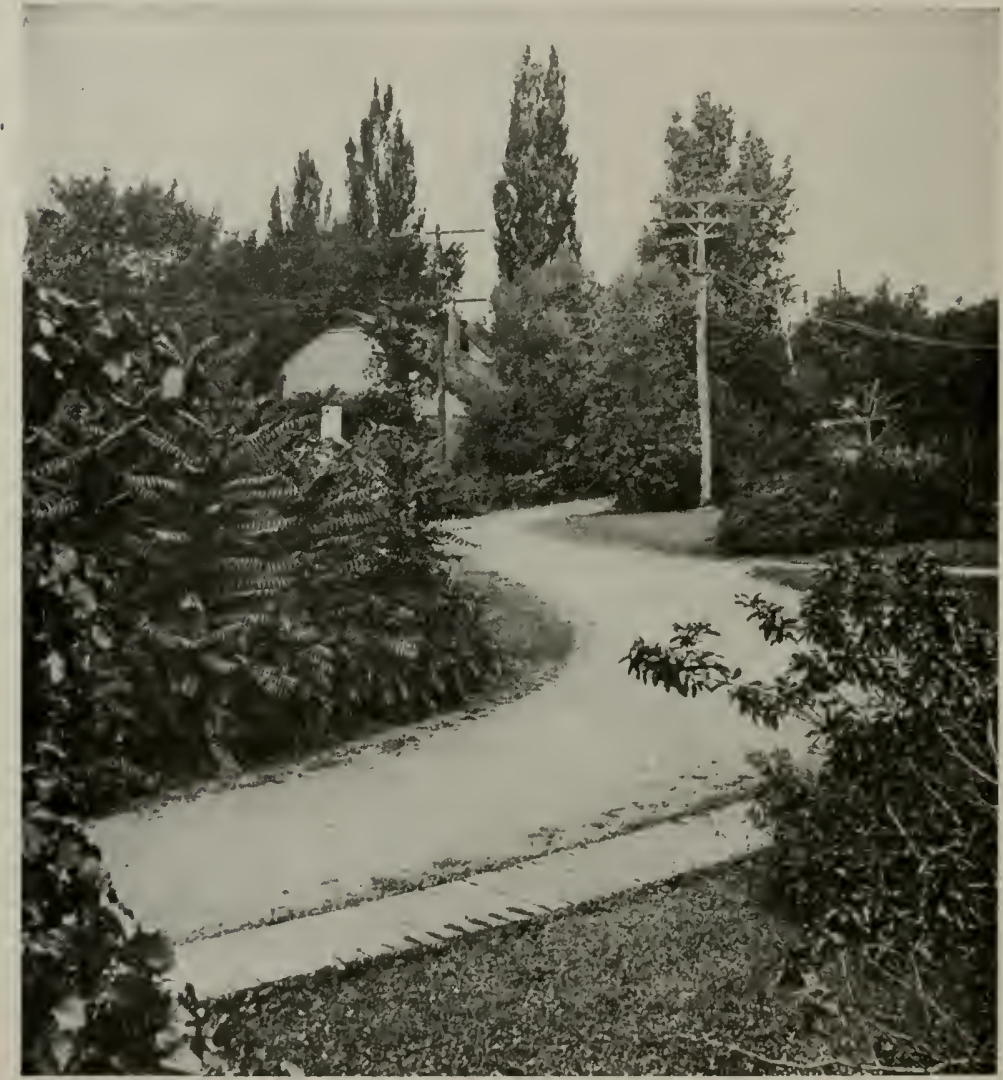

Fig. 266. - The trees and shrubbery about the farm home may be chiefly native plants obtained for little or no outlay of money. (U.S.D.A.)

we fail to plant shrubs along the base of buildings we give the effect that it needs clothes, beeause it seems to be bare-footed. All the plants should be so effective as to embellish the surroundings.

Grouping Trees.-Even trees may be grouped so that they will give an effect of massing after they have become large. When trees are scattered over the lawn it is difficult to mow the lawn 
with a horse mower or with a hand mower. They are always in the way of the machine and they are in the way of seeing the beautiful things you have planted. Better leave some plain greensward

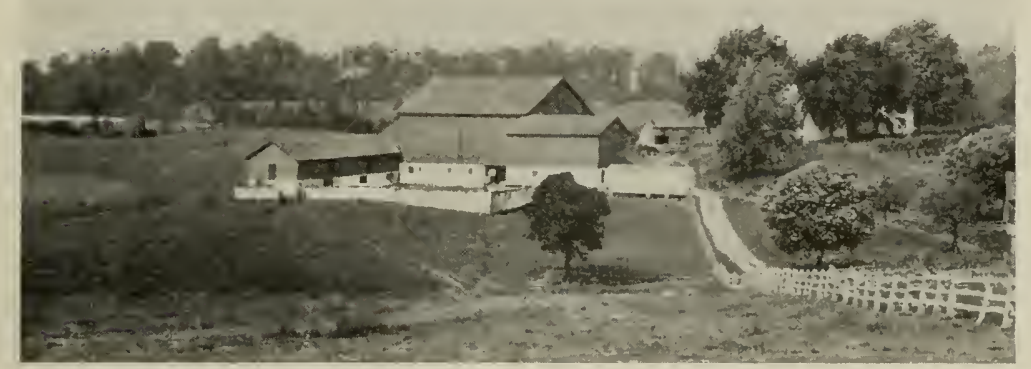

Fig. 267.-An ideal location for the farm buildings. The residence is among the trees on higher ground than the barns, which are also on a well-drained ridge. Note that all buildings are painted and kept up. (U.S.D.A.)

as part of the canvas of your picture. Put the trees as you do the shrubs, at the corners, angles, and along the borders. There is no objection to planting some straight lines of trees along roads,

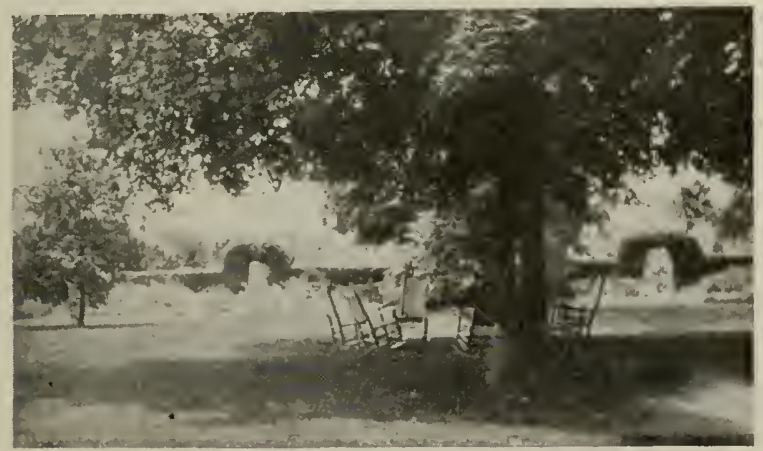

FIG. 268.-A few community meetings in the side yards of the neighborhood will encourage the beautification of the premises.

fences, etc. These straight lines may be broken occasionally; at least at the ends they may blend into masses of shrubbery.

Trees to Plant.-For quick effect, rapid growths are sometimes desired. Cottonwoods or poplars are sometimes used where shade must be produced quickly. Remember that the trees which grow 
fast are seldom permanent; they will die young. For more pernanent growths we would probably select elns, maples, oaks and other slow growing kinds.

Among those which grow rather quickly, and are also rather permanent might be mentioned walnut, hardy catalpa, hickory and tulip tree.

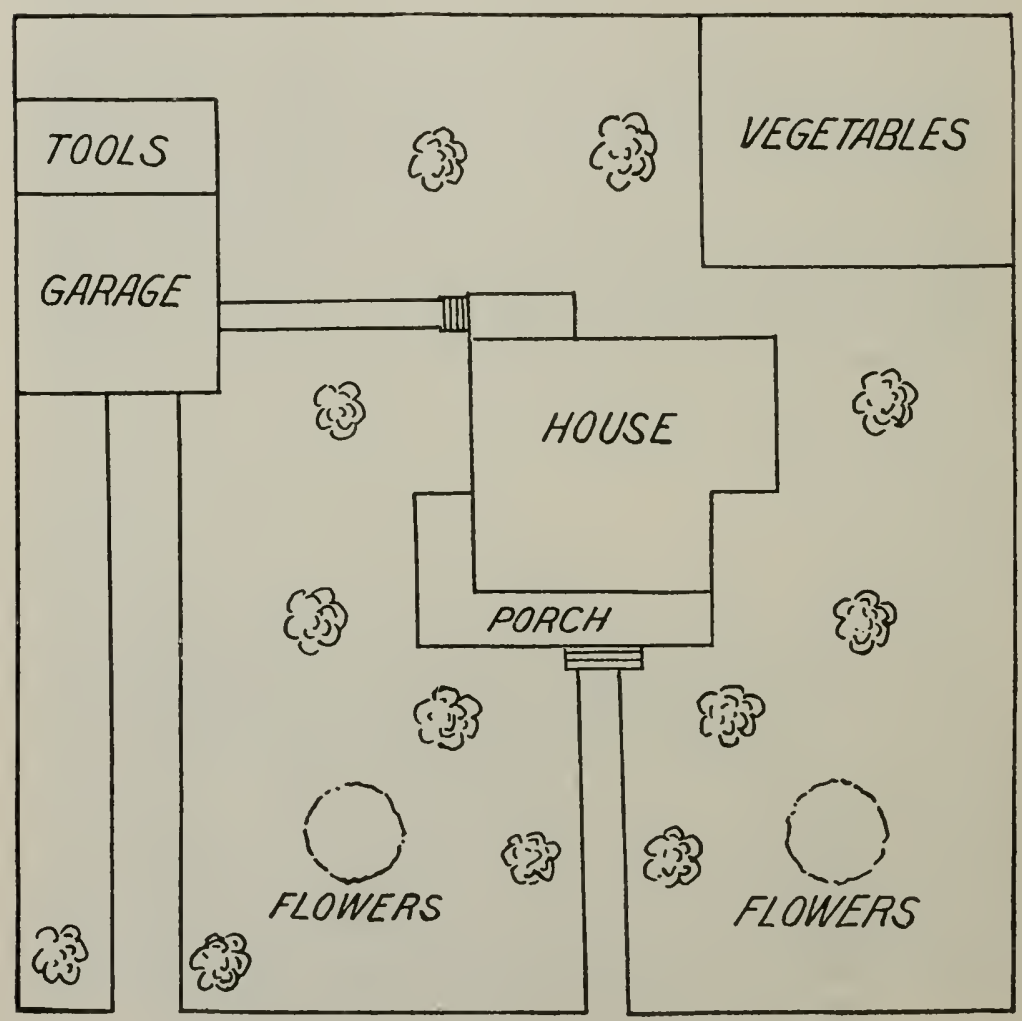

Fic. 269.-Show poorly planned walks, drives and planting.

For wet places we would select willows, swamp maple, sycamore, alder and others growing naturally along the water's edge of streams.

Shrubs to Plant.- It is well for the owner to select those shrubs which are native to his region. What is more beautiful as a shrub than the wild rose, wild blackberry, wild elderberry, and others 
which may perhaps be transplanted from their wild surroundings near by?

There are a number of other shrubs that are always popular and much to be desired. Lilac, spirea (Fig. 273), syringa, golden bell, deutzia, althea, hibiscus and others may be purchased at low prices and can be afterward greatly multiplied by easy methods. Many

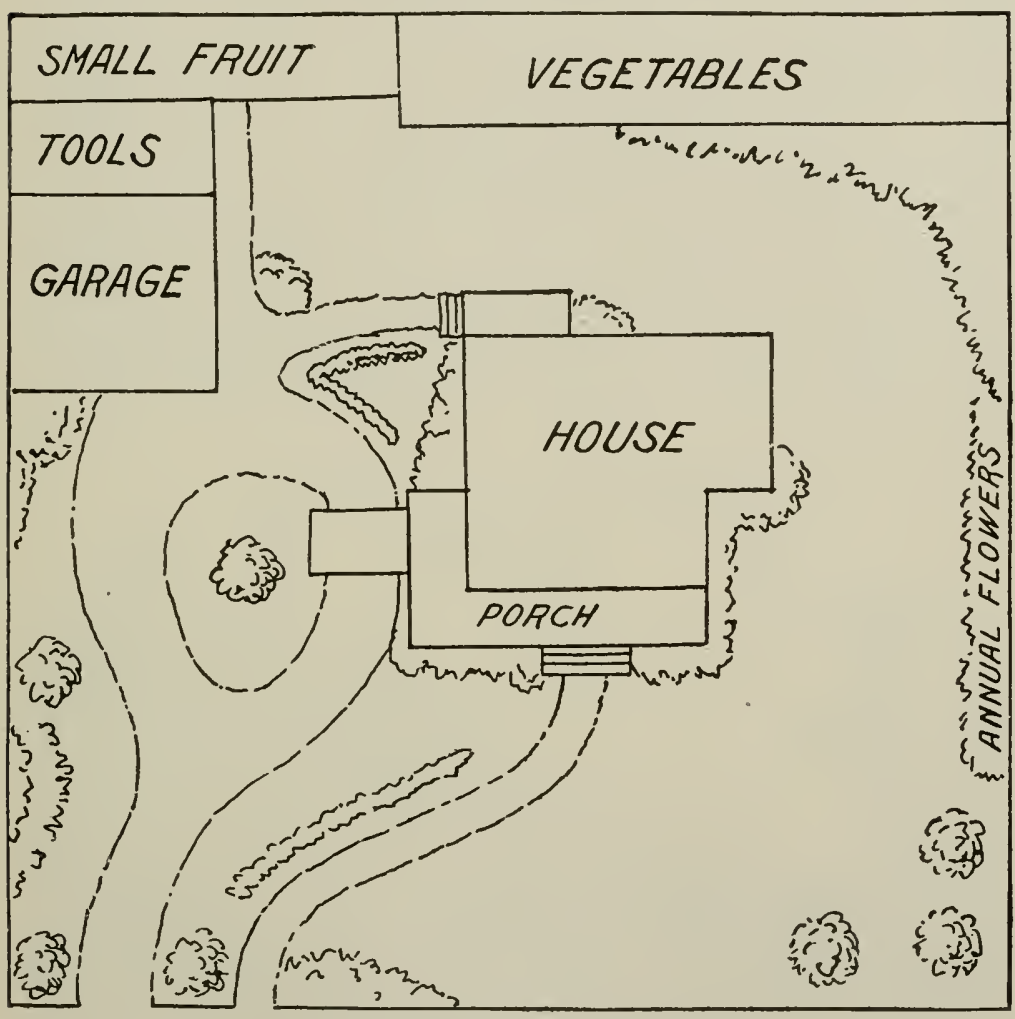

FIG. 270.-Same as figure 269, replanned.

of these may be grown by hard wood cuttings taken in the winter.

For hedges use such plants as California privet, Chinese privet, hemlock, cerlars, lilac, Japanese quince, Osage orange and others. Most of these can be trimmed to any form desired and made to produce dense growths. Some of these are sometimes used as formal plantings in parks (Fig. 274). 
The boxwood shrubs may be used either as ornamental clumps or for helges. The growth is extremely slow, but the beauty will (ompensate for waiting.
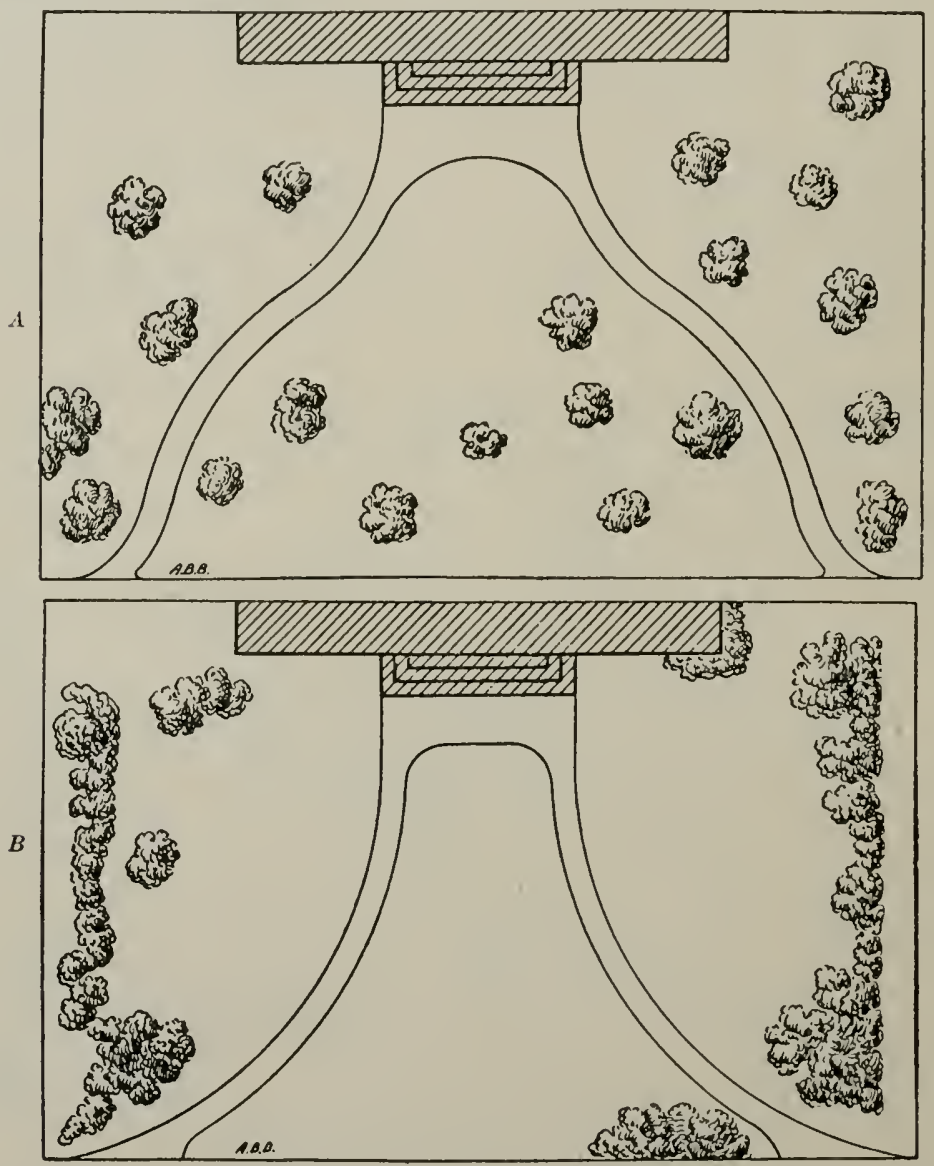

Fig. 271.-A. plan of school grounds showing improper planting. The trees and shrubs should not be seattered over the lawn. It is better to mass them in the corners, along borders, or in the angles and curves of walks and driveways. $B$, same grounds with planting well grouped. (U.S.I).A.)

Vines to Plant. - Vines have several ways of (climbing. Always ehoose those vines that will elimb upon the objert which you are trying to eover. Do not make the mistake of trying to make twining vines climb on stone walls or buildings. Give each its natural 


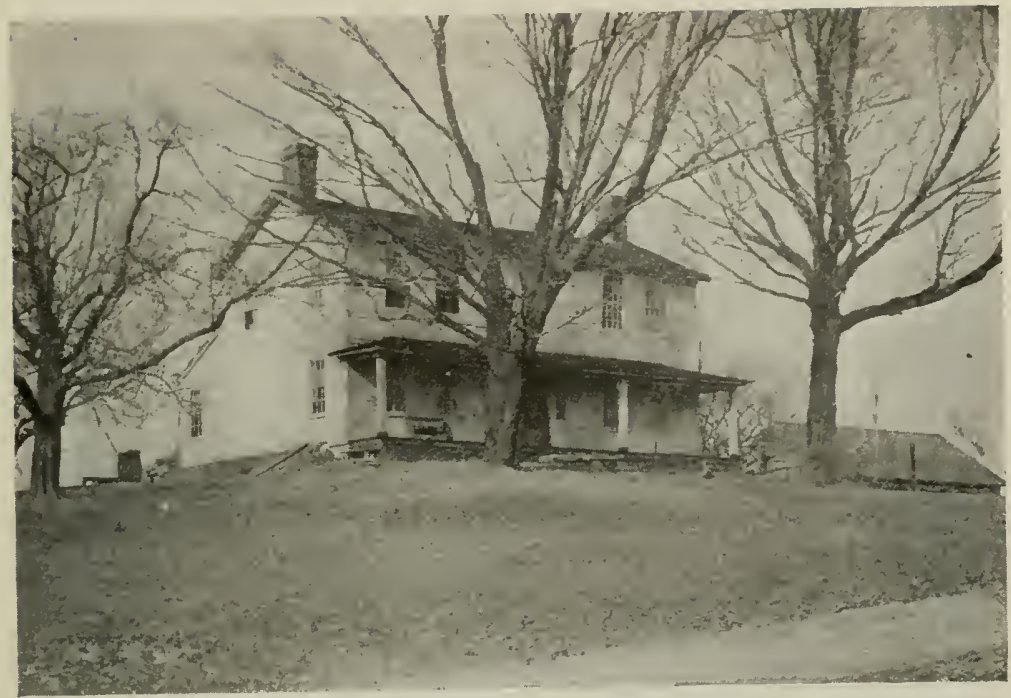

FIG. 272.-A high house on a hill is much relieved by large trees about it. Clumps of shrubbery to hide the base would be a great improvement. (Photo by Waugh.)

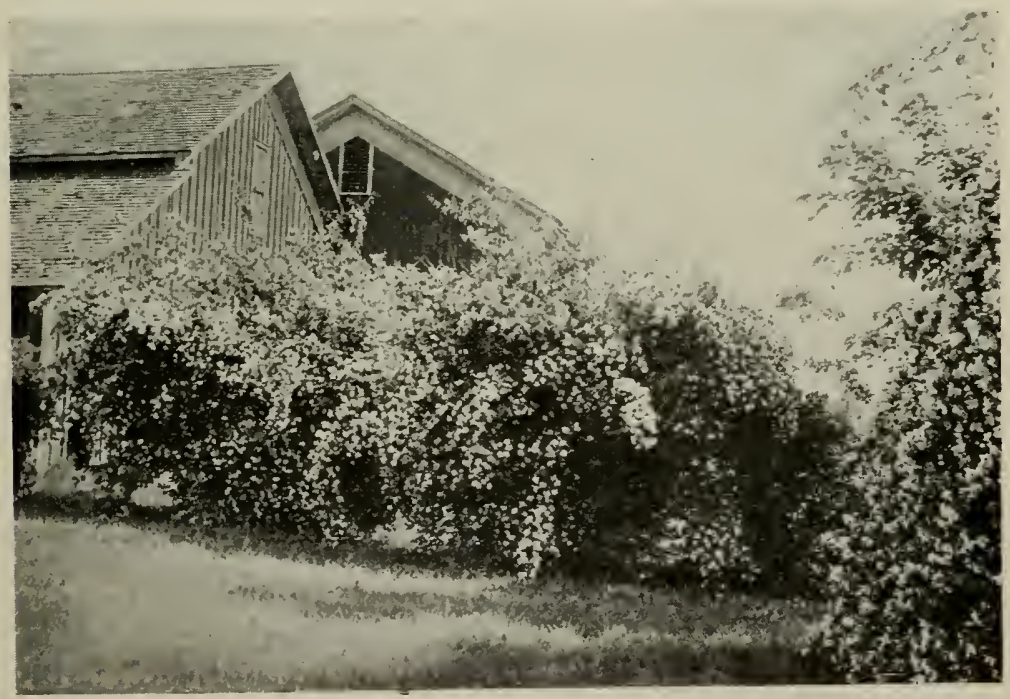

Fıg. 273.-Clumps of spirea may be used to adorn shops and barns. (Michigan Station.) 
way of climbing, and it will save you much effort in trying to make it ascend to the heights you desire. Crood plants for stone or brick surfaces are Boston ivy, English ivy, Englemann's ivy, and Virginia creeper on fences.

A good vine to cover dead trees, stumps and wooden buildings is trailing burning bush, (Euonymus radicans). Virginia creeper and trumpet vine are fairly well suited to such locations.

Vines for wire trellises are the grape, wisteria, Virginia creeper, Virginia clematis, pannicled clematis (Fig. 275), Madeira vine, the beans of various kinds, such as Japanese bean (Lablab), velvet bean, and others. Sometimes it is necessary to change the kind of

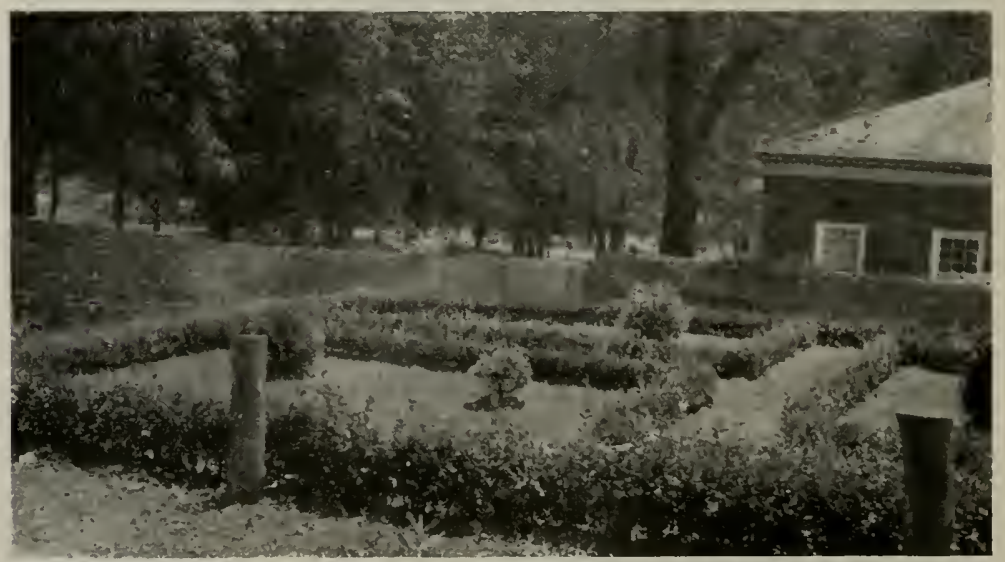

Fis. 274.-A striking example of formal gurdening with grass plots laid off in geometrie forms by the growth of evergreens and privet hedge.

support to suit the vine. If vines are already growing near some building a pole may be erected or a wire may be streteched up to accommodate them.

Annual vines should often be used where quick effects are desirecl, Among these might be mentioned cypress vine, gourds (Fig. 276) wild cucumber, morning glory, the different kinds of climbing beans, and moonvine. Where perennial kinds can be started at the same time this should be done to avoid having to replant each year and wait for the growth each season.

Annual plants may be used for quick effects. Castor beans, shown in figure 277, are very effective. Masses of hemp, sunflowers, hollyhocks from seeds, cosmos, and other shrub-like flowering plants of the herbacceous kinds are effective the first year. 
Encouraging Growth of Ornamentals.-When shrubs, vines and trees are planted for ormamental purposes they should be given as

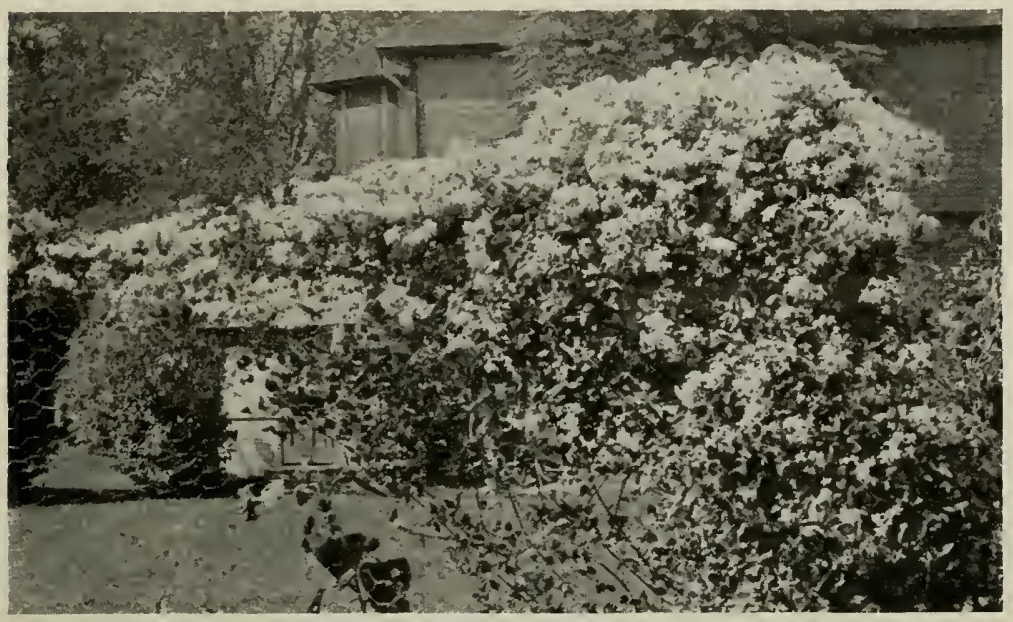

FIG. 275.-The panicled clematis is a perennial vine, producing a beautiful bower of white flowers in late summer and fall.

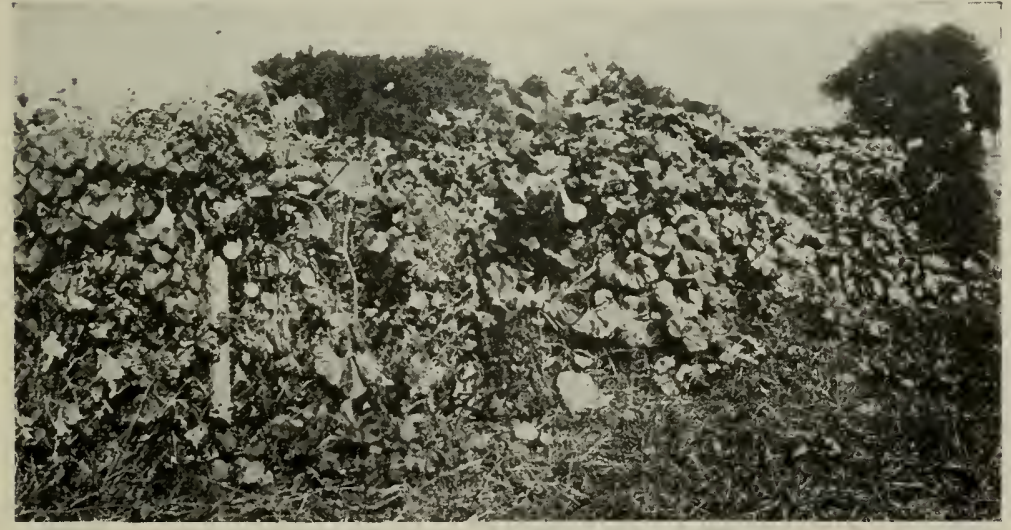

FIG. 276.-Gourds are annual vines which may be used to make a quick screen. Eastern Illinois Normal. (U.S.D.A.)

favorable conditions as if they were to yield a crop for profit. Make the soil rich and give them enough care to make them thrive. Do not expect vines to cover the buildings if the soil is poor. A 
forkful of manure well mixed with the soil at planting time will pay. The results seen in a thrifty flower garden or border are very encouraging (Figs. 278 and 279). When a fine old shrub is unthrifty investigate the case and remedy the trouble if possible. A little manure or a mulch applied in the fall will stimulate the growth next year.

Lawns.-Over the extensive area in which blue-grass thrives, good lawns are easily produced. Kentucky blue-grass is one of the best lawn grasses of the humid states. It thrives particularly well in regions where there is plenty of limestone, and in those regions will grow much farther south than elsewhere.

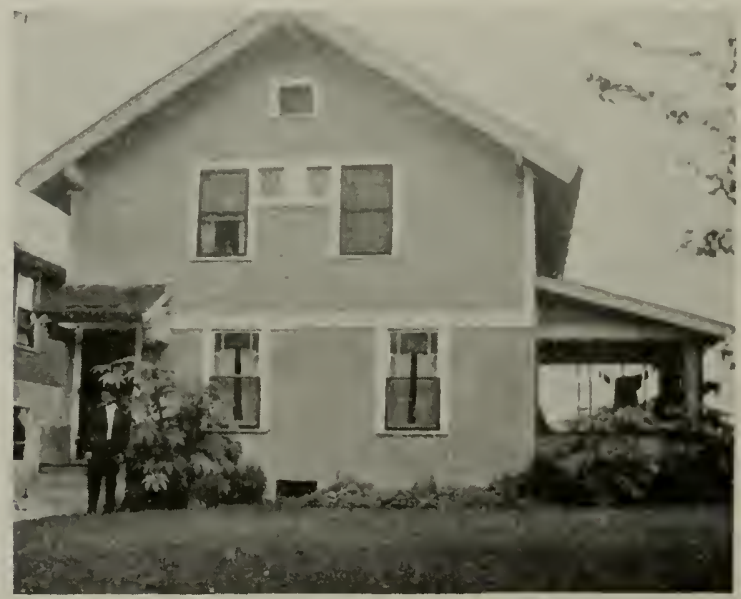

Fig. 277. - Even a few annual plants, such as caster beans, vines and flowers, well placed, hide the naked foundation and give a pleasing background for the lawn. Note how well the foundation is hidden by plants.

Other good lawn grasses are timothy, meadow fescue, red top and the rye grasses. All of these need to be trimmerl more closely or may be used better on large plantations where mowing is to be done by the field machines.

White clover is a low, creeping clover which mixes well with blue grass and other lawn grasses. It is easily grown in all of the regions where the rainfall is not too limited. It prefers some lime in the soil.

Bermuda grass is one of the best lawn grasses in use in the Gulf states and other states near them if there is little lime in the soil. It makes a dense carpet if kept trimmed closely, and is one of the 
most beautiful covers for any lawn where it will thrive. It may be grown as far north as the Ohio river. The leaves and stems do not remain over winter in regions where freezing is severe. The new growth has to come from the roots each spring, and the lawn has a dead appearance for several months each year.

For dry regions of the West smooth bromegrass is one of the best lawn grasses. It will become more dense and produce a better carpet after a few year's growth. The stems shooting up to bear seed should be kept trimmed off if the best effects are to be obtained.

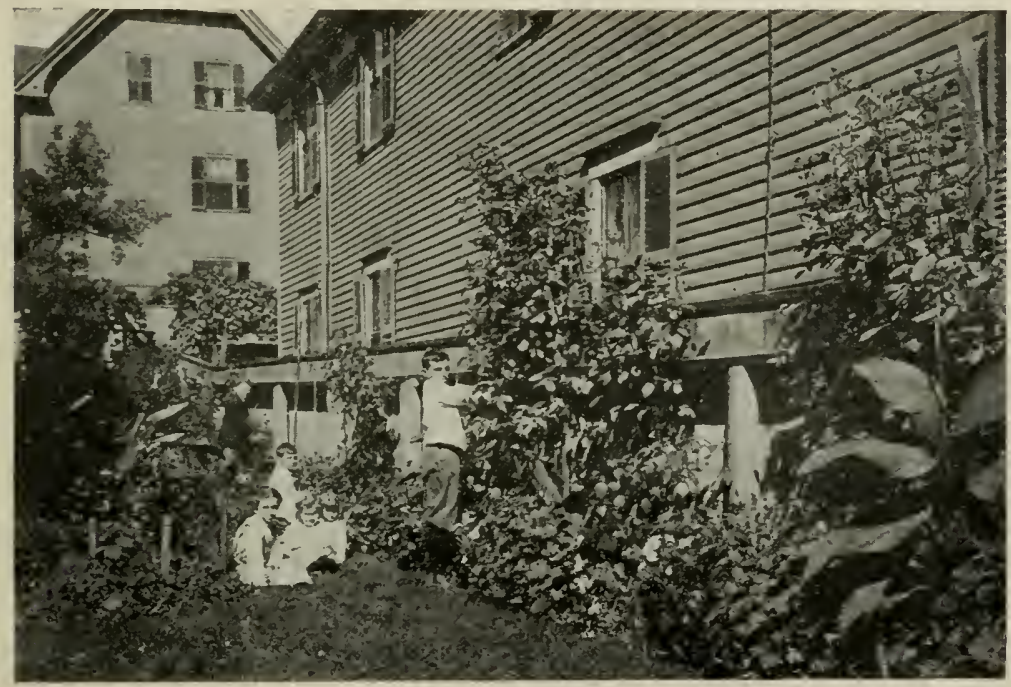

FIG. 278.-A city garden showing how to beautify barren spots between tenements. (R. I. State College, Ext. Dept.)

Starting Lawn Grass.-If the seed method is to be followed always sow the seed on a well prepared seed bed at that season of the year when the rainfall is heaviest. In some regions this is in February or March, while in others it may be in September or late fall. If the winter is very severe early spring is preferred to late fall, because the young grass should be allowed to make enough root growth to prevent being killed by freezing. In regions with light winters where the soil does not freeze many inches deep the fall seeding of lawns is recommended.

Principles in the Care of Lawns.- It is easier to care for a lawn that is not broken up by trees or scattered shrubs. The area to be 
mowed should be largely uninterrupted by such plants. It ismore difficult to mow all around a flower bed or shrub cluster than it is to mow along one side only.

Frequent mowings are less difficult than few mowings. If lawn mowers are used the work is measured by the height rather than by the number of times the lawn is gone over. Of course this is not the case when field mowers are used. These are suitable only for large lawns.

Never allow the seed stems of grasses to shoot up. This takes away the life of the grass. All good lawn grasses have other means

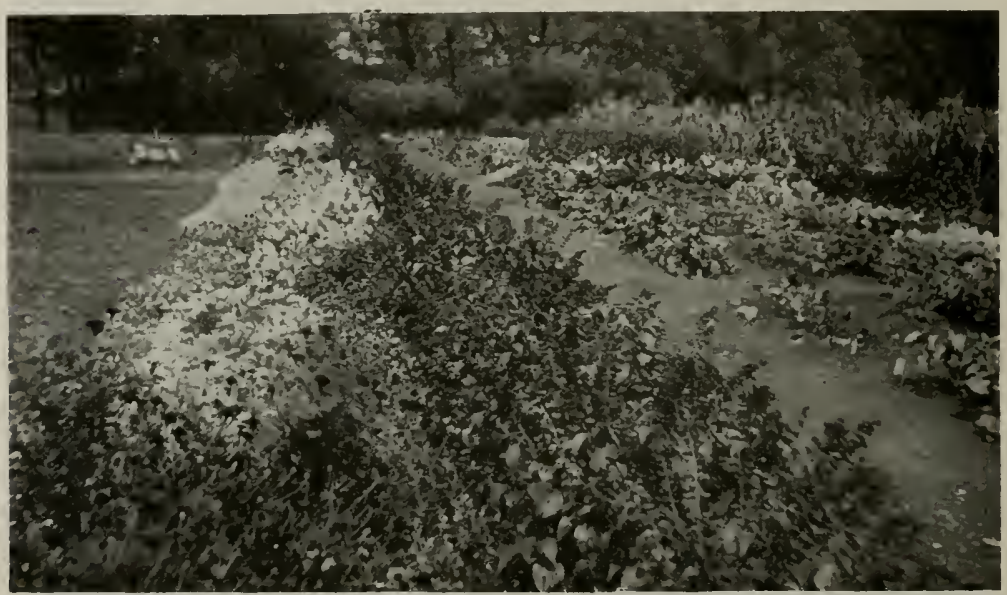

FIG. 279. - The vegetable garden whether at home or at school may be bordered with annual and perennial flowers. (R. 1. State College, Ext. Dept.)

of spreading than by seed. These other methods should be encouraged, and the seed method should be discouraged.

Another objection to neglecting the lawn is the presence of weeds. These are always more abundant on neglected lawns. Closely trimmed lawns are less weedy. Frequent cutting is hard on the weeds but good for the grass.

Flower Planting.-One of the most important factors in beautifying the home grounds is the liberal use of flowers. Do not make small beds of flowers. Let them be planted in borders or wide belts along the edge of the grounds. There is no objection to having some walks run through them but they should not be interrupted or surromeled with lawn grass. They are less thrifty, the lawn is 
not so easily cared for, and the effect is iess beautiful. Large bels are sometimes used near the main walks. A better plan is to have borders of flower's along these walks. Let the borders be wide enough to be really interesting all season.

A good plan in the planting of flowers is to place them at the foot of the buildings. At each side of the steps leading to the porch and in similar places would be good. Between walks and buildings is often a favorite spot for beautiful flowers.

Choice of Annuals and Perennials.-There are so many beautiful annual flowers that we should not omit planting them each year. Berls of zinnias, aster, the splendid salvia, marigold, verbenia,

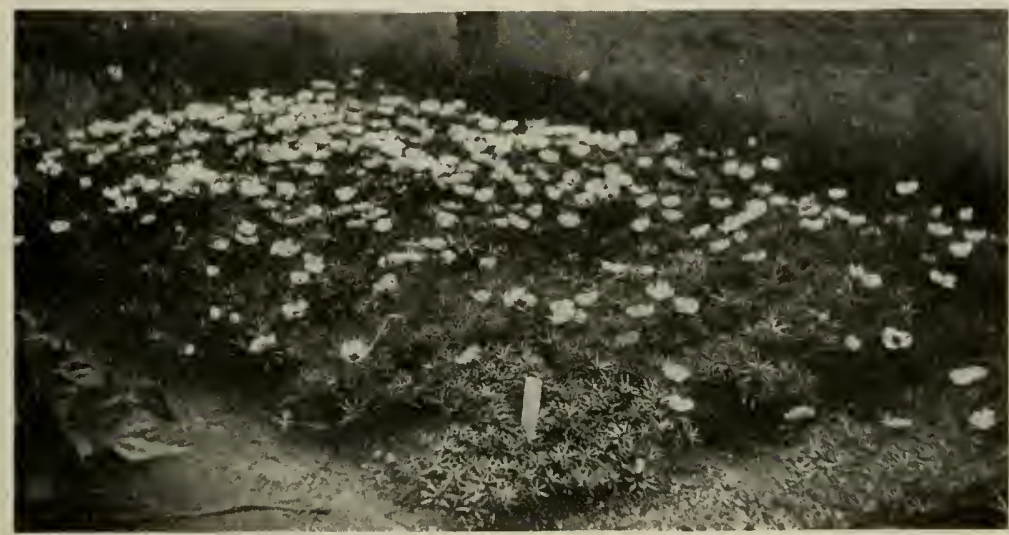

Fic. 280.-Annual flowering plants may be grown with much pleasure and profit by both girls and boys in the school and home gardens-a bed of Portulaees. (R. 1. Ntate: College, Ext. Dept.)

dwarf nasturtium, annual phlox, poppy, gaillardia, calliopsis, cosmos, golden Bartonia are always admired. A bed of portulateras is shown in figure 280.

Perennial flowers save much replanting, and the effect is more permanent. It is well to plant so that the show of blossoms will be pleasing at all times during the growing season.

A Continuous Show of Flowers. - Let there be a continuous show of flowers as much of the year as possible. Perennials which blossom early, such as violets and pansies may be followed by annuals or perennials which blossom during inid-summer. The late flowering plants, such as asters, zinnias, chrysanthemums dahlias, cannas, should be included in the planting list. 
Bulbs.-For winter and early spring blossoms we should make liberal use of jonquils, narcissus, tulips, hyafinths, ete.

Flowering Tables.-The accompanying flower tables give the time of flowering for a number of popular flowers. These will aid greatly in making selections for the flower beds and borders. Color effects should also be studied in this connection. Let color, time, height and other elements be considered in choosing the flowers to be planted.

Cultural Directions. - Special directions for the culture of each of the flowers are usually given on seed packages and in the garden catalogs published by seedsmen. Send for several catalogs and study them closely. The directions given for culture and management are usually quite reliable.

Perennial Flowers from Seeds. - Many perennial flowering herbaceous plants may be quickly grown from seeds. If the seed bed is planted in August and the young seedlings are soon transplanted and well watered, nourished during the first autumn, they may be expected to show some bloom the next season. They will become stronger and produce more flowers each year.

Planting Table of Perennial Flowers

\begin{tabular}{|c|c|c|c|c|c|}
\hline Name of Flower & $\begin{array}{c}\text { Dis- } \\
\text { tance } \\
\text { to } \\
\text { Trans- } \\
\text { plant } \\
\text { Feet }\end{array}$ & $\begin{array}{l}\text { Height } \\
\text { of Plants } \\
\text { Feet }\end{array}$ & Color of Flowers & $\begin{array}{l}\text { Blooming } \\
\text { Season }\end{array}$ & Adapted fol \\
\hline Achillea & 1 & 2 & White & June to Aug. & $\begin{array}{l}\text { Borders, cut- } \\
\text { flowers }\end{array}$ \\
\hline Baby's breath & 1 & $1 \frac{1}{2}$ to 2 & White & July to Aug. & Bonquets \\
\hline Blanket flower & 1 & 2 & Reddish-brown & June to frost & C'ut-flowers \\
\hline $\begin{array}{l}\text { Campion } \\
\text { (Lychnis) }\end{array}$ & 1 & 3 & Orange, scarlet & June to Sept. & Borders \\
\hline Columbine & 1 & $2 \frac{1}{2}$ to 3 & $\begin{array}{l}\text { White, blue, } \\
\text { yellow }\end{array}$ & June to Aug. & $\begin{array}{l}\text { Beds, cut - } \\
\text { flowers }\end{array}$ \\
\hline Coreopsis & $1 / 2$ & 1 to 2 & Yellow & May to frost & Cut-flowers \\
\hline Hollyhock & 2 & 4 to 7 & All colors & July to frost & Backgrounds \\
\hline Larkspur & 2 & 2 to 5 & Blue shades & June to Sept. & Backgrounds \\
\hline Pinks & $1 / 2$ & 1 to $1 \frac{1}{3}$ & Pink, white, red & May to July & Borders \\
\hline Poppies, Iceland & $1 / 2$ & & All colors & June, Oct. & Borders \\
\hline Poppies, Oriental & $1 / 2$ & 2 & All colors & June, July & Borders \\
\hline Snapdragon & 1 & 1 to & $\begin{array}{l}\text { Red, purple, } \\
\text { white }\end{array}$ & July to frost & Borders \\
\hline $\begin{array}{l}\text { Stokesia or corn- } \\
\text { flower aster }\end{array}$ & 1 & $1 \frac{1}{2}$ & $\begin{array}{l}\text { White and light } \\
\text { lavender }\end{array}$ & July to Oct. & Cut-flowers \\
\hline Sweet William & 1 & $1 \frac{1}{2}$ to 2 & $\begin{array}{l}\text { All shades of } \\
\text { red, white and } \\
\text { variegated }\end{array}$ & June to Aug. & $\begin{array}{l}\text { Beds, b o r- } \\
\text { ders, cut- } \\
\text { flowers }\end{array}$ \\
\hline
\end{tabular}


Prepare a small bed of rich sandy loam in a spot partially shaded Drill the seeds in rows a few inches apart. Cover very slightly by sifting soil over them and gently packing. Water well. Transplant the seedlings soon after they form their second pairs of leaves. It may be well to shift them a second time to the clistan ce indicated in the table. Protect them with a light mulch of strawy manure when the ground begins to freeze.

Annual Flowers.-The accompanying table gives important points regarding some common annual flowers. These are useful for beds and borders. The seeds may be carefully sown in beds of rich sandy loam in hot berls, coldframes or in the open, later in the spring. The seedlings are nearly all improved by transplanting. Cover seeds by sifting soil over them to a depth of one-eighth to one-fourth inch. Water them often and protect them from drying winds, hot sun, and severe cold nights. The distances between plants at shifting time should be governed by the effects desired and by the heights of the plants. See also the planting table in this author's book "School and Home Gardening," Chapter XII.

Planting Table of Annual Flowers

\begin{tabular}{|c|c|c|c|c|}
\hline Name of flower & $\left|\begin{array}{c}\text { Height } \\
\text { cf } \\
\text { plant } \\
\text { inches) }\end{array}\right|$ & $\begin{array}{l}\text { Blooming } \\
\text { season }\end{array}$ & Color & Best use \\
\hline Ageratum. & $5-18$ & July to frost & $\begin{array}{l}\text { White, blue, } \\
\text { rose }\end{array}$ & Carpeting \\
\hline Alyssum. & $3-12$ & $\begin{array}{l}\text { End of June } \\
\text { to frost }\end{array}$ & White & Borders \\
\hline Aster, dwarf. & $6-12$ & Aug. to frost & All colors & Solid beds \\
\hline Balsam & $12-30$ & July to frost & $\begin{array}{l}\text { Pink, white, } \\
\text { cream }\end{array}$ & Borders \\
\hline Candytuft. . & $6-12$ & $\begin{array}{l}\text { End of June } \\
\text { to frost }\end{array}$ & Assorted & Borders \\
\hline Cosmos & $30-60$ & July to frost & Many colors & Background \\
\hline Eschscholzi & 12 & July to frost & $\begin{array}{l}\text { Yellow, white, } \\
\text { red }\end{array}$ & Ribbon beds \\
\hline Marigold. & $6-36$ & July to frost & Yellow & $\begin{array}{l}\text { Dwarf for borders; } \\
\text { tall for beds }\end{array}$ \\
\hline Orange daisy ...... & 12 & July to frost & Orange & Solid beds \\
\hline Petunia (creeping) & $10-18$ & Aug. to frost & $\begin{array}{l}\text { White, blue, } \\
\text { striped }\end{array}$ & Carpeting \\
\hline Phlox (Drummond) & $4-12$ & $\begin{array}{l}\text { July and } \mathrm{Au}- \\
\text { gust }\end{array}$ & All colors & Ribbon beds \\
\hline $\begin{array}{l}\text { Portulacea (crecp- } \\
\text { ing) }\end{array}$ & 6 & Aing. to frost & $\begin{array}{l}\text { Good assort- } \\
\text { ment }\end{array}$ & Carpeting \\
\hline Verbena (crocping) & $8-10$ & Aug. to frost & S'rveral rolors & Carpeting \\
\hline Zinnia........... & $4-36$ & Aug. to frost & All colurs & $\begin{array}{l}\text { Dwarf for borders; } \\
\text { tall for beds }\end{array}$ \\
\hline
\end{tabular}


Other annual flowers are here listed in groups by their most common colors:

White flowers: Dianthus, iheris, poppy, stocks.

Yellow flowers: Mignonette, "alendula, cacalia, coryopsis nasturtium, hibiscus, celosia.

Blue flowers: Centaurea, lobelia, mimulus, ageratum.

Red flowers: Adonis, agrostemma, cacalia, celosia, Clarkia, dianthus, gaillardia, stocks, saponaria, nasturtium.

Many colors: Godetia, mirabilis, nigella, swect peas, pansies.

Foliage Plants.-Annuals with ornamental foliage are often used for bedding and border plantings. In some instances these have no showy flowers, but their leaves are always beautiful. In this group may be mentioned, amarantus, centaurea, coleus, euphorbja, perilla, pyrethrum, racinus (castor bean).

\section{CONTESTS, SCORING, AND JUDGING}

1. Scoring Home Grounds.-Make in score card for use in judging the lome grounds of any region. Assign scoring values to each item. Include:

(1) Plan of walks, roads, etc., with reference to surroundings, and buildings.

(2) Plan of planting of shrubs.

(3) Location of trees.

(4) Choice of trees, shrubs, and vines.

(5) Flower beds-arrangement. kinds, etc.

(6) Paint or whitewash on fences, buildings, etc.

(7) Lawns-linds, success, care. ete.

(8) General effeets.

(9) Permaneney of plantings and improvements.

(10) Economy of improvements, maintenance, and care.

2. Use the seore card in juldging home grounds in the neighborhood. This may be done "before" and "after" improvements have been made.

3. Contests in improving home premises mav be started. If possible premiums may be offered for first, sccond, and third best. Photographs should be taken before and after the contests. Committees or judges to deeide the contest should be brought from outside the contest district.

4. List of plants of all kinds used in planting should be made. In the vine list indieate the method of elimbing. In the shrubs indieate the height, special value, ete. Of the lawn gralsses state which are hest for sod formation. Deseribe the trees as to shade production, length of life, rapiclity of growth, general shape, ete.

5. Make plans for planting the house grounds and school grounds. Any school building should be beautified by the planting of shrubs, flowers, vines and trees. What should be used for your school grounds? See figures 267, 270, and 271 .

\section{QUESTIONS}

1. Why should a country home be beautified?

2. Of what educational value is this to young people?

3. What are the financial benefits?

4. Cive some suggestion: for plans in planting the home grounds. 
5. Discuss the planting to suit buildings.

6. What is meant by grouping or massing trees and shrubs?

7. Give a list of trees suitable for use in your region.

s. What wild shrubs in your region should be used in planting the home grounds?

9. Mention good plints for hedges in your region.

10. Mention good perennial vines and tell the kinds of supports required for each.

11. Same for annual vines.

12. What lawn grasses are best for your region?

13. What are the best seasons for sowing grass seeds, and for sodding slopes?

14. Give principles in the case of lawns.

15. Give suggestions regarding the choice and planting of flowers.

References.-U. S. Farmers' Bulletins: 494, Lawns and Lawn Soils; 750, Roses for the Home; S14, Berinuda Grass. See also Rural Improvement, Waugh, Orange Judd Co. 


\section{CHAPTER XIX}

\section{ATTRACTING BIRDS}

Tire gardener and the orchardist should always be interested in attracting birds which destroy insects. It is estimated that the loss to agriculture due to insects is about three billion dollars annually in this country alone. Birds will aid materially in keeping insects in control. The gardener or fruit grower who makes a special effort to attract birds will find his efforts abundantly rewarded.

The man with a cherry orchard is apt to think that birds do more harm than good. The robin, for example, that destroys many insects will also eat cherries and some other fruits. The damage, compared with the benefit, is only slight; allow the birds to take a little compensation for the good they do. Frequently the fruit-eating birds are in need of water. They often bite fruit merely for a little juice, because there is no water supply available to them.

There are a number of ways of attracting birds and making them feel at home on your grounds. These will be discussed in this chapter.

Fruit-Bearing Shrubs.-Grow shrubs and trees that bear seeds and fruits which birds love. Elderberry, blackberry, Japanese barberry, black haw, thornapple (hawthorn), wild eherries, mulberry, wild grapes and even the low buckbush all bear fruits which will aid in making the birds friendly on your place. Some of these keep their fruit on during the winter and will help feed our winter friends while they are hunting for egg clusters and pupx of some of the worst forms of insects. Let these trees, shrubs and vines be used for ornamenting the home grounds, and they will aid materially in protecting your main fruit plantation from attacks of birds themselves. Best of all this will keep the birds near your home, and if they make their homes near by they are certain to destroy millions of insects, particularly during the nesting season. They like to feed their young chiefly upon insect life.

Building Nests.-A popular way of attracting birds is to build bird boxes and other forms of houses in which they may nest. Ingenious devices have been constructed and popularly illustrated in bulletins, insect books, and many periodicals. They are sometimes made of gourds hollowed out for the purpose. Tin cans laid on the side and fastened to a post may attract some friendly birds. Have a perch in front for the parent birds to rest upon. Wooden boxes may be so constructed as to be very attractive and 
homelike for wild bird life. Put these nests on suitable supports where the parent birds will feel safe from harm. Paint them some natural color to match the bark of trees or green foliage.

Protection against Cats.-Among the worst enemies of birds are common house cats, which often run wild and prey upon birds' nests during the summer season. They are frequently found resting in trees to prey upon the parent birds or upon young birds which are just learning to fly. Their worst trick is to rob the nests after the young have hatched.

Much protection can be given the nests by wide bands of sticky fly paper placed around trunks of trees in which the nests are built

FIG. 281.
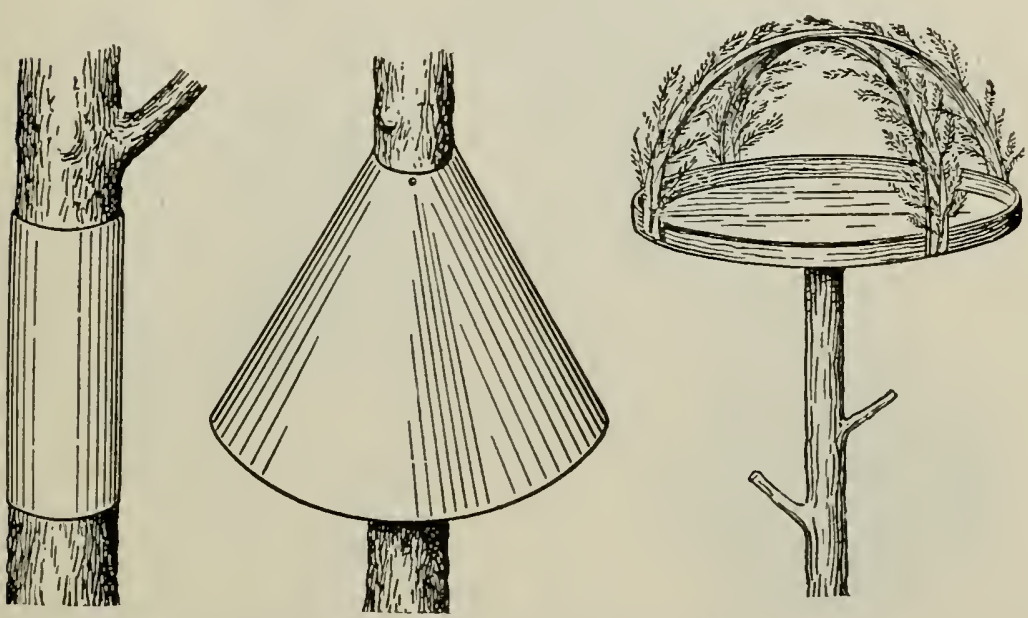

FIG. 281.- Metal tree guards will aid in keeping squirrels and cats from bird nests. Sticky fly paper (at left) may be fastened around the tree or nest pole. (U.S.D.A.)

FIG. 2S2.-Such a good tray may be placed where you may reach it from a box. (U.S.D.A.)

(Fig. 281). Cats dislike to be eaught in fly paper and will never attempt to climb a tree where they were once caught. Put wide metal collars around poles where blue birds or others are making their home. The artificial nests may be put on poles thus protected from the ascent of cats. When birds feel themselves secure from being robbed they grow more friendly month by month or year by year. Frequently the best remedy is to kill the cats. When cats are busy hunting birds' nests they seldom care to kill mice and rats. The lazy house cat often spends much of the night in preying upon birds in trees, and then sleeps during the day in your home. 
Damage by Dogs.- Many birds which nest 11 pon the ground of near the ground, such as quails, meatow larks, fickl sparrows and others have found their nests of eggs or young destroyed by dogs. A single bird dog with the strong sense of smell can find all the nests on a farm though there be scores of them, and is sometimes known to destroy them all in an hour's time. Quails, for example, are the best enemies of potato beetles. A flock of quails will protect the patch by eating the pests early in the season before

FIc. 284.
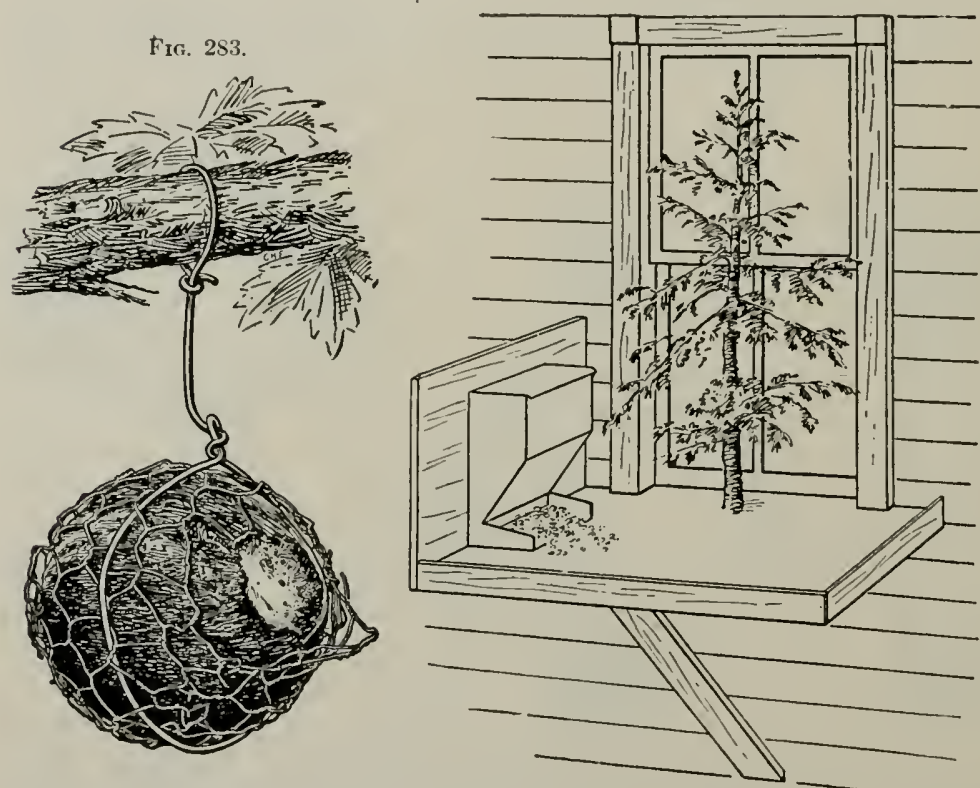

Fiv. 283.-A cocoanut shell hung in a wire mesh may serve either as a nest or as a dinimg room. (U.S.D.A.)

FIc. 284. - A feed shelf under a window is handy for the feeder and will bring the birds under the observation of children. (IT.S.D.A.)

they multiply. The protection of such a flock to the particular farm is of immense value. The dog which destroys the nests allows the insects to continue their work, and the farmer must fight the insect enemies as best he can while he is petting and feeding his dog. It has been said that it costs as much to feed a dog as it does to feed a pig. The same table waste or other feed which one gives the dogs could be used for pigs, and thus increase the supply of human food. 
Beware of dogs destroying the young and eggs of birds. Dogs which steal hen eggs often get the first lesson by stealing eggs from birds' nests. A dog with such bad training should be destroyed.

Feeding Birds in Winter Time.- When snow cover's the ground or when the weather is otherwise harmful to birds, food of some kind should be placed where the winter birds can obtain it. (Figs. 282 and 283). Seeds may be placed on top of walls or on the limbs

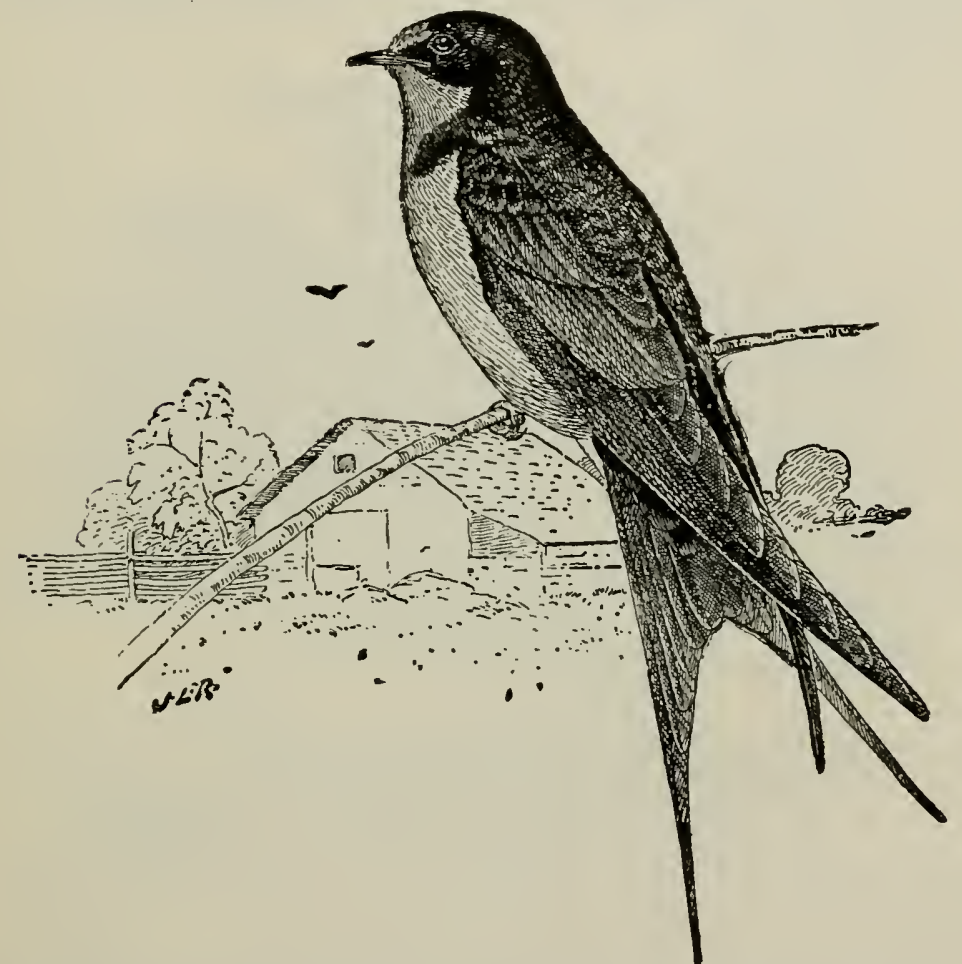

FIG. 285.-The barn swallow is found on almost every farm. Because it catches so many insects it ought to be encouraged and protected. (U. S. Biological Survey.)

of trees where they will find them. Use also rinds of meat cut fine, crumbs, scraps from the table, etc. Birds quickly become so friendly during the winter season that they will come to the window sill (Fig. 284) and beg for such food as you will give them.

Watering the Birds.-During hot, dry weather a supply of water where birds can find it should be kept in the shade of trees or other convenient place. It has been frequently noticed that birds 
which have access to streams of water seldom attack cherries or other fruits.

If the birds are suffering for water can they be blamed for biting the fruit for the juice they so much crave? Remember, they are destroying miliions of insects and saving your crop. Then why not give them a supply of water which costs you so little effort? A large basin or trough kept filled for this purpose would be an advantage. Have suitable places for the birds to alight while drinking.

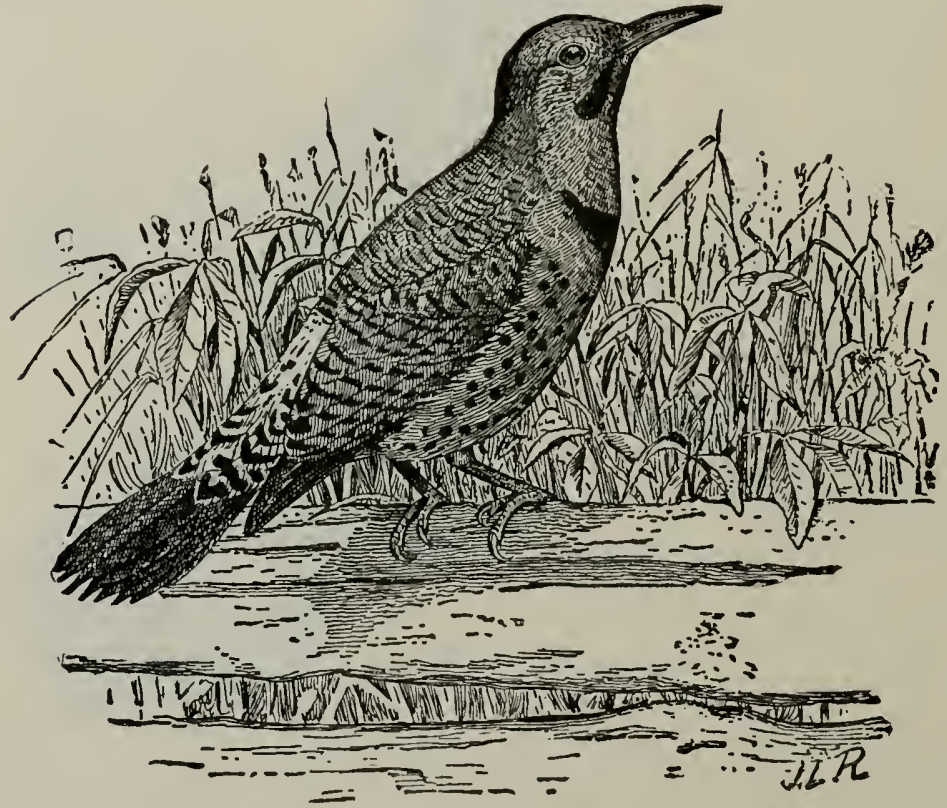

FIG. 286.-The flicker and other wood peckers are insect-eating birds and should be protected. (U.S. Biological Survey.)

If you keep honey bees the same watering place required by the bees will supply the birds. Even watering places for poultry will supply the birds if there is enough seclusion about them to encourage the birds to venture near.

\section{BIRD STUDIES, EXERCISES, AND CONTESTS}

1. Knowing the Birds. -Learn to know the common birds by sight, song, flight, ete. (Figs. 285 and 286i.)

2. Winter birds should be studied and listed in the winter. As others (one in the spring add them to the list with dates of arrivil. (Fig. 2S7). 
3. Nest boxes of several types should be made and put up in suitable places. See which kinds are used most eagerly by birds.

4. Fruit-bearing shrubs and trees that are wild in the region, should be listed and studied. Mark their loeations and transplant them to the home grounds during the dormant season.

5. Protect nests against eats in the different ways suggested. Study the results. Cats may be killed; then note the renewed friendship of the birds.

6. Feed and water the birds and note how much tamer they beeome.

7. Contests in attracting birds may be started. Let all the known methods be used as well as possible. Suceess may be judged by results.

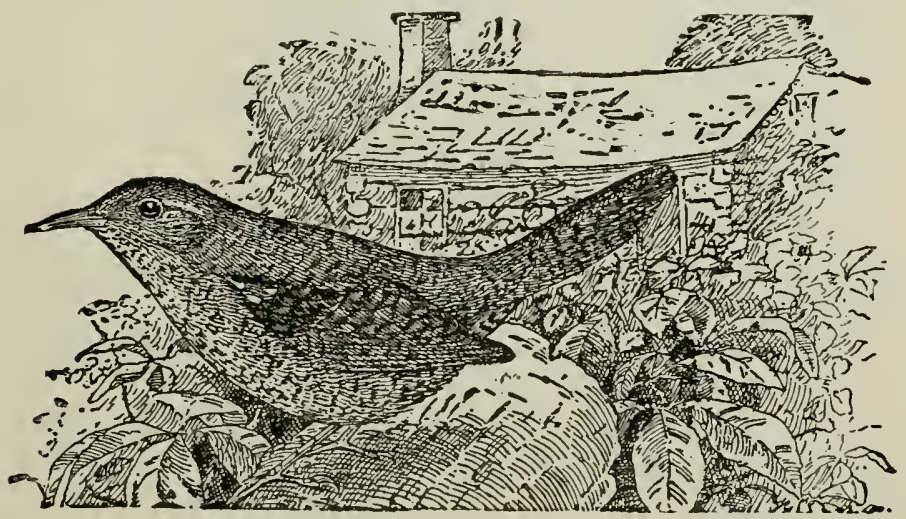

FIG. 287. -The house wren is one of the most friendly birds, and is easily attracted. Make a nest box with a hole the size of a silver twenty-five cent piece. This will let the wrens in, but keep the hated English sparrow out. (U. S. Biological Survey.)

\section{QUESTIONS}

1. What are the chief reasons for attracting birds?

2. What fruit-bearing shrubs will aid in attracting birds?

3. What forms of bird boxes have you seen put up for birds? Why should they be used?

4. Give suggestions for protection against eats.

5. How are dogs injurious to birds? How may this be prevented?

6. Discuss the feeding of birds in winter.

7. Under what conditions should water be provided for birds? How is this done?

8. Can you give other methods for attracting birds?

9. What enemies of birds have you ever seen?

References.-U. S. Farmers' Bulletins: 493, English Sparrow as a Pest; 609, Bird Houses; 630, Common Useful Birds; 456, Our Grosbeaks and their Value to Agriculture; 497, Some Common Game, Aquatic and Rapacious Birds in Relation to Man; 506, Food of Some Birds of Forest, Farm and Garden; 621, How to Attract Birds in Northeastern United States; 755, Common Birds of Southeastem United States; 760, How to Attract Birds in Northwestern United States; 912, How to Attract Birds in East Central States.

Insect Enemies and Bird Friends, Washburn, J. B. Lippineott Company. 


\section{APPENDIX}

\section{HORTICULTURAL WORKS FOR SCHOOL LIBRARIES}

Productive Vegetable Growing, Lloyd, J. B. Lippincott Company. School and House Gardening, Davis, J. B. Lippincott Company. Garden Farming, Corbett, Ginn \& Company.

Vegetable Gardening, Watts, Orange Judd Company.

Productive Plant Husbandry, Davis, J. B. Lippincott Company.

Nursery Manual, Bailey, Macmillan Company.

Principles of Floriculture, White, Macmillan Company.

Farm and Garden Rule Book, Bailey, Macmillan Company.

Standard Cyclopedia of Horticulture, (6 vols.) Macmillan Company.

Productive Orcharding, Sears, J. B. Lippincott Company.

Principles of Fruit Growing, Bailey, Macmillan Company.

Injurious Diseases and Useful Birds, Washburn, J. B. Lippincott Co Pruning Book, Bailey, Macmillan Company.

American Apple Orchard, Waugh, Orange Judd Company.

Systematic Pomology, Waugh, Orange Judd Company.

Plums and Plum Culture, Waugh, Orange Judd Company.

Productive Small Fruit Culture, Sears, J. B. Lippincott Company.

Productive Plant Husbandry, Davis, J. B. Lippincott Company.

\section{USUAL DISTANCES APART FOR PLANTING VEGETABLES}

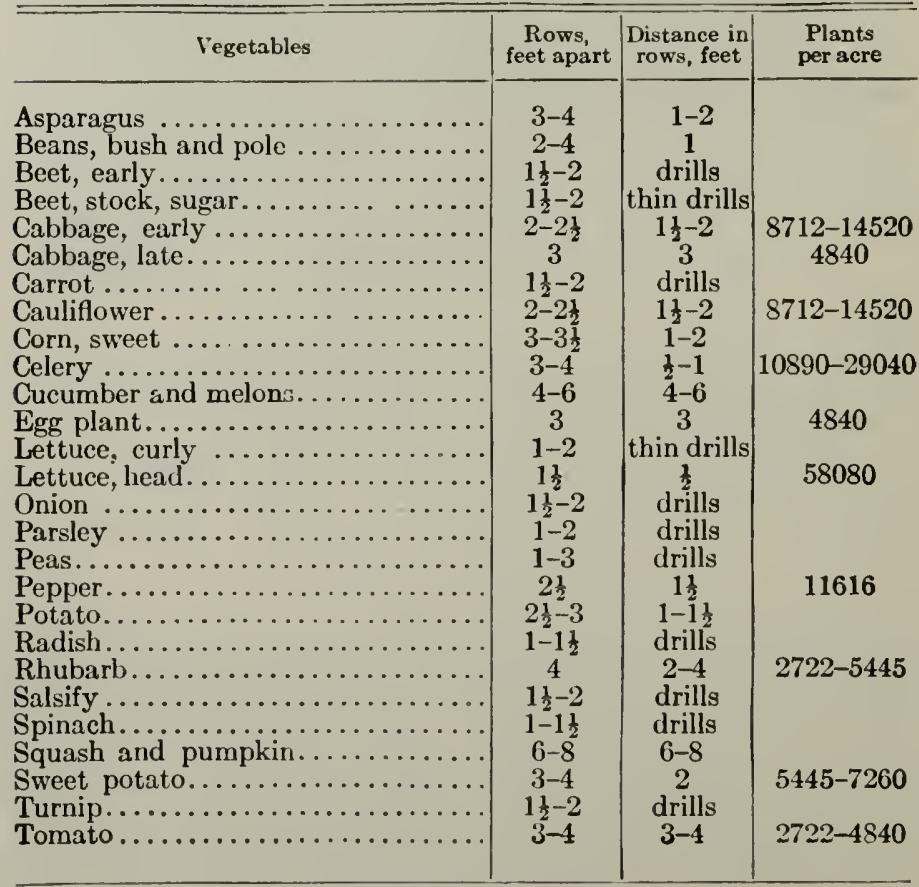




\section{VARIETIES OF VEGETABLES FOR GARDEN PLANTING.}

Asparagus,. . . . . . Palmetto, Columbia Thite, Colossal.

Beans, Bush....... Bountiful (early), Valentine, Refugee (extra early).

Beans, Lima....... Fordhook, Ford's Mammoth Podded. (Sce catalogs).

Beans, Pole........ Kentucky Wonder, Crease Back. (Sec catalogs).

Beets............. Basano (early), Crimson Globe.

Broccoli........... Early White Cape.

Brussels Sprouts ... Improved Half Dwarf.

Cabbage............ Charleston Wakefield (early), Succession (mid-season), Late Flat Dutch.

Cauliflower.......Early Snowball, Veitch's Autumn Giant.

Carrots........... Half Long Stump Rooted, Half-Long Danvers.

Celery .............. Golden Self Blanching (early), Giant Pascal (late).

Corn.............. Adam's Early Dwarf, Stowell's Evergreen (sweet), Country Gentleman (sweet).

Collards.......... Georgia.

Cress.............. Curled.

Cucumbers......... Im proved White Spine, Emerald, Green Prolific Pickling.

Egg Plant......... Ne w York Purple, Black Beauty, Florida High Bush.

Endive.......... Green Curled.

híale............ Early Curled Siberian.

Lettuce............Big Boston (early), Improved Hanson, Wood's Early Cabbage, Giant Crystal Head (late).

Mustard .......... Giant Southern Curled, Ostrich Plume.

Musk Melon...... Extra Early Hanover, Netted Gem, Rocky Ford, Perfection Melon.

Okra............. Clemson, Long White Velvet.

Onion............ Yellow Globe Danvers, Prize Taker, Extra Early White Pearl, Yellow Multiplier (fall).

Peas, Garden....... Philadelphia Extra Early, Horsford's Market Garden (medium), Telephone (late).

Pepper, Sweet...... Chinese Giant, Ruby King.

Pepper, Hot.........Long Red Cayenne.

Parsley ............. Moss Curled.

Parsnip............. Hollow Crown.

Potatoes, Irish..... Irish Cobbler, Carman No. 3, Early Triumph (p. 293).

Potatoes, Sweet.... Nancy Hall, Georgia, Yellow Jersey, Triumph.

Pumpkin.......... Sugar, Pie, Negro.

Radish..........Early White Tipped Scarlet, French Breakfast, Mammoth, Extra Early Scarlet.

Salsify ........... Mammoth Sandwich Island.

Spinach............ Long Standing.

Squash...........White Bush, Boston Marrow, Giant Summer Crookneck, Cushaw, Winter Hubbard.

Tomatoes.........Earliana, Acme, Stone, Ponderosa. (See next page).

Turnip.......... Extra Early Purple Top, Improved Red Top Globe, Seven Top (for greens), Yellow Aberdeen, Ru^a Baga.

Water Melon......Georgia Rattle Snake, Florida Favorite, Tom Watson, Kolb Gem (good shipper). 


\section{ESTIMATED YIELDS OF TOMATOES}

The Ohio Station gives the following yields in tons per aere of twentyone different varieties of tomatoes raised for canning.

\begin{tabular}{|c|c|c|c|c|c|}
\hline Variety & Season & 1915 & 1916 & 1917 & Average \\
\hline Bloomsdale . . . . . . . . . & Medium & & & 18.9 & 18.1 \\
\hline Bonny Best. . . . . . . . . . . & Medium & 5.9 & 11.2 & 8.2 & 8.1 \\
\hline 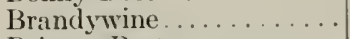 & Late & 2.7 & 7.9 & 7.3 & 5.9 \\
\hline Britons Best. & Medium & 5.0 & 15.9 & 12.3 & 11.0 \\
\hline Cumberland Red. & Late & 2.2 & 7.2 & 3.7 & 4.2 \\
\hline Delaware Beauty. & Late & 2.0 & 10.3 & 3.9 & 5.4 \\
\hline Early Jewell ...... & Medium & & & 12.7 & 12.7 \\
\hline Everlarge... & Late & 3.8 & 9.2 & 9.6 & 7.5 \\
\hline Greater Baltimore. . & Medium & & 9.0 & 6.6 & 7.8 \\
\hline Improved Stone......... & Late & 3.4 & 8.5 & 6.0 & 5.9 \\
\hline John Baer. . . . . . . . . . & Medium & & & 12.8 & 12.8 \\
\hline Landreth. . . . . . . . . . & Medium & 8.0 & 14.6 & 7.8 & 10.1 \\
\hline Matehless.. & Late & 2.5 & 6.7 & 4.3 & 4.5 \\
\hline My Maryland......... & Late & 2.7 & 11.1 & 4.6 & 6.1 \\
\hline No Substitute......... & Late & 3.6 & 15.2 & 7.2 & 8.6 \\
\hline Prosperity ........ & Medium & 6.2 & 15.2 & 10.8 & 10.7 \\
\hline Red Rock...... & Late & 3.8 & 7.8 & 4.5 & 5.4 \\
\hline Red Sunrise.... & Medium & & 17.0 & 10.1 & 13.5 \\
\hline Stone........... & Late & 3.2 & 9.4 & 3.2 & 5.2 \\
\hline San José Camner. . & Late & .6 & 13.6 & 6.6 & 6.9 \\
\hline Ten Ton........ & Late & 5.5 & 12.1 & 7.8 & 8.4 \\
\hline
\end{tabular}

\section{YIELDS OF STAKED TOMATOES AT WOOSTER}

Twelve varieties of tomatoes grown by the Ohio Station at Wooster were staked as in home gardens. The total yield in pounds of fruit per plant for three years, were recorded in the following table.

\begin{tabular}{|c|c|c|c|c|c|c|}
\hline \multirow{2}{*}{ Variety } & \multirow{2}{*}{ Season } & \multirow{2}{*}{$\begin{array}{l}\text { Size of } \\
\text { fruit }\end{array}$} & \multicolumn{4}{|c|}{ Yield per plant (pounds) } \\
\hline & & & 1914 & 1915 & 1916 & Average \\
\hline Beauty. & Late & Large & 4.1 & 5.3 & 4.8 & 4.7 \\
\hline Bonny Best. & Early & Medium & 7.1 & 3.3 & 4.0 & 4.8 \\
\hline Duke of York. & Late & Large & 4.3 & 4.0 & 3.0 & 3.7 \\
\hline Earliana...... & Very early & Medium & 4.1 & 5.0 & 4.9 & 4.6 \\
\hline Emperor.... & Late & Large. & 3.9 & 4.4 & 3.7 & 4.0 \\
\hline Hummer. . & Medium & Medium & 5.9 & 5.6 & 3.0 & 4.8 \\
\hline John Baer..... & Early & Medium & 6.1 & 4.9 & 4.5 & 5.1 \\
\hline MIagnus... & Late & Large & 5.3 & 5.2 & 2.7 & 4.4 \\
\hline Marketeer. . & Farly & Medium & 5.4 & 5.5 & 3.1 & 4.6 \\
\hline Noltes. & Early & Medium & 4.9 & 5.4 & 3.7 & 4.6 \\
\hline Pecrless. & Early & Small & 6.2 & 6.7 & 4.6 & 5.8 \\
\hline Red Rock. & Late & Large & 4.4 & 5.5 & 4.1 & 4.6 \\
\hline
\end{tabular}




\section{YIELDS OF POTATOES UNDER GARDEN CONDITIONS}

The Ohio Station gives the following classification and yield of the different varieties of Irish potatoes. The yields are for an a verage of two years, counting only the marketable potatoes.

\begin{tabular}{|c|c|c|}
\hline Group and type & Varieties & $\begin{array}{l}2 \text {-year average } \\
\text { yield of mar- } \\
\text { ketable tubers } \\
\text { per acre }\end{array}$ \\
\hline J-Cobbler. . & 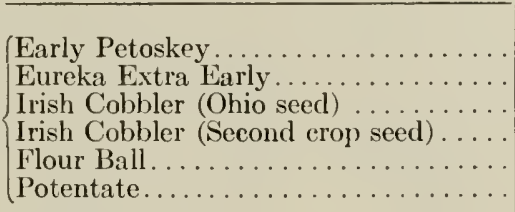 & $\begin{array}{c}\text { Bushels } \\
161.0 \\
71.9 \\
135.6 \\
222.1 \\
189.0 \\
122.3\end{array}$ \\
\hline II-Triumph. & 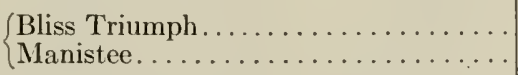 & $\begin{array}{l}204.0 \\
225.8\end{array}$ \\
\hline III-Early Michigan. & 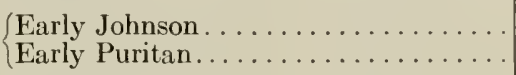 & $\begin{array}{l}108.7 \\
103.0\end{array}$ \\
\hline 1V-Rose. & 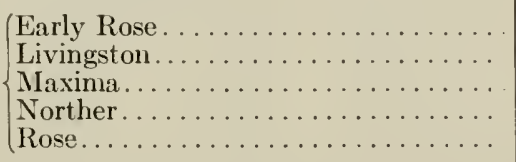 & $\begin{array}{r}\$ 3.1 \\
287.1 \\
190.4 \\
213.3 \\
196.4\end{array}$ \\
\hline V-Early Ohio... & 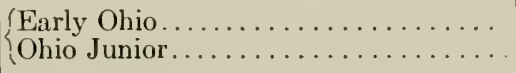 & $\begin{array}{r}117.7 \\
80.8\end{array}$ \\
\hline VI-Hebron. & $\left\{\begin{array}{l}\text { Crown Jewell } \ldots \ldots \ldots \ldots \ldots \ldots \ldots \ldots \ldots \\
\text { Early Bovee . . . } \ldots \ldots \ldots \ldots \ldots \ldots \ldots \ldots \ldots \\
\text { Early Harvest. . } \ldots \ldots \ldots \ldots \ldots\end{array}\right.$ & $\begin{array}{r}98.5 \\
229.1 \\
230.2\end{array}$ \\
\hline VII-Burbank. & 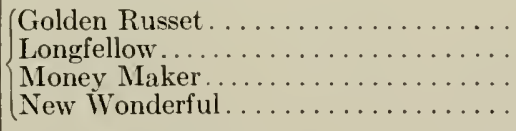 & $\begin{array}{r}94.3 \\
143.5 \\
140.4 \\
103.9\end{array}$ \\
\hline VIII-Green Mountain. & 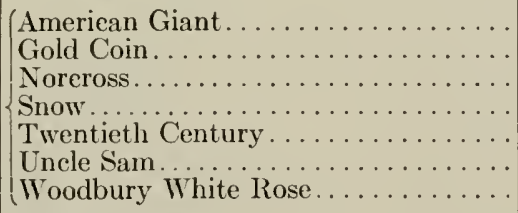 & $\begin{array}{l}108.0 \\
148.0 \\
111.8 \\
157.1 \\
176.7 \\
129.9 \\
185.2\end{array}$ \\
\hline IX-Rural. & 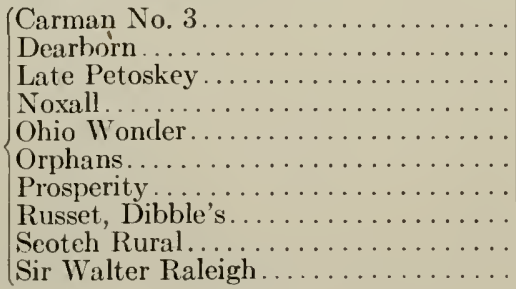 & $\begin{array}{l}167.6 \\
230.8 \\
173.7 \\
131.9 \\
164.6 \\
146.5 \\
155.9 \\
269.9 \\
129.0 \\
141.1\end{array}$ \\
\hline
\end{tabular}




\section{LOSSES IN CROP REMOVALS}

In the following table the amounts and commercial values of the three limiting elements removed per acre by several important vegetable and farm crops are presented. (From Illinois Station.)

Fertility Removed per Acre by Important Vegetables and Farm Crops ${ }^{1}$

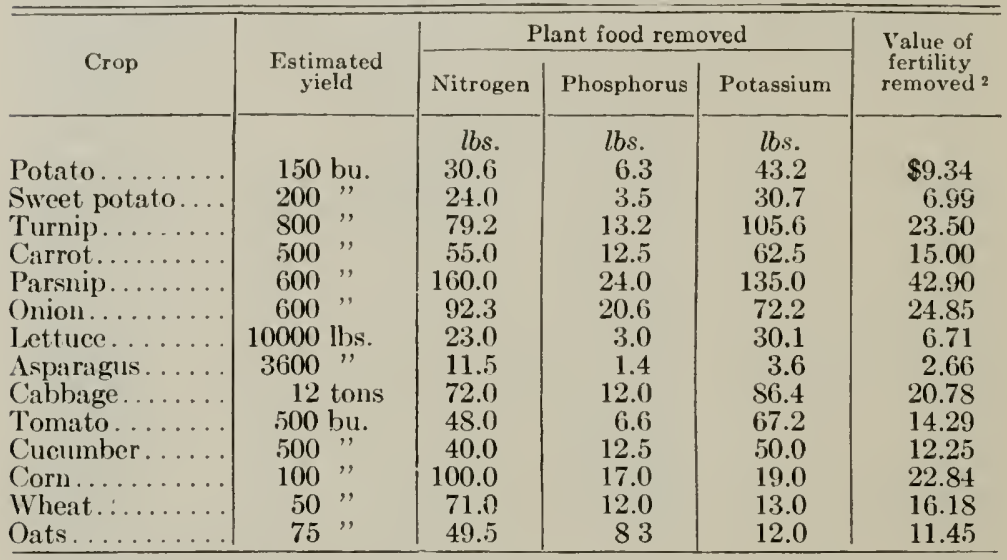

1 Compiled chiefly after Wolf and Goessinan.

2 In computing the values 1915 prices are used; 20 cents per pound has been allowed for the nitrogen, 10 cents for the phosphorus, and 6 cents for the potassium. These are the approximate prices prevailing at present for three elements in nitrate of soda, steamed bone neal, and potassium sulfate.

\section{SOURCES OF PLANT FOOD}

The following tables are taken from Illinois Station Circular 182.

Table 1.-Dry Matter and Nitrogen in Growth per Acre: (Delawaré Experiments) (Expressed in pounds)

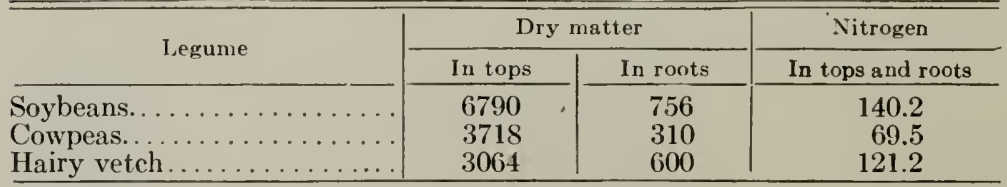

Table 2.-Dry Matter and Nitrogen in Growth per Acre: (Cornell Experiments) (Expressed in pounds)

\begin{tabular}{|c|c|c|c|}
\hline \multirow{2}{*}{ Legumr } & \multicolumn{2}{|c|}{ Dry matter } & \multirow{2}{*}{$\begin{array}{c}\text { Nitrogen } \\
\text { In tops and roots }\end{array}$} \\
\hline & In tops & In roots & \\
\hline $\begin{array}{l}\text { Hairy vetrh. } \\
\text { Cowpeas. . . . }\end{array}$ & $\begin{array}{l}6824 \\
2622\end{array}$ & $\begin{array}{l}567 \\
454\end{array}$ & $\begin{array}{r}256.1 \\
52.6\end{array}$ \\
\hline
\end{tabular}


Table 3.-Important Commercial Forms of Nitrogen.

\begin{tabular}{|c|c|c|c|}
\hline & $\begin{array}{l}\text { Pounds nitrogen }{ }^{1} \\
\text { per ton }\end{array}$ & $\begin{array}{c}\text { Cost } \\
\text { per ton }\end{array}$ & $\begin{array}{l}\text { Cost per } \\
\text { pound }\end{array}$ \\
\hline 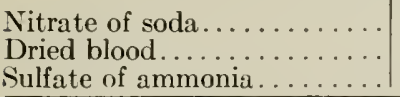 & $\begin{array}{l}310 \\
280 \\
400\end{array}$ & $\begin{array}{r}\$ 60.00 \\
54.50 \\
75.00\end{array}$ & $\begin{array}{r}.193 \\
.194 \\
.187\end{array}$ \\
\hline
\end{tabular}

${ }_{1}$ The amount of nitrogen varies, of course, with the grade.

Table 4.-Important Forms of Phosphorus.

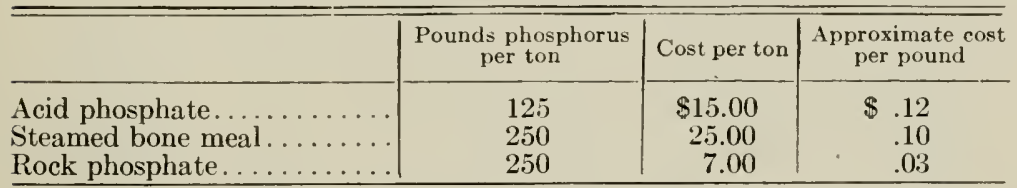

Table 5.-Important Forms of Potassium

\begin{tabular}{|c|c|c|c|}
\hline & $\begin{array}{l}\text { Pounds potassium } \\
\text { per ton }\end{array}$ & Cost per ton & Cost per pound \\
\hline $\begin{array}{l}\text { Muriate of potash } \ldots \ldots \ldots \ldots \\
\text { Sulfate of potash } \ldots \ldots \ldots \ldots \ldots \\
\text { Kainit . } \ldots \ldots \ldots \ldots \ldots \ldots \\
\text { Wood ashes } \ldots \ldots \ldots \ldots \ldots \ldots\end{array}$ & $\begin{array}{l}850 \\
850 \\
200 \\
100\end{array}$ & $\begin{array}{r}\$ 50.00 \\
55.00 \\
13.00 \\
7.00\end{array}$ & $\begin{array}{l}\$ .06 \\
.065 \\
.065 \\
.07\end{array}$ \\
\hline
\end{tabular}

\section{COST OF A YOUNG PEACH ORCHARD}

The following table shows a summary of the cost and income from a fifteenacre orchard at Wooster, Ohio, for each of the first six years, when the trees had reached their best paying age. (Ohio Station).

Summary for the First Six Years of a Peach Orchard-15 Acres

\begin{tabular}{|c|c|c|c|c|c|c|c|}
\hline Year. & Crop. & $\begin{array}{c}\text { Total } \\
\text { income. }\end{array}$ & $\begin{array}{c}\text { Total } \\
\text { cost. }\end{array}$ & $\begin{array}{l}\text { Income } \\
\text { per acre. }\end{array}$ & $\begin{array}{c}\text { Cost } \\
\text { per acre. }\end{array}$ & $\begin{array}{l}\text { Total } \\
\text { loss. }\end{array}$ & $\begin{array}{l}\text { Total } \\
\text { profit. }\end{array}$ \\
\hline 1907 & Corn & $\$ 509.50$ & $\$ 415.06$ & $\$ 33.96$ & $\$ 27.67$ & & $\$ 94.44$ \\
\hline 1908. & & & 225.25 & & 15.00 & $\$ 225.25$ & \\
\hline 1909 & & 65.00 & 204.60 & 4.33 & 13.64 & 139.60 & \\
\hline 1910 & & & 238.28 & & 15.88 & 238.28 & \\
\hline 1911. & Peach & $2,561.25$ & 773.03 & 170.75 & 51.52 & $\ldots \ldots \ldots$ & $1,788.22$ \\
\hline 1912. & Peach & $2,920.99$ & 832.84 & 194.74 & 55.52 & $\cdots$ & $2,088.15$ \\
\hline Totals. & & $\$ 6,056.74$ & $\$ 2,689.06$ & $\$ 403.78$ & $\$ 179.23$ & $\$ 603.13$ & $\$ 3,970.81$ \\
\hline
\end{tabular}

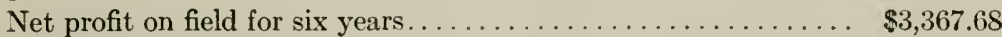

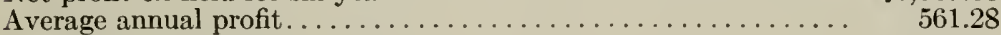

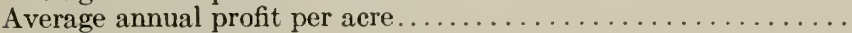

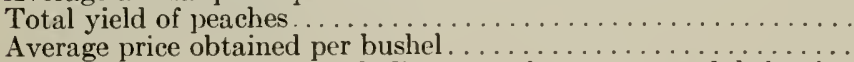

37.41

Total cost for six years, excluding cost of corn crop and deducting

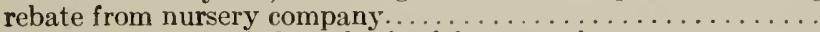

Average cost per bushel as obtained from total cost..........

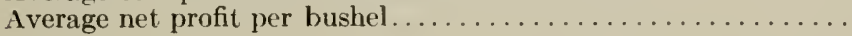

4,192 bu.

1.31

$2,395.08$ 
NUMBER OF SHRUBS OR PLANTS FOR AN ACRE

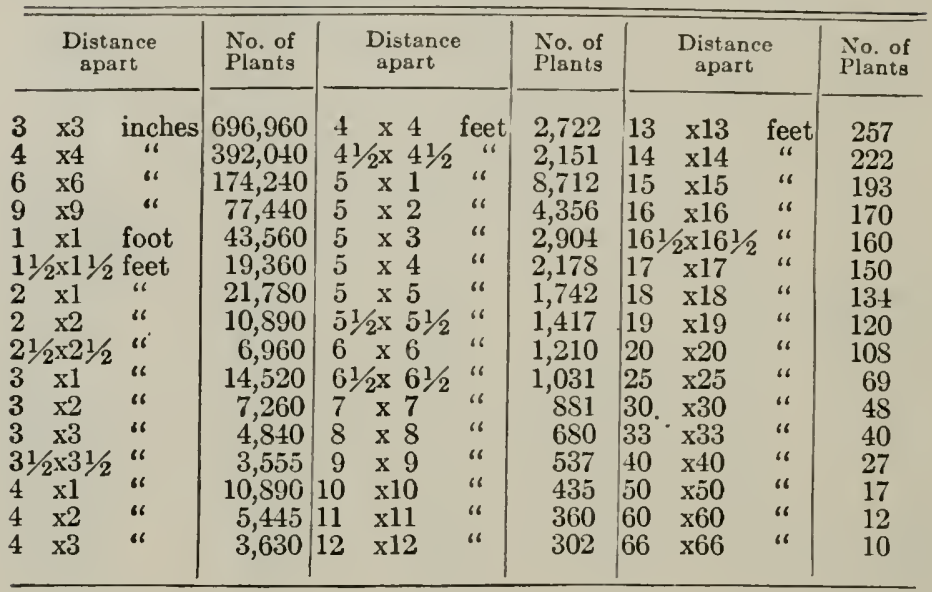

\section{SUITABLE DISTANCES FOR PLANTING}

Apples - Standard.................25 to 40 feet apart each way

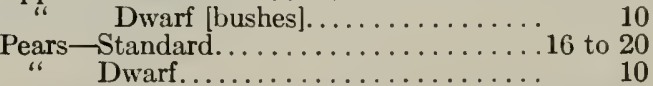

Cherries - Standard ...................... 18 to 20

" Dukes \& Morrellos.............16 to 18

Plums $\rightarrow$ Standard................16 to 20

Peaches......................... 16 to 18

Apricots........................ 16 to 18

Nectarines....................... 16 to 18

Quinces...........................10 to 12

Currants.............................. 3 to 4

Gooseberries..................... 3 to 4

Raspberries.................... 3 to 5

Blackberries................. 6 to 7

Grapes........................ 8 to 12

" " " " " "“ " " " " "

To estimate the number of plants required for an acre, at any given distance, multiply the distance between the rows by the distance between the plants, which will give the number of square feet allotted to each plant, and divide the number of square feet in an acre $[43,560]$ by this number. The quotient will be the number of plants required. 


\section{HOW TO MAKE LIME-SULFUR AND USE HYDROMETER}

How to Use the Hydrometer. - Nearly fill the glass cylinder with the concentrated material. Lower the hydrometer (Fig. 216) into it and note the reading at the surface of the solution. Record this number on the vessel.

For the proper dilution refer to the following table.

\begin{tabular}{|c|c|c|c|}
\hline \multirow{2}{*}{\multicolumn{2}{|c|}{ When hydrometer reads }} & Winter spray & Summer spray \\
\hline & & \multirow{2}{*}{$\begin{array}{l}\text { Use the following amounts } \\
\text { of lime-sulf ur to make } \\
50 \text { gallons of spray for } \\
\text { seale control. } \\
\text { Should test about } \\
5 \text { degrees Baumé }\end{array}$} & \multirow{2}{*}{$\begin{array}{l}\text { Use the following amounts } \\
\text { of lime-sulf ur to make } \\
50 \text { gallons of spray for } \\
\text { summer sprays on apples, } \\
\text { pears or cherries. } \\
\text { should test about } \\
1 \text { degree Baumé }\end{array}$} \\
\hline $\begin{array}{l}\text { Specific } \\
\text { gravity }\end{array}$ & $\begin{array}{l}\text { Degrees } \\
\text { Baumié }\end{array}$ & & \\
\hline 1.318 & 35 & $5 \mathrm{gal} .1 \mathrm{qt}$. & 1 gal. 1 pt. \\
\hline 1.306 & 34 & 5 gal. 2 qt. & 1 gal. 112 pt. \\
\hline 1.295 & 33 & 5 gal. 3 qt. & 1 gal. $1 \mathrm{qt}$. \\
\hline 1.283 & 32 & 6 gal. & 1 gal. 1 qt. $1 / 2$ pt. \\
\hline 1.272 & 31 & 6 gal. 1 qt. & 1 gal. 1 qt. 1 pt. \\
\hline 1.261 & 30 & 6 gal. 3 qt. & $1 \mathrm{gal} .1 \mathrm{qt} .11 / 2 \mathrm{pt}$. \\
\hline 1.250 & 29 & 7 gal. & 1 gal. 2 qt. \\
\hline 1.239 & 28 & 7 gal. 1 qt. & 1 gal. 2 qt. $1 / 2$ pt. \\
\hline 1.229 & 27 & 7 gal. 3 qt. & 1 gal. 2 qt. $11 / 2$ pt. \\
\hline 1.218 & 26 & 8 gal. 1 qt. & 1 gal. 3 qt. \\
\hline 1.208 & 25 & 8 gal. 3 qt. & 1 gal. 3 qt. 1 pt. \\
\hline 1.198 & 24 & 9 gal. 1 qi. & 2 gal. \\
\hline 1.188 & 23 & 9 gal. 3 qt. & 2 gal. 1 pt. \\
\hline 1.179 & 22 & 10 gal. 2 qt. & 2 gal. 1 qt. \\
\hline 1.169 & 21 & 11 gal. 1 qt. & 2 gal. 1 qt. $11 / 2$ pt. \\
\hline 1.160 & 20 & 12 gal. & 2 gal. 2 qt. 1 pt. \\
\hline 1.151 & 19 & 12 gal. 3 qt. & 2 gal. 3 qt. $1 / 2$ pt. \\
\hline 1.142 & 18 & 13 gal. 3 qt. & 3 gal. \\
\hline 1.133 & 17 & 14 gal. 2 qt. & 3 gal. 11/2 pt. \\
\hline 1.124 & 16 & 15 gal. 2 qt. & 3 gal. i qt. 1 pt. \\
\hline
\end{tabular}

For those who may be interested in making their concentrated lime-sulfur solution the following directions should be followed: Slake. forty pounds of high grade freshly burned lime in an iron kettle, then carefully sift in eighty pounds of flowers of sulfur, stir to make a uniform paste and add enough water to make fifty gallons of solution. Bring this to a boil and boil for one hour, taking care at all times to add enough water to keep the volume as near fifty gallons as possible. This material will boil over very easily unless it is stirred frequently. If it should get beyond control add some cold water suddenly and reduce the fire.

This will make a concentrated solution which when cool should test between 24 degrees and 26 degrees Baumé. Strain it and store in a good barrel. (Indiana Station.) 


\section{DILUTION TABLE FOR LIME-SULFUR SOLUTIONS.}

Commercial concentrated lime-sulfur testing 33 degrees should be used as a dormant spray at the rate of one gallon to cight of water, and as a summer spray at the rate of one gallon to forty of water. When using the weaker home-made solutions they must be diluted to a less degree to give the same strength. The amount of this dilution for any strength between 15 and 36 degrees Bealumé (Fig. 216) is given in the following dilution table. (West Virginia station.)

\begin{tabular}{|c|c|c|}
\hline \multirow{2}{*}{$\begin{array}{l}\text { Reading on } \\
\text { Beaumé } \\
\text { lyydrometer }\end{array}$} & \multicolumn{2}{|c|}{ Number of gallons of water to one gallon of lime-sulfur solution } \\
\hline & $\begin{array}{l}\text { For San Jose scale. } \\
\text { Dormant spraying only }\end{array}$ & For sumner spraying \\
\hline 36 degrees & 9 & 45 \\
\hline $35 \pi$ & $8^{3} / 4$ & $431 / 4$ \\
\hline 34 & $81 / 4$ & $41 \frac{1}{2}$ \\
\hline $33 \quad 4$ & 8 & 40 \\
\hline $32 \quad 6$ & $71 / 2$ & $373 / 4$ \\
\hline $31 \quad " 6$ & $71 / 4$ & $361 / 4$ \\
\hline $30 " 6$ & $63 / 4$ & $341 / 4$ \\
\hline 29 & $61 / 2$ & $323 / 4$ \\
\hline 28 “ & 6 & 31 \\
\hline 27 & $53 / 4$ & $291 / 2$ \\
\hline 26 & $51 / 4$ & $273 / 4$ \\
\hline 25 & 5 & 26 \\
\hline 24 & $41 / 2$ & $241 / 4$ \\
\hline 23 & $41 / 4$ & 223 \\
\hline 22 & $33 / 4$ & $211 / 4$ \\
\hline 21 & $31 / 2$ & $193 / 4$ \\
\hline 20 & $31 / 4$ & $181 / 4$ \\
\hline 19 & 3 & 17 \\
\hline 18 & $23 / 4$ & 16 \\
\hline 17 & $21 \frac{1}{2}$ & 15 \\
\hline 16 & $21 / 4$ & 14 \\
\hline 15 & 2 & $123 / 4$ \\
\hline
\end{tabular}




\section{GUIDE FOR BOX PACKING OF APPLES}

Apples are usually packed in boxes with the stems down, until the top layer is reached when they should be packed stem end up. When the cheek pack is used with the apples on their sides the eore line may be parallel to the box side or diagonal to it. Apples are never packed crosswise of the box or with the core line at right angles to the box side.

When the sizing and grading for box packing has been done and the fruit is ready to be packed, the following table will be found helpful in deciding what pack to use. The completed box should be stenciled on one end with (a) The name and address of the packer (b) The variety and grade of apples (c) The tier and number of contained fruits. (Indiana Station.)

\begin{tabular}{|c|c|c|c|c|c|c|c|}
\hline \multicolumn{3}{|c|}{$\begin{array}{l}\text { Approximate } \\
\text { lateral } \\
\text { circumference } \\
\text { of apple }\end{array}$} & \multirow{3}{*}{$\begin{array}{l}\text { Style of pack } \\
\text { Straight } 3 \\
\text { Straight } 3\end{array}$} & \multirow{3}{*}{$\begin{array}{c}\begin{array}{c}\text { Number } \\
\text { apples } \\
\text { per box }\end{array} \\
45 \\
54\end{array}$} & \multirow{3}{*}{$\begin{array}{c}\begin{array}{c}\text { Layers and } \\
\text { number in } \\
\text { each }\end{array} \\
3 \times 15 \\
3 \times 18\end{array}$} & \multirow{3}{*}{ 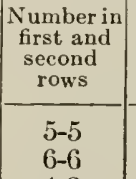 } & $\begin{array}{c}\text { Box } \\
\text { marked }\end{array}$ \\
\hline A & 12 in & ches & & & & & 3 tier \\
\hline $\mathrm{B}$ & 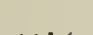 & 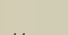 & & & & & 3 \\
\hline $\mathrm{C}$ & $11 \frac{1}{2}$ & " & 2-2 Diagonal & 56 & $4 \times 14$ & $4-3$ & $31 / 2 "$ " \\
\hline D & & 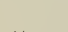 & Straight 3 & 63 & $3 \times 21$ & $7-7$ & 3 \\
\hline $\mathrm{E}$ & 11 & $"$ & 2-2 Diagonal & 64 & $4 \times 16$ & $4-4$ & $31 / 2 "$ \\
\hline$F$ & $10^{3} / 4$ & " & 2-2 Diagonal & 72 & $4 \times 18$ & $5-4$ & $31 / 2 " 6$ \\
\hline G & $101 / 2$ & $" 6$ & 2-2 Diagonal & 80 & $4 \times 20$ & $5-5$ & $31 / 2 " 6$ \\
\hline H & 10 & "6 & 2-2 Diagonal & 88 & $4 \times 22$ & $6-5$ & $31 / 2$ \\
\hline J & $\begin{array}{l}97 / 8 \\
03\end{array}$ & " & 2-2 Diagonal & 96 & $4 \times 24$ & $6-6$ & $31 / 2 "$. \\
\hline II & $9 \% / 4$ & & 2-2 Diagonal & 104 & $4 \times 26$ & $7-6$ & $31 / 2$ tier \\
\hline L & $91 / 2$ & $"$ & 3-2 Diagonal & 113 & $\begin{array}{l}3 \times 23 \\
2 \times 22\end{array}$ & $5-4$ & $41 / 2$ \\
\hline M & 9 & $"$ " & Straight 4 & 96 & $4 \times 24$ & $6-6$ & \\
\hline $\begin{array}{l}\mathrm{N} \\
0\end{array}$ & & & Straight 4 & 112 & $4 \times 28$ & $7-7$ & 4 \\
\hline 0 & & & 3-2 Diagonal & 125 & $5 \times 25$ & $5-5$ & $41 / 2 "$ \\
\hline $\mathrm{Q}$ & & & 3-2 Diagonal & 138 & $\begin{array}{l}3 \times 28 \\
2 \times 27\end{array}$ & $6-5$ & $41 / 2$ \\
\hline $\mathrm{R}$ & $87 / 8$ & " & 4-4 Offset & 140 & $5 \times 28$ & & $41 / 2 " 6$ \\
\hline S & $8 \frac{1}{2}$ & $"$ & 3-2 Diagonal & 150 & $5 \times 30$ & $6-6$ & $4 \frac{1}{2} "$ \\
\hline $\mathrm{T}$ & & & 3-2 Diagonal & 163 & $\begin{array}{l}3 \times 33 \\
2 \times 32\end{array}$ & $7-6$ & $41 / 2 "$ \\
\hline $\mathrm{U}$ & 8 & " & 3-2 Diagonal & 175 & $5 \times 35$ & $7-7$ & $4 \frac{1}{2} "$ \\
\hline W & & & 3-2 Diagonal & 188 & $\begin{array}{l}3 \times 38 \\
2 \times 37\end{array}$ & $8-7$ & $41 / 2 "$ \\
\hline $\begin{array}{l}X \\
Y\end{array}$ & $71 / 2$ & "6 & Straight 5 & 200 & $5 \times 40$ & $8-8$ & 5 \\
\hline$Y$ & & & Straight 5 & 225 & $5 \times 45$ & $9-9$ & 5 \\
\hline
\end{tabular}


QUALITY IN APPLES (OHIO AND OREGON STATIONS).

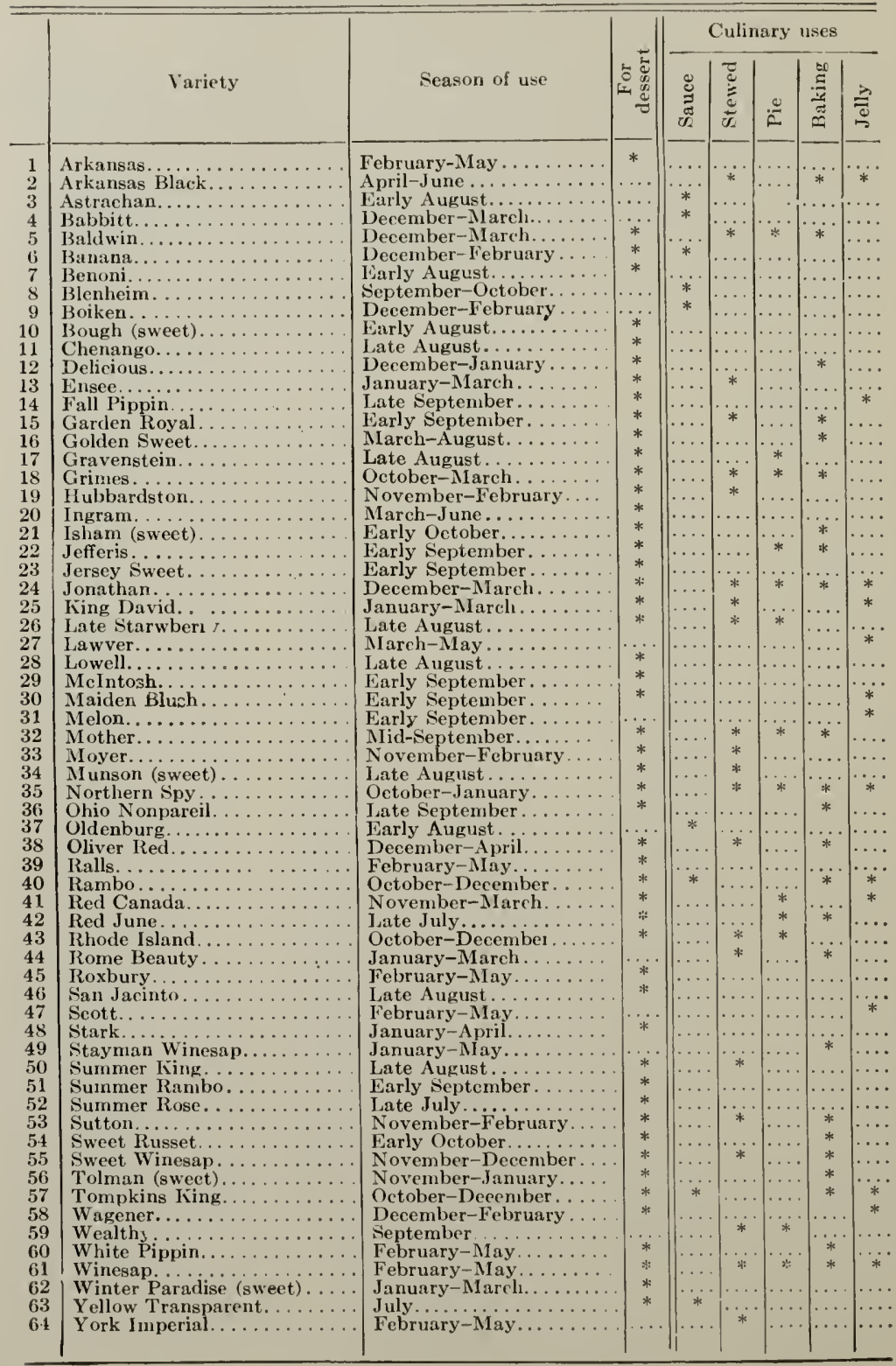




\title{
SHRUBBERY LIST
}

The following is a list of the best hardy flowering shrubs for mass planting. The list includes those most easily grown, and which are very ornamental in planting the home grounds. These are suitable for use in humid climates, both south and north. Those marked with star are also very suitable for hedges. The color and approximate season of bloom, or showy parts, are given after the name. The numbers indicate height in feet.

Almond, flowering, rose, early, 2-3.

Azalea, flame-colored, orange, early, 6-7.

*Barberry, Japanese, red berries in winter, 3-4.

Buddleia, hybrid, violet, summer, 4-6.

Buffalo berry, (Shepperdia argentea), yellowish, fruit edible, 6-10.

Burning bush, yellow, early, s-10.

Cranberry, highbush, white, early, 7-8.

*Deutzias, white, early, 5-8, slender 2-3.

Dogwood, red osier, white, summer, 6-S.

Dogwood, Siberian, nearly white, June, 6-8.

Elder, American, white, summer, 8-12.

Elder, golden, white, sumner, 6-8.

*Forsythia, "golden bell," yellow, early spring, 7-8.

Hazel nut, American, leaves purple, spring, 4-7.

Hibiscus or rose of Sharon, various colors, late summer, 8-10.

Honeysuckle, fragrant (semi-hardy), pink, early, 6-8.

Honeysuckle, Tartarian, white to pink, early summer, 6-8.

Hydrangea, large-flowered, whitish, late summer, 6-7.

*Lilac, common purple or white, early, 6-10.

*lilac, Persian, purple, early, 6-S.

Mock orange (Philadelphus), white, early summer, 6-8.

*Privet, California, (semi-hardy), whitish, summer, 4-10.

*Privet, common, whitish, summer, 4-10.

*Privet, iboda, fruit blue, late, 4-8.

*Quince, Japanese, crimson pink, spring, 4-6.

Rhododendron, (semi-hardy), rose, summer, 8-10.

*Rose, Japanese, pink, white, summer, 4-6.

Rose, prairie, pink, summer, 5-6.

Sheepberry, (V. lentago), white, early, 8-10.

Snowball, Japanese, and common, white, early, 6-8.

Snowberry, white-fruited, pink, summer, 3-5.

Spirea arguta, white, summer, 5-6.

Spirea, bumalda, pink, summer, 2-3.

Spirea, Thunberg's, white, early, 3-4.

* Spirea, Van Houtti's, white, early, 5-6.

Sumac, (R. Canadensis), yellow, early, 3-6.

Tamarix, pink, summer, 4-7.

Weigelia, species white or crimson, early summer, 4-7.

\section{HARDY VINES WITH BEST SUPPORTS}

\author{
Akebia, (semi-hardy), twining on trellis. \\ Bitter-sweet or wax-work, trellis. \\ Clematis, panicled, trellis and fence. \\ Clematis, Virginia, trellis and fence. \\ Evonymus radicans, (spindle vine), masonry walls and stumps. \\ Grapes, on fence and trellis. \\ Honeysuckle, Japanese, trellis and fence. \\ Ivy, Boston or Japanese, wood, brick, and stone walls and buildings. \\ Ivy, English (semi-hardy) stone walls and woody surfaces. \\ Pipe vine, Dutchman's pipe, trellis. \\ Roses, climbing, white to red, trellises. \\ Trumpet vine, hardy species, walls, stumps, etc. \\ Virginia creeper, fences, trellises and old trees. \\ Virginia creeper, Engleman's, brick and stone walls and buildings. \\ Wisteria, American, on fence and trellis.
}





\section{INDEX}

Acme harrow, 332

Air for plants, 2

Almonds, 270 acreage map, 279

Ammoniacal copper carbonate, 306, 320

Analysis of seeds, 19

Annual flowers, 379, 381

Annuals, choice of, 379 colors of, 381-2 ornamental, 374,376

Aphids, 314,320

Apple, acreage map, 174

bitter rot, 199

borers, 196-7

canker, 201

chapter on, 173

curculio, 202

dwarf, 183

frog-eye, 201-2

harvesting, 186

orchard, exposure, 173

orchard work, 329

packing in boxes, $190-1$

planting, 176

rust, 200-1

scab, 198, 309, 320

scab remedies, 198

soils, 173

spraying, year's work, 333

storage, 187

sun scald, 201

tree, top-worked, 187

twig blight, 199

varieties of, 175

Apples, box packing, 399

enemies of, 195

forms of, 193

per box, 399

propagation of, 53

quality of, 400

spraying, 196

top-working, 55

uses of, 400

varieties of, 400

Apricot, 228

April fruit and orchard work, 338, 342

garden work, 117, 161

home grounds in, 338,342

Aquarium, 7

Arsenate of lead, 311,320

of lead with lime-sulfur, 311
Arsenic, white, 310

Arsenite of zinc, 311

Artichoke, globe, 118

Jerusalem, 119

Ashes for lime and potash, 296-7

Asparagus, 116

forcing, 120

August garden work, 150, 166

home grounds in, 340,343

orchard and fruit work, 310,343

Authors, Horticultural, referred to

Agee, 302

Bailey, 60, 390

Cook, 9

Corbett, 390

Davis, 60, 105, 390

Georgia, 354

Lloyd, 80, 105, 390

Pammel, 354

Roberts, 302

Sears, 60, 346, 390

Washburn, 389, 390

Watts, 390

Waugh, 60, 232, 316, 383, 390

White, 390

Avacado, figured, 277

orchard, 278

propagation, 278

yield and harvest, $27 \mathrm{~S}$

Barn swallow, 387

Barnyard manure, 290-1

Barrel sprayers, 318,322

Baumé test, 308, 397, 398

Beans, 122

bush, 123

lima, 122-3

Bedding sweet potatoes, 141

Beets, 114

Benefits of beautifying, 366, 375

Berry boxes, 343

Bird boxes, 384

contests, 385-9

exercises, 3SS-9

nests, 381,386

shelf for food, 385

studies, 3S8-9

tray for food, 38:

Birds, attracting, 381

chapter on, $3 \mathrm{~S} 1$

destroyed by dogs, 386

feeding, $355-7$ 
Birds, fruit shrubs for, 384

in winter, $387-8$

knowing, $38 \mathrm{~S}$

watering, 387

Biting insects, fighting, 312

poisons for, 310

Bitter rot, 199

Blackberry enemies, 262

locations, 258

marketing, 262

permanency, 262

picking, 262

planting, 261

protection, 262

pruning, 261

section, 258

soils, 258

varieties, 258, 261

uses, 262

"Black leaf 40," 320

Black rot of grapes, 250

Blasting for orchards, 298

Blooming seasons of flowers, 380

Blossoming dates, 221, 232

Blossoms, strawberry, 234

Blueberry planting and care, 267 section, 266

soils, 267

uses, 267

Book authors, see Authors

Books for libraries, 390

Bordeaux mixture, 304-5, 320

Border, vege table, 65

Borders, flower, 378

Borers of apples, 196-7 grapes, 249

peaches, $215,217,218$

Box packing guide, 399

Breathing by leaves, 3

Breeding applied in garden and orehard, 22 of plants, 22 pluts, 28

Bridge grafting, 56

Broccoli, 101

Brown rot of cherries, 227 peaches, 218-9 plums, 231

Brussels sprouts, 101

Bucket pump, 318

Buckwheat, wild, 353

Bud formation, 7, 9 scales, 7

Budding and grafting, 49

chip, 53

flute, 53

June, 51
Budding and grafting, materials for, 51 methods of, 49,60

peaches, 50

prong and plate, 52

September, 50 .

shield, 49,50

types of, 52

Buds, fruit, 8

kinds of, 8

Bulblets, 36

of hyacinth, 37

Bulbous plants propagated, 34

Bulbs, multiplying by, 38

of different types, $34,35,38$

winter and spring, 380

Buttercup, division of, 36

Building, beautified, $368,373,376$, 377

tall, 367

Buildings, planting to suit, 367 well located, 369

Bulletin references, end of each chapter

Bush fruits, acreage map, 252

chapter on, 252

exercises, 269

picking, 269

projects, 269

propagation, 269

surveys, 269

Cabbage, 98

in flat, 91

resistant to yellor:s, 100

types of heads, 99

Calcium, 6

Calendar for spraying, 318, 320, 321

of fruit work, 338, 311

of garden work, 146,157

Callousing cuttings, 40

Canker on apple, 201

worm, 197

worms on apple, 313

Canning vegetables, 119

Cantaloupes, 127

Carbon, 6

Carbonate of copper, 306

Carbon dioxide obtained by plants, 2

Carrots, 112

Castor beans, 376

Catalpa seedlings, 360

Cats destroy birds, 385 protection from, 385

Cauliflower, 101, 102

Cedar apple, 200

trees, 359

Celeriac, 104 
Celery, 102, 105

blanching, 103

Characteristies, power to impress, 23

Characters, dominant, 24

pairs of, 26,27

recessant, 24

Chard, Swiss, 109

Cherries and plums, chapter on, 222 enemies of, 226

picking, 226

propagation, $51,52,60$

uses of, 226

Cherry, acreage map, 223

Montmorency, 224

orchard cultivation, 225

orchard location, 223

propagation, 221

pruning, 225

soils, 222

sour, 222

starting the orchard, 224

varieties, 223

Chestnuts, 270

Chip-budding, 53

Chives, 109

Chlorophyll, disappearance of, 8 in leaves, 3,8

Christmas rose, 34

Citrus fruit exercises, 278 section, 278

Cleft grafting, 55, 56

Cleistagamous flowers, 13

Clematis, panicled, 375

Clumps of shrubs, 373

Codling moth, 195-6 remedies for, $195-6$

Coldframe and hotbed, 85 cabbage in, 86

chapter, 81

contest, 88

studies, 88

uses of, 86

Collards, 110

Compressed air sprayers, $318-9$

Contact insecticides, 313,320

Contest in attracting birds, 388-9

in beautifying, 382

in fruit scoring, 192

in seed saving, 20

in strawberries, 240

with hotbeds, etc., 88

Cool season crops, 90, 91, 92, 95, 106

Co-operative packing, 329

Copper sulfate, 306,320

Corn breeding, 29

field. 122

improving, 29, 30, 32
Corn breediug, pop, 122 salad, 98 sweet, 121

Cost of peaches, 395

Cover crop in gardens, 288 peaches, 208 vineyard, 248

Cover crops, 74, 80, 180

Cowpeas for orchards, 298

Crab grass, 359

Cranberry, care, 268

flooding, 267

gathering, 268

planting, 268

propagation, 268

section, 267

soils, 267

uses, 268

Cress garden, 98

upland, 111

Cross, pollination, 12

Crude oil emulsion, 314

Cucumber, 126 salting and pickling, 130

Cultivating with horse, 162

Cultivation of strawberries, 237

Culture of cranberries, 268

currants, 264

flowers, 380

gooseberries, 266

grapes, 244

orchards, 179, 300

oranges, 281

pineapples, 274

years', orchard, 330

Curculio bites, 336

on core fruits, 202

on plum, 217

Currant, cultivation, 264

enemies, 265

fertilizing, 264

leaf-spot, 265

locations, 263

maggot, 265

mulching, 264

picking, 264

planting, 264

pruning, 264

renewals, 265

sawfly, 245

scale, 265

section, 263

soils, 263

types and varieties, 263

Cuttings and layerings, 39 callousing, 40

care of, 41 
Cut tings and layerings, examples of, 43 green wood, 42,47

hard wood, 40

how stored, 40

management, 44

planting, 40

principles of, 43

root, 39,47

stems for, 39

trees and shrubs grown from, 42 , 147

types of, $39,40,47$

Cut worms, 317

December garden work, 156,170

home groumds in, 341,345

orchard and fruit work, 341,345

De Vries, 23

Dewberries, 263

Diseases, blackberry, 262

collecting, 202

currant, 265

fruit, 320,321

gooseberry, 266

grape, 249,250

orange, 282

preventing, 309

raspberry, 257

strawberry, 239

Disk harrow, 331

Dividing and transplanting, 34

Division of roots, 33

Dogs, damage by, 386

Downy mildew on grapes, 249

Drainage, 74,80 work by students, 154

Drouth resistance, 236, 239

Drying vegetables, 119

Duster at work, 326

Dusting potatoes, 144 vs. spraying, 324,325

Dwarf apple trees, 183

Ear-row system, 30

Eggplant, 125-6

Emulsions of oil, 313-4

Endive, 112

Enemies, combating, 202

losses from, 202

of apple, pear, quince, 195

of cherries, 226

of plants, 3

of plums, $2: 31$

Evaporation from leaves, 6

Exereises at close of each chajpter bush iruit, 269

forest, 365
Exercise at close of each chapter grape, 251

lrome grounds, 382

orchard, 221, 232

pruning, 346

soil improvement, 301

spraying, 327

strawberry, 240

weed, 354

with birds, 388-9

fruit, 192

orchard enemies, 202

wood lot, 365

Exhibits of fruit, 192

garden products, 130, 153, 169 scoring, 192

Exposure for orchards, 173, 192, 203, 223,228

Farmers' bulletins, end of each chapter

Farm garden, 67, 68, 69

February garden work, 146, 159

home grounds in, $337,3 \pm 1$

orchard work, 337,341

Feeding birds, 387, 389

Fertility, forms of, 395

from legunies, 394, 395

removed by crops, 394

Fertilizer, commercial, 291

effect in orchard, 291

formulas, 291

home mixtures, 292

materials, collection of, 9 need of, 292

Fertilizers in gardens, $72,73,80$

for Irish potatoes, 133, 144

Fertilizing currants, 264

grapes, 245

orchards, 180, 211, 213, 221, 232, 291

strawberries, 237

Field and laboratory exercises, close of each chapter

Field studies of weeds, 354

Figs, 272 caprification of, 273

Fillers in orchards, 207, 210

Five-finger, 351

Fixation of type, 25

Flat of cabbage, 91

Flats in hotbeds, 82 making, 92 transplanting into, 93

Flicker, 388

Flooding cranberries, 267

Flower borders, $37 \mathrm{~S}$ 
Flower borders, parts of, 10, 11 pit chapter, 81 planting, $37 \mathrm{~s}$ structure shown, 11 studies, SS

uses, 57

work, see each month

Flowering tables, 380-1

Flowers, annual, 379, 381, 382

best use of, 380-1

color of, 380, 381-2

diøeeious, 11

distances for, 380-1

heights of, 380-1

moncecious, 11

of several types, 11

perfect, 11

show of, 379

Flute buclding, 53

Foliage plants, 382

Food in seeds, 20

Food supply for plants, 2

Foreing asparagus and rhubarb, 120

Forest benefits, 364

carpet, 365

harvesting, 361-2

nursery, 360

planting and care, 361

profits, 363

projects and exercises, 365

studies, 365

Formal gardening, 374

Frames for beds, 85

hotbeds, 81

Freezing, resistance to, 105, 119

Frog-eye on apple leaf, 201-2

Fruit-bearing shrubs, 384, 389, 401

Fruit barrel, press and clamp, 189

buds, 8

descriptions, 192

exhibits, scoring, 192

reminders, see months

spurs, 181

table for packing and sorting, 188

Fruits, time to spray, 320

Fungicides, using, 309, 320, 321

Garden calendar, 146, 157

eity, 65

cleaning up season, 171

cover crops, 74

cress, 98

drainage, 74

farm, 67-8-9

for all seasons, 70

irrigation, $74-5$

planned with long rows, 158
Garden calender, practices against insects, 317

products, exhibits of, $130,153,169$

projects, 79, 130

seeds, saving, 14

small market, 68

soils, 71,80

surveys, 79

tenement, 377

tillage, $72-3$

truck, 69,79

Gardening, 61

back yard, 66

door-yard, 62

fertilizers in, 73

horse-culture, 67

importance of, 61

landscape, 366

plan for, $63,64,65,68,69,79$

projects, 66,79

tools for, $62,64,65,70,75,76,77$ 79,108

Garlic, 108

Gas sprayers, 319

Gasoline engine sprayers, 323

Germination, conditions for, 4 exercises in, 8 of seeds, 3

Glass for hotbeds, 81

Globe artichoke, 118

Golden rod, 352

Gooseberry culture, 266

enemies, 266

harvesting and use, 266

section, 265

varieties, 265

Gourds, ornamental, 375

Grafting, 49, 53

bridge, 56

cleft, 55,56

cutting method, 57

inlaying, 57

saddle, 57

shield, 57

side, 57

splice, 57

tongue, 53

top-working, 57, 60

types of, 57,60

veneer, 57

wax making, 58, 60

Grafts, setting, 54

Grape flea-beetle, 247

leaf-folder, 246

leaf-hopper, 246

phylloxera, 249

projects, 251 
Grape flea-beetle, root-borer, 249 soils, 241 winter cover crop, $24 \mathrm{~S}$

Grapefruit acreage map), 279 culture, 282

Grapes, chapter on, 241 cultivating, 244 Downy mildew on, 247 enemies of, 246 to 251 fertilizing, 245 from cuttings, 44,47 location for, 241 marketing, 246 packing, 246 picking, 245 pruning, 243 rose chafer on, 247 rots on, 250 starting, 242 trellising, 242, 248, 251 varieties of, 241

Green manure, 289 manuring, 180 wood cuttings, 42

Greens, short season, 92 . that endure summer heat, 91

Grounds, beautifying, 366 cost to improve, 366 home, 366 plans for, 370,372 scoring, 382 see each month well planted, 368

Grasses for lawns, 376 in orchards, 351 starting, 377

Gullying, study of, 363

Hardwood-evergreen mixture, 360 Hardy vegetables, 89

Harrows, 331-2

Harvesting apples, 186 avocadoes 278 blackberries, 262 bush fruits, 269 cherries, 226 cranberries, 268 currants, 264 forest trees, 361-2 gooseberries, 266 grapes, 245 olives, 274 oranges, 281-2 peaches, 214, 330 pears, 190 pineapples, 275 plums, 230
Harvesting raspberries, 254 st rawberries, 238

Hill-row improvement of potatoes, 29 strawberries, 237

Heading, high, 179 height of, 178

Hedge rows of strawberries, 236

Heclges, formal, 374 to plant, 371,401

Heeling in trees, 177, 208

Hellebore, 312

Herbs, propagation of, 33

Heredity, 22

Home gardening, 61, 64 grounds, by months, 337,341 chapter on, 366 plans for, $370-1,352$ seoring, 382 see each month

Home projects, garden, 66, 78, 79 close of each chapter

Home vegetable garden, 61

Horse-culture gardening, 67

Horse radish, 115 preserving, 119

Horticulture, books on, 390

Hose for spraying, 323

Hotbed becomes coldframe, $s t$ contest, 88 studies, 88 watering, 84

Hotbeds, elhapter on, 81 drawing of, $\$ 3$ frames for, 81 flats for, 82 glass for, 81,84 how heated, 82 placing, 82 ventilation of, 82

Humus, adding, 289 for gardens, 7280

Hyacinth section, 37

Hybridizing, project in, 31

Hybrids, 21

Hydrastis, division of, 36

Hydrogen, 6

Hydrometer test for sprays, 308 tests. 397

Hydrophytes, 2

Improvement in plants, need of, 27 Impurities, identifying, 20

Inlaying, 57

Inoculating for legumes, 287

Insect enemies fighting, 309, 317, 331 320 of blacklerries. 262 
Insect enemies, of currants 265 of gooseberries, 266

of grapes, 246

of oranges, 282

of raspberries, 256

of strawberries, 239

Insecticides, contact, $313,320,321$ poison, $310,320,321$

Insects, collecting, 202 practices against, 317 special fighting for, 317 spraying for, $310,312,316,320$

Inspection form, 59

Inter-cropping orchards, 179, 192, 208, 209

Inter-tillage, 299

Irish potatoes, 132

Irrigation, $74,75,80,281$

of orchards, 183-4

orange groves, 281

January garden work, 146, 157

home grounds in, 337,341

orchard work, 337,341

Jerusalem artichoke, 119

Johnson grass, 349

Judging home gardens, 78 home grounds, 382 strawbermes, 240

July garden work, 149 home grounds in, 339,343 orchard and fruit work. 339, 343

June garden work, 149, 164 home grounds in, 339,342 orchard and fruit work, 339,342

Kale, 112 sea, 118

Kerosene emulsion, $313,320,321$

Knapsack pump, 318

Kínife, pruning, 335

Kohl rabi, 101

Labor, economy of, 61

Laboratory exercises, close of each chapter

Ladder for picking fruit, 187

Landscape gardening, 366

Lawns, care of, 377,341

grasses for, 376

see months

starting, 377

Layerings, 39,44

mound 46

pot. 47

planting, 44

rooting, 44
Layerings, tip, 45 vine, 44,45

Leaf, cross section of, 4 function and structure, 3 structure, S, 9

Leaves, evaporation from, 6 importance of, 6

Leeks, 108

Legumes as winter covers, 288 furnish nitrogen, $394-5$ inoculating, 287 section on, 286 value of, 286

Lemons, acreage map, 279 culture of, 281

Lenticle spots, 6

Lettuce, 96, 104

Library, books for, 390

Light requirements of plants, 3

Like and unlike, survival of, 22

Lime, burned, 296-7 chart, 297 danger of, 296

forms of, $296-7$

ground stone, 296-7

hydrated, 296-7 uses of, 295,297

Liming garden soil, 72, 80 of soils, 295 projects, 301

Limes, acreage map, 279 growth of, 284

Lime-sulfur,commercial,308,316,320 dilutions, 397-8

for scab, 309

home boiled, 307

self-boiled, 308

spraying with, 326

testing, 308

vs. Bordeaux, 303

Livers of sulfur, 306

London purple, 311

Longevity of seeds, 17

Manure and humus, 72, 80 barnyard, 290

cautions in using, 291 composting, 290 green, 289

surveys, 301

Mangoes, 275-6-7

Maple sugar and syrup, 256

March garden work, 147, 160 home grounds in, 338,342 orchard and fruit work, 338, 342

Marker for garden, 65

Market garden, 68-9 
Marketing blackberries, 262 fruits, 192

grapes, 246

oranges, $281,283,285$

pineapples, 275

vegetables, etc., 148

Materials for budding, 51 spraying, 303, 320

Matted row of strawberries, 236

May garden work, 148, 163

home grounds in, 339, 342

orchard and fruit work, 339, 342

Mendel's law, 25

limits of, 26

results of, 26

Mesophytes, 2

Methods of pollination, 20

Mice, 56,58 protection against, 198

Miscible oils, 315

Mixtures of fertilizers, 292

Moisture for plant growth, 1, 2

Mound layering, 46 and root division, 47 examples of, 46

Mulch for currants, 264 for strawberries, 236, 239 of loose soil, 299

Mushrooms, 129

Muskmelons, 127, 128

Mustard, 97, 351

Nests for birds, 384, 388 protect, 389

Nicofume, 315,321

Nicotine sulfate, 315,321

Nitrate of soda, 293

Nitrogen, 6, 286-7

from legumes, 394-5

-gathering bacteria, 287-9 in air, 8 sources of, 282

November garden work, 154, 169 home grounds in, 340,345 orehard and fruit work, 340,345

Nozzles for spraying, 324 work of, 325

Nursery, a cherry, 60

a peach, 60

a plum, 60

and orehard projects, 60

forest, 360

inspection, 58

form, 59

of apples and pears, 60

problems, 58

Nuts, chapter on, 270
Nuts, exercises, 285

October garden work, 152, 168

lome grounds in, 340,344

orchard and fruit work, 340,344

Oil emulsions, 313-4

Oils, niscible, 315

Olives, 273-4 acreage map, 279

Okra, 125

Onion group, 91

Onions, $106-7$

curing, 109

types, 110

Orchard, avocado, 278

blasting, 298

cherry, 203-4

culture, $179,230,300,301,331$

diseased and starved, 186

ellemies, 202, 224-5

fertilizers, $180,211,213221,232$

fillers, 207, 210

harrows, 331-2

inter-cropping, 179, 192, 208

mango, 277

olive, 274

peach, 205-6

plum, 229

projects, 192

renovation, 184

spraying, 303

weeds, 351

work by months, 337,341

years' work, 329,330

Oranges, 278

acreage map, 279

culture, 281

enemies, 282

grove, 281

harvesting and marketing, 281-2 packing, 283

propagation, 280

pruning, 280

setting, 280

Valencia, 280

Organic matter, adding, 289

Ornamentals, growing: ?75

Osmosis apparatus, 6 by roots, 5 experiments, 8

Oxygen, 6 for plants, 2,8

Oyster shell lime, 296, 297

Packing apples in boxes, 190-2, 399 cherries, 226

co-operative, 329

peaches, 212, 214-5

Parenchyma cells, 3 
Paris green, 310

Parsley, 111

Parsnip, 113

Pcach, acreage map, 203

brown rot of, 218-9

chapter on, 203

fertilizers, 211, 213

leaf curl, 219

orchard, exposure, 203-4

laying out, 206, 209, 210

packing, $212,214-5$

pruning, 209, 212-4

scab, 219

soil, 204-5

trees, as fillers, 207, 210

borers, $215,217,218$

getting, 206-7

June budded, 206-7

September budded, 206-7

varieties, 205

yellows, 219

Peaches, cost of, 395

improving, 27, 32

picking, 330

propagation of, 50,60

thinned, 344

Pear, acreage map, 174

enemies of, 195

harvesting, 190, 192

nursery, 60

propagation of, 53

pruning, 189, 191

section on, 189

soils, 189

spraying, 196

twig blight, 199

varieties, 189

Peas, early, 92

English garden, 96, 105

Pecans, 271

Pedigreed seed, 27

Peony, propagation of, 34

Perennial flowers, 380 vegetables, 92,115 to 119

Perennials, choice of, 379

Peppers, sweet, 90, 124

Pests in seeds, 15 to spray, 320

Phosphate, acid, 293

Phosphoric acid, sources, 294

Phosphorous, 6

forms of, 395 properties of, 9

Picking apples, 186

Pickling, 130

Pineapples, 274 field, 275
INDEX

411

Pineapples, harvesting and marketing, 275

propagation, 274

soils and culture, 274

Pine trees, 358-9

Pistil, 11, 12

Pits for flowers and vegetables, 87

rroject, 88

special uses, 87

Plan for planting orchards, 177 garden, 63, 64, 65, 69, 79

Plans for home grounds, 366, 382 poor and good, 370-1

Plant breeding, principles of, 22 enemies, 3

food, a vailable, 8 supply, 2, 6

growth, conditions for, 1

lice on apples, 320 on melons, 314

life, chapter on, 1 parts of , 4

societies, 2

Plantain, buckhorn, 348

Planting, annuals, 374,376

an orchard tree, 178

apple orchards, 176

blackberries, 261

blueberries, 267

board, 178

bush fruits, 269

by colors, $381-2$

cranberries, 268

currants, 263

flowers, 378

forest trees, 361,365

grapes, 242

hedges, 371

home grounds, 366-7

oranges, 280

plan for apples, 176-7

plans for strawberries, 235,240

raspberries, 253

rate of, for potatoes, 136

shade trees, 369

shrubs, 370

tables, 88, 92, 93, 380, 381, 396

vines, 372

Plants, air for, 2

carbon dioxide for, 2

foliage, 382

influenced by surroundings, 23

importance of, 1

light for, 3

lists of, $380,381,382,401$

oxygen for, 2,8

propagation of, 10,33

Plate budding, 52 
Plowing, deep, 298

fall, 298

repacking after, 299

spring, 298

Plum, acreage map, 227

American, 228

brown rot of, 231

curculio, 217

exposure, 228

Golden Beauty, 229

harvesting, 230

insect enemics of, 231

Milton, 229

orchard culture, 230

starting, 229

pruning, 229

Simon, 228

types and varieties, 228

Plums, propagation of, 51, 60

section on, 227

soils for, 227

stocks for, 51

uses of, 231

Poison sprays,

Pollen, how carried, 13

Pollination and bagging, 31

artificial, 31

by insects, $12,13,20$

by wind, 13

cross, 12,13

methods of, 11,20

self, $11,12,13$

tools for, 31

underground, 13

Pomelo, see grapefruit, 282

Pop-corn, 122

Potash, sources of. 291

Potassium, 6

forms of, 395

properties of, 9

sulfide, 306

Potato, project, 143

seed, quantity of, $3 \mathrm{~S}$

varieties and types, 393

yields, 2S, 393

Potatoes, Burbank, 135

chapter on. 132

Cobbler, 135

culture of, 137,144

cutting, 134

dusting, 144

fertilizer for, 133, 140

good and poor seed, 24

harvesting, 139

improving, 28

Irish, 132

planting, 136
Potatocs, rate of planting, 135-6, 144 seed. 134. 144

soils for, 132,140

spraying, $13 \mathrm{~S}$

sprouting seed, 136-7

storing, 139,144

sweet, 140

treating for scab, 136, 144

varicties, 134

Pot layering, 47

Prepotency, 23

Prickly lettuce, 350

Project, close of each chapter

bush fruit, 269

fertilizer, 301

forest, 365

garden, see each month

garden, 79, 130

score card, 78

grape, 251

home grounds, 382

in crop growing, 301

in drainage, $15 t$

in soil management. 301

orchard, 192, 221, 232, 346

spraying, 327

strawberry, 240

weed, 354

with potatoes, 143

Prong-budding, .52

Propagation, by true roots, 37

by underground parts, 33

of apples, 53. 55, 60

of a vocado, $27 \mathrm{~s}$

of bulbous plants, 34

of bush fruits, 269

of cherries, $51,60,224$

of cranberries, 268

of mangoes. 276

of olives, 273

of oranges, 280

of peaches, 50,60

of pineapples, 274

of plants, 10, 33

of plums, 51, 60

Properties of phosphorous and potassium, 9

Props for trees, 179

Protection of blackberries, 262

of cranberries, 267

of raspberries, 251

Pruning, blackberries, 261

before planting, 177

currants, 264

exercises, 346

good and bad, 182

grapes, 243 
Pruning, oranges, 280

peaches, 209, 211, 213

pears, 189,191

plums, 229

raspberries, 254, 255

saws, 334

shears, 76

summer, 213

the orchard, 180-1

tools, 335

years', 333

Pulsatilla, division of, 35

Pumpkins, 129

Purslane, 348

Pyrethrum, 316

Questions at close of each chapter

Quince, culture, 191

enemies of, 195

section on, 190

twig blight, 199

Quality of apples, 400

Rabbits, 56, 58, 59

and mice, protection against, 198

trap for, 59

Radishes, 95

Rag doll tester, 18

Rake, garden, 77

Raspberries, propagation of, 45 section on, 252

Raspberry, crown gall, 258

diseases, 257

harvesting, 254

hill system, 256

insects, 256

locations, 253

planting, 253, 257

projects, 269

pruning, 254-5

soils, 253

training, 254

uses, 256

varieties, 253

winter protection, 254

Reference library, 390

References to books and bulletins, see end of each chapter

Rejuvenated Baldwin orehard, 185

Renovating old orchards, $18 \pm-5$

Renovation, steps in, $18 t$

Reversion, 23

Rhubarb, 115 forcing, 120

Ripe woorl cuttings, 40

Ripening dates, 232

Rod for spraying, 323
Romaine, 96

Root crops and tubers, 91 euttings, 39 division, $33,38,47$

Root hairs shown, 6 structure of, 5 work of, 5

Rooting layers, 44

Roots, absorption by, 5 osmosis in, 5 propagation by, 37,47 work of, 5

Rose chafer, 247

Rotation in gardens, 165, 171

Rust on apples and cedars, 200

Salsify, 114

Salting cucumbers, 130

San José scale, 215-6

Sauerkraut, 105

Saws, pruning, 334

Scab, apple, 198, 309, 320 potato, $136-7$

Scale insects, $215-6$

Scoring home grounds, 382

Sea kale, 118

Seasonal work by months, 337,341

Seed, analysis, 19

crop, securing, 15

effect of weight of, 30

formation, 20

laboratories, 350

large and small, 25

pedigrees, 27

potatoes, 134, 144

cutting, 135

improving, 28, 31

planting, 135

sprouting, 137

treating, 136

samples, impurities in, 19

saving contest, 20

selection, 15

sources in America, 15, 16

testers, 18

trial grounds, 15, 16

Seeds, analysis of, 19

buying, 16,19

choice of, 20

detecting age of, 17

food in, 20

for market, 20

forest, 365

garden, 14

germination of, 3

growth of, 14

how produced, 10 
Seeds, infested with pests, 15 longevity of, 17 nourishment in, 11 storing, 15 testing, 18 weight of, 32 why produced, 10

Selection, by growers, 30 careful, 24 in plant breeding, 24

September garden work, 151, 167 home grounds in, 340,344 orehard and fruit work, 340,344

Shallot, 108

Shears, pruning, 335

Shelter belts, $35 \mathrm{~S}$

Shield-buddling, 49 ,50 of peaches, 50

Shrubs and plants per acre, 396 from cuttings, 42,47 fruit-bearing, 384,389 in elumps, 366 propagation of, 33,38 to plant, 370,401

Sifting and weighing seeds, 30

Size and weight of seed, 30

Smartweed, Pennsylvania, 353

Soaps for spraying, 315

Sod-mulch system, 300

Soil, aclding humus, 72 amendments, 286-301 clods of, 72 influence of, 33 liming, 72 modifying, 72 mulch, 299 types, 71

Soils, for apples, 173 blackberries, 258 blueberries, 267 cherries, 222 cranberries, 267 currants, 263 gooseberries, 266 grapes, 241 Irish potatoes, 132 mangoes, 276 peaches, 204-5 pears, 189 pineapples, 274 plums, 227 raspherries, 253 strawberries, 233, 240 sweet potatoes, 140 wood lot, 256 garder 71,80 packing, 299
Soils, preparing potato, 133

Soybeans with bicteria, 287, 289

Spinach, 97

New Zealand, 111

Spirea, 37:3

Sports, 23

Spray, calendar, $318,320,321$

hose and rod, 323

materials for potatoes, 138,144 nozzles, 324

Sprayer, barrel, 318, 322

bueket, 318

compressed air, 318-9

gas, 319

hand, 318

knapsack, 318

tank, 319, 322-3

Spraying, campaigns, 328-9, 330, 333. 336

equipment, 318

exercises, $327-8$

for blight and beetles, 138, 144

high pressure, 325

improves quality, 304

materials, 303,320

principles of, 303,320

projects, 303,327

vs. no spraying, 327

Sprays, contact, 313 poison, 310

Spring greens, 91, 92

vegetables, 95

Spruce trees, 359

Squash, culture, 128 vines on fence, 150

Stamens, 11, 12

Starch, grains, 20 made by plants, 3

State, analysis of seeds, 19 seed regulations, 20

Stem, cross section, 5

Stocks for propagation, 50-3

Stone fruits, annual eampaign, 329 spraying, 336

Storage of vegetables, 119

Storing, apples, 187, 192 potatoes, 139,144 sweet potatoes, 143-4

Strawberries, acreage map, 233 blossoms, 234

chapter on, 233

contests, 240

culture of, $2: 37$

enemies of, 239

fertilizer for, 237

forcing, 240

in pots, 240 
Strawberries, judging, 240 location for, 233

mulch for, 236, 239

picking, 238

plans for growing, 235-7, 240

replanting, 239

runners of, 240

soils, 233

varieties, 234

Strawberry, improving the, 27 runners, 46

Streams, forestry effects on, 365

Sweet corn, 121

Sweet potato, culture, 142, 144 enemies, 142

plant, 142

storage, 143

Sweet potatoes, 140

harvesting, 142

starting, 140, 144

transplanting, 141

Swiss chard, 129

Subtropical fruits, 270 exercises, 285

Suckers, propagation by, 33, 38

Sucking insects, fighting, 312, 316

Sun scald of trees, 201

Surveys, bush fruit, 269 cherry and plum, 232

garden, 79

grape, 251

hotbed, 88

manure, 301

of cultural methods, 104

orchard, 192, 221

potato, 143

spraying, 327

strawberry, 240

Survival of like and unlike, 22

Table, box packing guide, 399 cost of peaches, 395

flower, 380-1

fruit, 189

of apple packing, 399

apple varieties, 400

fertility removed, 391

fertilizers, $394-5$

lime-sulfur, 397-8

planting distances, 396

plants per acre, 396

vegetable varieties, 391-2

planting, $88,92,93,380,381$

potato, 393

spraying, 320,321

tomato, 392
Tank sprayer, $319,322-3$

Taxation, relief from, 363

Temperature for plants, 1

Tender vegetables, 89, 121

Tent caterpillar, 197

Testing seeds, 18,20

Thinned peaches, 344

Thinning fruit, 182 objects of, 182, 214

Tillage, 73,80

implements, 63, 70, 72

practices, 301

section on, 297

systems for orchards, 300-1

Tip layering, 45, 47 of raspberries, 45 plants from, 45

Tobacco dust, 316, 320 extract, 316

Tomato varieties, 392 yields, 392

Tomatoes, $123-4$

improving, 28

staked, 89,392

transplanting, 124 tying up, 125

Tools for gardening, 62, 75-7, 79, 108, 154

Top working trees, $55,60,187$

by budding, 56

Tongue grafting, 53 of apples, 53

Towers for spraying, 323

Trap for rabbits, 59

Transpiration, 7

Transplanting, 34

autumn crops, 90

crops for, $S S-9$

dates for, 88

distances, 88

effects of, 124

layered plants, 44

machine, 143

spring crops, 90

sweet potatoes, 141,143

warm season crops, 89,92

Transplanted plants, 87, 88, 92, 143

Tree guards for cats, 385

Trees, along streams, 357, 364

and shrubs at home, 355

benefits of, 364

for forest planting, 359

high buildings, 373 .

shade, 369

grown from cuttings, 42

growth of, 58-9 
Trees, harvesting, 301-2 heeling in, 177,208 knowing the, 365 on rocky areas, 375 on poor land, 363

Trellising grapes, 242-8, 251 raspherries, 254

Trips to orehards, 346

Truck garden, 69, 79

Tubers and rootrerops, 91

Turnips, 99, 105

Type, fixing, 25-6

Types of bulbs, 34-5 flowers, 11

Upland cress, 111

U.S. bulletins, end of each chapter

Variation, causes of, 22 extreme, 30 extreme or sudden, 23 studying, 30

Varieties, of apples, 175, 192, 400 of blackberries, 258,261

of cherries, 223

of currants, 263

of gooseberries, 265

of grapes, 241

of oranges, 280

of peaches, 205

of pears, 189, 192

of plums, 223

of potatoes, 134, 391

of raspberries, 253

of strawberries, 234

of vegetables, 391

study of, 104

Variety trials, 232

Vegetable, border, 65 gardening, 61 market, 148 varieties, 391 work, see each month

Vegetables, autumn, 90, 95 canning, 119

cool spring, $90,92,95$ cultural methods, 104 drying, 119 effect of heat on, 119 food losses of, 394 forcing, 120 hardy, 89 perennial, 92, 115-119 resistance to freezing, 119 storage, 119, 139 table of, $88,92-3$
Vegetables, tender, $\$ 9$ uses of, 104

warm season, 89, 92

Vencer grafting, 57

Ventilation of hotbeds, 82

Vine layering, 44, 47

Vines to plant, 372,401

Vineyard, see grapes, 241-251

Violet, hidden blossoms of, 14

Walks in gardens, 151

Walnuts, acreage map, 279 English, 271-2 native, 271

Warm season crops, 89, 90, 92, 121

Varmth for plant growth, 1

Watering birds, 387,389

Watermelons, 127-8

Wax making, 58, 60

Weed control laboratories, 350

Weeds, chapter on, 347 control of, 349

collections, 354

dissemination of, 348

escaped, 354

groups of, 354

in orchards, 351

identifying, 354

losses from, 351

of neighbors, 354

seeds, 354

special fighting, 354

type and control, 347

Weight of seeds, 32

White, arsenic, 310 clover with bacteria, $28 S$ pines for lumber, 358

Wheei hoc, 63,79 double, 108, 161

Wind breaks, 358

Winter, preparation for, 6,9

Wood lot, exercises, 365 home, 355

location, 356-7, 363

of maples, 356

products, $355-6$

projects, 365

soils, 356

tax exempt, 363

Woods. collection of, 365 .

Woody stem, cross section of, 5

Wren louse, 389

Xerophytes, 2

Yellows of peach, 219, 220 



